\title{
International Energy Agency Building Energy Simulation Test and Diagnostic Method (IEA BESTEST) \\ In-Depth Diagnostic Cases for Ground Coupled Heat Transfer Related to Slab-On-Grade Construction
}

\author{
(Revised Cover) \\ By \\ J. Neymark \\ J. Neymark \& Associates, Wheat Ridge, Colorado, U.S. \\ R. Judkoff \\ National Renewable Energy Laboratory, Golden, Colorado, U.S. \\ With \\ I. Beausoleil-Morrison \\ Natural Resources Canada, Ottawa, Canada \\ A. Ben-Nakhi \\ Public Authority for Applied Education and Training, Kuwait, State of Kuwait \\ M. Crowley \\ Dublin Institute of Technology, Dublin, Ireland \\ M. Deru \\ National Renewable Energy Laboratory, Golden, Colorado, U.S. \\ R. Henninger \\ GARD Analytics, Park Ridge, Illinois, U.S. \\ H. Ribberink \\ Natural Resources Canada, Ottawa, Canada \\ J. Thornton \\ Thermal Energy System Specialists, Madison, Wisconsin, U.S. \\ A. Wijsman \\ VABI Software BV, Delft, The Netherlands \\ M. Witte \\ GARD Analytics, Park Ridge, Illinois, U.S.
}

Link to Required Zipped Data Files (6MB)

Link to IEA Participant Zipped Simulation Input File Archive (100MB)
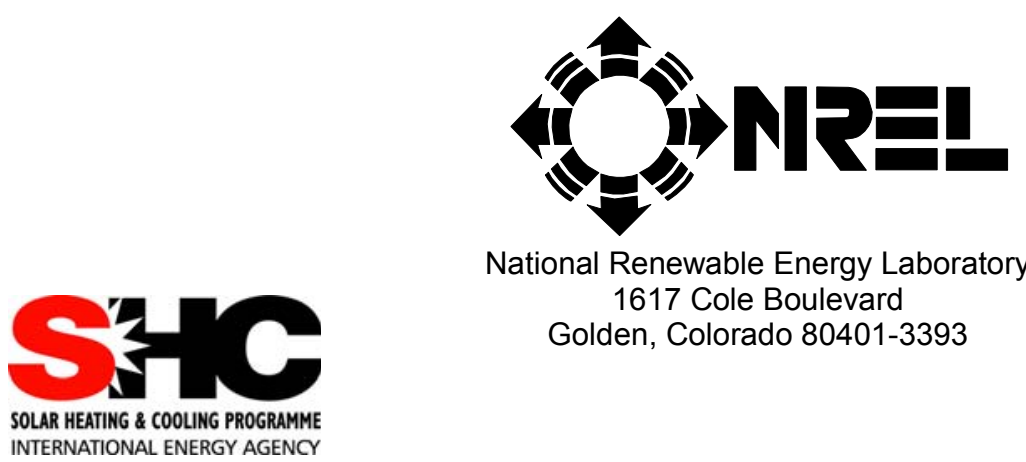

National Renewable Energy Laboratory 1617 Cole Boulevard Golden, Colorado 80401-3393

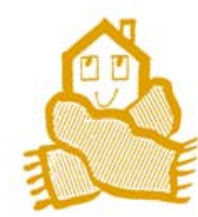




\section{International Energy Agency Building Energy Simulation Test and Diagnostic Method (IEA BESTEST)}

\section{In-Depth Diagnostic Cases for Ground Coupled Heat Transfer Related to Slab-on-Grade Construction}

Technical Report NREL/TP-550-43388

September 2008

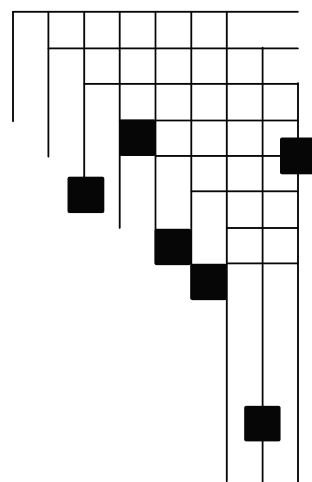

J. Neymark

J. Neymark \& Associates

R. Judkoff

National Renewable Energy Laboratory

Contributors:

I. Beausoleil-Morrison

A. Ben-Nakhi

M. Crowley

M. Deru

R. Henninger

H. Ribberink

J. Thornton
A. Wijsman
M. Witte
VABI Software
GARD Analytics

Natural Resources Canada

Public Authority for Applied Education and Training

Dublin Institute of Technology

National Renewable Energy Laboratory

GARD Analytics

Natural Resources Canada

Thermal Energy System Specialists

Prepared under Task No. BEC7.6051

National Renewable Energy Laboratory

1617 Cole Boulevard, Golden, Colorado 80401-3393

303-275-3000 • www.nrel.gov

Operated for the U.S. Department of Energy

Office of Energy Efficiency and Renewable Energy

by Midwest Research Institute • Battelle

Contract No. DE-AC36-99-G010337 


\section{NOTICE}

This report was prepared as an account of work sponsored by an agency of the United States government. Neither the United States government nor any agency thereof, nor any of their employees, makes any warranty, express or implied, or assumes any legal liability or responsibility for the accuracy, completeness, or usefulness of any information, apparatus, product, or process disclosed, or represents that its use would not infringe privately owned rights. Reference herein to any specific commercial product, process, or service by trade name, trademark, manufacturer, or otherwise does not necessarily constitute or imply its endorsement, recommendation, or favoring by the United States government or any agency thereof. The views and opinions of authors expressed herein do not necessarily state or reflect those of the United States government or any agency thereof.

Available electronically at http://www.osti.gov/bridge

Available for a processing fee to U.S. Department of Energy and its contractors, in paper, from:

U.S. Department of Energy

Office of Scientific and Technical Information

P.O. Box 62

Oak Ridge, TN 37831-0062

phone: 865.576 .8401

fax: 865.576 .5728

email: mailto:reports@adonis.osti.gov

Available for sale to the public, in paper, from:

U.S. Department of Commerce

National Technical Information Service

5285 Port Royal Road

Springfield, VA 22161

phone: 800.553 .6847

fax: 703.605.6900

email: orders@ntis.fedworld.gov

online ordering: http://www.ntis.gov/ordering.htm 


\section{Acknowledgments}

The work described in this report was a cooperative effort involving the members of the International Energy Agency (IEA) Testing and Validation of Building Energy Simulation Tools Experts Group. The group was composed of experts from the IEA Solar Heating and Cooling (SHC) Programme, Task 34, and Energy Conservation in Buildings and Community Systems (ECBCS) Programme Annex 43.

For assistance with interpreting the analytical solution that provides the mathematical foundation of the analytical verification methodology used here, we wish to thank one of its authors, A. Delsante of Commonwealth Scientific and Industrial Research Organisation (CSIRO), Australia. P. Hollmuller of Université de Genève, Switzerland, provided an early review of the applicability of CSIRO's analytical solution and a preliminary comparative analysis.

We appreciate the support and guidance of D. Crawley, U.S. Department of Energy (DOE) program manager for this IEA research task and DOE representative to the IEA SHC Programme Executive Committee; and R. Karney, DOE representative to the IEA ECBCS Programme Executive Committee. 


\section{Preface}

This report is a product of a joint effort between the International Energy Agency (IEA) Solar Heating and Cooling (SHC) and Energy Conservation in Buildings and Community Systems (ECBCS) Programmes. SHC monitors this work as Task 34 and ECBCS monitors this work as Annex 43. Ron Judkoff of the National Renewable Energy Laboratory (NREL) was the Operating Agent for IEA SHC 34/ECBCS 43 on behalf of the United States Department of Energy.

\section{International Energy Agency}

The International Energy Agency (IEA) was established in 1974 within the framework of the Organisation for Economic Co-operation and Development (OECD) to implement an international energy programme. A basic aim of the IEA is to foster co-operation among the twenty-four IEA participating countries and to increase energy security through energy conservation, development of alternative energy sources and energy research, development and demonstration (RD\&D).

\section{Solar Heating and Cooling Programme}

The Solar Heating and Cooling Programme was one of the first IEA Implementing Agreements to be established. Since 1977, its members have been collaborating to advance active solar and passive solar technologies and their application in buildings and other areas, such as agriculture and industry. Current members are:

$\begin{array}{lll}\text { Australia } & \text { Finland } & \text { Portugal } \\ \text { Austria } & \text { France } & \text { Spain } \\ \text { Belgium } & \text { Italy } & \text { Sweden } \\ \text { Canada } & \text { Mexico } & \text { Switzerland } \\ \text { Denmark } & \text { Netherlands } & \text { United States } \\ \text { European Commission } & \text { New Zealand } & \\ \text { Germany } & \text { Norway } & \end{array}$

A total of 39 Tasks have been initiated, 30 of which have been completed. Each Task is managed by an Operating Agent from one of the participating countries. Overall control of the program rests with an Executive Committee comprised of one representative from each contracting party to the Implementing Agreement. In addition to the Task work, a number of special activities-Memorandum of Understanding with solar thermal trade organizations, statistics collection and analysis, conferences and workshops - have been undertaken.

The Tasks of the IEA Solar Heating and Cooling Programme, both underway and completed are as follows:

\section{Current Tasks:}

Task 36

Task 37

Task 38

Task 39
Solar Resource Knowledge Management

Advanced Housing Renovation with Solar \& Conservation

Solar Assisted Cooling Systems

Polymeric Materials for Solar Thermal Applications

\section{Completed Tasks:}

Task 1

Task 2
Investigation of the Performance of Solar Heating and Cooling Systems Coordination of Solar Heating and Cooling R\&D 
Task 3 Performance Testing of Solar Collectors

Task 4

Task 5

Task 6

Task 7

Task 8

Task 9

Task 10

Task 11

Task 12

Task 13

Task 14

Task 16

Task 17

Task 18

Task 19

Development of an Insolation Handbook and Instrument Package

Use of Existing Meteorological Information for Solar Energy Application

Performance of Solar Systems Using Evacuated Collectors

Central Solar Heating Plants with Seasonal Storage

Passive and Hybrid Solar Low Energy Buildings

Solar Radiation and Pyranometry Studies

Solar Materials R\&D

Passive and Hybrid Solar Commercial Buildings

Building Energy Analysis and Design Tools for Solar Applications

Advance Solar Low Energy Buildings

Advance Active Solar Energy Systems

Photovoltaics in Buildings

Measuring and Modeling Spectral Radiation

Advanced Glazing and Associated Materials for Solar and Building Applications

Solar Air Systems

Task 20

Solar Energy in Building Renovation

Task 21

Daylight in Buildings

Task 23

Task 22

Optimization of Solar Energy Use in Large Buildings

Task 24

Building Energy Analysis Tools

Task 25

Solar Procurement

Task 26

Task 28

Task 27

Task 29

Task 31

Task 32

Task 33

Task 34

Solar Assisted Air Conditioning of Buildings

Solar Combisystems

Solar Sustainable Housing

Performance of Solar Facade Components

Solar Crop Drying

Daylighting Buildings in the 21st Century

Advanced Storage Concepts for Solar and Low Energy Buildings

Solar Heat for Industrial Processes

Testing and Validation of Building Energy Simulation Tools

Task 35

PV/Thermal Solar Systems

Completed Working Groups:

CSHPSS, ISOLDE, Materials in Solar Thermal Collectors, and the Evaluation of Task 13 Houses

To find more IEA Solar Heating and Cooling Programme publications or learn about the Programme visit our Internet site at www.iea-shc.org or contact the SHC Executive Secretary, Pamela Murphy, e-mail: pmurphy@MorseAssociatesInc.com.

\section{Energy Conservation in Buildings and Community Systems}

The IEA sponsors research and development in a number of areas related to energy. The mission of one of those areas, the ECBCS - Energy Conservation for Building and Community Systems Programme, is to facilitate and accelerate the introduction of energy conservation, and environmentally sustainable technologies into healthy buildings and community systems, through innovation and research in decisionmaking, building assemblies and systems, and commercialisation. The objectives of collaborative work within the ECBCS R\&D program are directly derived from the on-going energy and environmental challenges facing IEA countries in the area of construction, energy market and research. ECBCS addresses major challenges and takes advantage of opportunities in the following areas: 
- exploitation of innovation and information technology;

- impact of energy measures on indoor health and usability;

- integration of building energy measures and tools to changes in lifestyles, work environment alternatives, and business environment.

\section{The Executive Committee}

Overall control of the program is maintained by an Executive Committee, which not only monitors existing projects but also identifies new areas where collaborative effort may be beneficial. To date the following projects have been initiated by the executive committee on Energy Conservation in Buildings and Community Systems (completed projects are identified by $(*)$ ):

Annex 1: $\quad$ Load Energy Determination of Buildings (*)

Annex 2: $\quad$ Ekistics and Advanced Community Energy Systems (*)

Annex 3: $\quad$ Energy Conservation in Residential Buildings (*)

Annex 4: $\quad$ Glasgow Commercial Building Monitoring (*)

Annex 5: $\quad$ Air Infiltration and Ventilation Centre

Annex 6:

Annex 7:

Annex 8:

Annex 9:

Energy Systems and Design of Communities (*)

Local Government Energy Planning (*)

Annex 10:

Annex 11:

Annex 12:

Inhabitants Behaviour with Regard to Ventilation (*)

Minimum Ventilation Rates (*)

Annex 13:

Annex 14:

Building HVAC System Simulation (*)

Energy Auditing (*)

Windows and Fenestration $(*)$

Annex 15:

Annex 16:

Annex 17:

Annex 18:

Energy Management in Hospitals $\left(^{*}\right)$

Condensation and Energy (*)

Annex 19:

Energy Efficiency in Schools (*)

Annex 20:

BEMS 1- User Interfaces and System Integration $(*)$

Annex 21:

BEMS 2- Evaluation and Emulation Techniques $\left(^{*}\right)$

Annex 22:

Demand Controlled Ventilation Systems (*)

Annex 23:

Low Slope Roof Systems (*)

Annex 24:

Air Flow Patterns within Buildings (*)

Annex 25:

Annex 26:

Annex 27:

Annex 28:

Annex 29:

Thermal Modelling $(*)$

Annex 30:

Annex 31:

Annex 32:

Annex 33:

Annex 34:

Annex 35:

Annex 36:

Annex 37:

Annex 38:

Energy Efficient Communities $(*)$

Multi Zone Air Flow Modelling (COMIS) $(*)$

Heat, Air and Moisture Transfer in Envelopes (*)

Real time HEVAC Simulation (*)

Energy Efficient Ventilation of Large Enclosures (*)

Evaluation and Demonstration of Domestic Ventilation Systems (*)

Low Energy Cooling Systems $(*)$

Daylight in Buildings $(*)$

Bringing Simulation to Application (*)

Energy-Related Environmental Impact of Buildings $(*)$

Integral Building Envelope Performance Assessment (*)

Advanced Local Energy Planning (*)

Computer-Aided Evaluation of HVAC System Performance (*)

Design of Energy Efficient Hybrid Ventilation (HYBVENT) $(*)$

Retrofitting of Educational Buildings (*)

Low Exergy Systems for Heating and Cooling of Buildings (LowEx) (*)

Solar Sustainable Housing (*)

Annex 39: $\quad$ High Performance Insulation Systems (*) 
Annex 40: $\quad$ Building Commissioning to Improve Energy Performance (*)

Annex 41: Whole Building Heat, Air and Moisture Response (MOIST-ENG)

Annex 42: The Simulation of Building-Integrated Fuel Cell and Other Cogeneration Systems (FC+COGEN-SIM)

Annex 43: $\quad$ Testing and Validation of Building Energy Simulation Tools

Annex 44: Integrating Environmentally Responsive Elements in Buildings

Annex 45: $\quad$ Energy Efficient Electric Lighting for Buildings

Annex 46: Holistic Assessment Tool-kit on Energy Efficient Retrofit Measures for Government Buildings (EnERGo)

Annex 47: $\quad$ Cost-Effective Commissioning for Existing and Low Energy Buildings

Annex 48: $\quad$ Heat Pumping and Reversible Air Conditioning

Annex 49: $\quad$ Low Exergy Systems for High Performance Built Environments and Communities

Annex 50: $\quad$ Prefabricated Systems for Low Energy / High Comfort Building Renewal

Working Group - Energy Efficiency in Educational Buildings (*)

Working Group - Indicators of Energy Efficiency in Cold Climate Buildings (*)

Working Group - Annex 36 Extension: The Energy Concept Adviser (*)

$(*)$ - Completed

\section{Participating countries in ECBCS:}

Australia, Belgium, CEC, Canada, Czech Republic, Denmark, Finland, France, Germany, Greece, Israel, Italy, Japan, the Netherlands, New Zealand, Norway, Poland, Portugal, Sweden, Switzerland, Turkey, United Kingdom and the United States of America.

\section{SHC Task 34/ECBCS Annex 43: Testing and Validation of Building Energy Simulation Tools}

\section{Goal and Objectives}

The goal of this Task/Annex is to undertake pre-normative research to develop a comprehensive and integrated suite of building energy analysis tool tests involving analytical, comparative, and empirical methods. These methods will provide for quality assurance of software, and some of the methods will be enacted by codes and standards bodies to certify software used for showing compliance to building energy standards. This goal will be pursued by accomplishing the following objectives:

- Create and make widely available a comprehensive and integrated suite of IEA Building Energy Simulation Test (BESTEST) cases for evaluating, diagnosing, and correcting building energy simulation software. Tests will address modeling of the building thermal fabric and building mechanical equipment systems in the context of innovative low energy buildings.

- Maintain and expand analytical solutions for building energy analysis tool evaluation.

- Create and make widely available high-quality empirical validation data sets, including detailed and unambiguous documentation of the input data required for validating software, for a selected number of representative design conditions.

\section{Scope}

This Task/Annex investigates the availability and accuracy of building energy analysis tools and engineering models to evaluate the performance of innovative low-energy buildings. Innovative lowenergy buildings attempt to be highly energy efficient by using advanced energy efficiency technologies or a combination of energy efficiency and solar energy technologies. To be useful in a practical sense, such tools must also be capable of modeling conventional buildings. The scope of the Task is limited to building energy simulation tools, including emerging modular type tools, and to widely used innovative 
low-energy design concepts. Activities will include development of analytical, comparative and empirical methods for evaluating, diagnosing, and correcting errors in building energy simulation software.

The audience for the results of the Task/Annex is building energy simulation tool developers, and codes and standards (normes) organizations that need methods for certifying software. However, tool users such as architects, engineers, energy consultants, product manufacturers, and building owners and managers are the ultimate beneficiaries of the research, and will be informed through targeted reports and articles.

\section{Means}

The objectives are to be achieved by the participants in the following projects.

\section{Comparative and Analytical Verification Tests:}

Project A: Ground-Coupled Heat Transfer with Respect to Floor Slab and Basement Constructions Project B: Multi-Zone Buildings and Air Flow

\section{Empirical Validation and Comparative Tests:}

Project C: Shading/Daylighting/Load Interaction

Project D: Mechanical Equipment and Controls

Project E: Buildings with Double-Skin Facades

Other:

Project G: Web Site for Consolidation of Tool Evaluation Tests

\section{Participants}

The participants in the Task are Australia, Belgium, Canada, Czech Republic, Denmark, France, Germany, Japan, The Netherlands, Spain, Sweden, Switzerland, the United Kingdom, and the United States. The United States served as the Operating Agent for this Task; Ron Judkoff of National Renewable Energy Laboratory provided Operating Agent services on behalf of the U.S. Department of Energy.

This report documents work carried out under Project A: Ground-Coupled Heat Transfer with Respect to Floor Slab and Basement Constructions. 


\section{Table of Contents}

Preface

Electronic Media Contents

Executive Summary

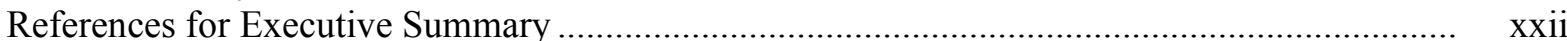

Introduction

References for Introduction

xxvi

xxviii

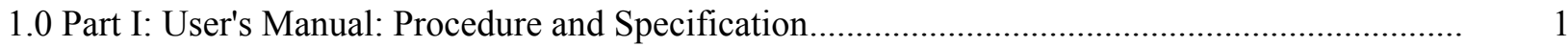

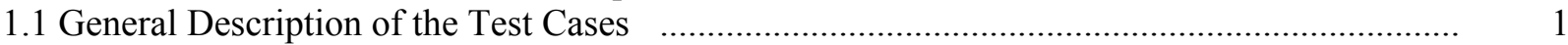

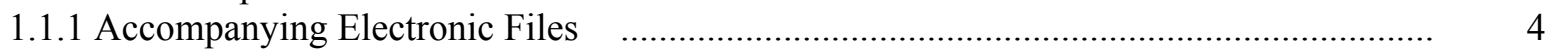

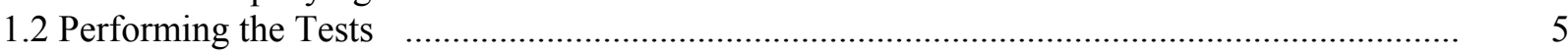

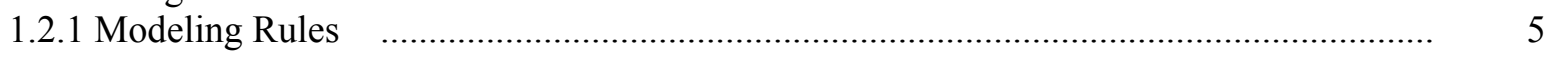

1.2.2 Comparing Your Output to the Analytical Solution, Verified Numerical-Model

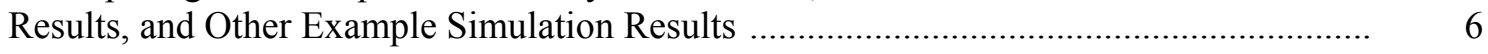

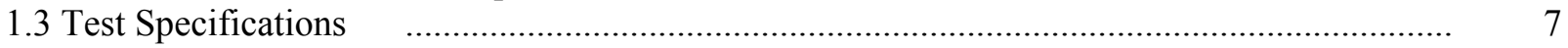

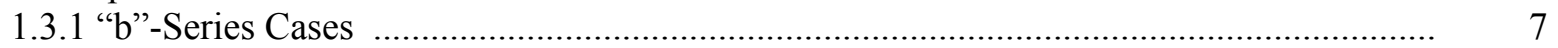

1.3.1.1 Case GC30b - Steady-State Comparative Test Base Case .................................. 7

1.3.1.1.1 Objective ................................................................................... 7

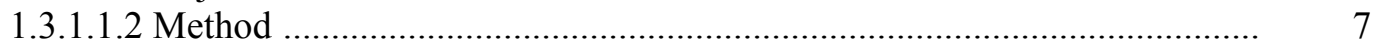

1.3.1.1.3 Input Specification .......................................................................... 8

1.3.1.1.4 Output Requirements .......................................................................... 13

1.3.1.2 Case GC40b - Harmonic Variation of Ambient Temperature ............................. 15

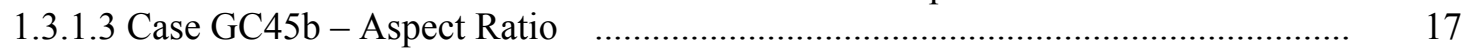

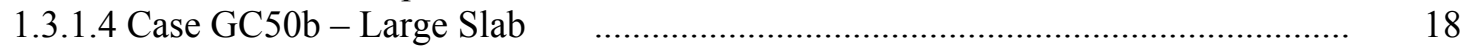

1.3.1.5 Case GC55b - Shallow Deep Ground Temperature ........................................ 19

1.3.1.6 Case GC60b - Steady State with Typical Interior Convective Surface Coefficient 19

1.3.1.7 Case GC65b - Steady State with Typical Interior and Exterior Convective

Surface Coefficients......................................................................................... $\quad 20$

1.3.1.8 Case GC70b - Harmonic Variation of Ambient Temperature with Typical

Interior and Exterior Convective Surface Coefficients ........................................... 21

1.3.1.9 Case GC80b - Reduced Slab and Ground Conductivity ...................................... 21

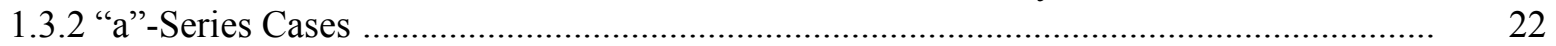

1.3.2.1 Case GC10a - Steady-State Analytical Verification Base Case ............................ 22

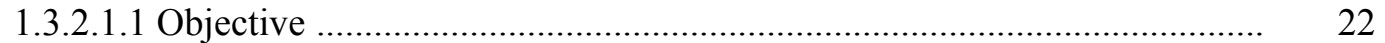

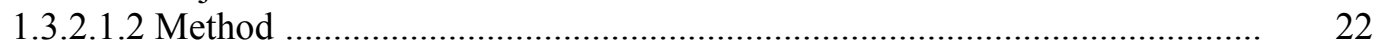

1.3.2.1.3 Input Specification .......................................................................... 22

1.3.2.1.4 Output Requirements ........................................................................ 24

1.3.2.1.5 Analytical Solution for Steady-State Heat Flow through the Floor Slab .. 24

1.3.2.2 Case GC30a - Steady-State Comparative Test Base Case with Direct Input of

Surface Temperatures .......................................................................................... 26

1.3.2.3 Case GC40a - Harmonic Variation of Direct-Input Exterior Surface Temperature 27

1.3.3 "c"-Series Cases ................................................................................................... 28

1.3.3.1 Case GC30c - Steady-State Comparative Test Base Case with BASESIMP Boundary Conditions ...................................................................................... 28

1.3.3.2 Case GC40c - Harmonic Variation of Direct-Input Exterior Surface Temperature with BASESIMP Boundary Conditions .............................................................. 29

1.3.3.3 Case GC45c - Aspect Ratio with BASESIMP Boundary Conditions $\quad$................ 30 
1.3.3.4 Case GC55c - Shallow Deep Ground Temperature with BASESIMP Boundary Conditions

1.3.3.5 Case GC80c - Reduced Slab and Ground Conductivity with BASESIMP

Boundary Conditions

Appendix A: TMY2 File Format

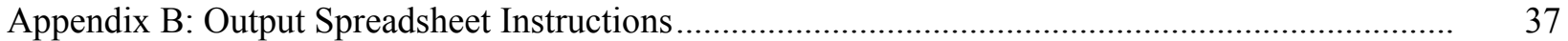

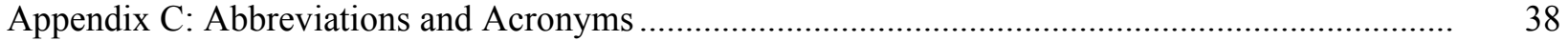

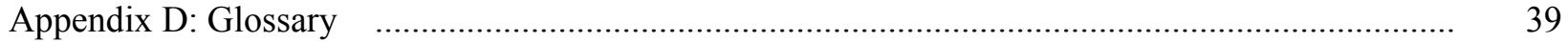

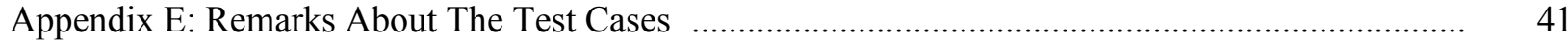

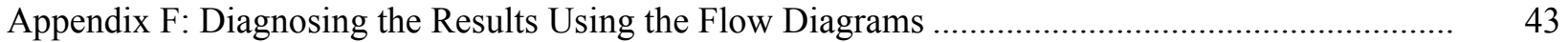

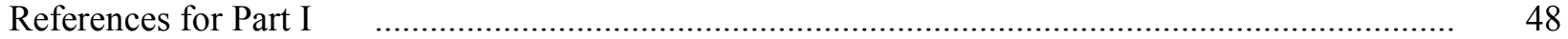

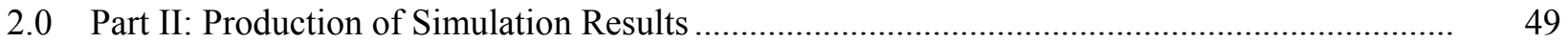

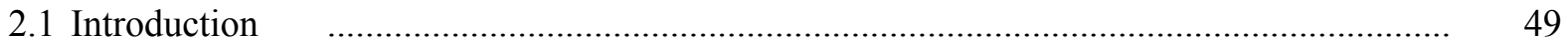

2.2 Selection of Simulation Programs and Modeling Rules for Simulations ............................. 50

2.3 Improvements to the Test Specification as a Result of the Field Trials................................. 51

2.4 Examples of Error Trapping with BESTEST Diagnostics................................................... 56

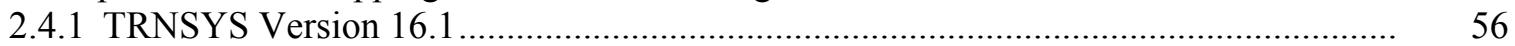

2.4.2 DIT 3-D Numerical Model using MATLAB Version 7.0........................................... 59

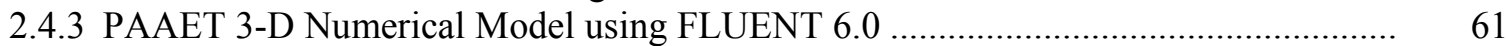

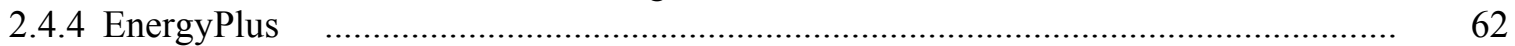

2.4.5 VA114 Version 2.20 with ISO 13370 Ground Heat Transfer Model ............................. 68

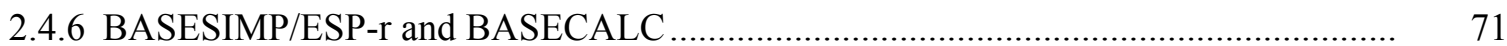

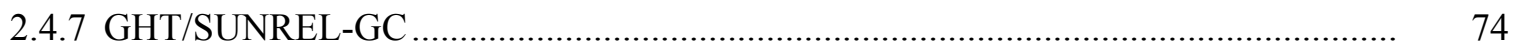

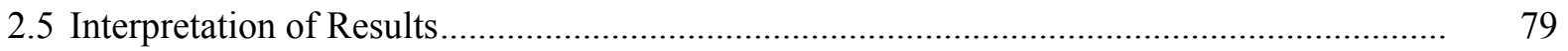

2.5.1 Developing a Secondary Mathematical Truth Standard Based on an Analytical

Solution and Verified Numerical Models ........................................................... $\quad 79$

2.5.2 Comparing Typical Simulation Model Results to Verified Numerical-Model Results $\quad 82$

2.5.3 Improvements to Simulations during the Field Trials.............................................. 82

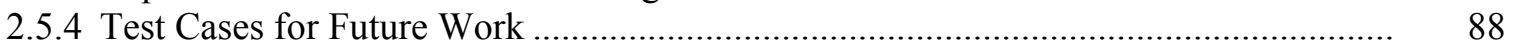

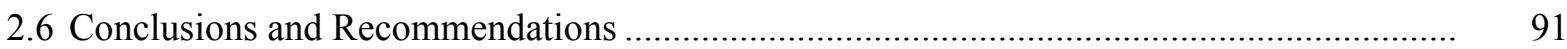

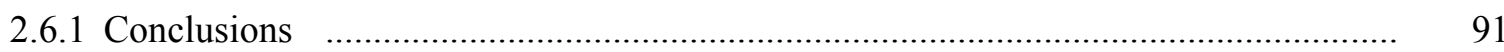

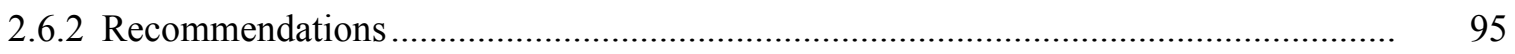

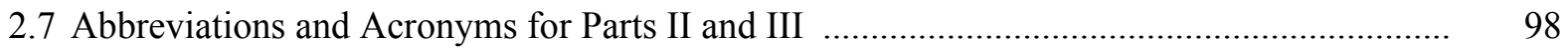

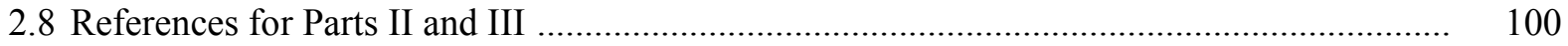

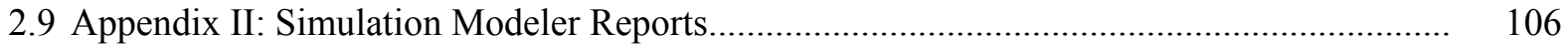

Appendix II-A: TRNSYS, Thermal Energy System Specialists, United States ................ 107

Appendix II-B: FLUENT, Public Authority of Applied Education and Training, Kuwait 125

Appendix II-C: MATLAB, Dublin Institute of Technology, Ireland ............................... 136

Appendix II-D: EnergyPlus, GARD Analytics, United States ...................................... 148

Appendix II-E: BASECALC and BASESIMP/ESP-r, CETC/NRCan, Canada ............... 163

Appendix II-F: VA114/ISO-13370, VABI Software, The Netherlands .......................... 178

Appendix II-G: GHT/SUNREL-GC, National Renewable Energy Laboratory, US ........ 197

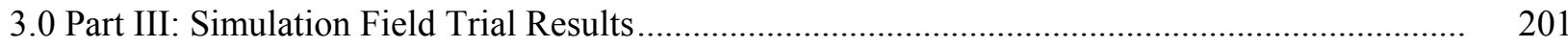

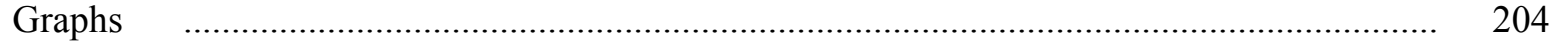

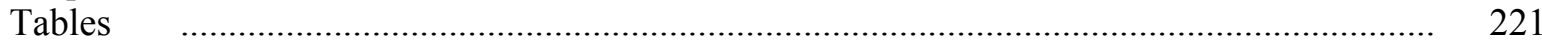




\section{Electronic Media Contents}

The following files apply as they are called out in the test procedure; these are included in the .zip file link on the cover page of the posted electronic version of this document; click on "Link to Required Zipped Data Files (6 MB)":

- README-GC-InDepth.DOC: Electronic media contents

- GCSS-W40.TM2: TMY2 weather data for $10^{\circ} \mathrm{C}$ constant ODB, $40.0 \mathrm{~m} / \mathrm{s}$ wind speed

- GCSS-W20.TM2: TMY2 weather data for $10^{\circ} \mathrm{C}$ constant ODB, $19.9 \mathrm{~m} / \mathrm{s}$ wind speed

- GCSS-W01.TM2: TMY2 weather data for $10^{\circ} \mathrm{C}$ constant ODB, $1.0 \mathrm{~m} / \mathrm{s}$ wind speed

- GCSP-W40.TM2: TMY2 data for harmonically varying $\left(10^{\circ} \mathrm{C}\right.$ mean $) \mathrm{ODB}, 40.0 \mathrm{~m} / \mathrm{s}$ wind speed

- GCSP-W20.TM2: TMY2 data for harmonically varying $\left(10^{\circ} \mathrm{C}\right.$ mean $) \mathrm{ODB}, 19.9 \mathrm{~m} / \mathrm{s}$ wind speed

- GCSP-W01.TM2: TMY2 data for harmonically varying $\left(10^{\circ} \mathrm{C}\right.$ mean $) \mathrm{ODB}, 1.0 \mathrm{~m} / \mathrm{s}$ wind speed

- GC-InDepth-Out.XLS: Raw output data spreadsheet

- GC-InDepth-Results.XLS: Results spreadsheet to assist users with plotting their results versus the example simulation results

- GC-InDepth-Results.DOC: Documentation for navigating GC-InDepth-Results.XLS.

The IEA SHC Task 34/ECBCS Annex 43 participant simulation input files are included in the .zip file link on the cover page of the posted electronic version of this document; click on "Link to IEA Participant Zipped Simulation Input File Archive (100 MB)." These files are not necessary to run the test cases. The .zip file will unzip to the folder structure shown below. Each subfolder contains files used to develop the results for the listed programs provided in Part III.

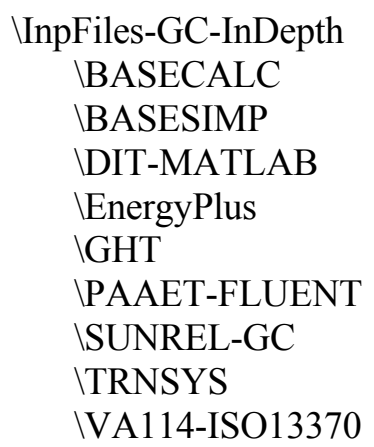




\section{Executive Summary}

This report documents a set of idealized in-depth diagnostic test cases for use in validating groundcoupled floor slab heat transfer models. These test cases represent an extension to IEA BESTEST, ${ }^{1}$ which originally focused on testing and validation of building thermal fabric models, but addressed only cursorily the modeling of heat transfer between the building and the ground. This new work was conducted by the National Renewable Energy Laboratory (NREL), United States in collaboration with a working group of international experts under International Energy Agency (IEA) Solar Heating and Cooling (SHC) Programme Task 34 and IEA Energy Conservation in Buildings and Community Systems (ECBCS) Programme Annex 43. Ron Judkoff of NREL was the operating agent for IEA 34/43.

\section{Background}

The development of practical procedures and data for tool evaluation and improvement is part of an overall IEA validation methodology that $\mathrm{NREL}^{2,3,4}$ and the IEA $^{5,6}$ have been developing for many years. The methodology combines empirical validation, analytical verification, and comparative analysis techniques; details are discussed in the Background Section of HVAC BESTEST Volume $1 ;{ }^{7}$ updates are published in the 2005 ASHRAE Handbook of Fundamentals ${ }^{8}$ and elsewhere. ${ }^{4}$ NREL originally developed the BESTEST method in IEA SHC Task 12 to test building thermal fabric (envelope) models, and to diagnose sources of predictive disagreements. ${ }^{1}$ This method of test was adopted with some refinements by the American Society of Heating, Refrigerating and Air-Conditioning Engineers (ASHRAE) in accordance with procedures of the American National Standards Institute (ANSI), and now forms the basis for ANSI/ASHRAE Standard 140, Method of Test for the Evaluation of Building Energy Analysis Computer Programs. ${ }^{9,10,11}$ Since Standard 140 was first published, three HVAC BESTEST test suites developed within IEA SHC Task 22 have been added: two that address unitary space cooling equipment, ${ }^{7,12}$ and one that addresses fuel-fired furnaces. ${ }^{13}$

\section{Importance of the Ground Heat Transfer Problem}

As above-grade components of the building thermal fabric become more energy efficient, the heat transfer between the building and the ground becomes relatively more important. Ground-coupled heat transfer is a complex phenomenon that involves three-dimensional (3-D) thermal conduction, moisture transport, long time constants, and the heat storage properties of the ground. Based on simulations by NREL discussed in the Introduction of this report, typical slab-on-grade floor heat loss can range from $15 \%$ to $45 \%$ of the annual heating load. This result depends on a wide variety of parameters, including climate, above-grade thermal properties of the building, presence of slab and/or perimeter insulation, and the ground heat transfer model used for the calculation. Estimates of the range of disagreement among models used for calculating uninsulated slab-on-grade heat transfer are $25 \%$ to $60 \%$ or higher for simplified models versus detailed models, depending on the models being compared, building construction characteristics, and climate.

\section{Brief History of Ground Heat Transfer Model Development}

During the early 1990s computers were substantially less powerful than they are today; such computers typically allowed only the use of simplified models for calculating ground heat transfer. A common simplified model is ASHRAE's slab-on-grade perimeter heat-loss calculation, which uses perimeter length $(\mathrm{m})$ and an F-factor heat loss coefficient $(\mathrm{W} /(\mathrm{m} \cdot \mathrm{K}))$ to assimilate a typical steady-state thermal conductance (UA-value $[\mathrm{W} / \mathrm{K}]) .{ }^{14,15}$ For basement heat loss ASHRAE provides a simplified steady-state calculation method based on heat transfer path lengths that occur at given increments of basement wall depth. ${ }^{15,16,17}$ These models can be modified to include one-dimensional (1-D) dynamic conduction 
modeling of a limited amount of ground, including thermal mass storage, ${ }^{18}$ but addressing further detail was typically beyond the capability of most computers.

Because of recent improvements to computers, the state-of-the-art in ground heat transfer modeling has improved. Consequently, a number of mid-level detailed models have been developed and applied to building energy simulation software, including the following examples of models tested in this work:

- BASECALC - produces quasi-3-D analysis by combining two dimensional (2-D) finite element simulations with corner correction factors ${ }^{19}$

- BASESIMP - correlation method based on more than 100,000 BASECALC simulations ${ }^{20}$

- EnergyPlus - monthly 3-D numerical analysis in a preprocessor ${ }^{21,22,23}$

- EN ISO 13370 - European standard below-grade heat transfer calculation methodology applying a 3-D heat loss component varied monthly and a 1-D heat loss component varied hourly; VA114 applies this method; however, the 3-D heat loss component is varied daily. ${ }^{24,25}$

Recent ground heat transfer simulation improvements include the development of stand-alone 3-D detailed numerical models that have also been integrated with whole-building energy simulation programs. Such models used in this work include TRNSYS's 3-D finite difference model ${ }^{26}$ and the GHT 3-D finite element model that interfaces with SUNREL-GC. ${ }^{27}$ Two detailed models not linked to wholebuilding simulation programs, but used as stand-alone models in this project, were developed using FLUENT $^{28,29}$ and MATLAB. ${ }^{30,31}$

\section{Evolution of BESTEST Ground-Coupled Heat Transfer Test Cases}

The BESTEST ground-coupled heat transfer test cases have evolved in parallel with model development. The initial IEA BESTEST ${ }^{1}$ ground-coupled heat transfer test case published in 1995 was developed when simplified tools were predominant. This test case included a half basement, did not define all boundary conditions that would be required for use by detailed models, and had a wide range of disagreement among the results. Because of its cursory nature, this was the only case from IEA BESTEST excluded from ASHRAE Standard 140.

HERS BESTEST, ${ }^{18}$ also published in 1995, is designed to test simplified tools commonly used with residential modeling, and includes cases designed to test simplified ground heat transfer models for slabon-grade and basement configurations. The ground coupling results set within HERS BESTEST also displayed a wide range of disagreement among the simplified models that were tested. Because of the simplified nature of the tests, running HERS BESTEST with detailed models would require modeling assumptions not documented in the test specification, which would cause variations among results.

Several building energy software producers are developing relatively detailed ground-coupled heat transfer models and integrating them with whole-building energy simulation computer programs. However, there is little to no quantitative information about the accuracy of these new models, or about how well they compare to each other or to previously developed, simpler models. Furthermore, it is extremely difficult and expensive to collect good empirical data on ground-coupled heat transfer phenomena because of the disturbance to the earth and to temperature profiles resulting from the construction of a building and placement of sensors, the long time constants associated with large ground mass, and the variability in field conditions. For these reasons, NREL collaborated with the previous IEA SHC Task 22 to develop a BESTEST-type method to test and diagnose the more advanced groundcoupled heat transfer models. The SHC Task 22 cases tested various relatively realistic slab-on-grade and basement constructions. ${ }^{32}$ The cases were defined to test the following aspects of ground-coupled heat transfer models: (1) interaction of the building with the atmosphere through the ground; (2) effects of solar radiation on ground-coupled surfaces; (3) effects of calculated versus constant surface heat transfer 
coefficients; (4) slab-on-grade geometries with and without insulation; (5) basement geometries with and without insulation; (6) interaction of the building with the deep ground conditions; and (7) walkout basement construction. Preliminary results from the Task 22 project for cases that isolated the effects of the ground heat transfer models (e.g., no windows, near-adiabatic above-grade construction) are shown in Figure ES-1. The results indicate some large disagreements among the detailed ground-coupled heat transfer models linked to whole-building energy simulation software, even after a major algorithmic limitation was fixed in one of the programs. However, the sources of these disagreements could not be readily determined because the cases were designed to be relatively realistic, not diagnostic, and there was no mathematical or empirical truth standard.
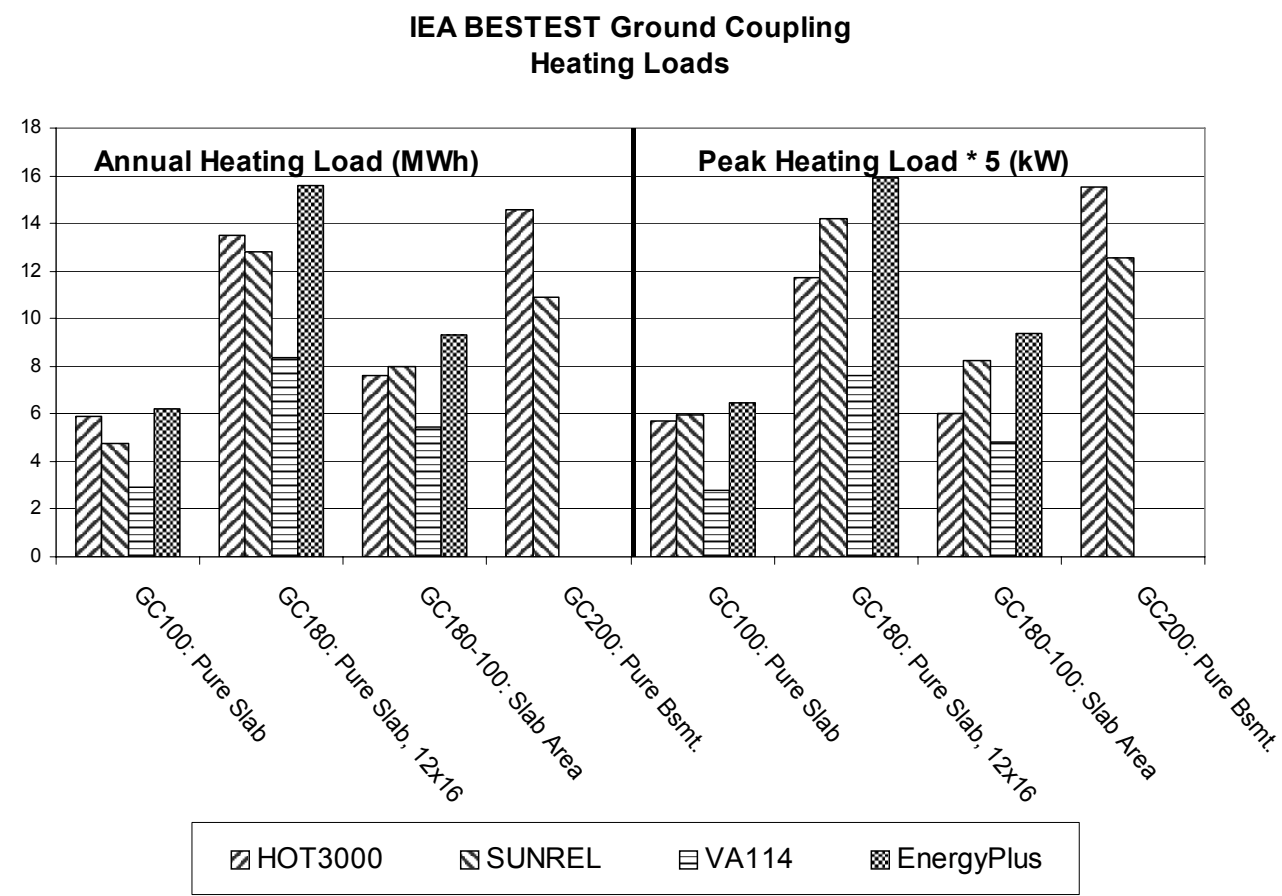

Figure ES-1. Results from IEA SHC Task 22 test cases isolating ground-coupled heat transfer effects ${ }^{32}$

Based on these unresolved disagreements, NREL concluded, and the participants agreed, that before proceeding with other realistic test cases in-depth diagnostics had to be developed to resolve or better understand the causes of differences found during the SHC Task 22 work. The participants also agreed that after the in-depth test cases were completed, the past Task 22 tests should be revised and rerun, and that other realistic tests should be considered for development.

In parallel with the Task 22 work, ASHRAE published a compilation of analytical solutions ${ }^{33}$ that included a 3-D steady-state analytical solution for a slab-on-grade related heat transfer problem with rectangular geometry originally developed by Commonwealth Scientific and Industrial Research Organization (CSIRO), Australia. ${ }^{34}$ This spawned the idea to design a test suite beginning with the CSIRO analytical solution, which would then step methodically toward more realistic boundary conditions and parametric assumptions. Furthermore, if detailed stand-alone 3-D numerical models were applied to the test cases using a solution process that demonstrates convergence, and good agreement was verified, those numerical models could be established as quasi-analytical solutions. Such solutions would provide a powerful secondary mathematical truth standard, based on their range of disagreement, for checking other ground-coupling models typically used with whole-building energy simulation programs. (Definitions of the following terms are provided in the glossary of Part I, Appendix D: "analytical 
solution," "quasi-analytical solution," "verified numerical model," "mathematical truth standard," and "secondary mathematical truth standard.”)

\section{The Current IEA 34/43 In-Depth Diagnostic Analytical Verification Test Cases}

This report documents a set of idealized in-depth diagnostic analytical verification test cases for use in validating ground-coupled floor slab heat transfer models. The logic for the cases may be summarized as follows:

- Identify or develop exact analytical solutions that may be used as mathematical truth standards for testing detailed numerical models using parameters and simplifying assumptions of the analytical solution.

- Apply a numerical solution process that demonstrates convergence in the space and time domains for the analytical-solution test cases and additional test cases where numerical models are applied.

- Once validated against the analytical solutions, use the numerical models to develop reference results for test cases that progress toward more realistic (less idealized) conditions, and that do not have exact analytical solutions.

- Check the numerical models by carefully comparing their results to each other while developing the more realistic cases, and make corrections as needed.

- Good agreement for the set of numerical models versus the analytical solution - and versus each other for subsequent test cases - verifies them as a secondary mathematical truth standard based on the range of disagreement among their results.

- Use the verified numerical-model results as reference results for testing other models that have been incorporated into whole-building simulation computer programs.

This approach represents an important methodological advance to extend the analytical verification method beyond the constraints inherent in classical analytical solutions. It allows a secondary mathematical truth standard to be developed in the form of a set of stand-alone detailed numerical models (quasi-analytical solutions). Once verified against all available classical analytical solutions, and compared with each other for cases that do not have exact analytical solutions, the set of verified numerical models can be used together to test other models as implemented in whole-building simulation programs. This allows for much greater enhanced diagnostic capability than the purely comparative method, and it allows somewhat more realistic boundary conditions to be used in the test cases than are possible with pure analytical solutions. A more detailed description of the new methodology is given in Part II, Section 2.5.1.

The CSIRO analytical solution ${ }^{34}$ was the only 3-D analytical solution with rectangular surface geometry we found, and formed the basis for the test cases included in Part I. This analytical solution is for a steady-state condition. We investigated the possibility of finding or developing a comparable 3-D solution for a harmonic boundary condition. However, we did not find a ready-made solution, and several applied mathematicians advised that such a solution would be difficult, if not impossible, to derive.

The new test cases use an idealized uninsulated slab-in-grade configuration. This simplified configuration is required by the CSIRO analytical solution, is appropriate for developing robust ground-coupling test cases, is compatible with the tested programs, and facilitated the development of accurate model results by minimizing chances for input errors. These cases, as they step away from the analytical solution, also test parametric sensitivities to variation of floor-slab aspect ratio, slab area, water table depth (constant deep ground temperature depth), slab-interior and ground-exterior surface heat transfer coefficients, and slab and ground thermal conductivity. The cases use steady-state and harmonic boundary conditions as applied within artificially constructed annual weather data, along with an adiabatic above-grade building 
envelope to isolate the effects of ground-coupled heat transfer. Because the zone heating load is driven exclusively by the slab heat losses, it is equal to the slab conduction heat loss. This is convenient for testing programs that may not readily disaggregate floor conduction losses in their output. Various output values - including steady-state, annual total steady-periodic, and annual peak-hour steady-periodic results for floor conduction and zone heating load, along with time of occurrence of peak-hour loads and other supporting output - are compared and used in conjunction with a formal diagnostic method to determine algorithms responsible for predictive differences.

\section{Results}

Field trials of the new IEA BESTEST cases were conducted with a number of detailed state-of-the-art numerical models and state-of-the art whole-building energy simulation programs, which contained a variety of ground-coupled heat transfer models from around the world (see Table ES-1). The field-trial process was iterative in that executing the simulations led to refinement of the BESTEST cases, and the results of the tests led to improving and debugging the ground-coupled heat transfer models.

Table ES-1. Participating Organizations and Models

\begin{tabular}{|c|c|c|}
\hline $\begin{array}{l}\text { Analytical Solution, } \\
\text { Case GC10a }\end{array}$ & Authoring Organization & Implemented by \\
\hline $\begin{array}{l}\text { Delsante, Stokes, and } \\
\text { Walsh }^{34}\end{array}$ & $\begin{array}{l}\text { Commonwealth Scientific and Industrial } \\
\text { Research Organisation, Australia }\end{array}$ & NREL/JNA, ${ }^{a, b}$ United States \\
\hline $\begin{array}{l}\text { Verified Numerical } \\
\text { Model }\end{array}$ & Authoring Organization & Implemented by \\
\hline FLUENT 6.0.20 & Fluent, Incorporated, United States & PAAET, ${ }^{c}$ Kuwait \\
\hline MATLAB 7.0.4.365 (R14) & The MathWorks, Inc., United States & Dublin Institute of Technology, Ireland \\
\hline TRNSYS 16.1 & University of Wisconsin/TESS, ${ }^{d}$ United States & TESS, ${ }^{\mathrm{d}}$ United States \\
\hline Simulation Program & Authoring Organization & Implemented by \\
\hline BASECALC V1.0e & CETC, ${ }^{e}$ Canada & CETC, ${ }^{e}$ Canada \\
\hline EnergyPlus 2.0.0.025 & LBNL/UIUC/DOE-BT, ${ }^{\mathrm{f}, \mathrm{g}, \mathrm{h}}$ United States & GARD Analytics, Inc., United States \\
\hline ESP-r/BASESIMP & CETC/ESRU, ${ }^{\mathrm{e}, \mathrm{i}}$ Canada/United Kingdom & CETC, ${ }^{\mathrm{e}}$ Canada \\
\hline GHT & NREL, ${ }^{a}$ United States & NREL, ${ }^{a}$ United States \\
\hline SUNREL-GC 1.14.01 & NREL, ${ }^{a}$ United States & NREL, ${ }^{a}$ United States \\
\hline VA114 2.20/ISO-13370 & $\begin{array}{l}\text { VABI Software BV, The Netherlands; } \\
\text { CEN/ISO }\end{array}$ & VABI Software BV, The Netherlands \\
\hline
\end{tabular}

${ }^{a}$ NREL: National Renewable Energy Laboratory, United States

bJNA: J. Neymark \& Associates, United States

'PAAET: Public Authority for Applied Education and Training, Kuwait

${ }^{\mathrm{d}}$ TESS: Thermal Energy Systems Specialists, United States

${ }^{\text {e}}$ CETC: CANMET Energy Technology Centre, Natural Resources Canada, Canada

'LBNL: Lawrence Berkeley National Laboratory, United States

IUIUC: University of Illinois Urbana/Champaign, United States

hDOE-BT: U.S. Department of Energy, Office of Building Technologies, Energy Efficiency and Renewable Energy, United States

'ESRU: Energy Systems Research Unit, University of Strathclyde, United Kingdom

${ }^{\mathrm{j}} \mathrm{CEN}$ : European Committee for Standardisation, Belgium

kISO: International Organization for Standardization, Switzerland 
The agreement among simulation results improved with each iteration of the field trials. Improvements to the simulation programs are evident when the initial results set (see Figure ES-2 for the steady-state cases and Figure ES-4 for the steady-periodic cases) is compared to the final results set (see Figure ES-3 for the steady-state cases and Figure ES-5 for the steady-periodic cases). (In these figures verified numericalmodel results are shown with blue shaded background and the analytical solution result [Case GC10a] is shown with magenta background.) Improvements to simulation programs or simulation inputs made by participants were required to have a mathematical and a physical basis, and to be applied consistently across tests. Arbitrary modification of a simulation program's input or internal code to more closely match a given set of results was not allowed. All improvements were required to be documented and justified in the modeler reports.

These results indicate that there was initially a 9\%-55\% disagreement among the cases for the simulated energy consumption results, with substantial scatter among the programs. Here disagreement is the difference between the maximum and minimum results for each case, divided by the mean of the results for each case ((max-min)/mean). These results include two estimates for results that would have occurred before fixes were made during preliminary work of IEA SHC Task 22 documented in Section 2.4, which were not previously published; see Figure ES-2 results for Case GC60b and Figure ES-4 results for Case GC70b. After correcting software errors using BESTEST diagnostics - 24 disagreements were found among the programs, which resulted in 19 fixes so far - the remaining disagreements for the models are $1 \%-24 \%$ with reduced scatter among results. This may be a reasonable range of disagreement, given the complexity of the modeling problem, although a few remaining disagreements identified in Section 2.4 could be addressed later. Agreement is also improved among the detailed numerical models (results shown with blue shaded background), where initial disagreements up to $12 \%$ were reduced to $0 \%-4 \%$ for the verified numerical-model results over the course of the project.

\section{Findings}

Several important technology advances were made as a result of running the test cases:

- The detailed numerical-methods modelers used the analytical solution to improve their models e.g., a TRNSYS node meshing refinement (finer mesh near perimeter boundaries) resulted in a $10 \%$ results improvement versus the analytical solution; compare results for Case GC10a in Figures ES-2 and ES-3.

- There were three participating stand-alone 3-D numerical models with excellent agreement with the analytical solution and with each other for the remaining cases (see results with blue background in Figures ES-3 and ES-5 and the GC10a result with magenta background in Figure ES-3). These verified numerical-model results form a secondary mathematical truth standard based on their range of disagreement.

- The high level of agreement among the verified numerical models allowed diagnosis of errors in other mid-level detailed models integrated with whole-building energy simulation software; some may have been missed without the secondary mathematical truth standard.

- Of 24 found disagreements, 19 were diagnosed and fixed, 3 are planned for investigation by the software authors, and 2 were judged as acceptable by the authors of mid-level detailed models (after they had fixed previous disagreements). Several of the found errors affected some individual results by more than $20 \%$; this was after two major problems were fixed as a result of the Task 22 work. A listing of the problems found among the tested models appears in Table 2-8 (see Section 2.6.1 of Part II), with supporting details included in Section 2.4 of Part II.

- Based on this work and previous work of IEA SHC Task 22, there are a number of recommended areas for further investigation with respect to developing additional validation test cases for modeling ground-coupled heat transfer. These are described in detail in Section 2.5.4 of Part II. 


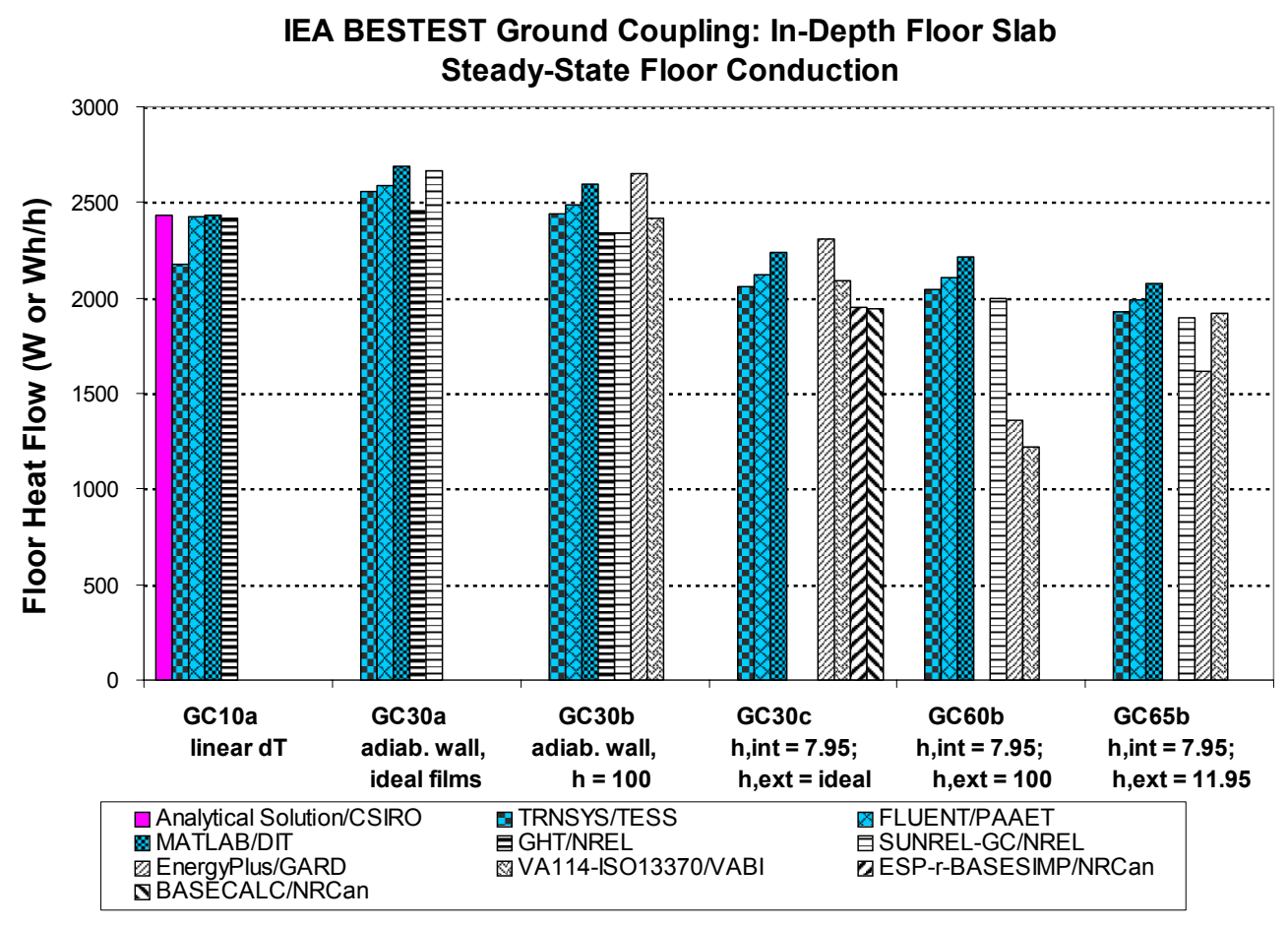

Figure ES-2. BESTEST slab/ground heat transfer steady-state cases - floor conduction, before BESTESTing (Abbreviations along the $\mathrm{x}$-axis are shorthand for the case descriptions; see Part I for full case descriptions.)

IEA BESTEST Ground Coupling: In-Depth Floor Slab Steady-State Floor Conduction

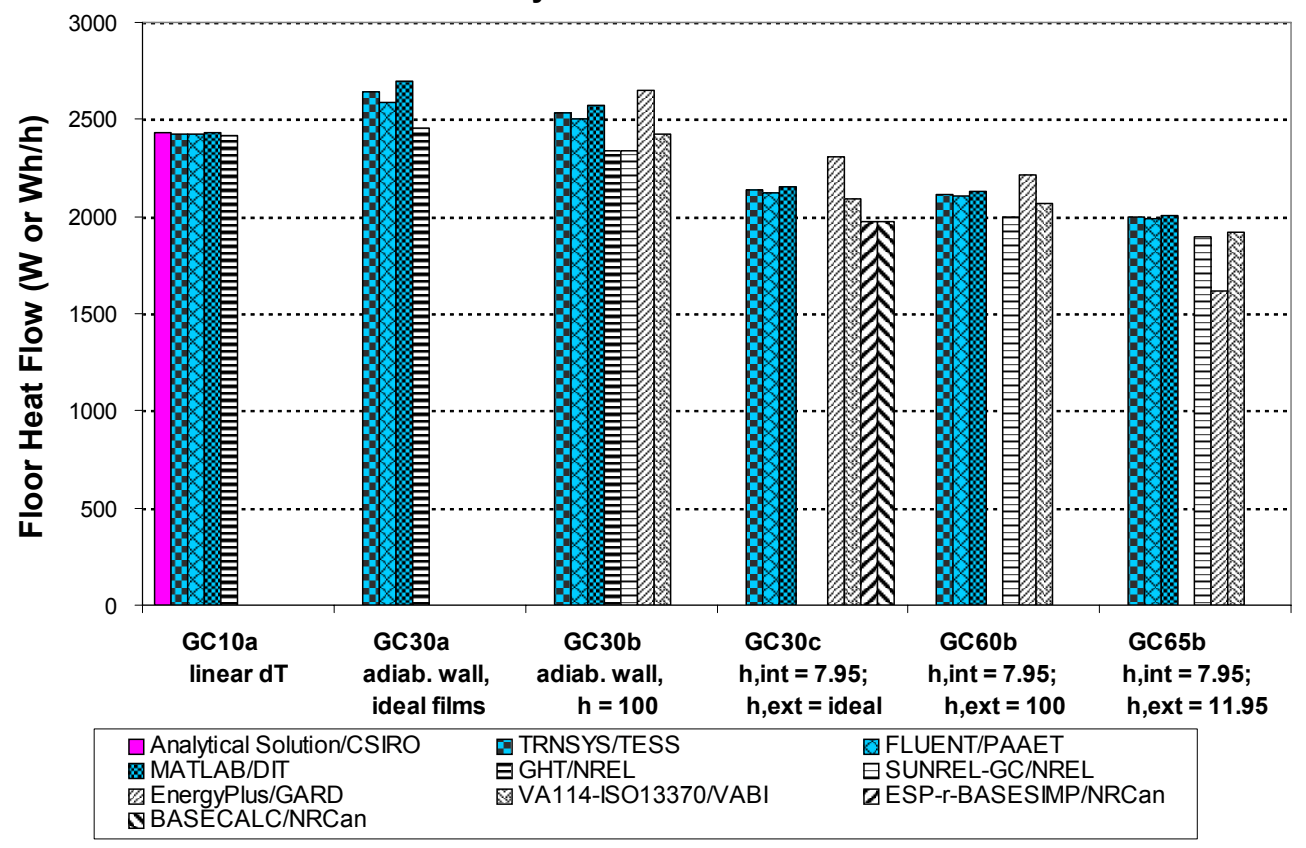

Figure ES-3. BESTEST slab/ground heat transfer steady-state cases - floor conduction, after BESTESTing (Abbreviations along the $\mathrm{x}$-axis are shorthand for the case descriptions; see Part I for full case descriptions.) 


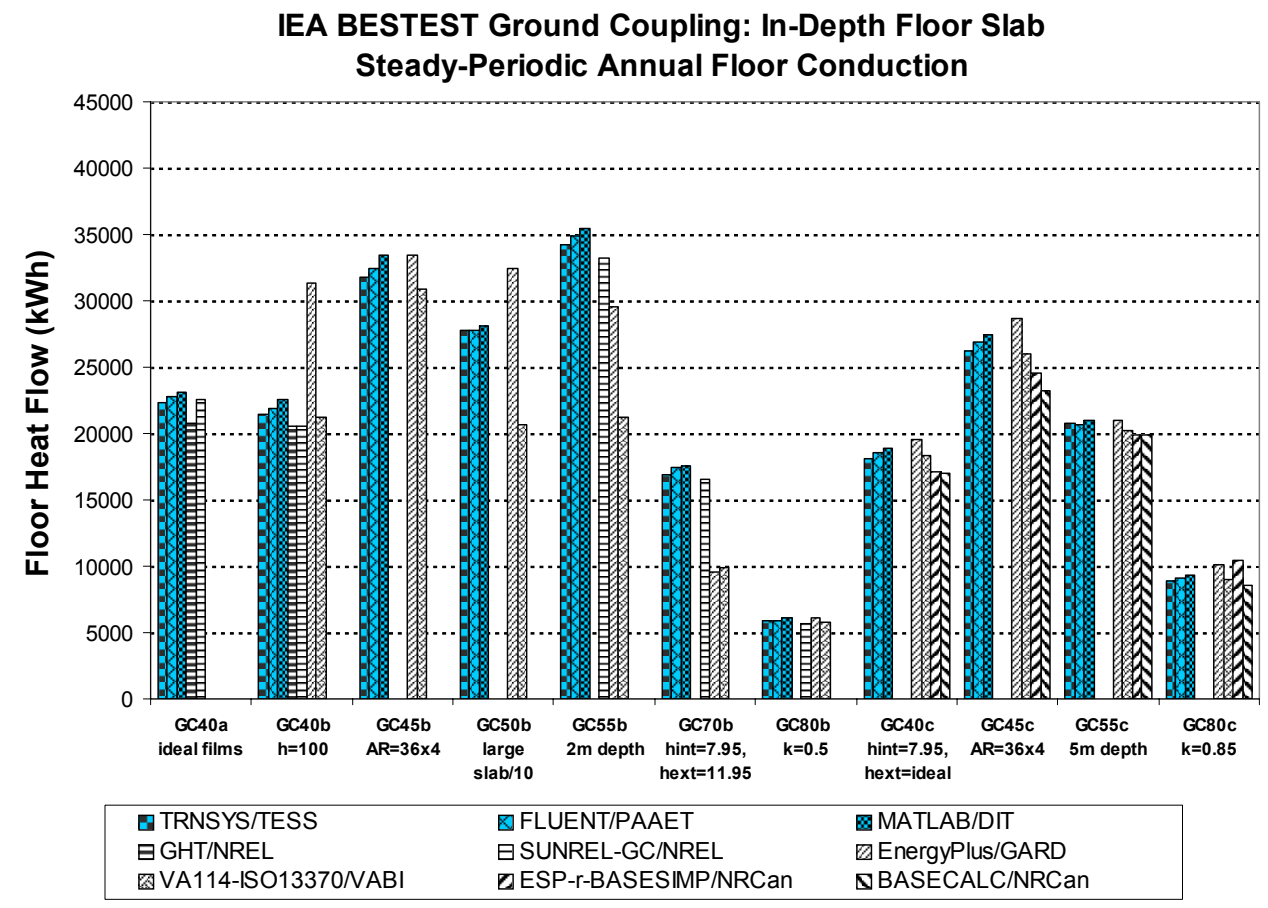

Figure ES-4. BESTEST slab/ground heat transfer state-periodic cases - floor conduction, before BESTESTing (Abbreviations along the $\mathrm{x}$-axis are shorthand for the case descriptions; see Part I for full case descriptions.)

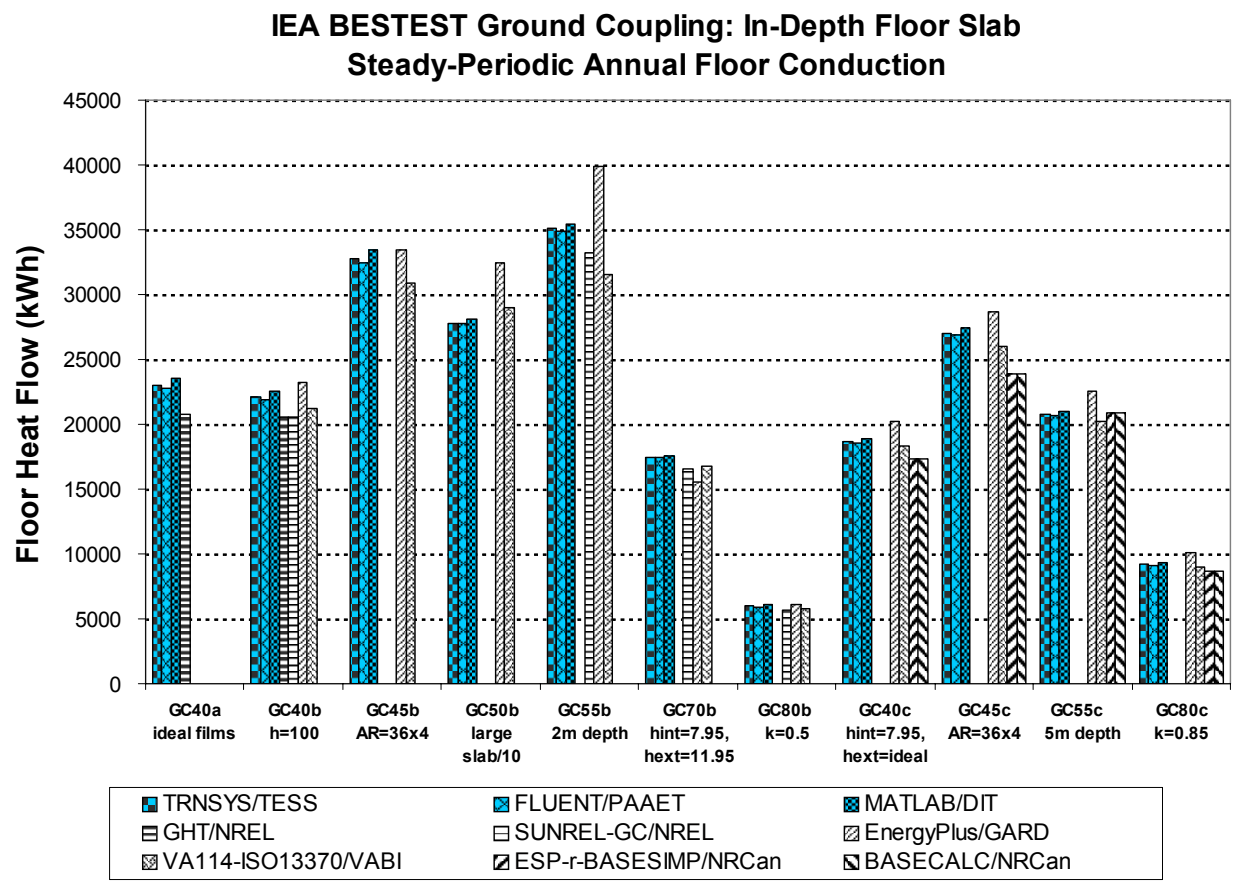

Figure ES-5. BESTEST slab/ground heat transfer steady-periodic cases - floor conduction, after BESTESTing (Abbreviations along the $\mathrm{x}$-axis are shorthand for the case descriptions; see Part I for full case descriptions.) 
Based on results after several iterations of BESTESTing, and resulting model improvements, all tested programs now appear to be generally reliable for modeling ground-coupled heat transfer related to slabon-grade construction, although some remaining disagreements should be addressed. The verified numerical-model results may be used as a reference or benchmark against which other software can be tested. For applications where ground-coupled heat transfer is a major component of a given simulation problem, the superior accuracy of the verified numerical models may justify adapting highly detailed models to more whole-building energy simulation programs, especially as computer hardware continues to improve and the detailed models become more user friendly.

\section{Conclusions}

\section{Major Accomplishments}

The major accomplishments of this project were:

- The IEA BESTEST building thermal fabric envelope tests were expanded to include in-depth diagnostic analytical verification test cases for ground-coupled heat transfer related to slab-ongrade construction.

- A formal methodology was developed to facilitate using and verifying numerical models to establish a secondary mathematical truth standard. This method applies to the test case development and to numerical model implementation, and allows quasi-analytical solutions to be developed for more realistic (less constrained) cases than exact analytical solutions allow.

- A set of verified numerical-model results was developed for all test cases, using the newly developed methodology. This represents a secondary mathematical truth standard founded on the range of disagreement of the numerical-model results.

- The accuracy of all models that participated in the field trials of the test cases was improved: 19 errors were diagnosed and fixed; initial disagreement ranges of $9 \%-55 \%$ for the test cases were reduced to $1 \%-24 \%$ by applying the diagnostic logic of the test cases to expose problems with the models; initial disagreement ranges for only the numerical models were narrower (up to $12 \%$ ), and were similarly reduced to $0 \%-4 \%$ for the verified numerical-model results over the course of the project.

With respect to the value of the test cases to software developers, one software developer/vendor participant made the following comment about this project:

Without this IEA subtask for ground coupling, we would have had no means to check the results from our model, nor had a reason to make improvements to our model. There should be no question that the IEA subtask has improved the TRNSYS ground coupling model and, in doing so, has also provided energy modelers a greatly increased sense of confidence when modeling heat transfer to the ground. ${ }^{26}$

\section{Closing Remarks}

The work presented in this report, other work of IEA SHC Task 34/ECBCS Annex 43, and the work that has preceded it in IEA SHC Tasks 8, 12, and 22 is important for two reasons: (1) the methods have been extremely successful at correcting software errors in advanced building energy simulation programs throughout the world; and (2) the methods are finding their way into industry by being adopted as the theoretical basis for formalized standard methods of test and software certification procedures; in this sense the work may be thought of as pre-normative research. 
Along with the overall validation methodology that has recently been added to the ASHRAE Handbook of Fundamentals, ${ }^{2,3,4,8}$ the following test suites developed in conjunction with the IEA have been codelanguage adapted and formally approved as a standard method of test, ANSI/ASHRAE Standard 1402007: $:^{11}$

- IEA BESTEST, building thermal fabric comparative tests ${ }^{1}$

- HVAC BESTEST Volume 1, unitary cooling equipment analytical verification tests ${ }^{7}$

- HVAC BESTEST Volume 2, unitary cooling equipment comparative tests ${ }^{12}$

- HVAC BESTEST fuel-fired furnace analytical verification and comparative tests. ${ }^{13}$

The new in-depth slab-on-grade ground heat transfer test cases described in this report are also planned for inclusion in Standard 140.

Standard 140 and the reports that comprise the test suites contained therein are being referenced and used by a growing number of code promulgation authorities worldwide. ASHRAE Standard 90.1, ${ }^{35,36}$ which is ASHRAE's consensus energy code for commercial buildings and for non-low-rise residential buildings, requires that software used for demonstrating performance compliance with Standard 90.1 be tested using ASHRAE Standard 140-2004. ${ }^{10}$ Software used to calculate energy savings for the energy-efficient commercial building tax deductions in the United States must be tested with Standard 140-2007. ${ }^{37}$ As part of building energy performance assessments under the European Community's Energy Performance Directive, ${ }^{38}$ several countries are using software tools that have been checked with BESTEST. Further details of international use of BESTEST, along with growing evidence that the BESTEST procedures are becoming part of software developers' normal in-house quality control efforts, are included in Section 2.6.2 of this report and elsewhere. ${ }^{4}$

Computer scientists universally accept the merits of software testing. A well-known rule of thumb is that in a typical programming project more than $50 \%$ of the total cost is expended in testing the program or system being developed. ${ }^{39}$ Of this, about $20 \%$ of development time goes toward system testing. ${ }^{40}$ Because new energy-related technologies are continually being introduced into the buildings market, there will always be a need to further develop simulation models, combined with a substantial program of testing and validation. Such an effort should contain all the elements of an overall validation methodology, ${ }^{4,8}$ including:

- Analytical verification

- Comparative testing and diagnostics

- Empirical validation.

Future work should therefore encompass:

- Continued production of a standard set of analytical tests

- Development of a set of diagnostic comparative tests that emphasize the modeling issues important in large commercial buildings, including more tests for heating, ventilating, and air-conditioning systems, and other mechanical equipment, including on-site power generation equipment

- Development of a sequentially ordered series of high-quality data sets for empirical validation.

Finally, the authors wish to acknowledge that the expertise available through the IEA and the dedication of the participants were essential to the success of this project. Over the 4-year field trial effort, there were several revisions to the BESTEST specifications and subsequent re-executions of the computer simulations. This iterative process led to the refining of the new BESTEST cases, and the results of the tests led to improving and debugging of the simulation models. The process underscores the leveraging of resources for the IEA countries participating in this project. Such extensive field trials, and resulting 
enhancements to the tests, were much more cost effective with the participation of the IEA SHC Task 34/Annex 43 experts.

\section{References for Executive Summary}

${ }^{1}$ Judkoff, R.; Neymark, J. (1995). International Energy Agency Building Energy Simulation Test (IEA BESTEST) and Diagnostic Method. NREL/TP-472-6231. Golden, Colorado, US: National Renewable Energy Laboratory. www.nrel.gov/docs/legosti/old/6231.pdf.

${ }^{2}$ Judkoff, R.; Wortman, D.; O’Doherty, B.; Burch, J. (2008). A Methodology for Validating Building Energy Analysis Simulations. NREL/TP-550-42059. Golden, Colorado, US: National Renewable Energy Laboratory. Based on unpublished report of 1983 with same authors and title, previously referenced as SERI/TR-254-1508. www.nrel.gov/docs/fy08osti/42059.pdf

${ }^{3}$ Judkoff, R. (1988). "Validation of Building Energy Analysis Simulation Programs at the Solar Energy Research Institute." Energy and Buildings, 10(3), 235. Lausanne, Switzerland: Elsevier Sequoia.

${ }^{4}$ Judkoff, R.; Neymark, J. (2006). "Model Validation and Testing: The Methodological Foundation of ASHRAE Standard 140." ASHRAE Transactions, 112 (2) 367-376. Atlanta GA: American Society of Heating, Refrigerating and Air-Conditioning Engineers.

${ }^{5}$ Bloomfield, D., ed. (1989). Design Tool Evaluation: Benchmark Cases. IEA T8B4. Solar Heating and Cooling Programme, Task VIII: Passive and Hybrid Solar Low-Energy Buildings. Building Research Establishment. Garston, Watford, UK: Building Research Establishment.

${ }^{6}$ Lomas, K. (1991). "Dynamic Thermal Simulation Models of Buildings: New Method of Empirical Validation.” Building Services Engineering Research and Technology 12(1):25-37.

${ }^{7}$ Neymark J.; Judkoff, R. (2002). International Energy Agency Building Energy Simulation Test and Diagnostic Method for Heating Ventilating and Air-Conditioning Equipment Models (HVAC BESTEST), Volume 1: Cases E100-E200. NREL/TP-550-30152. Golden, Colorado, US: National Renewable Energy Laboratory. www.nrel.gov/docs/fy02osti/30152.pdf.

${ }^{8}$ ASHRAE. (2005). 2005 Handbook of Fundamentals, Atlanta, Georgia, US: American Society of Heating, Refrigerating and Air-Conditioning Engineers.

${ }^{9}$ ANSI/ASHRAE Standard 140-2001. (2001). Standard Method of Test for the Evaluation of Building Energy Analysis Computer Programs. Atlanta, Georgia, US: American Society of Heating, Refrigerating and Air-Conditioning Engineers.

${ }^{10}$ ANSI/ASHRAE Standard 140-2004. (2004). Standard Method of Test for the Evaluation of Building Energy Analysis Computer Programs. Atlanta, Georgia, US: American Society of Heating, Refrigerating and Air-Conditioning Engineers.

${ }^{11}$ ANSI/ASHRAE Standard 140-2007. (2007). Standard Method of Test for the Evaluation of Building Energy Analysis Computer Programs. Atlanta, Georgia, US: American Society of Heating, Refrigerating and Air-Conditioning Engineers. 
${ }^{12}$ Neymark, J.; Judkoff, R. (2004). International Energy Agency Building Energy Simulation Test and Diagnostic Method for Heating, Ventilating, and Air-Conditioning Equipment Models (HVAC BESTEST), Volume 2: Cases E300-E545. NREL/TP-550-36754. Golden, Colorado, US: National Renewable Energy Laboratory. www.nrel.gov/docs/fy05osti/36754.pdf.

${ }^{13}$ Purdy, J.; Beausoleil-Morrison, I. (2003). Building Energy Simulation Test and Diagnostic Method for Heating, Ventilation, and Air-Conditioning Equipment Models (HVAC BESTEST): Fuel-Fired Furnace Test Cases. Ottawa, Ontario, Canada: CANMET Energy Technology Centre, Natural Resources Canada. Available from www.iea-shc.org/task22/deliverables.htm.

${ }^{14}$ ASHRAE. (2001). 2001 ASHRAE Handbook Fundamentals. Atlanta, Georgia, US: American Society of Heating, Refrigerating and Air-Conditioning Engineers. See pp. 28.12, 28.13.

${ }^{15}$ Wang, F.S. (1979). "Mathematical Modeling and Computer Simulation of Insulation Systems in Below Grade Applications." ASHRAE/DOE Conference on Thermal Performance of the Exterior Envelopes of Buildings. December 3-5, 1979, Kissimmee, FL.

${ }^{16}$ ASHRAE. (1993). 1993 ASHRAE Handbook Fundamentals. Atlanta, Georgia, US: American Society of Heating, Refrigerating and Air-Conditioning Engineers, Inc. See pp. 25.10, 25.11.

${ }^{17}$ Latta, J.K.; Boileau, G.G. (1969). “Heat Losses from House Basements.” Canadian Building 19(10):39.

${ }^{18}$ Judkoff, R.; Neymark, J. (1995). Home Energy Rating System Building Energy Simulation Test (HERS BESTEST). NREL/TP-472-7332. Golden, Colorado, US: National Renewable Energy Laboratory.

Volume 1: Tier 1 and Tier 2 Tests User's Manual, NREL/TP-472-7332a.

www.nrel.gov/docs/legosti/fy96/7332a.pdf;

Volume 2: Tier 1 and Tier 2 Tests Reference Results, NREL/TP-472-7332b.

www.nrel.gov/docs/legosti/fy96/7332b.pdf.

${ }^{19}$ Beausoleil-Morrison, I. (1996). "BASECALC : A Software Tool for Modelling Residential- TM Foundation Heat Losses." Third Canadian Conference on Computing in Civil and Building Engineering. Montreal, pp.117-126.

${ }^{20}$ Beausoleil-Morrison I.; Mitalas G. (1997). "BASESIMP: A Residential-Foundation Heat-Loss Algorithm for Incorporating into Whole-Building Energy-Analysis Programs", Proceedings of Building Simulation '97, (2) 1-8, Int Building Performance Simulation Association, Prague, Czech Republic.

${ }^{21}$ Bahnfleth, W.P.; Pedersen, C.O. (1990). A Three Dimensional Numerical Study of Slab-on-Grade Heat Transfer. ASHRAE Transactions Pt. 2, 96:61-72.

${ }^{22}$ Clements, E. (2004). Three Dimensional Foundation Heat Transfer Modules for Whole-Building Energy Analysis, MS Thesis, Pennsylvania State University.

${ }^{23}$ Crawley, D.; Lawrie, L.; Pedersen, C.; Winkelmann, F.; Witte, M.; Strand, R.; Liesen, R.; Buhl, W.F.; Huang, Y.J.; Henninger, R.; Glazer, J.; Fisher, D.; Shirey, D.; Griffith, B.; Ellis, P.; Gu, L. (2004). "EnergyPlus: New Capable and Linked," in Proceedings of the SimBuild 2004 Conference, August 2004, Boulder, Colorado, US: IBPSA-USA.

${ }^{24}$ ISO 13370. (1998). Thermal Performance of Buildings - Heat Transfer via the Ground-Calculation Methods. European Committee for Standardization. Brussels, Belgium. 
${ }^{25}$ VABI Software BV. (2007). VA114, the Dutch Building Performance Simulation tool. Delft, The Netherlands. Initial development by TNO, further development, distribution, maintenance, and support by Vabi Software BV.

${ }^{26}$ Thornton, J. (2007). Modeler Report for BESTEST Cases GC10a-GC80c, TRNSYS Version 16.1. Madison Wisconsin, US: Thermal Energy System Specialists. Included with Section 2.9, Appendix II-A, of this final report.

${ }^{27}$ Deru, M. (2003). A Model for Ground-Coupled Heat and Moisture Transfer from Buildings. NREL/TP550-33954. Golden, CO: National Renewable Energy Laboratory. www.nrel.gov/docs/fy03osti/33954.pdf

${ }^{28}$ Nakhi, A. (2007). Modeler Report for BESTEST Cases GC10a-GC80c, FLUENT Version 6.0.20.

Kuwait, State of Kuwait: Public Authority for Applied Education and Training. Included with Section 2.9, Appendix II-B, of this final report.

${ }^{29}$ Fluent 6.3 User's Guide. (2007). Lebanon, New Hampshire, US: Fluent Incorporated.

${ }^{30}$ Crowley, M. (2007). Modeler Report for BESTEST Cases GC10a-GC80c, MATLAB 7.0.4.365 (R14) Service Pack 2. Dublin, Ireland: Dublin Institute of Technology. Included with Section 2.9, Appendix II$\mathrm{C}$, of this final report.

${ }^{31}$ The MathWorks, Inc. (2007). Getting Started with MATLAB. Natick, Massachusetts, US: The MathWorks, Inc.

${ }^{32}$ Deru, M.; Judkoff, R.; Neymark, J. (2003). Proposed IEA BESTEST Ground-Coupled Cases. Golden, CO: National Renewable Energy Laboratory. In conjunction with International Energy Agency, Solar Heating and Cooling Programme, Task 22. IEA Working Document. Draft, September 19, 2003.

${ }^{33}$ Spitler, S.; Rees, S.; Xiao, D. (2001). Development of An Analytical Verification Test Suite for Whole Building Energy Simulation Programs - Building Fabric. Final Report for ASHRAE 1052-RP. Stillwater, OK: Oklahoma State University School of Mechanical and Aerospace Engineering.

${ }^{34}$ Delsante A.E., A.N. Stokes, P.J. Walsh. (1983). Application of Fourier Transforms to Periodic Heat Flow into the Ground under a Building. International Journal of Heat Mass Transfer, 26(1): 121-132.

${ }^{35}$ ANSI/ASHRAE/IESNA Standard 90.1-2007. (2007). Energy Standard for Buildings Except Low-Rise Residential Buildings. Atlanta, Georgia, US: American Society of Heating, Refrigerating and AirConditioning Engineers. References ANSI/ASHRAE Standard 140-2004.

${ }^{36}$ ANSI/ASHRAE/IESNA Standard 90.1-2004, Addendum L, Energy Standard for Buildings Except LowRise Residential Buildings. (2005). Atlanta, Georgia, US: American Society of Heating, Refrigerating and Air-Conditioning Engineers. References ANSI/ASHRAE Standard 140-2004.

${ }^{37}$ U.S. Internal Revenue Service. (2008). Amplification of Notice 2006-52, Deduction for Energy Efficient Commercial Buildings. IRS Notice 2008-40. Appears in Internal Revenue Bulletin (IRB) No. 2008-14, April 7, 2008. Washington, DC, US: U.S. Department of Treasury, Internal Revenue Service.

${ }^{38}$ European Union. (2002). On the Energy Performance of Buildings. Directive 2002/91/EC of the European Parliament and of the Council, Official Journal of the European Communities, December. 
${ }^{39}$ Myers, G. (2004). The Art of Software Testing. Hoboken, New Jersey, US: John Wiley \& Sons. See p. xiii.

${ }^{40}$ McConnell, S. (2004). Code Complete: A Practical Handbook of Software Construction. Microsoft Press, p. 502. 


\section{Introduction}

A method of test for evaluating building energy simulation computer programs - International Energy Agency Building Energy Simulation Test and Diagnostic Method (IEA BESTEST) - was developed by the National Renewable Energy Laboratory (NREL) in collaboration with IEA SHC Task 12 and ECBCS Annex 21 (Judkoff and Neymark 1995a). During follow-on IEA SHC Task 22, preliminary test cases were developed to extend the capabilities of IEA BESTEST for testing detailed models of ground-coupled heat transfer with respect to various slab-on-grade and basement constructions. (Deru, Judkoff, and Neymark 2003). Results of the Task 22 project indicated substantial disagreements among detailed ground-coupled heat transfer models linked to whole-building energy simulation software, where the sources of such disagreements could not be readily determined. New work presented herein, which follows up Task 22, was conducted by NREL in collaboration with the participants of IEA SHC Task 34/ ECBCS Annex 43, Project A (Ground-Coupled Heat Transfer with respect to Floor Slab and Basement Constructions). The objective of Project A is to develop in-depth diagnostic test cases for ground-coupled heat transfer models that can identify the causes of differences in results found during the Task 22 work, so they can be corrected.

\section{Background}

As above-grade components of the building thermal fabric become more energy efficient, the heat transfer between the building and the ground becomes relatively more important. Ground-coupled heat transfer is a complex phenomenon that involves three-dimensional thermal conduction, moisture transport, long time constants, and the heat storage properties of the ground. To estimate the importance of ground-coupled heat transfer, we reviewed SERIRES/SUNCODE simulations for Colorado Springs Colorado (6415 HDD65) for the Home Energy Rating Systems (HERS) BESTEST (Judkoff and Neymark 1995b) uninsulated and insulated slab-on-grade test cases. These HERS BESTEST cases use a singlestory house with typical roof and wall insulation characteristics, and specify slab-on-grade soil geometry and material property characteristics consistent with the ASHRAE perimeter method simplified ground heat transfer model (ASHRAE 2001; Wang 1979). SERIRES/SUNCODE simulation results for an uninsulated slab-on-grade, using two simplified ground heat transfer models, indicate that $41 \%-45 \%$ of building heating load is generated by heat transfer through the floor, depending on the model. These simulation results also indicate that the type of ground heat transfer model applied in the HERS BESTEST uninsulated slab-on-grade case causes a variation in the calculated floor heat flow of $25 \%$, and variation in the overall building heating load of $13 \%$. Similarly, for the HERS BESTEST insulated slab case SERIRES/SUNCODE indicates $25 \%-28 \%$ of heating load is caused by heat transfer through the floor. These simulation results further indicate that the type of simplified ground heat transfer model applied in the HERS BESTEST insulated slab case causes a variation in the calculated floor heat flow of $26 \%$, and variation in the overall building heating load of $12 \%$. Simulations of the HERS-BESTEST house for five California (generally milder) climates indicate heat flow through an uninsulated slab-ongrade floor (with carpet) represents $17 \%-45 \%$ of annual heating loads and $4 \%-22 \%$ of peak-hour heating load, depending on climate and ground modeling technique (Neymark 2007). Furthermore, the range of disagreement of floor conduction heating loads varied $60 \%-300 \%$ for a given climate depending on the models. This is consistent with work by Beausoleil-Morrison (2006) who presented study results indicating a 40\%-55\% uninsulated slab-on-grade heat loss difference for ASHRAE's simplified method versus more advanced methods. These estimates indicate a high degree of uncertainty, especially for simplified ground heat transfer models typically applied in building energy simulations.

A brief history of ground heat transfer model development, evolution of the BESTEST ground-coupled heat transfer cases, and summary discussion of the new in-depth diagnostic cases for ground-coupled heat transfer related to slab-on-grade construction, are provided in the Executive Summary. 


\section{Advantages of BESTEST Methodology}

An advantage of the BESTEST methodology is that a program is examined over a broad range of parametric interactions based on a variety of output types. This minimizes the possibility that compensating errors will conceal problems. The tests resulted in quality improvements to all slab-ongrade heat transfer models and building energy simulation programs used in the field trials. Although the advancement of the state-of-the-art in ground heat transfer modeling is relatively recent, some of the bugs that were found may well have been present for several years. The fact that they have just now been uncovered shows the power of BESTEST and suggests the importance of continuing to develop formalized validation and diagnostic methods. Only after coding bugs have been eliminated can the assumptions and approximations in the algorithms be evaluated.

Checking a building energy simulation program for the first time with the BESTEST in-depth slab-ongrade heat transfer cases requires about one person-week for an experienced simulation user, not including improvements to software if necessary. Subsequent program checks are faster because input files may be reused. Because the simulation programs have taken many years to produce, the new BESTEST cases provide a very cost-effective way of testing them. As we continue to develop new test cases, we will adhere to the principle of parsimony so the entire suite of BESTEST cases may be implemented by users with a reasonable time commitment.

Software developers, architects, engineers, and researchers can use these new BESTEST cases to:

- Compare output from building energy simulation programs to a set of analytical and quasianalytical solutions that constitute a reliable set of theoretical results given the underlying physical assumptions in the case definitions.

- Compare several building energy simulation programs to determine the degree of disagreement among them.

- Diagnose the algorithmic sources of prediction differences among several building energy simulation programs.

- Compare predictions from other building energy simulation programs to the analytical solution, verified numerical-model results, and simulation results in this report.

- Check a program against a previous version of itself after internal code modifications to ensure only the intended changes resulted.

- Check a program against itself after a single algorithmic change to understand the sensitivity among algorithms.

\section{Other BESTEST Procedures}

As a BESTEST user, if you have not already tested your software with previously developed BESTEST procedures, we strongly recommend that you run all the building thermal fabric and mechanical equipment cases currently included in ANSI/ASHRAE Standard 140-2007. (ANSI/ASHRAE 2007; Judkoff and Neymark 1995a; Neymark and Judkoff 2002, 2004; Purdy and Beausoleil-Morrison 2003.) Another set of building thermal fabric test cases, which were designed to test simplified tools such as those currently used for home energy rating systems, is included in HERS BESTEST (Judkoff and Neymark 1995b; Judkoff and Neymark 1997). HERS BESTEST, which is being adapted for Standard 140, has a more realistic base building than the IEA BESTEST building thermal fabric test cases that are currently included with Standard 140; however, its ability to diagnose sources of results differences is less robust (Neymark and Judkoff 1997). 


\section{Report Structure}

This report is divided into three parts. Part I is a user's manual that furnishes instructions on how to apply this BESTEST procedure. Part II describes the development, field-testing, and production of results data for the procedure. Part III presents the simulation program example results in tables and graphs along with disagreement statistics that compare the simulation programs to each other; these data can be used to compare results from other programs to Part III results.

\section{References for Introduction}

ANSI/ASHRAE Standard 140-2007. (2007). Standard Method of Test for the Evaluation of Building Energy Analysis Computer Programs. Atlanta, Georgia, US: American Society of Heating, Refrigerating and Air-Conditioning Engineers.

ASHRAE. (2001). 2001 ASHRAE Handbook Fundamentals. Atlanta, Georgia, US: American Society of Heating, Refrigerating and Air-Conditioning Engineers. See pp. 28.12-13.

Beausoleil-Morrison, I. (2006). "Heat Losses through Basement and Slab-On-Grade Foundations." ASHRAE Annual Meeting, Seminar 45. June 24-28, 2006. Quebec City, Quebec, Canada.

Deru, M.; Judkoff, R.; Neymark, J. (2003). Proposed IEA BESTEST Ground-Coupled Cases. Golden, CO: National Renewable Energy Laboratory. In conjunction with IEA SHC Programme, Task 22. IEA Working Document. Draft, September 19, 2003.

Judkoff, R.; Neymark, J. (1995a). International Energy Agency Building Energy Simulation Test (BESTEST) and Diagnostic Method. Golden, Colorado, US: National Renewable Energy Laboratory, NREL/TP-472-6231, www.nrel.gov/docs/legosti/old/6231.pdf.

Judkoff, R.; Neymark, J. (1995b). Home Energy Rating System Building Energy Simulation Test (HERS BESTEST). Golden, Colorado, US: National Renewable Energy Laboratory, NREL/TP-472-7332.

Volume 1: Tier 1 and Tier 2 Tests User's Manual, NREL/TP-472-7332a, www.nrel.gov/docs/legosti/fy96/7332a.pdf;

Volume 2: Tier 1 and Tier 2 Tests Reference Results, NREL/TP-472-7332b, www.nrel.gov/docs/legosti/fy96/7332b.pdf.

Judkoff, R.; Neymark, J. (1997). Home Energy Rating System Building Energy Simulation Test for Florida (Florida-HERS BESTEST). Golden, Colorado, US: National Renewable Energy Laboratory, NREL/TP-550-23124, www.nrel.gov/docs/legosti/fy97/23124a.pdf.

Neymark J. (2007). Uncertainty in Ground Heat Transfer Based on Modeling Method and California Climate. Wheat Ridge, CO: J. Neymark \& Associates. Draft.

Neymark, J.; Judkoff, R. (1997). “A Comparative Validation Based Certification Test for Home Energy Rating System Software.” Proceedings of Building Simulation '97. September 8-10, Prague, Czech Republic. International Building Performance Simulation Association.

Neymark J.; Judkoff, R. (2002). International Energy Agency Building Energy Simulation Test and Diagnostic Method for Heating, Ventilating, and Air-Conditioning Equipment Models (HVAC BESTEST), Volume 1: Cases E100-E200. NREL/TP-550-30152. Golden, Colorado, US: National Renewable Energy Laboratory. www.nrel.gov/docs/fy02osti/30152.pdf. 
Neymark, J.; Judkoff, R. (2004). International Energy Agency Building Energy Simulation Test and Diagnostic Method for Heating, Ventilating, and Air-Conditioning Equipment Models (HVAC BESTEST), Vol. 2: Cases E300-E545. Golden, Colorado, US: National Renewable Energy Laboratory, NREL/TP550-36754, www.nrel.gov/docs/fy05osti/36754.pdf.

Purdy, J.; Beausoleil-Morrison, I. (2003). Building Energy Simulation Test and Diagnostic Method for Heating, Ventilating, and Air-Conditioning Equipment Models (HVAC BESTEST): Fuel-Fired Furnace Test Cases. Ottawa, Canada: Natural Resources Canada, CANMET Energy Technology Centre. www.ieashc.org/task22/deliverables.htm.

Wang, F.S. (1979). "Mathematical Modeling and Computer Simulation of Insulation Systems in Below Grade Applications." ASHRAE/DOE Conference on Thermal Performance of the Exterior Envelopes of Buildings. December 3-5, 1979, Kissimmee, FL. 


\subsection{Part I: BESTEST User's Manual: Procedure and Specification Cases GC10a - GC80c}

\subsection{General Description of the Test Cases}

Seventeen test cases are summarized in Tables 1-1 and 1-2. The test cases are designed to use the results of verified detailed numerical ground-coupled heat transfer models as a secondary mathematical truth standard for comparing the results of simplified and mid-level detailed ground-coupled heat transfer models typically used with whole-building energy simulation software. The new test cases use an idealized uninsulated slab-in-grade configuration. This simplified configuration is required by the analytical solution of Case GC10a, is appropriate for developing robust ground-coupling test cases, is compatible with all of the programs run in field trials of the test procedure, and facilitated development of accurate model results by minimizing chances for input errors. Parametric variations versus a steady-state base case (Case GC30b) include periodic ground surface temperature variation, floor slab aspect ratio, slab area, deep ground temperature depth (water table depth), slab and ground thermal conductivity, and slab-interior and ground-exterior surface heat transfer coefficients (realistic versus high values to test the effect of surface temperature uniformity). The cases use both steady-state and harmonic boundary conditions applied with artificially constructed annual weather data, along with an adiabatic above-grade building envelope to isolate the effects of ground-coupled heat transfer. Because the zone-heating load is driven exclusively by the slab heat losses, it is equal to the slab conduction heat loss. This is convenient for testing programs that may not readily disaggregate floor conduction losses in their output. Various output values - including steady-state, annual total steady-periodic, and annual peak hour steady-periodic results for floor conduction and zone heating load, along with time of occurrence of peak-hour loads and other supporting output - are compared and used in conjunction with a formal diagnostic method to determine algorithms responsible for predictive differences. The test cases are divided into three categories:

- "a"-series cases are for the most detailed numerical-methods programs (e.g., three-dimensional [3-D] numerical models that have been developed for whole-building energy simulation programs such as TRNSYS and SUNREL-GC, and similarly detailed models developed using FLUENT and MATLAB); the intent of these cases is to demonstrate that the numerical models have been properly applied.

- "b"-series cases are for more constrained models used in whole-building simulation programs (e.g. EnergyPlus and the ISO 13370 calculation method), allowing comparison with the more detailed/flexible models.

- "c"-series cases apply boundary conditions that are compatible with BASESIMP, allowing comparison of BASESIMP with the other models.

A preliminary analytical verification case (Case GC10a) is included for comparing detailed 3-D numerical models to a 3-D steady-state analytical solution (Delsante, Stokes, and Walsh 1983) that incorporates boundary conditions that may be difficult to model in the context of a whole-building simulation. Case GC10a provides an analytical solution reference result for checking detailed numerical models for overall correctness and proper application in this context.

The test specification is structured such that the " $b$ "-series cases, which are likely to be possible for more programs than the "a"- or "c"-series cases, are presented first. The "a"- and "c"-series cases, which are derived from the "b"-series cases, are presented in later sections. If the program being tested can run the "a"-series cases as they are described, run the "a"-series cases before running any of the other cases. 
Table 1-1. Ground Coupling In-Depth Diagnostic "a"-Series and "b"-Series Cases

\begin{tabular}{|c|c|c|c|c|c|c|c|c|c|}
\hline Case & Description/Test & Dynamic & $\begin{array}{c}\text { Slab } \\
\text { Dimen. } \\
(\mathrm{m} \times \mathrm{m}) \\
\end{array}$ & $\begin{array}{c}\text { h,int } \\
\left(W / m^{2} K\right) \\
\end{array}$ & $\begin{array}{c}\mathrm{h}, \mathrm{ext} \\
\left(\mathrm{W} / \mathrm{m}^{2} \mathrm{~K}\right)\end{array}$ & $\begin{array}{c}\text { Ground } \\
\text { Depth } \\
(\mathrm{m}) \\
\end{array}$ & $\begin{array}{l}\text { Far-Field } \\
\text { Bound }^{\mathrm{b}} \\
(\mathrm{m}) \\
\end{array}$ & $\begin{array}{l}\text { Cond. } \\
(\mathrm{W} / \mathrm{mK})\end{array}$ & Comments \\
\hline \multicolumn{10}{|c|}{ Analytical Verification Tests } \\
\hline GC10a & $\begin{array}{l}\text { Analytical Base Case } \\
\text { Original Delsante et al. (1983) } \\
\text { Rectangular floor slab, } \\
\text { steady-state, 3-d conduction }\end{array}$ & steady state & $12 \times 12$ & const $\mathrm{T}^{\mathrm{a}}$ & const $\mathrm{T}^{\mathrm{a}}$ & infinite & infinite & 1.9 & $\begin{array}{l}\text { Analytical verification of detailed numerical-methods models, including } \\
\text { set up of node meshing and boundary conditions. } \\
\text { Boundary Conditions: constant temperature floor }(\mathrm{Ti}) \text { and exterior ground } \\
\text { (To) surfaces; linear dT across slab perimeter surface boundary } \\
\text { Other Inputs: } 24 \mathrm{~cm} \text { perimeter boundary width, } \mathrm{To}=10^{\circ} \mathrm{C}, \mathrm{Ti}=30^{\circ} \mathrm{C} \text {, } \\
\text { suppress all other modes of heat transfer. }\end{array}$ \\
\hline \multicolumn{10}{|c|}{ Comparative Tests } \\
\hline GC30a & $\begin{array}{l}\text { Comparative Base Case } \\
\text { for "a"-series }\end{array}$ & steady state & $12 \times 12$ & const $\mathrm{T}^{\mathrm{a}}$ & const $\mathrm{T}^{\mathrm{a}}$ & 30 & 20 & 1.9 & $\begin{array}{l}\text { Boundary Conditions: slab perimeter surface is adiabatic } \\
\text { GC30a-GC10a tests adiabatic versus linear dT slab perimeter surface b.c. }\end{array}$ \\
\hline $\mathrm{GC} 30 \mathrm{~b}$ & $\begin{array}{l}\text { Comparative Base Case } \\
\text { for "b"-series }\end{array}$ & steady state & $12 \times 12$ & 100 & 100 & 15 & 15 & 1.9 & $\begin{array}{l}\text { Most robust version of } \mathrm{G} C 30 \mathrm{a} \text { possible for EnergyPlus and SUNREL-GC } \\
\text { Inputs: To, } \mathrm{a}=10^{\circ} \mathrm{C}, \mathrm{Ti}, \mathrm{a}=30^{\circ} \mathrm{C} \text {. } \\
\text { GC30b-GC30a tests } \mathrm{h}=100 \text { versus direct } \mathrm{T}^{\mathrm{c}}\end{array}$ \\
\hline GC40a & Harmonic Variation & harmonic & $12 \times 12$ & $\operatorname{direct} \mathrm{T}^{\mathrm{a}}$ & $\operatorname{direct} \mathrm{T}^{\mathrm{a}}$ & 30 & 20 & 1.9 & $\begin{array}{l}\text { Annual "harmonic" variation of To or To,a: mean }=10^{\circ} \mathrm{C} \text {, low }=2^{\circ} \mathrm{C} \text {, high }=18^{\circ} \mathrm{C} \\
\text { GC40 tests phase shift of varying q versus varying To }\end{array}$ \\
\hline GC40b & Harmonic Variation & harmonic & $12 \times 12$ & 100 & 100 & 15 & 15 & 1.9 & GC40-GC30 tests annual mean q for varying versus steady To \\
\hline GC45b & Aspect Ratio (AR) & harmonic & $36 \times 4$ & 100 & 100 & 15 & 15 & 1.9 & GC45b-GC40b tests aspect ratio, high perimeter heat transfer fraction \\
\hline GC50b & Large Slab & harmonic & $80 \times 80$ & 100 & 100 & 15 & 15 & 1.9 & GC50b-GC40b tests large slab, high core heat transfer fraction \\
\hline GC55b & Shallow Deep Ground Temp. & harmonic & $12 \times 12$ & 100 & 100 & 2 & 15 & 1.9 & $\begin{array}{l}\text { GC55b-GC40b tests shallow deep ground temperature, high core heat } \\
\text { transfer fraction }\end{array}$ \\
\hline GC60b & h,int & steady state & $12 \times 12$ & 7.95 & 100 & 15 & 15 & 1.9 & GC60b-GC30b tests h,int and resulting floor surface Temp. distribution \\
\hline GC65b & $\mathrm{h}$,int and $\mathrm{h}, \mathrm{ext}$ & steady state & $12 \times 12$ & 7.95 & 11.95 & 15 & 15 & 1.9 & $\begin{array}{l}\text { GC65b-GC60b tests } h \text {,ext and resulting ground surface Temp. distribution } \\
\text { GC65b-GC30b tests combined effects of } h \text {,int and } h \text {,ext }\end{array}$ \\
\hline GC70b & Harmonic $\mathrm{h}$,int and $\mathrm{h}$,ext & harmonic & $12 \times 12$ & 7.95 & 11.95 & 15 & 15 & 1.9 & $\begin{array}{l}\text { GC70b-GC40b tests combined effects of h,int and h,ext in dynamic context } \\
\text { GC70b-GC65b tests annual mean q for varying versus steady To }\end{array}$ \\
\hline GC80b & Ground Conductivity & harmonic & $12 \times 12$ & 100 & 100 & 15 & 15 & 0.5 & GC80b-GC40b tests ground conductivity \\
\hline \multicolumn{3}{|c|}{$\begin{array}{l}\text { Abbreviations: } \\
\text { "b.c." = boundary condition } \\
\text { "Cond." = slab \& soil conductivity } \\
\text { "const T" = direct input constant temperature } \\
\text { "Dimen." = dimension }\end{array}$} & \multicolumn{5}{|c|}{$\begin{array}{l}\text { "direct T" = direct input temperature (varies hourly) } \\
\text { "dT" = temperature variation } \\
\text { "h,ext" = exterior surface convective coefficient } \\
\text { "h,int" = interior surface convective coefficient } \\
\text { "q" = heat flow through floor slab }\end{array}$} & & $\begin{array}{l}\text { "Temp." = temperature } \\
\text { "Ti" = slab interior surface temperature } \\
\text { "Ti,a" = zone air temperature } \\
\text { "To" = exterior ground surface temperature } \\
\text { "To,a" = outdoor dry-bulb temperature } \\
\end{array}$ \\
\hline \begin{tabular}{|l} 
Dimer \\
Notes:
\end{tabular} & \multicolumn{9}{|c|}{$\begin{array}{l}\text { a For models that require air temperature inputs (i.e., that do not allow direct input of surface temperatures), convective surface coefficients are effectively infinite. } \\
\text { b Distance from slab edge. } \\
{ }^{c} \text { GC30c-GC30a also includes minor difference in amount of soil modeled. }\end{array}$} \\
\hline
\end{tabular}


Table 1-2. Ground Coupling In-Depth Diagnostic "c"-Series Cases

\begin{tabular}{|c|c|c|c|c|c|c|c|c|c|}
\hline Case & Description/Test & Dynamic & $\begin{array}{l}\text { Slab } \\
\text { Dimen. } \\
(\mathrm{m} \times \mathrm{m})\end{array}$ & $\begin{array}{c}\text { h,int } \\
\left(\mathrm{W} / \mathrm{m}^{2} \mathrm{~K}\right) \\
\end{array}$ & $\begin{array}{c}\mathrm{h}, \mathrm{ext} \\
\left(\mathrm{W} / \mathrm{m}^{2} \mathrm{~K}\right)\end{array}$ & $\begin{array}{l}\text { Ground } \\
\text { Depth } \\
(\mathrm{m})\end{array}$ & $\begin{array}{c}\text { Far-Field } \\
\text { Bound }^{\mathrm{b}} \\
(\mathrm{m})\end{array}$ & $\begin{array}{l}\text { Cond. } \\
(\mathrm{W} / \mathrm{mK})\end{array}$ & Comments \\
\hline GC30c & $\begin{array}{l}\text { Comparative Base Case } \\
\text { for "c"-series }\end{array}$ & steady state & $12 \times 12$ & 7.95 & const $\mathrm{T}^{\mathrm{a}}$ & 15 & 8 & 1.9 & $\begin{array}{l}\text { Most robust version of GC30 that can be done by BASESIMP } \\
\text { Inputs: } \mathrm{To}=10^{\circ} \mathrm{C}, \mathrm{Ti}, \mathrm{a}=30^{\circ} \mathrm{C} \text {. } \\
\text { GC30c-GC } 30 \mathrm{a} \text { tests reduced } \mathrm{h} \text {, int }=\text { versus direct } \mathrm{T}^{\mathrm{c}}\end{array}$ \\
\hline GC40c & Harmonic Variation & harmonic & $12 \times 12$ & 7.95 & $\operatorname{direct} \mathrm{T}^{\mathrm{a}}$ & 15 & 8 & 1.9 & $\begin{array}{l}\text { GC40c tests phase shift of varying q versus varying To } \\
\text { GC40c-GC30c tests annual mean q for varying versus steady To }\end{array}$ \\
\hline GC45c & Aspect Ratio (AR) & harmonic & $36 \times 4$ & 7.95 & $\operatorname{direct} \mathrm{T}^{\mathrm{a}}$ & 15 & 8 & 1.9 & GC45c-GC40c tests aspect ratio, high perimeter heat transfer fraction \\
\hline GC55C & Shallow Deep Ground Temp. & harmonic & $12 \times 12$ & 7.95 & $\operatorname{direct} \mathrm{T}^{\mathrm{a}}$ & 5 & 8 & 1.9 & $\begin{array}{l}\text { GC55c-GC40c tests shallow deep ground temperature, high core heat } \\
\text { transfer fraction }\end{array}$ \\
\hline GC80c & Ground Conductivity & harmonic & $12 \times 12$ & 7.95 & $\operatorname{direct} \mathrm{T}^{\mathrm{a}}$ & 15 & 8 & 0.85 & GC80c-GC40c tests ground conductivity \\
\hline \multicolumn{3}{|c|}{$\begin{array}{l}\text { "Cond." = slab and soil conductivity } \\
\text { "const T" = direct input constant temperature } \\
\text { "Dimen." = dimension } \\
\text { "direct T" = direct input temperature (varies hourly) }\end{array}$} & \multicolumn{5}{|c|}{$\begin{array}{l}\text { "h,ext" = exterior surface convective coefficient } \\
\text { "h,int" = interior surface convective coefficient } \\
\text { "q" = heat flow through floor slab } \\
\text { "Temp." = temperature }\end{array}$} & & $\begin{array}{l}\text { "Ti,a" = zone air temperature } \\
\text { "To" = exterior ground surface temperature }\end{array}$ \\
\hline Notes: & \multicolumn{9}{|c|}{$\begin{array}{l}\text { a For models that require air temperature inputs (which do not allow direct input of surface temperatures), convective surface coefficients are effectively infinite. } \\
\text { b Distance from slab edge. } \\
{ }^{c} \text { GC30c-GC30a also includes minor difference in amount of soil modeled. }\end{array}$} \\
\hline
\end{tabular}




\subsubsection{Accompanying Electronic Files}

The files described below are included in the .zip file link on the cover page of the posted electronic version of this document; click on "Link to Required Zipped Data Files (6 MB)."

\subsubsection{Weather Data Files}

The following TMY2-format weather data files are included with the accompanying electronic media:

\section{GCSS-W40.TM2, GCSS-W20.TM2, GCSS-W01.TM2, GCSP-W40.TM2, GCSP-W20.TM2, GCSP-W01.TM2.}

A summary of site and weather parameters is given in Table 1-3. These apply to the test cases as follows:

\begin{tabular}{ll|ll} 
Case & Weather Data & Case & Weather Data \\
\hline GC10a & none & GC65b & GCSS-W01.TM2 \\
GC30a & GCSS-W40.TM2 & GC70b & GCSP-W01.TM2 \\
GC30b & GCSS-W20.TM2 & GC80b & GCSP-W20.TM2 \\
GC40a & GCSP-W40.TM2 & GC30c & GCSS-W40.TM2 \\
GC40b & GCSP-W20.TM2 & GC40c & GCSP-W40.TM2 \\
GC45b & GCSP-W20.TM2 & GC45c & GCSP-W40.TM2 \\
GC50b & GCSP-W20.TM2 & GC55c & GCSP-W40.TM2 \\
GC55b & GCSP-W20.TM2 & GC80c & GCSP-W40.TM2 \\
GC60b & GCSS-W20.TM2 & &
\end{tabular}

Table 1-3. Site and Weather Summary for Ground-Coupled Heat Transfer Tests-TMY2 Data

\begin{tabular}{|c|c|c|c|}
\hline \multicolumn{3}{|l|}{ Weather Type } & Artificial Conditions \\
\hline \multicolumn{3}{|l|}{ Weather Format } & TMY2 \\
\hline \multicolumn{3}{|l|}{ Latitude } & $25.8^{\circ}$ North \\
\hline \multicolumn{3}{|l|}{ Longitude (local site) } & $80.3^{\circ}$ West \\
\hline \multicolumn{3}{|l|}{ Altitude } & $2 \mathrm{~m}(6.6 \mathrm{ft})$ \\
\hline \multicolumn{3}{|c|}{ Time Zone (Standard Meridian Longitude) } & $5\left(75^{\circ}\right.$ West $)$ \\
\hline \multicolumn{3}{|l|}{ Site } & $\begin{array}{l}\text { Flat, unobstructed, located } \\
\text { exactly at weather station }\end{array}$ \\
\hline \multicolumn{3}{|c|}{ Dew Point Temperature (constant) } & $-56.6^{\circ} \mathrm{C}\left(-69.9^{\circ} \mathrm{F}\right)$ \\
\hline \multicolumn{3}{|c|}{ Humidity Ratio (constant) } & $\begin{array}{l}0.000007 \mathrm{~kg} \text { moisture } / \mathrm{kg} \text { dry air } \\
(0.000007 \mathrm{lb} \text { moisture/lb dry air) }\end{array}$ \\
\hline \multicolumn{3}{|c|}{ Global Horizontal Solar Radiation Annual Total } & $0 \mathrm{MJ} / \mathrm{m}^{2}\left(0 \mathrm{kBtu} / \mathrm{ft}^{2}\right)$ \\
\hline \multicolumn{3}{|c|}{ Direct Normal Solar Radiation Annual Total } & $0 \mathrm{MJ} / \mathrm{m}^{2}\left(0 \mathrm{kBtu} / \mathrm{ft}^{2}\right)$ \\
\hline \multicolumn{3}{|c|}{ Diffuse Horizontal Solar Radiation Annual Total } & $0 \mathrm{MJ} / \mathrm{m}^{2}\left(0 \mathrm{kBtu} / \mathrm{ft}^{2}\right)$ \\
\hline $\begin{array}{l}\text { Quantities That Vary } \\
\text { between Data Sets }\end{array}$ & $\begin{array}{l}\text { Mean Ambient Dry- } \\
\text { Bulb Temperature }\end{array}$ & $\begin{array}{l}\text { Mean Ambient } \\
\text { Relative Humidity }\end{array}$ & Constant Annual Wind Speed \\
\hline GCSS-W40.TM2 & $\begin{array}{l}10^{\circ} \mathrm{C}\left(50.0^{\circ} \mathrm{F}\right) \\
\text { constant }\end{array}$ & $0.09 \%$, constant & $40.0 \mathrm{~m} / \mathrm{s}(89.48 \mathrm{miles} / \mathrm{h})$ \\
\hline GCSS-W20.TM2 & $\begin{array}{l}10^{\circ} \mathrm{C}\left(50.0^{\circ} \mathrm{F}\right) \\
\text { constant }\end{array}$ & $0.09 \%$, constant & $19.9 \mathrm{~m} / \mathrm{s}$ (44.52 miles $/ \mathrm{h})$ \\
\hline GCSS-W01.TM2 & $\begin{array}{l}10^{\circ} \mathrm{C}\left(50.0^{\circ} \mathrm{F}\right) \\
\text { constant }\end{array}$ & $0.09 \%$, constant & $1.0 \mathrm{~m} / \mathrm{s}(2.24 \mathrm{miles} / \mathrm{h})$ \\
\hline GCSP-W40.TM2 & $\begin{array}{l}10^{\circ} \mathrm{C}\left(50.0^{\circ} \mathrm{F}\right), \\
\text { harmonically varying }\end{array}$ & $\begin{array}{l}0.09 \%, \text { harmonically } \\
\text { varying }\end{array}$ & $40.0 \mathrm{~m} / \mathrm{s}$ (89.48 miles $/ \mathrm{h})$ \\
\hline GCSP-W20.TM2 & $\begin{array}{l}10^{\circ} \mathrm{C}\left(50.0^{\circ} \mathrm{F}\right) \\
\text { harmonically varying }\end{array}$ & $\begin{array}{l}0.09 \%, \text { harmonically } \\
\text { varying }\end{array}$ & $19.9 \mathrm{~m} / \mathrm{s}$ (44.52 miles $/ \mathrm{h})$ \\
\hline GCSP-W01.TM2 & $\begin{array}{l}10^{\circ} \mathrm{C}\left(50.0^{\circ} \mathrm{F}\right), \\
\text { harmonically varying }\end{array}$ & $\begin{array}{l}0.09 \%, \text { harmonically } \\
\text { varying }\end{array}$ & $1.0 \mathrm{~m} / \mathrm{s}(2.24 \mathrm{miles} / \mathrm{h})$ \\
\hline
\end{tabular}




\subsubsection{Other Accompanying Electronic Files}

For reporting output use the following file provided with the accompanying electronic media:

\section{GC-InDepth-Output.XLS.}

\subsection{Performing the Tests}

\subsubsection{Modeling Rules}

\subsubsection{Consistent Modeling Methods}

If a simulation program has options for modeling a specific thermal behavior, consistent modeling methods shall be used for all cases. For example, if the program being tested gives the user a choice of methods for modeling floor slabs, the same floor slab modeling method shall be used for all cases. To generate the example results, the IEA SHC Task 34/ECBCS Annex 43 (IEA 34/43) participants used the most detailed level of modeling that was allowed by their simulation programs and that was consistent with the level of detail provided in this test specification; more discussion about this is included in Part II (Section 2.2). When a program has options for modeling this specification, these were discussed in the IEA 34/43 participant modeler reports included in Part II (Section 2.9).

\subsubsection{Equivalent Modeling Methods}

If a program or specific model within a program does not allow direct input of specified values, or if input of specified values causes instabilities in a program's calculations, modelers should develop equivalent inputs that match the intent of the test specification as nearly as the software being tested allows. Such equivalent inputs shall be developed based on the data provided in the test specification, shall have a mathematical, physical, or logical basis, and shall be applied consistently throughout the test cases. Document the equivalent modeling method in the modeler report for the tested program.

\subsubsection{Nonapplicable Inputs}

Some specifications include input values that do not apply to the input structure of the program being tested. When nonapplicable input values are found, either use approximation methods suggested in the user's manual of the program being tested, or disregard the nonapplicable inputs and continue. Such inputs are in the specification for programs that may need them.

\subsubsection{Time Convention}

References to time in this specification are to local standard time. Assume that hour 1=0:00-1:00 (the interval from midnight to 1:00 A.M.). Do not use daylight saving time or holidays for scheduling. The required typical meteorological year 2 (TMY2) data are in hourly bins corresponding to standard time, consistent with all other schedules.

\subsubsection{Geometry Convention}

If the program being tested includes the thickness of walls in a 3-D definition of the building geometry, the wall, roof, and floor thicknesses should be defined such that the interior air volume of each zone remains as specified (e.g., $12 \mathrm{~m} \times 12 \mathrm{~m} \times 2.7 \mathrm{~m}=388.8 \mathrm{~m}^{3}$ ). 


\subsubsection{Simulation Preconditioning}

If the program being tested allows for preconditioning (iterative simulation of an initial time period until temperatures or fluxes, or both, stabilize at initial values), use that capability.

\subsubsection{Simulation Duration}

Use the weather data provided to run the full annual simulation; some models may need to run for a number of years to satisfy the requirements of specific test cases. Give outputs as required per the test case descriptions.

\subsubsection{Simulation Input Files}

All supporting data required for generating results with the tested software shall be saved, including:

- Input files

- Processed weather data

- Intermediate files containing calculations used for developing inputs

- A "Readme-softwarename-yymmdd.pdf" file that briefly describes the contents of the files according to their file type (their ".xyz" file extension).

\subsubsection{Omitted Test Cases}

If a program being tested omits a test case, provide an explanation in the modeler report.

\subsubsection{Modeler Reports}

The IEA-34/43 participants submitted modeler reports along with their simulation results (see Part II, Section 2.9). Users developing modeler reports may consider using the structure of any of those modeler reports as a template.

\subsubsection{Comparing Your Output to the Analytical Solution, Verified Numerical-Model Results, and Other Example Simulation Results}

For detailed numerical models that can do Case GC10a, output should be compared with the Case GC10a analytical solution. For all cases that the program being tested can do, output may also be compared with the verified numerical-model results and other example simulation results provided in Part III, or with other results that were generated using this test procedure.

\subsubsection{Criteria for Determining Agreement between Results}

There are no formal criteria for when results agree or disagree. Determination of when results agree or disagree is left to the user. In making this determination the user should consider:

- Magnitude of results for individual cases

- Magnitude of difference in results between certain cases (e.g., Case GC45b-Case GC40b)

- Same direction of sensitivity (positive or negative) for differences in results between certain cases (e.g., Case GC45b-Case GC40b)

- If results are logically counterintuitive with respect to known or expected physical behavior 
- Availability of analytical or verified numerical-model results (mathematical truth standard or secondary mathematical truth standard as described in Sections 2.5.1 and 2.5.2)

- If a mathematical or secondary mathematical truth standard is provided, the degree of disagreement that occurred for other simulation results versus such an analytical verification truth standard

- Example simulation results - other than the verified numerical-model results - do not represent a truth standard.

For any given case, a tested program may fall outside the range of example results without necessarily being incorrect. However, it is worthwhile to investigate the source of significant differences, as the collective experience of the authors of this test procedure is that such differences often indicate problems with the software or its usage, including, but not limited to:

- User input error, where the user misinterpreted or incorrectly entered one or more program inputs

- A problem with a particular algorithm in the program

- One or more program algorithms used outside their intended range.

Also, for any given case, a program that yields values in the middle of the range established by the example results should not be perceived as better or worse than a program that yields values at the borders of the range.

\subsubsection{Diagnostic Logic for Determining Causes of Differences among Results}

To help you identify which algorithm in the tested program is causing specific differences between programs, we have included diagnostic flow charts in Appendix F.

\subsubsection{Rules for Modifying Simulation Programs or Simulation Inputs}

Modifications to simulation programs or simulation inputs shall have a mathematical, physical, or logical basis, and shall be applied consistently across tests. Such improvements must be documented in modeler reports. Arbitrary modification of a simulation program's input or internal code to more closely match a given set of results shall not be allowed.

\subsection{Test Case Specifications}

\subsection{1 “b"-Series Cases}

\subsubsection{Case GC30b - Steady-State Comparative Test Base Case}

1.3.1.1.1 Objective. Compare steady-state heat flow results from whole-building simulation programs to the verified numerical-model results (secondary mathematical truth standard).

1.3.1.1.2 Method. This case drives floor conduction based on the temperature difference between zone air and ambient air (and deep ground boundary condition) using an adiabatic zone except for the floor, with an adiabatic wall/ground interface boundary (see Figure 1-1), and interior and exterior air temperatures with high convective surface coefficients. High convective surface coefficients facilitate robust floor conduction, and establish somewhat uniform temperatures for the interior slab surface and exterior ground surfaces. Soil and far-field boundary conditions are also described. These boundary conditions are allowed by more whole-building simulation programs than those of Case GC10a or Case GC30a. Hourly 
TMY2-format weather data with constant ambient temperature are provided. Comparison of GC30b versus GC30a (GC30b-GC30a) checks the sensitivity to high convective surface coefficients versus direct-input constant and uniform surface temperature boundary conditions. Note: Previous sensitivity tests of $60 \mathrm{~m}$ ground depth ( $40 \mathrm{~m}$ far field) versus $15 \mathrm{~m}$ deep ground boundary depth (15 $\mathrm{m}$ far field) indicate a $1 \%$ effect for the given slab geometry, so the effect of decreased boundary depth between the "b"- and "a"-series cases should be smaller than that of varying the surface boundary condition.

1.3.1.1.3 Input Specification. The bulk of the work for implementing the test cases is assembling an accurate base case model. Thoroughly checking the Case GC30b inputs before going on to the other cases is recommended.

1.3.1.1.3.1 Geometry and General Description. Geometry and location of boundary conditions are described in Figures 1-1 and 1-2. Interior edges of zone walls begin at the edges of the surface defined by the area $\mathrm{B} \times \mathrm{L}$ in Figure 1-2. The slab edge detail is described in Figure 1-3. Parameters related to these figures and other input parameters are described in Table 1-4 and the accompanying text (following sections).

Assumptions and boundary conditions are applied as described in the following sections; any variations from the given specifications are to be noted in the modeler's report.

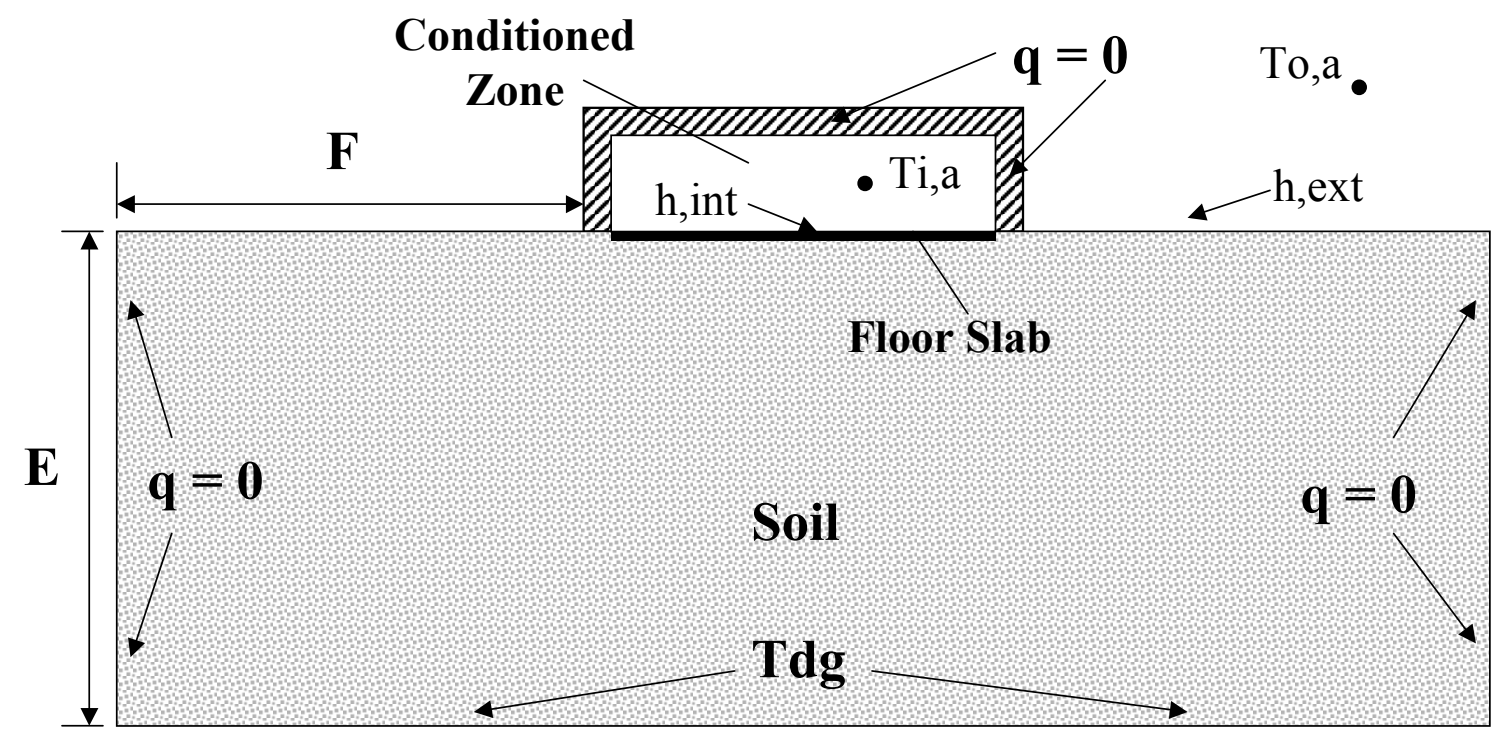

\section{$\underline{\text { Elevation Section }}$}

Figure 1-1. Case GC30b conceptual schematic diagram including boundary conditions and soil dimensions 


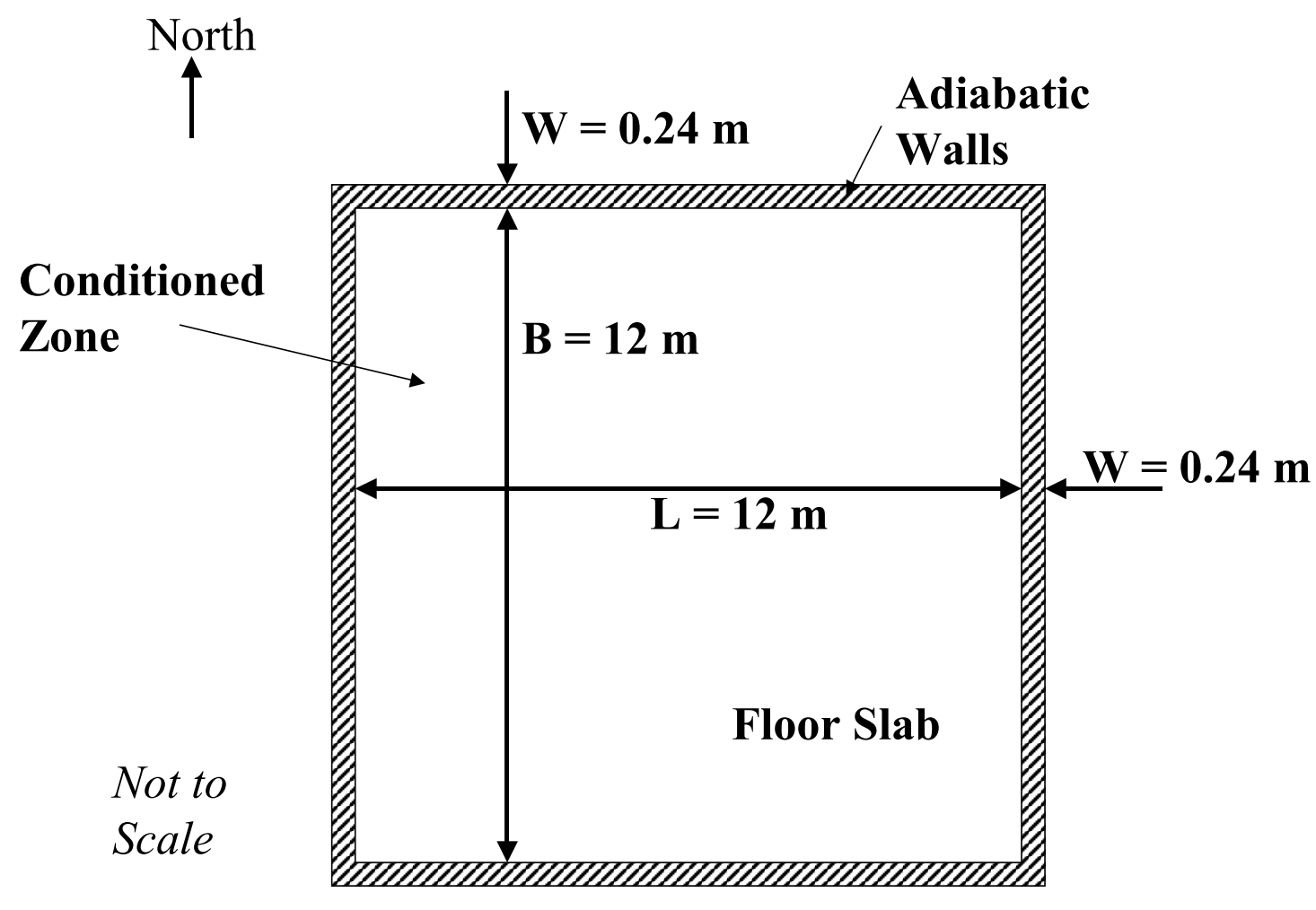

$\underline{\text { Plan View }}$

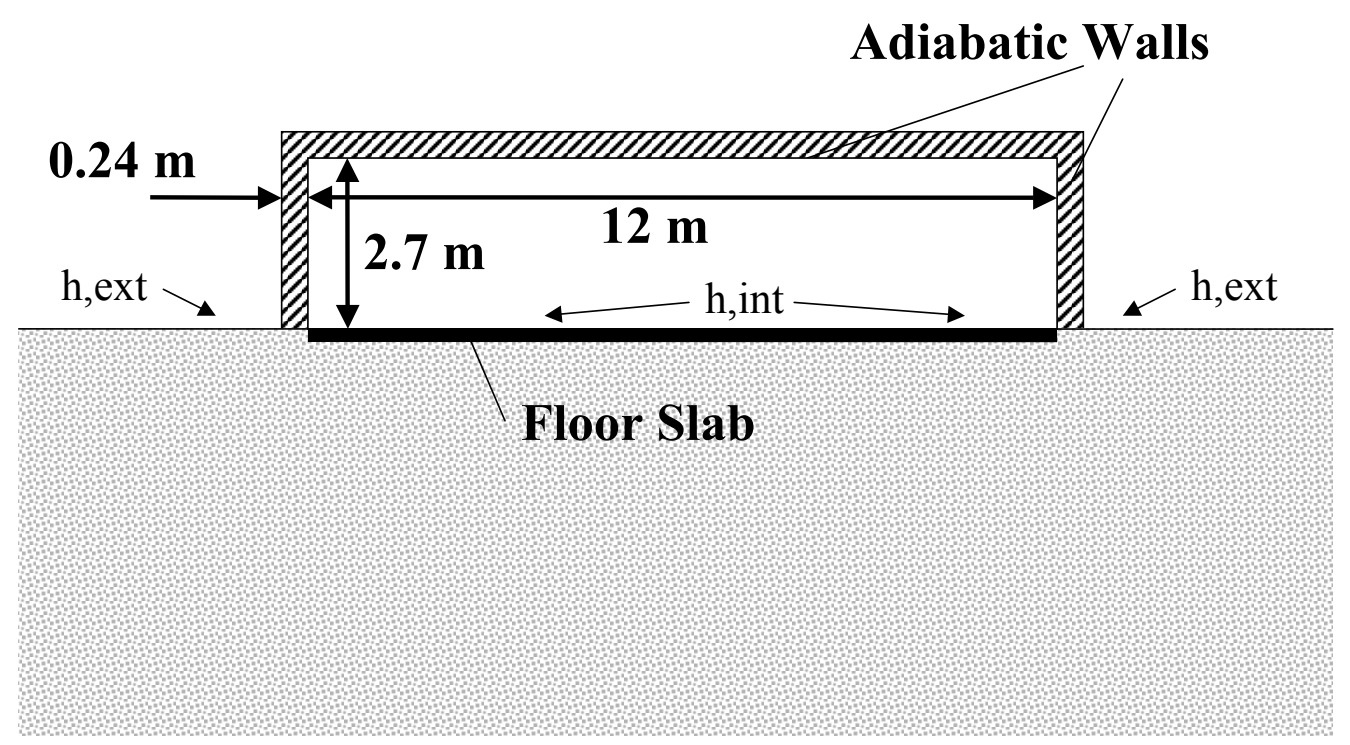

$\underline{\text { Elevation Section }}$

Figure 1-2. Case GC30b floor slab and conditioned zone adiabatic wall dimensions 


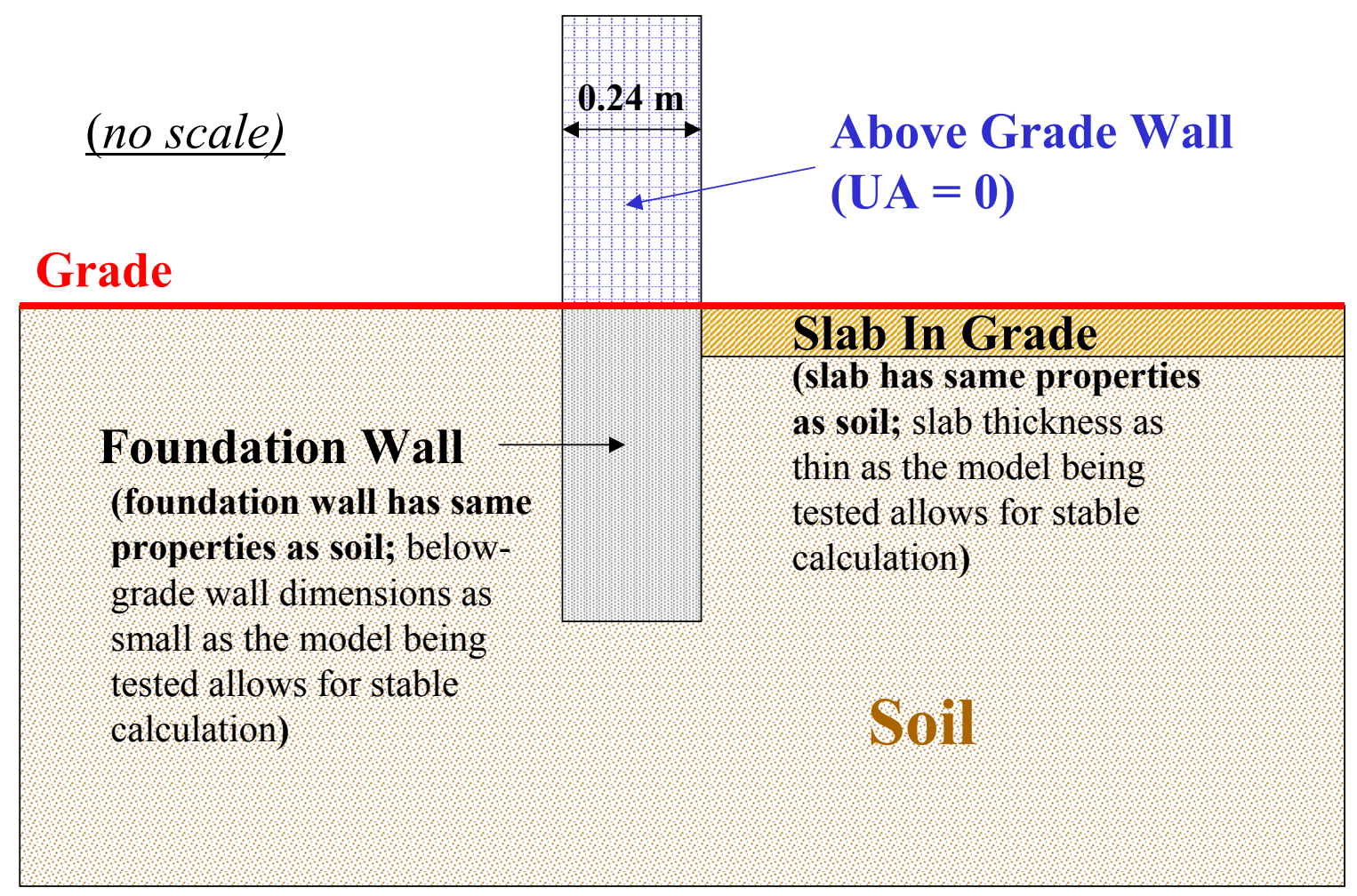

Figure 1-3. Case GC30b slab edge detail

Table 1-4. Input parameters

\begin{tabular}{|l|c|r|}
\hline Test parameters & SI Units & \multicolumn{1}{|c|}{ IP Units } \\
\hline Slab length $(\mathrm{L})$ & $12 \mathrm{~m}$ & $39.37 \mathrm{ft}$ \\
\hline Slab width $(\mathrm{B})$ & $12 \mathrm{~m}$ & $39.37 \mathrm{ft}$ \\
\hline Wall thickness $(\mathrm{W})$ & $0.24 \mathrm{~m}$ & $0.7874 \mathrm{ft}$ \\
\hline Inside zone air temperature $(\mathrm{Ti}, \mathrm{a})$ & $30^{\circ} \mathrm{C}$ & $86^{\circ} \mathrm{F}$ \\
\hline Outside air temperature $(\mathrm{To}, \mathrm{a})$ & $10^{\circ} \mathrm{C}$ & $50^{\circ} \mathrm{F}$ \\
\hline Deep ground temperature $(\mathrm{Tdg})$ & $10^{\circ} \mathrm{C}$ & $50^{\circ} \mathrm{F}$ \\
\hline Deep ground boundary depth $(\mathrm{E})$ & $15 \mathrm{~m}$ & $49.21 \mathrm{ft}$ \\
\hline Far field boundary distance $(\mathrm{F})$ & $15 \mathrm{~m}$ & $49.21 \mathrm{ft}$ \\
\hline
\end{tabular}

\subsection{Soil and Slab Thermal Properties and Boundary Conditions}

- For these test cases, the soil and floor slab properties are constant and equal to:

Thermal conductivity $=1.9 \mathrm{~W} /(\mathrm{m} \cdot \mathrm{K})\left(1.098 \mathrm{Btu} /\left(\mathrm{h} \cdot \mathrm{ft} \cdot{ }^{\circ} \mathrm{F}\right)\right)$

Density $\quad=1490 \mathrm{~kg} / \mathrm{m}^{3}\left(93.125 \mathrm{lb} / \mathrm{ft}^{3}\right)$

Specific heat $\quad=1800 \mathrm{~J} /(\mathrm{kg} \cdot \mathrm{K})\left(0.4302 \mathrm{Btu} /\left(\mathrm{lb} \cdot{ }^{\circ} \mathrm{F}\right)\right)$.

- Initially (time $<0)$ the ground and slab are at $10^{\circ} \mathrm{C}\left(50^{\circ} \mathrm{F}\right)$ throughout; at the beginning of the simulation $($ time $=0)$ the zone air temperature steps to $30^{\circ} \mathrm{C}\left(86^{\circ} \mathrm{F}\right)$ and slab and soil temperatures begin to change accordingly. 
- No surface radiation exchange; one possible method to disable radiation exchange is to set exterior solar absorptances and infrared emittances to 0 , or as low as the program being tested allows (e.g., 0.000001).

- The ground is not shaded except by the building (if the program accounts for this); shading and orientation are not relevant with radiative exchange disabled.

- The ground surface is assumed to be uniform and flat.

- Interior floor slab and outside ground surfaces are level with each other.

- For models requiring input of slab thickness, use the least thickness that the software allows for a stable calculation.

- For models requiring input for below-grade foundation walls, use the same thermal properties as soil, with foundation wall dimensions as small as the model being tested allows for a stable calculation.

- Deep ground temperature is constant and uniform at the given depth.

- Far-field ground conditions are adiabatic for vertical planes penetrating the ground at the given far-field distance from the surface.

- Ambient air temperature is uniform (well mixed air).

- If the program being tested can model evapotranspiration, it should be turned off or reduced to its lowest level.

\subsection{Above-Grade Construction}

- $\quad$ Building height $=2.7 \mathrm{~m}(8.858 \mathrm{ft})$.

- Zone air volume $=388.8 \mathrm{~m}^{3}\left(13730 \mathrm{ft}^{3}\right)$.

- All surfaces of the zone except the floor are adiabatic (thermal conductance $=0 \mathrm{~W} /\left(\mathrm{m}^{2} \cdot \mathrm{K}\right)$ ). If the program being tested does not allow adiabatic surfaces, use the lowest thermal conductance the program allows (e.g., $\left.0.000001 \mathrm{~W} /\left(\mathrm{m}^{2} \cdot \mathrm{K}\right)\right)$ and document those values in your modeler report.

- All surfaces except the floor are massless. If the program being tested does not allow massless surfaces, use the lowest density or thermal capacitance, or both, that the program allows (e.g., $0.000001 \mathrm{~kg} / \mathrm{m}^{3}$ or $\mathrm{J} /(\mathrm{kg} \cdot \mathrm{K})$, or both) and document those values in your modeler report.

- The adiabatic walls contact, but do not penetrate, the ground. Heat may flow within the ground just below the adiabatic walls; heat cannot flow from the ground into the adiabatic walls (or out of the adiabatic walls into the ground).

- No surface radiation exchange occurs. One possible method to disable radiation exchange is to set interior and exterior solar absorptances and infrared emittances to 0 , or as low as the program being tested allows (e.g., 0.000001).

- No windows.

- No infiltration or ventilation.

- No internal gains.

\subsection{Convective Surface Coefficients}

- Interior convective surface coefficients $(\mathrm{h}, \mathrm{int})=100 \mathrm{~W} /\left(\mathrm{m}^{2} \cdot \mathrm{K}\right)\left(17.61 \mathrm{Btu} /\left(\mathrm{h} \cdot \mathrm{ft}^{2} \cdot{ }^{\circ} \mathrm{F}\right)\right)$

- Exterior convective surface coefficients $(\mathrm{h}, \mathrm{ext})=100 \mathrm{~W} /\left(\mathrm{m}^{2} \cdot \mathrm{K}\right)\left(17.61 \mathrm{Btu} /\left(\mathrm{h} \cdot \mathrm{ft}^{2} \cdot{ }^{\circ} \mathrm{F}\right)\right)$.

These values apply to surface coefficients for the floor, adiabatic surfaces, and exterior ground surface as appropriate. If the program being tested cannot model these convective surface coefficients, use the largest value the program allows. Document values for convective surface coefficients in your modeler report. 
If the program being tested allows direct user input of convective surface coefficients and surface infrared (IR) emittances, ignore the remainder of this paragraph. If the program being tested allows only direct user input of combined surface coefficients, set that value to $100 \mathrm{~W} /\left(\mathrm{m}^{2} \cdot \mathrm{K}\right)\left(17.61 \mathrm{Btu} /\left(\mathrm{h} \cdot \mathrm{ft}^{2} \cdot{ }^{\circ} \mathrm{F}\right)\right)$. If the program being tested does not allow direct user input of convective surface coefficients or combined surface coefficients, input a value for IR emittance such that an equivalent value for combined surface coefficient of $100 \mathrm{~W} /\left(\mathrm{m}^{2} \cdot \mathrm{K}\right)$ is obtained, or nearly obtained if possible (based on the convective surface coefficient that the program being tested automatically calculates). Discuss in your modeler report any deviation from the specified convective surface coefficient.

1.3.1.1.3.5 Mechanical System. The mechanical system provides sensible heating only (no cooling), and is ideal. The purpose of the heating system is to give results for energy consumption that are equal to the sensible heating load. Model the heating system as closely as the program being tested allows, as follows:

- Set points

$$
\begin{array}{rlrl}
\circ & \text { Heat } & =\mathrm{ON} \text { if temperature }<30^{\circ} \mathrm{C}\left(86^{\circ} \mathrm{F}\right) \text {; } \text { otherwise Heat }=\mathrm{OFF} \\
\circ & \mathrm{Cool}=\text { always OFF. }
\end{array}
$$

- Set the heating system capacity as needed so there is at least enough capacity to maintain the zone air temperature set point; for example, $1000 \mathrm{~kW}(3412 \mathrm{kBtu} / \mathrm{h})$.

- Uniform zone air temperature (well mixed air).

- $100 \%$ efficiency.

- $100 \%$ convective air system.

- Ideal controls (zone always at set point); for example, assume the heat addition rate equals the equipment capacity (non-proportional control) and there is continuous ON/OFF cycling within the hour as needed.

- Thermostat sensing the zone air temperature only.

1.3.1.1.3.6 Weather Data. Use constant temperature TMY2-format weather data provided with the file:

\section{GCSS-W20.TM2}

TMY2 weather data format is described in Appendix A. Table 1-3 (see Section 1.1.1.1) provides a summary of site and weather data parameters. This weather data file is based on Miami.TM2, but includes many data elements set to: 0 or approximate lower limits, approximate higher limits, or neutral (nonextreme) constant values. A description follows:

- Global horizontal, direct normal, and diffuse horizontal radiation and illuminance all set to 0 .

- Extraterrestrial horizontal and direct normal radiation were left unchanged from the original weather data file.

- $\quad$ Total and opaque sky cover $=10$ tenths, implying the entire sky dome is covered by clouds to reduce exterior IR radiation exchange.

- Outdoor dry-bulb temperature $(\mathrm{To}, \mathrm{a})=10^{\circ} \mathrm{C}\left(50^{\circ} \mathrm{F}\right)$.

- Outdoor dew-point temperature $=-56.6^{\circ} \mathrm{C}\left(-69.9^{\circ} \mathrm{F}\right)$ (corresponds with humidity ratio of $0.000007 \mathrm{~kg} / \mathrm{kg}$ and standard atmospheric pressure); calculation of dew-point temperature applies common psychrometric formulae (ASHRAE 2001 [Chapter 6]; Brandemuehl 1993). TMY2 documentation indicates that $-60^{\circ} \mathrm{C}$ is the lower limit for TMY2 data.

- Relative humidity $=0.09 \%$ (corresponds with humidity ratio of $0.000007 \mathrm{~kg} / \mathrm{kg}$, standard atmospheric pressure, and given dry-bulb temperature); calculations apply common psychrometric formulae (ASHRAE 2001 [Chapter 6]; Brandemuehl 1993). This value rounds to $0 \%$ in the weather data.

- $\quad$ Atmospheric pressure $=1013$ millibars $(=$ standard atmosphere of 14.696 psia $)$. 
- Wind speed $=19.9 \mathrm{~m} / \mathrm{s}$ (44.52 miles/h). Extrapolating (see ASHRAE 2005 Handbook of Fundamentals, p. 25.1) equations described by Walton (1983) and assuming a rough surface, this may correspond with combined radiative/convective $\mathrm{h}, \mathrm{ext}=104.47 \mathrm{~W} /\left(\mathrm{m}^{2} \cdot \mathrm{K}\right)$. Subtracting out the equivalent radiative portion of the combined coefficient of $4.63 \mathrm{~W} /\left(\mathrm{m}^{2} \cdot \mathrm{K}\right)$ based on IEA BESTEST (Judkoff and Neymark 1995), Appendix D, yields convective only h,ext $=99.84$ $\mathrm{W} /\left(\mathrm{m}^{2} \cdot \mathrm{K}\right)$ (rounds to $100 \mathrm{~W} /\left(\mathrm{m}^{2} \cdot \mathrm{K}\right)$ ).

- Visibility $=20 \mathrm{~km}$ (rough annual average for Miami and Denver).

- Ceiling height $=2000 \mathrm{~m}$ (rough annual average for Miami and Denver).

- Present weather: no rain, hail, etc.

- Precipitable water $=0 \mathrm{~mm}$.

- Aerosol optical depth $=0.1$ broadband turbidity (rough annual average of Miami and Denver)

- Snow depth $=0 \mathrm{~cm}$, with $\geq 88$ days since last snowfall.

1.3.1.1.4 Output Requirements. If possible for the software being tested, the simulation should be run long enough that there is $\leq 0.1 \%$ variation between the floor slab conduction for the last hour of the last year of the simulation and the last hour of the preceding year of the simulation; i.e., $\leq 0.1 \%$ variation over an interval of 8760 hours.

If a numerical model is being tested that allows variation of thermal node meshing, it is recommended to demonstrate for a subset of the steady-state and steady-periodic cases (e.g., GC30b, GC40b, and others if desired) that the tested mesh detail yields negligible $(\leq 0.1 \%)$ change in results versus a less detailed mesh, or that the mesh is as detailed as possible for the available computing hardware.

If the software being tested allows user specification of convergence tolerance, it is recommended to demonstrate for a subset of the steady-state and steady-periodic cases (e.g., GC30b, GC40b) that the current level of heat-flow or temperature convergence tolerance yields negligible $(\leq 0.1 \%)$ change in results versus the next finer convergence tolerance.

Provide the following outputs for the last hour of the simulation:

- Conduction through the floor slab $\left(\mathrm{q}_{\mathrm{ffloor}}\right)$ in $\mathrm{W}$ or $\mathrm{Wh} / \mathrm{h}$; this is specifically conduction through the interior surface of the slab defined by dimensions $B \times L$ in Figure 1-2.

- Zone load $\left(\mathrm{q}_{\text {zone }}\right)$ in $\mathrm{W}$ or $\mathrm{Wh} / \mathrm{h}$; this output should only vary from floor slab conduction if the program being tested does not allow fully adiabatic above-grade walls; if the program being tested (particularly for models run independently of whole-building simulations) does not have different outputs for zone load and floor conduction, report the output where it is most appropriate and leave the other output blank (e.g., report the results only as floor conduction, and do not report any zone load results).

- Zone air temperature $\left(\mathrm{T}_{\text {zone }}\right)\left({ }^{\circ} \mathrm{C}\right)$; this output checks the temperature that results from the given thermostat set point.

- "Steady state" near-surface temperatures $\left(\mathrm{T}_{\text {surf,n }}\right)\left({ }^{\circ} \mathrm{C}\right)$ as described in Table 1-5 and Figure 1-4; for defining coordinates the center of the floor slab is designated as " $(0,0)$ " as shown in Figure 14; Figure 1-4 represents a single quadrant of the symmetric slab/perimeter-boundary/exterior surfaces. Provide temperatures (at consistent depth) for the uppermost-modeled layer of soil just below the ground.

Provide the following other outputs:

- Duration of simulation $\left(\mathrm{t}_{\mathrm{sim}}\right)$ in hours. This is the number of hours simulated; e.g., if 10 years are simulated, indicate 87600 hours. 
Table 1-5. $x$ and $y$ Coordinates of Near-Surface Temperature Outputs

\begin{tabular}{|c|c|c|c|}
\hline Location,n & y (cm) & $\mathbf{x ( \mathbf { c m } )}$ & Tsurf,n $\left({ }^{\circ} \mathrm{C}\right)$ \\
\hline 1 & 0 & 0 & \\
\hline 2 & 0 & 433 & \\
\hline 3 & 0 & 554 & \\
\hline 4 & 0 & 587 & \\
\hline 5 & 0 & 596 & \\
\hline 6 & 0 & 600 & \\
\hline 7 & 0 & 602 & \\
\hline 8 & 0 & 605 & \\
\hline 9 & 0 & 612 & \\
\hline 10 & 0 & 619 & \\
\hline 11 & 0 & 622 & \\
\hline 12 & 0 & 624 & \\
\hline 13 & 0 & 628 & \\
\hline 14 & 0 & 640 & \\
\hline 15 & 0 & 687 & \\
\hline 16 & 0 & 876 & \\
\hline 17 & 0 & 1628 & \\
\hline 18 & 0 & 4624 & \\
\hline Location, $\mathrm{n}$ & $y(\mathrm{~cm})$ & $x(\mathrm{~cm})$ & Tsurf,n $\left({ }^{\circ} \mathrm{C}\right)$ \\
\hline 1 & 0 & 0 & \\
\hline 19 & 433 & 433 & \\
\hline 20 & 554 & 554 & \\
\hline 21 & 587 & 587 & \\
\hline 22 & 596 & 596 & \\
\hline 23 & 600 & 600 & \\
\hline 24 & 602 & 602 & \\
\hline 25 & 605 & 605 & \\
\hline 26 & 612 & 612 & \\
\hline 27 & 619 & 619 & \\
\hline 28 & 622 & 622 & \\
\hline 29 & 624 & 624 & \\
\hline 30 & 628 & 628 & \\
\hline 31 & 640 & 640 & \\
\hline 32 & 687 & 687 & \\
\hline 33 & 876 & 876 & \\
\hline 34 & 1628 & 1628 & \\
\hline 35 & 4624 & 4624 & \\
\hline
\end{tabular}




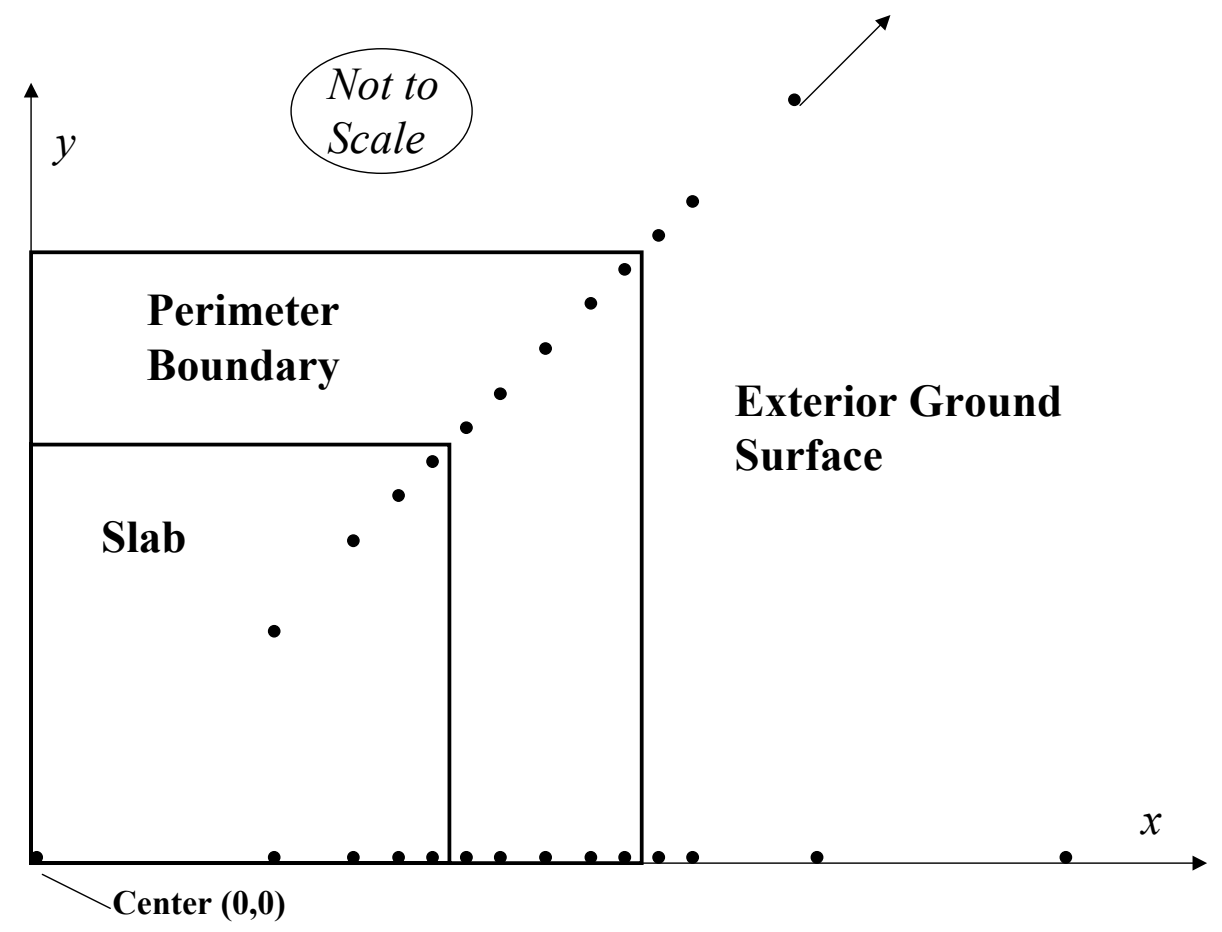

Figure 1-4. Conceptual plan view of near-surface temperature outputs

\subsubsection{Case GC4Ob - Harmonic Variation of Ambient Temperature}

1.3.1.2.1 Objective. Compare heat flow results for approximate steady-periodic (harmonic) variation of ambient temperature (To,a) from whole-building simulation programs versus verified numerical-model results. Analyze the phase shift between variation of heat flow and ambient air temperature.

1.3.1.2.2 Method. This case is similar to Case GC30b but uses harmonically varying To,a. Hourly TMY2 format weather data are provided for approximating a sinusoidal annual cycle of varying daily average temperatures with a sinusoidal diurnal temperature cycle overlaid (a high frequency cycle overlaid on a low frequency cycle). Comparing GC40b with GC30b (GC40b-GC30b) annual hourly average floor conduction checks the sensitivity of average floor heat loss of the harmonic condition versus the steadystate condition.

1.3.1.2.3 Input Specification. This case is exactly as Case GC30b except for the following changes:

1. Use weather data provided with the file GCSP-W20.TM2.

GCSP-W20.TM2 is the same as GCSS-W20.TM2 except harmonically varying outdoor air temperatures are approximated. In this file atmospheric pressure and dew-point temperature were set to constant values, and relative humidity was adjusted to be consistent with other listed values using common psychrometric formulae. (ASHRAE 2001 [Chapter 6]; Brandemuehl 1993).

TMY2 weather data format is described in Appendix A. Table 1-3 (see Section 1.1.1.1) provides a summary of site and weather data parameters. 
In these weather data To, a varies hourly according to the following formula:

To, $\mathrm{a}=$ Tday - Tswingday $*(\cos (($ IHOUR-ILOWHOUR $) / 24 * 2 * \mathrm{PI}))$

where

Tday $=$ Tmean - Tswingseason $*(\cos (($ IDAY-ILOWDAY $) / 365 * 2 *$ PI $))$

where:

- Tswingday is diurnal temperature swing $( \pm),=2^{\circ} \mathrm{C}$, for $4^{\circ} \mathrm{C}$ diurnal range from minimum to maximum

- IHOUR is the daily hour counter, from 1 to 24 with reset to 1 after end of day

- ILOWHOUR is hour of lowest temperature, $=4$, for $4^{\text {th }}$ hour

- $\quad \mathrm{PI}=3.1415927(\approx \pi)$; cosine function uses radians

- $\quad$ Tmean $=$ annual mean temperature, $=10^{\circ} \mathrm{C}$

- Tswingseason is seasonal temperature variation $( \pm),=6^{\circ} \mathrm{C}$, for $12^{\circ} \mathrm{C}$ range (minimum to maximum) of average daily temperature over the year

- IDAY is the day counter, from 1 to 365

- ILOWDAY is the day of lowest temperature, $=15$, for January 15.

From this, To,a varies over a range of $16^{\circ} \mathrm{C}$ : from a minimum of $2^{\circ} \mathrm{C}$ to maximum of $18^{\circ} \mathrm{C}$ over the year.

2. Set the heating system capacity as needed so there is at least enough capacity to maintain the zone air temperature set point during the peak heating-load hour (and therefore all other hours).

1.3.1.2.4 Output Requirements. If possible for the software being tested, the simulation should be run long enough that there is $\leq 0.1 \%$ variation between the annual floor slab conduction for the last year of the simulation and the preceding year of the simulation.

If a numerical model is being tested that allows variation of thermal node meshing, it is recommended to demonstrate that the tested mesh detail yields negligible $(\leq 0.1 \%)$ change in results versus a less detailed mesh, or that the mesh is as detailed as possible for the available computing hardware.

If the software being tested allows user specification of convergence tolerance, it is recommended to demonstrate that the current level of heat-flow or temperature convergence tolerance yields negligible $(\leq 0.1 \%)$ change in results versus the next finer convergence tolerance.

Provide the following outputs for only the last full year of the simulation:

- Annual total conduction through the floor slab $\left(\mathrm{Q}_{\text {floor }}\right)(\mathrm{kWh} / \mathrm{y})$; this is specifically conduction through the interior surface of the slab defined by dimensions $B \times \mathrm{L}$ in Figure 1-2.

- Annual total zone load $\left(\mathrm{Q}_{\text {zone }}\right)(\mathrm{kWh} / \mathrm{y})$; this output should vary from floor slab conduction only if the program being tested does not allow fully adiabatic above-grade walls; if the program being tested (particularly for models run independently of whole-building simulations) does not have different outputs for zone load and floor conduction, report the output where it is most appropriate and leave the other output blank (e.g., report the results only as floor conduction, and do not report any zone load results). 
- Annual average zone temperature $\left(\mathrm{T}_{\text {zone,mean }}\right)\left({ }^{\circ} \mathrm{C}\right)$; this output checks the temperature that results from the given thermostat set point.

- Annual hourly integrated peak floor conduction $\left(\mathrm{q}_{\mathrm{floor}, \max }\right)(\mathrm{Wh} / \mathrm{h}$ or $\mathrm{W})$ for the year including hour of occurrence; this is specifically the peak conduction through the interior surface of the slab defined by dimensions $\mathrm{B} \times \mathrm{L}$ in Figure 1-2.

- Annual hourly integrated peak zone load $\left(\mathrm{q}_{\mathrm{zone}, \max }\right)(\mathrm{Wh} / \mathrm{h}$ or $\mathrm{W})$ for the year, including hour of occurrence; this output should only vary from floor slab conduction if the program being tested does not allow fully adiabatic above-grade walls.

- Minimum hourly ambient temperature $\left(\mathrm{T}_{\mathrm{ODB}, \min }\right)\left({ }^{\circ} \mathrm{C}\right)$ and first hour of occurrence.

- Number of hours with minimum hourly To,a.

- Hourly floor conduction $(\mathrm{Wh} / \mathrm{h}$ or $\mathrm{W})$ for the entire year; this is specifically hourly conduction through the interior surface of the slab defined by dimensions $\mathrm{B} \times \mathrm{L}$ in Figure 1-2.

- Hourly time convention; e.g., Hour $1=0: 00-1: 00$, or Hour $1=0: 30-1: 30$, etc.

Provide the following other outputs:

- Duration of simulation ( $\left.\mathrm{t}_{\mathrm{sim}}\right)$ in hours. This is the number of hours simulated, e.g., if 10 years are simulated, indicate 87600 hours.

\subsubsection{Case GC45b - Aspect Ratio}

1.3.1.3.1 Objective. Test the sensitivity to variation of aspect ratio (AR) in the context of steady-periodic (harmonic) variation of To,a. The AR for a given slab area directly affects the ratio of perimeter heat transfer to core heat transfer. In this context the use of the term perimeter is different from the perimeter boundary described in Case GC10a. Here, perimeter heat transfer is the heat transfer driven by the zone to ambient air temperature difference, through a relatively thin layer of soil; core heat transfer is driven by the zone to deep ground temperature difference, through a relatively thick layer of soil.

1.3.1.3.2 Method. This case is similar to Case GC40b. It uses a slab with same surface area, but different AR. Comparison of results for GC45b versus GC40b (GC45b-GC40b) checks the sensitivity of AR. Compare heat-flow results from whole-building simulation programs to verified numerical-model results. Analyze phase shift between variation of heat flow and To,a.

1.3.1.3.3 Input Specification. This case is exactly as Case GC40b except for the slab dimensions, as noted in Table 1-6.

Table 1-6. Input parameters

\begin{tabular}{|l|r|r|}
\hline Test parameters & SI Units & IP Units \\
\hline Slab length $(L)$ & $36 \mathrm{~m}$ & $118.11 \mathrm{ft}$ \\
\hline Slab width $(B)$ & $4 \mathrm{~m}$ & $13.12 \mathrm{ft}$ \\
\hline
\end{tabular}

Set the heating system capacity as needed so there is at least enough capacity to maintain the zone air temperature set point during the peak heating-load hour (and therefore all other hours).

1.3.1.3.4 Output Requirements. See Case GC40b. However, do not provide hourly floor conduction outputs for the entire year. 


\subsubsection{Case GC50b - Large Slab}

1.3.1.4.1 Objective. Test the sensitivity to variation of slab size in the context of steady-periodic (harmonic) variation of To,a. Increasing the slab size yields a larger fraction of core-driven ground heat transfer that is driven by the difference between the zone air temperature and the deep ground temperature.

1.3.1.4.2 Method. This case is similar to Case GC40b but uses a large slab. Comparing results for heat flow per unit floor area (flux) for GC50b versus GC40b (GC50b-GC40b) checks the sensitivity to heat transfer caused by increasing the slab size. Compare heat-flow results from whole-building simulation programs to verified numerical-model results. Analyze phase shift between variation of heat flow and To,a.

1.3.1.4.3 Input Specification. This case is exactly as Case GC40b except for the following.

Adjust dimensions as noted in Figure 1-5 and Table 1-7.

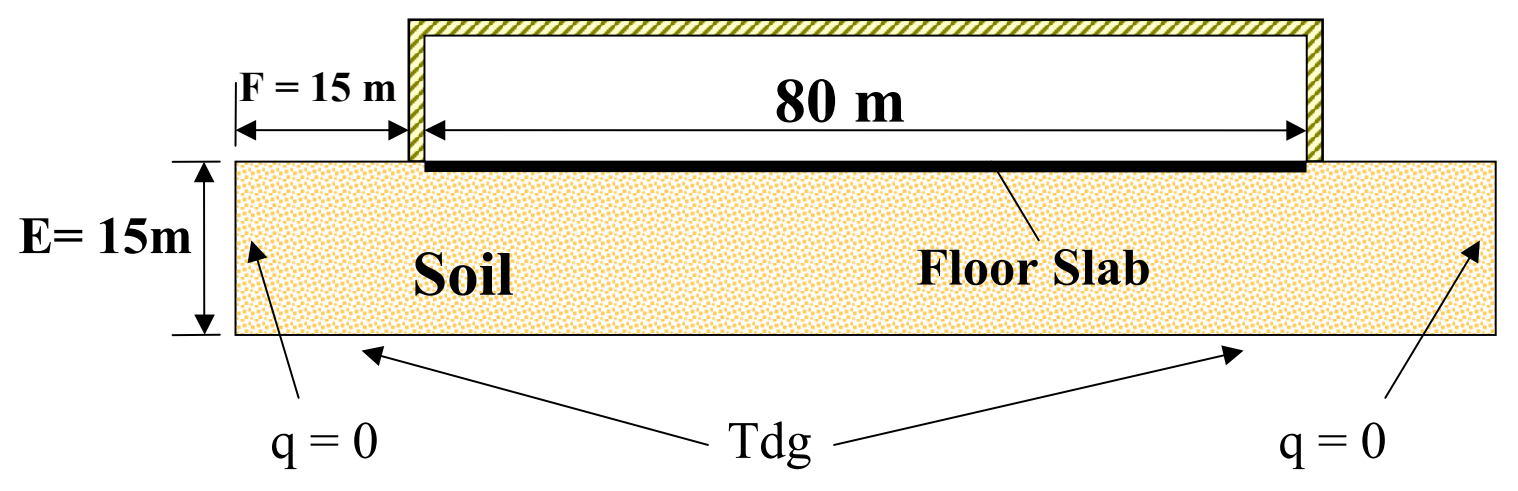

$\underline{\text { Elevation Section }}$

Figure 1-5. Case GC50b-1 dimensions and below-grade boundary donditions

Table 1-7. Input parameters

\begin{tabular}{|l|c|r|}
\hline Test parameters & SI Units & IP Units \\
\hline Slab length $(\mathrm{L})$ & $80 \mathrm{~m}$ & $262.47 \mathrm{ft}$ \\
\hline Slab width $(\mathrm{B})$ & $80 \mathrm{~m}$ & $262.47 \mathrm{ft}$ \\
\hline Deep ground boundary depth $(\mathrm{E})$ & $15 \mathrm{~m}$ & $49.21 \mathrm{ft}$ \\
\hline Far field boundary distance $(\mathrm{F})$ & $15 \mathrm{~m}$ & $49.21 \mathrm{ft}$ \\
\hline
\end{tabular}

Set the heating system capacity as needed so there is at least enough capacity to maintain the zone air temperature set point during the peak heating-load hour (and therefore all other hours).

1.3.1.4.4 Output Requirements. See Case GC40b. However, do not provide hourly floor conduction outputs for the entire year. 


\subsubsection{Case GC55b - Shallow Deep Ground Temperature}

1.3.1.5.1 Objective. Test the sensitivity to variation of deep ground temperature depth in the context of steady-periodic (harmonic) variation of To,a. This case is relevant for areas with a relatively shallow groundwater table, which increases the effect of core heat flow that is driven by the difference between the zone air temperature and the deep ground temperature.

1.3.1.5.2 Method. This case is similar to Case GC40b but uses a shallower deep ground boundary (heat sink) location. Comparison of results for GC55b versus GC40b (GC55b-GC40b) checks the sensitivity of deep ground temperature depth. Compare heat-flow results from whole-building simulation programs to verified numerical-model results. Analyze phase shift between variation of heat flow and To,a.

1.3.1.5.3 Input Specification. This case is exactly as Case GC40b except for the deep ground temperature boundary depth as noted in Table 1-8.

Table 1-8. Input parameters

\begin{tabular}{|l|c|c|}
\hline Test parameters & SI Units & IP Units \\
\hline Deep ground boundary depth $(\mathrm{E})$ & $2 \mathrm{~m}$ & $6.562 \mathrm{ft}$ \\
\hline
\end{tabular}

Set the heating system capacity as needed so there is at least enough capacity to maintain the zone air temperature set point during the peak heating-load hour (and therefore all other hours).

1.3.1.5.4 Output Requirements. See Case GC40b. However, do not provide hourly floor conduction outputs for the entire year.

\subsubsection{Case GC60b - Steady State with Typical Interior Convective Surface Coefficient}

1.3.1.6.1 Objective. Test sensitivity to the use of a more realistic interior convective surface heat transfer coefficient (h,int) in the steady-state context. With a more realistic coefficient, the zone floor surface temperature will be less uniform, and will exhibit greater decrease outward from the center toward the zone perimeter boundary.

1.3.1.6.2 Method. This case is similar to Case GC30b but uses decreased h,int. Comparison of results for GC60b versus GC30b (GC60b-GC30b) checks the sensitivity of h,int. Compare heat-flow results from whole-building simulation programs to verified numerical-model results.

1.3.1.6.3 Input Specification. This case is exactly as Case GC30b except for h,int (see Table 1-9). This value of $h$,int is applied to the interior side of the floor and other zone surfaces (walls and ceiling).

Table 1-9. Input parameters

\begin{tabular}{|l|c|c|}
\hline Test parameters & SI Units & IP Units \\
\hline h,int (interior convective surface coefficient) & $7.95 \mathrm{~W} /\left(\mathrm{m}^{2} \cdot \mathrm{K}\right)$ & $1.3999 \mathrm{Btu} /\left(\mathrm{h} \cdot \mathrm{ft}^{2} \cdot{ }^{\circ} \mathrm{F}\right)$ \\
\hline
\end{tabular}

Recall the simplification that surface IR emittances have been specified as 0 (or as low as the program being tested allows). If the program being tested allows direct user input of interior convective surface coefficients and interior surface IR emittances, ignore the remainder of this paragraph. If the program being tested allows direct user input of combined interior surface coefficients only, set that value to 7.95 
$\mathrm{W} /\left(\mathrm{m}^{2} \cdot \mathrm{K}\right)\left(1.3999 \mathrm{Btu} /\left(\mathrm{h} \cdot \mathrm{ft}^{2} \cdot{ }^{\circ} \mathrm{F}\right)\right)$. If the program being tested does not allow direct user input of convective surface coefficients or combined surface coefficients, input a value for IR emittance such that an equivalent value for combined surface coefficient of $7.95 \mathrm{~W} /\left(\mathrm{m}^{2} \cdot \mathrm{K}\right)$ is obtained (based on the convective surface coefficient that the program being tested automatically calculates). Discuss in your modeler report any deviation from the convective surface coefficient.

1.3.1.6.4 Output Requirements. See Case GC30b.

\subsubsection{Case GC65b - Steady State with Typical Interior and Exterior Convective Surface Coefficients}

1.3.1.7.1 Objective. Test sensitivity to the use of a more realistic exterior convective surface coefficient (h,ext) in the steady-state context. With a more realistic coefficient the exterior ground surface temperature will be less uniform, and will exhibit greater increase near the exterior side of the adiabatic wall.

1.3.1.7.2 Method. This case is similar to Case GC60b but uses decreased h,ext. Comparison of results for GC65b versus GC60b (GC65b-GC60b) checks the sensitivity of h,ext. Comparison of results for GC65b versus GC30b (GC65b-GC30b) checks the combined effect of sensitivity to h,int and h,ext. Compare heat-flow results from whole-building simulation programs to verified numerical-model results.

1.3.1.7.3 Input Specification. This case is exactly as Case GC60b except:

1. Use h,ext as listed in Table 1-10. This value of h,ext is applied to the exterior ground surface, and to other zone exterior surfaces (walls and ceiling). The value for $h$,int is repeated in Table 1-10 for convenience.

Table 1-10. Input parameters

\begin{tabular}{|l|c|c|}
\hline Test parameters & SI Units & IP Units \\
\hline $\mathrm{h}$,int (interior convective surface coefficient) & $7.95 \mathrm{~W} /\left(\mathrm{m}^{2} \cdot \mathrm{K}\right)$ & $1.3999 \mathrm{Btu} /\left(\mathrm{h} \cdot \mathrm{ft}^{2} \cdot{ }^{\circ} \mathrm{F}\right)$ \\
\hline $\begin{array}{l}\mathrm{h}, \text { ext (exterior [ground] convective surface } \\
\text { coefficient) }\end{array}$ & $11.95 \mathrm{~W} /\left(\mathrm{m}^{2} \cdot \mathrm{K}\right)$ & $2.1043 \mathrm{Btu} /\left(\mathrm{h} \cdot \mathrm{ft}^{2} \cdot{ }^{\circ} \mathrm{F}\right)$ \\
\hline
\end{tabular}

Recall the simplification that surface IR emittances have been specified as 0 (or as low as the program being tested allows). If the program being tested allows direct user input of h,ext and exterior surface IR emittances, ignore the remainder of this paragraph. If the program being tested allows direct user input of combined exterior surface coefficients only, set that value to 11.95 $\mathrm{W} /\left(\mathrm{m}^{2} \cdot \mathrm{K}\right)\left(2.1043 \mathrm{Btu} /\left(\mathrm{h} \cdot \mathrm{ft}^{2} \cdot{ }^{\circ} \mathrm{F}\right)\right)$. If the program being tested does not allow direct user input of convective surface coefficients or combined surface coefficients, input a value for IR emittance such that an equivalent value for combined surface coefficient of $11.95 \mathrm{~W} /\left(\mathrm{m}^{2} \cdot \mathrm{K}\right)$ is obtained (based on the convective surface coefficient that the program being tested automatically calculates). Discuss in your modeler report any deviation from the convective surface coefficient.

2. Use weather data provided with the file GCSS-W01.TM2.

GCSS-W01.TM2 is the same as GCSS-W20.TM2 except that wind speed is set to $1.0 \mathrm{~m} / \mathrm{s}(2.24$ miles $/ \mathrm{h}) .1 .0 \mathrm{~m} / \mathrm{s}$ wind speed is consistent with convective $\mathrm{h}$,ext $=11.95 \mathrm{~W} /\left(\mathrm{m}^{2} \cdot \mathrm{K}\right)$. This value for $\mathrm{h}$,ext comes from a resulting combined convective/radiative coefficient of $16.58 \mathrm{~W} /\left(\mathrm{m}^{2} \cdot \mathrm{K}\right)$ for 1.0 
$\mathrm{m} / \mathrm{s}$ based on equations described by Walton (1983) and assuming ground surface roughness is equivalent to that for typical brick or rough plaster, and then subtracting out the equivalent radiative portion of the combined coefficient of $4.63 \mathrm{~W} /\left(\mathrm{m}^{2} \cdot \mathrm{K}\right.$ ) based on IEA BESTEST (Judkoff and Neymark 1995), Appendix D. TMY2 weather data format is described in Appendix A. Table 1-3 (see Section 1.1.1.1) provides a summary of site and weather data parameters.

1.3.1.7.4 Output Requirements. See Case GC30b.

\subsubsection{Case GC70b - Harmonic Variation of Ambient Temperature with Typical Interior and Exterior Convective Surface Coefficients}

1.3.1.8.1 Objective. Test sensitivity to the use of more realistic h,int and h,ext in the context of steadyperiodic (harmonic) variation of To,a.

1.3.1.8.2 Method. This case is similar to Case GC40b but uses decreased h,int and h,ext. Comparison of results for GC70b versus GC40b (GC70b-GC40b) checks the combined sensitivities of h,int and h,ext. Compare heat-flow results from whole-building simulation programs to verified numerical-model results. Analyze phase shift between variation of heat flow and To,a. Comparison of GC70b versus GC65b (GC70b-GC65b) annual hourly average floor conduction checks the sensitivity of average floor heat loss of the harmonic versus the steady-state condition in the context of using realistic convective surface coefficients.

1.3.1.8.3 Input Specification. This case is exactly as Case GC40b except:

1. Use h,int and h,ext of Table 1-10 (see Section 1.3.1.7.3).

2. Use weather data provided with the file GCSP-W01.TM2.

GCSP-W01.TM2 is the same as GCSP-W20.TM2 except that constant wind speed is set to 1.0 $\mathrm{m} / \mathrm{s}(2.24 \mathrm{miles} / \mathrm{h}) .1 .0 \mathrm{~m} / \mathrm{s}$ wind speed is consistent with convective $\mathrm{h}, \mathrm{ext}=11.95 \mathrm{~W} /\left(\mathrm{m}^{2} \cdot \mathrm{K}\right)$. This value for $h$,ext comes from a resulting combined convective/radiative coefficient of 16.58 $\mathrm{W} /\left(\mathrm{m}^{2} \cdot \mathrm{K}\right)$ for $1.0 \mathrm{~m} / \mathrm{s}$ based on equations described by Walton (1983) and assuming ground surface roughness is equivalent to that for typical brick or rough plaster, and then subtracting out the equivalent radiative portion of the combined coefficient of $4.63 \mathrm{~W} /\left(\mathrm{m}^{2} \cdot \mathrm{K}\right)$ based on IEA BESTEST (Judkoff and Neymark 1995), Appendix D. TMY2 weather data format is described in Appendix A. Table 1-3 (see Section 1.1.1.1) provides a summary of site and weather data parameters.

1.3.1.8.4 Output Requirements. See Case GC40b. However, do not provide hourly floor conduction outputs for the entire year.

\subsubsection{Case GC80b - Reduced Slab and Ground Conductivity}

1.3.1.9.1 Objective. Test sensitivity to reduced slab and ground conductivity in the context of steadyperiodic (harmonic) variation of To,a.

1.3.1.9.2 Method. This case is similar to Case GC40b but uses decreased slab and ground conductivity. Comparison of results for GC80b versus GC40b (GC80b-GC40b) checks the sensitivity of slab and 
ground conductivity. Compare heat-flow results from whole-building simulation programs to verified numerical-model results. Analyze phase shift between variation of heat flow and To,a.

1.3.1.9.3 Input Specification. This case is exactly as Case GC40b except:

Soil and slab thermal conductivity $=0.5 \mathrm{~W} /(\mathrm{m} \cdot \mathrm{K})\left(0.289 \mathrm{Btu} /\left(\mathrm{h} \cdot \mathrm{ft} \cdot{ }^{\circ} \mathrm{F}\right)\right)$

1.3.1.9.4 Output Requirements. See Case GC40b. However, do not provide hourly floor conduction outputs for the entire year.

\subsection{2 “a”-Series Cases}

\subsubsection{Case GC10a - Steady-State Analytical Verification Base Case}

1.3.2.1.1 Objective. Compare steady-state heat flow results for detailed 3-D numerical models used independently from whole-building energy simulation programs, versus an analytical solution. Users of such detailed models are to determine appropriate inputs to match the boundary conditions and assumptions of the analytical solution, including appropriate meshing, the amount of ground that needs to be modeled, length of simulation, etc. Attention to such modeling details is needed to obtain consistent high-quality results throughout these test cases. In later cases where exact analytical solutions are not known - and if there is good agreement among detailed numerical models, and appropriate application of the models is well documented - the detailed numerical-model results can then be used to establish quasianalytical solutions. Such solutions provide a secondary mathematical truth standard, founded on the range of disagreement of the verified numerical-model results, for comparing results of other models typically used with whole-building energy simulation programs.

1.3.2.1.2 Method. This case is based on Delsante et al. (1983; see also Spitler et al. 2001), which calculates steady-state heat flow using fundamental 3-D heat transfer analysis of a semi-infinite solid. Figure 1-6 shows the boundary conditions at the upper surface of the semi-infinite solid and describes a rectangular floor surface bounded by a concentrically rectangular perimeter surface of finite width that separates the rectangular floor surface from the exterior ground surface. The concentrically rectangular surface may also be thought of as the base of a wall that separates the interior floor surface from the exterior ground surface.

Check sensitivity (if applicable) to mesh detail, length of simulation, amount of ground modeled, convergence tolerance, etc., and demonstrate that the modeling is at a level of detail where including further detail yields negligible sensitivity to results.

1.3.2.1.3 Input Specification. Geometry is described in Figure 1-6. Parameters related to Figure 1-6 and other input parameters are described in Table 1-11. 


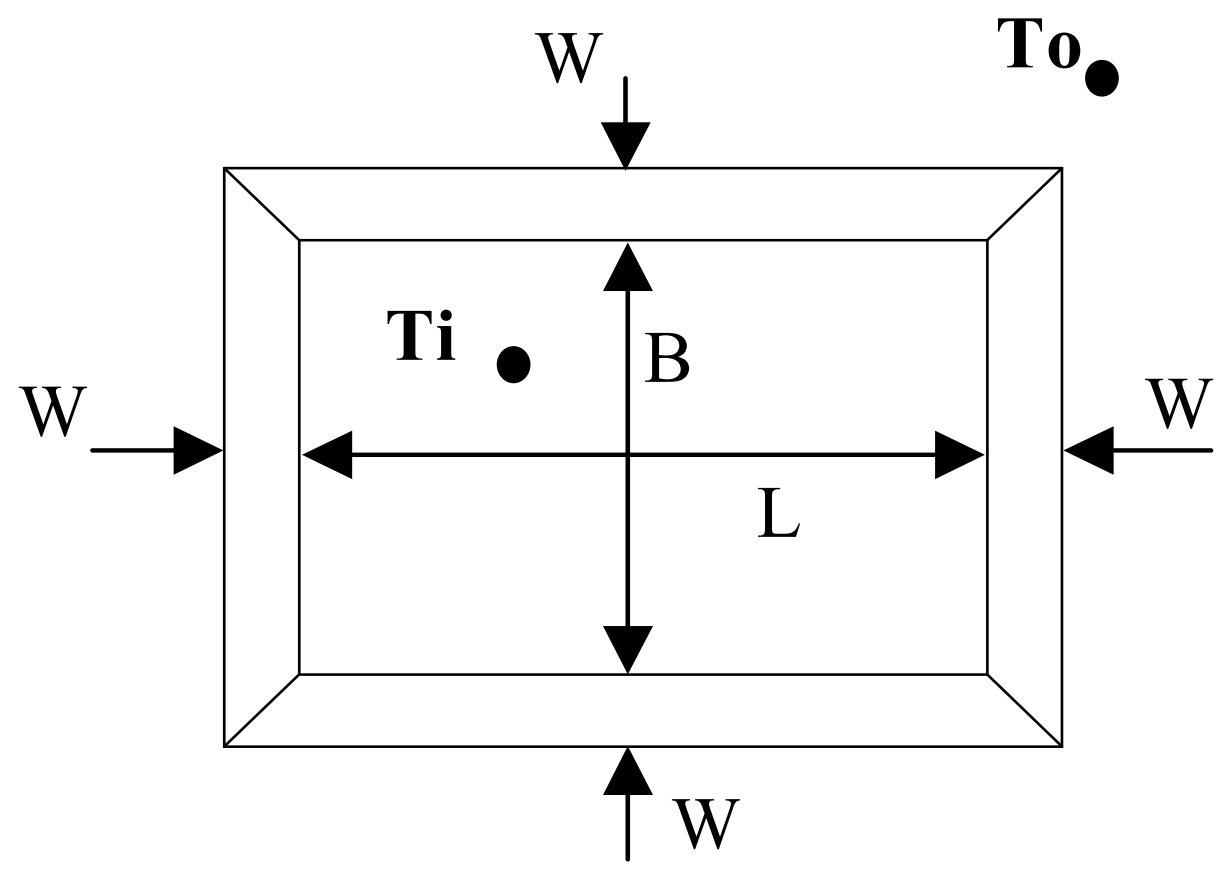

Figure 1-6. Plan view of the floor geometry

Table 1-11. Input parameters

\begin{tabular}{|l|c|c|}
\hline Test parameters & SI Units & IP Units \\
\hline Slab length $(\mathrm{L})$ & $12 \mathrm{~m}$ & $39.37 \mathrm{ft}$ \\
\hline Slab width $(\mathrm{B})$ & $12 \mathrm{~m}$ & $39.37 \mathrm{ft}$ \\
\hline Perimeter surface boundary width $(\mathrm{W})$ & $0.24 \mathrm{~m}$ & $0.7874 \mathrm{ft}$ \\
\hline Interior (slab) surface temperature $(\mathrm{Ti})$ & $30^{\circ} \mathrm{C}$ & $86^{\circ} \mathrm{F}$ \\
\hline Exterior (ground) surface temperature $(\mathrm{To})$ & $10^{\circ} \mathrm{C}$ & $50^{\circ} \mathrm{F}$ \\
\hline Thermal conductivity of the slab and soil & $1.9 \mathrm{~W} /(\mathrm{m} \cdot \mathrm{K})$ & $1.098 \mathrm{Btu} /\left(\mathrm{h} \cdot \mathrm{ft} \cdot{ }^{\circ} \mathrm{F}\right)$ \\
\hline
\end{tabular}

The following boundary conditions and assumptions are applied:

- Interior floor surface temperature (Ti) is constant and everywhere equal.

- Exterior ground surface temperature (To) is constant and everywhere equal.

- Linear variation between Ti and To over a perimeter surface boundary of finite width (W) is imposed only at the surface of the ground (this avoids a discontinuity at the interior/exterior boundary).

- Semi-infinite solid: the ground surface extends outward infinitely in all horizontal directions from the perimeter surface boundary defined in Figure 1-6, and the ground extends infinitely downward from all points on the infinite horizontal surface (including from the surfaces of Figure 1-6 and beyond).

- $\quad$ Deep ground boundary condition at infinite soil depth $=$ To.

- Thermal conductivities of slab and soil are equal.

- There is no radiative exchange. 
1.3.2.1.4 Output Requirements. Run the simulation long enough that there is $\leq 0.1 \%$ variation between the floor slab conduction for the last hour of the last year of the simulation and the last hour of the preceding year of the simulation, i.e., $\leq 0.1 \%$ variation over an interval of 8760 hours.

Similarly, demonstrate that the current level of modeling detail yields negligible $(\leq 0.1 \%)$ change in results versus a lesser level of detail; examine the effects of shallower deep ground boundary, shorter farfield boundary distance, and less detailed mesh (if applicable). For ground depth and far-field length variations, increase the number of mesh nodes proportionally to the increase in soil volume being modeled. (The IEA-34/43 numerical-methods modelers documented sensitivity tests for this in their modeler reports.)

If the software being tested allows user specification of convergence tolerance, demonstrate that the current level of heat-flow or temperature convergence tolerance yields negligible $(\leq 0.1 \%)$ change in results versus the next finer convergence tolerance.

Provide the following outputs for the last hour of the simulation:

- Steady-state conduction through the floor $\mathrm{slab}\left(\mathrm{q}_{\text {floor }}\right)$ in $\mathrm{W}$ or $\mathrm{Wh} / \mathrm{h}$; this is specifically hourly conduction through the interior surface of the slab defined by dimensions $\mathrm{B} \times \mathrm{L}$ in Figure 1-6.

- Steady-state near-surface temperatures $\left(\mathrm{T}_{\text {surf,n }}\right)\left({ }^{\circ} \mathrm{C}\right)$ as described in Figure 1-4 and Table 1-5 (see Section 1.3.1.1.4); to define coordinates the center of the floor slab is designated as $(0,0)$ per Figure 1-4; Figure 1-4 represents a single quadrant of the symmetric slab/perimeterboundary/exterior surfaces. Provide temperatures (at consistent depth) for the uppermost modeled layer of soil just below the ground. These outputs are for comparison with models that do not provide results precisely at the surface.

- Steady-state surface temperatures $\left(\mathrm{T}_{@ \text { surf,n }}\right)\left({ }^{\circ} \mathrm{C}\right)$ as described for $\mathrm{T}_{\text {surf,n }}$ in Figure 1-4 and Table 1-5 (see Section 1.3.1.1.4); to define coordinates the center of the floor slab is designated as " $(0,0)$ " as shown in Figure 1-4; Figure 1-4 represents a single quadrant of the symmetric slab/perimeterboundary/exterior surfaces. These outputs are for checking proper application of surface temperature boundary conditions.

Provide the following other outputs:

- Duration of simulation $\left(\mathrm{t}_{\text {sim }}\right)$ in hours

- Deep ground temperature depth (E, see Figure 1-1 [Section 1.3.1.1.3])

- Far-field boundary distance (F, see Figure 1-1 [Section 1.3.1.1.3]).

1.3.2.1.5 Analytical Solution for Steady-State Heat Flow through the Floor Slab. For the conditions of Figure 1-6, given the slab of area $L \times B$ surrounded by a perimeter surface boundary of thickness $W$, assume the surface temperature of the floor is $T_{i}$, and the temperature falls linearly across the perimeter boundary from $T_{i}$ to the exterior ground surface temperature $T_{o}$, the exact solution for the problem under steady state 3-D conditions is given by Delsante et al. (1983). The total heat flow through the slab into the ground is:

$$
q=k\left(T_{i}-T_{o}\right) \frac{1}{\pi} F(L, B, W)
$$

Where: $\quad T_{i}=$ surface temperature of the floor, ${ }^{\circ} \mathrm{C}$

$$
T_{o}=\text { temperature of the outside ground, }{ }^{\circ} \mathrm{C}
$$




$$
k=\text { conductivity of floor slab and soil, } \mathrm{W} /(\mathrm{m} \cdot \mathrm{K})
$$

And $F(L, B, W)$ is a function of $L, B$, and $W$ with the units of length (m):

$$
\begin{aligned}
& F(L, B, W)=\left(2+\frac{L+B}{W}\right)\left[(L+W)^{2}+(B+W)^{2}\right]^{1 / 2}-\sqrt{2}\left(1+\frac{L}{2 W}\right)\left[L^{2}+(L+2 W)^{2}\right]^{1 / 2} \\
& -\sqrt{2}\left(1+\frac{B}{2 W}\right)\left[B^{2}+(B+2 W)^{2}\right]^{1 / 2}-\left(\frac{L+B}{W}\right)\left(L^{2}+B^{2}\right)^{1 / 2} \\
& +\left(\frac{\mathrm{L}^{2}+\mathrm{B}^{2}}{\mathrm{~W}}\right)[1+\sqrt{2} \ln (\sqrt{2}-1)]+2 W[\sqrt{2}+\ln (\sqrt{2}-1)] \\
& -\frac{\sqrt{2} G^{2}}{W} \ln \left\{\frac{\left[G^{2}+(D+2 W)^{2}\right]^{1 / 2}+D+2 W}{\left(G^{2}+D^{2}\right)^{1 / 2}+D}\right\} \\
& +\left[\frac{G^{2}-(B+W)^{2}}{W}\right] \times \ln \left\{\frac{\left[(L+W)^{2}+(B+W)^{2}\right]^{1 / 2}+B+W}{L+W}\right\} \\
& +\left[\frac{G^{2}-(L+W)^{2}}{W}\right] \times \ln \left\{\frac{\left[(L+W)^{2}+(B+W)^{2}\right]^{1 / 2}+L+W}{B+W}\right\} \\
& +\left[\frac{\mathrm{L}(2 \mathrm{~B}-\mathrm{L})}{W}\right] \ln \left\{\frac{\left(L^{2}+B^{2}\right)^{1 / 2}+B}{L}\right\}+\left[\frac{\mathrm{B}(2 \mathrm{~L}-\mathrm{B})}{W}\right] \ln \left\{\frac{\left(L^{2}+B^{2}\right)^{1 / 2}+L}{B}\right\} \\
& -\left(\frac{\mathrm{L}^{2}-W^{2}}{W}\right) \ln \left\{\frac{\left[W^{2}+(L+W)^{2}\right]^{1 / 2}+W}{L+W}\right\} \\
& -\left(\frac{\mathrm{B}^{2}-W^{2}}{W}\right) \ln \left\{\frac{\left[W^{2}+(B+W)^{2}\right]^{1 / 2}+W}{B+W}\right\} \\
& +(2 \mathrm{~L}+\mathrm{W}) \ln \left\{\frac{\left[W^{2}+(L+W)^{2}\right]^{1 / 2}+L+W}{W}\right\} \\
& +(2 \mathrm{~B}+\mathrm{W}) \ln \left\{\frac{\left[W^{2}+(B+W)^{2}\right]^{1 / 2}+B+W}{W}\right\} \\
& +\frac{\sqrt{2} L^{2}}{W} \ln \left\{\frac{\left[L^{2}+(L+2 W)^{2}\right]^{1 / 2}+L+2 W}{L}\right\} \\
& +\frac{\sqrt{2} B^{2}}{W} \ln \left\{\frac{\left[B^{2}+(B+2 W)^{2}\right]^{1 / 2}+B+2 W}{B}\right\}
\end{aligned}
$$

$(\mathrm{GC} 10 \mathrm{a}-2)$

Where $G=L-B$, and $D=L+B$ 


\subsubsection{Case GC30a - Steady-State Comparative Test Base Case with Direct Input of Surface Temperatures}

1.3.2.2.1 Objective. Compare steady-state heat flow results from detailed numerical models to each other. Compare whole-building simulation programs (if possible) versus verified numerical-model results. Constant temperature surface boundary conditions may limit the number of models that can run this case.

1.3.2.2.2 Method. This case drives floor conduction based on the direct-input temperature difference between the interior surface of the floor slab and the exterior surface of the ground (and deep ground boundary condition). This case is similar to Case GC10a but uses an adiabatic wall/ground interface boundary (see Figure 1-1 [Section 1.3.1.1.3]). The adiabatic wall/ground interface boundary replaces the linearly varying temperature perimeter surface boundary of Case GC10a. Soil and far-field boundary conditions are also described. Hourly TMY2-format weather data with constant ambient temperature are provided. Comparison of GC30a versus $\mathrm{GC} 10 \mathrm{a}(\mathrm{GC} 30 \mathrm{a}-\mathrm{GC} 10 \mathrm{a})$ checks the sensitivity to perimeter surface boundary conditions for an adiabatic versus a linearly varying temperature condition.

For programs that cannot directly input surface temperatures, but can input very high surface coefficients $\left(\mathrm{h}>>100 \mathrm{~W} /\left(\mathrm{m}^{2} \cdot \mathrm{K}\right)\right)$, a constant/uniform surface temperature can be mimicked with $\mathrm{h} \geq 5000 \mathrm{~W} /\left(\mathrm{m}^{2} \cdot \mathrm{K}\right)$.

Check sensitivity (if applicable) to mesh detail, length of simulation, amount of ground modeled, convergence tolerance, etc., and demonstrate that the modeling is at a level of detail where including further detail yields negligible sensitivity to results.

1.3.2.2.3 Input Specification. This case is exactly as Case GC30b except for the following changes.

1.3.2.2.3.1 Soil and Slab Thermal Properties and Boundary Conditions. Changes to surface temperatures and soil geometry are given in Table 1-12.

Table 1-12. Input parameters

\begin{tabular}{|l|c|c|}
\hline Test parameters & SI Units & IP Units \\
\hline Interior slab surface temperature (Ti) & $30^{\circ} \mathrm{C}$ & $86^{\circ} \mathrm{F}$ \\
\hline Exterior ground surface temperature (To) & $10^{\circ} \mathrm{C}$ & $50^{\circ} \mathrm{F}$ \\
\hline Deep ground boundary depth (E) & $30 \mathrm{~m}$ & $98.43 \mathrm{ft}$ \\
\hline Far field boundary distance (F) & $20 \mathrm{~m}$ & $65.62 \mathrm{ft}$ \\
\hline
\end{tabular}

Ti and To are applied directly to the surfaces and are constant and everywhere equal.

Although this case provides a zone description (per Case GC30b), for programs that can input surface temperatures directly and output resulting floor conductance, only the floor slab needs to be modeled; the other above-grade (adiabatic) surfaces of the zone do not need to be modeled.

For programs that cannot directly input surface temperatures, but can input very high surface coefficients (h), sensitivity tests indicate that a constant/uniform surface temperature can be mimicked by setting zone and ambient air temperatures to Ti and To and applying $\mathrm{h} \geq 5000 \mathrm{~W} /\left(\mathrm{m}^{2} \cdot \mathrm{K}\right)$. If the program being tested allows input of such very high surface coefficients, use the greatest value allowed and document the values in your modeler report. Be aware that very high surface coefficients may cause some programs to become unstable. For programs that do not allow direct input of surface temperatures and do not allow convective surface coefficients much greater than $100 \mathrm{~W} /\left(\mathrm{m}^{2} \cdot \mathrm{K}\right)$, run Case GC30b instead of Case GC30a. 
1.3.2.2.3.2 Weather Data. Use constant temperature TMY2-format weather data provided with the file:

\section{GCSS-W40.TM2.}

TMY2 weather data format is described in Appendix A. Table 1-3 (see Section 1.1.1.1) provides a summary of site and weather data parameters. This weather data file is based on the weather data file used for Case GC30b (GCSS-W20.TM2), except that wind speed $=40 \mathrm{~m} / \mathrm{s}(89.48 \mathrm{miles} / \mathrm{h})$. The wind speed given in the weather data file is the maximum of the value range indicated by TMY2 weather data documentation (Marion and Urban, 1995). Extrapolating (see ASHRAE 2005 Handbook of Fundamentals, p. 25.1) equations described by Walton (1983) and assuming a rough surface, this may correspond with combined radiative/convective $\mathrm{h}, \mathrm{ext}=219.89 \mathrm{~W} /\left(\mathrm{m}^{2} \cdot \mathrm{K}\right)$. Subtracting out the equivalent radiative portion of the combined coefficient of $4.63 \mathrm{~W} /\left(\mathrm{m}^{2} \cdot \mathrm{K}\right)$ based on IEA BESTEST (Judkoff and Neymark 1995), Appendix D, yields convective only h,ext $=215.26 \mathrm{~W} /\left(\mathrm{m}^{2} \cdot \mathrm{K}\right)$. Because some wholebuilding energy simulation software may flag weather data values outside of TMY2 documented limits (e.g. DOE-2.1E), a value greater than $40 \mathrm{~m} / \mathrm{s}(99.9 \mathrm{~m} / \mathrm{s}$ is format limit) was not used.

1.3.2.2.4 Output Requirements. See Case GC30b. If the model being tested uses direct input of interior slab surface temperature such that modeling of a building zone is not necessary, then do not include results for:

- Zone load $\left(\mathrm{q}_{\mathrm{zone}}\right)$ in $\mathrm{W}$ or $\mathrm{Wh} / \mathrm{h}$

- Zone air temperature $\left(\mathrm{T}_{\text {zone }}\right)\left({ }^{\circ} \mathrm{C}\right)$.

\subsubsection{Case GC40a - Harmonic Variation of Direct-Input Exterior Surface Temperature}

1.3.2.3.1 Objective. Compare heat flow results for approximate steady-periodic (harmonic) variation of exterior ground surface temperature (To) from detailed numerical models to each other. Compare wholebuilding simulation programs (if possible) to verified numerical-model results. Analyze the phase shift between variation of heat flow and To. Direct-input surface temperature boundary conditions may limit the number of models that can run this case.

1.3.2.3.2 Method. This case is similar to Case GC30a but uses harmonically varying To,a for input as To. Hourly TMY2-format weather data are provided for approximating a sinusoidal annual cycle of varying daily average temperature with sinusoidal diurnal temperature cycle overlaid (a high-frequency cycle overlaid on a low-frequency cycle). Comparison of GC40a versus GC30a (GC40a-GC30a) annual hourly average floor conduction checks the sensitivity of average floor heat loss of the harmonic condition versus the steady-state condition.

For programs that cannot directly input surface temperatures, but can input very high surface coefficients $\left(\mathrm{h}>>100 \mathrm{~W} /\left(\mathrm{m}^{2} \cdot \mathrm{K}\right)\right)$, a constant/uniform surface temperature can be mimicked with $\mathrm{h} \geq 5000 \mathrm{~W} /\left(\mathrm{m}^{2} \cdot \mathrm{K}\right)$.

Check sensitivity (if applicable) to mesh detail, length of simulation, amount of ground modeled, convergence tolerance, etc., and demonstrate that the modeling is at a level of detail where including further detail yields negligible sensitivity to results.

1.3.2.3.3 Input Specification. This case is exactly as Case GC30a except for the following changes:

1. Use weather data provided with the file GCSP-W40.TM2. 
GCSP-W40.TM2 is the same as GCSS-W40.TM2 except harmonically varying To,a is approximated by using the same method as for GCSP-W20.TM2 (see Case GC40b, Section 1.3.1.2.3, for a detailed description). In this file atmospheric pressure and dew-point temperature were set to constant values, and relative humidity was adjusted to be consistent with other listed values using common psychrometric formulae. (ASHRAE 2001 [Chapter 6]; Brandemuehl 1993). TMY2 weather data format is described in Appendix A. Table 1-3 (see Section 1.1.1.1) provides a summary of site and weather data parameters.

2. Set the heating system capacity as needed so there is at least enough capacity to maintain the zone air temperature set point during the peak heating-load hour (and therefore all other hours).

1.3.2.3.4 Output Requirements. Output for GC40a is the same as for Case GC40b except:

If the model being tested uses direct input of interior slab surface temperature such that modeling of a building zone is not necessary, do not include results for:

- Annual total zone load $\left(\mathrm{Q}_{\mathrm{zone}}\right)(\mathrm{kWh} / \mathrm{y})$

- Annual average zone temperature $\left(\mathrm{T}_{\text {zone,mean }}\right)\left({ }^{\circ} \mathrm{C}\right)$

- Annual hourly integrated peak zone load $\left(\mathrm{q}_{\mathrm{zone}, \max }\right)(\mathrm{Wh} / \mathrm{h}$ or $\mathrm{W})$ for the year including hour of occurrence.

\subsection{3 "c"-Series Cases}

\subsubsection{Case GC30c - Steady-State Comparative Test Base Case with BASESIMP Boundary Conditions}

1.3.3.1.1 Objective. Compare whole-building simulation programs versus verified numerical-model results. The constant temperature exterior surface boundary condition may limit the number of models that can run this case.

1.3.3.1.2 Method. This case drives floor conduction based on the difference between the zone air temperature and To (and deep ground boundary temperature). This case is similar to GC30a and GC30b but uses boundary conditions compatible with assumptions of BASESIMP. Comparison of GC30c versus GC30a (GC30c-GC30a) checks the sensitivity to reduced interior surface coefficient; sensitivity may also be affected (secondarily) by reduced ground depth and reduced far-field ground distance.

For programs that cannot directly input exterior surface temperatures, but can input very high exterior surface coefficients $\left(\mathrm{h}>>100 \mathrm{~W} /\left(\mathrm{m}^{2} \cdot \mathrm{K}\right)\right)$, a constant/uniform exterior surface temperature can be mimicked with $\mathrm{h} \geq 5000 \mathrm{~W} /\left(\mathrm{m}^{2} \cdot \mathrm{K}\right)$.

1.3.3.1.3 Input Specification. This case is exactly as Case GC30b except for the following changes.

1.3.3.1.3.1 Soil and Slab Thermal Properties and Boundary Conditions. Table 1-13 documents changes to interior and exterior surface boundary conditions and the amount of soil modeled (versus Case GC30b).

If the program being tested allows direct user input of combined interior surface coefficients, ignore the remainder of this paragraph. If the program being tested allows direct user input of convective surface coefficients, but allows only automatically calculated surface IR radiative exchange, set the convective surface coefficient to $7.95 \mathrm{~W} /\left(\mathrm{m}^{2} \cdot \mathrm{K}\right)\left(1.3999 \mathrm{Btu} /\left(\mathrm{h} \cdot \mathrm{ft}^{2} \cdot{ }^{\circ} \mathrm{F}\right)\right.$ ) and set the surface IR emittance to 0 (or as 
low as the program being tested allows). If the program being tested does not allow direct user input of convective surface coefficients or combined surface coefficients, input a value for IR emittance such that an equivalent value for combined surface coefficient of $7.95 \mathrm{~W} /\left(\mathrm{m}^{2} \cdot \mathrm{K}\right)$ is obtained (based on the convective surface coefficient that the program being tested automatically calculates). Discuss in your modeler report any deviation from the combined surface coefficients.

Table 1-13. Input parameters

\begin{tabular}{|l|c|c|}
\hline Test parameters & SI Units & IP Units \\
\hline Interior combined surface coefficient (h,int) & $7.95 \mathrm{~W} /\left(\mathrm{m}^{2} \cdot \mathrm{K}\right)$ & $1.3999 \mathrm{Btu} /\left(\mathrm{h} \cdot \mathrm{ft}^{2} \cdot{ }^{\circ} \mathrm{F}\right)$ \\
\hline Exterior ground surface temperature (To) & $10^{\circ} \mathrm{C}$ & $50^{\circ} \mathrm{F}$ \\
\hline Far field boundary distance (F) & $8 \mathrm{~m}$ & $26.24 \mathrm{ft}$ \\
\hline
\end{tabular}

Exterior ground surface temperature (To) is applied directly to the surface and is constant and everywhere equal. For programs that cannot directly input To, but can input very high h,ext, sensitivity tests indicate that a constant/uniform surface temperature can be mimicked by setting To,a to To and applying h,ext $\geq$ $5000 \mathrm{~W} /\left(\mathrm{m}^{2} \cdot \mathrm{K}\right)$. If the program being tested does not allow input of such very high h, ext, use the greatest value allowed and document the values in your modeler report. Be aware that very high surface coefficients may cause some programs to become unstable.

1.3.3.1.3.2 Weather Data. Use constant temperature TMY2-format weather data provided with the file:

\section{GCSS-W40.TM2.}

TMY2 weather data format is described in Appendix A. Table 1-3 (see Section 1.1.1.1) provides a summary of site and weather data parameters. This weather data file is based on the weather data file used for Case GC30b (GCSS-W20.TM2), except that wind speed $=40 \mathrm{~m} / \mathrm{s}(89.48 \mathrm{miles} / \mathrm{h})$. The wind speed given in the weather data file is the maximum of the value range indicated by TMY2 weather data documentation (Marion and Urban 1995). Extrapolating (see ASHRAE 2005 Handbook of Fundamentals, p. 25.1) equations described by Walton (1983) and assuming a rough surface, this may correspond with combined radiative/convective $\mathrm{h}, \mathrm{ext}=219.89 \mathrm{~W} /\left(\mathrm{m}^{2} \cdot \mathrm{K}\right)$. Subtracting out the equivalent radiative portion of the combined coefficient of $4.63 \mathrm{~W} /\left(\mathrm{m}^{2} \cdot \mathrm{K}\right)$ based on IEA BESTEST (Judkoff and Neymark 1995), Appendix D, yields convective only $\mathrm{h}, \mathrm{ext}=215.26 \mathrm{~W} /\left(\mathrm{m}^{2} \cdot \mathrm{K}\right)$. Because some whole-building energy simulation software may flag weather data values outside of TMY2 documented limits (e.g. DOE-2.1E), a value greater than $40 \mathrm{~m} / \mathrm{s}(99.9 \mathrm{~m} / \mathrm{s}$ is format limit) was not used.

1.3.3.1.4 Output Requirements. See Case GC30b. However, do not provide steady-state near-surface temperature (Tsurf,n) results.

\subsubsection{Case GC40c - Harmonic Variation of Direct-Input Exterior Surface Temperature with BASESIMP Boundary Conditions}

1.3.3.2.1 Objective. Compare heat flow results for approximate steady-periodic (harmonic) variation of exterior ground surface temperature (To) from whole-building simulation programs versus verified numerical-model results. Analyze the phase shift between variation of heat flow and To. The direct-input To boundary condition may limit the number of models that can run this case.

1.3.3.2.2 Method. This case is similar to Case GC30c but uses harmonically varying To,a for input as To. Hourly TMY2-format weather data are provided for approximating a sinusoidal annual cycle of varying 
daily average temperature with sinusoidal diurnal temperature cycle overlaid (a high-frequency cycle overlaid on a low-frequency cycle). Comparison of GC40c versus GC30c (GC40c-GC30c) annual hourly average floor conduction checks the sensitivity of average floor heat loss of the harmonic condition versus the steady-state condition.

For programs that cannot directly input To, but can input very high exterior surface coefficients $(\mathrm{h}>>100$ $\left.\mathrm{W} /\left(\mathrm{m}^{2} \cdot \mathrm{K}\right)\right)$, a constant/uniform exterior surface temperature can be mimicked with $\mathrm{h} \geq 5000 \mathrm{~W} /\left(\mathrm{m}^{2} \cdot \mathrm{K}\right)$.

1.3.3.2.3 Input Specification. This case is exactly as Case GC30c except for the following changes:

1. Use weather data provided with the file GCSP-W40.TM2.

GCSP-W40.TM2 is the same as GCSS-W40.TM2 except harmonically varying To,a is approximated using the same method as for GCSP-W20.TM2 (see Case GC40b, Section 1.3.1.2.3, for a detailed description). In this file atmospheric pressure and dew-point temperature were set to constant values, and relative humidity was adjusted to be consistent with other listed values using common psychrometric formulae. (ASHRAE 2001 [Chapter 6]; Brandemuehl 1993). TMY2 weather data format is described in Appendix A. Table 1-3 (see Section 1.1.1.1) provides a summary of site and weather data parameters.

2. Set the heating system capacity as needed so there is at least enough capacity to maintain the zone air temperature set point during the peak heating-load hour (and therefore all other hours).

1.3.3.2.4 Output Requirements. Output for GC40c is the same as for Case GC40b.

\subsubsection{Case GC45c - Aspect Ratio with BASESIMP Boundary Conditions}

1.3.3.3.1 Objective. Test the sensitivity to variation of AR in the context of steady-periodic (harmonic) variation of To. The AR for a given slab area directly affects the ratio of perimeter heat transfer to core heat transfer. In this context the term perimeter is different from the perimeter boundary described in Case GC10a. Here, perimeter heat transfer is the heat transfer driven by the zone to ambient air temperature difference, through a relatively thin layer of soil; core heat transfer is driven by the zone to deep ground temperature difference, through a relatively thick layer of soil.

1.3.3.3.2 Method. This case is similar to Case GC40c. It uses a slab with same surface area, but a different AR. Comparison of results for GC45c versus GC40c (GC45c-GC40c) checks the sensitivity of AR. Compare heat-flow results from whole-building simulation programs to verified numerical-model results. Analyze phase shift between variation of heat flow and To.

1.3.3.3.3 Input Specification. This case is exactly as Case GC40c except for the slab dimensions as noted in Table 1-14.

Table 1-14. Input parameters

\begin{tabular}{|l|c|c|}
\hline Test parameters & SI Units & IP Units \\
\hline Slab length $(\mathrm{L})$ & $36 \mathrm{~m}$ & $118.11 \mathrm{ft}$ \\
\hline Slab width $(\mathrm{B})$ & $4 \mathrm{~m}$ & $13.12 \mathrm{ft}$ \\
\hline
\end{tabular}

Set the heating system capacity as needed so there is at least enough capacity to maintain the zone air temperature set point during the peak heating-load hour (and therefore all other hours). 
1.3.3.3.4 Output Requirements. See Case GC40b. However, do not provide hourly floor conduction outputs for the entire year.

\subsubsection{Case GC55c - Shallow Deep Ground Temperature with BASESIMP Boundary Conditions}

1.3.3.4.1 Objective. Test the sensitivity to variation of deep ground temperature depth in the context of steady-periodic (harmonic) variation of To. This case is relevant for areas with a relatively shallow groundwater table, which increases the effect of core heat flow that is driven by the difference between the zone air temperature and the deep ground temperature.

1.3.3.4.2 Method. This case is similar to Case GC40c but uses a shallower deep ground boundary (heat sink) location. Comparison of results for GC55c versus GC40c (GC55c-GC40c) checks the sensitivity of deep ground temperature depth. Compare heat-flow results from whole-building simulation programs to verified numerical-model results. Analyze phase shift between variation of heat flow and To.

1.3.3.4.3 Input Specification. This case is exactly as Case GC40c except for the deep-ground temperature boundary depth as noted in Table 1-15.

Table 1-15. Input parameters

\begin{tabular}{|l|c|c|}
\hline Test parameters & SI Units & IP Units \\
\hline Deep ground boundary depth (E) & $5 \mathrm{~m}$ & $16.40 \mathrm{ft}$ \\
\hline
\end{tabular}

Set the heating system capacity as needed so there is at least enough capacity to maintain the zone air temperature set point during the peak heating-load hour (and therefore all other hours).

1.3.3.4.4 Output Requirements. See Case GC40b. However, do not provide hourly floor conduction outputs for the entire year.

\subsubsection{Case GC80c - Reduced Slab and Ground Conductivity with BASESIMP Boundary Conditions}

1.3.3.5.1 Objective. Test sensitivity to reduced slab and ground conductivity in the context of steadyperiodic (harmonic) variation of To.

1.3.3.5.2 Method. This case is similar to Case GC40c but uses decreased slab and ground conductivity. Comparison of results for GC80c versus GC40c (GC80c-GC40c) checks the sensitivity of slab and ground conductivity. Compare heat-flow results from whole-building simulation programs to verified numerical-model results. Analyze phase shift between variation of heat flow and To.

1.3.3.5.3 Input Specification. This case is exactly as Case GC40c except:

Soil and slab thermal conductivity $=0.85 \mathrm{~W} /(\mathrm{m} \cdot \mathrm{K})\left(0.491 \mathrm{Btu} /\left(\mathrm{h} \cdot \mathrm{ft} \cdot{ }^{\circ} \mathrm{F}\right)\right)$.

1.3.3.5.4 Output Requirements. See Case GC40b. However, do not provide hourly floor conduction outputs for the entire year. 


\section{Appendix A. TMY2 File Format}

This format information was taken from the TMY2 User's Manual (Marion and Urban 1995), and can be found at www.nrel.gov.

\section{Data and Format}

For each station, a TMY2 file contains 1 year of hourly solar radiation, illuminance, and meteorological data. The files consist of data for the typical calendar months during 1961-1990 that are concatenated to form the typical meteorological year for each station.

Each hourly record in the file contains values for solar radiation, illuminance, and meteorological elements. A two-character source and uncertainty flag is attached to each data value to indicate whether the data value was measured, modeled, or missing, and to provide an estimate of the uncertainty of the data value.

\section{File Header}

The first record of each file is the file header that describes the station. The file header contains the WBAN number, city, state, time zone, latitude, longitude, and elevation. The field positions and definitions of these header elements are given in Table A-1, along with sample FORTRAN and C formats for reading the header.

Table A-1. TMY2 weather file header format (for first record of each file)

\begin{tabular}{|c|c|c|}
\hline Field Position & Element & Definition \\
\hline $002-006$ & WBAN Number & $\begin{array}{l}\text { Station's Weather Bureau Army Navy } \\
\text { number (see Table 2-1 of Marion and Urban } \\
\text { [1995]) }\end{array}$ \\
\hline $008-029$ & City & $\begin{array}{l}\text { City where the station is located (maximum of } 22 \\
\text { characters) }\end{array}$ \\
\hline $031-032$ & State & $\begin{array}{l}\text { State where the station is located (abbreviated to } \\
\text { two letters) }\end{array}$ \\
\hline $034-036$ & Time Zone & $\begin{array}{l}\text { Time zone is the number of hours by which the } \\
\text { local standard time is ahead of or behind } \\
\text { Universal Time. For example, Mountain Standard } \\
\text { Time is designated }-7 \text { because it is } 7 \text { hours } \\
\text { behind Universal Time. }\end{array}$ \\
\hline $\begin{array}{l}038-044 \\
038 \\
040-041 \\
043-044\end{array}$ & Latitude & $\begin{array}{l}\text { Latitude of the station } \\
\mathrm{N}=\text { North of equator } \\
\text { Degrees } \\
\text { Minutes }\end{array}$ \\
\hline $\begin{array}{l}046-053 \\
046 \\
048-050 \\
052-053\end{array}$ & Longitude & $\begin{array}{l}\text { Longitude of the station } \\
W=\text { West, } E=\text { East } \\
\text { Degrees } \\
\text { Minutes }\end{array}$ \\
\hline $056-059$ & Elevation & Elevation of station in meters above sea level \\
\hline \multicolumn{3}{|c|}{ 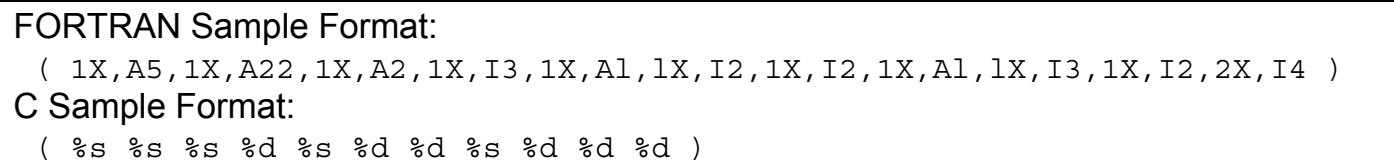 } \\
\hline
\end{tabular}




\section{Hourly Records}

Following the file header, 8760 hourly data records provide 1 year of solar radiation, illuminance, and meteorological data, along with their source and uncertainty flags. Table A-2 provides field positions, element definitions, and sample FORTRAN and C formats for reading the hourly records.

Each hourly record begins with the year (field positions 2-3) from which the typical month was chosen, followed by the month, day, and hour information in field positions 4-9. The times are in local standard time (previous TMYs based on SOLMET/ERSATZ data are in solar time).

For solar radiation and illuminance elements, the data values represent the energy received during the 60 minutes preceding the hour indicated. For meteorological elements (with a few exceptions), observations or measurements were made at the hour indicated. A few of the meteorological elements had observations, measurements, or estimates made at daily, instead of hourly, intervals. Consequently, the data values for broadband aerosol optical depth, snow depth, and days since last snowfall represent the values available for the day indicated.

\section{Source and Uncertainty Flags}

With the exception of extraterrestrial horizontal and extraterrestrial direct radiation, the two field positions immediately following the data value provide source and uncertainty flags both to indicate whether the data were measured, modeled, or missing, and to provide an estimate of the uncertainty of the data. Source and uncertainty flags for extraterrestrial horizontal and extraterrestrial direct radiation are not provided because these elements were calculated using equations considered to give exact values.

For the most part, the source and uncertainty flags in the TMY2 data files are the same as the ones in NSRDB, from which the TMY2 files were derived. However, differences do exist for data that were missing in the NSRDB, but then filled while developing the TMY2 data sets. Uncertainty values apply to the data with respect to when the data were measured, and not as to how "typical" a particular hour is for a future month and day. More information on data filling and the assignment of source and uncertainty flags is found in the TMY2 User's Manual (Marion and Urban 1995). 
Table A-2. TMY2 data records

\begin{tabular}{|c|c|c|c|}
\hline $\begin{array}{l}\text { Field } \\
\text { Position }\end{array}$ & Element & Values & Definition \\
\hline $\begin{array}{l}002-009 \\
002-003 \\
004-005 \\
006-007 \\
008-009\end{array}$ & $\begin{array}{l}\text { Local Standard Time } \\
\text { Year } \\
\text { Month } \\
\text { Day } \\
\text { Hour }\end{array}$ & $\begin{array}{l}61-90 \\
1-12 \\
1-31 \\
1-24\end{array}$ & $\begin{array}{l}\text { Year, 1961-1990 } \\
\text { Month } \\
\text { Day of month } \\
\text { Hour of day in local standard time }\end{array}$ \\
\hline $010-013$ & $\begin{array}{l}\text { Extraterrestrial Horizontal } \\
\text { Radiation }\end{array}$ & $0-1415$ & $\begin{array}{l}\text { Amount of solar radiation in } \mathrm{Wh} / \mathrm{m}^{2} \\
\text { received on a horizontal surface at the } \\
\text { top of the atmosphere during the } 60 \\
\text { minutes preceding the hour indicated }\end{array}$ \\
\hline $014-017$ & $\begin{array}{l}\text { Extraterrestrial Direct } \\
\text { Normal Radiation }\end{array}$ & $0-1415$ & $\begin{array}{l}\text { Amount of solar radiation in } \mathrm{Wh} / \mathrm{m}^{2} \\
\text { received on a surface normal to the } \\
\text { sun at the top of the atmosphere } \\
\text { during the } 60 \text { minutes preceding the } \\
\text { hour indicated }\end{array}$ \\
\hline $\begin{array}{l}018-023 \\
018-021 \\
022 \\
023\end{array}$ & $\begin{array}{l}\text { Global Horizontal Radiation } \\
\text { Data Value } \\
\text { Flag for Data Source } \\
\text { Flag for Data Uncertainty }\end{array}$ & $\begin{array}{l}0-1200 \\
A-H, ? \\
0-9\end{array}$ & $\begin{array}{l}\text { Total amount of direct and diffuse } \\
\text { solar radiation in } \mathrm{Wh} / \mathrm{m}^{2} \text { received on } \\
\text { a horizontal surface during the } 60 \\
\text { minutes preceding the hour indicated }\end{array}$ \\
\hline $\begin{array}{l}\mathbf{0 2 4}-\mathbf{0 2 9} \\
024-027 \\
028 \\
029\end{array}$ & $\begin{array}{l}\text { Direct Normal Radiation } \\
\text { Data Value } \\
\text { Flag for Data Source } \\
\text { Flag for Data Uncertainty }\end{array}$ & $\begin{array}{l}0-1100 \\
A-H, ? \\
0-9\end{array}$ & $\begin{array}{l}\text { Amount of solar radiation in } \mathrm{Wh} / \mathrm{m}^{2} \\
\text { received within a } 5.7^{\circ} \text { field of view } \\
\text { centered on the sun during the } 60 \\
\text { minutes preceding the hour indicated }\end{array}$ \\
\hline $\begin{array}{l}030-035 \\
030-033 \\
034 \\
035\end{array}$ & $\begin{array}{l}\text { Diffuse Horizontal Radiation } \\
\text { Data Value } \\
\text { Flag for Data Source } \\
\text { Flag for Data Uncertainty }\end{array}$ & $\begin{array}{l}0-700 \\
A-H, ? \\
0-9\end{array}$ & $\begin{array}{l}\text { Amount of solar radiation in } \mathrm{Wh} / \mathrm{m}^{2} \\
\text { received from the sky (excluding the } \\
\text { solar disk) on a horizontal surface } \\
\text { during the } 60 \text { minutes preceding the } \\
\text { hour indicated }\end{array}$ \\
\hline $\begin{array}{l}036-041 \\
036-039 \\
040 \\
041\end{array}$ & $\begin{array}{l}\text { Global Horiz. Illuminance } \\
\text { Data Value } \\
\text { Flag for Data Source } \\
\text { Flag for Data Uncertainty }\end{array}$ & $\begin{array}{l}0-1300 \\
\text { I, ? } \\
0-9\end{array}$ & $\begin{array}{l}\text { Average total amount of direct and } \\
\text { diffuse illuminance in hundreds of lux } \\
\text { received on a horizontal surface } \\
\text { during the } 60 \text { minutes preceding the } \\
\text { hour indicated } \\
0 \text { to } 1300=0 \text { to } 130,000 \text { lux }\end{array}$ \\
\hline $\begin{array}{l}042-047 \\
042-045 \\
046 \\
047\end{array}$ & $\begin{array}{l}\text { Direct Normal Illuminance } \\
\text { Data Value } \\
\text { Flag for Data Source } \\
\text { Flag for Data Uncertainty }\end{array}$ & $\begin{array}{l}0-1100 \\
\text { I, ? } \\
0-9\end{array}$ & $\begin{array}{l}\text { Average amount of direct normal } \\
\text { illuminance in hundreds of lux } \\
\text { received within a } 5.7^{\circ} \text { field of view } \\
\text { centered on the sun during the } 60 \\
\text { minutes preceding the hour indicated. } \\
0 \text { to } 1100=0 \text { to } 110,000 \text { lux }\end{array}$ \\
\hline $\begin{array}{l}048-053 \\
048-051 \\
052 \\
053\end{array}$ & $\begin{array}{l}\text { Diffuse Horiz. Illuminance } \\
\text { Data Value } \\
\text { Flag for Data Source } \\
\text { Flag for Data Uncertainty }\end{array}$ & $\begin{array}{l}0-800 \\
\text { I, ? } \\
0-9\end{array}$ & $\begin{array}{l}\text { Average amount of illuminance in } \\
\text { hundreds of lux received from the sky } \\
\text { (excluding the solar disk) on a } \\
\text { horizontal surface during the } 60 \\
\text { minutes preceding the hour indicated. } \\
0 \text { to } 800=0 \text { to } 80,000 \text { lux }\end{array}$ \\
\hline
\end{tabular}




\begin{tabular}{|c|c|c|c|}
\hline $\begin{array}{l}\text { Field } \\
\text { Position }\end{array}$ & Element & Values & Definition \\
\hline $\begin{array}{l}054-059 \\
054-057 \\
058 \\
059\end{array}$ & $\begin{array}{l}\text { Zenith Luminance } \\
\text { Data Value } \\
\text { Flag for Data Source } \\
\text { Flag for Data Uncertainty }\end{array}$ & $\begin{array}{l}0-7000 \\
\text { l, ? } \\
0-9\end{array}$ & $\begin{array}{l}\text { Average amount of luminance at the } \\
\text { sky's zenith in tens of } \mathrm{Cd} / \mathrm{m}^{2} \text { during } \\
\text { the } 60 \text { minutes preceding the hour } \\
\text { indicated. } \\
0 \text { to } 7000=0 \text { to } 70,000 \mathrm{Cd} / \mathrm{m}^{2}\end{array}$ \\
\hline $\begin{array}{l}060-063 \\
060-061 \\
062 \\
063\end{array}$ & $\begin{array}{l}\text { Total Sky Cover } \\
\text { Data Value } \\
\text { Flag for Data Source } \\
\text { Flag for Data Uncertainty }\end{array}$ & $\begin{array}{l}0-10 \\
A-F \\
0-9\end{array}$ & $\begin{array}{l}\text { Amount of sky dome in tenths } \\
\text { covered by clouds or obscuring } \\
\text { phenomena at the hour indicated }\end{array}$ \\
\hline $\begin{array}{l}064-067 \\
064-065 \\
066 \\
067\end{array}$ & $\begin{array}{l}\text { Opaque Sky Cover } \\
\text { Data Value } \\
\text { Flag for Data Source } \\
\text { Flag for Data Uncertainty }\end{array}$ & $\begin{array}{l}0-10 \\
A-F \\
0-9\end{array}$ & $\begin{array}{l}\text { Amount of sky dome in tenths } \\
\text { covered by clouds or obscuring } \\
\text { phenomena that prevent observing the } \\
\text { sky or higher cloud layers at the hour } \\
\text { indicated }\end{array}$ \\
\hline $\begin{array}{l}068-073 \\
068-071 \\
072 \\
073\end{array}$ & $\begin{array}{l}\text { Dry Bulb Temperature } \\
\text { Data Value } \\
\text { Flag for Data Source } \\
\text { Flag for Data Uncertainty }\end{array}$ & $\begin{array}{l}-500 \text { to } 500 \\
\text { A-F } \\
0-9\end{array}$ & $\begin{array}{l}\text { Dry bulb temperature in tenths of }{ }^{\circ} \mathrm{C} \\
\text { at the hour indicated } \\
-500 \text { to } 500=-50.0 \text { to } 50.0^{\circ} \mathrm{C}\end{array}$ \\
\hline $\begin{array}{l}074-079 \\
074-077 \\
078 \\
079\end{array}$ & $\begin{array}{l}\text { Dew Point Temperature } \\
\text { Data Value } \\
\text { Flag for Data Source } \\
\text { Flag for Data Uncertainty }\end{array}$ & $\begin{array}{l}-600 \text { to } 300 \\
\text { A - F } \\
0-9\end{array}$ & $\begin{array}{l}\text { Dew point temperature in tenths of } \\
{ }^{\circ} \mathrm{C} \text { at the hour indicated } \\
-600 \text { to } 300=-60.0 \text { to } 30.0^{\circ} \mathrm{C}\end{array}$ \\
\hline $\begin{array}{l}080-084 \\
080-082 \\
083 \\
084\end{array}$ & $\begin{array}{l}\text { Relative Humidity } \\
\text { Data Value } \\
\text { Flag for Data Source } \\
\text { Flag for Data Uncertainty }\end{array}$ & $\begin{array}{l}0-100 \\
A-F \\
0-9\end{array}$ & $\begin{array}{l}\text { Relative humidity in percent at the } \\
\text { hour indicated }\end{array}$ \\
\hline $\begin{array}{l}085-090 \\
085-088 \\
089 \\
090\end{array}$ & $\begin{array}{l}\text { Atmospheric Pressure } \\
\text { Data Value } \\
\text { Flag for Data Source } \\
\text { Flag for Data Uncertainty }\end{array}$ & $\begin{array}{l}700-1100 \\
A-F \\
0-9\end{array}$ & $\begin{array}{l}\text { Atmospheric pressure at station in } \\
\text { millibars at the hour indicated }\end{array}$ \\
\hline $\begin{array}{l}091-095 \\
091-093 \\
094 \\
095\end{array}$ & $\begin{array}{l}\text { Wind Direction } \\
\text { Data Value } \\
\text { Flag for Data Source } \\
\text { Flag for Data Uncertainty }\end{array}$ & $\begin{array}{l}0-360 \\
\text { A - F } \\
0-9\end{array}$ & $\begin{array}{l}\text { Wind direction in degrees at the hour } \\
\text { indicated. }(N=0 \text { or } 360, E=90 \text {, } \\
S=180, W=270) \text {. For calm winds, } \\
\text { wind direction equals zero. }\end{array}$ \\
\hline $\begin{array}{l}096-100 \\
096-098 \\
099 \\
100 \\
\end{array}$ & $\begin{array}{l}\text { Wind Speed } \\
\text { Data Value } \\
\text { Flag for Data Source } \\
\text { Flag for Data Uncertainty }\end{array}$ & $\begin{array}{l}0-400 \\
\text { A - F } \\
0-9\end{array}$ & $\begin{array}{l}\text { Wind speed in tenths of meters per } \\
\text { second at the hour indicated. } \\
0 \text { to } 400=0 \text { to } 40.0 \mathrm{~m} / \mathrm{s}\end{array}$ \\
\hline $\begin{array}{l}101-106 \\
101-104 \\
105 \\
106\end{array}$ & $\begin{array}{l}\text { Visibility } \\
\text { Data Value } \\
\text { Flag for Data Source } \\
\text { Flag for Data Uncertainty }\end{array}$ & $\begin{array}{l}0-1609 \\
A-F, ? \\
0-9\end{array}$ & $\begin{array}{l}\text { Horizontal visibility in tenths of } \\
\text { kilometers at the hour indicated. } \\
7777=\text { unlimited visibility } \\
0 \text { to } 1609=0.0 \text { to } 160.9 \mathrm{~km} \\
9999=\text { missing data }\end{array}$ \\
\hline $\begin{array}{l}107-113 \\
107-111 \\
112 \\
113\end{array}$ & $\begin{array}{l}\text { Ceiling Height } \\
\text { Data Value } \\
\text { Flag for Data Source } \\
\text { Flag for Data Uncertainty }\end{array}$ & $\begin{array}{l}0-30450 \\
A-F, ? \\
0-9\end{array}$ & $\begin{array}{l}\text { Ceiling height in meters at the hour } \\
\text { indicated. } \\
77777=\text { unlimited ceiling height } \\
88888=\text { cirroform } \\
99999=\text { missing data }\end{array}$ \\
\hline
\end{tabular}




\begin{tabular}{|c|c|c|c|}
\hline $\begin{array}{l}\text { Field } \\
\text { Position }\end{array}$ & Element & Values & Definition \\
\hline $114-123$ & Present Weather & $\begin{array}{l}\text { See } \\
\text { Appendix B } \\
\text { of Marion and } \\
\text { Urban (1995) }\end{array}$ & $\begin{array}{l}\text { Present weather conditions denoted by } \\
\text { a } 10 \text {-digit number. See Appendix B in } \\
\text { the Marion and Urban (1995) for key to } \\
\text { present weather elements. }\end{array}$ \\
\hline $\begin{array}{l}124-128 \\
124-126 \\
127 \\
128\end{array}$ & $\begin{array}{l}\text { Precipitable Water } \\
\text { Data Value } \\
\text { Flag for Data Source } \\
\text { Flag for Data Uncertainty }\end{array}$ & $\begin{array}{l}0-100 \\
\text { A - F } \\
0-9\end{array}$ & $\begin{array}{l}\text { Precipitable water in millimeters at } \\
\text { the hour indicated }\end{array}$ \\
\hline $\begin{array}{l}129-133 \\
129-131 \\
132 \\
133\end{array}$ & $\begin{array}{l}\text { Aerosol Optical Depth } \\
\text { Data Value } \\
\text { Flag for Data Source } \\
\text { Flag for Data Uncertainty }\end{array}$ & $\begin{array}{l}0-240 \\
\text { A - F } \\
0-9\end{array}$ & $\begin{array}{l}\text { Broadband aerosol optical depth } \\
\text { (broad-band turbidity) in thousandths } \\
\text { on the day indicated. } \\
0 \text { to } 240=0.0 \text { to } 0.240\end{array}$ \\
\hline $\begin{array}{l}134-138 \\
134-136 \\
137 \\
138 \\
\end{array}$ & $\begin{array}{l}\text { Snow Depth } \\
\text { Data Value } \\
\text { Flag for Data Source } \\
\text { Flag for Data Uncertainty }\end{array}$ & $\begin{array}{l}0-150 \\
A-F, ? \\
0-9\end{array}$ & $\begin{array}{l}\text { Snow depth in centimeters on the day } \\
\text { indicated. } \\
999=\text { missing data }\end{array}$ \\
\hline $\begin{array}{l}139-142 \\
139-140 \\
141 \\
142\end{array}$ & $\begin{array}{l}\text { Days Since Last Snowfall } \\
\text { Data Value } \\
\text { Flag for Data Source } \\
\text { Flag for Data Uncertainty }\end{array}$ & $\begin{array}{l}0-88 \\
A-F, ? \\
0-9\end{array}$ & $\begin{array}{l}\text { Number of days since last snowfall } \\
88=88 \text { or greater days } \\
99=\text { missing data }\end{array}$ \\
\hline \multicolumn{4}{|c|}{ 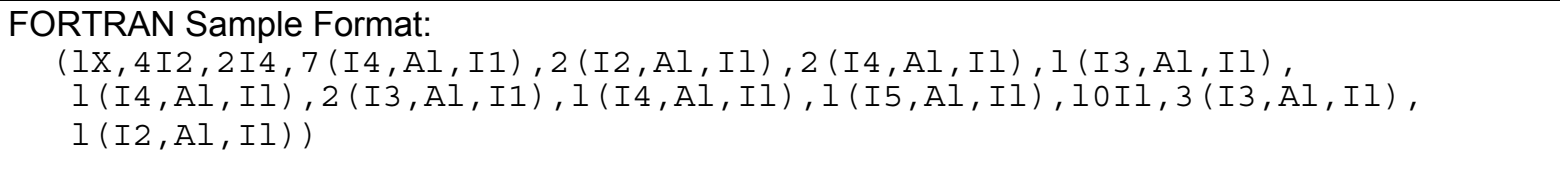 } \\
\hline \multicolumn{4}{|c|}{ 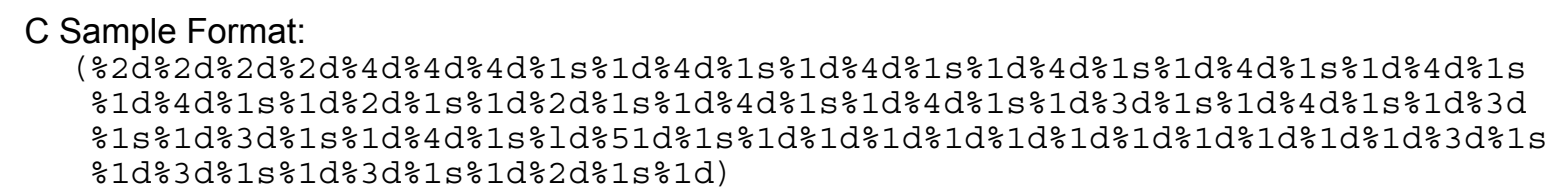 } \\
\hline
\end{tabular}




\section{Appendix B. Output Spreadsheet Instructions}

GC-InDepth-Out.XLS

Output spreadsheet for Ground Coupling In-Depth Cases: GC10a-GC80c

\section{INSTRUCTIONS}

1. Use specified units

2. Data entry is restricted to the following ranges:
E53, I53, L53:
Software Name, Version, and Date of Results
E58..H63; J58, K58:
Steady-State Case Outputs
E70..R70:
Harmonic Case "a"-Series Outputs
E71..R76:
Harmonic Case "b"-Series Outputs
E77..R80:
Harmonic Case "c"-Series Outputs
G86..K103; G105..K122:
Steady-State Near-Surface Temperature Outputs
M86..M103; M105..M122
G126:
E131..G8890: GC10a At-Surface Temperature Outputs
Hourly Time Convention
Hourly Floor Conduction Outputs

3. Annual sums and means are values for the entire final year of the multiyear simulation. Similarly, annual means, maxima, and minima are values that occur for the final year of the entire multiyear simulation.

4. Output terminology is defined in the output section of the specification for each case, where applicable.

5. Format dates using the appropriate two-digit date followed by a three-letter month code and two-digit hour code (24-hour clock) as shown below.

\section{MONTH CODES:}

$\begin{array}{ll}\text { MONTH } & \text { CODE } \\ \text { JANUARY } & \text { Jan } \\ \text { FEBRUARY } & \text { Feb } \\ \text { MARCH } & \text { Mar } \\ \text { APRIL } & \text { Apr } \\ \text { MAY } & \text { May } \\ \text { JUNE } & \text { Jun } \\ \text { JULY } & \text { Jul } \\ \text { AUGUST } & \text { Aug } \\ \text { SEPTEMBER } & \text { Sep } \\ \text { OCTOBER } & \text { Oct } \\ \text { NOVEMBER } & \text { Nov } \\ \text { DECEMBER } & \text { Dec }\end{array}$

For example, a maximum value occurring on August 16 during the 15th hour interval (2:00 p.m. to 3:00 p.m.), should be input as:

Date Hour

16-Aug 15 


\section{Appendix C. Abbreviations and Acronyms}

\begin{tabular}{|c|c|}
\hline $\begin{array}{l}\mathrm{AR} \\
\mathrm{ASHR} A \mathrm{~F}\end{array}$ & aspect ratio \\
\hline ASHRAE & American Society of Heating, Refrigerating and Air-Conditioning Engineers \\
\hline $\mathrm{B}$ & floor slab length in north/south direction \\
\hline BESTEST & Building Energy Simulation Test and Diagnostic Method \\
\hline Coeff. & coefficient \\
\hline E & deep ground boundary depth $(\mathrm{m})$ \\
\hline ECBCS & Energy Conservation in Building and Community Systems Programme of IEA \\
\hline $\mathrm{F}$ & far field boundary distance $(\mathrm{m})$ \\
\hline $\begin{array}{l}\text { h } \\
\text { h,int } \\
\text { h,ext } \\
\text { h.t. }\end{array}$ & $\begin{array}{l}\text { convective surface coefficient } \\
\text { interior convective surface coefficient } \\
\text { exterior convective surface coefficient } \\
\text { heat transfer }\end{array}$ \\
\hline IEA & International Energy Agency \\
\hline IEA $34 / 43$ & IEA SHC Task 34/ECBCS Annex 43 \\
\hline ISO & International Organization for Standardization \\
\hline $\mathrm{k}_{\text {soil }}$ & soil/slab thermal conductivity $(\mathrm{W} /(\mathrm{m} \cdot \mathrm{K}))$ \\
\hline $\mathrm{L}$ & floor slab length in east/west direction \\
\hline $\mathrm{N}, \mathrm{E}, \mathrm{S}, \mathrm{W}$ & north, east, south, west \\
\hline NSRDB & National Solar Radiation Data Base \\
\hline q & heat flow $(\mathrm{W}$ or $\mathrm{Wh} / \mathrm{h})$ \\
\hline $\mathrm{q}_{\text {floor }}$ & floor conduction (W or $\mathrm{Wh} / \mathrm{h}$ ) \\
\hline $\mathrm{q}_{\text {floor,max }}$ & annual hourly integrated peak floor conduction $(\mathrm{Wh} / \mathrm{h}$ or $\mathrm{W})$ \\
\hline $\mathrm{q}_{\text {zone }}$ & zone load $(\mathrm{W}$ or $\mathrm{Wh} / \mathrm{h})$ \\
\hline $\mathrm{q}_{\text {zone,max }}$ & annual hourly integrated peak zone load (Wh/h or W) \\
\hline$Q_{\text {floor }}$ & annual total floor conduction $(\mathrm{kWh} / \mathrm{y})$ \\
\hline $\mathrm{Q}_{\text {zone }}$ & annual total zone load $(\mathrm{kWh} / \mathrm{y})$ \\
\hline $\mathrm{SHC}$ & Solar Heating and Cooling Programme of IEA \\
\hline $\mathrm{Tdg}$ & deep ground temperature $\left({ }^{\circ} \mathrm{C}\right)$ \\
\hline Temp. & temperature \\
\hline $\mathrm{Ti}$ & interior slab surface temperature $\left({ }^{\circ} \mathrm{C}\right)$ \\
\hline Ti,a & zone air temperature $\left({ }^{\circ} \mathrm{C}\right)$ \\
\hline To & exterior ground surface temperature $\left({ }^{\circ} \mathrm{C}\right)$ \\
\hline To,a & ambient air temperature $\left({ }^{\circ} \mathrm{C}\right)$ \\
\hline $\mathrm{T}_{\mathrm{ODB}, \min }$ & minimum hourly ambient temperature $\left({ }^{\circ} \mathrm{C}\right)$ \\
\hline$t_{\text {sim }}$ & number of hours simulated (hours) \\
\hline $\mathrm{T}_{\text {surf,n }}$ & near-surface temperature $\left({ }^{\circ} \mathrm{C}\right)$ \\
\hline $\mathrm{T}_{@ \text { surf,n }}$ & at-surface temperature, Case GC10a only $\left({ }^{\circ} \mathrm{C}\right)$ \\
\hline $\mathrm{T}_{\text {zone }}$ & zone air temperature $\left({ }^{\circ} \mathrm{C}\right)$ \\
\hline $\mathrm{T}_{\text {zone,mean }}$ & annual average zone air temperature $\left({ }^{\circ} \mathrm{C}\right)$ \\
\hline TMY2 & typical meteorological year 2 \\
\hline UA & conductance $\left(\mathrm{W} /{ }^{\circ} \mathrm{C}\right)$ \\
\hline $\mathrm{W}$ & slab/soil perimeter boundary width or wall thickness \\
\hline WBAN & Weather Bureau Army Navy \\
\hline
\end{tabular}




\section{Appendix D. Glossary}

Note: This glossary highlights terms that are either already defined in ANSI/ASHRAE Standard 140-2007 (ANSI/ASHRAE 2007), or may be included or revised in a later version of Standard 140. Italicized terms are defined elsewhere in the glossary.

Adiabatic is without loss or gain of heat; an adiabatic boundary does not allow heat to flow through it.

Analytical solution is the mathematical solution of a model that has an exact result for a given set of parameters and simplifying assumptions.

Analytical verification is where outputs from a program, subroutine, algorithm, or software object are compared to results from a known analytical solution, or to results from a set of closely agreeing quasianalytical solutions or verified numerical models.

Annual hourly integrated peak floor conduction is the hourly floor conduction that represents the maximum for the final year of the simulation period.

Annual hourly integrated peak zone load is the hourly zone load that represents the maximum for the final year of the simulation period.

Aspect ratio is the ratio of the floor slab length to the floor slab width.

Convective surface coefficient is a constant of proportionality relating the rate of convective heat transfer at a surface to the temperature difference across the air film on that surface.

Convergence tolerance is, for an iterative solution process, the maximum acceptable magnitude of a selected error estimate; when the error criterion is satisfied, the process is considered to have converged on a sufficiently accurate approximate solution.

Deep ground temperature is the ground temperature at the deep ground boundary depth.

Detailed ground heat transfer model employs transient 3-D numerical-methods (finite-element or finite-difference) heat transfer modeling throughout the modeled domain.

Mathematical truth standard is the standard of accuracy for predicting system behavior based on an analytical solution.

Mid-level detailed ground heat transfer model is based on a transient 2-D or 3-D numerical-methods heat transfer model, applying some simplification(s) for adaptation to a whole-building energy simulation program; such models include correlation methods based on extensive 2-D or 3-D numerical analysis.

Quasi-analytical solution is the mathematical solution of a model for a given set of parameters and simplifying assumptions, which may include minor interpretation differences that cause minor results variations; such a solution may be computed by generally accepted numerical methods or other means, provided that such calculations occur outside the environment of a whole-building energy simulation program and can be scrutinized.

Secondary mathematical truth standard is the standard of accuracy for predicting system behavior based on the range of disagreement of a set of closely agreeing verified numerical models or other quasianalytical solutions, to which other simulations may be compared. 
Simplified ground heat transfer model is based on a 1-D dynamic or steady-state heat transfer model; implementation of such a model usually requires no modification to a whole-building energy simulation program.

Verified numerical model is a numerical model with solution accuracy verified by close agreement with an analytical solution and/or other quasi-analytical or numerical solutions, according to a process that demonstrates solution convergence in the space and time domains. Such numerical models may be verified by applying an initial comparison with an analytical solution(s), followed by comparisons with other numerical models for incrementally more realistic cases where analytical solutions are not available. 


\section{Appendix E. Remarks about the Test Cases}

The following remarks relate to development of the test cases.

\section{GC30b}

$\mathrm{k}=1.9 \mathrm{~W} /(\mathrm{m} \cdot \mathrm{K})$ matches upper limit of BASESIMP.

Per M. Deru of NREL, an adiabatic far-field boundary condition is typically what ground heat transfer specialists have assumed for years, and a reasonable physical basis would be a similar neighboring building that generates similar isotherms. For a relatively large far-field dimension $(F)$, the floor conduction heat will either have surfaced via the exterior ground surface or gone to the deep ground sink, which is also compatible with an adiabatic far-field assumption.

\section{GC40b}

This is used as the base case for sensitivity tests of aspect ratio (GC45b), deep ground temperature (GC55b), etc. because:

- Harmonic variation of outside air temperature variation provides a more realistic dynamic.

- High convective surface coefficients provide a more uniform floor surface temperature, which may match assumptions of some simulations.

- High convective surface coefficients allow more heat transfer overall (a more robust signal to work with).

\section{GC45b}

Per M. Deru of NREL, for much less than $4 \mathrm{~m}$ width there is little reduction in core surface area (where heat transfer is to deep ground boundary condition).

\section{GC50b}

Fifteen meter ground depth (same as GC30b) gives a good comparison of core and perimeter flux effects versus GC30b. Far-field dimension $(\mathrm{F})=15 \mathrm{~m}$ is consistent with GC30b; F much greater than $15 \mathrm{~m}$ is probably a waste of computer time (an issue when we model a lot of ground).

\section{GC60b}

h,int $=7.95 \mathrm{~W} /\left(\mathrm{m}^{2} \cdot \mathrm{K}\right)$ was chosen because it is equal to the combined convective/radiative surface coefficient that is the hardwired assumption of BASESIMP. Note: the Standard-140 default combined surface coefficient for downward heat transfer on a horizontal surface is $6.13 \mathrm{~W} /\left(\mathrm{m}^{2} \cdot \mathrm{K}\right)$, which is based on values of the 2005 ASHRAE Handbook of Fundamentals (p. 25.2).

To document the disagreement effect of BASESIMP's geometry assumption differences, direct-input exterior surface temperature boundary conditions, and other assumptions, BASESIMP results for GC30c may be compared with other programs' results for GC60b and GC65b (GC60b is better according to the verified numerical-model results), and BASESIMP results for GC40c may be compared with other programs' results for GC70b. 


\section{GC80b}

A lower limit of $\mathrm{k}=0.5 \mathrm{~W} /(\mathrm{m} \cdot \mathrm{K})$ was recommended by M. Deru of NREL as representative of dry clay.

\section{GC10a}

An additional aspect ratio test (Case GC15a?) in this context seems unnecessary unless the numericalmodel results disagree for Case GC45b. The current geometry incorporates elements of core driven and perimeter driven heat transfer in the results; a $36 \mathrm{~m} \times 4 \mathrm{~m}$ slab puts greater emphasis on perimeter heat transfer. If an AR test is included here, put surface temperature outputs along the narrower axis for that case to examine a more extreme temperature gradient than would occur over the longer axis; outputs remain symmetric along the diagonal.

\section{GC30c}

EnergyPlus can match the constraints of GC30c (and therefore GC40c, GC45c, and GC80c) except for the direct-input exterior surface temperature boundary condition. Use of h,ext $=120 \mathrm{~W} /\left(\mathrm{m}^{2} \cdot \mathrm{K}\right)$ (approximate $\mathrm{E}+$ limit) versus direct-input exterior surface temperature is expected to cause about $2 \%$ results variation.

\section{GC80C}

$\mathrm{k}=0.85 \mathrm{~W} /(\mathrm{m} \cdot \mathrm{K})$ is the lower limit for BASESIMP.

\section{Harmonic Weather Data}

Harmonic weather data have more than one occurrence of the minimum hourly ambient temperature because of limited precision allowed by TMY2 format.

\section{SI to I-P Unit Conversions}

I-P units given in Part I were calculated during an early version of the test specification using conversion factors of ASHRAE (2001). Updated conversion factors published by ASHRAE (2005) yield slightly different values for I-P units. The effect of the difference is $<0.1 \%$ for the listed I-P values. 


\section{Appendix F. Diagnosing the Results Using the Flow Diagrams}

\section{F.1 General Description}

Figures F-1, F-2, and F-3 contain a set of flow diagrams that serve as a guide for diagnosing the cause of disagreeing results that may arise from using this test. These flow diagrams list the features being tested and indicate potential sources of algorithmic differences. Flow diagrams are included here for the "a"series cases (Figure F-1), the " $\mathrm{b}$ "-series cases (Figure F-2), and the "c"'-series cases (Figure F-3). For detailed numerical models the "a"-series cases are to be run first. For most other models the "b"-series cases should be run first. The "c"-series cases are for models that can match the constraints of NRCan's BASESIMP model.

For slab-on-grade models integrated with whole-building energy simulation programs, the flow diagrams may be used in two ways. The most powerful but time-consuming way is to perform all "b"-series and "c"-series cases (and the "a"-series cases if the model being tested is a detailed numerical model), and then use the diagnostic logic in the flow diagrams to analyze the results. The least time-consuming way is to perform the tests in sequence according to the flow diagrams, beginning with Figure F-1 for detailed numerical models, and Figure F-2 for other less detailed models.

\section{F.2 Comparing Tested Software Results to Verified Numerical-Model Results and Example Simulation Results}

Verified numerical-model and example simulation results are presented in Part III. At a minimum, the user should compare output with the verified numerical-model results. The user may also choose to compare output with the example simulation results, or with other results that were generated with this test procedure. Information about how the analytical solutions and example simulation results were produced is included in the modeler reports of Part II (Section 2.9). For convenience to users who wish to plot or tabulate their results along with the analytical solution or example simulation results, or both, an electronic version of the example results has been included with the file GC-InDepth-Results.XLS with the accompanying electronic files.

There are no formal for when results agree or disagree; determination of the agreement or disagreement of results is left to the user. In making this determination, the user should consider that the verified numerical-model results represent a "secondary mathematical truth standard" based on acceptance of the underlying physical assumptions represented by the case specifications. The authors recognize that the underlying physical assumptions of the case definitions are a simplification of reality and may not fully represent empirical behavior. As discussed in Part I, Section 1.2.2.1, in making a determination about the agreement of results, the user should also consider:

- Magnitude of results for individual cases

- Magnitude of difference in results between certain cases (e.g., "Case GC45b-Case GC40b")

- Same direction of sensitivity (positive or negative) for difference in results between certain cases (e.g., "Case GC45b-Case GC40b")

- If results are logically counterintuitive with respect to known or expected physical behavior

- Availability of analytical solution or verified numerical-model results (i.e., a mathematical truth standard or secondary mathematical truth standard)

- Where a mathematical or secondary-mathematical truth standard is provided, the degree of disagreement that occurred for other simulation results versus such an analytical-verification truth standard

- Example simulation results - other than the verified numerical-model results - do not represent a secondary mathematical truth standard. 
Check the program being tested for agreement with verified numerical-model results for the absolute outputs and the sensitivity (or "delta") outputs. For example, when comparing to the analytical solution results for Case "GC45b-GC40b" in Figure F-2, the program results are compared with the Case GC45b results and the Case GC45b-GC40b sensitivity results.

Compare all available output types specified for each case that can be produced by the program being tested. This includes appropriate floor conduction, zone heating load, peak-hour results, and supporting results presented in Part III, for all the listed output that the software being tested can produce. A disagreement with any output type may be cause for concern.

Performing/analyzing results of the tests in logical blocks as shown in the flow diagrams, or all at once for each series of cases, is recommended. The diagnostic logic indicates that for some cases (e.g., GC45b) if a disagreement is uncovered other cases (e.g. GC50b) may be run without fixing the previous disagreement. However, the found disagreement should be fixed if possible, and all the cases rerun.

The flow diagram of Figure F-2 begins with a basic performance test (Case GC30b). It is very important to have confidence in your Case GC30b results before proceeding to the other cases. If output from the tested program agrees satisfactorily with the verified numerical-model results for Case GC30b, continue to check output for the remaining cases according to the flow diagram. If output from the tested program disagrees with verified numerical-model results for Case GC30b, check for input errors. If no input error is found, run all other test cases and follow the diagnostic logic accordingly, as this may help to isolate the source of the difference to one of the specifically tested parameters.

In some cases it is possible to proceed even if disagreements were uncovered in the previous case. For example, in Case GC55b, the inability to model a shallow deep ground boundary (water table) depth does not necessarily affect the usefulness or testability of the program for modeling scenarios with more typical deep ground boundary depth. Thus, the flow diagram has an extra arrow connecting Case GC55b and Case GC70b, which denotes that you may proceed regardless of the results for Case GC55b. Where cases are connected by a single arrow, a satisfactory result is required to proceed to the next case. For example, in Case GC60b, the inability to model the effect of the realistic interior surface coefficient makes it difficult to proceed with Case GC65b until the disagreement is reconciled.

When testing detailed numerical models with the "a"-series cases, experience from field trials of the test procedure indicates to initially begin by checking the results of each case individually before moving on to additional cases. Specifically, first run only Case GC10a and check the results versus the analytical solution. If the result is satisfactory, move on to only Case GC30a, and similarly for GC40a, then GC30b, then GC40b, as each addresses a fundamental change in boundary conditions for steady-state and dynamic modeling. After each case is checked, it is reasonable to proceed with batch-running the remaining cases: recommend to run GC60b, GC65b and GC30c as one batch followed by the remaining "b"- and "c"-series dynamic cases. Because of geometry variations for GC45b, GC45c, and GC50c it may be preferable to run those cases last.

\section{F.2.1 If Tested Software Results Disagree with Example Results}

If the tested program shows disagreement with the verified numerical-model results, recheck the inputs against the specified values. Use the diagnostic logic flow diagrams to help isolate the source of the difference. If no input error can be found, look for an error in the software. If an error is found, fix it and rerun the tests. If in the engineering judgment of the user the disagreement is caused by a reasonable difference in algorithms between the tested software and the example results, continue with the next test case. 


\section{F.2.2 Example}

A program shows disagreement with GC80b. Figure F-2 suggests the potential source of algorithmic differences includes modeling of interior and exterior surface heat transfer coefficients. The user is directed to check diagnostics B1 and B2. If the disagreement persists for B1, the cause is likely related to modeling of the slab interior surface heat transfer coefficient. If there is no disagreement for B1, go on to B2. If the disagreement appears for B2, its cause is likely related to modeling the exterior surface heat transfer coefficient. If there is no disagreement for B1 or B2, the difference could be related to dynamic modeling versus steady-state modeling or some other problem.

Section 2.4 (Part II) gives examples of how the tests were used to trace and correct specific algorithmic and input errors in the programs used in the field trials.

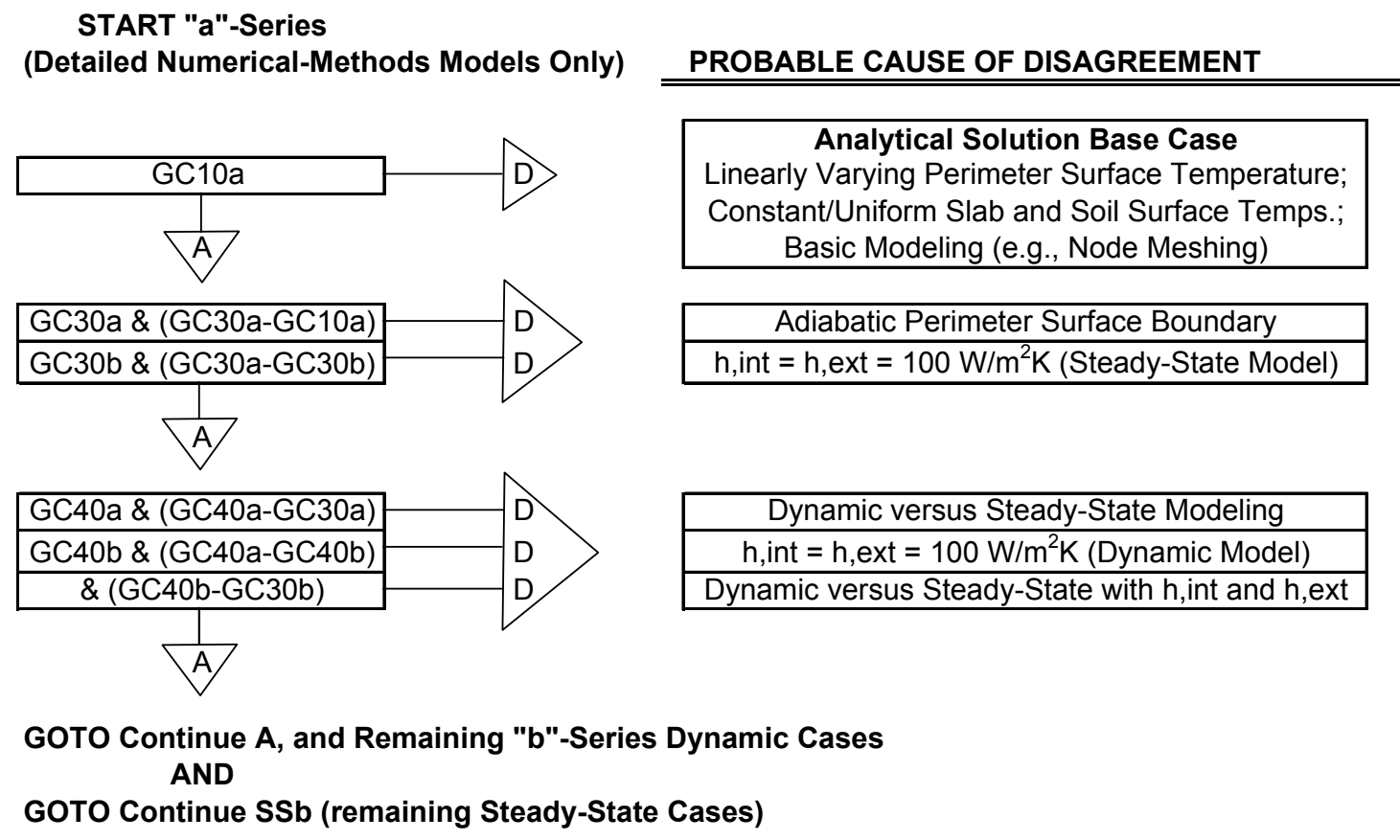

ABBREVIATIONS

$A=$ Agree; $D=$ Disagree. For these test cases, agreement/disagreement is determined relative to quasi-analytical solution results, including listed sensitivity cases.

Figure F-1. Diagnostic logic flow diagram "a"-series cases 
START

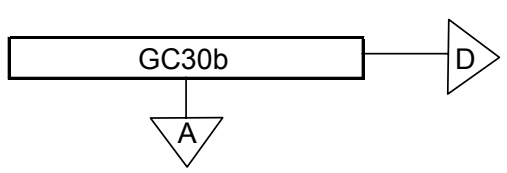

("b"-Series Dynamic Cases)

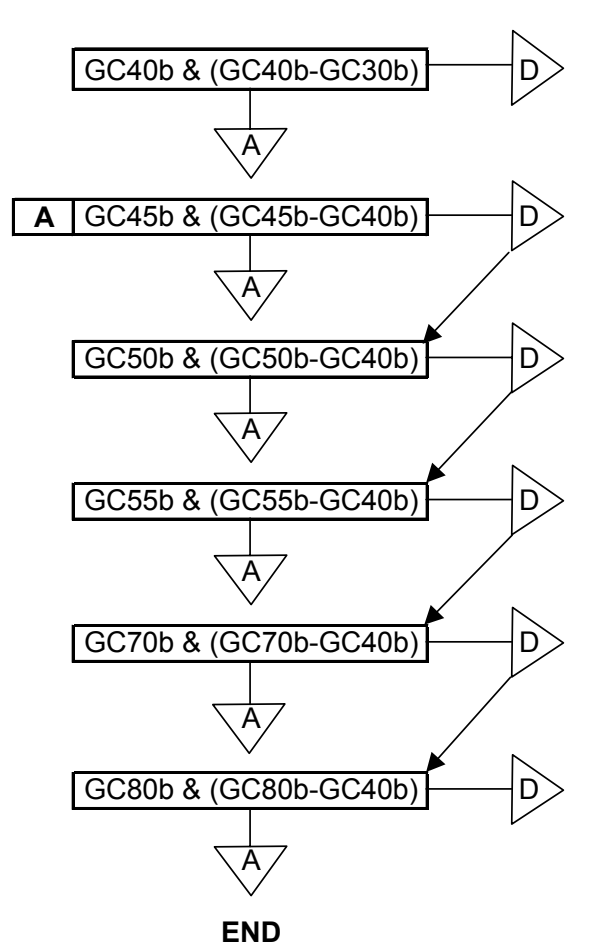

CONTINUE SSb (Steady-State Cases)

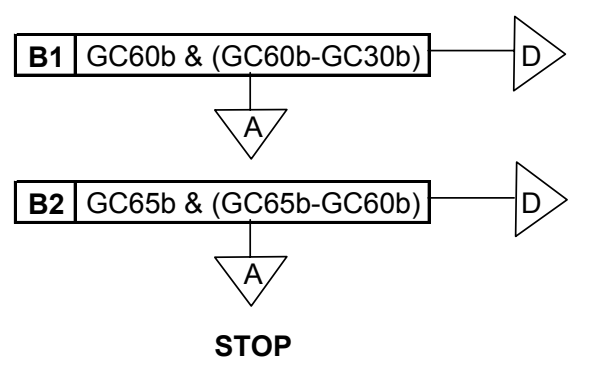

PROBABLE CAUSE OF DISAGREEMENT

DIAGNOSE (GOTO)

Steady-State Base Case
Constant ODB; $h$,int $=h$, ext $=100 \mathrm{~W} / \mathrm{m}^{2} \mathrm{~K} ;$
$\mathrm{k}_{\text {soil }}=1.9 \mathrm{~W} / \mathrm{mK} ;$ adiabatic above-grade wall

$\mathrm{k}_{\text {soil }}=1.9 \mathrm{~W} / \mathrm{mK}$; adiabatic above-grade wall

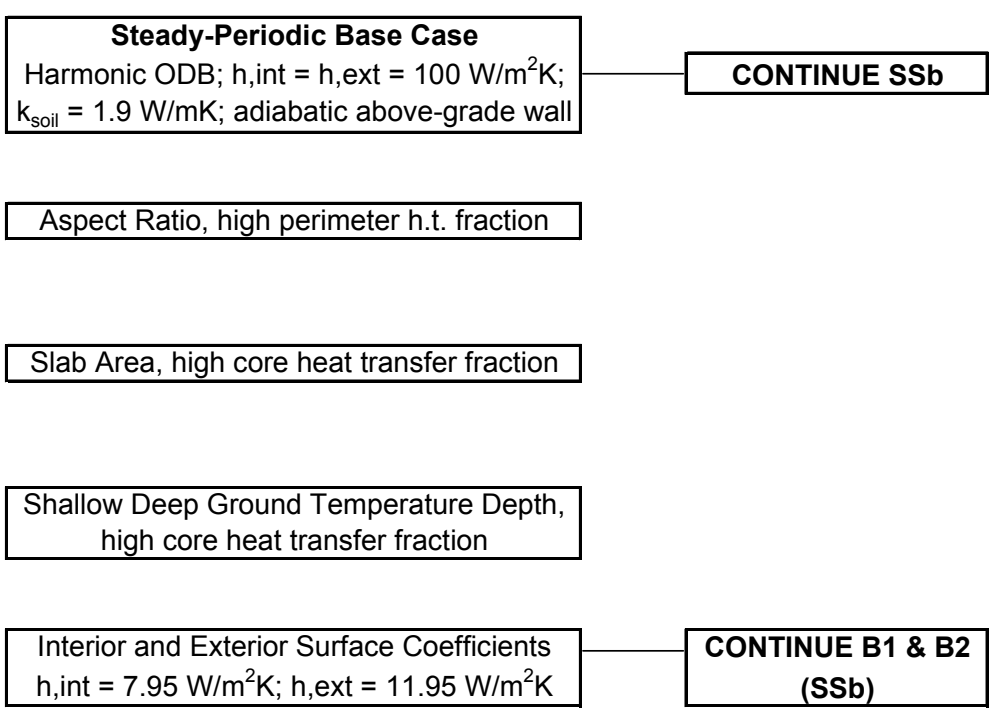

Slab/Soil Conductivity, ksoil $=0.5 \mathrm{~W} / \mathrm{mK}$
Interior Surface Coeff., h,int $=7.95 \mathrm{~W} / \mathrm{m}^{2} \mathrm{~K}$ (Steady-State Model)

Exterior Surface Coeff., h,ext $=11.95 \mathrm{~W} / \mathrm{m}^{2} \mathrm{~K}$ (Steady-State Model)

\section{ABBREVIATIONS}

$A=$ Agree $; D=$ Disagree. For these test cases, agreement/disagreement is determined relative to quasi-analytical solution results, including listed sensitivity cases.

Figure F-2. Diagnostic logic flow diagram for "b"- series cases 


\section{START ("c"-Series Diagnostic Logic)}
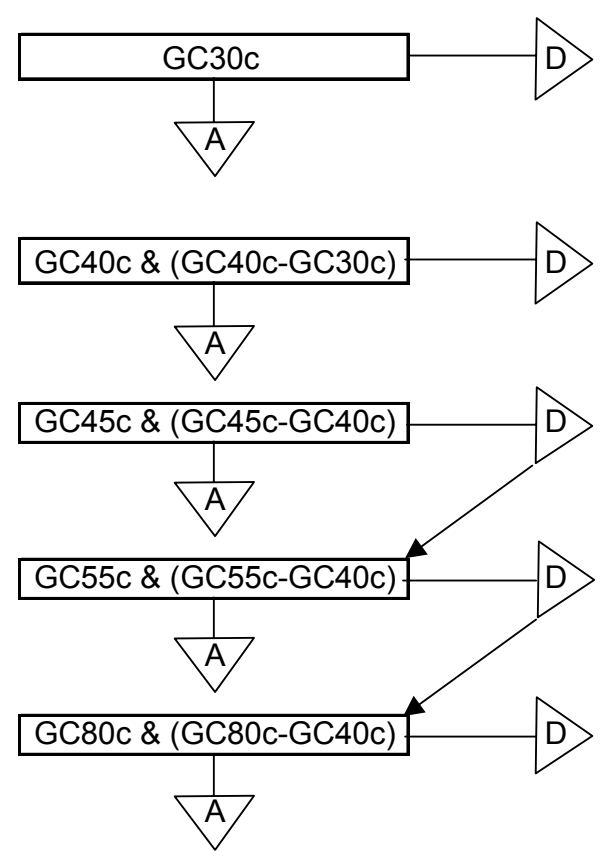

PROBABLE CAUSE OF DISAGREEMENT

\begin{tabular}{c}
\hline "c"-Series Steady-State Base Case \\
Constant ODB; $\mathrm{h}$, int $=\mathrm{h}, \mathrm{ext}=100 \mathrm{~W} / \mathrm{m}^{2} \mathrm{~K} ;$ \\
$\mathrm{k}_{\text {soil }}=1.9 \mathrm{~W} / \mathrm{mK} ;$ adiabatic above-grade wall \\
\hline
\end{tabular}

\begin{tabular}{|c|}
\hline "c"-Series Steady-Periodic Base Case \\
Harmonic ODB; $\mathrm{h}$,int $=\mathrm{h}, \mathrm{ext}=100 \mathrm{~W} / \mathrm{m}^{2} \mathrm{~K} ;$ \\
$\mathrm{k}_{\text {soil }}=1.9 \mathrm{~W} / \mathrm{mK}$; adiabatic above-grade wall
\end{tabular}

Aspect Ratio, high perimeter h.t. fraction

Shallow Deep Ground Temperature Depth, high core heat transfer fraction

Slab/Soil Conductivity, ksoil $=0.85 \mathrm{~W} / \mathrm{mK}$

\section{END}

\section{ABBREVIATIONS}

$A=$ Agree; $D=$ Disagree. For these test cases, agreement/disagreement is determined relative to quasi-analytical solution results, including listed sensitivity cases.

Figure F-3. Diagnostic logic flow diagram for "c"- series cases 


\section{References for Part I}

ANSI/ASHRAE Standard 140-2007. Standard Method of Test for the Evaluation of Building Energy Analysis Computer Programs. (2007). Atlanta, GA: American Society of Heating, Refrigerating, and AirConditioning Engineers.

ASHRAE. (2005). Handbook of Fundamentals. Atlanta, Georgia, US: American Society of Heating, Refrigerating and Air-Conditioning Engineers.

ASHRAE. (2001). Handbook of Fundamentals. Atlanta, Georgia, US: American Society of Heating, Refrigerating and Air-Conditioning Engineers.

Brandemuehl M. (1993). HVAC 2 Toolkit. Atlanta, Georgia, US: American Society of Heating, Refrigerating and Air-Conditioning Engineers. (See p. 7-15.)

Delsante A.E.; Stokes, A.N.; Walsh, P.J. (1983). Application of Fourier Transforms to Periodic Heat Flow into the Ground under a Building. International Journal of Heat Mass Transfer, 26(1): 121-132.

Judkoff, R.; Neymark, J. (1995). International Energy Agency Building Energy Simulation Test (BESTEST) and Diagnostic Method. NREL/TP-472-6231, Golden, Colorado, US: National Renewable Energy Laboratory. www.nrel.gov/docs/legosti/old/6231.pdf.

Marion, W.; Urban, K. (1995). User's Manual for TMY2s. Golden, Colorado, US: National Renewable Energy Laboratory.

Spitler, J.D.; Rees, S.J.; Xiao, D. (2001). Development of an Analytical Verification Test Suite for Whole Building Energy Simulation Programs - Building Fabric. Final Report for ASHRAE 1052-RP. Atlanta, Georgia, US: American Society of Heating, Refrigerating and Air-Conditioning Engineers.

Walton, G. (1983). Thermal Analysis Research Program Reference Manual (TARP). NBSIR 83-2655. Washington, D.C.: National Bureau of Standards (now called National Institute of Standards and Technology). 


\section{Part II: Production of Simulation Results}

\subsection{Introduction}

In this section we describe what the working group members did to produce quasi-analytical solutions with verified state-of-the-art numerical models, along with other example results for several mid-level detailed models typically used with state-of-the-art whole-building energy simulation programs in Europe and North America. The objectives of developing the simulation results were to:

- Demonstrate the applicability and usefulness of the Building Energy Simulation Test In-Depth Diagnostic Cases for Ground-Coupled Heat Transfer Related to Slab-on-Grade Construction test suite.

- Improve the test procedure through field trials.

- Identify the range of disagreement that may be expected for simulation programs relative to each other (see Part III).

- Establish a methodology for developing a secondary mathematical truth standard based on the range of disagreement of verified numerical models.

The field trial effort took about 3 years and involved revisions to the test specifications and subsequent reexecution of the computer simulations. The process was iterative in that executing the simulations led to the refinement of the test suite, and the results of the tests led to improving and debugging the groundcoupled heat transfer models in the programs. This process underscores the importance of International Energy Agency (IEA) participation in this project; such extensive field trials, and resulting enhancements to the tests, were much more cost-effective with the participation of the IEA Solar Heating and Cooling (SHC) Programme Task 34/Energy Conservation in Buildings and Community Systems (ECBCS) Annex 43 experts.

Table 2-1 describes the models used to generate the simulation results. Appendix II (Section 2.9) presents reports written by the modelers for each simulation program.

The tables and graphs in Part III present the final results from all the models used in this study.

Abbreviations and acronyms used in Sections 2.2 through 2.6 are given in Section 2.7. References cited in Section 2.2 through 2.6 are given in Section 2.8. 
Table 2-1. Participating Organizations and Models

\begin{tabular}{|c|c|c|}
\hline $\begin{array}{l}\text { Analytical Solution, } \\
\text { Case GC10a }\end{array}$ & Authoring Organization & Implemented by \\
\hline $\begin{array}{l}\text { Delsante, Stokes, and } \\
\text { Walsh (1983) }\end{array}$ & $\begin{array}{l}\text { Commonwealth Scientific and Industrial } \\
\text { Research Organisation, Australia }\end{array}$ & NREL/JNA, ${ }^{\mathrm{a}, \mathrm{b}}$ United States \\
\hline $\begin{array}{l}\text { Verified Numerical } \\
\text { Model }\end{array}$ & Authoring Organization & Implemented by \\
\hline FLUENT 6.0.20 & Fluent, Incorporated, United States & PAAET, ${ }^{\mathrm{c}}$ Kuwait \\
\hline MATLAB 7.0.4.365 (R14) & The MathWorks, Inc., United States & Dublin Institute of Technology, Ireland \\
\hline TRNSYS 16.1 & University of Wisconsin/TESS, ${ }^{d}$ United States & TESS, ${ }^{\mathrm{d}}$ United States \\
\hline Simulation Program & Authoring Organization & Implemented by \\
\hline BASECALC V1.0e & CETC, ${ }^{e}$ Canada & CETC, ${ }^{e}$ Canada \\
\hline EnergyPlus 2.0.0.025 & LBNL/UIUC/DOE-BT, ,, $\mathrm{h}^{\mathrm{h}}$ United States & GARD Analytics, Inc., United States \\
\hline ESP-r/BASESIMP & CETC/ESRU, ${ }^{e, i}$ Canada/United Kingdom & CETC, ${ }^{\mathrm{e}}$ Canada \\
\hline GHT & NREL, ${ }^{a}$ United States & NREL, ${ }^{a}$ United States \\
\hline SUNREL-GC 1.14 .01 & NREL, ${ }^{a}$ United States & NREL, ${ }^{a}$ United States \\
\hline VA114 2.20/ISO-13370 & $\begin{array}{l}\text { VABI Software BV, The Netherlands; } \\
\text { CEN/ISO }\end{array}$ & VABI Software BV, The Netherlands \\
\hline
\end{tabular}

${ }^{a}$ NREL: National Renewable Energy Laboratory, United States

'JNA: J. Neymark \& Associates, United States

'PAAET: Public Authority for Applied Education and Training, Kuwait

'TESS: Thermal Energy Systems Specialists, United States

${ }^{\text {e}} \mathrm{CETC}$ : CANMET Energy Technology Centre, Natural Resources Canada, Canada

fLBNL: Lawrence Berkeley National Laboratory, United States

'UIUC: University of Illinois Urbana/Champaign, United States

hDOE-BT: U.S. Department of Energy, Office of Building Technologies, Energy Efficiency and Renewable Energy, United States

'ESRU: Energy Systems Research Unit, University of Strathclyde, United Kingdom

${ }^{\mathrm{j} C E N}$ : European Committee for Standardization, Belgium

kISO: International Organization for Standardization, Switzerland

\subsection{Selection of Simulation Programs and Modeling Rules for Simulations}

The countries participating in this IEA task made the initial selections of the simulation programs used in this study. For the numerical models used to develop quasi-analytical solutions, the selection criteria required:

- 3-D modeling

- Ability to model all boundary conditions of Case GC10a, for true analytical verification

- Adjustable node meshing

- Adjustable duration of simulation (e.g., more than 5 years)

- Adjustable convergence tolerance, where applicable

- Adjustable ground depth and far-field dimensions

- Calculative time increments of 1 hour or less 
- Meeting quasi-analytical solution definitional requirements

- Calculations occur outside the environment of a whole-building energy simulation program

(i.e., a means to run the slab/ground model by itself without interacting with additional calculation routines of a larger whole-building simulation)

$\circ$ Ability to scrutinize calculations (supporting input files and detailed modeler reports provided).

For the mid-level detailed models, the selection criteria required:

- The whole-building simulation program platform be a true simulation based on hourly weather data and calculative time increments of 1 hour or less, and be representative of the state-of-the-art in whole-building energy simulation as defined by the country making the selection.

- The mid-level detailed ground heat transfer model used by the whole-building simulation platform be representative of the state-of-the-art as defined by the country making the selection.

The modeling rules were somewhat more stringent for the simulation programs used for Part III example results than for a given program to be normally tested with this BESTEST suite (see Section 1.2.1, Modeling Rules). For the Part III simulation results, we allowed a variety of modeling approaches. However, we required that these cases be modeled in the most detailed way possible for each simulation program. Whenever possible with all ground-coupled heat transfer models (required for verified numerical models) demonstrate that modeling is at a level of detail where including further detail yields negligible sensitivity ( $0.1 \%$ or lower) to results versus the previous level of detail. Sensitivity tests, when possible (required for verified numerical models), should cover at least the following aspects of the models: node mesh detail, simulation duration (for non-steady-state cases or when dynamic models are applied to steady-state cases), convergence tolerance (when applicable), and amount of ground modeled (for Case GC10a only). Such sensitivity tests may be performed for a subset of the test cases if the modeler can logically demonstrate that the appropriate level of detail identified for a given case (e.g. GC40a or GC40b) will also be appropriate for other cases (GC70b, etc.).

To minimize the potential for user error, we encouraged more than one modeler to develop input files for each program. Where only a single modeler was involved, we strongly recommended that another modeler familiar with the program check the inputs carefully.

Where improvements to simulation programs or simulation inputs were made as a result of running the tests, such improvements must have a mathematical and physical basis, and must be applied consistently across tests. In addition, all improvements were required to be documented in modeler reports. Arbitrary modification of a simulation program's input or internal code just for the purpose of more closely matching a given set of results is not allowed. The diagnostic process of trapping bugs discussed in Section 2.4 also isolated input errors that were corrected, as noted there and in the modeler reports (Section 2.9).

\subsection{Improvements to the Test Specification as a Result of the Field Trials}

Based on comments by the IEA SHC Task 34/ECBCS Annex 43 participants during the field trials, we made a number of improvements and revisions to the test specification. Although researching the comments and communicating specification revisions to the field trial participants was very time consuming, the importance of the accuracy and clarity of the test specification for this type of work cannot be overstated.

The contribution of the IEA SHC Task 34/ECBCS Annex 43 participating countries was particularly valuable because the project experts supplied continuous feedback throughout the 3 -year field trial effort. Their feedback resulted in several revisions to the test specifications and subsequent re-execution of the computer simulations. This iterative process led to refinement of the test cases, and the results of the tests 
led to the improvement and debugging of the programs. The process underscores the leveraging of resources for the IEA countries participating in this project. Such extensive field trials, and resulting enhancements to the tests, would not have occurred without the participation of the IEA SHC Task 34/ ECBCS Annex 43 experts.

\subsubsection{Revisions to the Initial Draft Test Specification}

The initial draft of these in-depth diagnostic test cases was issued in June 2004. The parametric sensitivity tests in that version formed the basis of the current test cases; details were revised for the final version as documented below.

Observations of the initial results based on simulations of the June 2004 version of the test specification indicated the following issues.

- Convective surface coefficients $>100 \mathrm{~W} /\left(\mathrm{m}^{2} \cdot \mathrm{K}\right)$ are too high for some models.

- The base case ground depth $(60 \mathrm{~m})$ is too deep for some models.

- Case GC50's $200 \mathrm{~m} \times 200 \mathrm{~m}$ slab is too large for the models.

- NRCan identified a number of hardwired assumptions and limitations in BASECALC and BASESIMP that caused modeling difficulties for the GC30 base case, along with inability to model (or fully model) several of the sensitivity test cases. NRCan requested specification of at least one test case for directly comparing BASECALC/BASESIMP/ESP-r to the detailed numerical models.

Based on these issues, other participant comments, and further consideration by the lead authors, the following revisions were made for the June 2005 version of the test specification:

- To accommodate the wide variety of capabilities and constraints of participating software, the number of test cases was expanded from 9 to 17, and subdivided into 3 categories:

○ "a"-series cases to demonstrate proper application of detailed numerical models ( 3 cases)

$\circ$ "b"-series cases to test mid-level detailed models used with whole-building energy simulation programs ( 9 cases)

- "c"-series cases conforming to specific BASESIMP model constraints (5 cases).

- Test case revisions included a number of parameter adjustments for better compatibility with the simulation models, and more robust sensitivity tests, including:

○ Ground conductivity change from $2.0 \mathrm{~W} /(\mathrm{m} \cdot \mathrm{K})$ to $1.9 \mathrm{~W} /(\mathrm{m} \cdot \mathrm{K})$ for all test cases, to be compatible with BASESIMP's allowable maximum value.

$\circ$ Ground depth (E) and far-field (F) dimensions were reduced from $60 \mathrm{~m}$ and $40 \mathrm{~m}$, respectively, as follows:

- For "a"-series cases (except GC10a), E = $30 \mathrm{~m}$ and F = $20 \mathrm{~m}$; per TRNSYS sensitivity tests greater values do not affect results (but cause longer run times).

- For "b"-series cases (except GC50b and GC55b), E = $15 \mathrm{~m}$ and F =15 m; $15 \mathrm{~m}$ ground depth allowed EnergyPlus to use its automated grid feature (EnergyPlus has since been revised to facilitate use of this feature), and $\mathrm{E}=15 \mathrm{~m}$ matches BASESIMP's maximum depth; per TRNSYS sensitivity tests for $\mathrm{E}=15 \mathrm{~m}, \mathrm{~F}>$ $15 \mathrm{~m}$ does not affect results (but causes longer run times).

- For "c"-series cases (except GC55c), E = $15 \mathrm{~m}$ and F $=8 \mathrm{~m}$, to match BASESIMP maxima.

- Convective surface coefficients (h,int and h,ext) were changed from $5000 \mathrm{~W} /\left(\mathrm{m}^{2} \cdot \mathrm{K}\right)$ for various cases as follows: 
- $\quad$ For GC30a and GC40a, h,int = h,ext = infinity, which is equivalent to directly applying a uniformly constant or uniformly varying surface temperature boundary condition to an entire given surface.

- For "b"-series cases (except where $h$ is varied in GC60b, GC65b, and GC70b), $\mathrm{h}$,int $=\mathrm{h}$,ext $=100 \mathrm{~W} /\left(\mathrm{m}^{2} \cdot \mathrm{K}\right)$, which results in roughly $4 \%$ reduced floor conduction versus a constant temperature boundary condition.

- For GC60b, GC65b, and GC70b, h,int $=7.95 \mathrm{~W} /\left(\mathrm{m}^{2} \cdot \mathrm{K}\right)$, to match BASESIMP's assumption for combined convective and radiative heat transfer; this value falls between ASHRAE's $\left(2005\right.$, p. 25.2) listing of $6.13 \mathrm{~W} /\left(\mathrm{m}^{2} \cdot \mathrm{K}\right)$ for downward heat transfer on a horizontal surface and BESTEST's (Judkoff and Neymark 1995a) default of $8.29 \mathrm{~W} /\left(\mathrm{m}^{2} \cdot \mathrm{K}\right)$ for programs that do not allow scheduling of horizontal surface coefficients. For simplification of the test specification $h$,int $=7.95$ $\mathrm{W} /\left(\mathrm{m}^{2} \cdot \mathrm{K}\right)$ is specified as a convection-only coefficient, along with surface emittance $=0$ (or as low as possible) so that radiative exchange is suppressed.

- For GC65b and GC70b, h,ext $=11.95 \mathrm{~W} /\left(\mathrm{m}^{2} \cdot \mathrm{K}\right)$, which is consistent with wind speed of $1.0 \mathrm{~m} / \mathrm{s}$ (Walton 1983; Judkoff and Neymark 1995a).

- For "c"-series cases, h,int $=7.95 \mathrm{~W} /\left(\mathrm{m}^{2} \cdot \mathrm{K}\right)$ and $\mathrm{h}$,ext $=$ infinity (directly applied surface temperature boundary condition); this matches the BASESIMP assumptions.

- For Case GC10a appropriate mesh detail demonstration, added specification "For ground depth and far-field length variations, increase the number of mesh nodes proportionally to the increase in soil volume."

- Aspect ratio of $24 \mathrm{~m} \times 6 \mathrm{~m}$ of Case GC45 was changed to $36 \mathrm{~m} \times 4 \mathrm{~m}$ for cases GC45b and GC45c, which gives a more robust sensitivity test versus GC40b and GC40c; further increasing this ratio would cause negligible further decrease in the "core" surface area (area over which heat flow is generally considered to go to deep ground rather than to the exterior perimeter surface).

- Ground depth (E) of Case GC55 was changed from $\mathrm{E}=3 \mathrm{~m}$ as follows

- For GC55b, $\mathrm{E}=2 \mathrm{~m}$, for more robust sensitivity test

- For GC55c, E $=5 \mathrm{~m}$, to match BASESIMP minimum.

- Ground conductivity test cases were added with soil/slab conductivities (k) as:

○ For GC80b, $\mathrm{k}=0.5 \mathrm{~W} /(\mathrm{m} \cdot \mathrm{K})$ (realistic minimum for dry clay)

○ For GC80c, $\mathrm{k}=0.85 \mathrm{~W} /(\mathrm{m} \cdot \mathrm{K})$ (to match BASESIMP minimum soil conductivity).

- Added specification to demonstrate that next level of detail for convergence tolerance changes heat flow results by $0.1 \%$ or lower.

- Added specification that for models requiring input of slab thickness, use the least slab thickness allowed by the model.

- For cases GC40a, GC40b, and GC40c, added specification for hourly outputs for the last full year of the simulation for ODB and floor conduction, and to describe the simulation's time convention (e.g., hour $1=0: 00-1: 00$ or $0: 30-1: 30$ ).

- New weather data files were provided as follows:

- GCSS-W20.TM2 and GCSP-W20.TM2 were provided for the "b"-series test cases; these have wind speed set to $19.9 \mathrm{~m} / \mathrm{s}$ to match h,ext $=100 \mathrm{~W} /\left(\mathrm{m}^{2} \cdot \mathrm{K}\right)$ (Walton 1983; Judkoff and Neymark 1995a).

- GCSS-W01.TM2 and GCSP-W01.TM2 were provided for GC65b and GC70b; these have wind speed set to $1.0 \mathrm{~m} / \mathrm{s}$ to match $\mathrm{h}$,ext $=11.95 \mathrm{~W} /\left(\mathrm{m}^{2} \cdot \mathrm{K}\right)$ (Walton 1983; Judkoff and Neymark 1995a).

- GCSS-W40.TM2 and GCSP-W40.TM2 were provided for GC30a, GC40a, and the "c"series cases; these have wind speed set to $40.0 \mathrm{~m} / \mathrm{s}$, which is the maximum value documented in the TMY2 data manual (Marion and Urban 1995). 
- The test specification was reorganized to present GC30b as the primary base case, presuming that most programs being tested would primarily apply the "b"-series cases.

- Added specification of modeling rules to match HVAC BESTEST Volume 2 (Neymark and Judkoff 2004), Section 1.2.2.

- Added section "Comparing Your Output to the Analytical Solution and Example Simulation Results" based on HVAC BESTEST Volume 2 (Neymark and Judkoff 2004), Section 1.2.3.

- Editorial revisions.

As the $200 \mathrm{~m} \times 200 \mathrm{~m}$ slab initially proposed for Case GC50 was too large for the programs (that tried) to model, modifications were proposed (for discussion) to reduce the slab area to $80 \mathrm{~m} \times 80 \mathrm{~m}$, which would be the maximum allowed by EnergyPlus and would have a more reasonable run time. Deep ground boundary depth of $20 \mathrm{~m}$ (new EnergyPlus maximum for automated grid) versus $15 \mathrm{~m}$ (as in GC40b) was also discussed among the participants. Far-field dimension of $60 \mathrm{~m}$ was also proposed.

\subsubsection{Second Round of Revisions}

The primary observation regarding the second iteration of results, based on simulations of the June 2005 version of the test specification, was the importance of understanding the geometry assumptions of the various models as well as possible. To address this issue, a proforma model description template (table) was developed by NREL and distributed to the project participants in November 2005. The proforma template surveyed modeling capabilities and assumptions with respect to geometry and material properties, with the intent to revise the test cases, if appropriate, based on the results of the survey. Conclusions of the proforma survey were that for the " $b$ "-series test cases, the current test case geometry is appropriate for the variety of models being tested, and that use of uniform material properties (floor slab = foundation wall $=$ footer $=$ soil) is appropriate for the models.

For the "c"-series cases, which apply the same geometry as the "b"-series cases, NRCan noted that the BASECALC/BASESIMP slab-on-grade model (which is derived from their basement model) assumes that the floor slab upper surface is $5 \mathrm{~cm}$ below grade, and that assumptions about above-grade wall material properties are also included in this model. Because locating a slab floor surface $5 \mathrm{~cm}$ below grade is not typical for slab-on-grade construction, and because BASECALC's most insulating above-grade wall $(\mathrm{k}=$ $0.1 \mathrm{~W} /(\mathrm{m} \cdot \mathrm{K})$ ) is not adiabatic (which could compensate for the additional soil resistance for the $5 \mathrm{~cm}$ belowgrade slab), the specified "c"-series case geometry was not changed.

Based on the observations and recommendations from field trials of the June 2005 version of the test specification, the following revisions were made for the test specification version dated March 2006:

- Deleted hourly ODB from output requirements for GC40a, GC40b, and GC40c; reporting 8760 hours of ODB is unnecessary as minimum ODB and time of occurrence are already reported, and hourly ODB is given in the raw weather data.

- Defined ground/adiabatic wall interface temperatures (for cases GC30a, GC30b, GC60b, GC65b) as for uppermost-modeled layer of soil just below the interface; surface temperatures at soil/adiabatic wall interface are not definable.

- Rearranged steady-state surface temperatures in the output spreadsheet template to facilitate chart development.

- Added GC50b large slab case using $80 \mathrm{~m} \times 80 \mathrm{~m}$ floor slab with ground depth (E) of $15 \mathrm{~m}$ and farfield dimension $(\mathrm{F})$ of $15 \mathrm{~m}$.

- Added clarifications including:

○ Schematic diagram of slab edge detail 
$\circ$ Uniform scaling in figure for Case GC30b, which defines floor slab and conditioned zone dimensions

- Foundation wall dimensions (if needed) are as small as the software being tested allows; foundation wall material properties same as soil

- Floor conduction output is specifically through area of $\mathrm{B} \times \mathrm{L}$ at interior of slab surface

$\circ$ If software doesn't have different outputs for floor load and zone conduction, report only one of them.

- Added clauses from ANSI/ASHRAE Standard 140-2004, Addendum $b$ (ANSI/ASHRAE 2004b) regarding:

$\circ \quad$ Equivalent modeling methods (ANSI/ASHRAE 2007, Section 5.1.5)

- To include input files with final results (ANSI/ASHRAE 2007, Section 4.3.2)

- Explaining test case results omissions (ANSI/ASHRAE 2007, Section 4.3.1)

- Changes to software must have a logical basis (revisions to previous language) (ANSI/ASHRAE 2007, Section 4.4.3).

- Added proforma survey materials to modeler report template.

- Editorial revisions.

\subsubsection{Third Round of Revisions}

Field trials of the March 2006 test specification engendered further revisions as listed below:

- Previously required output of cumulative first 3-year floor conduction was deleted, because

- Many mid-level detailed programs give only 1 year of output

- Detailed numerical models that run a true steady-state simulation cannot give this result

- Detailed numerical dynamic models can have results differences caused by differences in initial conditions

- Cases with harmonically varying temperature boundary conditions address dynamic mass-storage behavior of the models.

- Redefined all surface temperature outputs for GC10a, GC30a, GC30b, GC60b, and GC65b as for uppermost-modeled layer of soil ("near-surface") just below the interface (consistent depth); this matches the actual final results submitted by the IEA-34/43 project participants. Previously, we requested at-surface temperatures except for at the soil/adiabatic wall interface, which caused an inconsistency in the temperature profiles. For GC10a, at-surface temperature results are also specified in addition to "near-surface" temperatures, to check proper application of boundary conditions.

- Clarified that peak hour results are annual hourly integrated peak results; this matches the actual final results submitted by the IEA-34/43 project participants.

Additional minor clarifications were made for the final version of the user's manual, including:

- Introductory discussion of the development of quasi-analytical solutions based on verified 3-D numerical models to be used as a secondary mathematical truth standard for comparing other simulation results. Other relevant language was revised throughout to be consistent with this discussion.

- Typical users to apply consistent modeling methods; IEA-34/43 field trial participants applied most detailed methods their program allowed.

- For "b"- and "c"'-series cases, for typical users we relaxed (to a recommendation) the IEA$34 / 43$ participant requirement to demonstrate (where possible) that the modeling is at a level of detail where including further detail (node meshing, simulation duration, etc.) yields negligible sensitivity to results. 
- For the "a"-series cases the requirement remains to demonstrate that modeling is at a level of detail where including further detail yields negligible sensitivity to results.

- For Case GC10a, clarified the definition of semi-infinite solid; this matches the assumption of the IEA-34/43 numerical-methods modelers (where they had demonstrated that their finite ground depth and far-field dimensions were large enough to well-approximate a semi-infinite domain).

- For convenience to future users we added the following appendices:

- Appendix C, "Abbreviations and Acronyms"

○ Appendix D, "Glossary"

- Appendix E, "Remarks about the Test Cases"; this consolidates informational remarks previously included with each case into one section (for background)

- Appendix F, Diagnosing the Results Using the Flow Diagrams.

- Editorial revisions

$\circ$ Section, table, and figure numbering

- Other miscellaneous.

\subsection{Examples of Error Trapping with BESTEST Diagnostics}

This section summarizes examples that demonstrate how the IEA BESTEST in-depth diagnostic cases for ground-coupled heat transfer related to slab-on-grade construction were used to isolate and correct bugs in the simulation programs used for the field trials of the test specification. Further descriptions may be found in the individual modeler reports presented in Appendix II (see Section 2.9).

Simulations were performed for each test case with the participating computer programs. At each stage of the exercise, output data from the simulations were compared to each other, to numerical-models being developed as quasi-analytical solutions, and to the Case GC10a analytical solution, according to the diagnostic logic of the test cases. The test diagnostics revealed (and led to the correction of) bugs, faulty algorithms, input errors, or some combination of those in all of the models. In the following examples improvements to the numerical models that were used for developing quasi-analytical solutions (i.e. TRNSYS, PAAET's FLUENT model, and DIT's MATLAB model) are presented first in sections 2.4.1 to 2.4.3. Improvements and issues identified for other models (e.g., EnergyPlus, VA114/ISO-13370, BASESIMP/ESP-r, BASECALC, and SUNREL-GC) follow in sections 2.4.4 to 2.4.7.

\subsubsection{TRNSYS Version 16.1}

TRNSYS (Klein et al. 2007) is a modular system simulation tool that has been widely used in the study of buildings, renewable energy technologies, and HVAC systems. The program was originally written by the Solar Energy Laboratory at the University of Wisconsin; but recently has been maintained, supported, and distributed by a consortium of international companies and government agencies. TRNSYS Version 16.1 was used for the most recent analysis as well as an extended library of TRNSYS components written by Thermal Energy System Specialists (TESS) LLC of Madison, WI. The 3-D numerical finite difference ground conduction model used for this analysis is part of the commercially available TESS ground-coupling library for TRNSYS. This model was established as a quasi-analytical solution method based on rigorous comparison with the Case GC10a analytical solution and comparison with the FLUENT and MATLAB detailed 3-D numerical-model results for other cases.

\subsubsection{First noding algorithm improvement, $10 \%$ floor conduction increase for Case GC10}

The original preliminary model - applied before the January 2005 initial TRNSYS results were submitted employed a user-specified number of nodes along the slab and in the near field ( $\mathrm{X}$ and $\mathrm{Y}$ directions) as well 
as a user-specified number of nodes in the depth direction. In this case a $22 \times 22 \times 22$ mesh of uniformly spaced nodes for a model of one-fourth of the slab (maximum amount of rectangular slab/soil volume needed for application of symmetry principles) was employed. As shown in Table 2-2, this model had a nearly $12 \%$ disagreement versus the analytical solution. (Thornton 2007a). For the January 2005 field trial results submittal, the assumption of uniformly sized nodes under the slab was changed to a user-specified number of nodes under the slab with the nodes growing in size by a factor of 2 as they progressed inward, outward and downward from the edges of the slab. As shown in Table 2-2 (see results labeled "1/14/05"), this improvement caused a $10 \%$ increase in floor conduction versus the original node mesh, but still had about a 3\% disagreement with the analytical solution.

Table 2-2. Initial Results for the TRNSYS Ground Heat Transfer Model

\begin{tabular}{|l|c|r|}
\hline \multicolumn{3}{|c|}{ Steady-State Analytical Verification, Case GC10 } \\
\hline & $\begin{array}{c}\mathrm{q}_{\mathrm{floor}} \\
(\mathrm{W})\end{array}$ & $\begin{array}{c}\text { \% Difference versus } \\
\text { Analytical Solution }\end{array}$ \\
\hline Analytical Solution & $\mathbf{2 5 6 1}$ & -- \\
\hline TRNSYS (Initial Results) & 2261 & $-11.71 \%$ \\
\hline TRNSYS (Results of 1/14/05) & 2486 & $-2.93 \%$ \\
\hline
\end{tabular}

\subsubsection{Second noding algorithm improvement, $2 \%$ floor conduction increase for Case GC10a}

For the next improvement an automatic noding scheme was applied using

$$
\text { Size }_{i}=\text { Size }_{\text {Nom }} * X^{i-1}
$$

where SizeNom is the user input size of the smallest node (typically 1 inch); $\mathrm{X}$ is a user-input scalar (typically 1.2 to 2$)$; and $\mathrm{i}$ is a nodal indicator $(1=$ next to the slab/surface). The algorithm also limits the size of $i$, keeping identical size nodes beyond a fixed point. This algorithm groups small nodes close to the edges and soil surface and increases the sizes of the nodes as they progress away from these edges. The results for this new algorithm (submitted in June 2005) applied the following specifications:

- $\quad$ SizeNom $=1$ inch

- $\mathrm{X}=1.5$ to 2 , depending on the test

- Maximum $\mathrm{i}=10$.

These results are shown in Table 2-3 (labeled "6/21/2005") along with the results submitted in January 2005 (labeled " $1 / 14 / 2005$ "). Note when comparing " $1 / 14 / 05$ " versus " $6 / 21 / 05$ " results in this table that there are specification differences for cases GC30 versus GC30a and GC40 versus GC40a, where the "a"-series cases specify $\mathrm{k}_{\text {soil }}=1.9$ and constant temperature surface boundaries, and the prior preliminary series cases specified $\mathrm{k}_{\text {soil }}=2.0$ along with interior and exterior surface coefficients of $h=5000 \mathrm{~W} /\left(\mathrm{m}^{2} \cdot \mathrm{K}\right)$. The difference in ground conductivity should reduce floor conduction in the "a"-series cases versus the preliminary cases; the effect of varying the surface boundary condition should be negligible, as $h=5000$ $\mathrm{W} /\left(\mathrm{m}^{2} \cdot \mathrm{K}\right)$ approximates a constant temperature surface boundary condition. 
Table 2-3. TRNSYS Results Summary for Three Iterations of Simulations

\begin{tabular}{|c|c|c|c|c|c|c|}
\hline \multirow{2}{*}{\begin{tabular}{|r|} 
Submittal Date \\
Noding Scheme
\end{tabular}} & \multicolumn{2}{|c|}{$1 / 1 / 14 / 2005$} & \multicolumn{2}{|c|}{ 6/21/2005 } & \multicolumn{2}{|c|}{ 5/23/2006 } \\
\hline & "x (2)" & Full slab & "x (1.5)" & $1 / 4$ slab & "x (1.2 to 1.3$) "$ & $1 / 4$ slab \\
\hline \multicolumn{7}{|c|}{ Steady-State Analytical Verification } \\
\hline & \multicolumn{2}{|c|}{ GC10 } & \multicolumn{4}{|c|}{ GC10a } \\
\hline & $\begin{array}{l}q_{\text {floor }} \\
(W)\end{array}$ & $\begin{array}{l}\text { del \% v. } \\
\text { AnnSoln }\end{array}$ & $\begin{array}{l}\mathrm{q}_{\text {floor }} \\
(\mathrm{W})\end{array}$ & $\begin{array}{l}\text { del \% v. } \\
\text { AnnSoln }\end{array}$ & $\begin{array}{l}\mathrm{q}_{\text {floor }} \\
(\mathrm{W})\end{array}$ & $\begin{array}{l}\text { del \% v. } \\
\text { AnnSoln }\end{array}$ \\
\hline Analytical Soln. & 2561 & $\mathrm{n} / \mathrm{a}$ & 2433 & $\mathrm{n} / \mathrm{a}$ & 2433 & $\mathrm{n} / \mathrm{a}$ \\
\hline TRNSYS & 2486 & $-2.93 \%$ & 2417 & $-0.64 \%$ & 2427 & $-0.24 \%$ \\
\hline \multicolumn{7}{|c|}{ 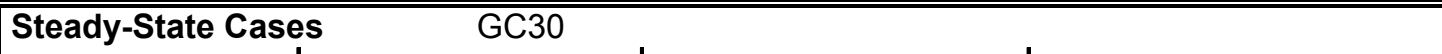 } \\
\hline & $\begin{array}{l}q_{\text {floor }} \\
(W)\end{array}$ & $\begin{array}{c}\text { del \% v. } \\
\text { previous }\end{array}$ & $\begin{array}{l}q_{\text {floor }} \\
(W)\end{array}$ & $\begin{array}{l}\text { del } \% \text { v. } \\
\text { previous }\end{array}$ & $\begin{array}{l}q_{\text {floor }} \\
(W)\end{array}$ & $\begin{array}{l}\text { del \% v. } \\
\text { previous }\end{array}$ \\
\hline GC30 \& GC30a & 2620 & $\mathrm{n} / \mathrm{a}$ & 2606 & $-0.52 \%$ & 2642 & $1.34 \%$ \\
\hline GC30b & & & 2494 & $\mathrm{n} / \mathrm{a}$ & 2533 & $1.53 \%$ \\
\hline GC $30 \mathrm{c}$ & & & 2104 & $\mathrm{n} / \mathrm{a}$ & 2137 & $1.56 \%$ \\
\hline GC60b & & & 2085 & $\mathrm{n} / \mathrm{a}$ & 2113 & $1.36 \%$ \\
\hline GC65b & & & 1965 & $\mathrm{n} / \mathrm{a}$ & 1994 & $1.43 \%$ \\
\hline \multirow[t]{2}{*}{ Harmonic Cases } & \multicolumn{6}{|c|}{$\overline{\mathrm{GC} 40}$} \\
\hline & $\begin{array}{c}Q_{\text {floor }} \\
(k W h / y)\end{array}$ & $\begin{array}{l}\text { del \% v. } \\
\text { previous }\end{array}$ & $\begin{array}{c}Q_{\text {floor }} \\
(k W h / y)\end{array}$ & $\begin{array}{l}\text { del } \% \text { v. } \\
\text { previous }\end{array}$ & $\begin{array}{c}Q_{\text {floor }} \\
(\mathrm{kWh} / \mathrm{y})\end{array}$ & $\begin{array}{l}\text { del } \% \text { v. } \\
\text { previous }\end{array}$ \\
\hline GC40 \& GC40a & 22994 & $\mathrm{n} / \mathrm{a}$ & 22831 & $-0.71 \%$ & 23033 & $0.88 \%$ \\
\hline $\mathrm{GC} 40 \mathrm{~b}$ & & & 21852 & $\mathrm{n} / \mathrm{a}$ & 22099 & $1.12 \%$ \\
\hline GC45b & & & 32405 & $\mathrm{n} / \mathrm{a}$ & 32758 & $1.08 \%$ \\
\hline GC55b & & & 34952 & $\mathrm{n} / \mathrm{a}$ & 35075 & $0.35 \%$ \\
\hline GC70b & & & 17214 & $\mathrm{n} / \mathrm{a}$ & 17396 & $1.05 \%$ \\
\hline GC80b & & & 5970 & $\mathrm{n} / \mathrm{a}$ & 6029 & $0.97 \%$ \\
\hline GC40c & & & 18425 & $\mathrm{n} / \mathrm{a}$ & 18649 & $1.20 \%$ \\
\hline GC45c & & & 26735 & $\mathrm{n} / \mathrm{a}$ & 27004 & $1.00 \%$ \\
\hline GC55c & & & & & 20760 & $\mathrm{n} / \mathrm{a}$ \\
\hline GC80c & & & 9086 & $\mathrm{n} / \mathrm{a}$ & 9192 & $1.16 \%$ \\
\hline
\end{tabular}

\subsubsection{Third noding algorithm improvement, $0.4 \%$ floor conduction increase for Case} GC10a, 1\%-2\% floor conduction increase for cases GC30a-GC80c

Based on the results of June 2005, the TRNSYS model node meshing was further revised so that the mesh size increases by a factor of 1.2 to 1.3 moving away from the slab edge, and the size of node $i$ is allowed to increase without limit. Figure 2-1 shows the difference in mesh sizing between the meshing schemes.

The May 2006 results set applied the following specifications:

- Size $_{\text {Nom }}=1$ inch

- $\mathrm{X}=1.2$ to 1.3 , depending on the test

- Maximum $\mathrm{i}=$ infinity.

Final results using this noding scheme are also included in Table 2-3 (see results labeled "5/23/2006"). 


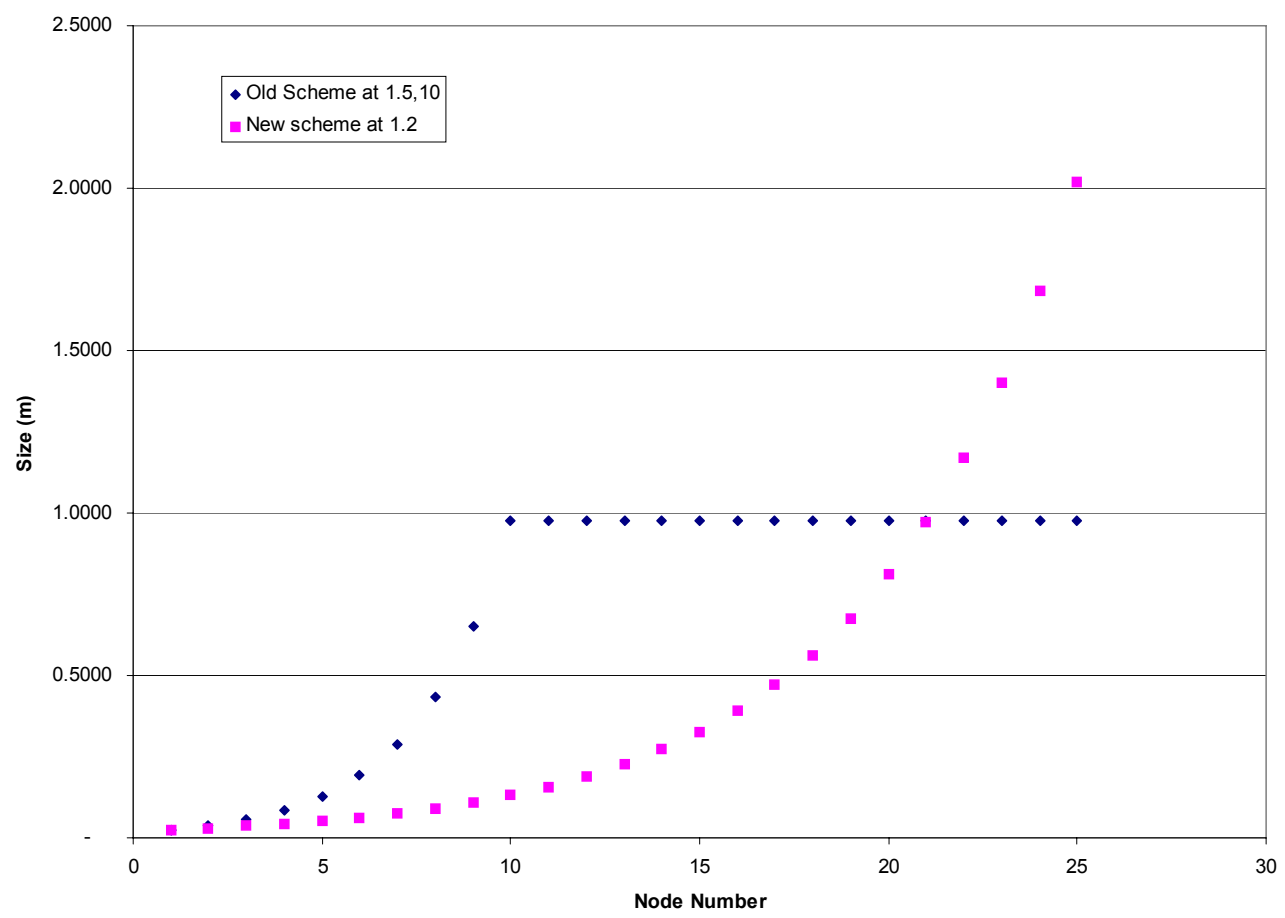

Figure 2-1. Comparison of TRNSYS model noding schemes

\subsubsection{DIT 3-D Numerical Model using MATLAB Version 7.0}

Dublin Institute of Technology (DIT) developed a 3-D numerical ground-coupled heat transfer model run independently of a whole-building energy simulation tool prepared within MATLAB 7.0 (The MathWorks, Inc., 2007). MATLAB's functions for interpolation and the solution of linear algebraic equations and ordinary differential equations were applied; a large part of the work of these functions is matrix processing, an area where MATLAB is considered state-of-the-art. This model was established as a quasi-analytical solution method based on rigorous comparison with the Case GC10a analytical solution and comparison with the FLUENT and TRNSYS detailed 3-D numerical-model results for other cases.

2.4.2.1 Surface convection modeling improvement, $1 \%-4 \%$ floor conduction decrease for cases GC30b, GC30c, GC60b, and GC65b

A programming error in DIT's model became apparent when convective boundary conditions were first introduced. Floor heat loss predictions for cases GC30b, GC30c, GC60b, and GC65b were initially 3\%-5\% higher than those of TRNSYS and FLUENT. An error in the modeling of convection within the edge loss routine was quickly located and corrected; the edge loss subprogram models floor heat loss just inside the perimeter boundary. Figure 2-2 shows MATLAB results versus TRNSYS and FLUENT results before and after DIT's model improvements. 


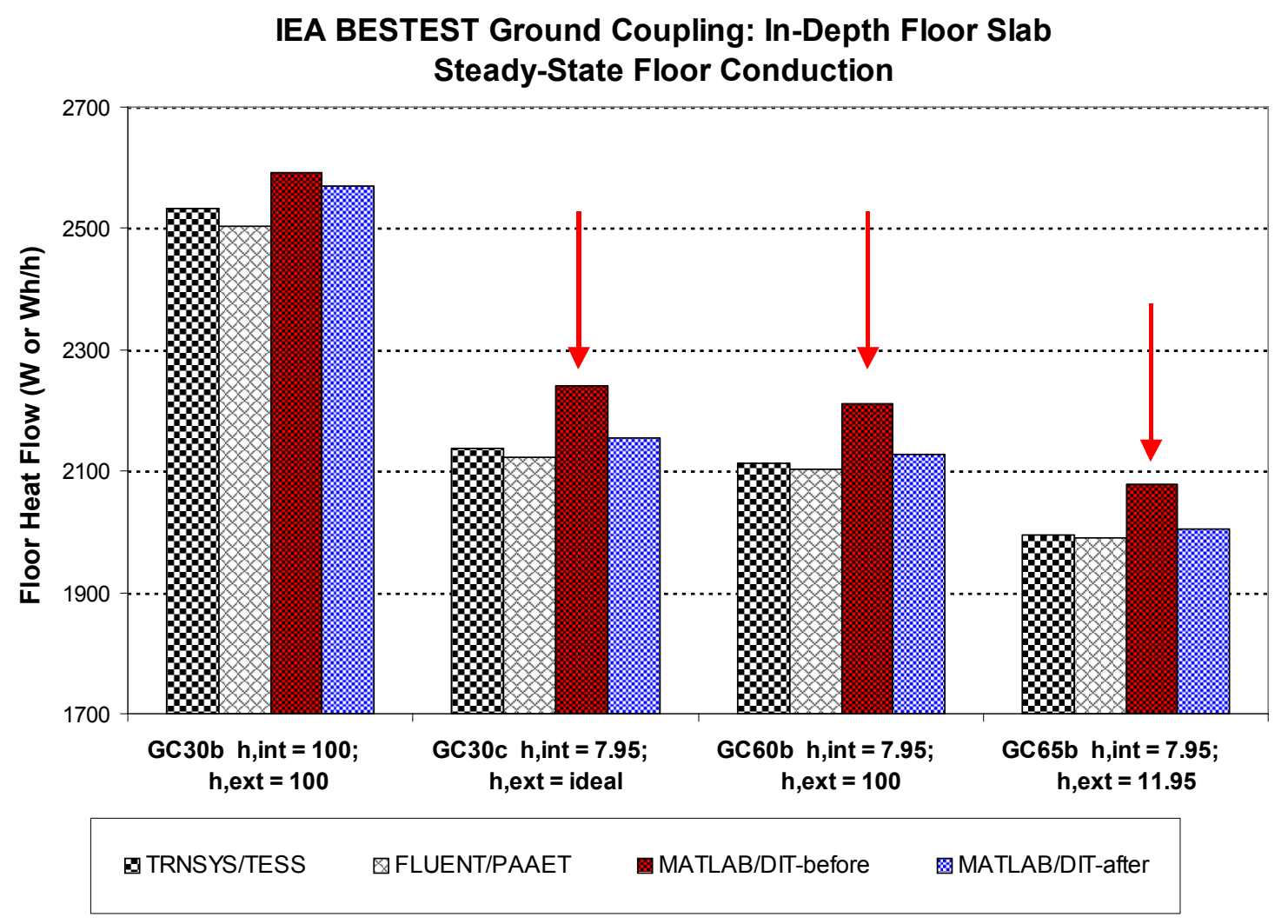

Figure 2-2. DIT's MATLAB results versus TRNSYS and FLUENT results, before and after DIT's slab edge model improvement (Increased minimum y-axis value magnifies differences.)

\subsubsection{Slab edge loss modeling improvement, $0.3 \%$ change for GC30a}

A further minor interpolation improvement was included in the edge loss routine, which models floor heat loss just inside the perimeter boundary. This resulted in a $0.3 \%$ change in the result for GC30a and a $0.002 \%$ (negligible) change in the result for GC10a (see Table 2-4; in this table $\mathrm{dx} 0, \mathrm{dz} 0$, fxL0, fxF0, and fz0 are node meshing input parameters, as described in DIT's modeler report in Section 2.9).

Table 2-4. Effects of Interpolation Improvement in Edge Loss Routine

\begin{tabular}{|l|c|c|c|c|c|c|c|c|c|l|}
\hline Case & $\begin{array}{c}\mathbf{F} \\
(\mathbf{m})\end{array}$ & $\begin{array}{c}\mathrm{E} \\
(\mathbf{m})\end{array}$ & $\begin{array}{c}\mathbf{d x 0} \\
(\mathbf{m})\end{array}$ & $\begin{array}{c}\mathbf{d z 0} \\
(\mathbf{m})\end{array}$ & $\mathbf{f x L 0}$ & $\mathbf{f x F 0}$ & $\mathbf{f z 0}$ & $\begin{array}{c}\text { Number } \\
\text { of nodes }\end{array}$ & $\begin{array}{c}\text { Floor slab } \\
\text { heat loss }\end{array}$ & Comments \\
\hline $\mathrm{GC10a}^{*}$ & 150 & 300 & 0.020 & 0.012 & 1.150 & 1.495 & 1.150 & 892,552 & $2431.87 \mathrm{~W}$ & Before improvement \\
\hline $\mathrm{GC10a}^{*}$ & 150 & 300 & 0.020 & 0.012 & 1.150 & 1.495 & 1.150 & 892,552 & $2431.82 \mathrm{~W}$ & After improvement \\
\hline $\mathrm{GC30a}$ & 20 & 30 & 0.015 & 0.009 & 1.135 & 1.4755 & 1.135 & 840,840 & $2686.33 \mathrm{~W}$ & Before improvement \\
\hline $\mathrm{GC} 30 \mathrm{a}$ & 20 & 30 & 0.015 & 0.009 & 1.135 & 1.4755 & 1.135 & 840,840 & $2694.99 \mathrm{~W}$ & After improvement \\
\hline
\end{tabular}

${ }^{*}$ Analytical solution is $2432.60 \mathrm{~W}$.

\subsubsection{Near-surface temperature reporting improvement, no effect on floor conduction}

A 3-D interpolation function was initially used to produce two lines of subsurface temperatures emanating from the origin at exact locations specified for the steady-state tests (see Part I, Figure 1-4 and Table 1-5). 
The results disagreed with FLUENT and TRNSYS (see the DIT modeler report, Section 2.9, Figure 2C-2). Use of a 1-D interpolation function, where the required interpolation points are collinear with the subsurface nodes, produced better agreement (see final results in Part III). The nature of the problem with the 3-D interpolation method was not established with certainty. However, MATLAB's 3-D interpolation function applied for determining these temperatures uses 64 neighboring points, and may have used nonrepresentative nodal temperatures considering the small scale of the perimeter boundary and the large temperature gradients in its vicinity. The method used for reporting temperatures at specific locations called out by the test specification has no effect on the floor conduction calculated by the model.

\subsubsection{PAAET 3-D Numerical Model Using FLUENT 6.0}

Public Authority for Applied Education and Training (PAAET) developed a 3-D numerical groundcoupled heat transfer model run independently of a whole-building energy simulation tool, prepared with FLUENT 6.0 (FLUENT Inc. 2001). FLUENT is a state-of-the-art computer program for modeling fluid flow and heat transfer in complex geometries. PAAET ran the test cases using an earlier version of FLUENT (6.0) than was available at the time of testing (version 6.2). PAAET's model was established as a quasi-analytical solution method based on rigorous comparison with the Case GC10a analytical solution and comparison with the TRNSYS and MATLAB detailed 3-D numerical-model results for other cases.

\subsubsection{Two output-reporting issues, no effect on overall floor conduction; fixed in later version of FLUENT before this testing}

Two output reporting issues occurred in FLUENT 6.0:

- The monitored values of hourly heat flux through the floor slab differed from those obtained for the same variable via FLUENT's postprocessing utilities. The total heat flux through the inside slab can be obtained in two ways from the postprocessing utilities: (1) via report "fluxes", (2) via report "surface integrals". These two postprocessing methods for calculating total heat flux through the inside slab produced the same value that is different from that provided by the monitoring utility (a built-in utility for automatic reporting of the value of a predefined variable at the end of each solver iteration or time step). This issue occurred only for monitoring of coplanar surfaces; for example, the slab, perimeter, and outside surfaces, which are all within a single plane at the same level (top surface) and have similar slope (in this case horizontal). PAAET hypothesized that this may be an interpolation related issue because nodes at adjacent surfaces have different boundary conditions. For example, when FLUENT performs integration over the floor slab, it uses values of nodes adjacent to the slab (the perimeter surface, which has a different boundary condition). PAAET bypassed this issue by defining a postprocessing surface (dummy surface used for data presentation purposes) that exactly overlaps the inside slab. The monitored heat flux through the created dummy surface matched the heat flux values provided by both postprocessing utilities. PAAET hypothesized that this may occur because FLUENT works with dummy surfaces in isolation as defined by the user, without investigating what is adjacent to the dummy surface.

- A bug in FLUENT produced diagonal surface temperature profile results twice (each node value is reported twice within a single file). FLUENT facilitates two types of lines for postprocessing purposes: "line" and "rake". "Line" was used to report the temperature profile across the diagonal of the upper surface of the domain. The values reported across the "line" are at actual nodes of the domain mesh. PAAET bypassed the double reporting issue by using the "rake" option, which allows the number of reporting points to be specified at equal spacing, although "rake" produces interpolated values at the specified points instead of exact node values. 
Fluent Inc. later investigated the above reporting errors and confirmed that both were present in FLUENT 6.0; both errors were already fixed before this testing for FLUENT 6.2 (Watve 2006).

\subsubsection{Modeling error, 0.7\% increase for Case GC30b}

During early results development and comparison, PAAET reported a modeling error for Case GC30b. (Ben-Nakhi 2006) The initially submitted result had floor conduction of $2487 \mathrm{~W}$; the fixed result has floor conduction of $2504 \mathrm{~W}$.

\subsubsection{EnergyPlus}

EnergyPlus (2007) is developed and maintained by DOE, and is the department's next-generation building energy simulation program. The EnergyPlus Slab program, which is used for ground heat transfer analysis, is run independently of EnergyPlus; output from the Slab program is manually input to the main EnergyPlus program. Table 2-5 describes field trial iterations by GARD Analytics (GARD) for this project and for selected preliminary work that occurred during IEA SHC Task 22. Input file and software modifications for each iteration are also shown. A single results set was submitted corresponding to changes described in each row of the table.

Table 2-5. Summary of EnergyPlus Changes that Were Implemented

\begin{tabular}{|c|c|c|}
\hline Version & Code Changes & Input File Changes \\
\hline $\begin{array}{l}\text { 1.0.3.019 } \\
\text { (December 2002) }\end{array}$ & Initially tested version for IEA SHC Task 22 & Initial Task 22 input files \\
\hline $\begin{array}{l}1.1 .0 .003 \\
\text { (April 2003) }\end{array}$ & $\begin{array}{l}\text { - Allow user to define interior convective } \\
\text { surface coefficients adjacent to floor slab }\end{array}$ & $\begin{array}{l}\text { - User input h,int (slab surface) } \\
\text { applied }\end{array}$ \\
\hline $\begin{array}{l}\text { 1.2.1.012 } \\
\text { (December 2004) }\end{array}$ & $\begin{array}{l}\text { Initially tested version for IEA SHC Task 34/ } \\
\text { Annex } 43 \text { in-depth cases }\end{array}$ & $\begin{array}{l}\text { Initial Task 34/Annex } 43 \text { input } \\
\text { files }\end{array}$ \\
\hline $\begin{array}{l}1.2 .2 .031 \\
\text { (June 2005) }\end{array}$ & $\begin{array}{l}\text { - Allow user input for Tdg } \\
\text { - Allow user input for h,ext (ground surface) } \\
\text { - Documentation clarified input description } \\
\text { for far-field boundary distance } \\
\text { - Gridding scheme improvements } \\
\text { - Allow separate simulation of perimeter and } \\
\text { core portions of floor } \\
\text { - Allow user input deep boundary depth }\end{array}$ & $\begin{array}{l}\text { - User input h,ext (ground } \\
\text { surface) applied } \\
\text { - Far-field and deep ground } \\
\text { boundary inputs corrected } \\
\text { - Slab perimeter and core } \\
\text { temperatures input for GC40 } \\
\text { (corrected previous input) } \\
\text { - User input of deep ground } \\
\text { boundary depth applied to } \\
\text { GC55b, GC55c }\end{array}$ \\
\hline $\begin{array}{l}\text { 1.3.0.007 } \\
\text { (March 2006) }\end{array}$ & $\begin{array}{l}\text { - Slab program output added to facilitate } \\
\text { separate simulation of slab perimeter and } \\
\text { core areas in a building }\end{array}$ & - Run Case GC50b (large slab) \\
\hline
\end{tabular}

\subsubsection{Allow user-defined interior convective surface coefficient, increased floor conduction by a factor of 2.7 (270\%) for IEA SHC Task 22 preliminary Case GC180}

Initial annual heating load results disagreements for EnergyPlus versus BASESIMP-HOT3000 and SUNREL-GC are shown in Figure 2-3 for preliminary in-depth cases of IEA SHC Task 22 (Deru, Judkoff, and Neymark 2003). The cause of the disagreements was that EnergyPlus did not allow the user to input constant interior surface coefficients adjacent to the floor slab. The interior surface convective coefficient value initially calculated and used by EnergyPlus was $0.948 \mathrm{~W} /\left(\mathrm{m}^{2} \cdot \mathrm{K}\right)$, which is greatly different from the value of $3.16 \mathrm{~W} /\left(\mathrm{m}^{2} \cdot \mathrm{K}\right)$ that IEA BESTEST (Judkoff and Neymark 1995a) indicates 
could accompany a specified combined convective/radiative coefficient of $8.29 \mathrm{~W} /\left(\mathrm{m}^{2} \cdot \mathrm{K}\right)$. Based on this problem, the code authors added new capability to the software that allows the user the option to set a constant value for interior and exterior convective heat transfer coefficients for a surface. The modelers then reran the simulations to model the specified combined interior surface coefficient by inputting 8.29 $\mathrm{W} /\left(\mathrm{m}^{2} \cdot \mathrm{K}\right)$ as an interior surface convective coefficient and setting the interior surface emittances to 0.001 . This resulted in improved agreement.

\section{IEA BESTEST Ground Coupling} Annual Heating Load

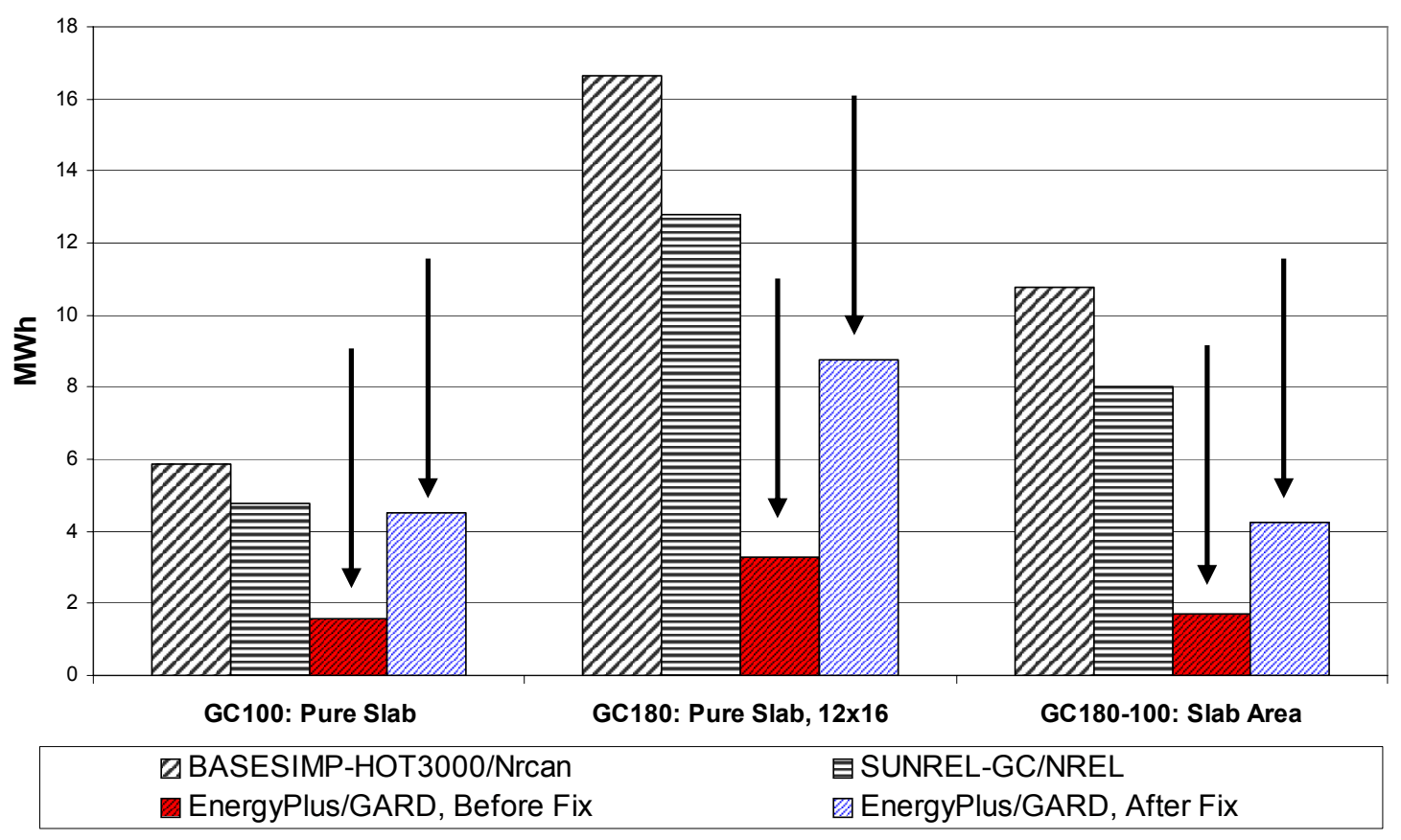

Figure 2-3. EnergyPlus annual heating load disagreements: IEA SHC Task 22 preliminary cases GC100, GC180, and GC180-GC100

\subsubsection{Allow user-defined lower deep ground boundary temperature, no effect on floor conduction}

User definition of a specific lower deep boundary temperature was added to match requirements of the test specification. Before this enhancement was made, this temperature was calculated by the EnergyPlus Slab program and set to the annual mean outdoor dry-bulb temperature as determined from the weather file. The lower deep boundary temperature required by the specification was $10^{\circ} \mathrm{C}$ for all test cases and each weather file used as part of the test suite already had annual mean ambient dry-bulb air temperatures of $10^{\circ} \mathrm{C}$, so use of this new capability did not change the test results.

\subsubsection{Allow user-defined ground surface heat transfer coefficient, probably minor effect on floor conduction}

Most test cases required that this parameter be set to $100 \mathrm{~W} /\left(\mathrm{m}^{2} \cdot \mathrm{K}\right)$, a high value that is useful for robust diagnosis. However, cases GC65b and GC70b required that this parameter be set at $11.95 \mathrm{~W} /\left(\mathrm{m}^{2} \cdot \mathrm{K}\right)$. In the original version of the EnergyPlus Slab program, the user could not define this parameter; instead, it 
was calculated internally by the program as a function of the ambient temperature and wind speed from the weather file. A later version of EnergyPlus allowed direct user input of the exterior surface coefficient for the soil. We could not isolate the effect of this improvement because of other accompanying changes during the field trial iteration. However, the wind speeds of the weather data were set to match the specified exterior surface coefficient (using ASHRAE 2005, ch. 25), so the impact of this improvement on the test results is probably minor.

\subsubsection{Documentation clarified regarding the input parameter "Distance from edge of slab to domain edge"; misinterpretation can cause approximately 4\%-7\% error depending on ratio of far-field dimension to deep ground boundary depth, and caused the program to crash for the shallow deep ground boundary depth of GC55b}

Earlier versions of the Slab program documentation caused confusion about the input parameter "Distance from edge of slab to domain edge." Whether this was the horizontal far-field distance or the deep boundary depth was unclear. Later documentation changes clarified the definition of parameters for these inputs. Table 2-6 shows EnergyPlus sensitivity test results for three of the "b"-series and "c"-series cases that have far-field dimension not equal to deep-ground depth, which identifies the effect of the documentation improvement.

\section{Table 2-6. Effect of Juxtaposed Deep-Ground Boundary Depth and Far-Field Dimensions} on EnergyPlus Floor Conduction

\begin{tabular}{|l|c|c|c|}
\hline Case & $\begin{array}{l}\text { Juxtaposed Parameters, } \\
\text { Floor Conduction (kWh/y) }\end{array}$ & $\begin{array}{l}\text { Correct Parameters, } \\
\text { Floor Conduction, (kWh/y) }\end{array}$ & \% Effect \\
\hline GC40c & 20978 & 20255 & $3.6 \%$ \\
\hline GC55b & Crashed & 39932 & Allows run \\
\hline GC55c & 20951 & 22570 & $7.2 \%$ \\
\hline
\end{tabular}

\subsubsection{Input error related to manual interface between floor slab model and main EnergyPlus program, approximate 35\%-40\% decrease in floor conduction, Case GC40}

One issue that came up in the early stages of the work was a disagreement about the results of Case GC40 (Neymark, Judkoff, and Deru 2004); see Figure 2-4. This disagreement was traced to an input error where the monthly slab perimeter temperatures output by the slab model were input to the main EnergyPlus program, rather than the monthly overall average (of perimeter and core) slab temperatures. Figure 2-5 indicates corrected results, which show a roughly $45 \%$ decrease in floor conduction versus Figure $2-4$. A simultaneous secondary effect on these results is variation of soil conductivity from $2.0 \mathrm{~W} /(\mathrm{m} \cdot \mathrm{K})$ for Case GC40 to $1.9 \mathrm{~W} /(\mathrm{m} \cdot \mathrm{K})$ for Case GC40b, which should have about a $5 \%$ effect on all model results. Another secondary effect is the difference between the specified ideal (infinite) surface coefficients of Case GC40 and surface coefficients of $100 \mathrm{~W} /\left(\mathrm{m}^{2} \cdot \mathrm{K}\right)$ for Case GC40b. This secondary effect can account for at most a 4-5\% variation based on FLUENT, SUNREL-GC, and TRNSYS results for cases GC40a and GC40b, and is probably less because for Case GC40 EnergyPlus did not run for interior surface coefficient greater than $180 \mathrm{~W} /\left(\mathrm{m}^{2} \cdot \mathrm{K}\right)$. Therefore, the effect of correcting the input error is estimated at about a $35-40 \%$ decrease for floor conduction, i.e., $45 \%-(5 \%$ for reduced conductivity) - (a few percent for reduced surface coefficient). To assist users with the current manual interface between the Slab model and the main EnergyPlus program, the Slab model output was revised to include example floor model inputs to the main EnergyPlus program. Better automation of the interface between the Slab model and EnergyPlus is recommended. 


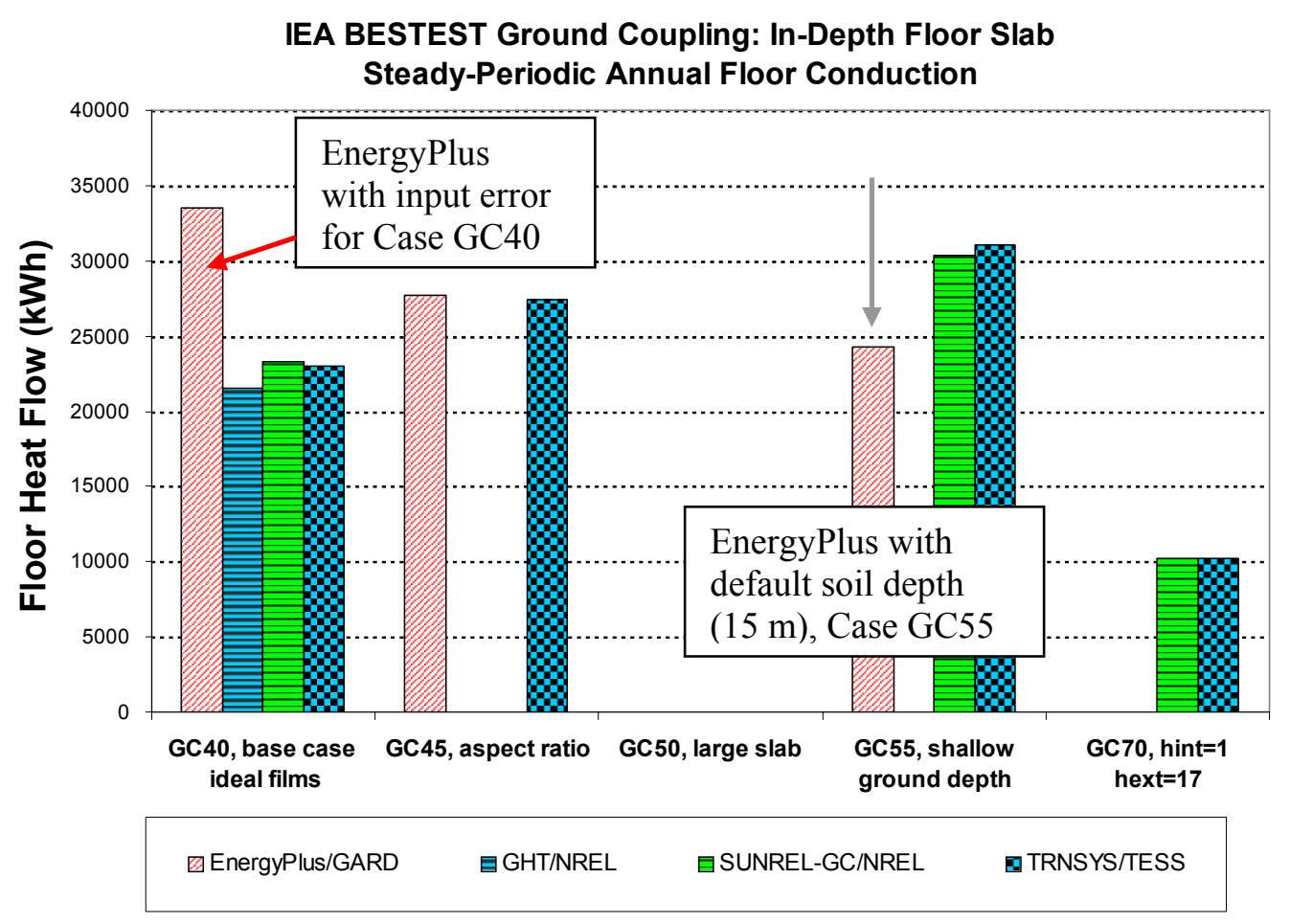

Figure 2-4. EnergyPlus GC40 and GC55 disagreements, shown with Feb 2005 results

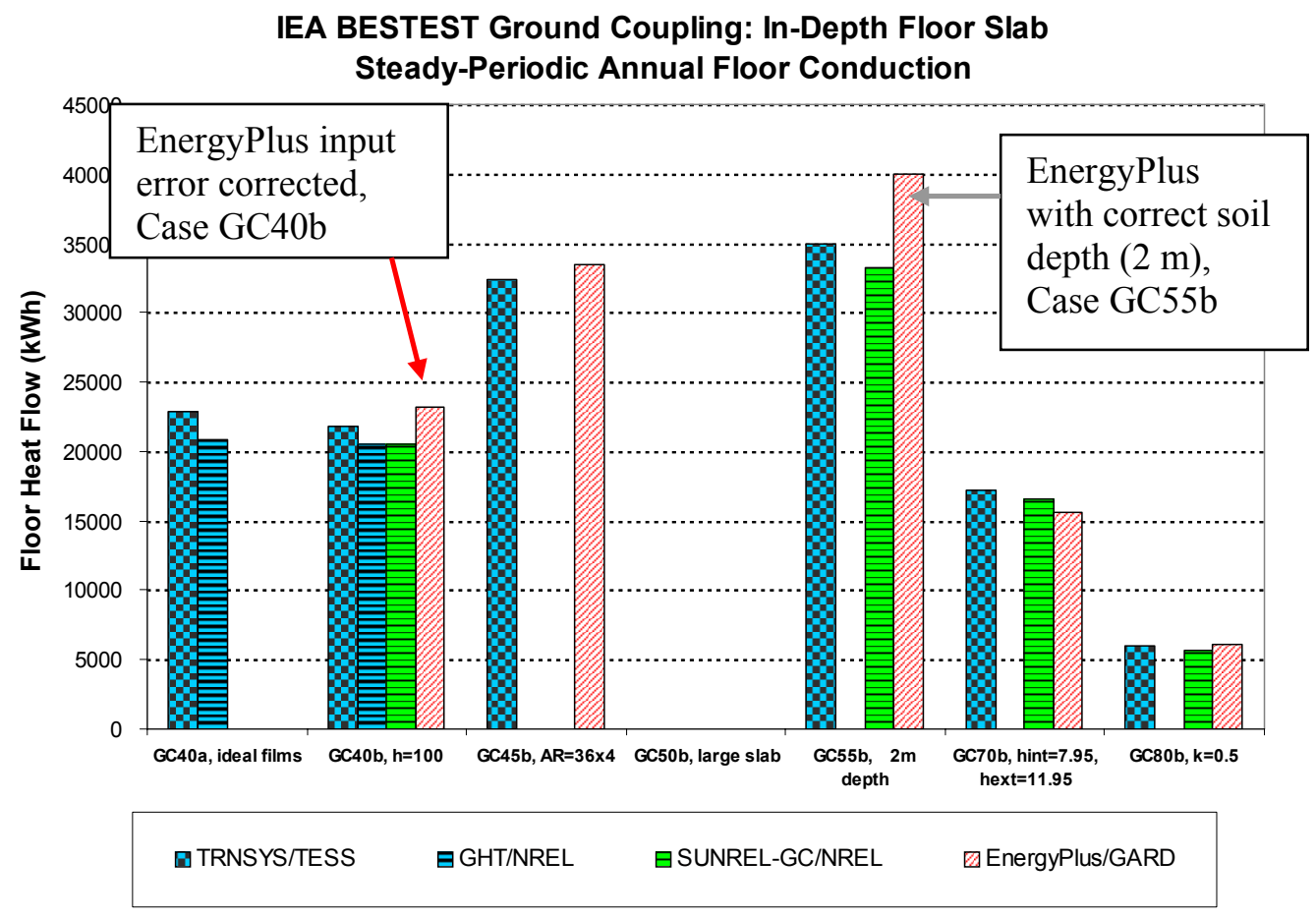

Figure 2-5. EnergyPlus with input error correction, and improvement to allow deep ground boundary depth as user input, shown with June 2005 results 


\subsubsection{Allow user-defined deep-ground boundary depth, estimated 35\% increase in floor conduction for Case GC55b (versus preliminary Case GC55)}

This capability was required because the test specification requested the simulation of shallow and deep boundary depths for the "b"-series and "c"-series cases ranging from $2 \mathrm{~m}$ to $15 \mathrm{~m}$. Before this enhancement was made deep boundary depth was automatically set to $15 \mathrm{~m}$ or $20 \mathrm{~m}$ depending on floor area/perimeter (A/P) ratio. This new capability was applied only for cases GC50b, GC55b, and GC55c because GC55b and GC55c specify deep ground boundary depth of $2 \mathrm{~m}$ and $5 \mathrm{~m}$, respectively, and because for all cases except GC50b the A/P ratio is such that EnergyPlus applies a deep ground boundary depth of $15 \mathrm{~m}$. Initial field-trial results submitted in December 2004 for preliminary Case GC55 without the ability to set ground depth shallower than $15 \mathrm{~m}$ were about $20 \%$ below the initial TRNSYS and SUNREL-GC numerical results (see Figure 2-4). The second iteration of results submitted in June 2005, which allows direct user input for shallow ground depth, are about $15 \%$ above the numerical-model results (see Figure 2-5). This indicates a roughly 35\% effect in EnergyPlus for including this change, and indicates that EnergyPlus has a greater sensitivity to soil depth than the numerical models. This issue is further discussed in Section 2.4.4.8.

\subsubsection{Sensitivity disagreement for variation of ground surface heat transfer coefficient, GC65b has $18 \%$ lower floor conduction than average of all other results}

From the current results set (see Figure 2-6) the EnergyPlus results are more sensitive to ground surface heat transfer coefficient than the verified numerical models and other programs. This disagreement may be caused by the EnergyPlus Slab program's shorter heat flow path underneath the adiabatic exterior wall (EnergyPlus assumes perimeter boundary width $=0$ ), which would overestimate the slab perimeter heat flow for the test cases. Also shown in Figure 2-6 (gray arrow) is the difference in the annual average floor conduction for Case GC70b versus the steady-state floor conduction of Case GC65b (see data for GC70b-GC65b). This difference occurs for the lower (more realistic) exterior ground surface heat transfer coefficient of GC70b-GC65b but not for the higher exterior ground surface heat transfer coefficient of GC40b-GC30. This smaller difference may be related to ground surface heat transfer modeling, or some other aspect of the model. The EnergyPlus development team is examining these issues.

\subsubsection{Sensitivity disagreement for variation of soil depth, $15 \%$ higher floor conduction than verified numerical model results for shallow soil depth (Case GC55b)}

Also, from the current results set (see Figure 2-7), EnergyPlus has good agreement with verified numerical model results for $15 \mathrm{~m}$ soil depth, but has $15 \%$ greater floor conduction for shallow soil depth (GC55b) and comparable oversensitivity to reduction of ground depth (GC55b-GC40b). The ISO-13370 model implemented in VA114 also indicates good agreement at $15 \mathrm{~m}$ soil depth, but has $9 \%$ lower floor conduction versus the verified numerical-model results at shallow soil depth (see gray arrows in Figure 27). The similar magnitude of the EnergyPlus and ISO-13370 differences versus the verified numericalmodel results indicates that such differences may be reasonable for less detailed models. However, the EnergyPlus development team is examining this issue. 
IEA BESTEST Ground Coupling: In-Depth Floor Slab

Steady-State Floor Conduction

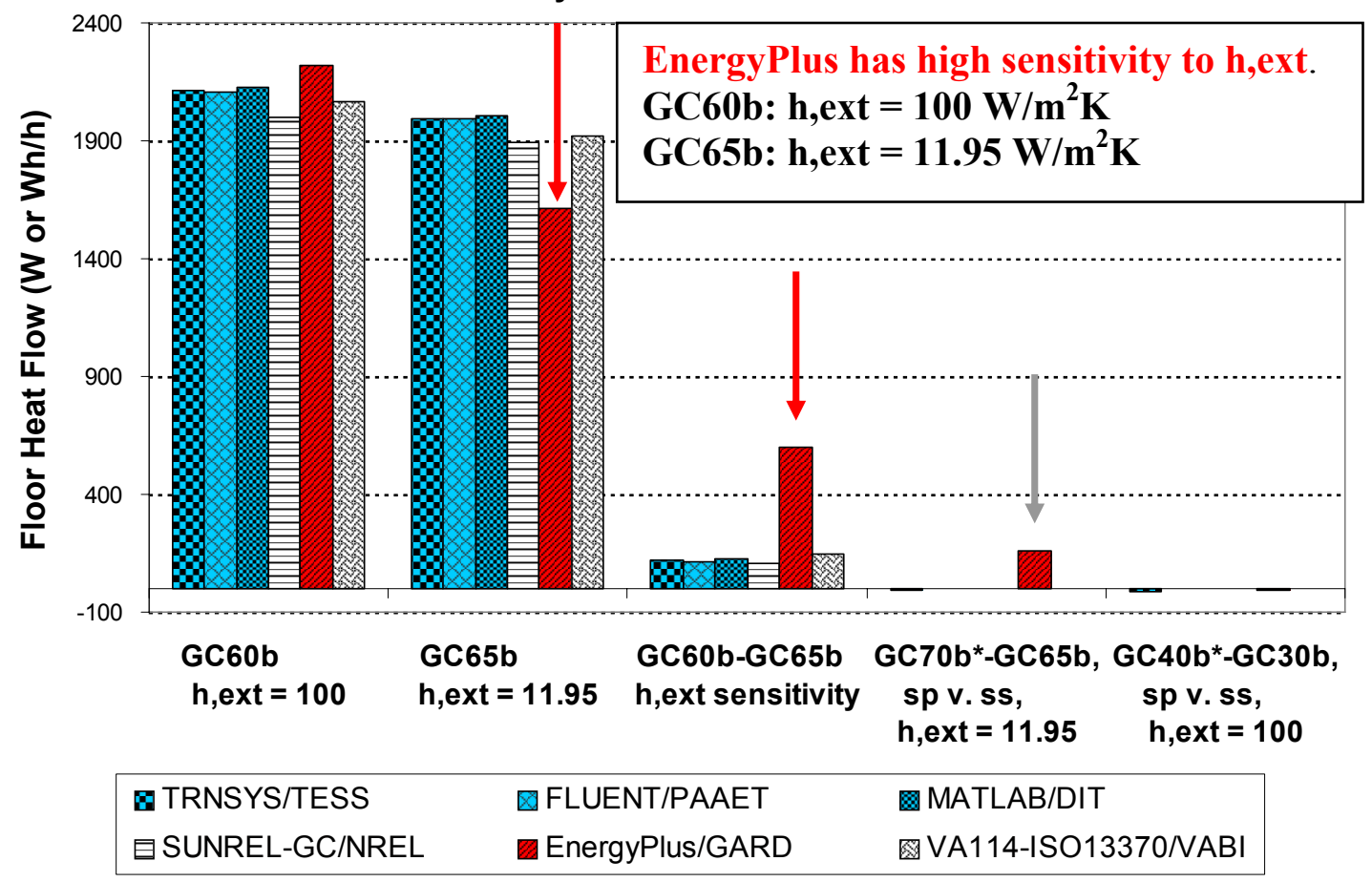

Figure 2-6. EnergyPlus exterior ground surface heat transfer coefficient sensitivity disagreement

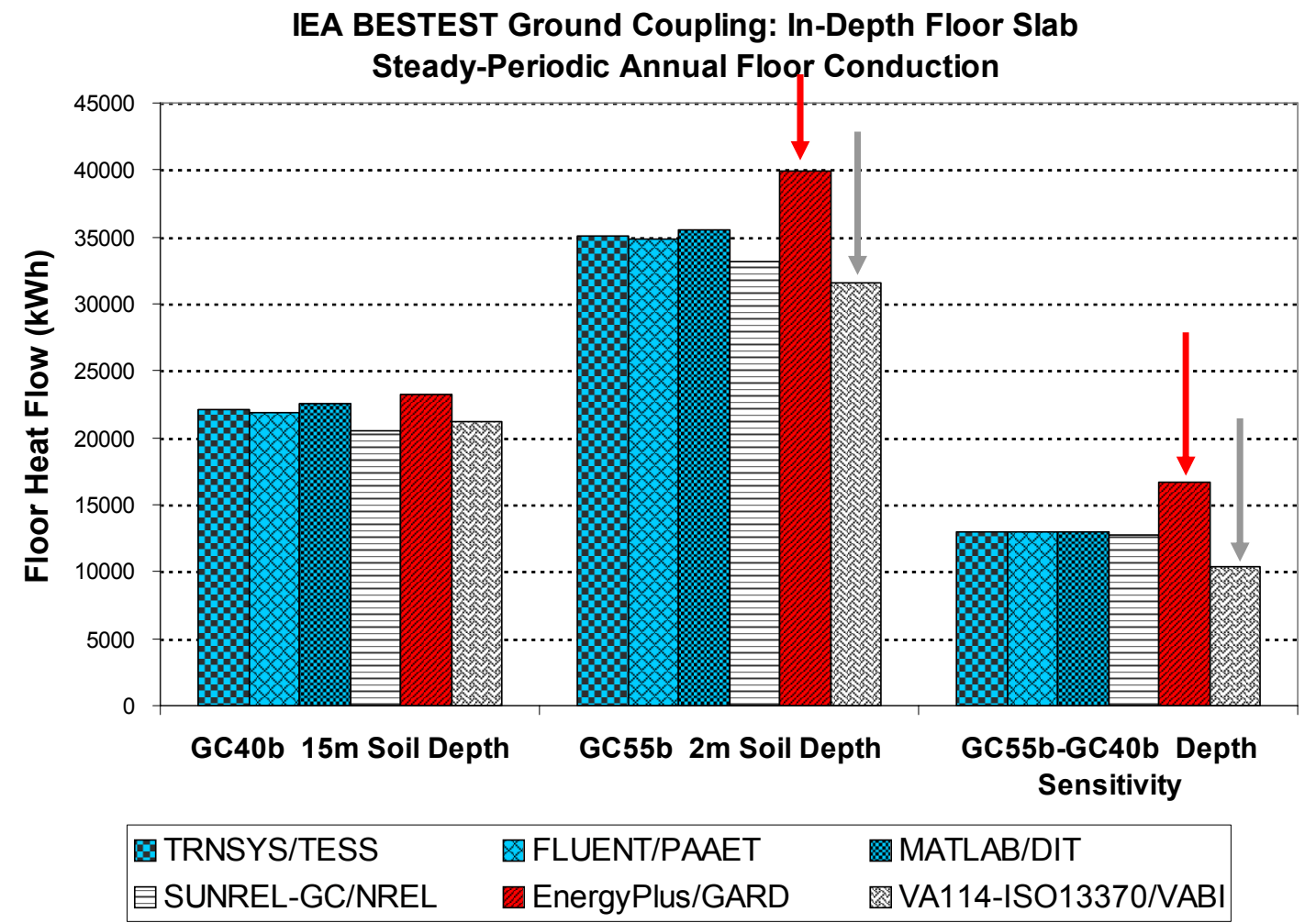

Figure 2-7. EnergyPlus soil depth sensitivity disagreement 


\subsubsection{VA114 Version 2.20 with ISO 13370 Ground Heat Transfer Model}

VA114 (VABI 2007), initial development by TNO, current development and distribution, maintenance, and support by VABI Software BV, The Netherlands, is widely used in The Netherlands. VABI is adapting the ISO-13370 European standard ground heat transfer calculation method (ISO 13370:1998) for VA114.

2.4.5.1 Adapt ISO-13370 ground heat transfer calculation method for VA114, 100\% and $70 \%$ increases in annual heating load for preliminary IEA SHC Task 22 cases GC100 and GC180, respectively

In preliminary work during IEA SHC Task 22 (Deru, Judkoff, and Neymark 2003), results for the Task 22 cases using VA114's 1-D conduction model indicated low heating loads compared with other programs. Based on these results, VABI decided to explore implementing the ISO-13370 (ISO 11370:1998) ground heat transfer model into VA114. Figure 2-8 shows VA114 results versus results of other models before and after initial implementation of ISO 13370 (Neymark 2003; Wijsman 2005).

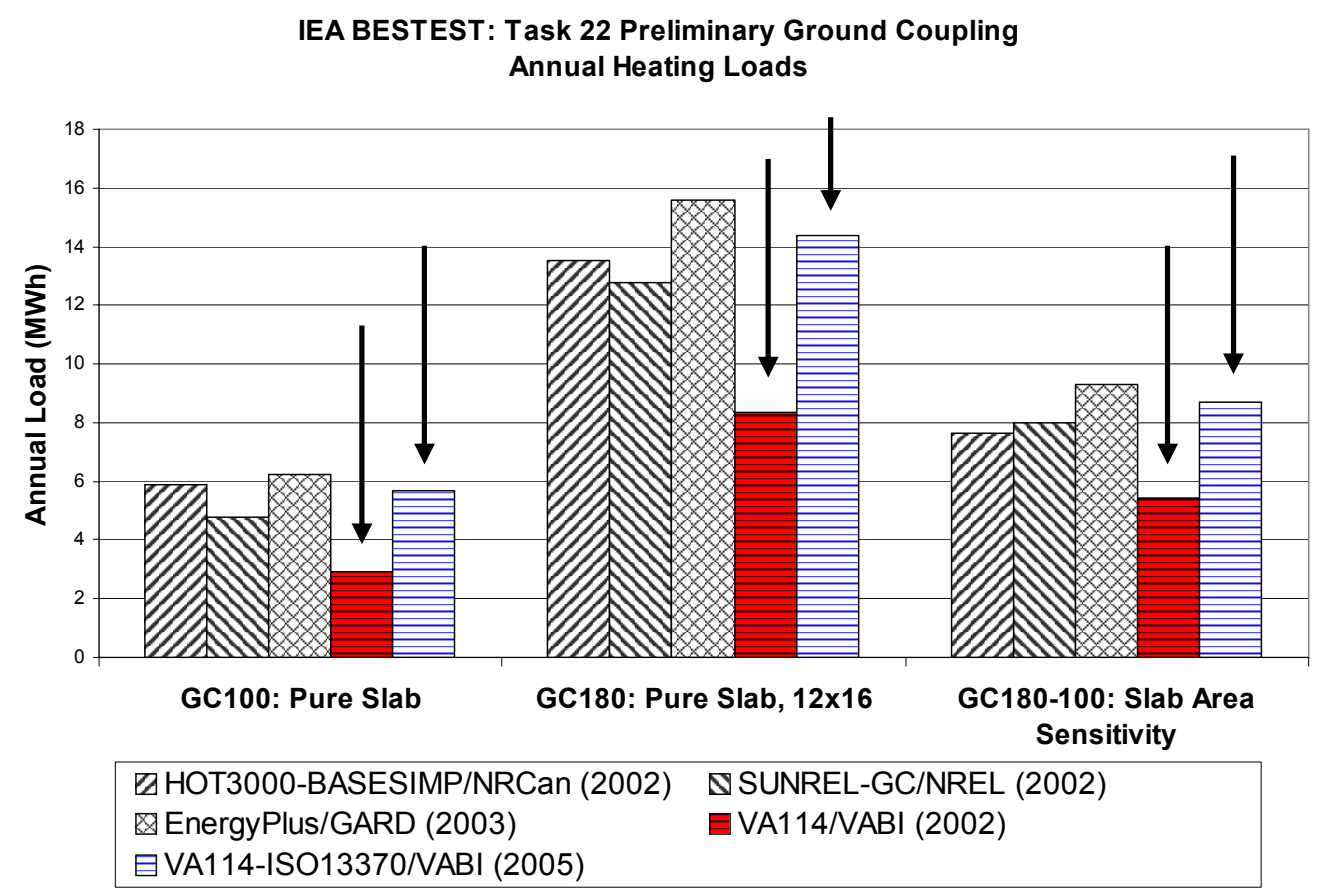

Figure 2-8. IEA SHC Task-22 test results for VA114 versus other models, before ("VA114/VABI (2002)") and after ("VA114-ISO13370/VABI (2005)") preliminary adaptation of the ISO-13370 European standard ground heat transfer calculation method with VA114.

2.4.5.2 Implementation of ISO-13370 soil depth modeling for VA114, $29 \%$ and $49 \%$ increase in annual floor conduction for cases GC50b and GC55b, respectively

The initial implementation of ISO-13370 with VA114 was then tested using the IEA-34/43 test cases (see Figure 2-9). Except for cases GC50b and GC55b, good agreement is indicated for VA114/ISO 13370 versus the TRNSYS and SUNREL-GC detailed 3-D numerical models. The largest disagreement is for Case GC55b, which has shallow water table depth; Case GC50b is for large slab with no change in modeled soil depth versus GC40b, so in GC50b water table depth also becomes somewhat shallow relative to the slab 
surface area. The initial implementation of ISO 13370 in VA114 did not include ISO 13370's model for water table depth sensitivity. Based on these results, the ISO-13370 shallow water table depth model was implemented; improved agreement resulting from this implementation is shown in Figure 2-10.

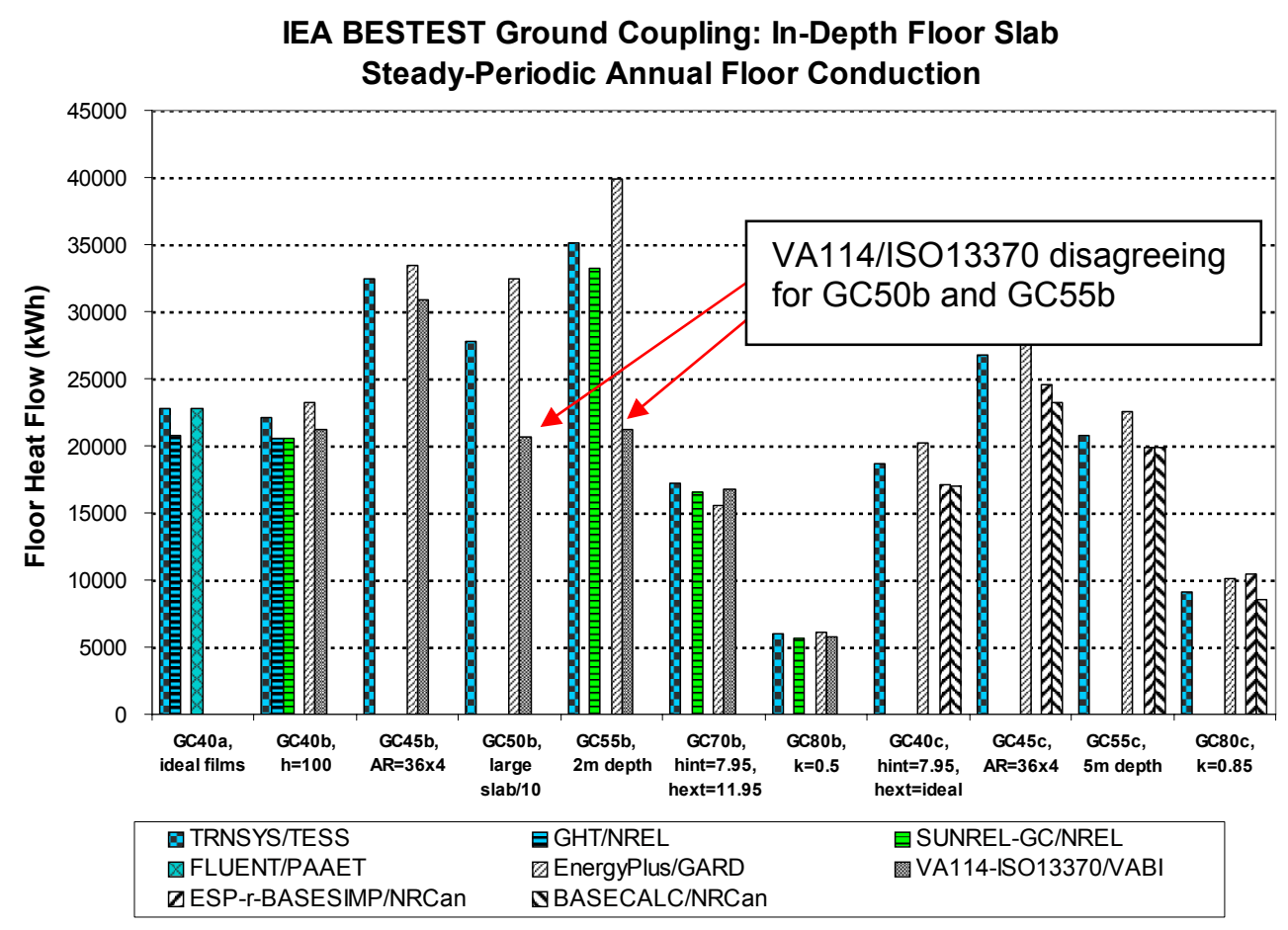

Figure 2-9. Steady-periodic annual floor conduction, from April 2006 results

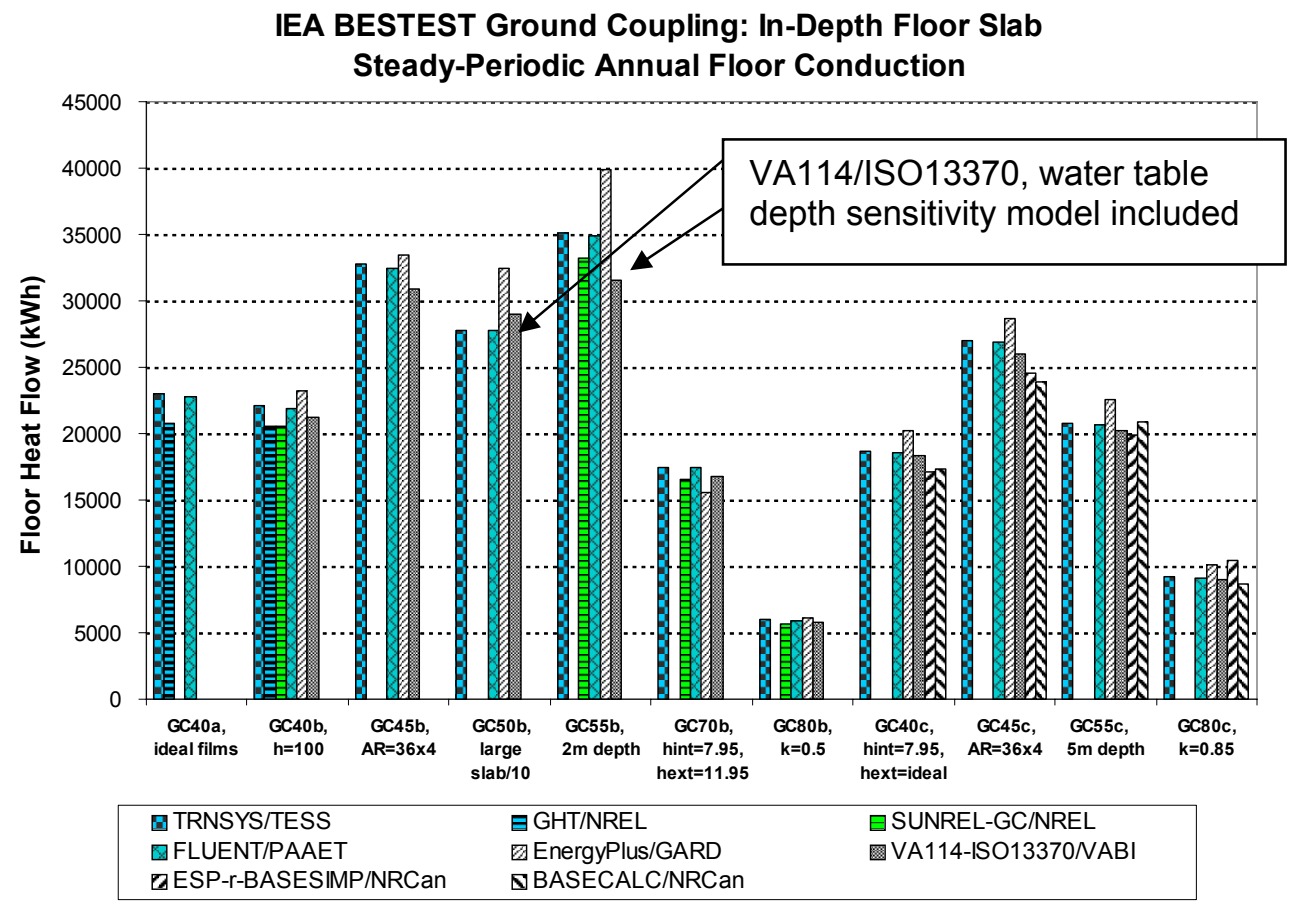

Figure 2-10. Steady-periodic annual floor conduction, from October 24, 2006 results 


\subsubsection{Time of occurrence for peak heat flow is later than for other models, peak delayed 700 hours for GC55b and 300-500 hours for other cases}

Final results for annual and peak-hour floor conduction (see Part III) show generally good agreement versus verified numerical models and other models. However, Figure 2-11 shows that time of peak occurrence is delayed by about 400 hours in Case GC40b. Figure 2-12 shows that peak occurrence is delayed about 700 hours for Case GC55b and about 600 hours for Case GC80b, and delayed 300-500 hours for other cases. The VA114 authors consider this disagreement about delayed occurrence of peak heat flow to be acceptable, especially compared with more fundamental disagreements before the ISO-13370 model was adapted, and have no plans to address this issue.

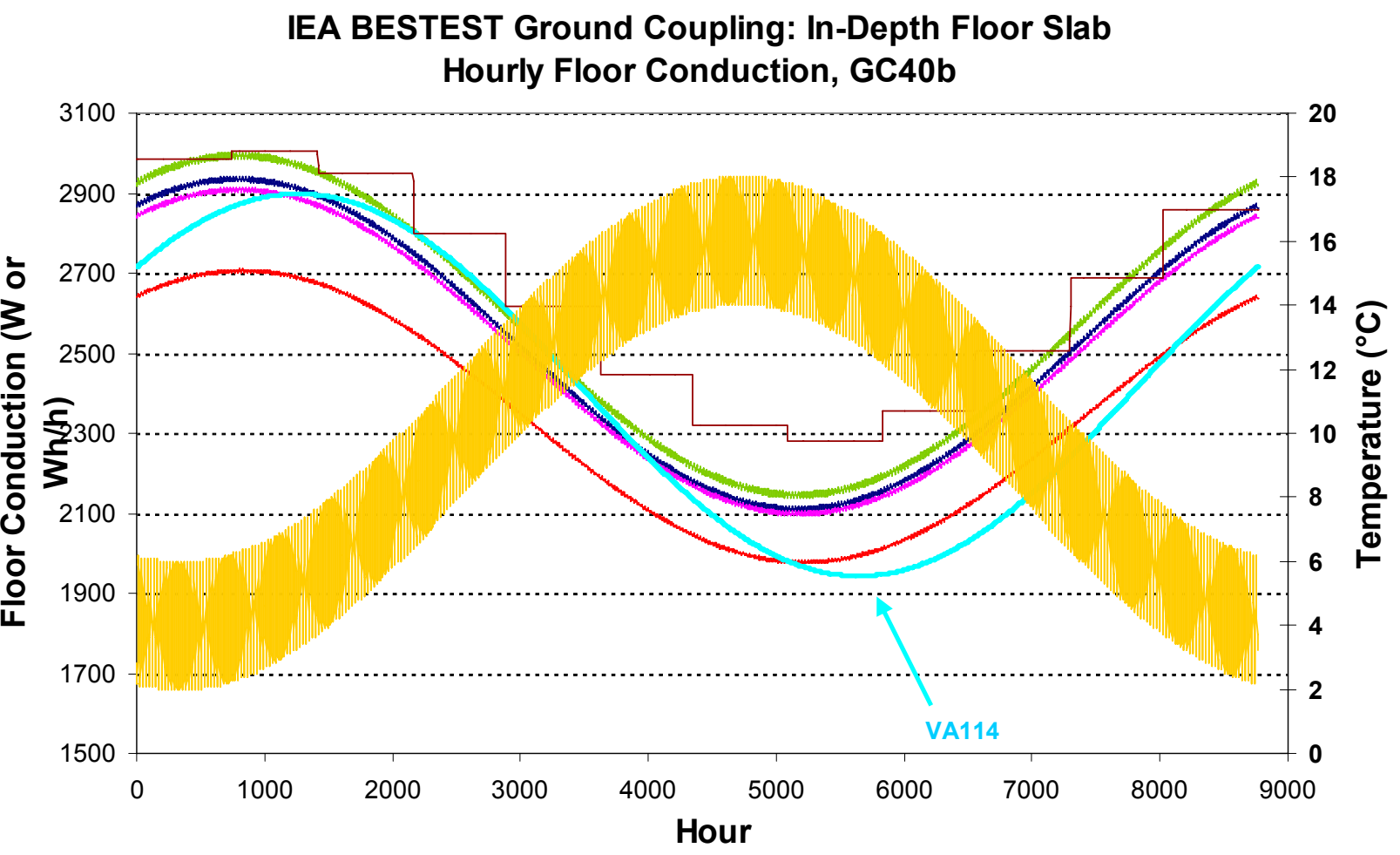

- TRNSYS - FLUENT - MATLAB —GHT —VA114 - EnergyPlus —ODB Temperature

Figure 2-11. Hourly floor conduction, Case GC40b 


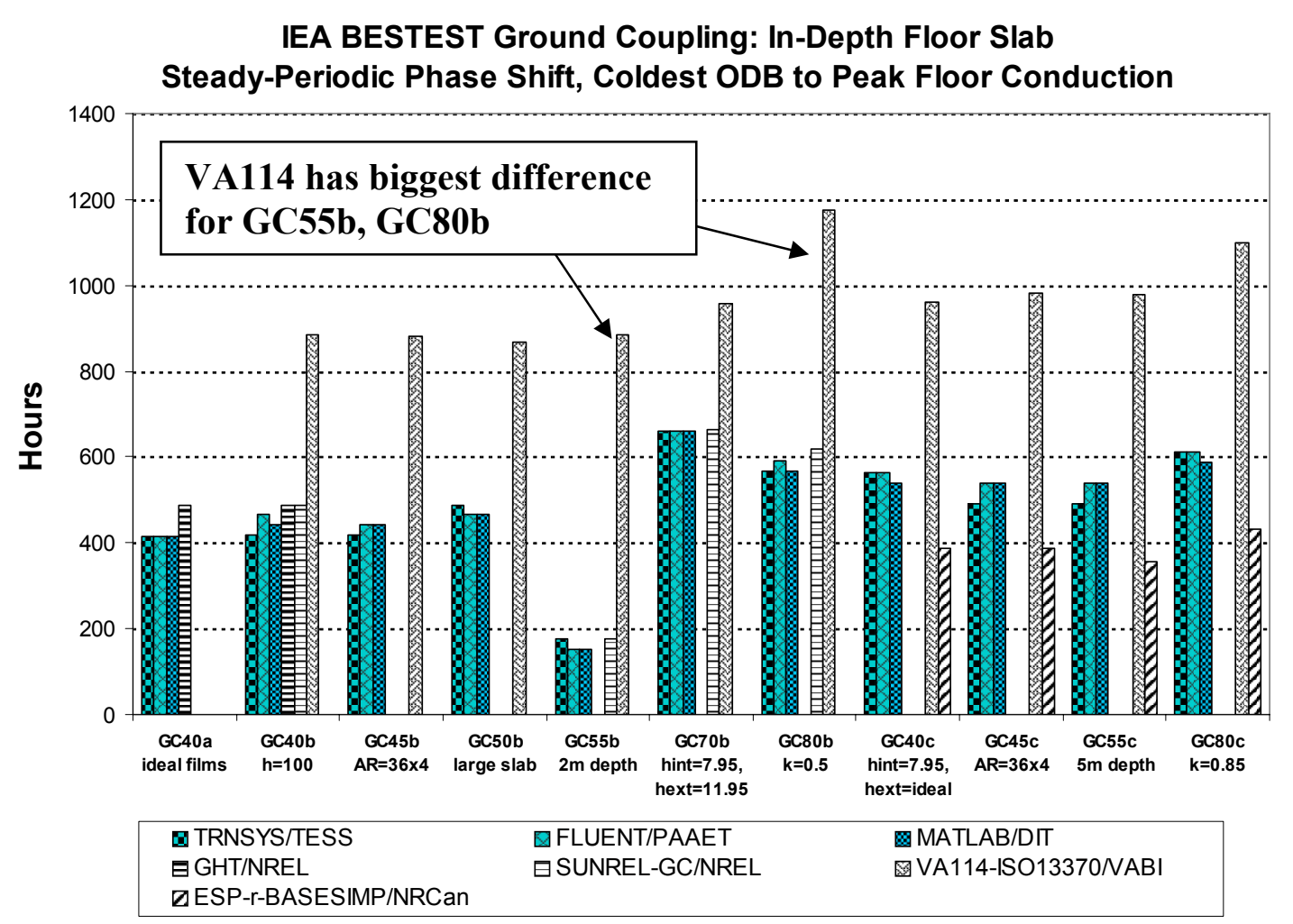

Figure 2-12. Steady-periodic phase shift, coldest ODB to peak floor conduction

\subsubsection{BASESIMP/ESP-r and BASECALC}

BASESIMP (Beausoleil-Morrison and Mitalas 1997) is developed by NRCan. It is a regression-based algorithm based on more than 100,000 BASECALC runs. Solutions by BASECALC, which was also developed by NRCan (Beausoleil-Morrison 1996), are obtained by performing three, 2-D finite element simulations and using corner correction factors to obtain quasi-3-D solutions. In this project, NRCan evaluated its implantation of BASESIMP within ESP-r (ESRU 2007; Beausoleil-Morrison 1999).

\subsubsection{BASECALC input error, $1 \%-5 \%$ for "c"-series cases}

As BASESIMP is a correlation method based on BASECALC, some disagreement (up to 5\%) may be expected. However, the $22 \%$ disagreement for GC80c and 6\% disagreement for GC45c (see Figure 2-13) were more than expected. Review by NRCan revealed an error in the BASECALC input files. Corrected BASECALC input yielded results shown in Figure 2-14. 


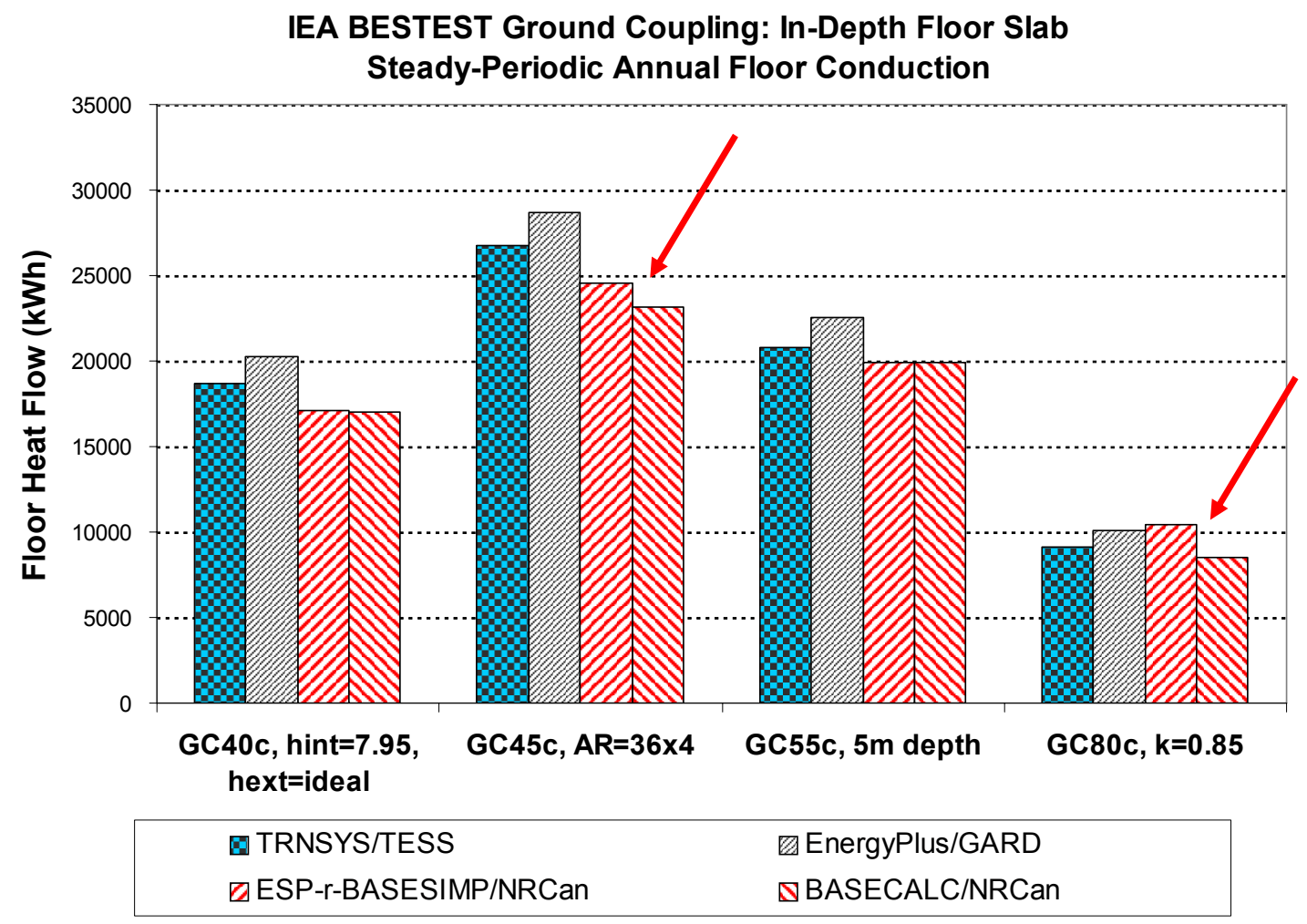

Figure 2-13. Results differences for BASESIMP versus BASECALC, for results submitted March 2006

IEA BESTEST Ground Coupling: In-Depth Floor Slab Steady-Periodic Annual Floor Conduction

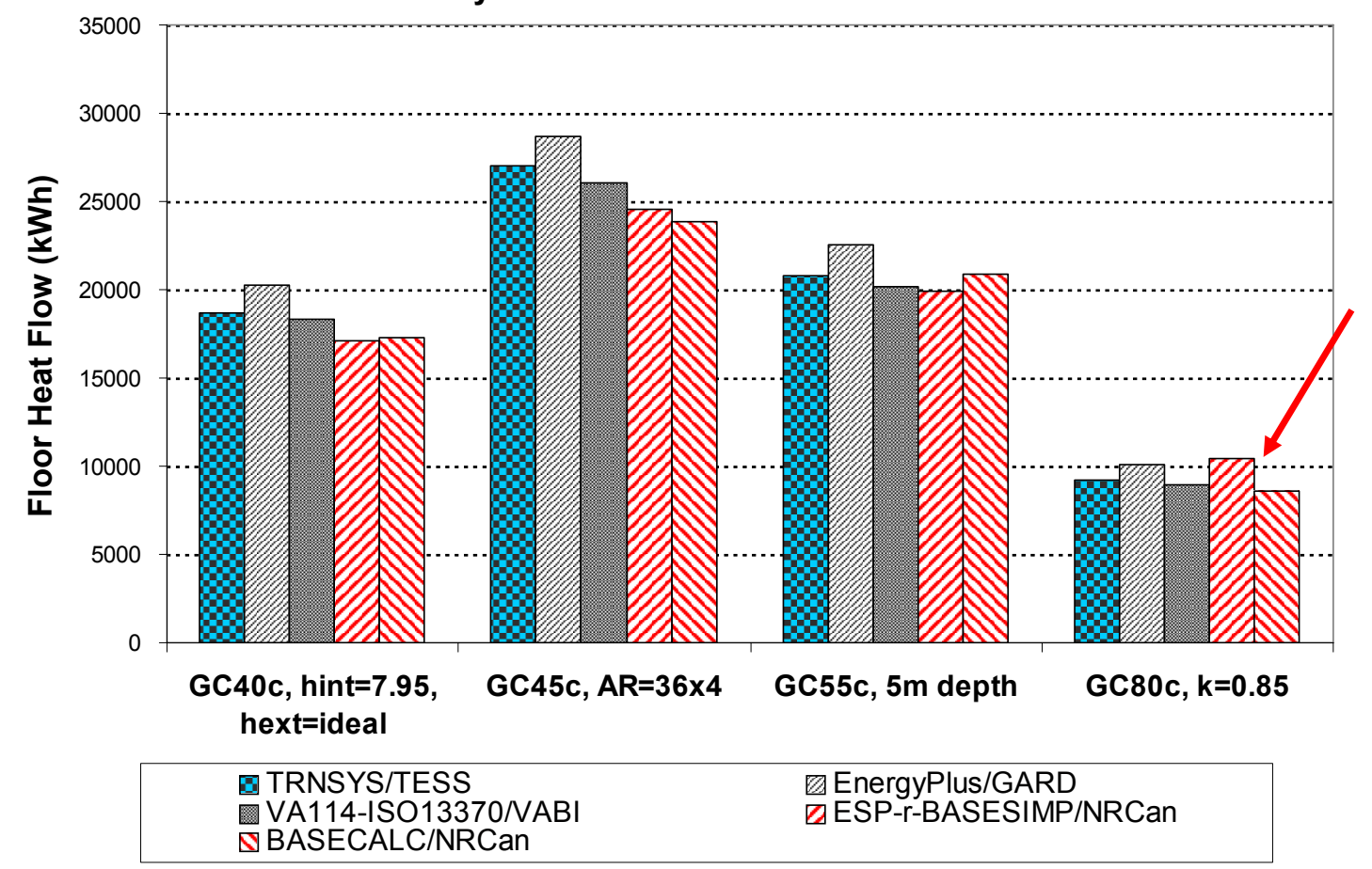

Figure 2-14. Results differences for BASESIMP versus BASECALC, for results submitted June 2006 

outside the range of parameter variations allowed by current heat loss correlations, $21 \%$ for GC80c, $1 \%-4 \%$ for other "c"-series cases

After the BASECALC input error was corrected the difference between results of BASESIMP and BASECALC for Case GC45c was reduced; however, Figure 2-14 shows that BASESIMP results for Case GC80c are still 21\% greater than the BASECALC results. NRCan's further review of BASESIMP revealed that this difference is caused because BASESIMP correlation range constraints do not allow modeling of all specified features of Case GC80c. Specifically, as a simplification for the numericalmethods modelers, Case GC80c applies the same low-range conductivity value for soil as to the slab and foundation walls $(0.85 \mathrm{~W} /(\mathrm{m} \cdot \mathrm{K}))$. Case GC $80 \mathrm{c}$ can be modeled by BASECALC; however, BASESIMP fixes conductivity of concrete for the slab and foundation wall conductivities at $1.73 \mathrm{~W} /(\mathrm{m} \cdot \mathrm{K})$ (a typical value for concrete). As this issue was discovered too late in the project to revise the test specification and rerun the other participants' numerical models, to test BASESIMP's ability to model low conductivity Case GC80c NRCan developed a new configuration type for BASESIMP that allows the user to input the specific heat loss coefficients calculated by BASECALC for configurations that would normally fall outside the range of parameter variations covered by the current BASESIMP heat loss correlations. As shown in Figure 2-15, the BASESIMP heat loss results for the new configuration type are identical to those of the BASECALC runs used to supply the heat loss coefficients.

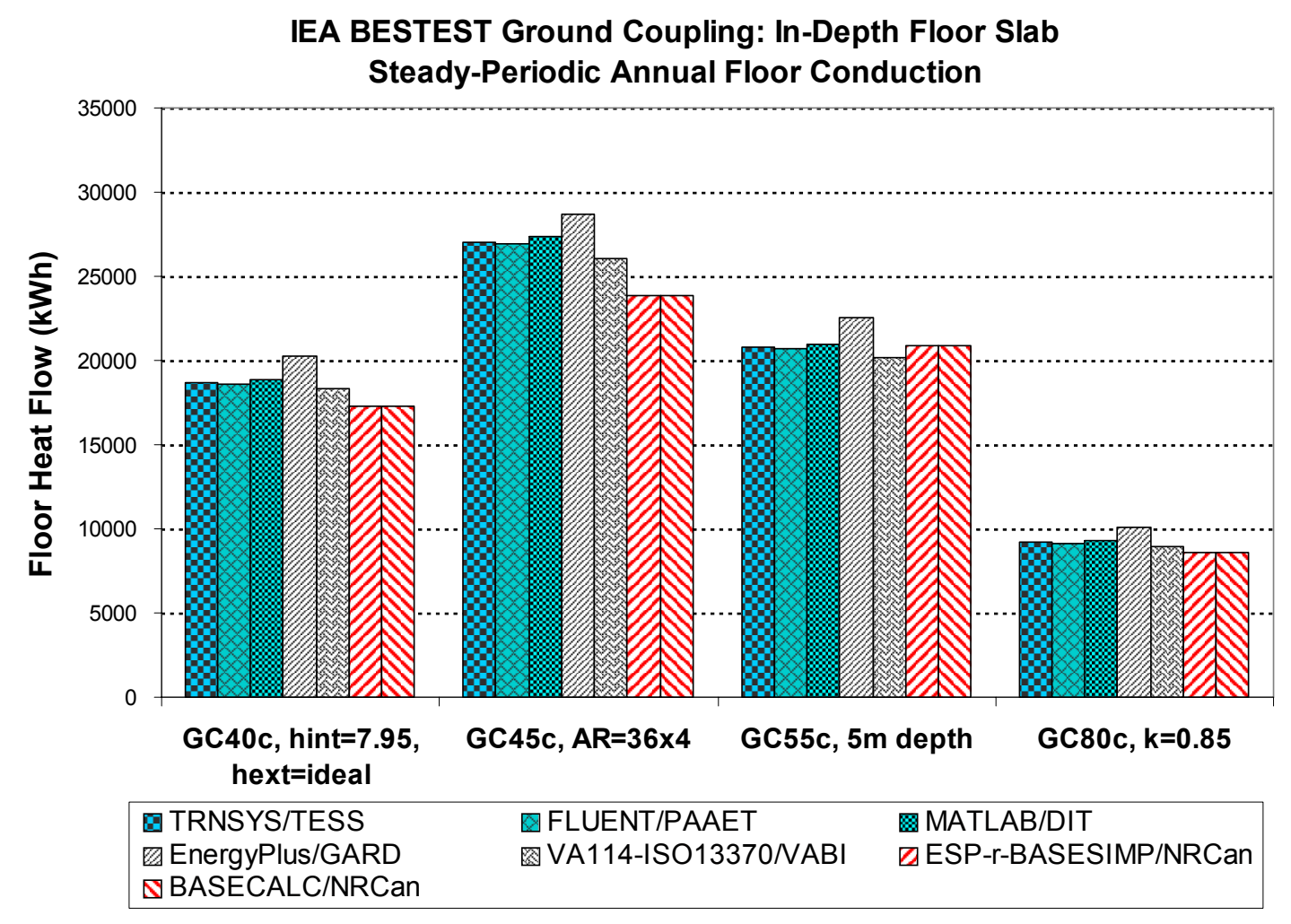

Figure 2-15. Final Results for BASESIMP versus BASECALC 


\subsubsection{BASECALC and BASESIMP results are $9 \%$ low versus verified numerical-model results for GC45C}

Figure 2-15 indicates that results for BASECALC and BASESIMP disagree with the verified numericalmodel results substantially more than the VA114-ISO13370 and EnergyPlus results. This indicates a disagreement with calculation of perimeter heat flow, and should be checked. The BASECALC authors consider this disagreement at this relatively extreme aspect ratio to be acceptable, and have no plans to address this issue.

\subsubsection{GHT/SUNREL-GC}

SUNREL was developed by NREL. SUNREL-GC is a special version of SUNREL coupled with a groundcoupled heat transfer program called GHT. GHT uses finite element analysis to model 2-D or 3-D heat conduction problems (Deru 2003), and can be run independently or integrated with SUNREL. This model has sufficient detail and flexibility to potentially qualify as a quasi-analytical solution method if the software developer can address the disagreements noted below.

\subsubsection{Better integration of GHT model with SUNREL-GC, $5 \%$ and $8 \%$ relative decrease in SUNREL-GC floor conduction for cases GC30 (versus GC3Ob) and GC40 (versus GC40b), respectively}

After the first field trial iteration, NREL revised integration of GHT with SUNREL-GC to improve the year-to-year data exchange between the programs and to make the specialized version of SUNREL easier to use. As shown in Figure 2-16, these revisions resulted in 5\% and 8\% decreases in floor conduction modeled by SUNREL-GC relative to GHT for cases GC30 (versus GC30b) and GC40 (versus GC40b), respectively. Also, for the initial results of preliminary cases GC30 and GC40, SUNREL-GC appears to have had better agreement with TRNSYS before these changes were made, although this could be evidence of initially compensating errors if a further error remains.

2.4.7.2 Disagreements versus TRNSYS, MATLAB, and FLUENT results, $7 \%$ and $10 \%$ below average of verified numerical-model results for cases GC30a and GC40a respectively; $5 \%-8 \%$ below average of verified numerical-model results for the "b"series cases

Figure 2-17 shows that current GHT results are within $1 \%$ of the analytical solution, but that GHT and SUNREL-GC results disagree with the verified numerical-model results by $5 \%-8 \%$ for the other steadystate cases. Similarly, Figure 2-18 shows that current SUNREL-GC results for cases with steady-periodic variation of outdoor temperature disagree with the verified numerical-model results by $5 \%-10 \%$, where the greatest percentage disagreement occurs for Case GC40a. 


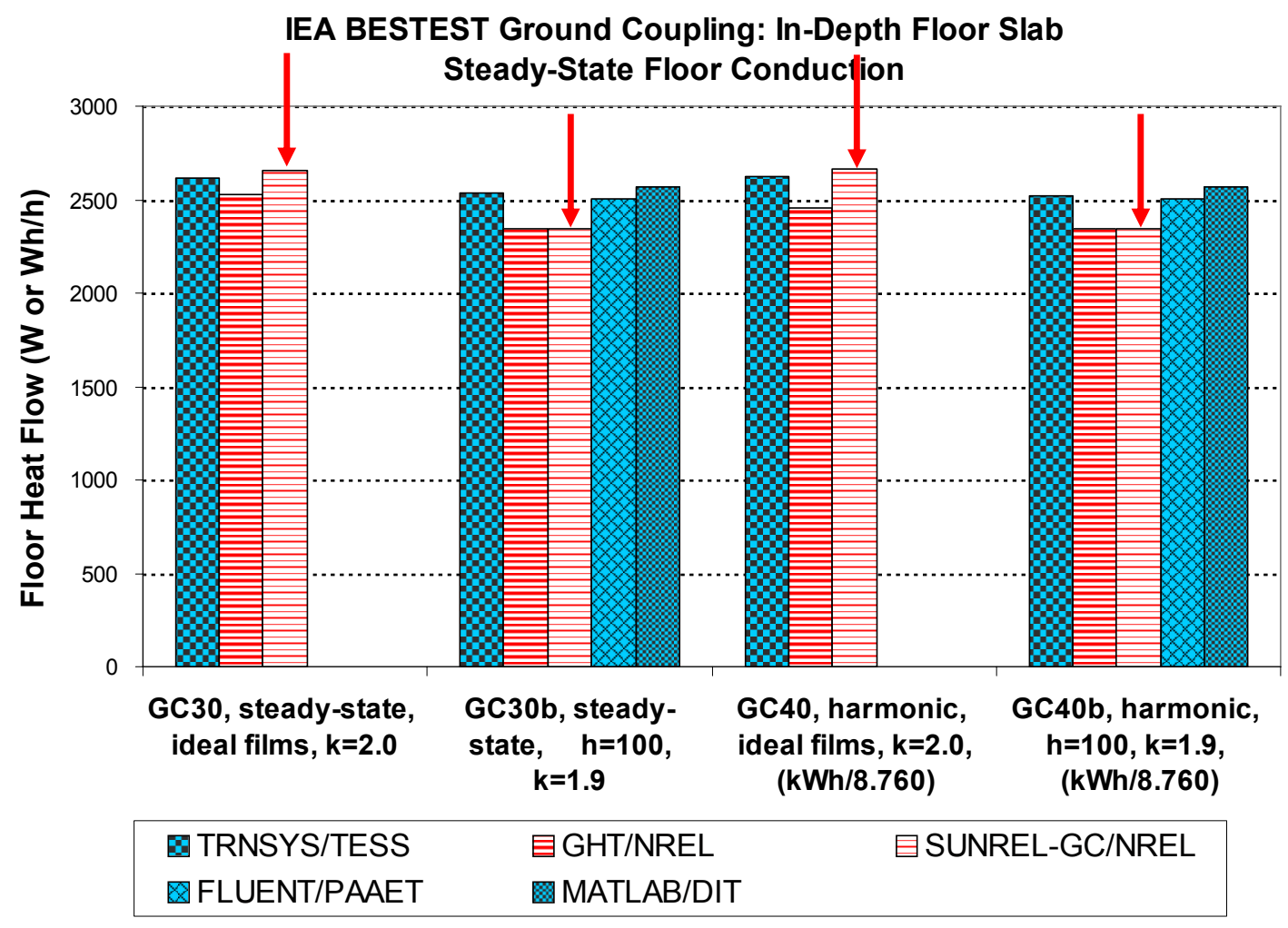

Figure 2-16. Selected floor conduction results for early versus later iterations of GHT and SUNREL-GC compared with other detailed numerical models

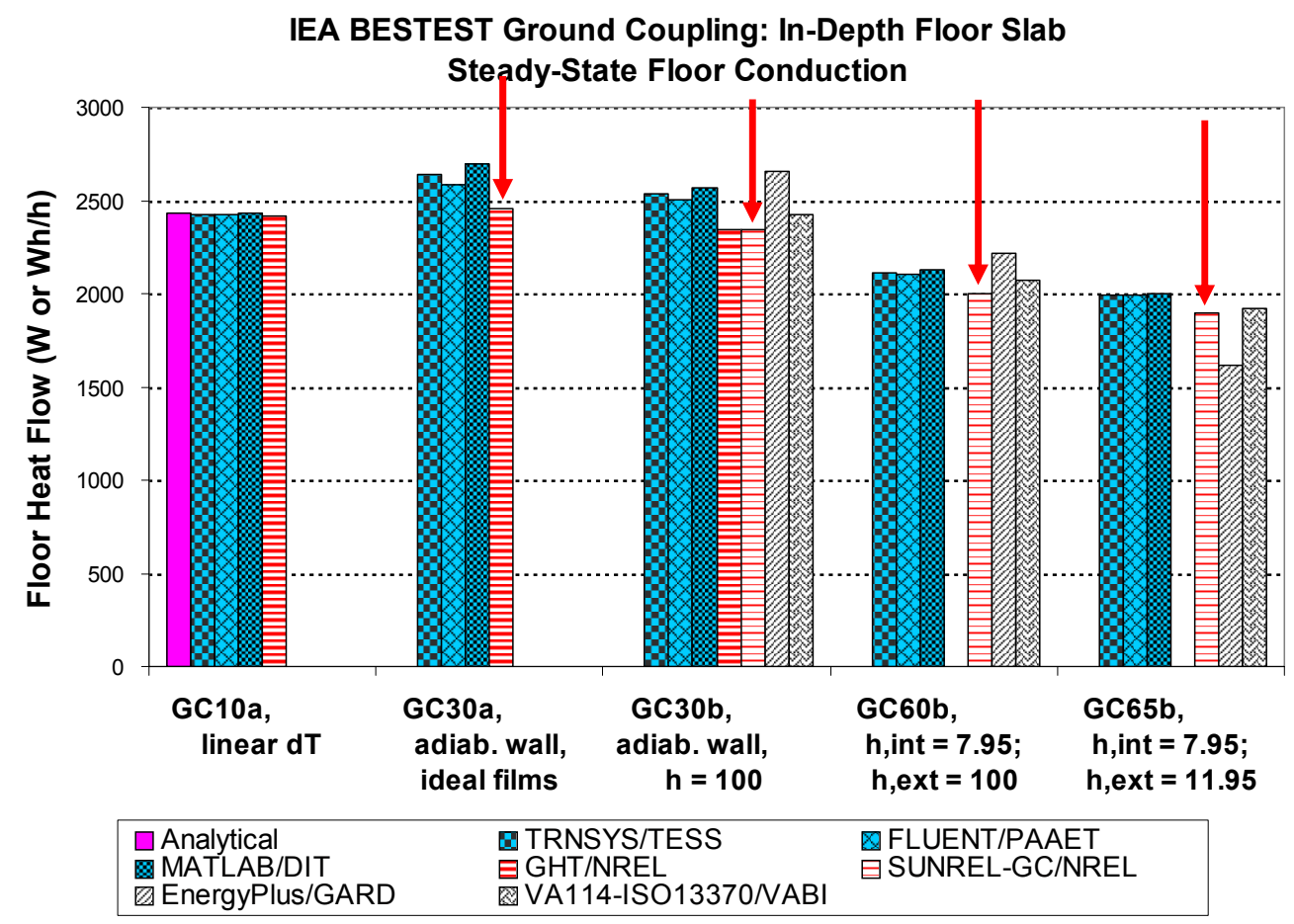

Figure 2-17. Floor conduction results for GHT/SUNREL-GC versus Other Models, Cases with Steady-State ODB 


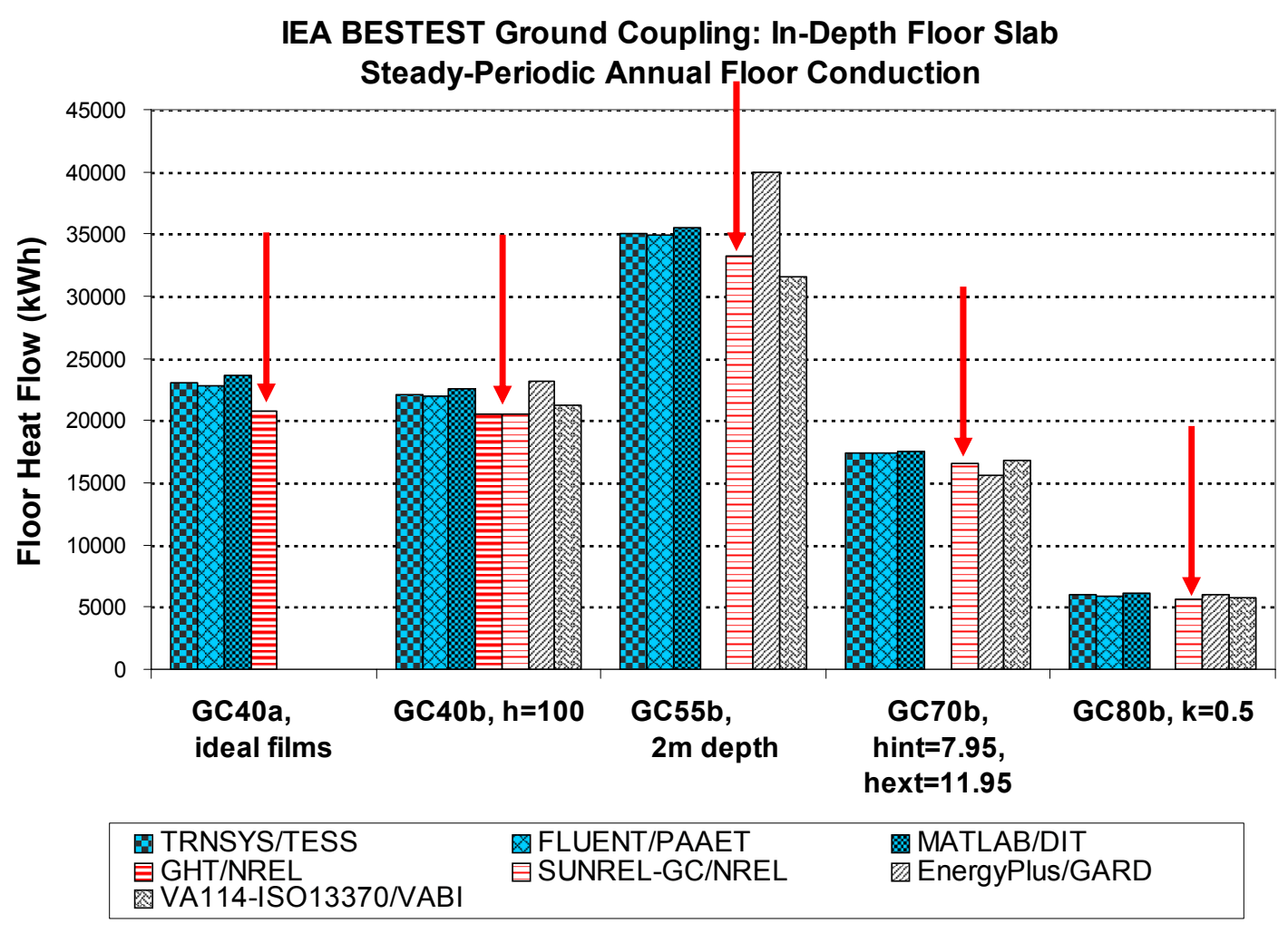

Figure 2-18. Floor conduction results for GHT/SUNREL-GC versus other models, cases with steady-periodic ODB

For diagnostic purposes GHT floor conduction differences versus the verified numerical-model results are further highlighted for the "a"-series cases in Figure 2-19. This figure shows that GHT has lower sensitivity $(1.5 \%)$ than the other models $(7 \%-10 \%)$ to varying the boundary condition from the linearly varying surface temperature of GC10a to the adiabatic surface of GC30a (see data labeled "GC30aGC10a"). Based on sensitivity tests by DIT using its MATLAB model (see Section 2.9 [DIT modeler report]), some of this difference may be attributable to node mesh density. However for the participant models, the finest node spacings are MATLAB $=0.9 \mathrm{~cm}$ (vertical), $1.5 \mathrm{~cm}$ (horizontal); TRNSYS $=2.5$ $\mathrm{cm}$; GHT $=3.5 \mathrm{~cm}$; and FLUENT $=6 \mathrm{~cm}$. As the node spacing for FLUENT is greater than that for GHT, coarse node spacing may not be the cause of the GHT "GC30a-GC10a" sensitivity difference, but is worth rechecking in the GHT model. Also in Figure 2-19, the difference for GHT between the annual average floor conduction of Case GC40a versus the steady-state conduction of Case GC30a (see data labeled "GC40a-GC30a") is greater than for the other models, where in this case a sensitivity equal to or near zero is expected. For the results shown the difference between the GC40a average value and the GC30a steady-state value is less than $0.6 \%$ for the verified numerical-model results (MATLAB's high mesh density models produced less than $0.01 \%$ variation), but is $3.3 \%$ for GHT. 


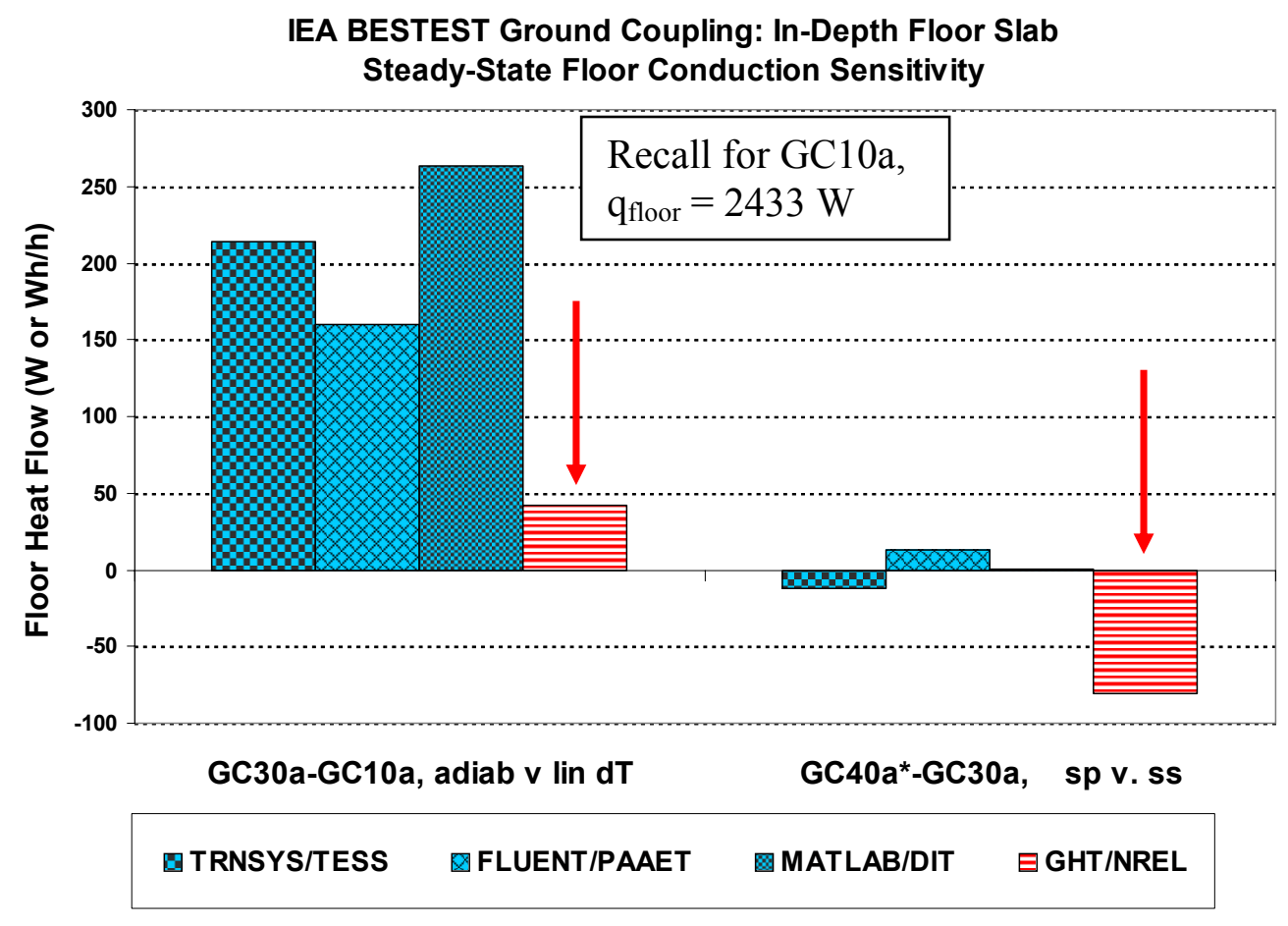

Figure 2-19. "a"-series floor conduction sensitivity results for GHT/SUNREL-GC versus verified numerical models

GHT also exhibits less sensitivity to variation of surface coefficients and soil conductivity than the verified numerical models, as shown in Figure 2-20 (see data labeled "GC40a-GC40b" and "GC40bGC70b" for heat transfer coefficient sensitivity, and "GC40b-GC80b" for soil conductivity sensitivity). Figure 2-21 shows results for phase shift between the hour with the coldest ambient temperature and the hour with the highest heating load, for the cases with steady-periodic temperature boundary conditions. Here disagreement for GHT versus the verified numerical models seems apparent in Case GC40a; GHT/SUNREL-GC results are within or near the range of disagreement among the verified numerical models for the "b"-series cases.

Given the agreement among the results for the TRNSYS, FLUENT, and MATLAB numerical models, and the rigorous effort to document improvements to those models when earlier disagreements were addressed, there are too many unaddressed disagreements for GHT/SUNREL-GC for this model to qualify as a quasi-analytical solution (verified numerical model). However, based on its model description, GHT/SUNREL-GC may have sufficient detail and flexibility to qualify as a quasi-analytical solution method if the software developer can address the disagreements.

The GHT/SUNREL-GC author has been notified of these issues. When diagnosing the source of these disagreements, the GHT/SUNREL-GC author should also consider early discussion about GHT's inability to model high convection coefficients greater than $100 \mathrm{~W} /\left(\mathrm{m}^{2} \cdot \mathrm{K}\right)($ Deru, Neymark, and Thornton 2005), which may be caused by GHT's explicit solution approach (where the temperature at any node at the current time step is a function of the temperature of the surrounding nodes at previous time steps). Also worth further considering is that SUNREL-GC had better agreement with TRNSYS-GC before changes described in Section 2.4.7.1 were made. 


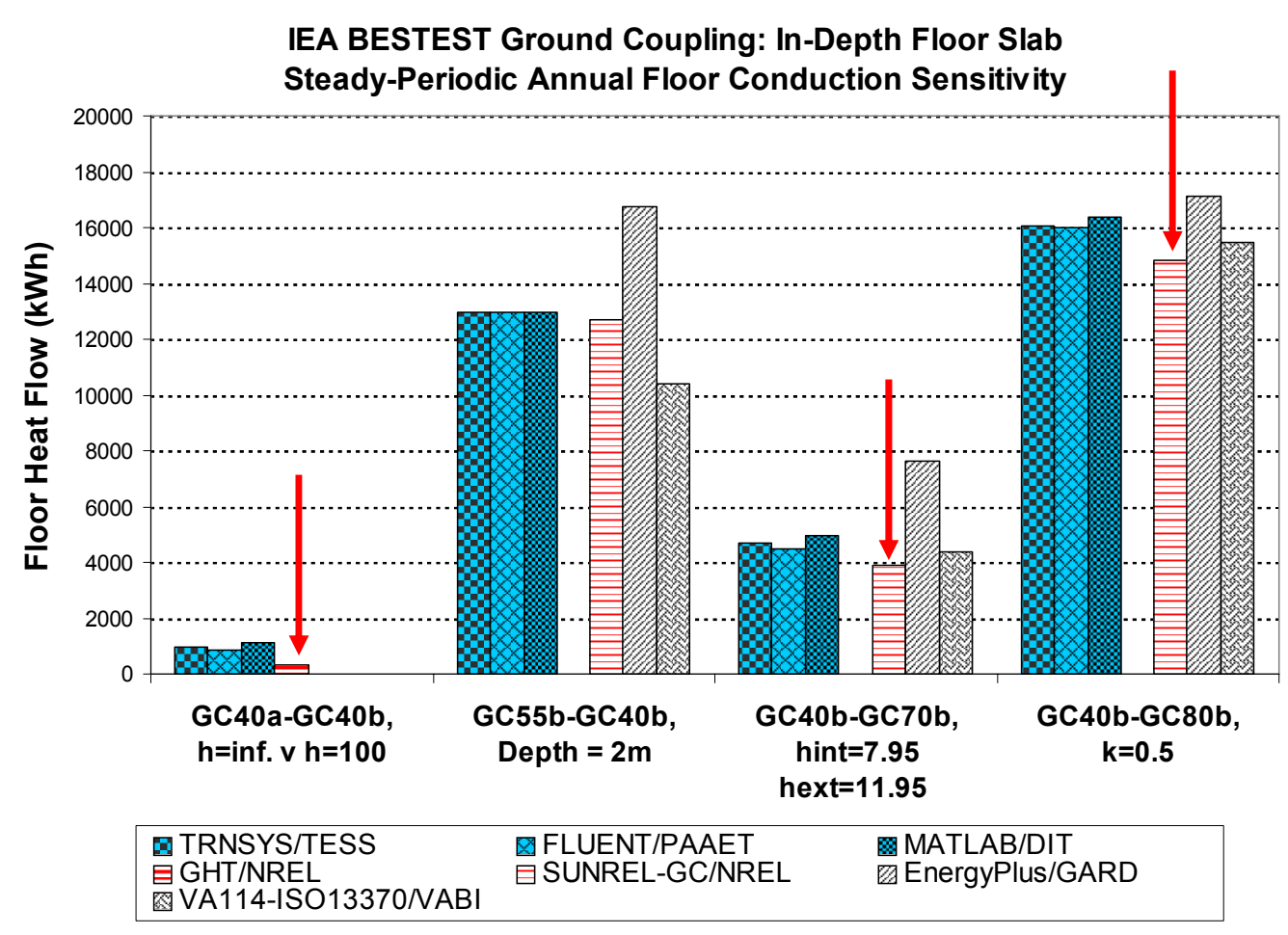

Figure 2-20. Results for "b"-series floor conduction sensitivity, GHT/SUNREL-GC versus other models

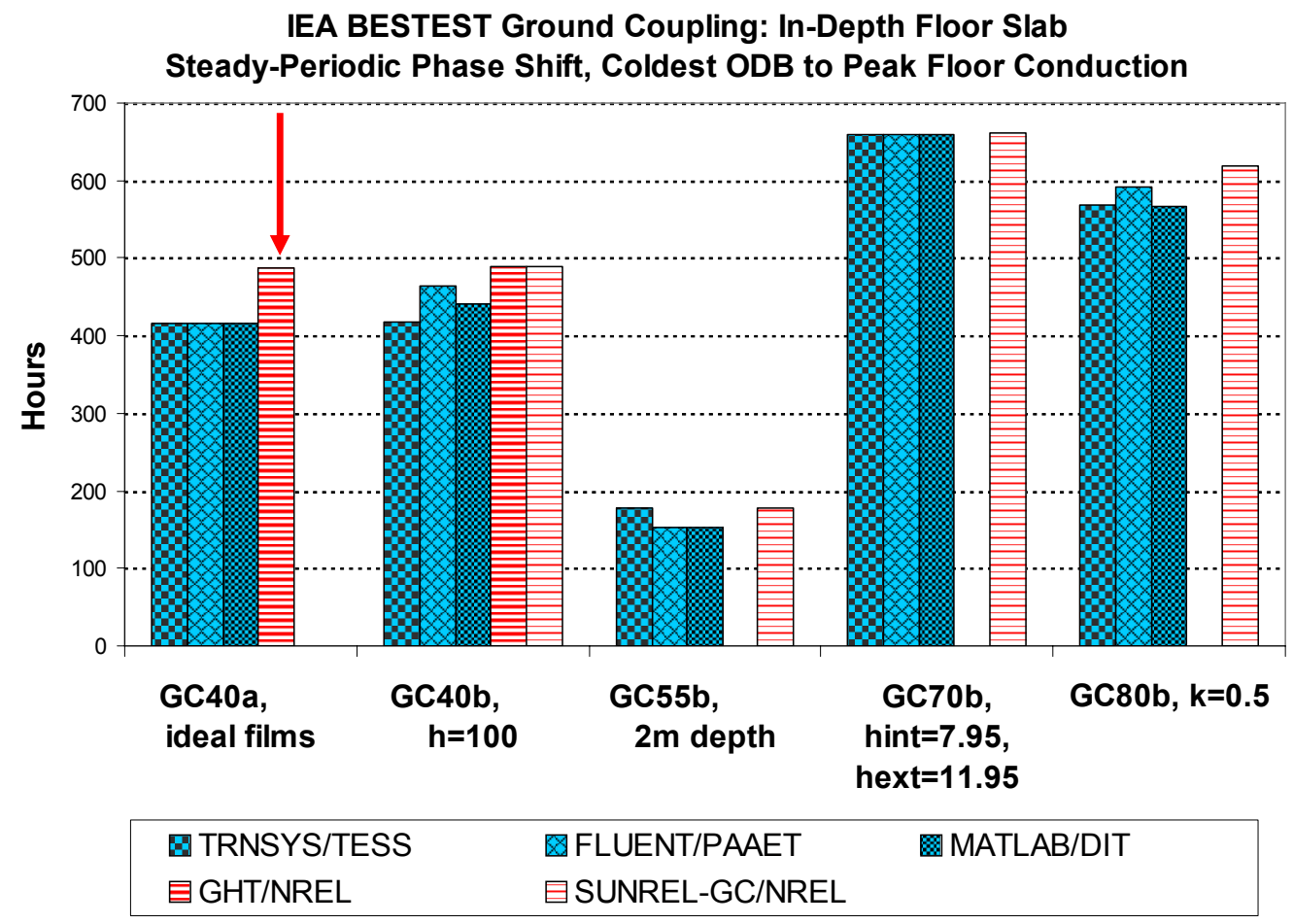

Figure 2-21. Steady-periodic phase shift for GHT/SUNREL-GC versus verified numerical models 


\subsection{Interpretation of Results}

\subsubsection{Developing a Secondary Mathematical Truth Standard Based on an Analytical Solution and Verified Numerical Models}

A major accomplishment of this work is the development of a set of quasi-analytical solutions using verified numerical-model results for all the test cases; this represents a secondary mathematical truth standard founded on the range of disagreement of the numerical-model results. Another major accomplishment is the development of a methodology for establishing such a secondary mathematical truth standard.

\subsubsection{Analytical Verification and Mathematical Truth Standards}

Analytical verification is where outputs from a program, subroutine, algorithm, or software object are compared to results from a known analytical solution, or to results from a set of closely agreeing quasianalytical solutions or verified numerical models. Here the term analytical solution is the mathematical solution of a model that has an exact result for a given set of parameters and simplifying assumptions. The term quasi-analytical solution is the mathematical solution of a model for a given set of parameters and simplifying assumptions, which may include minor interpretation differences that cause minor results variations; such a solution may be computed by generally accepted numerical methods or other means, provided that such calculations occur outside the environment of a whole-building energy simulation program and can be scrutinized. The term verified numerical model is a numerical model with solution accuracy verified by close agreement with an analytical solution and/or other quasi-analytical or numerical solutions, according to a process that demonstrates solution convergence in the space and time domains. Such numerical models may be verified by applying an initial comparison with an analytical solution, then compared with other numerical models for incrementally more realistic cases where analytical solutions are not available. (Also see the glossary of Part I, Appendix D, for definition of terms used here.)

In general, it is difficult to develop worthwhile test cases that can be solved analytically or quasianalytically, but such solutions are extremely useful when possible. An analytical solution provides an exact mathematical truth standard, limited to highly constrained cases for which exact analytical solutions can be derived. A secondary mathematical truth standard can be established based on the range of disagreement of a set of closely agreeing verified numerical models or other quasi-analytical solutions. Once verified against all available classical analytical solutions, and compared with each other for a number of other diagnostic test cases that do not have exact analytical solutions, the secondary mathematical truth standard can be used to test other models as implemented in whole-building simulation programs. Although an analytical solution provides the best possible mathematical truth standard, a secondary mathematical truth standard greatly enhances diagnostic capability for identifying software bugs and modeling errors relative to comparing simulation results to each other without a truth standard. This is because the range of disagreement among the results that comprise a secondary mathematical truth standard is typically much narrower than that among whole-building energy simulation results that may apply less rigorous modeling methods. The secondary mathematical truth standard also allows somewhat more realistic (less constrained) boundary conditions to be used in the test cases, extending the analytical verification method beyond the constraints inherent for classical analytical solutions.

In this work appropriate use of the numerical models is verified by comparing them with the Case GC10a analytical solution. Then the secondary mathematical truth standard is developed by carefully comparing the numerical-model results with each other as the cases progress toward more realistic conditions. For Case GC10a the underlying physical assumptions regarding the slab/ground geometry, thermal properties, 
and boundary conditions are specific to an idealized case for a rectangular floor geometry that has an exact steady-state analytical solution for 3-D heat flow (Delsante, Stokes, and Walsh 1983). The linearly varying perimeter floor surface temperature boundary condition for this case is not reproducible in simplified and mid-level detailed ground heat transfer models that are typically used with whole-building energy simulation software. However, Case GC10a serves as a mathematical truth standard for checking the proper implementation of numerical models that were used to develop a secondary mathematical truth standard for more realistic cases that are compatible with a greater variety of models.

The analytical solution used for Case GC10a was the only 3-D analytical solution with rectangular surface geometry we found. We investigated the possibility of finding or developing a comparable 3-D solution for a harmonic boundary condition. However, we did not find a ready-made solution, and several applied mathematicians advised that such a solution would be difficult, if not impossible, to derive.

\subsubsection{Methodology for Establishing a Secondary Mathematical Truth Standard}

The following methodology for verifying numerical models to develop a secondary mathematical truth standard facilitates extension of analytical verification techniques. The methodology applies to development of test cases and implementation of the numerical models. The logic for developing test cases may be summarized as follows:

- Identify or develop exact analytical solutions that may be used as a mathematical truth standard for testing detailed numerical models with parameters and simplifying assumptions of the analytical solution.

- Apply a numerical solution process that demonstrates convergence in the space and time domains for the analytical solution test cases and the additional test cases where numerical models are applied.

- Once validated against the analytical solutions, use the numerical models to develop reference results for test cases that progress toward more realistic (less idealized) conditions, and that do not have exact analytical solutions.

- Check the numerical models by carefully comparing their results to each other while developing the more realistic cases, and make corrections as needed.

- Good agreement for the set of numerical models versus the analytical solution - and versus each other for subsequent test cases - verifies them as a secondary mathematical truth standard based on the range of disagreement among their results.

- Use the verified numerical-model results as reference results for testing other models that have been incorporated into whole-building simulation computer programs.

Additional rules for developing and implementing analytical verification test cases - some of which generally apply for all test techniques - are:

- Make test cases as simple as possible, to minimize input errors.

- Make test cases as robust as possible, to maximize signal to noise ratio for a tested feature.

- Vary test cases incrementally - varying just a single parameter when possible - so disagreements among results can be quickly diagnosed.

- For numerical models, check sensitivity to spatial and temporal discretization, length of simulation, convergence tolerance, etc., and demonstrate that modeling is at a level of detail where including further detail yields negligible sensitivity to results; this work by the modelers is documented in the modeler reports included with Section 2.9.

- Use independently developed and implemented models, and revise the test specification as needed to accommodate various modeling approaches (including for less detailed models); this 
reduces bias by ensuring that the test specification clearly addresses different modeling approaches.

- For resolving disagreements among results that comprise a secondary truth standard, use an additional independent expert who is not directly involved in developing the results being compared.

- Corrections to models must have a mathematical and a physical basis and be consistently applied across all cases. Changing a model arbitrarily to better match the results from other models is not allowed.

This methodology was applied to extend the analytical solution based mathematical truth standard developed in Case GC10a for other cases that do not have exact analytical solutions. It allowed the participants to pinpoint relatively small errors in their models. This resulted in excellent agreement for annual and peak hour floor conduction (within $0.3 \%-4.2 \%$ for all cases) for three of the numerical models used in the study: FLUENT, MATLAB, and TRNSYS. This agreement is the basis of the secondary mathematical truth standard developed here. Such agreement also demonstrates that consistent and agreeing results are achievable by different modelers using different modeling tools, and that the test specification is clearly and consistently understandable to a variety of users. Furthermore, the use of more than two numerical models is better for diagnosing disagreements among the numerical models. If only two models are used, it may be difficult to identify which is causing the disagreement. For more than two models, if one disagrees with the others, an error likely lies with that model.

During the iterative process of developing the test specification and simulation results, we documented the following improvements to numerical models as part of the process of verifying them (Section 2.4 includes further details):

- TRNSYS: Initial improvement to automated node meshing algorithm resulted in a $10 \%$ increase in floor conduction for Case GC10a.

- TRNSYS: Second improvement to automated node meshing algorithm resulted in a $2 \%$ increase in floor conduction for Case GC10a.

- TRNSYS: Third improvement to automated node meshing algorithm resulted in a $0.4 \%$ increase in floor conduction for Case GC10a, and a 1-2\% increase in floor conduction for all other test cases.

- DIT/MATLAB: Improvement to slab edge modeling when convective boundary conditions are applied resulted in a $1 \%-4 \%$ decrease in floor conduction for steady-state cases GC $30 \mathrm{~b}, \mathrm{GC} 30 \mathrm{c}$, GC60b, and GC65b.

- DIT/MATLAB: Improvement to slab edge loss routine resulted in 0.3\% increase in GC30a floor conduction.

- DIT/MATLAB: Node temperature output interpolation issue was addressed to give more meaningful temperature results for layers near the slab and soil surfaces; this had no effect on floor conduction results.

- PAAET/FLUENT: Fixed modeling error resulting in a $0.7 \%$ increase in GC30b floor conduction.

These revisions - along with demonstration that modeling is at a level of detail where including further detail yields negligible sensitivity to results (provided in the modeler reports) - improved the quality of the numerical-model results and the related secondary mathematical truth standard that is based on the range of disagreement of the verified numerical-model (quasi-analytical solution) results. 


\subsubsection{Mathematical Truth Standard versus Absolute Truth Standard}

It is important to understand the difference between a mathematical truth standard and an absolute truth standard. In the former, we test the solution process for a model only, not for the appropriateness of the solution; that is, we accept the given underlying physical assumptions and recognize that these assumptions represent a simplification of physical reality. An approximate truth standard from an experiment tests the solution process and the appropriateness of the model within experimental uncertainty. The ultimate or absolute validation truth standard would be comparing simulation results with a perfectly performed empirical experiment, with all simulation inputs perfectly defined. In reality, an experiment is performed and the experimental object is specified within some acceptable range of uncertainty. Such experiments are possible, but expensive. We recommend developing a set of empirical validation experiments in the future.

For the results presented in Part III, the Case GC10a analytical solution represents a mathematical truth standard; for all other cases the verified numerical models represent a secondary mathematical truth standard.

\subsubsection{Comparing Typical Simulation Model Results to Verified Numerical-Model Results}

The tables and graphs of Part III present the final results from all the whole-building energy simulation programs, analytical solution, and verified numerical models applied in this study. Because the verified numerical-model results constitute a reliable set of theoretical results (a secondary mathematical truth standard) based on the underlying physical assumptions in the test case definitions, the primary purpose of including other simulation results for the "b"- and "c"- series cases in Part III is to allow simulationists to compare their relative agreement (or disagreement) versus the verified numerical-model results to that for other simulation results. Perfect agreement among simulations using simplified and mid-level detailed models versus verified numerical-model results is not necessarily expected. The Part III results indicate the sort of agreement that is possible between typical simulation results and the verified numerical-model results.

For simulation programs that can precisely model all the input assumptions of the test cases, a disagreement with the analytical solution results or verified numerical-model results indicates a coding error, questionable algorithm, documentation problem, input error, or a combination of such errors. Investigating the source of the error is strongly recommended.

Where simulation programs applying simplified and mid-level detailed models have results that disagree substantially with the analytical solution results or verified numerical-model results, investigating the sources of the differences is also recommended. In this case a difference does not necessarily mean that such a program or model is faulty, because differences among modeling techniques, boundary condition approximations, and other input assumptions may cause unavoidable differences among results. However, our collective experience in this task has indicated that when such programs show substantial disagreement with analytical solution results or verified numerical-model results, we often find a coding error, a questionable algorithm, a documentation problem, or an input error.

\subsubsection{Improvements to Simulations during the Field Trials}

Because of iterative correction of input errors, software bugs, and clarifications of the test specifications, the agreement among simulation results improved with each iteration of the field trials. Improvements to the simulation programs are evident when the initial results set - in Figure 2-22 for the steady-state cases and 
Figure 2-24 for the steady-periodic cases - is compared to the final results set in Figure 2-23 for the steady-state cases and Figure 2-25 for the steady-periodic cases. (In these figures verified numericalmodel results are shown with blue shaded background and the analytical solution result [Case GC10a] is shown with magenta background; abbreviations along the $\mathrm{x}$-axis are shorthand for the case descriptions given in Part I.) Improvements to simulation programs or simulation inputs made by participants were required to have a mathematical and a physical basis, and to be applied consistently across tests. Arbitrary modification of a simulation program's input or internal code to more closely match a given set of results was not allowed. All improvements were required to be documented in modeler reports.

Because a number of parameters for the final set of test cases varied substantially from the first round of test cases distributed in June 2004 (preliminary test cases without "a"-, "b"-, or "c"-series designations) see Section 2.3 - it was difficult to develop a direct comparison between cases for initial results that were submitted before the current test cases were developed in June 2005. Therefore, Figures 2-22 and 2-24 include some results that were determined based on estimates of what they would have been, had corrections not occurred during earlier test cases. We also included estimates for what selected initial results would have been before fixes were documented in preliminary IEA SHC Task 22 work (Deru, Judkoff, and Neymark 2003) that directly preceded this project. Estimates are based on examples of error trapping documented in Section 2.4. For Figures 2-22 and 2-24 initial results are included for each model as follows.

- TRNSYS: Initial results for Case GC10a were reduced based on Section 2.4.1.1, related to their earliest work with Case GC10. Results for remaining "a"- and "b"-series cases (except Case GC50b) were submitted after Case GC10 results, but still for the June 2004 cases; those results are reduced based on Section 2.4.1.2. Remaining results for "c"-series cases and Case GC50b were initially submitted for the June 2005 test cases; unadjusted initial results are included for those cases as they were submitted.

- PAAET/FLUENT: Results were initially submitted for cases GC10a and GC30a; results for $\mathrm{GC} 40 \mathrm{a}$ and $\mathrm{GC} 30 \mathrm{~b}$ were submitted soon afterward. PAAET found an error in its modeling for Case GC30b, which affected that case only (see Section 2.4.3.2). PAAET/FLUENT results submitted for the remaining cases, after fixing the Case GC30b error, were also the final results.

- DIT/MATLAB: Results were initially submitted for test cases GC10a, GC30a, and GC40a. Remaining steady-state case results were submitted in a later batch. Model improvements documented in Section 2.4.2 and node-meshing refinements documented in DIT's modeler report were then applied. MATLAB results submitted afterward for the remaining cases (and previously run cases) were also final results.

- GHT: Results were initially submitted for the preliminary (June 2004) cases, then submitted in June 2005 for the June 2005 test cases. As no model revisions were reported for GHT between these submittals, initial results for the current cases are included as submitted.

- SUNREL-GC: Results were initially submitted for the June 2004 test cases, and then submitted in June 2005 for the current test cases. For Figures 2-22 and 2-24, results for GC30a and GC40a were added and adjusted based on the model revision documented in Section 2.4.7.1 to show the earlier results disagreement versus GHT for preliminary cases GC30 and GC40. We showed this in the "a"-series context because preliminary cases GC30 and GC40 had slab and ground surface coefficients of $5000 \mathrm{~W} /\left(\mathrm{m}^{2} \cdot \mathrm{K}\right)$, which is similar to the specified constant surface temperature boundary conditions in current cases GC30a and GC40a. All other results are shown for the June 2005 cases as initially provided. 
IEA BESTEST Ground Coupling: In-Depth Floor Slab

Steady-State Floor Conduction

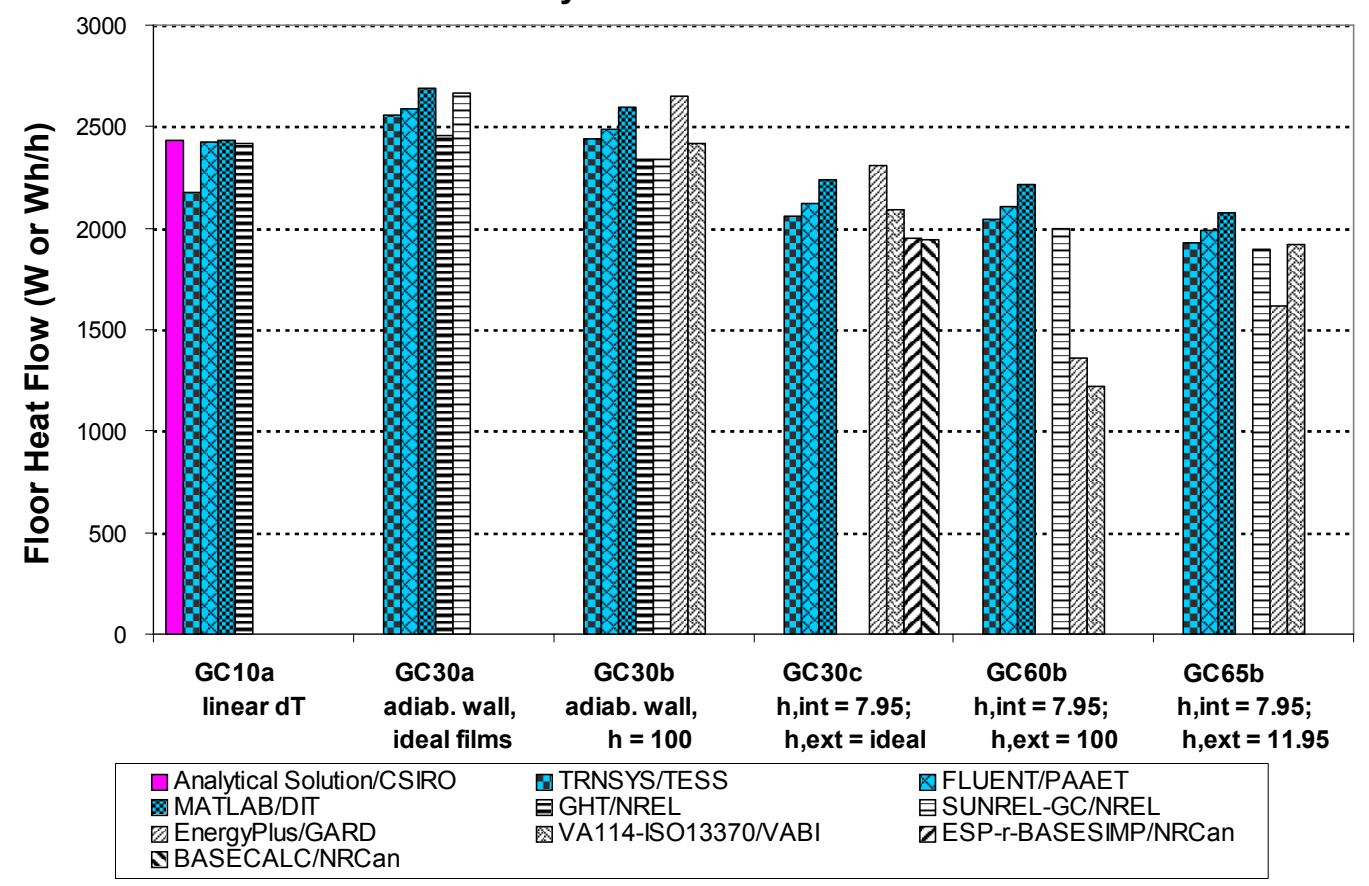

Figure 2-22. BESTEST slab/ground heat transfer steady-state cases - floor conduction, before BESTESTing

IEA BESTEST Ground Coupling: In-Depth Floor Slab Steady-State Floor Conduction

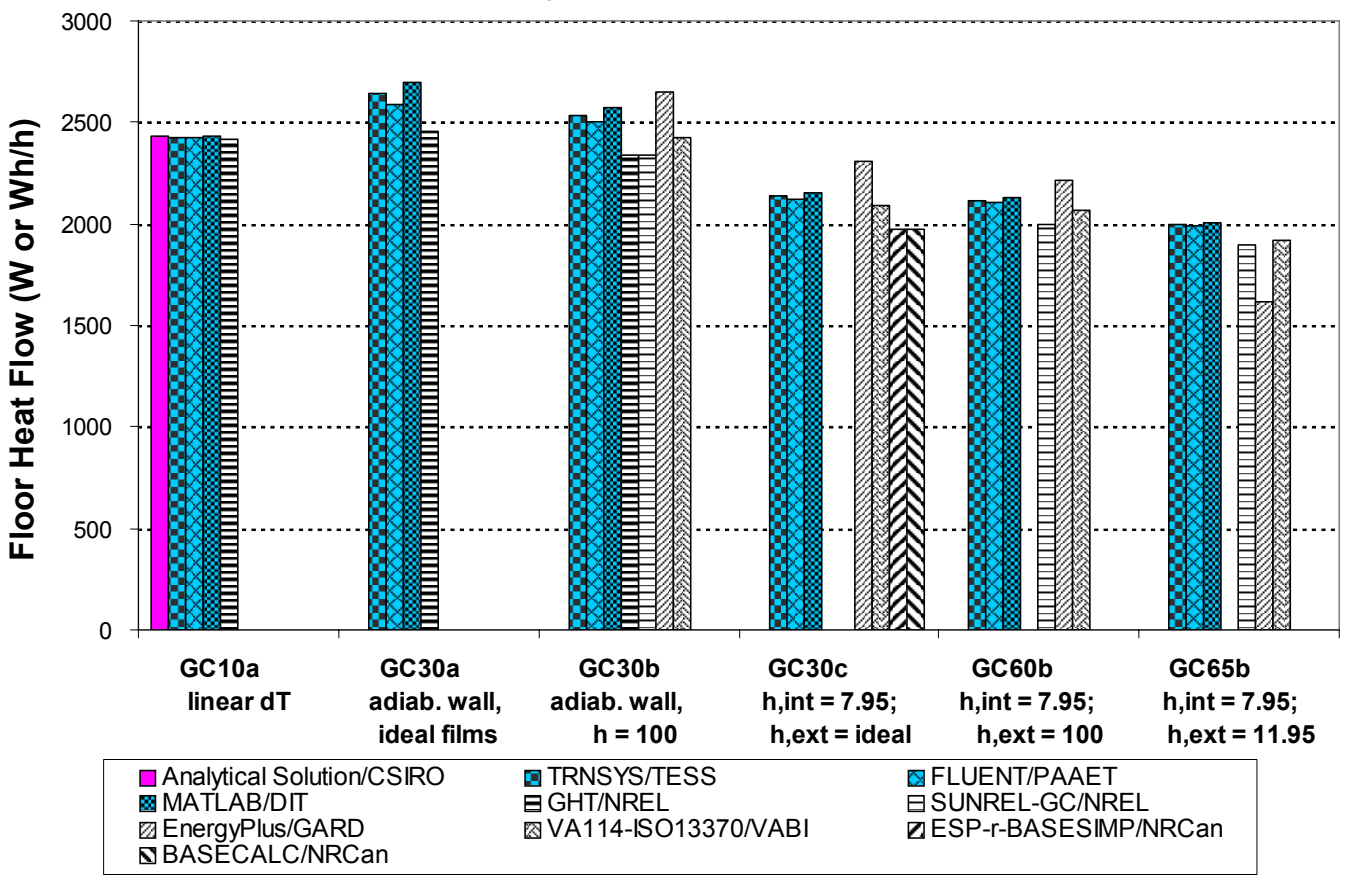

Figure 2-23. BESTEST slab/ground heat transfer steady-state cases - floor conduction, after BESTESTing 


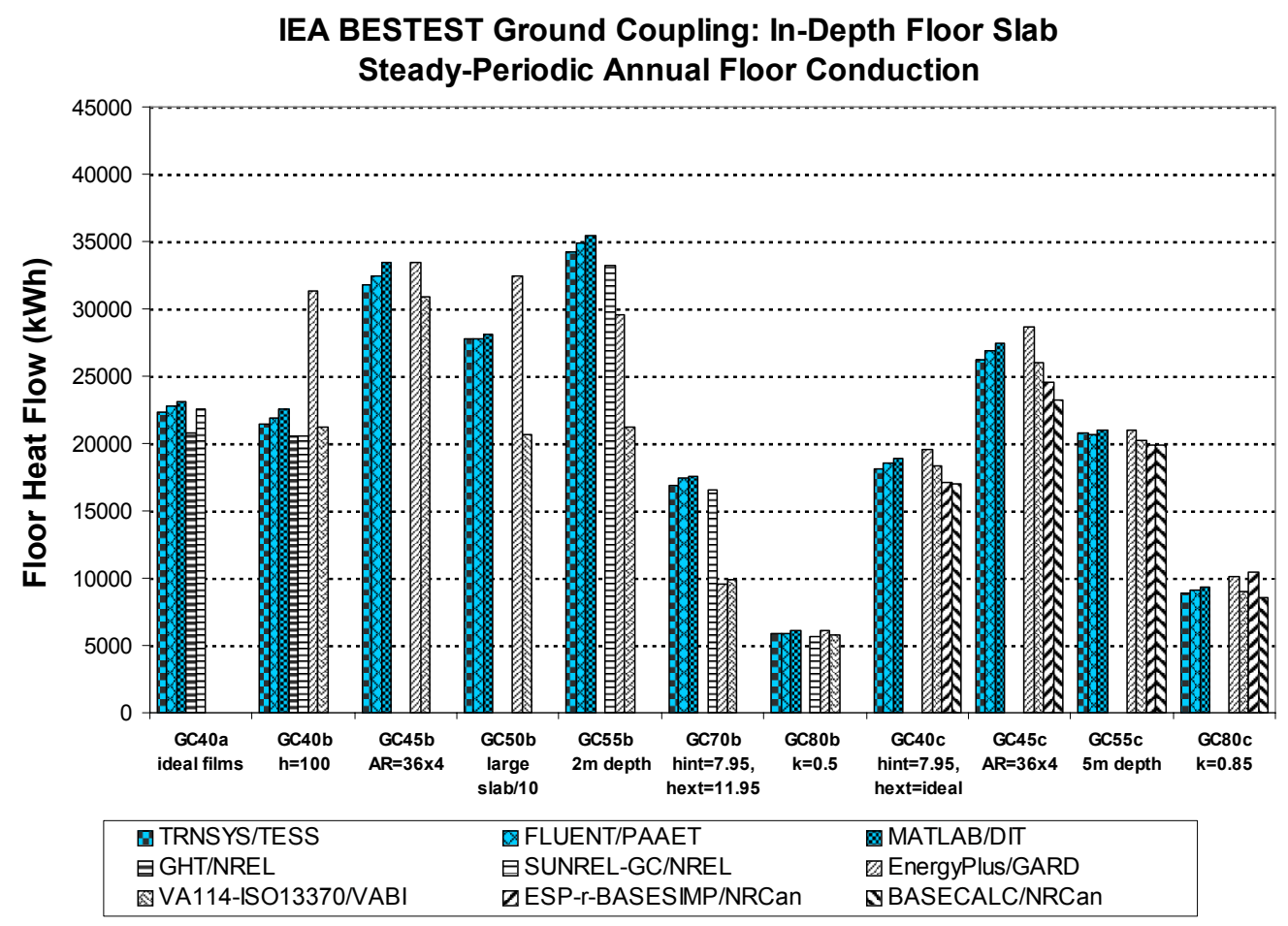

Figure 2-24. BESTEST slab/ground heat transfer steady-periodic cases - floor conduction, before BESTESTing

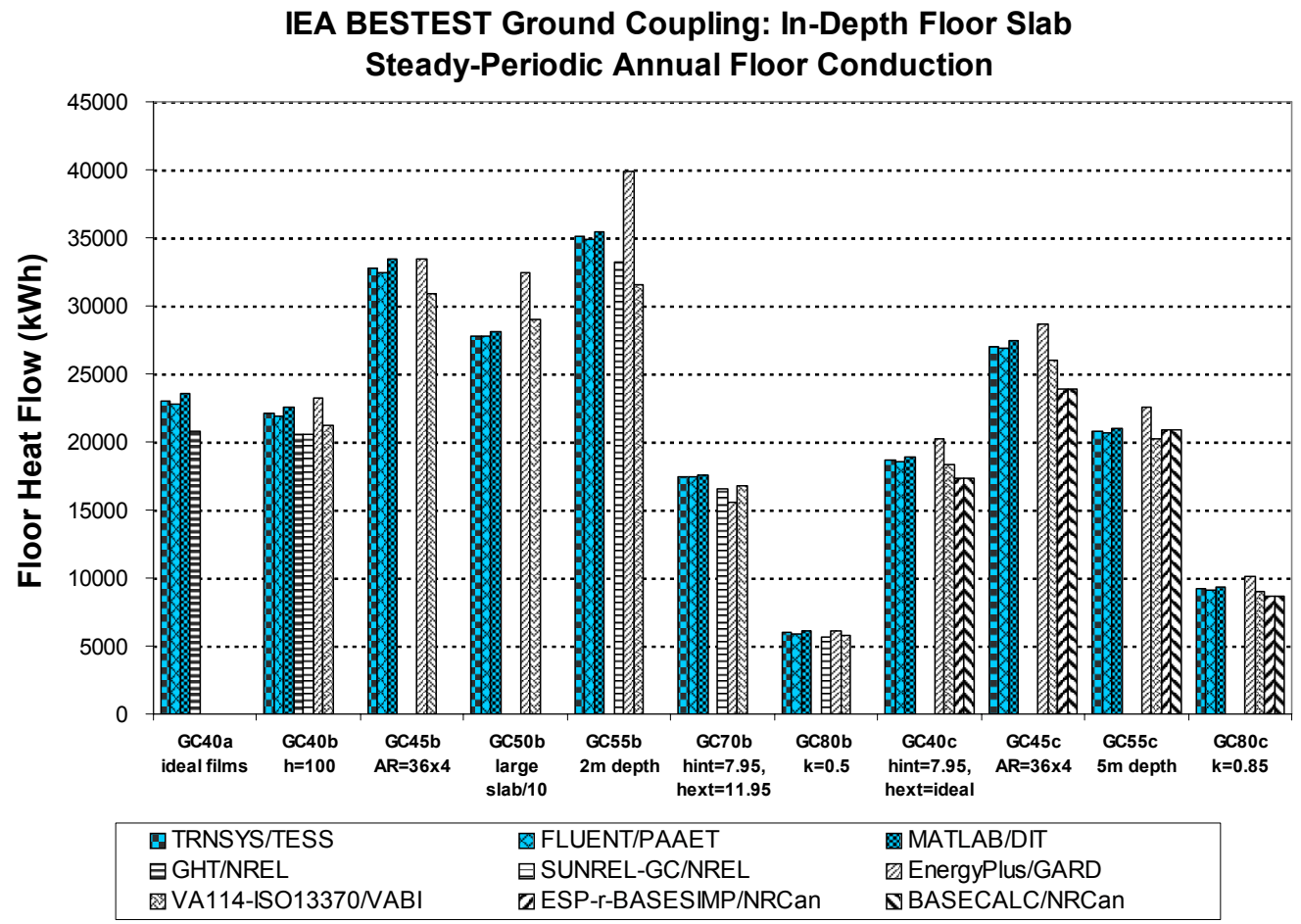

Figure 2-25. BESTEST slab/ground heat transfer steady-periodic cases - floor conduction, after BESTESTing 
- EnergyPlus: As documented in Section 2.4.4.1, EnergyPlus was modified during the preliminary IEA SHC Task 22 test cases to allow user input of interior surface coefficient adjacent to the floor slab. To estimate the EnergyPlus results before this fix, we reduced the initially submitted results for the June 2005 test cases by 63\% per Section 2.4.4.1 for a steady-state and a steady-periodic case with realistic interior surface coefficients (GC60b and GC70b, respectively). For this IEA34/43 project, EnergyPlus results were initially submitted for the June 2004 test cases, then submitted in June 2005 for the June 2005 test cases. Some early improvements to software to facilitate running the in-depth cases (see Section 2.4.4) indicated no or likely minor undetermined effects on results. Therefore, the June 2005 results are shown as they were submitted, except for the following adjustments to estimate results before improvements were made to the EnergyPlus model and an input error was corrected. The Case GC40b result was increased based on Section 2.4.4.5; the Case GC55b result was decreased based on Section 2.4.4.6; results for cases GC40c and GC55c were decreased based on Section 2.4.4.4; results for cases GC60b and GC70b were reduced based on Section 2.4.4.1.

- VA114: Results for this project were initially submitted for the June 2005 cases beginning in January 2006, after the code authors had begun adapting the ISO 13370 European standard ground heat transfer calculation method to VA114. As documented in Section 2.4.5.1, the adaptation of the ISO calculation was initiated because of large disagreements for the preliminary IEA SHC Task 22 tests. To estimate the VA114 results before ISO 13370 was adapted, initially submitted results were reduced by $70 \%$ per Section 2.4.5.1 for a steady-state and a steadyperiodic case with realistic interior surface coefficients (GC60b and GC70b, respectively). All other VA114 results are presented as initially submitted.

- ESP-r/BASESIMP and BASECALC: Results were initially submitted for the June 2004 cases. However, too many of the specified boundary conditions could not be matched with these programs, so the June 2005 cases included "c"-series cases that specifically match those boundary conditions, as discussed in Section 2.3. As it was unclear how to convert preliminary results for Case GC30 to initial results for GC30c and NRCan's modeler report does not indicate any software revisions were made based on preliminary results, the initially provided "c"-series results are presented as submitted.

The results shown in Figures 2-22 and 2-24 indicate that there was initially a 9\%-55\% and 10\%-55\% disagreement among the steady-state and steady-periodic cases, respectively, for the floor conduction results, and that there was substantial scatter among initial program results for cases with shallow water table depth (GC55b) and large slab area (GC50b), and for case results that emphasize errors uncovered during the Task 22 cases (GC60b and GC70b). Here, disagreement is the difference between the maximum and minimum result for each case, divided by the mean of the results for each case ((max$\min ) /$ mean).

Figures 2-23 and 2-25 show that after correcting software errors with BESTEST diagnostics, the remaining disagreements among all results for steady-state and steady-periodic floor conduction are 1\%$16 \%$ and $7 \%-24 \%$, respectively, with reduced scatter throughout. Agreement is also improved among the detailed numerical models, where disagreement ranges up to $12 \%$ were reduced to $0 \%-4 \%$ over the course of the project. This shows how the BESTEST method is used to diagnose and correct faulty algorithms in complex simulation programs.

Regarding parametric sensitivities in the final results, the sensitivity to reducing interior surface heat transfer coefficient is substantial (see results for steady-state cases GC30b and GC60b in Figure 2-23). This is because a bare slab floor is specified for the test cases, so the interior surface heat transfer coefficient is effectively the primary insulation layer between the conditioned zone and all the floor slab and adjacent ground. Placing a carpet on the slab surface would be expected to reduce the sensitivity to interior surface coefficient somewhat. However, even with a carpet the amount of insulation between 
conditioned zone air and the slab would be low, so the sensitivity underscores the importance of applying accurate interior surface coefficients when modeling ground-coupled heat transfer. Presumably the same is true for the exterior surface coefficient, although for this work varying it after varying the interior surface coefficient has likely obscured some of its significance (see GC65b versus GC60b in Figure 2-23) because overall thermal resistance was increased when interior surface coefficient was decreased for Case GC60b.

Final ranges of disagreement are summarized in Table 2-7 for predictions of various outputs. The outputs are disaggregated for Case GC10a, the other steady-state cases (GC30a, GC30b, GC30c, GC60b, GC65b), and the steady-periodic cases (GC40a through GC80c, excluding GC60b and GC65b). Results are also disaggregated for the verified numerical-model results and the other simulation results. The results indicate very good agreement for the verified numerical-model results, within $5 \%$ for floor conduction in all cases. Disagreement of other simulation results using mid-level detailed models are up to $24 \%$, which may be reasonable given the complexity of the modeling problem. The range of disagreement for peak loads differs little from that for annual loads, which is expected because solar gains are excluded from the test cases. The greatest range of annual floor conduction disagreement occurred for Case GC55b, which has the shallowest $(2 \mathrm{~m}$ ) deep ground temperature (or water table) depth and therefore the largest ratio of core-to-perimeter (deep ground temperature to air temperature) driven heat flow. Remaining disagreement issues for individual results are discussed in Section 2.4.

Table 2-7. Ranges of Disagreement among Simulation Results

\begin{tabular}{||l|l|l||}
\hline Output & $\begin{array}{l}\text { Verified Numerical } \\
\text { Models }\end{array}$ & Other Simulations \\
\hline $\begin{array}{l}\text { Case GC10a, Steady-State Floor } \\
\text { Conduction (W or Wh/h) }\end{array}$ & $0.3 \%$ & $0.5 \%$ (GHT only) \\
\hline $\begin{array}{l}\text { Steady-State Floor Conduction, } \\
\text { Other Cases (W or Wh/h) }\end{array}$ & $0.7 \%-4.2 \%$ & $10 \%-16 \%$ \\
\hline $\begin{array}{l}\text { Annual Steady-Periodic Floor } \\
\text { Conduction (kWh/y) }\end{array}$ & $0.9 \%-3.5 \%$ & $7 \%-24 \%$ \\
\hline $\begin{array}{l}\text { Steady-Periodic Annual Peak Hour } \\
\text { Floor Conduction (W or Wh/h) }\end{array}$ & $1.0 \%-4.2 \%$ & $2 \%-18 \%$ \\
\hline
\end{tabular}

Although disagreement among the verified numerical models is low for all cases, it disagreement is lower for Case GC10a than for cases where a mathematically derived closed-form analytical solution was not available. The reason for this is unclear, but could be the result of minor differences in node meshing schemes resulting from different soil domains modeled in GC10a versus the other cases. Anyhow, this agreement drift underscores the importance of using analytical solutions when available, and deriving new ones when possible.

Based on results after several iterations of BESTESTing, and resulting model improvements, all the tested programs now appear to be generally reliable for modeling ground-coupled heat transfer related to slabon-grade construction, although remaining disagreements for specific models noted in Section 2.4 should be addressed. The verified numerical-model results may be used as a reference or benchmark against which other software can be tested. For applications where ground-coupled heat transfer is a major 
component of a given simulation problem, the superior accuracy of the verified numerical models may justify adapting highly detailed models to more whole-building energy simulation programs, especially as computer hardware continues to improve and the detailed models become more user friendly.

\subsubsection{Test Cases for Future Work}

We suggest that additional work related to model testing and validation, outlined in the sections that follow, be considered.

\subsubsection{Additional Ground-Coupled Heat Transfer Cases}

This project developed a set of idealized in-depth diagnostic test cases for ground-coupled floor slab heat transfer models. The test cases allow comparison of models typically used with whole-building energy simulation programs to quasi-analytical solutions developed with state-of-the-art detailed 3-D numerical models. The test cases use an idealized uninsulated slab-in-grade configuration (see Figure 2-26). This simplified configuration is consistent with the analytical solution test case, is appropriate for developing robust ground-coupling test cases, is compatible with all the tested programs, and has facilitated the development of accurate detailed 3-D numerical-model results by minimizing chances for input errors that could occur with more detailed realistic geometry. The current cases provide the foundation for developing a numerical-model based secondary mathematical truth standard by transitioning from an analytically solvable case (GC10a) to other in-depth diagnostic cases that provide robust parametric sensitivity tests, using boundary conditions that are more typically applied by whole-building energy simulation programs. During this project, participants discussed other important test case configurations that could not be included with the current test cases because of resource constraints. These additional test cases would include:

- A more realistic slab-on-grade configuration and realistic above-grade wall construction (see Figure 2-27)

- Slab material properties different from soil properties

- Realistic full-year site weather data (e.g., TMY2), including robust climate sensitivity tests

- Insulated cases that test horizontal and vertical insulation configurations (see Figure 2-27), and test sensitivity to variation of vertical depth, horizontal width, and insulation thickness

- Other parametric sensitivity tests in a more realistic context, including variation of soil conductivity, slab aspect ratio, slab area, and water table depth

- Maximized robustness of sensitivity tests within realistic construction extremes

- Heated slab floors, having heating elements within or beneath the slab - the previously developed RADTEST (Achermann and Zweifel 2003) addresses radiant heating test cases, but does not address the ground-coupled heat transfer interaction

- Similar in-depth diagnostic and realistic cases for basement constructions.

A secondary mathematical truth standard enhances the ability to identify (and therefore diagnose) disagreements that may occur for tested simulation models. To facilitate continued use of numerical models for extending the set of results that may be used as a secondary mathematical truth standard, the following constraints would be applied to new in-depth test cases as appropriate:

- The above-grade zone is adiabatic, except for the above-grade wall extended to a limited height above the floor slab.

- Solar gains are excluded.

- IR radiation exchange is suppressed.

- Parametric variations are applied incrementally - both within the new test cases, and to transition from current test cases to new cases. 


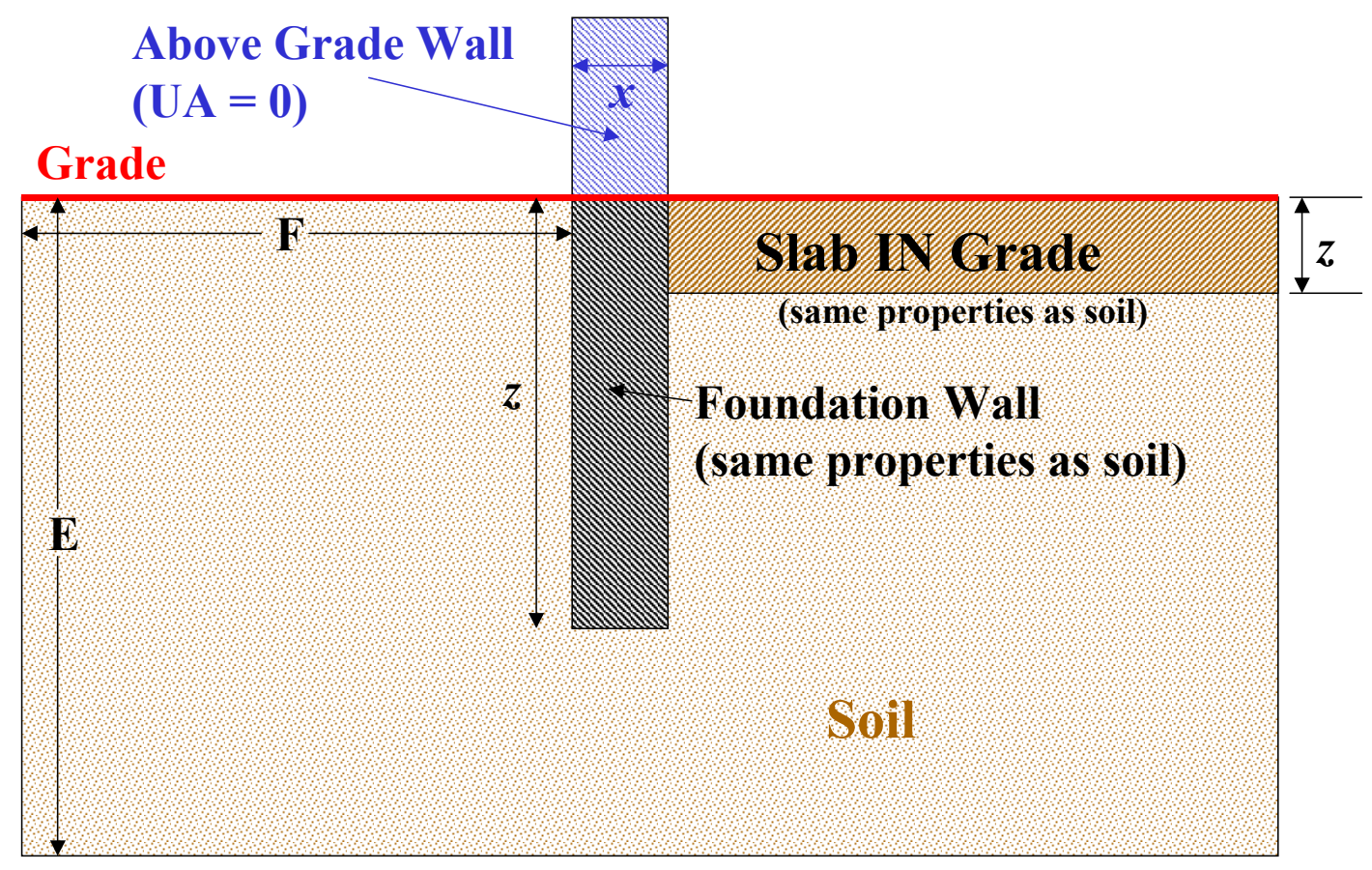

Figure 2-26. Current slab-in-grade configuration

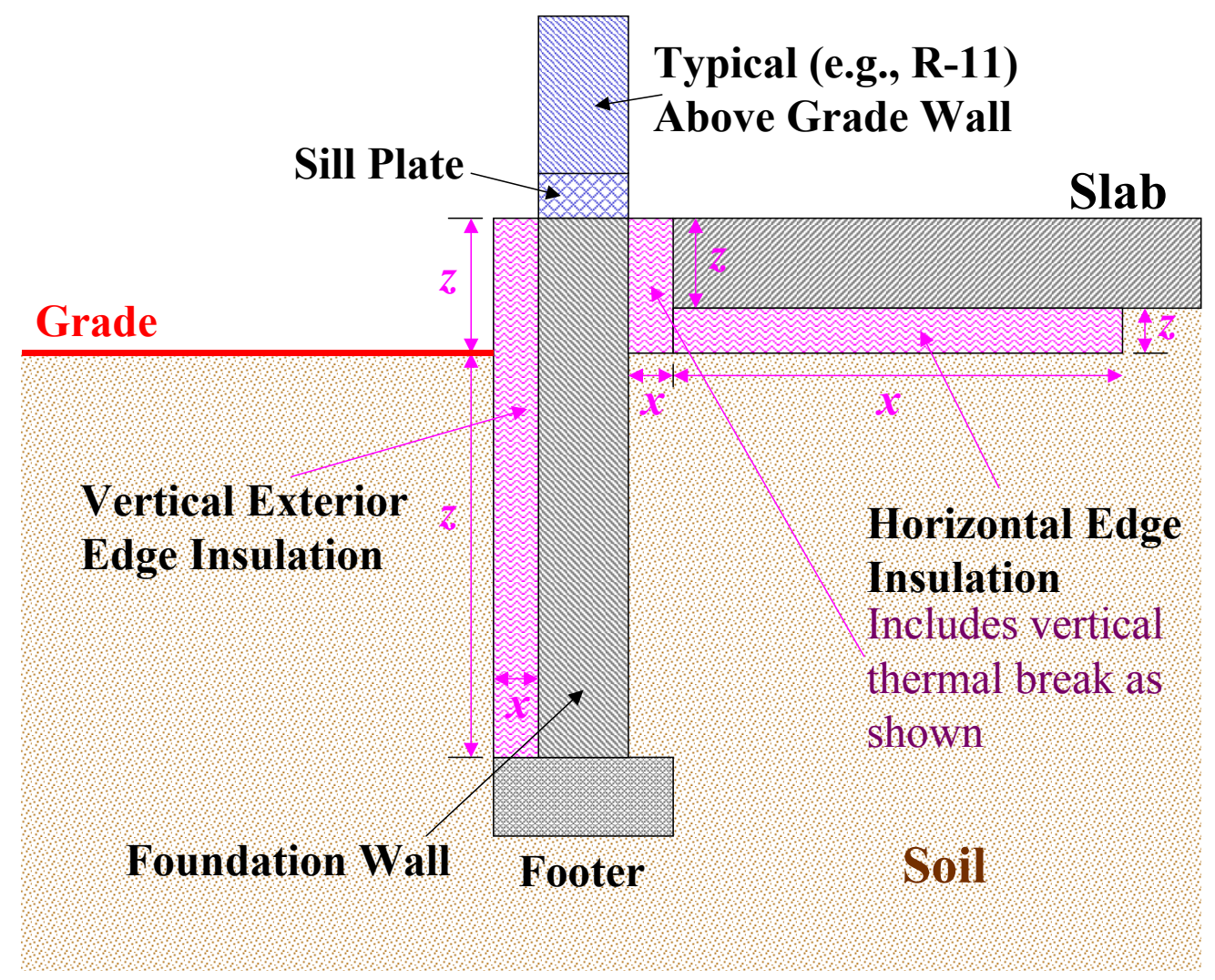

Figure 2-27. Slab-on-grade configuration for proposed additional test cases 
The ultimate goal of new test case development is to transition back to a more realistic set of test cases such as an updated version of the previous IEA SHC Task 22 ground-coupled heat transfer test cases (Deru, Judkoff, and Neymark 2003). These final cases would couple a realistic above-grade building construction with a realistic ground-coupled surface construction to test:

- Effects of solar radiation on ground-coupled surfaces

- Effects of IR radiation exchange on ground-coupled surfaces

- Effects of calculated versus constant heat transfer coefficients

- Interaction of floor slab thermal mass with dead-band and setback thermostat control

- Walkout basement construction

- Seasonally (or more frequently) varying soil properties and evapotranspiration, if enough models consider this.

The final revised set of realistic test cases would also include results for detailed numerical models integrated with whole-building simulation programs where possible - e.g., the detailed models included with TRNSYS and SUNREL-GC can be readily integrated with their respective main programs. This would allow for continued use of detailed models that were tested for accuracy in preceding cases. Such detailed models could also be applied to the four realistic - but only coarsely diagnostic - slab and basement simplified model test cases included with HERS BESTEST (Judkoff and Neymark 1995b), for comparison with results of simplified models. However, such comparisons would require documenting detailed modeling assumptions that are not included in HERS BESTEST.

The current "c"-series test cases provide examples of cases that were developed to conform with the constraints of specific models. Where there is a sufficient need and interest, additional test cases can be developed that are tailored to the constraints of other specific models. The need for such test cases could occur, for example, where a simplified model that has not been subjected to rigorous accuracy tests forms the basis of a codified standard calculation method. In general, it would be best for model authors to emphasize developing detailed, flexible ground-coupling models that can employ a great variety of realistic building configurations and parametric assumptions related to ground heat transfer.

The 3-D analytical solution applying the rectangular steady-state boundary conditions of Case GC10a allowed us to establish a robust foundation for extension of that mathematical truth standard to other test cases by using a secondary mathematical truth standard that was developed with verified numerical models. The utility of this steady-state analytical solution generated interest in trying to find an analytical solution for a similar 3-D rectangular geometry problem with harmonic boundary conditions. A search for such a solution by one project participant was not successful (Crowley 2007). Given the ability to verify results of TRNSYS, FLUENT, and MATLAB within a narrow $(0.3 \%-4.2 \%)$ range of disagreement for the current in-depth test cases, the urgency of obtaining additional analytical solutions was reduced. However, Table 2-7 does indicate increased disagreement among the verified numerical models for cases without analytical solutions, which underscores the importance of using analytical solutions when available. To establish an additional analytical solution as a further fundamental basis for verifying numerical-model results, it is worthwhile to consider additional research, perhaps through ASHRAE, to develop a solution for rectangular 3-D geometry with harmonic boundary conditions.

\subsubsection{Additional Building Thermal Fabric and Mechanical Equipment Test Cases}

Additional building thermal fabric and mechanical equipment model test cases for consideration to be developed in the future are summarized in HVAC BESTEST Volume 2 (Neymark and Judkoff 2004; Section 2.5.2). 


\subsection{Conclusions and Recommendations}

\subsubsection{Conclusions}

\subsubsection{Major Accomplishments}

The major accomplishments of this project were:

- The IEA BESTEST building thermal fabric envelope tests were expanded to include in-depth diagnostic analytical verification test cases for ground-coupled heat transfer related to slab-ongrade construction.

- A formal methodology was developed to facilitate using and verifying numerical models to establish a secondary mathematical truth standard; this method applies to the test case developement and to numerical model implementation, and allows quasi-analytical solutions to be developed for more realistic (less constrained) cases than exact analytical solutions allow.

- A set of verified numerical-model results was developed for all test cases, using the newly developed methodology; this represents a secondary mathematical truth standard founded on the range of disagreement of the numerical-model results.

- The accuracy of all models that participated in the field trials of the test cases was improved: 19 errors were diagnosed and fixed; initial disagreement ranges of $9 \%-55 \%$ for the test cases were reduced to $1 \%-24 \%$ by applying the diagnostic logic of the test cases to expose problems with the models; initial disagreement ranges for only the numerical models were narrower (up to $12 \%$ ), and were similarly reduced to $0 \%-4 \%$ for the verified numerical-model results over the course of the project.

With respect to the value of the test cases to software developers, one software developer/vendor participant made the following comment about this project:

Without this IEA subtask for ground coupling, we would have had no means to check the results from our model, nor had a reason to make improvements to our model. There should be no question that the IEA subtask has improved the TRNSYS ground coupling model and, in doing so, has also provided energy modelers a greatly increased sense of confidence when modeling heat transfer to the ground (Thornton 2007b).

\subsubsection{Summary of Findings}

Test cases for in-depth diagnosis of ground-coupled heat transfer related to uninsulated slab-on-grade construction have been added to the IEA's method for systematically comparing whole-building energy software and determining the algorithms responsible for prediction differences. The new test cases use an idealized uninsulated slab-in-grade configuration. This simplified configuration is required by the analytical solution case, is appropriate for developing robust ground-coupling cases, is compatible with all the tested programs, and facilitated the development of accurate model results by minimizing chances for input errors. These cases, as they step away from the analytical solution, also test parametric sensitivities to variation of floor-slab aspect ratio, slab area, water table depth (constant deep ground temperature depth), slab-interior and ground-exterior surface heat transfer coefficients, and slab and ground thermal conductivity.

This project developed an important methodological advance to extend the analytical verification method beyond the constraints inherent in classical analytical solutions. It allows a secondary mathematical truth standard to be developed in the form of a set of stand-alone detailed numerical models (quasi-analytical 
solutions). Once verified against all available classical analytical solutions and compared with each other for cases that do not have exact analytical solutions, the set of verified numerical models can be used together to test other models as implemented in whole-building simulation programs. This allows for greatly enhanced diagnostic capability versus the purely comparative method, and allows somewhat more realistic boundary conditions to be used in the test cases than are possible with pure analytical solutions.

This work applied an analytical solution result (Case GC10a) as a mathematical truth standard, and developed verified numerical-model results as a secondary mathematical truth standard for all test cases. The final range of disagreement among the verified numerical-model results is much narrower than that among the other simulation results, which improved the diagnostic capability of the cases. Therefore, where there is a disagreeing simulation result for a given test, there is a much stronger possibility of an algorithmic problem, coding error, or input error than when results are compared only with other simulation programs.

The procedure has been field-tested with a number of building energy simulation programs from around the world. The method has proven effective at isolating the sources of predictive differences. The diagnostic procedures revealed bugs, faulty algorithms, limitations, and input errors in all simulation models tested in this study. This includes the three detailed 3-D numerical models that were verified as quasi-analytical solutions - TRNSYS, DIT's model using MATLAB, and PAAET's model using FLUENT - along with the other tested simulation programs - BASECALC, BASESIMP, EnergyPlus, GHT/SUNREL-GC, and VA114 (which adapted the ISO-13370 European standard ground heat transfer calculation). A number of important technology advances were made as a result of running the test cases:

- The detailed numerical-methods modelers used the analytical solution to improve their models e.g., a TRNSYS node meshing refinement (finer mesh near perimeter boundaries) resulted in a $10 \%$ improvement versus the analytical solution.

- Three participating stand-alone 3-D numerical models showed excellent agreement with the analytical solution and with each other for the remaining cases; these verified numerical-model results form a secondary mathematical truth standard based on their range of disagreement.

- The high level of agreement among the verified numerical models allowed diagnosis of errors in other mid-level detailed models integrated with whole-building energy simulation software, some of which may have been missed without the secondary mathematical truth standard.

- Of 24 found disagreements, 19 were diagnosed and fixed, 3 are planned for investigation by the software authors, and 2 were judged as acceptable by the authors of mid-level detailed models (after they had fixed previous disagreements); Table 2-8 summarizes notable examples of error trapping - supporting details are provided in Section 2.4.

Many errors listed in Table 2-8 were significant, with greater than $20 \%$ floor conduction effect for several cases in this test suite. For unpublished preliminary in-depth cases developed during IEA SHC Task 22 (which spawned the current cases), two participants documented $270 \%$ and $70 \%-100 \%$ effects of model improvements on floor conduction dominated heating loads. In other instances for individual programs applying the current in-depth cases, some errors had relatively minor $(<2 \%)$ effect on floor conduction. Where a program had multiple errors of smaller magnitude, such errors did not necessarily compensate each other, and may have been cumulative in some cases. Therefore, correcting the minor and major errors was important.

After correcting software errors using BESTEST diagnostics, the remaining disagreements of floor conduction results are $0.3 \%-4.2 \%$ for the verified numerical models with very little scatter among them, and $1 \%-24 \%$ for the other simulation programs. This shows how the BESTEST method is used to diagnose and correct faulty algorithms in complex simulation programs. 
Table 2-8. Summary of Software Problems Found Using IEA BESTEST Slab-On-Grade Cases

\begin{tabular}{|c|c|c|c|}
\hline Model $^{\mathrm{a}}$ & Error Description $^{a}$ & $\begin{array}{l}\% \text { Floor Conduction Effect } \\
\text { or Disagreement }^{\mathrm{a}, \mathrm{b}}\end{array}$ & Resolution \\
\hline BASECALC & Input error & $1 \%-5 \%$ (“c"-series cases) & Fixed \\
\hline BASECALC & Perimeter heat flow disagreement & $9 \%(\mathrm{GC} 45 \mathrm{c})$ & No change $^{f}$ \\
\hline BASESIMP/ESP-r & $\begin{array}{l}\text { Test configurations fall outside range of } \\
\text { parameter variations allowed by correlations }\end{array}$ & $\begin{array}{l}21 \%(\mathrm{GC} 80 \mathrm{c}) \\
1 \%-4 \% \text { (other "c" cases) }\end{array}$ & Fixed \\
\hline DIT/MATLAB & Surface convection modeling by DIT & $\begin{array}{l}1 \%-4 \%(\text { GC30b, GC30c, } \\
\text { GC60b, GC65b) }\end{array}$ & Fixed \\
\hline DIT/MATLAB & Slab edge loss modeling by DIT & $0.3 \%(\mathrm{GC} 30 \mathrm{a})$ & Fixed \\
\hline DIT/MATLAB & Near-surface temperature reporting by DIT & No effect on floor conduction & Fixed \\
\hline EnergyPlus & $\begin{array}{l}\text { User cannot input floor slab interior surface } \\
\text { coefficient }\end{array}$ & 270\% (Task 22 Case GC180) & Fixed \\
\hline EnergyPlus & $\begin{array}{l}\text { User cannot define deep ground boundary } \\
\text { temperature }\left(T_{d g}\right)\end{array}$ & $\begin{array}{l}\text { No effect on test results } \\
\left(T_{d g}=\text { annual average ODB }\right)\end{array}$ & Fixed \\
\hline EnergyPlus & $\begin{array}{l}\text { User cannot define ground surface h,ext } \\
\text { (h,ext calculated from wind speed) }\end{array}$ & $\begin{array}{l}\text { Not isolated by participant, } \\
\text { probably minor effect }\end{array}$ & Fixed \\
\hline EnergyPlus & $\begin{array}{l}\text { Unclear documentation regarding inputs for } \\
\text { ground depth and far-field dimension }\end{array}$ & $\begin{array}{l}4 \%, 7 \%(\mathrm{GC} 40 \mathrm{c}, \mathrm{GC} 70 \mathrm{c}) \\
\text { Simulation crash (GC55b) }\end{array}$ & Fixed \\
\hline EnergyPlus & $\begin{array}{l}\text { Input error related to manual interface of } \\
\text { Slab subprogram and main EnergyPlus }\end{array}$ & $35 \%-40 \%(\mathrm{GC} 40)$ & Fixed $^{c}$ \\
\hline EnergyPlus & User cannot define ground depth & $35 \%$ (GC55b v. GC55) & Fixed \\
\hline EnergyPlus & $\begin{array}{l}\text { Disagreement for variation of ground } \\
\text { surface heat transfer coefficient }\end{array}$ & $18 \%(\mathrm{GC} 65 \mathrm{~b})$ & $\begin{array}{l}\text { Authors } \\
\text { notified }\end{array}$ \\
\hline EnergyPlus & Disagreement for variation of ground depth & $15 \%($ GC55b) & $\begin{array}{l}\text { Authors } \\
\text { notified }\end{array}$ \\
\hline GHT/SUNREL-GC & Integration of GHT model with SUNREL-GC & $\begin{array}{l}5 \%(\text { GC30b v.GC30) } \\
8 \%(G C 40 b \text { v.GC40) }\end{array}$ & Fixed \\
\hline GHT/SUNREL-GC & $\begin{array}{l}\text { Disagreements versus verified numerical } \\
\text { models }\end{array}$ & $\begin{array}{l}7 \%-10 \% \text { ("a"-series cases) } \\
5 \%-8 \% \text { ("b"-series cases) }\end{array}$ & $\begin{array}{l}\text { Authors } \\
\text { notified }\end{array}$ \\
\hline PAAET/FLUENT & PAAET modeling error & $0.7 \%(\mathrm{GC} 30 \mathrm{~b})$ & Fixed \\
\hline PAAET/FLUENT & Two output reporting issues by FLUENT & $\begin{array}{l}\text { No effect on overall floor } \\
\text { conduction }\end{array}$ & Fixed $^{d}$ \\
\hline TRNSYS & First noding algorithm improvement & $10 \%(\mathrm{GC} 10)$ & Fixed \\
\hline TRNSYS & Second noding algorithm improvement & $2 \%(\mathrm{GC} 10 \mathrm{a})$ & Fixed \\
\hline TRNSYS & Third noding algorithm improvement & $\begin{array}{l}0.4 \%(\mathrm{GC} 10 \mathrm{a}) \\
1 \%-2 \%(\mathrm{GC} 30 \mathrm{a}-\mathrm{GC} 80 \mathrm{c})\end{array}$ & Fixed \\
\hline VA114/ISO-13370 & One-dimensional conduction modeling & $\begin{array}{l}100 \%, 70 \% \text { (preliminary Task } \\
22 \text { cases GC100 and GC180) } \\
\end{array}$ & Fixed $^{\mathrm{e}}$ \\
\hline VA114/ISO-13370 & Insensitive to variation of ground depth & $29 \%, 49 \%$ (GC50b, GC55b) & Fixed \\
\hline VA114/ISO-13370 & Late time of occurrence for peak heat flow & $\begin{array}{l}\text { Peak delayed } 700,300-500 \\
\text { hours (GC55b, other cases) }\end{array}$ & No change ${ }^{f}$ \\
\hline
\end{tabular}

a Acronyms and abbreviations used in this column are defined in Section 2.7.

Effects are for floor conduction unless otherwise noted; specific cases relevant to the described effects are included in parentheses. For disagreements listed as fixed, listed percentage values are the effect of the change for new results versus previous results for a given model; otherwise, percentage values are remaining disagreement versus verified numerical models.

c Program developers later included example floor model inputs to main EnergyPlus as output from the Slab subprogram; however, better automation of interface between the EnergyPlus subprogram and main engine is recommended.

d Fixed in later version of FLUENT before this testing.

e Adapted ISO-13370 European standard ground heat transfer calculation method.

Software developer indicates this disagreement is acceptable for this model. 
Based on results after several iterations of BESTESTing, and resulting model improvements, all tested programs now appear to be generally reliable for modeling ground-coupled heat transfer related to slabon-grade construction, although some remaining disagreements (discussed in Section 2.4) should be addressed. The verified numerical-model results may be used as a reference or benchmark against which other software can be tested. For applications where ground-coupled heat transfer is a major component of a given simulation problem, the superior accuracy of the verified numerical models may justify adapting highly detailed models to more whole-building energy simulation programs, especially as computer hardware continues to improve and the detailed models become more user friendly.

Based on this work and previous work of Task 22, there are a number of recommended areas for further investigation with respect to developing additional validation test cases for modeling ground coupled heat transfer. These are described in detail in Section 2.5.4.1. For the longer term we hope to develop test cases that emphasize special modeling issues associated with more complex building types and HVAC systems as discussed in Section 2.5.4.2.

\subsubsection{Advantages of BESTEST Methodology}

Similar to previous test suites that applied the BESTEST method, these new cases have a variety of uses, including:

- Comparing output from building energy simulation programs to a set of analytical and quasianalytical solutions that constitute a reliable set of theoretical results given the underlying physical assumptions in the case definitions

- Comparing several building energy simulation programs to determine the degree of disagreement among them

- Diagnosing the algorithmic sources of prediction differences among several building energy simulation programs

- Comparing predictions from other building energy simulation programs to the analytical solution, verified numerical model results, and simulation results in this report

- Checking a program against a previous version of itself after the internal code has been modified, to ensure that only the intended changes actually resulted

- Checking a program against itself after a single algorithmic change to understand the sensitivity between algorithms.

An advantage of the BESTEST methodology is that a program is examined over a broad range of parametric interactions based on a variety of output types, minimizing the possibility that problems are concealed by compensating errors. Performing the tests resulted in quality improvements to all slab-ongrade heat transfer models and building energy simulation programs used in the field trials. Although the advancement of the state-of-the-art in ground heat transfer modeling is relatively recent, some bugs may well have been present for several years. The fact that they have just now been uncovered shows the power of BESTEST and suggests the importance of continuing to develop formalized validation and diagnostic methods. Only after coding bugs have been eliminated can the assumptions and approximations in the algorithms be evaluated.

Checking a building energy simulation program for the first time with the BESTEST in-depth slab-on-grade heat transfer test cases requires about one person-week for an experienced user, not including improvements to the software, if necessary. Subsequent program checks are faster because input files may be reused. Because the simulation programs have taken many years to produce, the new BESTEST cases provide a 
very cost-effective way of testing them. As we continue to develop new test cases, we will adhere to the principle of parsimony so the entire suite of BESTEST cases may be implemented by users with a reasonable time commitment.

\subsubsection{Recommendations}

\subsubsection{Adaptation of Test Procedures for ANSI/ASHRAE Standard 140}

The work presented in this report, other work of IEA SHC Task 34/ECBCS Annex 43, and the work that preceded it in IEA SHC Tasks 8, 12, and 22 are important for two reasons: (1) the methods have been extremely successful at correcting software errors in advanced building energy simulation programs throughout the world; and (2) the methods are finding their way into industry by being adopted as the theoretical basis for formalized standard methods of test and software certification procedures; in this sense the work may be thought of as pre-normative research.

Along with the overall validation methodology (Judkoff et al. 2008; Judkoff 1988; Judkoff and Neymark 2006 ) - that has recently been added to the ASHRAE Handbook of Fundamentals (ASHRAE 2005), the following test suites, developed in conjunction with IEA, have been code-language adapted and formally approved as standard test methods, ANSI/ASHRAE Standard 140-2007, Standard Method of Test for the Evaluation of Building Energy Analysis Computer Programs (ANSI/ASHRAE 2007):

- IEA BESTEST, building thermal fabric comparative tests (Judkoff and Neymark 1995a)

- HVAC BESTEST Volume 1, unitary cooling equipment analytical verification tests (Neymark and Judkoff 2002)

- HVAC BESTEST Volume 2, unitary cooling equipment comparative tests (Neymark and Judkoff 2004)

- HVAC BESTEST fuel-fired furnace analytical verification and comparative tests (Purdy and Beausoleil-Morrison 2003).

Within the BESTEST/Standard 140 structure is room to add new test cases. BESTEST is better developed in areas related to energy flows and energy storage in the architectural fabric of the building. BESTEST work related to mechanical equipment is still in its early phases in that there are many kinds and configurations of mechanical systems to test.

The new in-depth slab-on-grade ground heat transfer test cases described in this report are planned for inclusion in Standard 140. Additionally, HERS BESTEST (Judkoff and Neymark 1995b) is being codelanguage adapted for future inclusion with ASHRAE Standard 140 (SSPC-140 2008). Other completed test suites not yet included in ANSI/ASHRAE Standard 140 (ANSI/ASHRAE 2007) that have been developed within IEA SHC Task 34/ECBCS Annex 43 and IEA SHC Task 22, and will be considered for addition to Standard 140, include:

- IEA BESTEST Multi-Zone Non-Airflow In-Depth Cases (Neymark, Judkoff, et al. 2008)

- BESTEST Airflow Cases (Utsumi and Mitamura 2008)

- Shading/Daylighting/Load Interaction Empirical Validation Tests (Loutzenhiser, Manz, and Maxwell 2007)

- Chilled Water and Hot Water Mechanical Equipment and Control Comparative and Empirical Validation Tests (Felsmann 2008)

- Double-Skin Façade Comparative and Empirical Validation Tests (Kalyanova and Heiselberg 2008) 
- RADTEST Radiant Heating and Cooling Test Cases for hydronic systems (Achermann and Zweifel 2003).

Other test suites developed outside IEA research that are near-term candidates for inclusion with ASHRAE Standard 140 include:

- ASHRAE RP-865, Development of Accuracy Tests for Mechanical System Simulation(Yuill and Haberl 2002)

- ASHRAE RP-1052, Development of an Analytical Verification Test Suite for Whole Building Energy Simulation Programs - Building Fabric (Spitler, Rees, and Xiao 2001)

- Mechanical equipment test cases for low-rise residential construction included in, Procedures for Verification of International Energy Conservation Code Performance Path Calculation Tools (RESNET 2007).

\subsubsection{Closing Remarks}

Standard 140 and the BESTEST reports that comprise the test suites contained therein, are being referenced and used by a growing number of code promulagation authorities throughout the world. ASHRAE Standard 90.1 (ANSI/ASHRAE/IESNA 2007, 2005), which is ASHRAE's consensus energy code for commercial buildings and for non-low-rise residential buildings, requires that software used for demonstrating performance compliance with Standard 90.1 be tested using ASHRAE Standard 140-2004 (ANSI/ASHRAE 2004a). Similarly, software used for calculating energy savings for energy-efficient commercial building tax deductions in the United States must be tested with Standard 140-2007. (IRS 2008) DOE currently lists 10 building energy simulation programs as qualified for this purpose, by having been tested with Standard 140 . (DOE 2008) IEA BESTEST is also being used for simulation certification tests in The Netherlands (ISSO 2003), Australia (SEDA 2003; Pears 1998), New Zealand (Donn 2004), and Portugal (Maldonado 2005). As part of their building energy performance assessments under the European Community's Energy Performance Directive (European Union 2002), Austria, Denmark, Greece, and The Netherlands are using a new software tool that includes algorithms that have been checked with BESTEST (Balaras, Poel, and van Crutchen 2005). Also, CEN has used BESTEST to check its reference cooling load calculation general criteria of prEN ISO 13791 (CEN 2004a) and simplified methods of prEN ISO 13792 (CEN 2004b; Millet 2003) In the United States, the National Association of State Energy Officials (NASEO) Residential Energy Services Network (RESNET) has adopted Home Energy Rating System (HERS) BESTEST (Judkoff and Neymark 1995b) as the basis for certifying software to be used for home energy rating systems under the NASEO/RESNET national accreditation standard (NASEO/RESNET 2006). These citations indicate the importance of validation methods for improving the state-of-the-art in building energy simulation software, and for helping to certify such software for use with building energy codes, building energy tax credits, home energy rating standards, and other building energy incentive programs.

A growing body of evidence indicates that the BESTEST procedures are becoming part of software developers' normal in-house quality control efforts. Use of the BESTEST procedures has been documented by many software developers in the United States and elsewhere, including the developers of prominent programs such as DOE-2.1E, DOE-2.2, EnergyPlus, eQUEST, HAP (Carrier Corp.), TRACE (Trane), TRNSYS, ESP-r (United Kingdom), HOT3000 (Canada), VA114 (The Netherlands), and many others. A recent report compared 20 whole-building energy simulation tools (Crawley et al. 2005). The report indicates that 19 of the 20 tools reviewed have been tested with at least one of the four BESTEST procedures included in ANSI/ASHRAE Standard 140-2007, four have been tested with three procedures, two have been tested with all four procedures, and four have also been tested with HERS BESTEST, which is currently being adapted for Standard 140. Additional examples of the importance of software testing include: 
- The number of programs listed as having qualified for calculating energy savings for the energyefficient commercial building tax deductions in the United States, which require testing with ASHRAE Standard 140, increased from 1 to 10 between June 2006 and March 2008

- Software developers' use of Standard 140 and BESTEST, along with other validation tests, is documented on the DOE Building Energy Software Tools Directory (DOE 2008)

- At least one software developer has automated use of BESTEST within its software for testing new versions (Strachan, Kokogiannakis, and Macdonald 2005)

- Researchers in other countries have translated previous BESTEST work into Dutch, German, and Japanese (ISSO 2003; Neymark et al. 2003; Utsumi et al. 2006a, 2006b)

- We have received more than 1000 requests for the various BESTEST reports.

Along with this, the simplicity, diagnostic power, and building physics background content of BESTEST are evidenced by the BESTEST procedures being used as teaching tools for simulation courses at universities in the United States and Europe.

Computer scientists universally accept the merits of software testing. A well-known rule of thumb is that in a typical programming project more than $50 \%$ of the total cost is expended in testing the program or system being developed (Myers 2004). Of this, about 20\% of development time goes toward system testing (McConnell 2004). Because new energy-related technologies are continually being introduced into the buildings market, there will always be a need to further develop simulation models, combined with a substantial program of testing and validation. Such an effort should contain all the elements of an overall validation methodology (Judkoff and Neymark 2006; ASHRAE 2005, Chp. 32), including:

- Analytical verification

- Comparative testing and diagnostics

- Empirical validation.

Future work should therefore:

- Continue to produce a standard set of analytical tests.

- Develop a set of diagnostic comparative tests that emphasize the modeling issues important in large commercial buildings, including more tests for heating, ventilating, and air-conditioning systems, and other mechanical equipment including on-site power generation equipment.

- Develop a sequentially ordered series of high-quality data sets for empirical validation.

Continued support of model development and validation activities is essential because occupied buildings are not amenable to classical controlled, repeatable experiments. The few buildings that are truly useful for empirical validation studies have been designed primarily as test facilities. The energy, comfort, and lighting performance of buildings depend on the interactions among a large number of transfer mechanisms, components, and systems. Simulation is the only practical way to bring a systems integration problem of this magnitude within the grasp of designers. A growing body of literature and activity demonstrates the importance of simulation tools for greatly reducing the energy intensity of buildings through better design (e.g., Torcellini, Hayter, and Judkoff 1999; IBPSA 2005; GARD Analytics 2007). As building energy simulation programs are more widely used - such as in the United States. for establishing LEED ratings (USGBC 2007) and federal tax deductions, in Europe to comply with the European Performance Directive, in Australia to comply with greenhouse gas emission ratings, etc. - the design and engineering communities must continue to have confidence in the quality of these programs. Such confidence and quality are best established and maintained by combining a rigorous development and validation effort with user-friendly interfaces. 
The work described here represents a good start in the effort to develop carefully validated building energy simulation tools. Continued development and validation of whole-building energy simulation programs are two of the most important activities meriting the support of national energy research programs. DOE and the IEA executive committees for Solar Heating and Cooling and for Energy Conservation in Buildings and Community Systems should diligently consider future collaborations that would best support this essential research area.

Finally, the authors wish to acknowledge that the expertise available through IEA and the dedication of the participants were essential to the success of this project. Over the 4-year field trial effort, there were several revisions to the BESTEST specifications and subsequent re-executions of the computer simulations. This iterative process led to the refining of the new BESTEST cases, and the results of the tests led to improving and debugging the simulation models. The process underscores the leveraging of resources for the IEA countries participating in this project. Such extensive field trials, and resulting enhancements to the tests, were much more cost effective with the participation of the IEA SHC Task 34/ ECBCS Annex 43 experts.

\subsection{Abbreviations and Acronyms for Parts II and III}

These acronyms are used in Sections 2.2 through 2.6 and in Part III.

\begin{tabular}{|c|c|}
\hline Adiab & adiabatic \\
\hline ANSI & American National Standards Institute \\
\hline AR & aspect ratio \\
\hline ASHRAE & American Society of Heating, Refrigerating and Air-Conditioning Engineers \\
\hline BESTEST & Building Energy Simulation Test and Diagnostic Method \\
\hline $\mathrm{CEN}$ & European Committee for Standardization \\
\hline CETC & CANMET Energy Technology Centre, Natural Resources Canada \\
\hline CSIRO & Commonwealth Scientific and Industrial Research Organisation \\
\hline DIT & Dublin Institute of Technology \\
\hline DOE & U.S. Department of Energy \\
\hline $\mathrm{E}$ & deep ground depth \\
\hline ECBCS & Energy Conservation in Buildings and Community Systems Programme (of the IEA) \\
\hline ESRU & Energy Systems Research Unit, University of Strathclyde \\
\hline $\mathrm{F}$ & far field dimension \\
\hline GARD & GARD Analytics \\
\hline $\mathrm{h}$ & surface heat transfer coefficient \\
\hline HERS & Home Energy Rating System \\
\hline HVAC & heating, ventilating, and air-conditioning \\
\hline h,int & interior surface heat transfer coefficient \\
\hline h,ext & exterior surface heat transfer coefficient \\
\hline IBPSA & International Building Performance Simulation Association \\
\hline
\end{tabular}




\begin{tabular}{|c|c|}
\hline IEA & International Energy Agency \\
\hline IEA 34/43 & $\begin{array}{l}\text { International Energy Agency joint Solar Heating and Cooling Programme Task } 34 \text { and } \\
\text { Energy Conservation in Buildings and Community Systems Programme Annex } 43\end{array}$ \\
\hline IESNA & Illuminating Engineering Society of North America \\
\hline Inf. & infinity \\
\hline ISO & International Organization for Standardization \\
\hline ISO 13370 & $\begin{array}{l}\text { European Standard EN ISO 13370: Thermal performance of buildings - Heat transfer via the } \\
\text { ground - Calculation methods }\end{array}$ \\
\hline ISSO & $\begin{array}{l}\text { Instituut voor Studie en Stimulering van Onderzoek op het Gebied van Gebouwinstallaties } \\
\text { (The Netherlands) }\end{array}$ \\
\hline $\mathrm{k}$ & slab/soil thermal conductivity \\
\hline LBNL & Lawrence Berkeley National Laboratory \\
\hline LEED & Leadership in Energy and Environmental Design \\
\hline Lin dT & linearly varying perimeter boundary surface temperature (see Case GC10a, Section 1.3.2.1) \\
\hline Max & maximum \\
\hline Min & minimum \\
\hline NASEO & National Association of State Energy Officials \\
\hline NRCan & Natural Resources Canada \\
\hline NREL & National Renewable Energy Laboratory \\
\hline ODB & outdoor dry-bulb temperature \\
\hline $\begin{array}{l}\text { PAAET } \\
\text { prEN }\end{array}$ & $\begin{array}{l}\text { Public Authority for Applied Education and Training } \\
\text { project Norme Européenne (draft European Standard) }\end{array}$ \\
\hline $\mathrm{R}$ & thermal resistance \\
\hline RADTEST & radiant heating and cooling test cases \\
\hline RESNET & Residential Energy Services Network \\
\hline SEDA & Sustainable Energy Development Authority (Australia) \\
\hline SHC & Solar Heating and Cooling Programme (of the IEA) \\
\hline Soln. & solution \\
\hline $\mathrm{sp}$ & steady-periodic \\
\hline SS & steady-state \\
\hline SSPC & Standing Standard Project Committee (of ASHRAE) \\
\hline $\mathrm{Tdg}, \mathrm{T}_{\mathrm{dg}}$ & deep ground temperature \\
\hline TESS & Thermal Energy System Specialists \\
\hline TMY2 & Typical Meteorological Year 2 \\
\hline UA & thermal conductance \\
\hline USGBC & U.S. Green Buildings Council \\
\hline U.S. IRS & United States Internal Revenue Service \\
\hline
\end{tabular}




$\begin{array}{ll}\text { VABI } & \text { VABI Software BV } \\ \mathrm{x} & \begin{array}{l}\text { variable dimension along } \mathrm{x} \text {-axis } \\ \mathrm{z}\end{array} \\ \text { variable dimension along } \mathrm{z} \text {-axis } \\ \text { 1-D } & \text { one-dimensional } \\ \text { 2-D } & \text { two-dimensional } \\ \text { 3-D } & \text { three-dimensional }\end{array}$

\subsection{References for Parts II and III}

Achermann, M.; Zweifel, G. (2003). RADTEST Radiant Heating and Cooling Test Cases. Horw-Lucerne, Switzerland: Lucerne School of Engineering and Architecture, University of Applied Sciences of Central Switzerland. www.iea-shc.org/task22/reports/RADTEST final.pdf.

ANSI/ASHRAE Standard 140-2004. (2004a). Standard Method of Test for the Evaluation of Building Energy Analysis Computer Programs. Atlanta, Georgia, US: American Society of Heating, Refrigerating and Air-Conditioning Engineers.

ANSI/ASHRAE Standard 140-2004. (2004b). Addendum b. Standard Method of Test for the Evaluation of Building Energy Analysis Computer Programs. Atlanta, Georgia, US: American Society of Heating, Refrigerating and Air-Conditioning Engineers.

ANSI/ASHRAE Standard 140-2007. (2007). Standard Method of Test for the Evaluation of Building Energy Analysis Computer Programs. Atlanta, Georgia, US: American Society of Heating, Refrigerating and Air-Conditioning Engineers.

ANSI/ASHRAE/IESNA Standard 90.1-2007. (2007). Energy Standard for Buildings Except Low-Rise Residential Buildings. Atlanta, Georgia, US: American Society of Heating, Refrigerating and AirConditioning Engineers. References ANSI/ASHRAE Standard 140-2004.

ANSI/ASHRAE/IESNA Standard 90.1-2004, Addendum L, Energy Standard for Buildings Except LowRise Residential Buildings. (2005). Atlanta, GA: American Society of Heating, Refrigerating and AirConditioning Engineers. References ANSI/ASHRAE Standard 140-2004.

ASHRAE. (2005). 2005 Handbook of Fundamentals, Atlanta, Georgia, US: American Society of Heating, Refrigerating and Air-Conditioning Engineers.

Balaras, C.A.; Poel, B.; van Crutchen, G. (2005). Software for Energy Performance Assessment of Existing Dwellings. IBPSA News, Volume 15, Number 1. International Building Performance Simulation Association, April 2005.

Beausoleil-Morrison, I. (1996). "BASECALC : A Software Tool for Modeling Residential- TM Foundation Heat Losses." Third Canadian Conference on Computing in Civil and Building Engineering. Montreal. pp. 117-126.

Beausoleil-Morrison, I. (1999). BASESIMP ESP-r implantation (Fortran code). Ottawa, Canada: Natural Resources Canada. 
Beausoleil-Morrison, I.; Mitalas, G. (1997). "BASESIMP: A Residential-Foundation Heat-Loss Algorithm for Incorporating into Whole-Building Energy-Analysis Programs", Building Simulation '97, (2) 1-8, International Building Performance Simulation Association, Prague Czech Republic.

Ben-Nakhi, A. (2006). Private communications with J. Neymark. Kuwait, State of Kuwait: Public Authority for Applied Education and Training. May 2006.

CEN. (2004a). prEN ISO 13791. Thermal Performance of Buildings - Calculation of Internal Temperatures of a Room In Summer without Mechanical Cooling - General Criteria and Validation Procedures. Final Draft. Comité Européen de la Normalisation, Brussels.

CEN. (2004b). prEN ISO 13792. Thermal Performance of Buildings - Calculation of Internal Temperatures of a Room In Summer without Mechanical Cooling - Simplified Methods. Final Draft. Comité Européen de la Normalisation, Brussels.

Crawley, D.; Hand, J.; Kummert, M.; Griffith, B. (2005). Contrasting the Capabilities of Building Energy Performance Simulation Programs. Washington, DC: U.S. Department of Energy; Glasgow, Scotland, UK: University of Strathclyde; Madison, WI: University of Wisconsin.

http://gundog.lbl.gov/dirpubs/2005/05 compare.pdf.

Crowley, M. (2007). Private communication of January 18, 2007 with R. Judkoff and J. Neymark. Dublin, Ireland: Dublin Institute of Technology.

Delsante A.E.; Stokes, A.N.; Walsh, P.J. (1983). "Application of Fourier Transforms to Periodic Heat Flow into the Ground under a Building." International Journal of Heat Mass Transfer, 26(1): 121-132.

Deru, M. (2003). A Model for Ground-Coupled Heat and Moisture Transfer From Buildings. NREL/TP550-33954. Golden, CO: National Renewable Energy Laboratory.

Deru, M.; Judkoff, R.; Neymark, J. (2003). Proposed IEA BESTEST Ground-Coupled Cases. Golden, CO: National Renewable Energy Laboratory. In conjunction with International Energy Agency, Solar Heating and Cooling Programme, Task 22. IEA Working Document. Draft, September 19, 2003.

Deru, M.; Neymark, J.; Thornton, J. (2005). Private communications between Thornton (Thermal Energy Systems Specialists, Madison, WI) and Neymark (J. Neymark \& Associates, Wheat Ridge, CO) of May 16, 2005, and between Deru (National Renewable Energy Laboratory, Golden, CO) and Neymark of May 17-19, 2005.

Donn, M. (2004). May 2004 private communications with R. Judkoff and J. Neymark. Victoria, New Zealand: Victoria University.

EnergyPlus. (2007). U.S. Department of Energy, Energy Efficiency and Renewable Energy, Office of Building Technologies. www.energyplus.gov

ESRU. (2007). ESP-r web site. See www.esru.strath.ac.uk. Glasgow, Scotland, UK: University of Strathclyde, Energy Systems Research Unit.

European Union. (2002). On the Energy Performance of Buildings. Directive 2002/91/EC of the European Parliament and of the Council, Official Journal of the European Communites, December. 
Felsmann C. (2008). Mechanical Equipment and Control Strategies for a Chilled water and a Hot water system. Dresden, Germany: Dresden University of Technology. In conjunction with IEA: SHC Task 34/ ECBCS Annex 43, Project D. Draft.

FLUENT (2001). Fluent 6.0 User's Guide. Lebanon, New Hampshire, US: Fluent Incorporated.

GARD Analytics. (2007). BLDG-SIM@GARD.COM, mailing list for building energy simulation users. Park Ridge, Illinois, US: GARD Analytics.

IBPSA. (2005). Building Simulation 2005. Proceedings of The Ninth International IBPSA Conference, Montréal Canada, 15-18 August 2005. Edited by I. Beausoleil-Morrison and M. Bernier. The 2005 proceedings CD also includes proceedings from all international IBPSA conferences back to 1985 .

ISO 13370. (1998). Thermal Performance of Buildings - Heat Transfer Via The Ground - Calculation Methods. Brussels, Belgium: European Committee for Standardization.

ISSO. (2003). Energie Diagnose Referentie Versie 3.0. ISSO Publicatie 54. Rotterdam, The Netherlands: Institut voor Studie en Stimulering van Onderzoekop Het Gebied van Gebouwinstallaties (in Dutch).

Judkoff, R. (1988). "Validation of Building Energy Analysis Simulation Programs at the Solar Energy Research Institute." Energy and Buildings, 10 (3) 235. Lausanne, Switzerland: Elsevier Sequoia.

Judkoff, R.; Neymark, J. (1995a). International Energy Agency Building Energy Simulation Test (BESTEST) and Diagnostic Method. NREL/TP-472-6231, Golden, Colorado, US: National Renewable Energy Laboratory. www.nrel.gov/docs/legosti/old/6231.pdf.

Judkoff, R., and J. Neymark. (1995b). Home Energy Rating System Building Energy Simulation Test (HERS BESTEST). NREL/TP-472-7332. Golden, Colorado, US: National Renewable Energy Laboratory. www.nrel.gov/docs/legosti/fy96/7332a.pdf; www.nrel.gov/docs/legosti/fy96/7332b.pdf.

Judkoff, R.; Neymark, J. (2006). "Model Validation and Testing: The Methodological Foundation of ASHRAE Standard 140." ASHRAE Transactions, Volume 112 (2) 367-376. Atlanta, Georgia, US: American Society of Heating, Refrigerating and Air-Conditioning Engineers.

Judkoff, R.; Wortman, D.; O'Doherty, B.; Burch, J. (2008). A Methodology for Validating Building Energy Analysis Simulations. NREL/TP-550-42059. Golden, Colorado, US: National Renewable Energy Laboratory. Based on unpublished report of 1983 with same authors and title, previously referenced as SERI/TR-254-1508.

Kalyanova, O.; Heiselberg, P. (2008). Empirical Validation of Building Simulation Software: Modeling of Double Facades Final Report. Aalborg, Denmark: Aalborg University. In conjunction with IEA: SHC Task 34/ECBCS Annex 43, Project E. Draft.

Klein, et. al., (2007). TRNSYS -- A Transient System Simulation Program User Manual - Version 16.1. Madison, Wisconsin, US: The Solar Energy Laboratory, University of Wisconsin.

Loutzenhiser, P.; Manz, H; Maxwell, G. (2007). Empirical Validations of Shading/Daylighting/Load Interactions in Building Energy Simulation Tools. Duebendorf, Switzerland: Swiss Federal Laboratories for Materials Testing and Research; Ames, Iowa, US: Iowa State University. In conjunction with IEA: SHC Task 34/ECBCS Annex 43, Project C. August 2007. 
Maldonado, E. (2005). "Energy Certification of Buildings in Portugal." Presentation at Joint IEA ECBCS/SHC Executive Committee Meeting, Technical Day, June 15, 2005, Espinho, Portugal. Porto, Portugal: University of Porto.

Marion, W; Urban, K. (1995). User's Manual for TMY2s, Golden, Colorado, US: National Renewable Energy Laboratory.

McConnell, S. (2004). Code Complete: A Practical Handbook of Software Construction. Microsoft Press, p. 502.

Millet, J.R. (2003). Personal communication at IEA SHC Task Definition Workshop, April 24-25, 2003, Delft, The Netherlands. Paris, France: Centre Scientifique et Technique du Batiment.

Myers, G. (2004). The Art of Software Testing. Hoboken, New Jersey, US: John Wiley \& Sons. See p. xiii.

NASEO/RESNET. (2006). 2006 Mortage Industry National Home Energy Rating Systems Accreditation Eandards. Oceanside, California, US: Residential Energy Services Network, Inc. www.natresnet.com.

Neymark, J. (2003). IEA BESTEST Ground Coupling Project Plan Review. Presented at IEA SHC Task 34 Meeting, Duebendorf, Switzerland, September 29, 2003. Golden, Colorado, US: National Renewable Energy Laboratory and J. Neymark \& Associates. See "ProjLead-10Min-GroundCoup-NREL.PPT." Based on analysis in "GC-Task22-Results091903-revVABI090607.XLS."

Neymark, J.; Judkoff, R. (2002). International Energy Agency Building Energy Simulation Test and Diagnostic Method for Heating, Ventilating, and Air-Conditioning Equipment Models (HVAC BESTEST) Volume 1: Cases E100-E200. NREL/TP-550-30152. Golden, Colorado, US: National Renewable Energy Laboratory. www.nrel.gov/docs/fy02osti/30152.pdf.

Neymark, J.; Judkoff, R. (2004). International Energy Agency Building Energy Simulation Test and Diagnostic Method for Heating, Ventilating, and Air-Conditioning Equipment Models (HVAC BESTEST), Vol. 2: Cases E300-E545. NREL/TP-550-36754. Golden, Colorado, US: National Renewable Energy Laboratory. www.nrel.gov/docs/fy05osti/36754.pdf.

Neymark, J.; Judkoff, R.; Deru, M. (2004). Proposed IEA BESTEST In-Depth Diagnostic Cases for Ground Coupled Heat Transfer Related to Slab-on-Grade Construction. Draft. Golden, Colorado, US: National Renewable Energy Laboratory. In conjunction with International Energy Agency, Solar Heating and Cooling Programme Task 34, and Energy Conservation and Buildings and Community Systems Annex 43. June, 2004.

Neymark, J.; Judkoff, R.; with Alexander, D; Felsmann, C; Strachan, P; Wijsman, A. (2008). International Energy Agency Building Energy Simulation Test and Diagnostic Method (IEA BESTEST) Multi-Zone Non-Airflow In-Depth Diagnostic Cases: MZ320 - MZ360. Golden, Colorado, US: National Renewable Energy Laboratory. In conjunction with IEA: SHC Task 34/ECBCS Annex 43, Project B. Draft, August 2008.

Neymark, J.; Judkoff, R; Knabe, G.; Le, H.T.; Durig, M.; Glass, A.; Zweifel, G. (2003). “Analytische Verifikations-methode von Gebaudesimulationsprogrammen”. KI Luft- und Kaltetechnik. Baierbrunn, Germany: Kuba Kaltetechnik GmbH. April 2003. German translation team led by G. Knabe. 
Pears, A. (1998). Rating Energy Efficiency of Non-Residential Buildings: A Path Forward for New South Wales. Report for the Sustainable Energy Development Authority. Brighton, Victoria, Australia:

Sustainable Solutions Pty Ltd. www.abgr.com.au.

Purdy, J.; Beausoleil-Morrison, I. (2003). Building Energy Simulation Test and Diagnostic Method for Heating, Ventilating, and Air-Conditioning Equipment Models (HVAC BESTEST): Fuel-Fired Furnace Test Cases. Ottawa, Canada: Natural Resources Canada, CANMET Energy Technology Centre. www.ieashc.org/task22/deliverables.htm

RESNET. (2007). Procedures for Verification of International Energy Conservation Code Performance Path Calculation Tools. RESNET Publication No. 07-003. Oceanside, California, US: Residential Energy Services Network, Inc. March 2007.

SEDA. (2003). Guidelines for the Use of Simulation in Commitment Agreements. Grosvenor Place, New South Wales, Australia: Sustainable Energy Development Authority.

Spitler, S.; Rees, S.; Xiao, D. (2001). Development of An Analytical Verification Test Suite for Whole Building Energy Simulation Programs - Building Fabric. Final Report for ASHRAE 1052-RP. Stillwater, Oklahoma, US: Oklahoma State University School of Mechanical and Aerospace Engineering.

SSPC-140. (2008). Minutes SSPC-140 Standard Method of Test for Building Energy Software. ASHRAE Annual Meeting, New York City, New York, US. January 21, 2008. Atlanta, Georgia, US: American Society of Heating, Refrigerating, and Air-Conditioning Engineers.

Strachan, P.; Kokogiannakis, G; Macdonald, I.A. (2005). Encapsulation of Validation Tests in the ESP-r Simulation Program. Building Simulation 2005, August 15-18, Montreal Canada. Ninth International IBPSA Conference. International Building Performance Simulation Association.

The MathWorks, Inc. (2007). Getting started with MATLAB. Natick, Mass., US: The MathWorks, Inc.

Thornton, J. (2007a). Private communications from Thornton (Thermal Energy System Specialists, Madison, Wisconsin, US) to Neymark (J. Neymark \& Associates, Wheat Ridge, Colorado, US) of August 24, 2007.

Thornton, J. (2007b). Modeler Report for BESTEST Cases GC10a-GC80c, TRNSYS Version 16.1. Madison Wisconsin US: Thermal Energy System Specialists. September, 2007. Included with Section 2.9, Appendix II-A, of this final report.

Torcellini, P.; Hayter, S.; Judkoff, R. (1999). "Low Energy Building Design: The Process and a Case Study." ASHRAE Transactions 1999, Volume 105, Number 2. Atlanta, Georgia, US: American Society of Heating, Refrigerating, and Air-Conditioning Engineers.

United States Department of Energy (DOE). (2008). Building Energy Software Tools Directory. Washington, DC: U.S. Department of Energy, Office of Energy Efficiency and Renewable Energy, Building Technologies Program. www.eere.energy.gov/buildings/info/qualified software/

Also see www.eere.energy.gov/buildings/tools directory/

United States Internal Revenue Service (IRS). (2008). Amplification of Notice 2006-52, Deduction for Energy Efficient Commercial Buildings. IRS Notice 2008-40. Appears in Internal Revenue Bulletin (IRB) No. 2008-14, April 7, 2008. Washington, DC: United States Department of Treasury, Internal Revenue Service. 
U.S. Green Building Council (USGBC). (2007). www.usgbc.org.

Utsumi Y., et al. (2006a). Miyagi, Japan: Miyagi National College of Technology. Japanese translation of: Judkoff, R.; Neymark, J. (1995a). International Energy Agency Building Energy Simulation Test (IEA BESTEST) and Diagnostic Method. NREL/TP-472-6231. Golden, Colorado, US: National Renewable Energy Laboratory. IEA_BESTEST_Japanese.pdf

Utsumi, Y.; Mitamura, T. (2008). Air Flow Test Cases including Multi-Zone. Natori, Japan: Institutes of National Colleges of Technology; Ashikaga, Japan: Ashikaga Institute of Technology. In conjunction with IEA: SHC Task 34/ECBCS Annex 43, Project B. Draft, June 2008.

Utsumi, Y.; Mitamura, T; Hatakeyama, K; Zheng, M; Xian, Z; Kon-No, Y; Nakamura, K. (2006b). Miyagi, Japan: Miyagi National College of Technology. Japanese translation of Part I of: Neymark J.; Judkoff, R. (2002). International Energy Agency Building Energy Simulation Test and Diagnostic Method for Heating Ventilating and Air-Conditioning Equipment Models (HVAC BESTEST), Volume 1: Cases E100-E200. NREL/TP-550-30152. Golden, Colorado, US: National Renewable Energy Laboratory. 20061002HVAC_BESTEST_JapaneseTranslation.pdf

VABI Software BV. (2007). VA114, the Dutch Building Performance Simulation tool. Delft, Netherlands. Initial development by TNO, further development, distribution, maintenance and support by Vabi Software BV.

Walton, G. (1983). Thermal Analysis Research Program Reference Manual (TARP). NBSIR 83-2655. Washington, D.C., US: National Bureau of Standards (now called National Institute of Standards and Technology).

Watve, A. (2006). Lebanon, New Hampshire, US: Fluent Incorporated. Private communications with A. Nakhi and J. Neymark, Nov-Dec 2006.

Wijsman, A. (2005). VA114 Ground Coupling. Presented at IEA Meeting of IEA SHC Task 34/ECBCS Annex 43, Aalborg, Denmark, October 2005. Delft, Netherlands: VABI Software BV. See "AalborgGround Coupling October 2005.ppt".

Yuill, G.; Haberl, J. (2002). Development of Accuracy Tests for Mechanical System Simulation. Final Report for ASHRAE 865-RP. Omaha, NE: University of Nebraska. 


\subsection{APPENDIX II: Simulation Modeler Reports}

In Appendix II, we present reports written by the modelers for each simulation program. The modelers were asked to document:

- Modeling assumptions (required inputs not explicitly described in the test specification)

- Modeling options (alternative modeling techniques)

- Difficulties experienced in developing input files for the test cases with their programs

- Demonstration of appropriate level of modeling detail

- Bugs, faulty algorithms, documentation problems, and input errors uncovered during the field trials

- Source code or input modifications made because of the diagnostic results

- Comments on agreement or disagreement of results compared to other simulation results

- Any odd results obtained with their programs

- Sensitivity studies conducted to further understand the sources of differences between their programs and the others

- Conclusions and recommendations about their simulation models, the test specification, or both.

Modelers also filled out a pro-forma description that defines allowable ranges of inputs for geometry and material properties related to slab-on-grade construction. 


\title{
Appendix II-A
}

\section{Modeler Report for BESTEST Cases GC10a-GC80c TRNSYS Version 16.1}

\author{
by \\ Jeff Thornton \\ Thermal Energy System Specialists, LLC \\ United States
}

\author{
September 2007
}

\section{Introduction}

TRNSYS is a modular system simulation tool that has been widely used in the study of buildings, renewable energy technologies, and HVAC systems. The program was originally written by the Solar Energy Laboratory at the University of Wisconsin; but recently is maintained, supported, and distributed by a consortium of international companies and government agencies. TRNSYS Version 16.1 was used for the most recent analysis as well as an extended library of TRNSYS components written by Thermal Energy System Specialists (TESS) LLC of Madison, WI. The ground coupling models used for this analysis are part of the commercially available TESS ground-coupling library for TRNSYS.

The particular model that was used for this analysis is a part of a larger suite of slab-to-soil heat transfer models written by TESS for the TRNSYS simulation package that differ only in application. The core solution algorithm used for the suite of models is identical. For example, there are models for slab-on-grade situations, slab-in-grade situations, slabs that interact with detailed building models that calculate the radiant exchange between surfaces, slabs that interact with the simpler building models where only the zone air temperature is available, models where there is not a slab but simply a resistive cover over the ground surface, versions where the foundation walls (and insulation) are accounted for, etc.

In the IEA test procedure, the slab, soil, and foundation walls have identical thermal properties with no insulation beneath the slab or on the edges of the slab. The slab is assumed to be very thin and surrounded by adiabatic walls (all cases but GC10, which imposes a conductive boundary). The radiant exchange from the slab to the zone is ignored in the test cases. With these restrictions in place, we chose one of our models that best fit the requirements of these tests.

With the slab having the same thermal properties as the soil, being very thin, and communicating with the zone through convective exchange only, we were able to use one of our simpler models for these tests. The model that we chose simulates an exposed floor with a conductive covering that isolates the zone air from the soil. In these test cases, the resistance of the covering was set very small to mimic the test conditions.

The routine models the heat transfer from a horizontal surface to the soil beneath the surface. The heat transfer is assumed to be conductive only and moisture effects are not accounted for in the model. The model relies on a 3-dimensional rectangular finite difference representation of the soil and solves the resulting interdependent differential equations using a simple iterative method. The governing differential equations imposed by the energy balance on each soil node are solved using an implicit methodology; ensuring that the solution is stable over all ranges of simulation time steps. 
One of the philosophies of the TRNSYS simulation program is that individual component models should be formulated as generically as possible such that they may be re-used in other applications. This slab model is no exception.

Due to its implicit formulation, the model allows very high surface heat transfer coefficients (i.e., addresses large Biot Number issues) without the calculation instabilities that plague many of the other soil models currently being studied. This can be seen by the almost identical results from the constant surface temperature condition and the high convection coefficient condition shown later in this report. Each of the soil nodes at the surface conducts to the "local surface temperature" and not directly to the ambient or zone temperature. The "local surface temperature" is typically calculated from an energy balance on a massless, opaque plane located between the air and the soil node. This solution methodology requires another set of coupled iterative calculations within the model - but allows us quite a bit more freedom with the model - a requirement for a well-formulated TRNSYS model. The surface temperature can be calculated from an energy balance (just described), set from a long term average surface temperature correlation (Kasuda 1965), or provided to the model as an input (for example from a swimming pool model or parking lot model, etc.)

The soil volume surrounding the slab in the $\mathrm{x}, \mathrm{y}$, and $\mathrm{z}$ directions (Cartesian coordinate system) is referred to as the near field. The near field soil is assumed to be affected by the heat transfer from the slab into the soil. Nodes contained in the near field can vary in size in all three dimensions, typically becoming larger as they get farther from the edges/corners of the slab or get farther from the surface. The user controls the size and number of the nodes by providing parameters to the model for the noding algorithm, as described later in this document. The user also controls the size/volume of the near field by providing parameters to the model specifying the distance away from the edge of the slab that the soil is unaffected by the slab (far field distance), and the distance beneath the slab that the soil is unaffected by the slab (deep earth distance).

The near field is in turn surrounded by the far field, which is assumed to be an infinite energy sink/source (energy transfer with the far field does not result in a temperature change of the far-field). Like the near field nodes, the sizes of the far-field nodes typically increase as they get further from the soil surface. The boundary between the near field and far field may also be specified as adiabatic. The soil beneath the near field (below the deep earth boundary) is also assumed to be unaffected by the slab and may also be specified as an adiabatic boundary. The temperature of the far-field nodes can be calculated based on an energy balance (not a function of the near field temperatures but solely of the surface and deep earth temperatures) or can be specified by the Kasuda correlation (temperature a function of the time of year and distance below the surface). The deep earth temperature can also be an input to the model (for high water movement for example) or calculated from the Kasuda approach.

\section{Modeling Assumptions}

No assumptions beyond those imposed by the test were noted.

\section{Modeling Options}

The ground-coupling models may be operated independently of the building model (one of the benefits of TRNSYS) and, unless otherwise noted, were left uncoupled from the building model. By uncoupling the ground model from the building model, the speed of the simulations was increased as there are no iterative calculations between the building and the ground models. The test cases called for a fully-mixed zone-air condition with idealized controls to maintain the zone air temperature at the prescribed values. The intent of this specification was to mimic a constant zone air temperature - possible in the TRNSYS environment by simply providing the desired temperature to the ground model as an input for the zone air temperature (typically connected to the zone air temperature model output from the building). 
A simple building project with coupling to the soil model is shown below to illustrate the iterative nature of the solution.

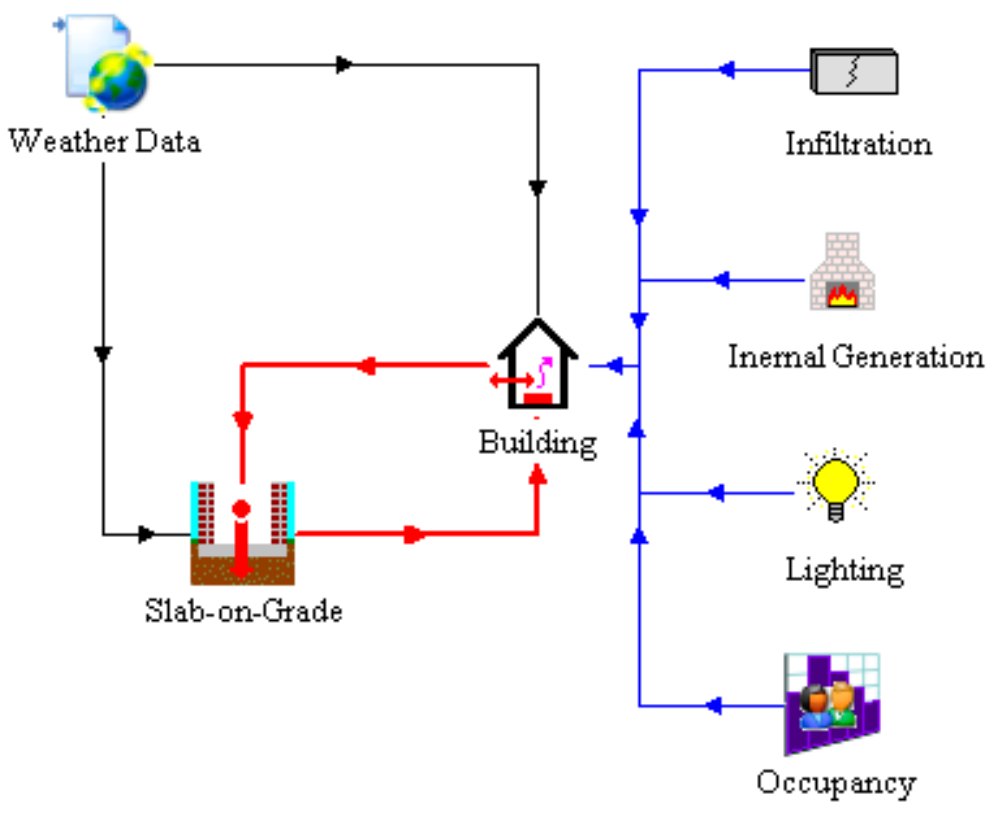

As the test procedure either specified the soil surface conditions or the ambient temperature along with either the zone air temperature or slab surface temperature, the coupling of the ground model to the building was not required. Instead a temperature profile could be connected to the ground model to simplify things as shown in the figure below.

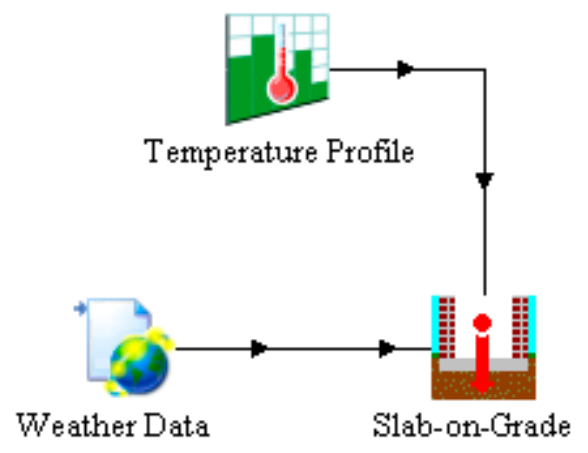

The ground coupling models, and TRNSYS in general may be operated at timesteps ranging from $1 / 100^{\text {th }}$ of a second to 1 hour. For these tests, as there is not an iterative solution required between component models, the simulations were run with a 1-hour timestep. 


\section{Modeling Difficulties}

The original models were not set up to allow for a conductive wall as called for in test case GC10. The models allowed us to insulate the ground surface surrounding the slab for a user-specified width (as called for in test case GC30) but had no mechanism for imposing a linear variation between the slab temperature (Ti) and the ground surface temperature (To) over the specified width (W). As the analytical solution provided us with a solid test case for our modeling assumptions, we created a slightly modified version of the standard model that attempted to meet the criteria imposed by test case GC10. In the original slab model, the user has an option to specify the surface temperature of the ground; set to $10^{\circ} \mathrm{C}$ for the entire ground surface for this test. However, being the model developer, we were able to modify a version of the source code and set the ground surface temperatures for the nodes representing the width (W) around the slab to have a linear variation from $30^{\circ} \mathrm{C}$ to $10^{\circ} \mathrm{C}$. In this way the conductive boundary approach specified by GC10 is modeled and we should be able to get a fairly good estimate to the analytical solution.

\section{Demonstration of Appropriate Level of Modeling Detail}

\section{For Case GC10 only, demonstrate the current level of modeling detail yields negligible (=0.1\%) change in results versus a lesser level of detail, including for: \\ - deep ground boundary depth and far-field boundary distance}

We ran a series of test cases for the GC10 specification (using a moderately noded soil) to study the impact of far-field and deep-earth distances on the slab-to-soil heat transfer rate. The results are presented below in tables showing the heat transfer rate at the end of the $10^{\text {th }}$ year of operation and showing the percent difference between each combination of deep earth and far-field distances as compared to the 40 $\mathrm{m} \times 40 \mathrm{~m}$ case.

The results show that we could have run with a deep earth distance of $30 \mathrm{~m}$ and a far-field distance of 20 $\mathrm{m}$ and met the $0.1 \%$ criteria for submittal. However with our expanding noding size scheme in the model, we were able to run at $40 \mathrm{~m} \times 40 \mathrm{~m}$ without a significant change in simulation speed as compared to the $30 \mathrm{~m} \times 20 \mathrm{~m}$ case. The results presented in the summary sections of this report for TRNSYS for the GC10a case utilize a denser noding than the results presented here and also utilize $40 \mathrm{~m} \times 40 \mathrm{~m}$ boundaries. It should also be noted that the boundaries for these tests were assumed to be conductive boundaries and not adiabatic boundaries.

\begin{tabular}{|c|c|c|c|c|c|}
\hline \multirow{2}{*}{\multicolumn{2}{|c|}{$\begin{array}{l}\text { Slab Heat Transfer } \\
\text { (Watts) }\end{array}$}} & \multicolumn{4}{|c|}{ Deep Earth Distance (m) } \\
\hline & & 10 & 20 & 30 & 40 \\
\hline \multirow{4}{*}{ 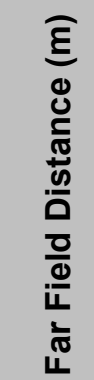 } & 10 & $2,459.04$ & $2,411.34$ & $2,408.91$ & $2,408.78$ \\
\hline & 20 & $2,458.39$ & $2,406.67$ & $2,403.29$ & $2,403.10$ \\
\hline & 30 & $2,458.38$ & $2,406.50$ & $2,403.05$ & $2,402.85$ \\
\hline & 40 & $2,458.38$ & $2,406.49$ & $2,403.04$ & $2,402.84$ \\
\hline
\end{tabular}




\begin{tabular}{|c|c|c|c|c|c|}
\hline \multirow{2}{*}{\multicolumn{2}{|c|}{$\begin{array}{l}\text { Percent Change from } \\
40 \times 40 \text { Case }\end{array}$}} & \multicolumn{4}{|c|}{ Deep Earth Distance (m) } \\
\hline & & 10 & 20 & 30 & 40 \\
\hline \multirow{4}{*}{ 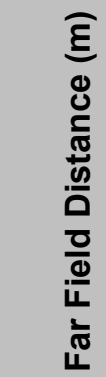 } & 10 & $2.34 \%$ & $0.35 \%$ & $0.25 \%$ & $0.25 \%$ \\
\hline & 20 & $2.31 \%$ & $0.16 \%$ & $0.02 \%$ & $0.01 \%$ \\
\hline & 30 & $2.31 \%$ & $0.15 \%$ & $0.01 \%$ & $0.00 \%$ \\
\hline & 40 & $2.31 \%$ & $0.15 \%$ & $0.01 \%$ & $0.00 \%$ \\
\hline
\end{tabular}

For Case GC10 only, demonstrate the current level of modeling detail yields negligible (=0.1\%) change in results versus a lesser level of detail, including for

- duration of simulation ( $\left.t_{\text {sim }}\right)$

Using the submittal results for test case GC10a (heavily-noded, $40 \mathrm{~m} \times 40 \mathrm{~m}$ boundary), the slab heat transfer as a function of time is shown graphically and numerically below. 


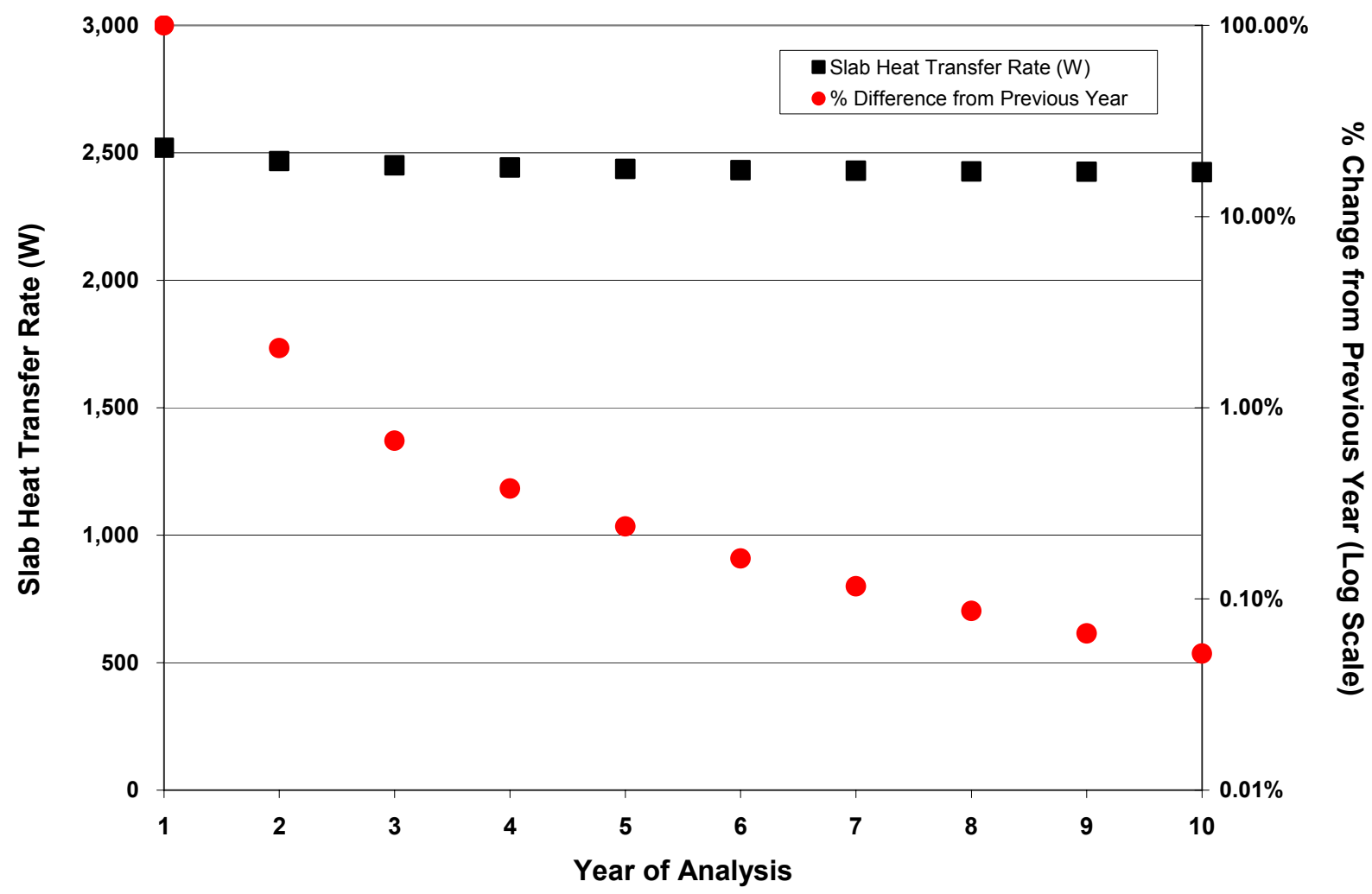

$\begin{array}{ccc}\text { Year } & \begin{array}{c}\text { Slab } \\ \text { Heat } \\ \text { Transfer } \\ \mathbf{( W )}\end{array} & \begin{array}{c}\text { \% } \\ \text { Change }\end{array} \\ & 2,519.46 & 100.00 \% \\ 1 & 2,467.79 & 2.05 \% \\ 2 & 2,451.21 & 0.67 \% \\ 3 & 2,441.96 & 0.38 \% \\ 4 & 2,436.12 & 0.24 \% \\ 5 & 2,432.16 & 0.16 \% \\ 6 & 2,429.33 & 0.12 \% \\ 7 & 2,427.23 & 0.09 \% \\ 8 & 2,425.63 & 0.07 \% \\ 9 & 2,424.37 & 0.05 \% \\ 10 & & \end{array}$

Although the slab heat transfer quickly stabilizes after only a few years, it should be pointed out that all heat transfers in the ground have not stabilized - even after 10 years. The following plot shows the heat transfer rates as a function of time. Notice that the amount of energy storage is decreasing, but still nonzero - indicating steady-state has not been fully reached. The bottom boundary and side boundary heat transfer rates are also increasing as the $10^{\text {th }}$ year is reached. 


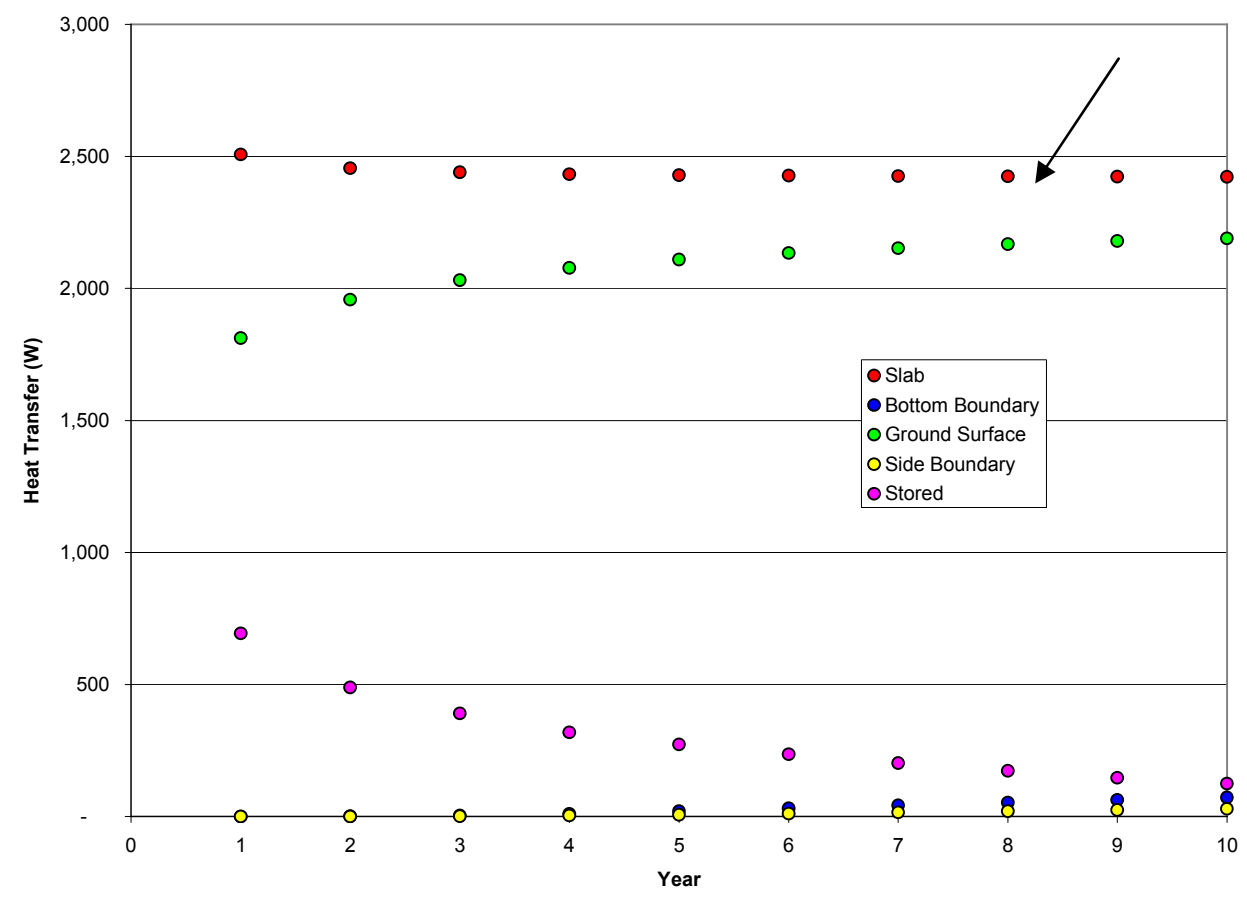

For Case GC10 only, demonstrate the current level of modeling detail yields negligible (=0.1\%) change in results versus a lesser level of detail, including for:

- convergence tolerance

As our model relies on an implicit and iterative approach to solve for the nodal temperatures and heat flows at each simulation timestep, the convergence tolerance may be a factor in the results. The model will iterate at each timestep until every calculated nodal temperature (which affects each surrounding nodal temperature) changes by less than the convergence tolerance from the previous iteration. However, we found that for the steady-state GC10a test case that the tolerance only affected the soil energy balance at each timestep and not the long-term (near steady-state) heat transfer rates as shown below:

\begin{tabular}{|r|r|}
\hline $\begin{array}{r}\text { Convergence } \\
\text { Tolerance (C) }\end{array}$ & $\begin{array}{c}\text { \% Difference } \\
\text { from Previous }\end{array}$ \\
\hline 0.00001 & N/A \\
\hline 0.00010 & $0.02 \%$ \\
\hline 0.00100 & $0.01 \%$ \\
\hline 0.01000 & $0.00 \%$ \\
\hline 0.10000 & $0.00 \%$ \\
\hline 1.00000 & $0.00 \%$ \\
\hline
\end{tabular}

While it may seem counterintuitive that the percent difference actually decreases as the tolerance gets larger we believe that this is actually correct. With a large tolerance, the temperatures of the nodes aren't updated as often each time step, but are still done at least once each time step. After 10 years of operation, the nodal temperatures are not changing more than about $0.01^{\circ} \mathrm{C}$ per hour, resulting in no change in slab heat transfer as we loosen the convergence tolerance further. For the submitted test cases we ran with a convergence tolerance of $0.001^{\circ} \mathrm{C}$. 
For Case GC10 only, demonstrate the current level of modeling detail yields negligible (=0.1\%) change in results versus a lesser level of detail, including for:

- $\quad$ numerical methods mesh.

The TRNSYS model relies on an algorithm that increases the sizes of the nodes in the $\mathrm{x}, \mathrm{y}$, and zdirections outwards and downwards from the edges of the slab and away from the surface boundary.

$$
\text { Size }_{i}=\text { Size }_{\text {Nom }} * X^{i-1}
$$

Where $i=1$ corresponds to the node nearest the edge of the slab or surface, Size $_{\text {Nom }}$ is the size of the smallest node (typically 1 inch for these cases) and $\mathrm{X}$ is a scalar (typically 1.2 to 2.0). Changing the size of $X$ from 2.0 to 1.2 significantly increases the number of nodes. For a $40 \mathrm{~m} \times 40 \mathrm{~m}$ boundary, changing the scalar from 2.0 down to 1.2 increases the total number of nodes by a factor of 18 for a 1-inch sized smallest node.

The heat transfer as a function of the number of nodes (for a smallest node size of 1 inch) and the percent difference from the analytical solution for each scalar value are show below.

\begin{tabular}{|c|c|}
\hline Scalar Value & $\begin{array}{c}\text { \% Difference } \\
\text { from } \\
\text { Delsante }\end{array}$ \\
\hline 2.0 & $4.5 \%$ \\
\hline 1.8 & $3.4 \%$ \\
\hline 1.6 & $2.2 \%$ \\
\hline 1.4 & $1.1 \%$ \\
\hline 1.3 & $0.6 \%$ \\
\hline 1.2 & $0.2 \%$ \\
\hline
\end{tabular}




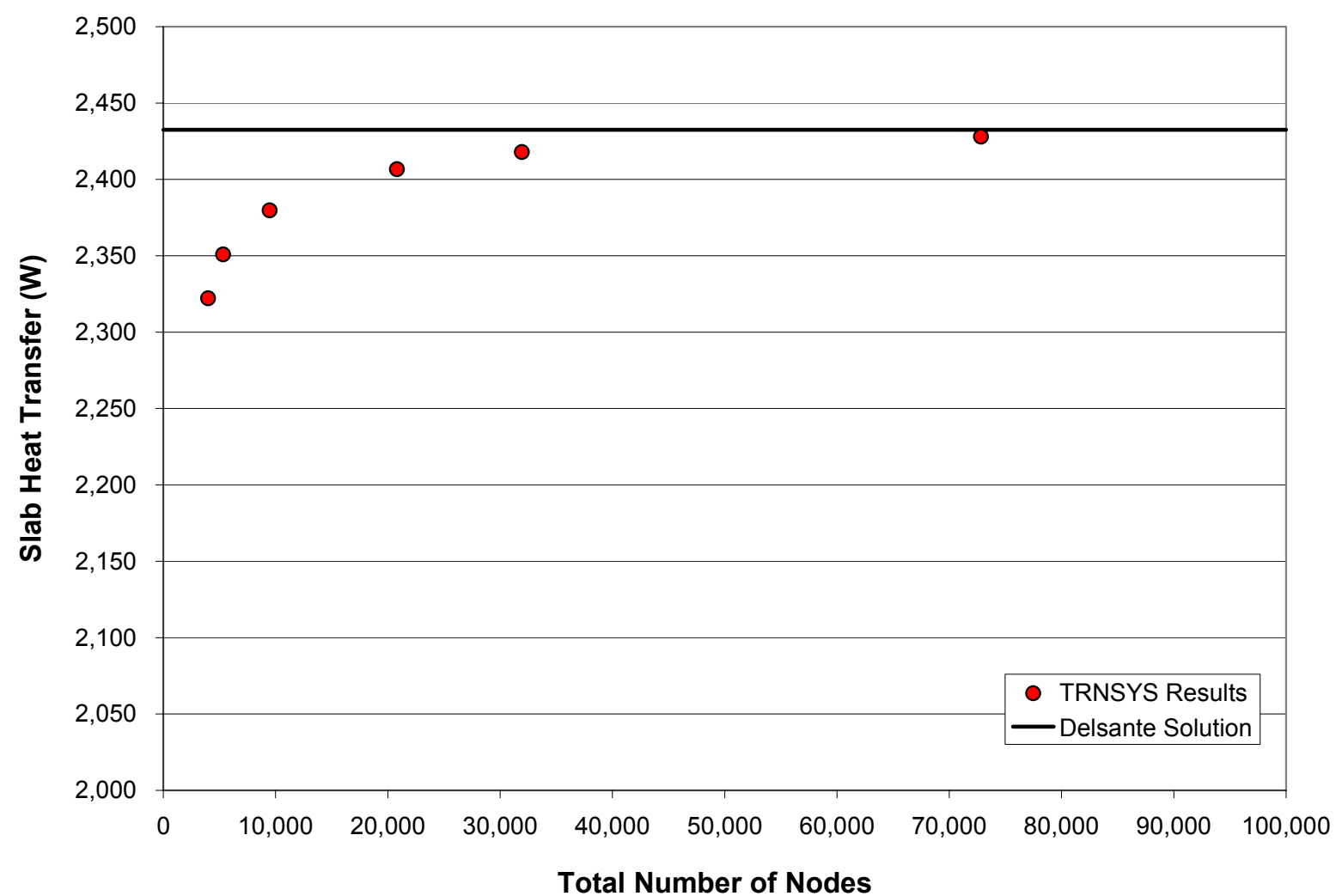

\section{Software Errors Discovered, and/or Comparison between Different Versions of the Same Software, and/or Lessons Learned Regarding Use of Detailed Models}

At the onset of this IEA task, our component models for soil heat transfer were brand new and had not yet been extensively tested or reviewed. It was only at the urging of the IEA task leaders that we agreed to submit our results for this project. They felt that having a detailed but flexible model in the test process would not only provide the project participants with another set of baseline results but may also ultimately improve the model itself. They were right.

We have changed our model several times during the process, mostly minor cosmetic changes to make the model easier to use or improving the output capabilities of the program. However, we did improve the noding algorithm substantially from its earliest incarnation. The original model employed a user-specified number of nodes along the slab and in the near field ( $\mathrm{X}$ and $\mathrm{Y}$ directions) as well as a user-specified number of nodes in the depth direction. Adjacent nodes in the near field increased in size by a factor of 2.0 from the edges of the slab outwards and downwards. The soil nodes directly beneath the slab surface were assumed to have constant $\mathrm{X}$ and $\mathrm{Y}$ dimensions (uniformly noded) with the user controlling the number of nodes in each direction. While we were aware that this uniform noding scheme under the slab was far from ideal, we felt that the change would be somewhat small and that the heat transfer would be limited by the amount of nodes in the soil beyond the slab. We were also concerned with the simulation speed slowdown that we were noticing as we began to heavily node the soil beneath the slab.

The original preliminary model, applied prior to the January 2005 initial TRNSYS results submittal, had the following nodal settings: 
- The entire slab was modeled, not just one-fourth of the slab as in later versions

- The size of the nodes directly under the slab in the $\mathrm{X}$ and $\mathrm{Y}$-directions was uniform

- The size of the nodes directly under the slab in the depth direction $(Z)$ increased by a factor of 2 for each node.

- The sizes of the nodes in the $\mathrm{X}, \mathrm{Y}$, and $\mathrm{Z}$ directions for the nodes not directly under the slab changed by a factor of 2 as the nodes proceed farther from the slab edge and deeper from the soil surface.

- The size of the smallest node in the $\mathrm{X}, \mathrm{Y}$, and $\mathrm{Z}$ directions was calculated as a function of the number of nodes allowed in each direction and the distance from the slab to the far-field and deep-earth boundaries.

Given its preliminary nature, we were not surprised that this early model had a nearly $12 \%$ disagreement versus the analytical solution. For the January 2005 field-trial results submittal, the assumption of uniformly sized nodes under the slab was changed to a user-specified number of nodes under the slab with the nodes growing in size by a factor of 2 as they progressed inwards, outwards and downwards from the edges of the slab. As shown below (see results labeled 1/14/05), this improvement caused a 10\% increase in floor conduction versus the original node mesh, but still had a 3\% disagreement with the analytical solution.

\begin{tabular}{|c|c|c|}
\hline \multicolumn{3}{|c|}{ Steady-State Analytical Verification, Case GC10 } \\
\hline & $\begin{array}{l}\mathrm{q}_{\text {floor }} \\
(\mathrm{W})\end{array}$ & $\begin{array}{l}\% \text { difference versus } \\
\text { Analytical Solution }\end{array}$ \\
\hline Analytical Soln. & 2561 & -- \\
\hline TRNSYS (Initial Results) & 2261 & $-11.71 \%$ \\
\hline TRNSYS (Results of $1 / 14 / 05$ ) & 2486 & $-2.93 \%$ \\
\hline
\end{tabular}

We could have easily increased the number of uniformly spaced slab nodes to compensate, but with an alarming increase in simulation time. For the same size largest node under the slab, the increasing size algorithm results in significantly more nodes than the uniform noding scheme at a cost of significant simulation time. It should be noted that the January 2005 submittal utilized very small nodes near the edges of the slab - smaller even than the 1-inch nodes used in latter submissions (but with a larger scalar as discussed below).

For the June 2005 submittal we thought that creating an automatic noding scheme with a few user-specified parameters was preferable to the user having to enter the number of the nodes in the $\mathrm{x}, \mathrm{y}$, and $\mathrm{z}$ directions (certainly the new approach is less flexible but easier to use). With this in mind we programmed an algorithm that uses a

$$
\text { Size }_{i}=\text { Size }_{\text {Nom }} * X^{i-1}
$$

approach, where Size Nom is the size of the smallest node (typically 1 inch), $\mathrm{X}$ is the scalar (typically 1.2 to 2 ) and $i$ is a nodal indicator $(1=$ next to the slab/surface). The algorithm also limits the size of $i$; keeping identical size nodes beyond a fixed point. This algorithm groups small nodes close to the edges and soil surface and increases the sizes of the nodes as they progress away from these edges.

To combat the slowdown issue, we removed some of the flexibility of the original model; which had allowed the user to have non-rectangular slab geometries. By imposing a rectangular geometry we were able to utilize symmetry to allow us to only model one fourth of the slab, significantly reducing the simulation times and allowing us to run with a higher nodal density than previous submittals. 
We submitted the June 2005 set with the following specifications:

- $\quad$ Size $_{\text {Nom }}=1$ inch

- $\mathrm{X}=1.5$ to 2 depending on the test

- Maximum $\mathrm{i}=10$

Based on the results of June 2005 and the new one-fourth approach, the TRNSYS model node meshing was further revised so that the mesh size increases by a factor of 1.2 to 1.3 moving away from the slab edge, and the size of node $\mathrm{i}$ is allowed to increase without limit. The difference in mesh sizing between the meshing schemes is shown in the figure below.

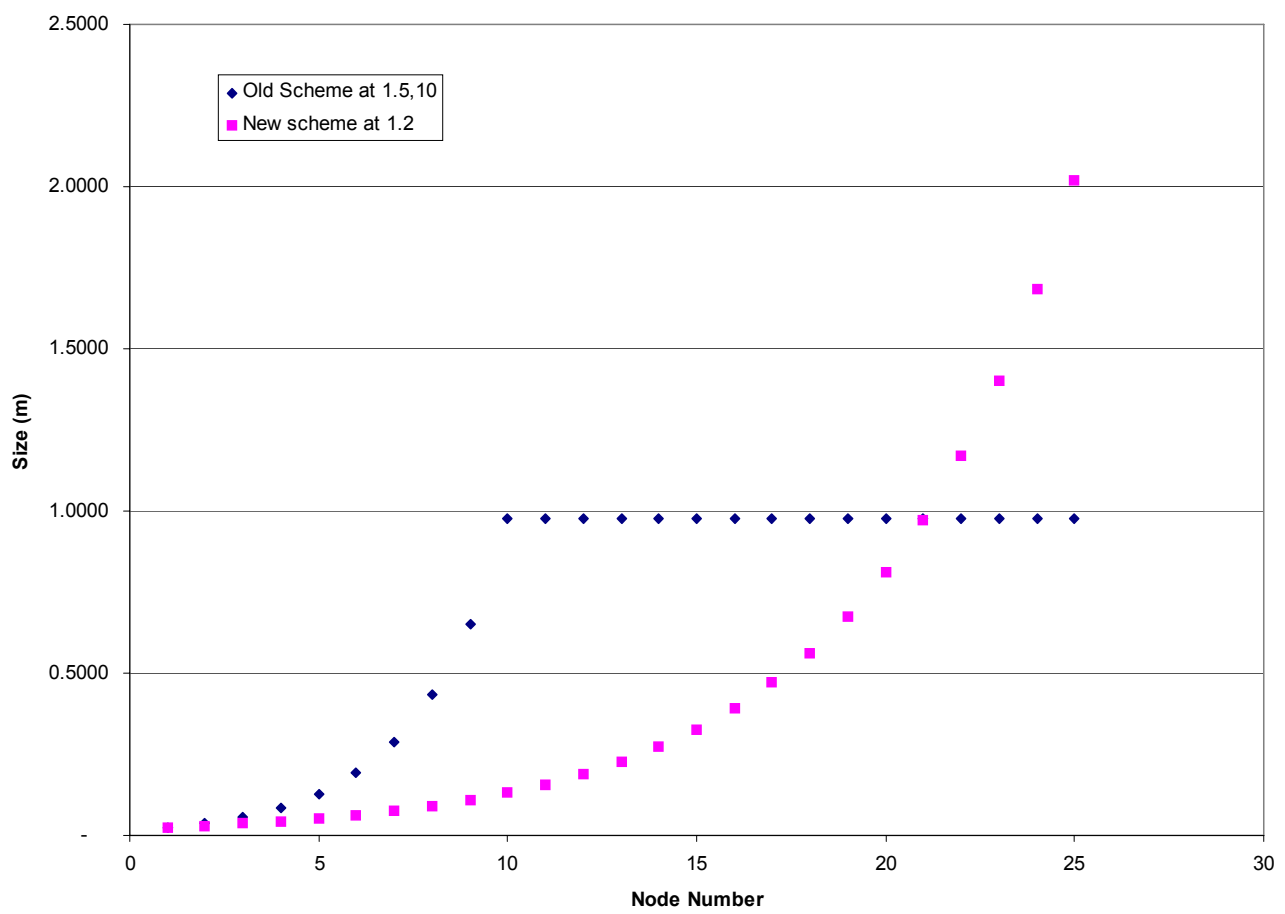

The newly modified algorithm allowed us to run with a similar number of nodes using a scalar of 1.2 to 1.3 than the previous cases which were run with a scalar of 1.5 for most cases for some of the larger-boundary tests.

We submitted the May 2006 set with the following specifications:

- $\quad$ Size $_{\text {Nom }}=1$ inch

- $\mathrm{X}=1.2$ to 1.3 depending on the test

- Maximum $\mathrm{i}=$ infinity

The three TRNSYS results sets produced for the project are summarized in the table below. Note that there are specification differences for cases GC30 and GC30a, and GC40 and GC40a, where the "a"-series cases specify kground $=1.9$ and constant temperature surface boundaries, and the preliminary-series cases specify kground $=2.0$ along with interior and exterior surface coefficients of $h=5000 \mathrm{~W} / \mathrm{m} 2 \mathrm{~K}$. The difference in ground conductivity should cause reduced floor conduction in the "a"-series cases versus the preliminary 
cases, while the effect of varying the surface boundary condition should be negligible as $\mathrm{h}=5000 \mathrm{~W} / \mathrm{m} 2 \mathrm{~K}$ approximates a constant-temperature surface boundary condition. However, the TRNSYS model noding scheme was also changed between January 2005 and June 2005, further affecting the results.

\section{TRNSYS results summary}

\begin{tabular}{|c|c|c|c|c|c|c|}
\hline \multirow{2}{*}{$\begin{array}{r}\text { Submittal Date } \\
\text { Noding Scheme }\end{array}$} & \multicolumn{2}{|c|}{$1 / 14 / 2005$} & \multicolumn{2}{|c|}{$6 / 21 / 2005$} & \multicolumn{2}{|l|}{$5 / 23 / 2006$} \\
\hline & \multicolumn{2}{|c|}{ "x (2)" Full slab } & \multirow[t]{2}{*}{ "x (1.5)" } & 1/4 Slab & \multicolumn{2}{|c|}{ "x(1.2-3)" 1/4 Slab } \\
\hline \multicolumn{6}{|c|}{ Steady-State Analytical Verification } & \\
\hline & \multicolumn{2}{|c|}{ GC10 } & \multicolumn{4}{|c|}{ GC10a } \\
\hline & $\begin{array}{l}\mathrm{q}_{\text {floor }} \\
(\mathrm{W})\end{array}$ & $\begin{array}{l}\text { del \% v. } \\
\text { AnnSoln }\end{array}$ & $\begin{array}{l}q_{\text {floor }} \\
\text { (W) }\end{array}$ & $\begin{array}{l}\text { del \% v. } \\
\text { AnnSoln }\end{array}$ & $\begin{array}{l}\mathrm{Q}_{\text {floor }} \\
(\mathrm{W})\end{array}$ & $\begin{array}{l}\text { del \% v. } \\
\text { AnnSoln }\end{array}$ \\
\hline Analytical Soln. & 2561 & $\mathrm{n} / \mathrm{a}$ & 2433 & $\mathrm{n} / \mathrm{a}$ & 2433 & $\mathrm{n} / \mathrm{a}$ \\
\hline TRNSYS & 2486 & $-2.93 \%$ & 2417 & $-0.64 \%$ & 2427 & $-0.24 \%$ \\
\hline \multicolumn{7}{|l|}{ Steady-State Cases } \\
\hline & $\begin{array}{l}\text { qfloor } \\
(W)\end{array}$ & $\begin{array}{l}\text { del } \% \text { v. } \\
\text { previous }\end{array}$ & $\begin{array}{l}q_{\text {floor }} \\
(W)\end{array}$ & $\begin{array}{l}\text { del } \% \text { v. } \\
\text { previous }\end{array}$ & $\begin{array}{l}\text { q floor } \\
(W)\end{array}$ & $\begin{array}{l}\text { del } \% \text { v. } \\
\text { previous }\end{array}$ \\
\hline GC30 \& GC30a & 2620 & $\mathrm{n} / \mathrm{a}$ & 2606 & $-0.52 \%$ & 2642 & $1.34 \%$ \\
\hline GC30b & & & 2494 & $\mathrm{n} / \mathrm{a}$ & 2533 & $1.53 \%$ \\
\hline GC30c & & & 2104 & $\mathrm{n} / \mathrm{a}$ & 2137 & $1.56 \%$ \\
\hline GC60b & & & 2085 & $\mathrm{n} / \mathrm{a}$ & 2113 & $1.36 \%$ \\
\hline GC65b & & & 1965 & $\mathrm{n} / \mathrm{a}$ & 1994 & $1.43 \%$ \\
\hline \multicolumn{7}{|l|}{ Harmonic Cases } \\
\hline & $\begin{array}{c}\begin{array}{c}Q_{\text {floor }} \\
(k W h / y)\end{array}\end{array}$ & $\begin{array}{l}\text { del } \% \text { v. } \\
\text { previous }\end{array}$ & $\begin{array}{c}\begin{array}{c}Q_{\text {floor }} \\
(k W h / y)\end{array}\end{array}$ & $\begin{array}{l}\text { del } \% \text { v. } \\
\text { previous }\end{array}$ & $\begin{array}{c}\begin{array}{c}\text { Qfloor } \\
(k W h / y)\end{array}\end{array}$ & $\begin{array}{l}\text { del } \% \text { v. } \\
\text { previous }\end{array}$ \\
\hline GC40 \& GC40a & 22994 & $\mathrm{n} / \mathrm{a}$ & 22831 & $-0.71 \%$ & 23033 & $0.88 \%$ \\
\hline GC40b & & & 21852 & $\mathrm{n} / \mathrm{a}$ & 22099 & $1.12 \%$ \\
\hline GC45b & & & 32405 & $\mathrm{n} / \mathrm{a}$ & 32758 & $1.08 \%$ \\
\hline GC55b & & & 34952 & $\mathrm{n} / \mathrm{a}$ & 35075 & $0.35 \%$ \\
\hline GC70b & & & 17214 & $\mathrm{n} / \mathrm{a}$ & 17396 & $1.05 \%$ \\
\hline GC80b & & & 5970 & $\mathrm{n} / \mathrm{a}$ & 6029 & $0.97 \%$ \\
\hline GC40c & & & 18425 & $\mathrm{n} / \mathrm{a}$ & 18649 & $1.20 \%$ \\
\hline $\mathrm{GC} 45 \mathrm{c}$ & & & 26735 & $\mathrm{n} / \mathrm{a}$ & 27004 & $1.00 \%$ \\
\hline GC55c & & & 19120 & $\mathrm{n} / \mathrm{a}$ & 20760 & $7.90 \%$ \\
\hline $\mathrm{GC} 80 \mathrm{c}$ & & & 9086 & $\mathrm{n} / \mathrm{a}$ & 9192 & $1.16 \%$ \\
\hline
\end{tabular}

The results from the June 2005 submittal show an uncharacteristic pattern/result for the GC55c test case that was pointed out by the IEA task leaders. We tried to go back and see if we could replicate the result or explain the differences that were noted, but we have been unable to unearth the cause of the discrepancy. It is likely a wrong parameter entered for that test case, an unfinished simulation that was reported, or user error entering the results into the spreadsheet. The May 2006 submittal does not show the same behavior and compares favorably to the other test cases.

After the June 2005 submittal we were asked to comment on the differences between the FLUENT results and the TRNSYS results for the soil surface temperatures. While the energy flows were nearly identical between the two detailed models, the surface temperature plots were very different. The reason, as it turns out, was simple. The TRNSYS results were being reported for the true surface condition while the FLUENT results were being reported for the node/element just beneath the surface. For example, in test case GC10a 
the specification calls for an exterior soil surface temperature of $10^{\circ} \mathrm{C}$, an interior surface temperature of $30^{\circ} \mathrm{C}$ and a linear temperature profile between $10^{\circ} \mathrm{C}$ and $30^{\circ} \mathrm{C}$ for the area beneath the exterior wall. The plots of the TRNSYS results for that test case show exactly that temperature profile while the FLUENT results show deviations from that profile that are especially noticeable for the area underneath the exterior wall. However, when we plot the TRNSYS results for the node directly beneath the surface (and not the surface temperature) versus the FLUENT results for the test cases we find near-identical results - confirming our suspicions about the differences.

The surface temperature results were especially pronounced after the June 2005 submittal for the GC30 test cases - with the TRNSYS results showing an odd behavior under the wall. For reference, the GC30 test case uses a non-constant surface temperature condition. The results were again due to the definition of the surface temperatures. The TRNSYS results again showed the surface temperatures, but for the area beneath the wall we were forced to use the temperatures of the nodes directly under the wall - and not the surface temperatures - as they could not be calculated for the adiabatic boundary specified beneath the wall. So the plots show surface temperatures on both sides of the wall, and temperatures 1 node down beneath the wall, which causes an inconsistency in the plot that was noticed by the task leaders. When the temperatures of the nodes directly beneath the surface are instead plotted and compared to the FLUENT results the graphs are nearly identical.

Another surface temperature anomaly (corner effects) noticed by the task leaders for the GC65 test case turned out to be an error in the algorithm we used to calculate the interpolated surface temperatures in the post-processing spreadsheet and not an error in the model itself.

\section{Results}

Our model matches up extremely well with the other verified detailed 3-D modeling programs (FLUENT and MATLAB) in both surface temperature profiles and slab heat transfer for all test cases.

\section{Other (optional)}

To assist with development of the test specification for some of the other less flexible modeling programs (the "b" and "c" test cases), a number of sensitivity tests requested by NREL were run. With the flexibility of our model, these analyses were quite easy to model, requiring very little preparation time. Some of the more interesting results of these tests are discussed below. These sensitivity tests do not necessarily apply all parameters in the final test specification, so results are not expected to exactly match final or interim TRNSYS results shown elsewhere. 
Figure 2A-1 and Tables 2A-1 and 2A-2 show the impacts of far field and deep earth distances as well as the impact of the convection coefficients on the steady-state slab heat transfer rate for preliminary Case GC30 (using very high surface coefficients). Based on this output "a"-series depth and far-field dimensions of $30 \mathrm{~m}$ and $20 \mathrm{~m}$, respectively, were applied in the test specification.

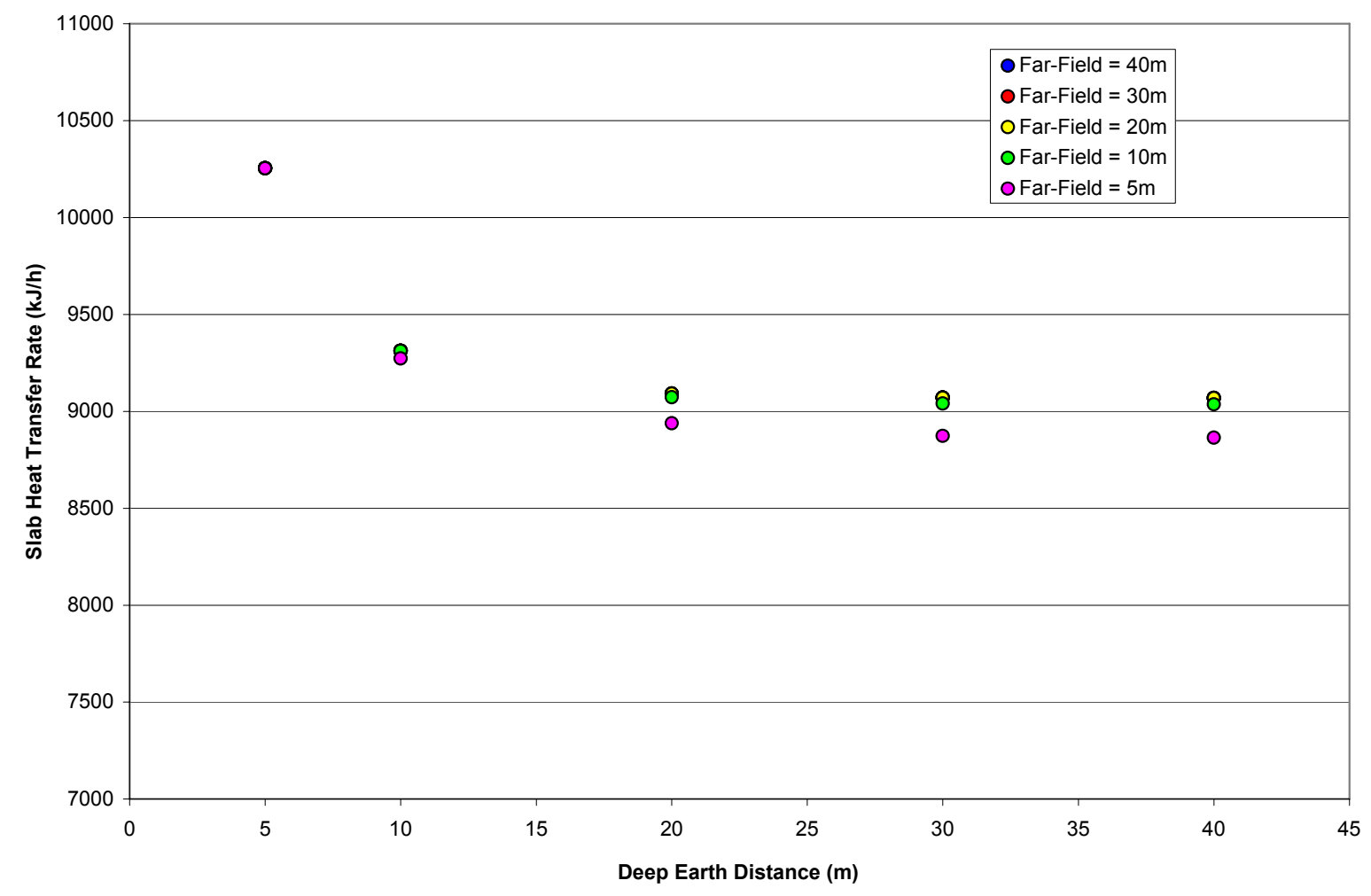

Figure 2A-1. Impact of deep earth and far-field dimensions on slab heat transfer rate, Case GC30

Table 2A-1. Varied Depth for $\mathbf{4 0} \mathrm{m}$ Far Field

\begin{tabular}{|rr|rr|}
\hline \multicolumn{1}{|c|}{$\begin{array}{c}\text { Deep } \\
\text { Earth }(\mathbf{m})\end{array}$} & $\begin{array}{c}\text { Far-Field } \\
(\mathbf{m})\end{array}$ & $\begin{array}{c}\text { Slab Heat } \\
\text { Transfer } \\
(\mathbf{k J} / \mathbf{h})\end{array}$ & $\begin{array}{c}\text { Change v. } \\
\mathbf{4 0 m} / \mathbf{4 0 m} \\
(\%)\end{array}$ \\
\hline 40 & 40 & 9069.0 & \\
$\mathbf{3 0}$ & $\mathbf{4 0}$ & $\mathbf{9 0 7 1 . 2}$ & $\mathbf{0 . 0 2 \%}$ \\
20 & 40 & 9091.8 & $0.25 \%$ \\
10 & 40 & 9312.7 & $2.69 \%$ \\
5 & 40 & 10254.4 & $13.07 \%$ \\
\hline
\end{tabular}

Table 2A-2 Varied Far Field for $30 \mathrm{~m}$ Depth

\begin{tabular}{|c|c|c|c|}
\hline $\begin{array}{c}\text { Deep } \\
\text { Earth }(\mathrm{m})\end{array}$ & $\begin{array}{c}\text { Far-Field } \\
(\mathrm{m})\end{array}$ & $\begin{array}{c}\text { Slab Heat } \\
\text { Transfer } \\
(\mathrm{kJ} / \mathrm{h})\end{array}$ & $\begin{array}{c}\text { Change v. } \\
30 \mathrm{~m} / 40 \mathrm{~m} \\
(\%)\end{array}$ \\
\hline 30 & 40 & 9071.2 & \\
\hline 30 & 30 & 9071.3 & $0.00 \%$ \\
\hline 30 & 20 & 9070.1 & $-0.01 \%$ \\
\hline 30 & 10 & 9040.9 & $-0.33 \%$ \\
\hline 30 & 5 & 8873.1 & $-2.18 \%$ \\
\hline
\end{tabular}

To establish a far-field dimension $(\mathrm{F})$ for the " $\mathrm{b}$ "-series cases $\left(\mathrm{h}=100 \mathrm{~W} / \mathrm{m}^{2} \mathrm{~K}\right)$, far-field dimensions were varied for ground depth $=15 \mathrm{~m}$. Based on results of Table 2A-3, far-field dimension of $15 \mathrm{~m}$ was chosen for the " $b$ "-series cases. Results variation for $F=15$ versus $F=8$ (specified for the "c"-series cases) is also shown. 
Table 2A-3 Variation of Far-Field for 30m Depth

\begin{tabular}{|r|rr|}
\hline $\begin{array}{c}\text { Far-Field } \\
(\mathrm{m})\end{array}$ & $\begin{array}{l}\text { Slab Heat } \\
\text { Transfer Rate } \\
(\mathrm{kJ} / \mathrm{h})\end{array}$ & $\begin{array}{c}\text { Change v. } \\
\text { Previous Detail } \\
(\%)\end{array}$ \\
\hline 8 & 8726 & \\
10 & 8737 & $0.13 \%$ \\
12 & 8741 & $0.05 \%$ \\
$\mathbf{1 5}$ & $\mathbf{8 7 4 6}$ & $\mathbf{0 . 0 6 \%}$ \\
20 & 8744 & $-0.02 \%$ \\
\hline
\end{tabular}

\section{Surface Coefficient Sensitivity Tests}

The effect of surface heat transfer coefficients on floor conduction was analyzed. Figure 2A-2 indicates slab heat transfer versus exterior heat transfer coefficient for Case GC30, and shows a 2\% decrease in floor conduction for $\mathrm{h}=100 \mathrm{~W} / \mathrm{m}^{2} \mathrm{~K}$ versus an idealized exterior high heat transfer coefficient that approximates a constant temperature surface boundary condition (i.e., $\mathrm{h}>5000 \mathrm{~W} / \mathrm{m}^{2} \mathrm{~K}$ ). If both interior and exterior heat transfer coefficients are set to $h=100 \mathrm{~W} / \mathrm{m}^{2} \mathrm{~K}$, the slab heat transfer decrease is $4 \%$ versus idealized boundary conditions. Note for units in the figure slab heat transfer is in $\mathrm{kJ} / \mathrm{h}$ and heat transfer coefficient is in $\mathrm{kJ} /\left(\mathrm{h} \cdot \mathrm{m}^{2} \mathrm{~K}\right)$, whereas the test specification uses $\mathrm{W}$ and $\mathrm{W} / \mathrm{m}^{2} \mathrm{~K}$ respectively.

Figure 2A-3 shows how Case GC30 slab heat transfer changes when interior and exterior heat transfer coefficients are varied separately and together, for $\mathrm{h} \leq 100 \mathrm{~W} / \mathrm{m}^{2} \mathrm{~K}$; the result for the constant temperature boundary condition is the dashed line (asymptote as $\mathrm{h}$ increases).

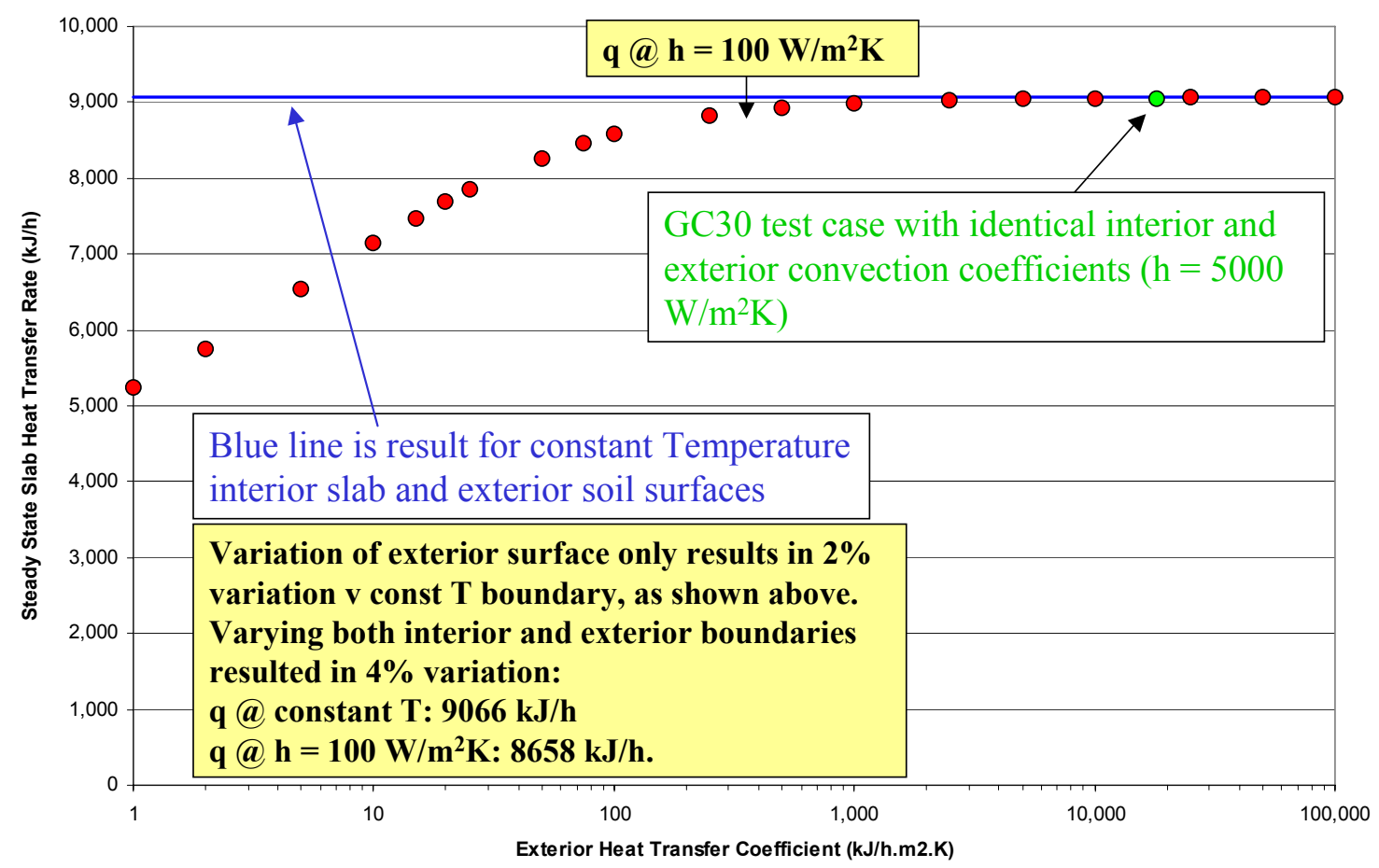

Figure 2A-2. Impact of exterior heat transfer coefficient on Case GC30 slab heat transfer results 


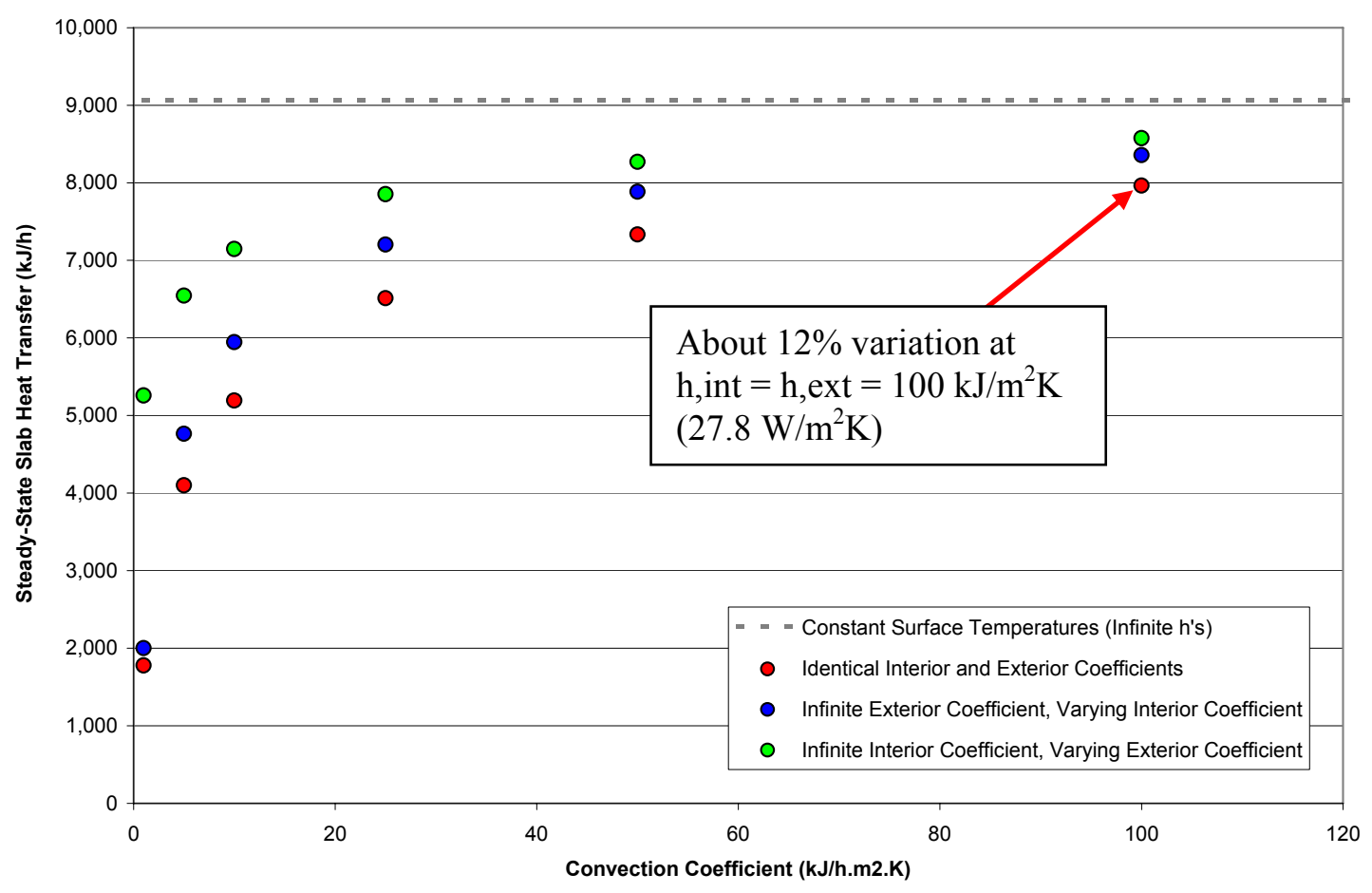

Figure 2A-3. Slab heat transfer as a function of the surface coefficients, TRNSYS Case GC30

\section{Conclusions and Recommendations}

Conclusions about your test results and/or IEA BESTEST in-depth diagnostic cases for ground coupled heat transfer related to slab-on-grade construction. Recommendations regarding future improvements to your software and/or this test specification.

1. We're excited to see that the results from our model match very closely with the published results from FLUENT and MATLAB for all cases and with GHT-SUNREL for many of the test cases. The fact that the three reference-standard programs can closely agree on these test cases gives an increased sense of confidence to all participants when comparing to the reference results.

2. The results for our GC10a simulation show a less than 1\% difference compared to the analytical solution.

3. We're convinced that the extra effort we put forth to make the model as flexible as possible paid off when we were able to run all of the test cases without having to "tweak" the model parameters and/or assumptions to mimic some of the test conditions. This flexibility also allowed us to assist the task leaders in assessing the impact of test specifications for the "b" and "c" test cases.

4. Without this IEA subtask for ground coupling, we would have had no means to check the results from our model, nor had a reason to make improvements to our model. There should be no question that the IEA subtask has improved the TRNSYS ground coupling model and, in doing so, has also provided energy modelers a greatly increased sense of confidence when modeling heat transfer to the ground.

\section{Recommendations}

Another analytical test that could easily be added to this project is the case of 1-D heat transfer using the conditions specified in GC40. Have the edges of the slab be heavily insulated in the depth direction to the 
location of the deep earth boundary (effectively setting F to zero). Referring to Figure 1-2 of Part I the steady state solution is then simply qslab $=$ ksoil $* \mathrm{~B} * \mathrm{~L} *($ Tia-Tdg) / E. This is one of the very first test cases we ran when creating our model.

\section{References}

Kasuda, T.; Archenbach, P.R. (1965). Earth Temperature and Thermal Diffusivity at Selected Stations in the United States. ASHRAE Transactions, 71 (1). 


\begin{tabular}{|c|c|c|c|c|c|c|c|c|c|}
\hline \multicolumn{7}{|c|}{\begin{tabular}{l|l|} 
Model and Version: TRNSYS v16 with Optional TESS Component Libraries \\
\end{tabular}} & \multicolumn{3}{|c|}{ Insulation Components } \\
\hline & \multicolumn{4}{|c|}{ Below-Grade High-Mass Components } & \multicolumn{2}{|c|}{ Low-Mass Components } & \multirow{2}{*}{$\begin{array}{l}\text { Horizontal } \\
\text { Edge } \\
\text { Insulation }\end{array}$} & \multirow{2}{*}{\begin{tabular}{c|} 
Vertical \\
Interior Edge \\
Insulation
\end{tabular}} & \multirow{2}{*}{$\begin{array}{l}\text { Vertical } \\
\text { Exterior Edge } \\
\text { Insulation }\end{array}$} \\
\hline & Slab & $\begin{array}{c}\text { Foundation } \\
\text { Wall }\end{array}$ & Footer & Soil & Sill Plate & $\begin{array}{c}\text { Above Grade } \\
\text { Wall }\end{array}$ & & & \\
\hline \multicolumn{10}{|l|}{ GEOMETRY* } \\
\hline $\begin{array}{r}\text { Floor Slab In (below) Grade ("yes" or "no") } \\
\text { Floor Slab On (above) Grade ("yes" or "no") } \\
\text { Floor Slab Minimum Thickness (cm) } \\
\text { Floor Slab Maximum Thickness (cm) }\end{array}$ & \begin{tabular}{|c|} 
yes \\
yes \\
$>0$ \\
+Infinity
\end{tabular} & $\begin{array}{l}\mathrm{n} / \mathrm{a} \\
\mathrm{n} / \mathrm{a} \\
\mathrm{n} / \mathrm{a} \\
\mathrm{n} / \mathrm{a}\end{array}$ & $\begin{array}{l}n / a \\
n / a \\
n / a \\
n / a\end{array}$ & $\begin{array}{l}n / a \\
n / a \\
n / a \\
n / a\end{array}$ & $\begin{array}{l}\mathrm{n} / \mathrm{a} \\
\mathrm{n} / \mathrm{a} \\
\mathrm{n} / \mathrm{a} \\
\mathrm{n} / \mathrm{a}\end{array}$ & $\begin{array}{l}\mathrm{n} / \mathrm{a} \\
\mathrm{n} / \mathrm{a} \\
\mathrm{n} / \mathrm{a} \\
\mathrm{n} / \mathrm{a}\end{array}$ & $\begin{array}{l}\mathrm{n} / \mathrm{a} \\
\mathrm{n} / \mathrm{a} \\
\mathrm{n} / \mathrm{a} \\
\mathrm{n} / \mathrm{a}\end{array}$ & $\begin{array}{l}n / a \\
n / a \\
n / a \\
n / a\end{array}$ & $\begin{array}{l}\mathrm{n} / \mathrm{a} \\
\mathrm{n} / \mathrm{a} \\
\mathrm{n} / \mathrm{a} \\
\mathrm{n} / \mathrm{a}\end{array}$ \\
\hline $\begin{array}{l}\text { Minimum } x \text {-Thickness or Width }(\mathrm{cm}) \\
\text { Maximum } x \text {-Thickness or Width }(\mathrm{cm})\end{array}$ & $\begin{array}{l}\mathrm{n} / \mathrm{a} \\
\mathrm{n} / \mathrm{a}\end{array}$ & $\begin{array}{c}\quad>0 \\
+ \text { Infinity }\end{array}$ & $\begin{array}{c}0 \\
\text { b (see below) }\end{array}$ & $\begin{array}{l}n / a \\
n / a\end{array}$ & \multicolumn{2}{|c|}{${ }^{\mathrm{a}}$ (see below) } & $\begin{array}{l}\text { c(see } \\
\text { below) }\end{array}$ & $\begin{array}{l}0 \\
0\end{array}$ & $\begin{array}{l}0 \\
0\end{array}$ \\
\hline $\begin{array}{r}\text { Minimum } z \text {-Thickness }(\mathrm{cm}) \\
\text { Maximum } z \text {-Thickness }(\mathrm{cm})\end{array}$ & $\begin{array}{l}\mathrm{n} / \mathrm{a} \\
\mathrm{n} / \mathrm{a}\end{array}$ & $\begin{array}{l}\mathrm{n} / \mathrm{a} \\
\mathrm{n} / \mathrm{a}\end{array}$ & $\begin{array}{c}0 \\
+ \text { Infinity }\end{array}$ & $\begin{array}{l}\mathrm{n} / \mathrm{a} \\
\mathrm{n} / \mathrm{a}\end{array}$ & & $\begin{array}{l}\mathrm{n} / \mathrm{a} \\
\mathrm{n} / \mathrm{a}\end{array}$ & $\begin{array}{l}0 \\
0\end{array}$ & $\begin{array}{l}\mathrm{n} / \mathrm{a} \\
\mathrm{n} / \mathrm{a}\end{array}$ & $\begin{array}{l}\mathrm{n} / \mathrm{a} \\
\mathrm{n} / \mathrm{a}\end{array}$ \\
\hline Minimum Bottom-Edge Depth Below Grade $(z, \mathrm{~cm})$ & $\mathbf{0}$ & $\mathbf{0}$ & $\mathbf{0}$ & $\mathrm{n} / \mathrm{a}$ & $\mathrm{n} / \mathrm{a}$ & $\mathrm{n} / \mathrm{a}$ & $\mathrm{n} / \mathrm{a}$ & \multirow{2}{*}{\multicolumn{2}{|c|}{${ }^{\mathrm{c}}$ (see below) }} \\
\hline Maximum Bottom-Edge Depth Below Grade $(z, \mathrm{~cm})$ & +Infinity & +Infinity & +Infinity & $\mathrm{n} / \mathrm{a}$ & n/a & $\mathrm{n} / \mathrm{a}$ & $\mathrm{n} / \mathrm{a}$ & & \\
\hline Minimum Top-Edge Height Above Grade $(z, \mathrm{~cm})$ & 0 & $>0$ & n/a & $\mathrm{n} / \mathrm{a}$ & n/a & n/a & $n / a$ & \multirow{2}{*}{\multicolumn{2}{|c|}{${ }^{\mathrm{c}}$ (see below) }} \\
\hline Maximum Top-Edge Height Above Grade $(z, \mathrm{~cm})$ & +Infinity & * (see below) & $\mathrm{n} / \mathrm{a}$ & $\mathrm{n} / \mathrm{a}$ & $\mathrm{n} / \mathrm{a}$ & n/a & $\mathrm{n} / \mathrm{a}$ & & \\
\hline $\begin{array}{r}\text { Minimum Soil Depth }(E, m) \\
\text { Maximum Soil Depth }(E, m)\end{array}$ & $\begin{array}{l}\mathrm{n} / \mathrm{a} \\
\mathrm{n} / \mathrm{a}\end{array}$ & $\begin{array}{l}\mathrm{n} / \mathrm{a} \\
\mathrm{n} / \mathrm{a}\end{array}$ & $\begin{array}{ll}n / a \\
n / a\end{array}$ & $\begin{array}{c}>0 \\
+ \text { +nfinity }\end{array}$ & $\begin{array}{ll}n / a \\
n / a\end{array}$ & $\begin{array}{l}n / a \\
n / a\end{array}$ & $\begin{array}{l}\mathrm{n} / \mathrm{a} \\
\mathrm{n} / \mathrm{a}\end{array}$ & $\begin{array}{ll}n / a \\
n / a\end{array}$ & $\begin{array}{ll}n / a \\
n / a\end{array}$ \\
\hline Minimum Soil Far-Field Distance $(F, m)$ & $\mathrm{n} / \mathrm{a}$ & $\mathrm{n} / \mathrm{a}$ & $\mathrm{n} / \mathrm{a}$ & $>0$ & $\mathrm{n} / \mathrm{a}$ & $\mathrm{n} / \mathrm{a}$ & $\mathrm{n} / \mathrm{a}$ & $\mathrm{n} / \mathrm{a}$ & $\mathrm{n} / \mathrm{a}$ \\
\hline Maximum Soil Far-Field Distance $(F, m)$ & $\mathrm{n} / \mathrm{a}$ & $\mathrm{n} / \mathrm{a}$ & $\mathrm{n} / \mathrm{a}$ & +Infinity & $\mathrm{n} / \mathrm{a}$ & $\mathrm{n} / \mathrm{a}$ & $\mathrm{n} / \mathrm{a}$ & $\mathrm{n} / \mathrm{a}$ & $\mathrm{n} / \mathrm{a}$ \\
\hline \multicolumn{10}{|l|}{ THERMAL PROPERTIES* } \\
\hline $\begin{array}{c}\text { Minimum Conductivity }(\mathrm{W} /(\mathrm{mK})) \\
\text { Maximum Conductivity }(\mathrm{W} /(\mathrm{mK}))\end{array}$ & $\begin{array}{c}>0 \\
+ \text { Infinity }\end{array}$ & $\begin{array}{c}>0 \\
+ \text { Infinity }\end{array}$ & $\begin{array}{c}\quad>0 \\
+ \text { Infinity }\end{array}$ & $\begin{array}{c}>0 \\
+ \text { Infinity }\end{array}$ & & & $\begin{array}{l}0 \\
0\end{array}$ & $\begin{array}{l}0 \\
0\end{array}$ & $\begin{array}{l}0 \\
0\end{array}$ \\
\hline $\begin{array}{l}\left.\text { Minimum R-Value }\left(\mathrm{m}^{2} \mathrm{~K} / \mathrm{W}\right)\right) \\
\left.\text { Maximum R-Value }\left(\mathrm{m}^{2} \mathrm{~K} / \mathrm{W}\right)\right)\end{array}$ & ** & $\begin{array}{ll}* * \\
* *\end{array}$ & ** & $\begin{array}{l}* * \\
* *\end{array}$ & & & \begin{tabular}{|c|}
0 \\
+ +nfinity
\end{tabular} & $\begin{array}{c}0 \\
+ \text { +Infinity }\end{array}$ & $\begin{array}{c}0 \\
+ \text { Infinity }\end{array}$ \\
\hline $\begin{array}{l}\text { Minimum Density }\left(\mathrm{kg} / \mathrm{m}^{3}\right) \\
\text { Maximum Density }\left(\mathrm{kg} / \mathrm{m}^{3}\right)\end{array}$ & \begin{tabular}{c|}
$>0$ \\
+Infinity
\end{tabular} & $\begin{array}{c}\quad>0 \\
+ \text { Infinity }\end{array}$ & $\begin{array}{c}\quad>0 \\
+ \text { +Infinity }\end{array}$ & $\begin{array}{c}>0 \\
\text { +Infinity }\end{array}$ & & & $\begin{array}{l}0 \\
0\end{array}$ & $\begin{array}{l}0 \\
0\end{array}$ & $\begin{array}{l}0 \\
0\end{array}$ \\
\hline $\begin{array}{l}\text { Minimum Specific Heat }(\mathrm{kJ} /(\mathrm{kgK})) \\
\text { Maximum Specific Heat }(\mathrm{kJ} /(\mathrm{kgK}))\end{array}$ & $\begin{array}{c}>0 \\
\text { +Infinity }\end{array}$ & $\begin{array}{c}>0 \\
+ \text { Infinity }\end{array}$ & $\begin{array}{c}>0 \\
+ \text { Infinity }\end{array}$ & $\begin{array}{c}>0 \\
+ \text { Infinity }\end{array}$ & & & $\begin{array}{l}\mathbf{0} \\
\mathbf{0}\end{array}$ & $\begin{array}{l}0 \\
0\end{array}$ & $\begin{array}{l}0 \\
0\end{array}$ \\
\hline \multicolumn{10}{|l|}{ COMMENTS } \\
\hline \multirow{2}{*}{$\begin{array}{r}\text { Uninsulated detail (Figure A-1) ok? ("yes" or "no") } \\
\text { Insulated detail (Figure A-2) ok? ("yes" or "no") } \\
\text { If no, include additional assumptions of your model } \\
\text { not covered here (add rows as needed) }\end{array}$} & \begin{tabular}{|l} 
yes $^{a}$ \\
yes $^{a}$
\end{tabular} & & & & & & & & \\
\hline & \multicolumn{9}{|c|}{$\begin{array}{l}\text { a the ground model does not directly apply above the top edge of the slab including sill plate, walls etc.; } \\
\text { limits for above grade components are those typical to the TRNSYS building type }\end{array}$} \\
\hline $\begin{array}{r}\text { Include other clarfications and/or comments here } \\
\text { (add rows as needed) }\end{array}$ & \multicolumn{9}{|c|}{$\begin{array}{l}\text { c insulation is only allowed adjacent to high-mass sections (ie cannot extend below the foundation wall etc.) } \\
\text { insulation modeled as an additional massless resistance located on the boundary between two nodes such that, } \\
\text { e.g.,: } R=d x(\mathrm{i}) / 2 . / \text { Conductivity }(\mathrm{i}, \mathrm{j}, \mathrm{k})+\mathrm{Rinsulation}+\mathrm{dx}(\mathrm{i}-1) / 2 . / \text { Conductivity(i-1,j,k)} \\
\text { note that this equation is an example for } 1 \text { surface along the } \mathrm{x} \text {-axis; there are } 6 \text { equations for each node, } \\
\text { one for each boundary. }\end{array}$} \\
\hline
\end{tabular}

\section{NOTES}

"n/a": not applicable

* If a listed input does not apply to your model, enter " 0 " in the relevant cells.

${ }^{* *}$ For below grade high-mass components, only list $R$-value input limits if there is some difference versus what would be calculated based on listed conductivity and thickness limits 
Appendix II-B

\title{
Modeler Report for BESTEST Cases GC10a-GC80c \\ FLUENT Version 6.0.20
}

\author{
by \\ Dr. Abdullatif Ben-Nakhi, Associate Professor \\ College of Technological Studies - Public Authority for Applied Education and Training \\ (PAAET), Kuwait
}

\author{
Edited by Joel Neymark, J. Neymark \& Associates, United States
}

September 2007

\section{Introduction}

\section{Modeling Software: FLUENT 6.0.20, by Fluent Incorporated, Centerra Resource Park, 10} Cavendish Court, Lebanon, NH 03766

- The model is independent of a whole-building simulation program. However, it requires a meshing tool. GAMBIT is commonly used to build and mesh models for FLUENT.

- In the current work, the ground is modeled without the building. The building is represented by a thermal boundary surface (e.g., fixed surface temperature, convective surface, etc.).

- Any positive time step is acceptable in principle; however, numerical stabilities should be respected. In the current work, the time step for all transient simulations was 1 hour.

- FLUENT is a state-of-the-art computer program for modeling fluid flow and heat transfer in complex geometries. In the current work, only heat transfer in simple geometries is considered. It was concluded that the post-processing facilities in FLUENT 6.0 are not optimal for the current project purposes, although the post-processing facilities in FLUENT are highly efficient for fluid flow problems.

\section{Modeling Assumptions}

FLUENT allows input of the linearly varying perimeter surface temperature boundary condition of GC10a. In all cases, it was necessary to model only one quarter of the domain, as the problem is symmetric. See Appendix A of this report for discussion of range of modeling possible with FLUENT.

Because analysis with FLUENT is done independently of a whole-building energy simulation program, outside surface temperatures are provided directly as boundary conditions. For the periodic cases the equation describing ODB variation provided in the test specification was used as basis to write a UDF (user defined function) within FLUENT to explicitly and directly set the outside surface temperature for Case GC40a, and to set the outside air temperature for the other periodic cases. The outside surface temperatures provided are produced by FLUENT via monitoring the temperature of the center of the outside surface (i.e., at the mid-distance between the perimeter and far-field surface). Because of limitations in FLUENT 6.0's built-in output reporting capabilities, it was not possible to monitor outside ambient temperature when a convective boundary is defined. However, the ODB UDF was validated by monitoring the outside surface temperature in GC40a, which defines the outside surface temperature. 


\section{Modeling Options}

FLUENT offers two major types of solvers: steady-state and transient. For all steady-state cases, the steady-state solver was used, which does not consider density and/or heat capacity in the governing equations. There is no time step in this solver; a steady-state run consists of several iterations (not time steps) until it converges (i.e., the governing equations are valid). This steady-state solver should give faster and more accurate results than steady-state results using the dynamic solver for many time steps.

\section{Modeling Difficulties}

The periodic cases require very long start-up period (i.e., several years). This is mainly due to the large thermal mass associated with the ground (i.e., domain). In order to overcome this problem, two options were implemented. In the first option, the temperature distribution at the end of simulation of another case of equivalent dimensions was used as the initial condition. When that was not available, the second option was used, in which the steady-state solution of the active periodic case was used as the initial condition for the problem. The steady-state solution for the active periodic case was created by replacing the periodic temperature with a steady temperature of $10^{\circ} \mathrm{C}$.

\section{Demonstration of Appropriate Level of Modeling Detail}

The figures below show the final grids that were employed. For example, Figure 2B-1 ("inside-m0p06r1p10") shows the structured mesh for the floor slab, where "m0p06" means mesh size for inside slab and perimeter is $0.06 \mathrm{~m}$ (i.e., uniform mesh size throughout both surfaces), and " $\mathrm{r} 1 \mathrm{p} 10$ " means mesh size increases in the $\mathrm{x}, \mathrm{y}$, and $\mathrm{z}$ directions with a ratio of 1.10 outside the internal and perimeter surfaces. Mesh size increase is shown, for example, in Figures 2B-2 ("outside-m0p06-r1p10”) and 2B-4 ("deepm0p06-r1p10”).

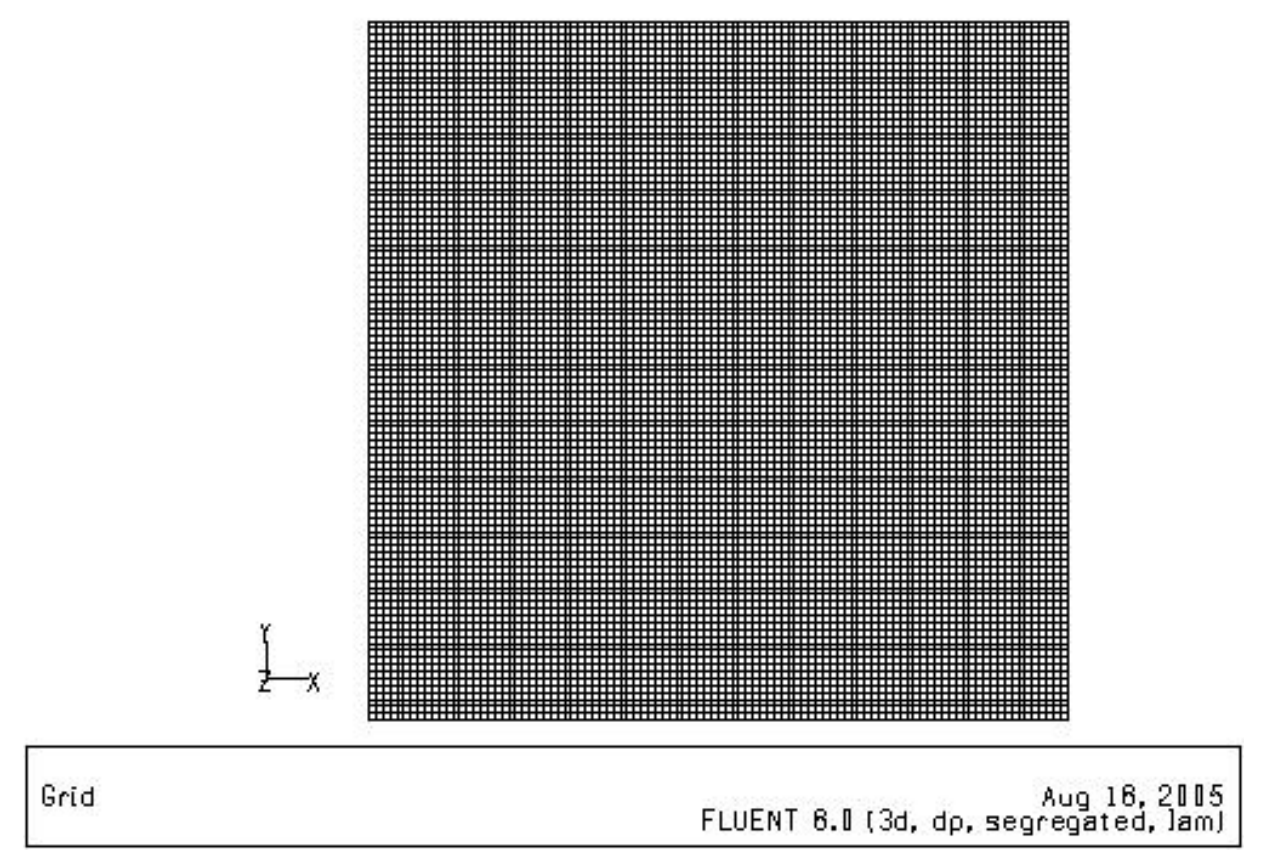

Figure 2B-1. (“inside-m0p06-r1p10"): mesh for inside slab surface; plan view of the slab-only showing uniform grid 


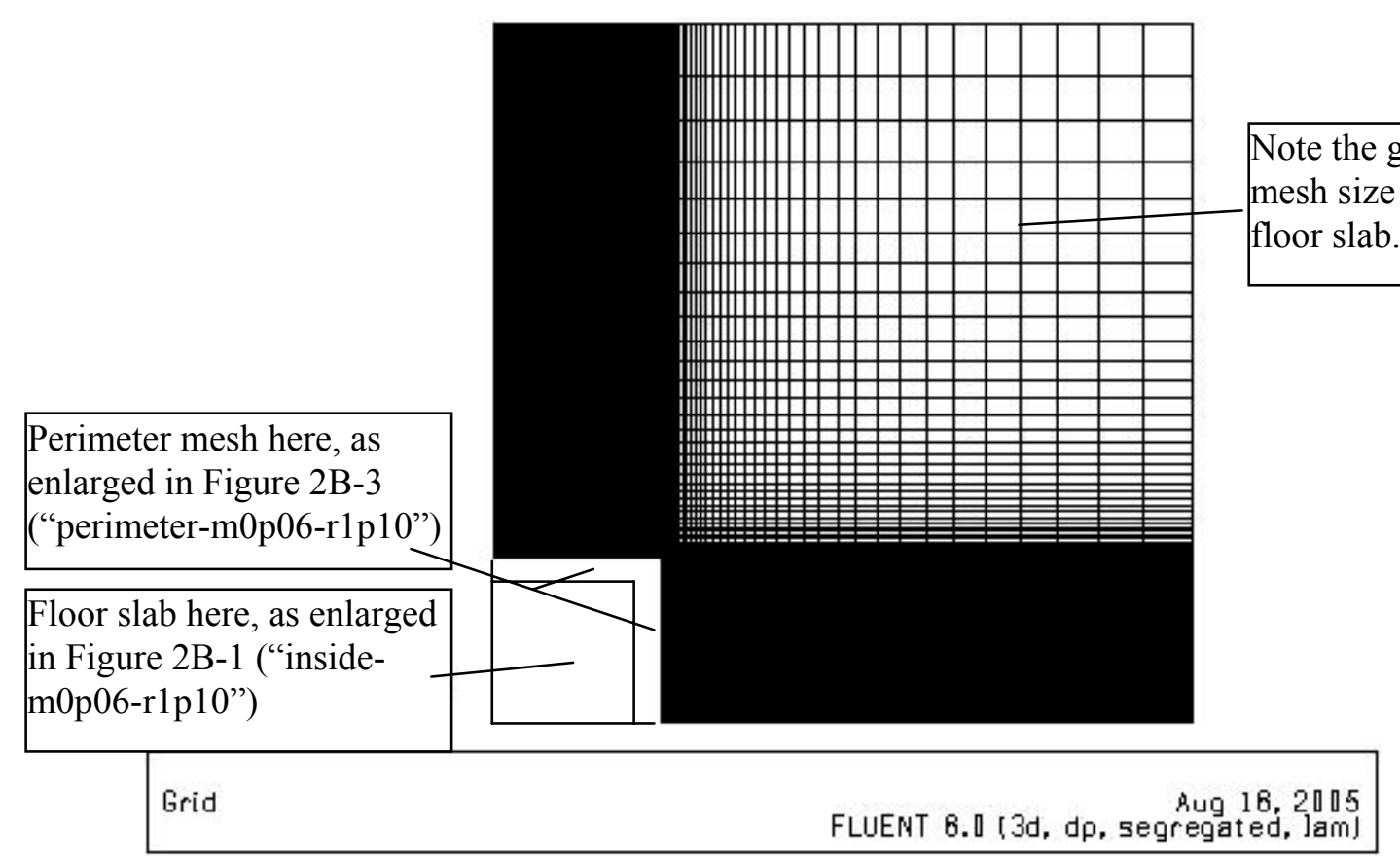

Figure 2B-2 (“outside-m0p06-r1p10”): mesh for outside boundary surface; plan view

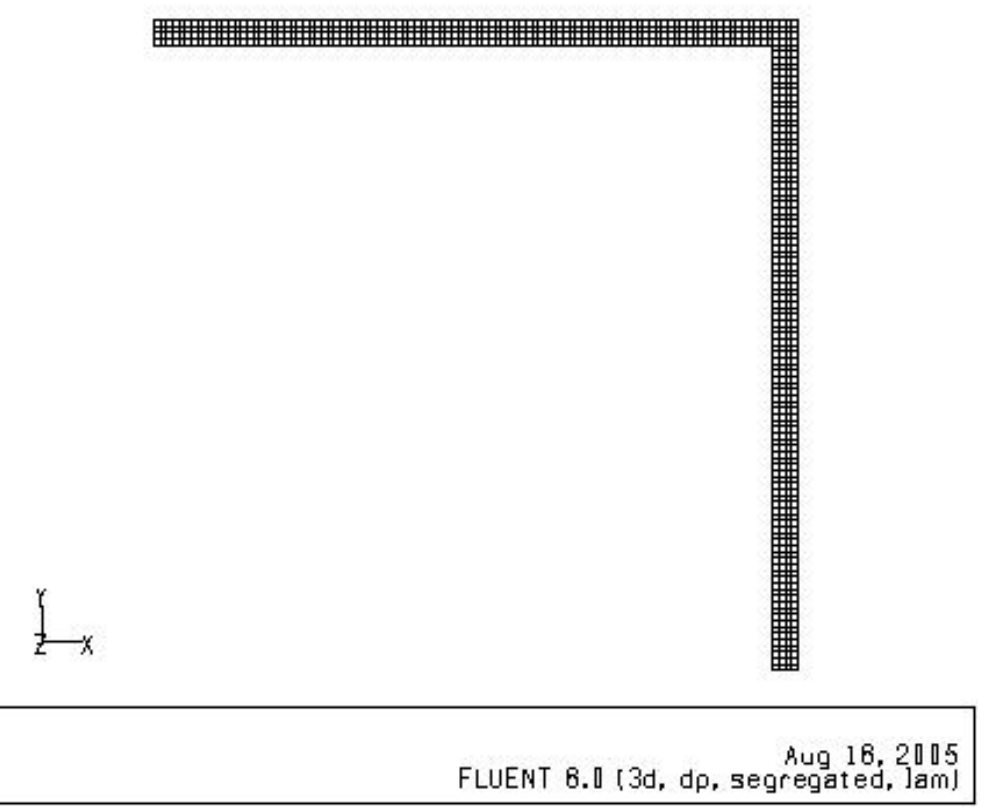

Figure 2B-3 ("perimeter-m0p06-r1p10"): uniform mesh for perimeter surface boundary; plan view 


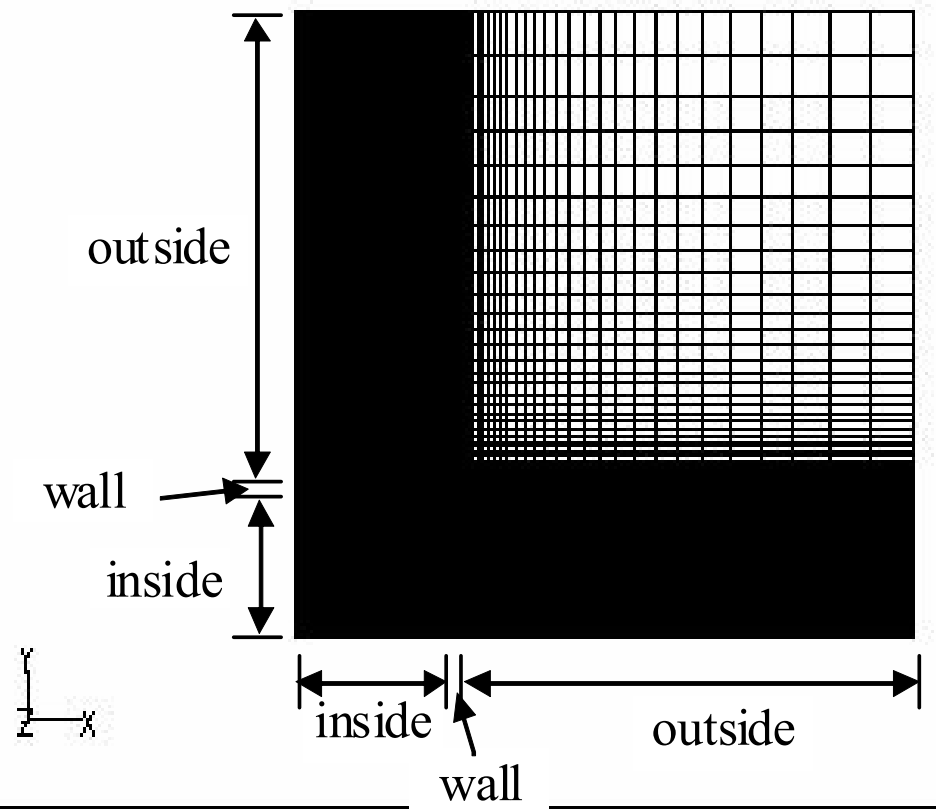

Grid

Rug 16,2005

FLUENT 6.0 [3d, dp, segregated, ]am)

\section{Figure 2B-4 (“deep-m0p06-r1p10"): structured mesh for deep ground boundary (plan view of bottom surface grid at GC10a deep ground depth of $\mathbf{4 0}$ meters)}

Figure 2B-4 ("deep-m0p06-r1p10") is a horizontal section drawing indicating node structure at the deep ground boundary depth of $40 \mathrm{~m}$ for Case GC10a. In this figure "inside," "wall," and "outside" indicate the relative locations of the slab, perimeter wall, and soil respectively at the surface (see Figure 2B-2 ["outside-m0p06-r1p10]); at the $40 \mathrm{~m}$ depth there is only soil, and no slab or perimeter wall. The same horizontal mesh structure continues from the surface to the deep ground depth, however, the distance between nodes increases in the vertical direction. This is shown in Figure 2B-5 ("far-m0p06-r1p10"), which indicates an isometric view (looking downward through the top surface) of only the far-field mesh structure for the bounding vertical planes descending from the slab/soil top surface to the deep ground depth. This results in an implemented mesh that is non-uniform (i.e., mesh size changes in space dimension, such as x-direction), orthogonal (mesh lines intersect perpendicularly), and structured (each 3$\mathrm{D}$ cell is connected to only one 3-D cell in each of the 6 directions (6 cells in total); and the indices (i.e., node number) of the adjacent nodes do not need to be saved as each adjacent node index can be determined based on the ordered geometry. For unstructured mesh the neighboring indices should be saved, as cells are not arranged in arrays. 


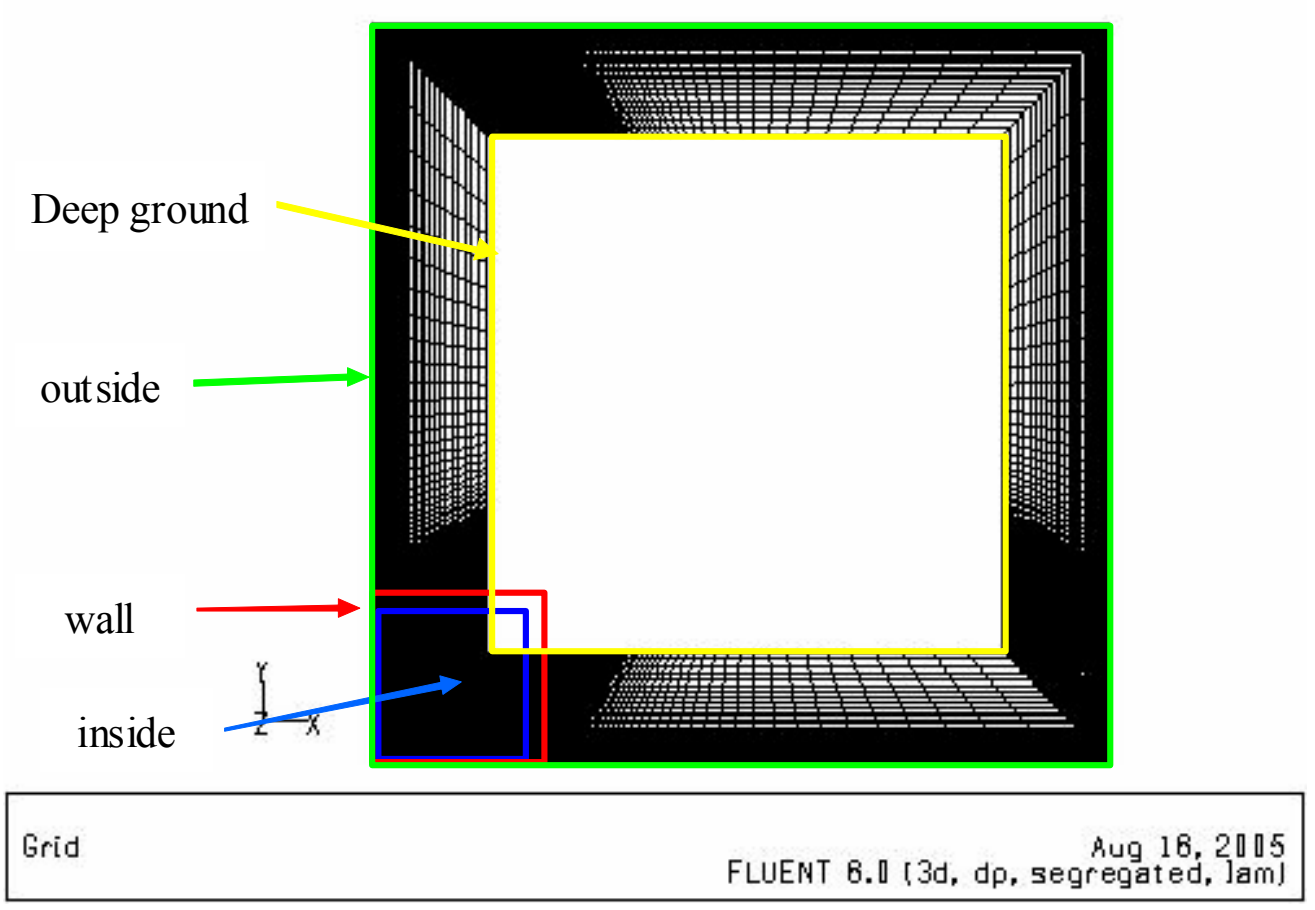

Figure 2B-5 ("far-m0p06-r1p10"): mesh for far field boundary, isometric view (looking downward from the surface) of the far-field mesh structure for the bounding vertical planes descending from the surface to the deep ground depth

Note in Figure 2B-5 ("far-m0p06-r1p10"): At the deep ground level Figure 2B-4 ("deep-m0p06-r1p10") fits in the yellow square labeled as "deep ground". At the surface level Figure 2B-2 ("outside-m0p06-r1p10") fits in the green square labeled "outside", and blue and red lines identify the slab and perimeter wall boundaries, respectively.

Figure 2B-6 (“deep-uns-m0p04-r1p10") is an earlier unstructured mesh version of the deep ground boundary structured mesh of Figure 2B-4 ("deep-m0p06-r1p10"). Several mesh approaches and densities were examined. The structured mesh was implemented because of the faster simulation compared to unstructured mesh such as the one shown below. 


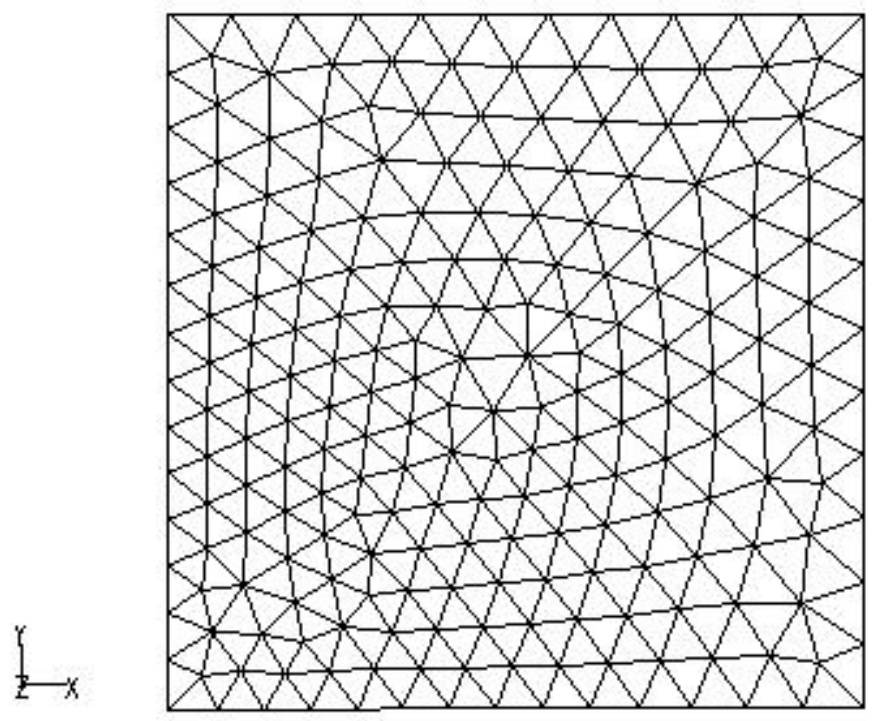

Figure 2B-6 (“deep-uns-m0p04-r1p10”): unstructured mesh for deep ground surface boundary

Demonstration of appropriate level of modeling detail is summarized as follows.

\section{Case gc10a:}

The results shown below are for $40 \mathrm{~m}$ deep-ground distance and $40 \mathrm{~m}$ far-field distance. As only onequarter of the domain is modeled, the values provided are for the results of the model multiplied by 4 .

\begin{tabular}{|l|l|l|l|l|}
\hline $\begin{array}{l}\text { Run } \\
\text { No. }\end{array}$ & Case Name & $\begin{array}{l}\text { Flux } \\
\text { (Watt) }\end{array}$ & $\begin{array}{l}\text { Result } \\
\text { Quality }\end{array}$ & $\begin{array}{l}\text { Number of } \\
\text { Nodes }\end{array}$ \\
\hline $\mathbf{1}$ & gc10a-e40-f40-m0p12-r1p10 & 2405.2 & Good & 322959 \\
\hline $\mathbf{2}$ & gc10a-e40-f40-m0p08-r1p10 & 2418.9 & Better & 629563 \\
\hline $\mathbf{3}$ & gc10a-e40-f40-m0p06-r1p10 & 2424.5 & Best & 999045 \\
\hline & analytical solution & 2432.6 & & \\
\hline
\end{tabular}

The relation between the flux increase and increase in number of nodes indicates that the target or exact solution for flux should be greater than $2424.5 \mathrm{~W}$ for the run where deep ground distance (e-distance) is $40 \mathrm{~m}$ and far field distance (f-distance) is $40 \mathrm{~m}$. The "m0p06-r1p10" mesh yields a heat flow result $0.2 \%$ greater than the previous level of detail ("m0p08-r1p10"), and is within $0.3 \%$ of the analytical solution.

Deep ground distance and far-field distance (amount of soil domain to model) were established based on the following results. 


\begin{tabular}{|l|l|l|l|l|}
\hline $\begin{array}{l}\text { Run } \\
\text { No. }\end{array}$ & Case Name & $\begin{array}{l}\text { Flux } \\
\text { (Watt) }\end{array}$ & $\begin{array}{l}\text { Result } \\
\text { Quality }\end{array}$ & $\begin{array}{l}\text { Number of } \\
\text { Nodes }\end{array}$ \\
\hline $\mathbf{4}$ & gc10a-e30-f20-m0p06-r1p10 & 2423.4 & Better & 846888 \\
\hline $\mathbf{3}$ & gc10a-e40-f40-m0p06-r1p10 & 2424.5 & Best & 999045 \\
\hline & analytical solution & 2432.6 & & \\
\hline
\end{tabular}

The $0.04 \%$ variation going from Run No. 4 to Run No. 3 indicates that increasing the soil depth beyond $40 \mathrm{~m}$ for depth and far-field dimensions can only have negligible effect, and upon consideration of runs No. 1 and No.2 suggests that to achieve better agreement with the analytical solution, one should apply a more dense mesh (if practical).

\section{Case gc30a:}

The results shown below are for $30 \mathrm{~m}$ deep ground distance and $20 \mathrm{~m}$ far field distance.

\begin{tabular}{|l|l|l|l|l|}
\hline $\begin{array}{l}\text { Run } \\
\text { No. }\end{array}$ & Case Name & $\begin{array}{l}\text { Flux } \\
\text { (Watt) }\end{array}$ & Result Quality & $\begin{array}{l}\text { Number of } \\
\text { Nodes }\end{array}$ \\
\hline $\mathbf{5}$ & gc30a-e30-f20-m0p12-r1p05 & 2501.9 & Good & 529254 \\
\hline $\mathbf{6}$ & gc30a-e30-f20-m0p08-r1p05 & 2558.4 & Better & 1080288 \\
\hline $\mathbf{7}$ & gc30a-e30-f20-m0p06-r1p10 & 2585.3 & Best & 846888 \\
\hline
\end{tabular}

The mesh of Run No. 6 is better than for Run No. 5 in that the wall mesh size for Run No. 6 is $0.08 \mathrm{~m}$ while it is $0.12 \mathrm{~m}$ for Run No. 5. The rate of mesh size increase away from the wall is 1.05 for both Runs No. 5 and No. 6. Due to memory limitation Run No. 7 was modeled with mesh increase ratio of 1.10 while the wall mesh size is $0.06 \mathrm{~m}$. Time constraints prevented simulation of an additional run with wall mesh size of $0.04 \mathrm{~m}$ and mesh increase ratio of 1.10. Had this more detailed run been performed, the result would probably be somewhat greater than $2585.3 \mathrm{~W}$ (and possibly a bit closer agreement with TRNSYS [2641.7 W] than the current $2 \%$ difference).

Regarding sufficient duration of simulation, results are provided showing the difference in the results for each year of the simulation. The results below give an example of this for GC40a, where 5 years were simulated for a detailed mesh utilizing double precision and 1087849 nodes.

\begin{tabular}{|l|c|c|c|c|c|c|c|c|c|}
\hline & 1st Year & 2nd Year & $\begin{array}{c}\text { \% change } \\
\text { v. prior } \\
\text { year }\end{array}$ & 3rd Year & $\begin{array}{c}\text { \% change } \\
\text { v. prior } \\
\text { year }\end{array}$ & 4th Year & $\begin{array}{c}\text { \% change } \\
\text { v. prior } \\
\text { year }\end{array}$ & 5th Year & $\begin{array}{c}\text { \% change } \\
\text { v. prior } \\
\text { year }\end{array}$ \\
\hline $\min (\mathbf{W})$ & 578.0642 & 548.5512 & 5.38 & 542.4594 & 1.12 & 540.065 & 0.44 & 538.8389 & 0.23 \\
\hline $\max (\mathbf{W})$ & 23183.79 & 777.7612 & 2880.84 & 765.9149 & 1.55 & 762.2567 & 0.48 & 760.5798 & 0.22 \\
\hline average (W) & 772.9901 & 660.9343 & 16.95 & 653.5455 & 1.13 & 650.8789 & 0.41 & 649.559 & 0.20 \\
\hline sum (kW) & 6771.394 & 5789.785 & 16.95 & 5725.058 & 1.13 & 5701.699 & 0.41 & 5690.137 & 0.20 \\
\hline
\end{tabular}

\section{Software Errors Discovered, and/or Comparison between Different Versions of the Same Software, and/or Lessons Learned regarding Use of Detailed Models}

Two output reporting issues occurred in FLUENT 6.0, as follows: 
a. FLUENT permits monitoring variables or their residuals in many forms (i.e., integral, maximum, minimum, mean, etc) during the simulation. Many of the post-processing utilities are available for monitoring during simulation per time step or iteration. For dynamic (i.e., transient) cases, the project output requires heat flux through inside slab per each time step of $3600 \mathrm{~s}(1 \mathrm{hr})$ period. This can be achieved by monitoring the integrated value of heat flux over all cells of the inside slab. However, when this option was invoked, it was noticed that the last monitored value of heat flux through inside slab differs from that obtained for the same variable via the post-processing utilities. The total heat flux through inside slab can be obtained in two ways from the post-processing utilities: 1) via report "fluxes", 2) via report "surface integrals". These two post-processing methods for calculating total heat flux through inside slab produced the same value that is different from that provided by the monitoring utility, which is based on automatically calling report "surface integrals" at the end of each time step and appending the value in a specified file. This issue occurs only when we want to monitor one of the coplanar surfaces, for example, the slab, perimeter, and outside surfaces, which are all encompassed by a single plane at the same level (top surface) and have similar slope (in this case horizontal). This may be an interpolation-related issue because there are nodes at adjacent surfaces having different boundary conditions. For example, when FLUENT performs integration over the inside slab, it uses values of nodes adjacent to the inside slab (i.e., the perimeter surface, which has a different boundary condition). This issue was bypassed by defining a post-processing surface (dummy surface used for data presentation purposes) that exactly overlaps the inside slab. The monitored heat flux through the created dummy surface matched the heat flux values provided by both post-processing utilities. This may be because FLUENT works with dummy surfaces in isolation as defined by the user, without investigating what is adjacent to the dummy surface. On the other hand, the outside temperature was monitored using only one node temperature. FLUENT facilitates monitoring the minimum, maximum, mean (or some other statistical forms) of temperature throughout the outside surface. A dummy (i.e., post-processing utility) point was defined that is located at the outside surface level ( $\mathrm{z}$ dimension) and at the mid-distance between the perimeter and far field surface ( $\mathrm{x}$ and $\mathrm{y}$ dimensions). The temperature of this dummy point was monitored as the outside surface temperature.

b. There is a bug in FLUENT that produces diagonal surface temperature profile results twice (i.e., each node value is reported twice within a single file). FLUENT facilitates two types of lines for postprocessing purposes: "line" and "rake". "Line" was used for reporting the temperature profile across the diagonal of the upper surface of the domain. The values reported across the "line" are at actual nodes of the domain mesh. It is possible to work-around the double reporting issue by using the "rake" option, which allows specifying the number of reporting points at equal spacing. However, "rake" produces interpolated values at the specified points instead of exact node values.

As discussed above, it was possible to work around these reporting issues to obtain proper outputs.

FLUENT Inc. investigated the above reporting errors and confirmed that both existed in FLUENT 6.0. They noted that both errors were already fixed for FLUENT 6.2, and that at the time of this writing FLUENT is currently at version 6.3.26. (Watve 2006)

\section{7. $\quad$ Results}

- Floor conduction for Case GC10a is within $0.33 \%$ of the analytical solution.

- For all other cases floor conduction results for FLUENT, TRNSYS, and MATLAB models are within $0.7 \%-4.2 \%$ of each other.

- Phase shift for peak floor conduction versus minimum ODB is consistent with the TRNSYS and 
MATLAB models in all cases.

If there were not practical limits for mesh detail using the PC computer available for this project, it may be possible to further reduce the disagreement versus the analytical solution, and obtain greater precision for the other results.

\section{Other}

Because of output limitations FLUENT does not allow precise reporting of the GC10a surface temperatures unless mesh density is increased beyond PC capabilities, which is not possible for this project. Figure 2B-7 shows that interpolated FLUENT surface temperatures for Case GC10a disagree with the TRNSYS surface temperatures. Figure 2B-8 shows TRNSYS temperatures for just below the surface agree with interpolated FLUENT results. As TRNSYS and FLUENT heat flow results are both within $0.4 \%$ of the GC10a analytical solution, and their sensitivities to variation of boundary conditions for Case GC30a appear to have good agreement, FLUENT output is consistent with correctly input boundary conditions for GC10a.

IEA BESTEST Ground Coupling: In-Depth Floor Slab TRNSYS Steady-State Surface Temperatures $(Y=0$, thru center of edge)

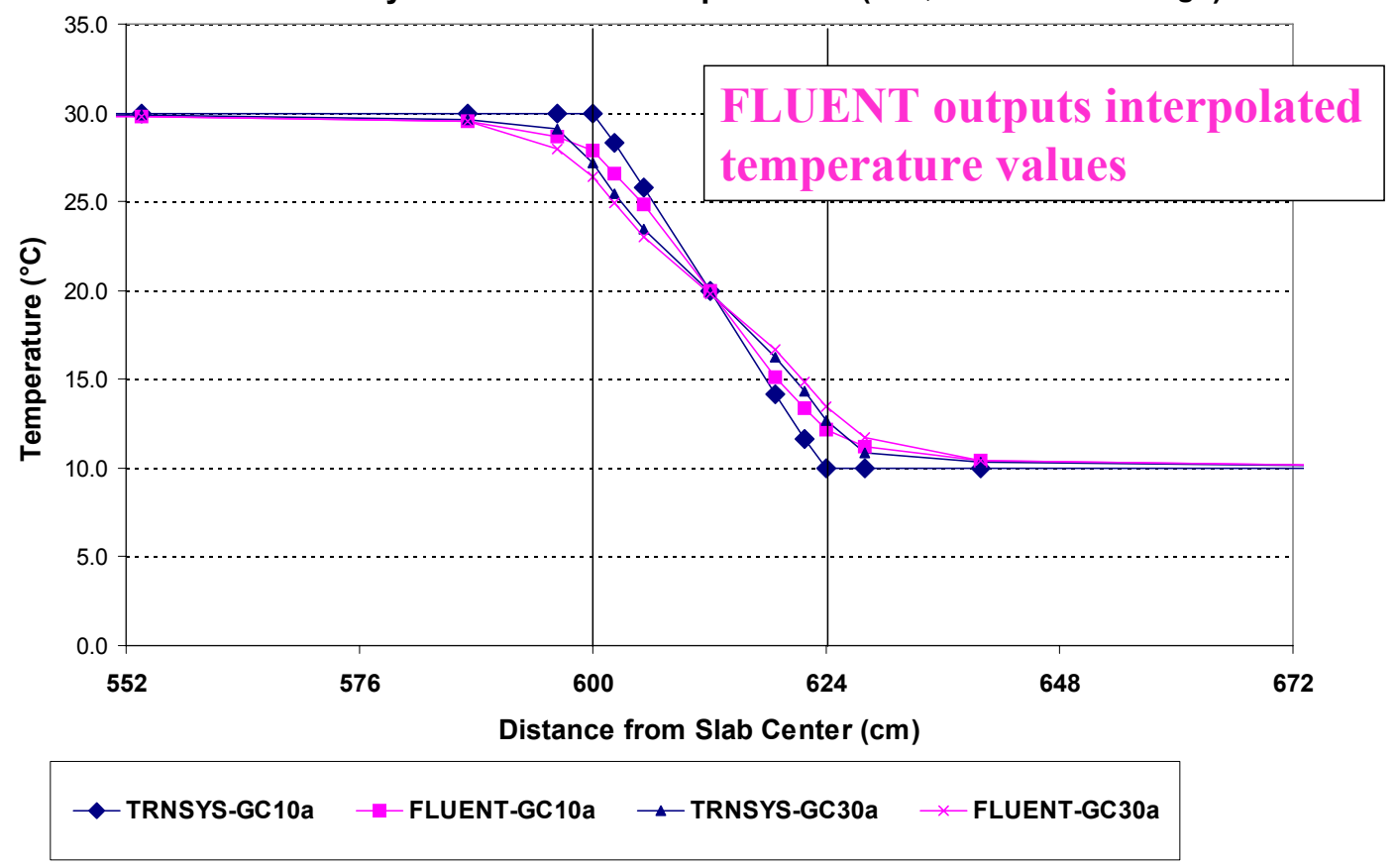

Figure 2B-7. 


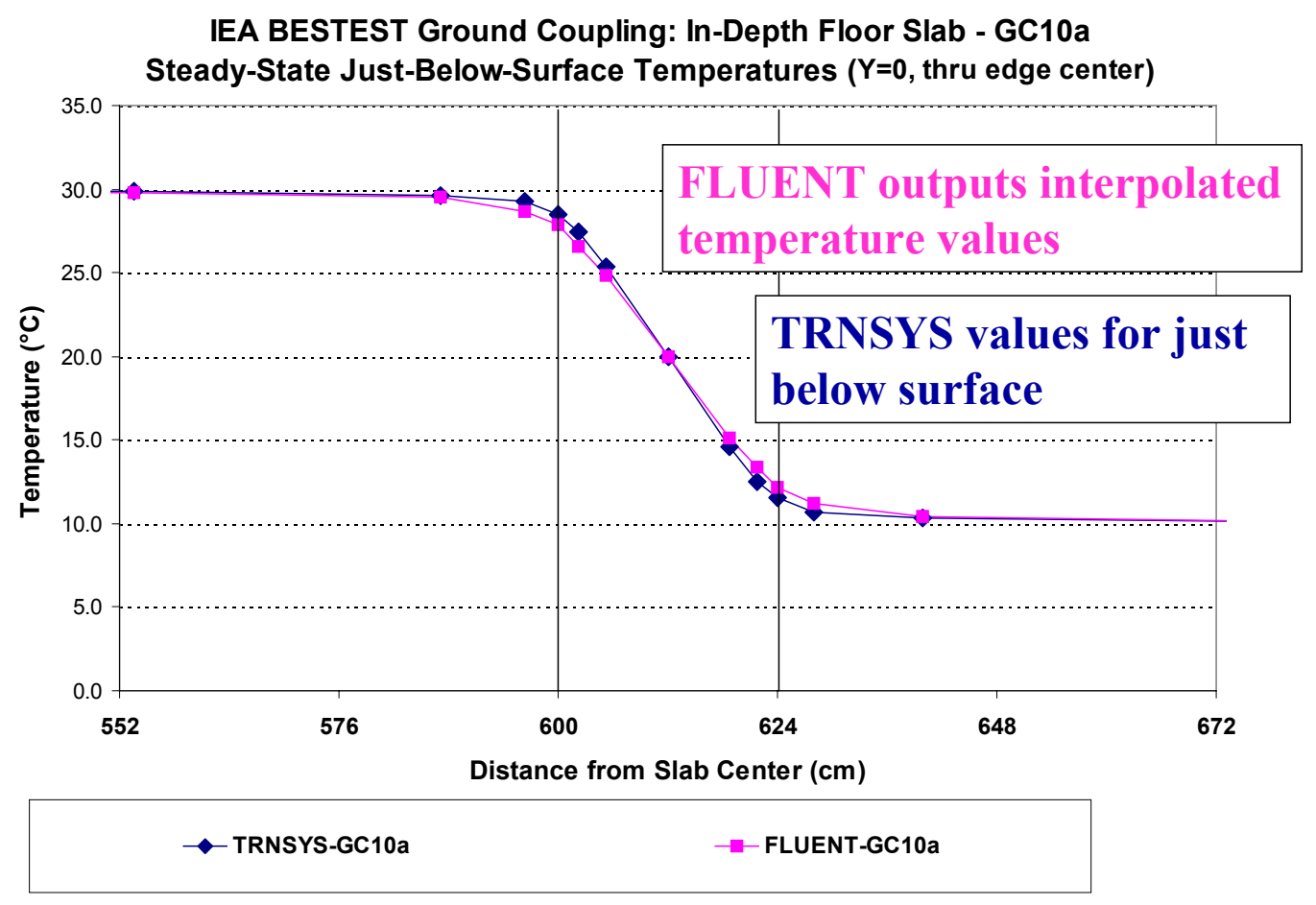

Figure 2B-8.

The above results represent the static temperature or total temperature as defined below. Inner-surface wall temperature and outer-surface wall temperature results were also submitted, but are not shown here. Outer and inner temperatures are reported at cell centers not nodes, so they cannot give exact surface temperature results for the nodes at $\mathrm{x}=600 \mathrm{~cm}$ and $\mathrm{x}=624 \mathrm{~cm}$. Based on the FLUENT User's Guide the temperatures differ as follows. For incompressible flows total temperature equals static temperature, where static temperature is the temperature moving with the fluid (in this solid conduction case, the fluid is not moving). Inner-surface wall temperature is the temperature of a bounding wall surface on the side (surface) of the wall away from an adjacent fluid, while outer-surface wall temperature is the temperature of a bounding wall surface on the side of the wall surface adjacent to the fluid. In this case a zerothickness wall was used for defining the surface boundary so that inner-surface wall temperature $=$ outersurface wall temperature.

In summary

- For solids, static temperature should equal to total temperature.

- Total temperature is available at boundary nodes.

- Inner and outer temperatures are available at cell centers.

Further documentation is included in the FLUENT User's Guide cited in the references; see Sections 25.8.2 and 27.1.2, and Table 27.3.4 of the FLUENT User's Guide.

\section{Conclusions and Recommendations}

[Editor's note: no comments were provided here by PAAET.] 


\section{References}

Fluent Inc. (2001). Fluent 6.0 User's Guide, Lebanon, New Hampshire, US: Fluent Incorporated.

Watve, A. (2006). Fluent Incorporated. Private communications with A. Nakhi and J. Neymark, Nov-Dec 2006.

\section{Appendix A: Model Geometry and Thermal Property Allowed Inputs}

In principle, there is no limitation for the geometry from FLUENT, so the pro-forma table and accompanying figures are not included. Of course, dimensions should be positive. The practical limitation for number of cells (or nodes) is dependent on the computer capabilities. That is, the bigger the RAM the larger number of nodes that can be handled. The array size and related run time of the FLUENT program (i.e., executable) is dynamic and is dependent on the number of nodes and variables to be simulated. The executable increases the array size as requested by the problem in hand. FLUENT incorporates dynamic storage, hence, limits are set by computer capabilities. There is no limitation for properties in FLUENT other than to avoid numerical instabilities. 


\title{
Appendix II-C
}

\section{Modeler Report for BESTEST Cases GC10a-GC80c MATLAB 7.0.4.365 (R14) Service Pack 2}

\author{
by \\ Michael Crowley \\ Dublin Institute of Technology \\ Republic of Ireland
}

September 2007

\section{Introduction}

The software package used for this work was MATLAB 7.0.4.365 (R14) Service Pack 2 written by The MathWorks, Inc., Massachusetts, United States of America. It is a general purpose mathematical package and is independent of building energy simulation. A series of ground-coupled heat transfer programs was prepared specifically for this task using the high-level language within MATLAB, which includes an extensive catalog of built-in functions. Functions for interpolation and the solution of linear algebraic equations (LAE) and ordinary differential equations (ODE) were of most use for the present work. A large part of the work of these functions is matrix processing and MATLAB is considered 'state-of-the-art' for matrix computation - incorporating the LAPACK and BLAS libraries (The MathWorks, Inc. 2007).

Each of MATLAB's built-in ODE solvers forms an estimate of the error for the proposed time step and, if necessary, varies the length of the step to keep the error close to the specified tolerance. At each step, the error $e$ in each nodal temperature $T$ satisfies $|e| \leq \max (\operatorname{RelTol} \times|T|, \mathrm{AbsTol})$. A relative tolerance (RelTol) of $10^{-5}$ and an absolute tolerance (AbsTol) of $10^{-8}$ were used here. Fixed time steps, if large, can lead to excessive error where the solution changes rapidly and, if small, can be unnecessarily accurate (slow) for a large part of the interval of integration. MATLAB does not offer fixed step size as an option.

MATLAB includes a range of direct and iterative solvers for linear algebraic equations. Direct methods were used exclusively here (for steady state problems) because they are generally more accurate and more reliable than iterative solvers (Heath 2002). Direct solvers (all based on Gaussian elimination) produce exact solutions in the absence of rounding error. Since MATLAB calculates in double precision, results can therefore be expected to be many orders of magnitude more accurate than the specified precision for this project unless the matrix of coefficients is ill-conditioned. MATLAB tests for this circumstance and issues a warning if necessary. All of the foregoing concerns rounding error. Truncation error is, of course, separately present and is reduced by decreasing the space increment.

The test problems are very large (approaching $10^{6}$ nodes/equations for the required precision) and this would usually necessitate the use of iterative methods on the PC available for the work (HP Compaq D330; Pentium 4, $2.8 \mathrm{GHz} ; 512 \mathrm{MB}$ RAM). In order to use direct solution methods operating entirely within fast memory (RAM), two steps were taken. Memory was increased to $4 \mathrm{~GB}$, of which $1 \mathrm{~GB}$ was reserved for the operating system. Also, the problems were programmed taking maximum advantage of symmetry. Three geometric symmetries are present in most of the problems and consequently only one-eighth of the problem domain need be considered. The system matrix is not fully symmetric and so no further efficiencies of this type are available. The matrix is, however, very sparse and this allowed two further efficiencies: (i) MATLAB can be programmed to store just the nonzero elements of a matrix, thus freeing up RAM for other 
uses and (ii) MATLAB's direct solvers take advantage of sparsity in that they do minimal wasteful processing of zero valued matrix elements (as well as minimizing fill-in during the elimination stage).

\section{Modeling Assumptions}

The modeling assumptions and inputs used were as described in the Test Specification and as shown in Table 2C-1 with the following exceptions:

Hourly ambient temperature data was provided as part of a weather file for the harmonic test cases. These data are normally interpolated within building energy models that produce output at less than hourly intervals. Some building energy models use linear interpolation, others use smoother functions. The programs prepared here include the harmonic function in Section 1.3.1.2.3 of the Test Specification (i.e. a cosine modulating a cosine) which was coded as a smooth function of time down to the limits of double precision accuracy (approx. $10^{-15}$ seconds). This is close to perfect interpolation and may be considered the ideal to be aspired to in building energy models. Including a simpler interpolation method (or none) may bias the test toward those using that specific (less than perfect) method. For the purpose of comparison, hourly integrated heat flow calculations were carried out for a small sample of ambient temperatures from the weather file (1 June, hours 1-24) using (i) the hourly temperatures as provided (no interpolation) and (ii) the smooth cosine function (perfect interpolation). The maximum difference was $0.8 \%$, occurring at hour 4 . The inclusion of even a simple interpolation routine would be expected to reduce this difference.

The Test Specification assumes that dynamic models (DM) will be used for the steady-state cases and that these models will be run to steady state to obtain the desired results. Since the boundary conditions do not change over time, these cases are more appropriately modeled using algebraic equations, i.e. steady-state models (SSM), which require just one application of an appropriate solver. SSMs are much quicker than DMs, in this case many orders of magnitude quicker, because the test cases are large (many nodes), moderately stiff and require exceptionally long integration intervals.

\section{Modeling Approach}

The models prepared here are 3-D finite difference approximations to the Heat Diffusion Equation. The SSMs include a second-order centered difference approximation to the space derivatives and the DMs include, in addition, a third-order forward difference representation of the time derivative. As such, they are all capable of converging (Fletcher 1991) onto their respective exact solutions provided the issues of stiffness, stability, matrix condition (and even the accumulation of the minute rounding error over some of the lengthy integration intervals to be discussed below) are dealt with correctly - and, of course, assuming sufficient computing power is available. The specific solvers employed were as follows: (i) a sparse LU decomposition method of the analyse/factorise/solve variety (Davis 2004) was applied to the LAEs arising in the SSMs, (ii) an explicit numerical method (Bogacki and Shampine 1989) was used to solve the ODEs presented in the DMs; the problems were not stiff enough to justify the costly matrix processing associated with implicit methods.

All the programs used here include mesh spacings that are independently variable in the x-direction (which, due to symmetry, includes the y-direction for problems with square perimeter boundaries) and the z-direction. The spacings are denser near to the perimeter boundary and a different spacing factor is used inside ( $\mathrm{fxL} 0$ ) and outside ( $\mathrm{fxF} 0$ ) the perimeter, and a third spacing factor (fz0) for the z-direction. Grid spacings increase by approximately these factors as the distance from the perimeter boundary increases; the program adjusts the factors slightly so that a whole number of grid spacings fits within the available dimension ( $\mathrm{L}, \mathrm{F}$, or $\mathrm{E}$ ). The initial grid spacings in the vicinity of the perimeter are $\mathrm{dx} 0$ in the $\mathrm{x}$ and $\mathrm{y}$ directions and dz0 in the $\mathrm{z}$ direction. Two of the test cases (GC45b and GC45c) have rectangular rather than 
square perimeter boundaries and so further grid spacing parameters were required for the y direction. They were tied to the existing parameters in the following way. The number of space increments in the y direction was made equal to the number in the $\mathrm{x}$ direction both inside and outside the perimeter boundary (Figure $2 \mathrm{C}$ 1). Outside the boundary, temperature gradients in the $\mathrm{x}$ and $\mathrm{y}$ directions are similar whereas inside the boundary, the rate of change of temperature along the very large y-dimension can be expected to be small. The chosen grid spacings are compatible with these expectations. The number of space increments within the perimeter boundary dimension (W) is the same in both directions.

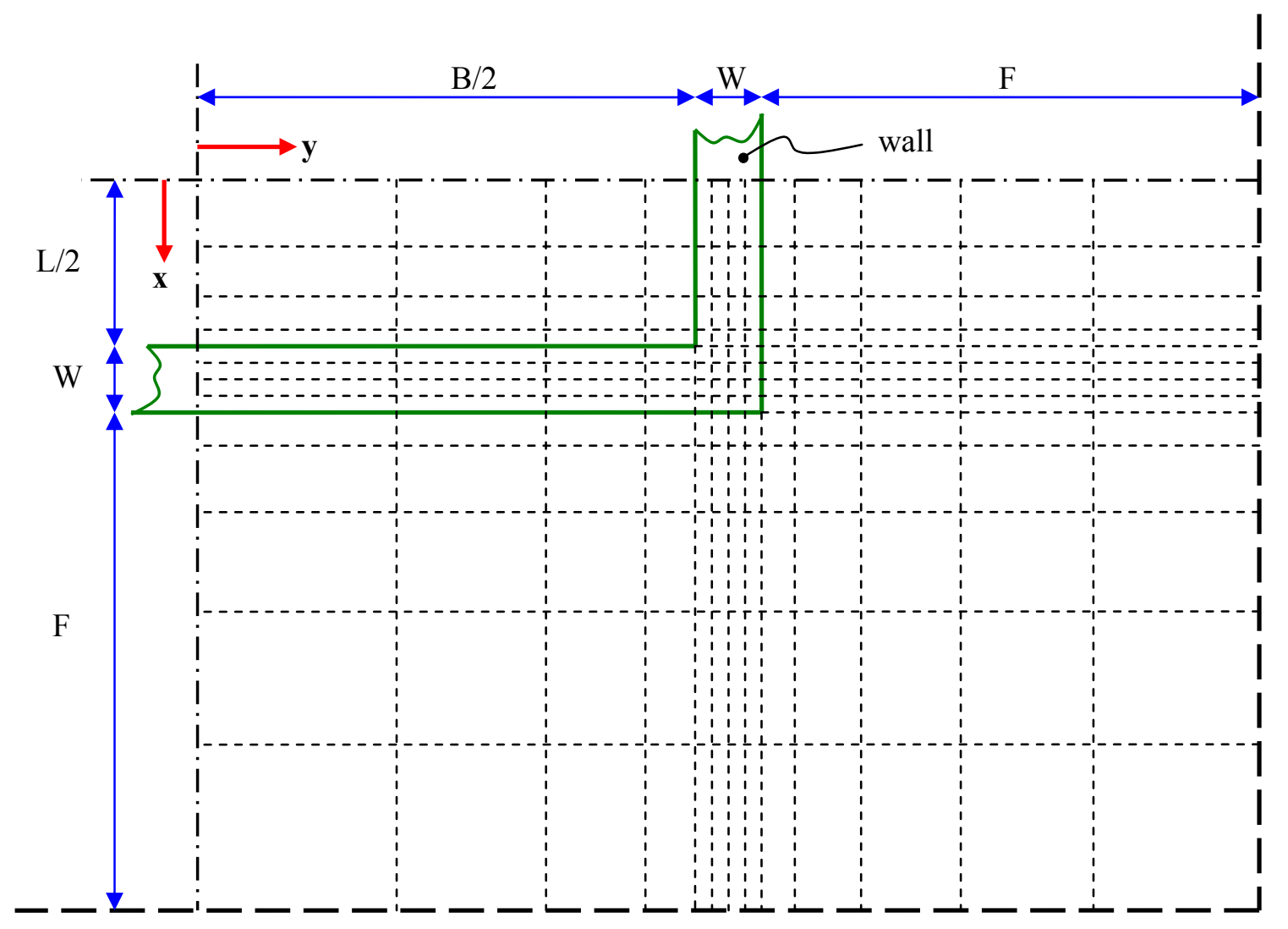

Figure 2C-1 Mesh pattern for cases GC45b and GC45c; one-fourth of domain modeled

In broad terms, the values of these parameters, together with $\mathrm{E}$ and $\mathrm{F}$ defining the extent of the modeled soil volume, were varied to minimize the error for Case GC10a within the constraints of the available PC. The final steady state heat loss through the floor slab was noted and compared with the analytical solution (Delsante et al. 1983). Dimensions E and F were then reduced to the values for Case GC30a and the small increase in computer resources was used to refine the grid further. This was the final opportunity to compare the analytical and finite difference solutions. The (perimeter) boundary conditions were next changed to those for Case GC30a - the SSM was otherwise unchanged - and the model was run to produce results. Most subsequent models, both SSMs and DMs, share this same mesh density (i.e. dx0, dz0, fxL0, fxF0, and fz0); the exceptions being GC45b and GC45c discussed above and the very large slab case, GC50b. DMs were evolved from SSMs by including mass and replacing the LAE solver with an ODE solver. DMs were initially tested by running them to quasi-steady state and comparing the averaged outcome with that of a SSM for the same problem; the results differed typically by $0.005 \%$ or less. In the case of GC10a, the quasisteady output of the DM can be compared with the exact solution. Further tests of SSMs and DMs are described in Section 6. 
The space traversed by varying the seven parameters $(\mathrm{dx} 0, \mathrm{dz} 0, \mathrm{fxL} 0, \mathrm{fxF} 0, \mathrm{fz} 0, \mathrm{E}$, and $\mathrm{F})$ is complex and discontinuous. The manual optimization described above is clearly not perfect and could possibly be improved by the use of formal methods. Nevertheless, those results which are verifiable were found to be well within specification, indicating that the level of discretization was at least adequate.

\section{Modeling Options}

Since bespoke programs were prepared specifically for this task, the question of options does not arise. All aspects were modeled as specified insofar as the finite difference domain allows. The three types of boundary condition (isothermal, adiabatic and convective), for example, were explicitly and separately modeled. Convective surface coefficients behaved well, even at large values. Unwanted aspects such as radiation and moisture played no part because they were not included in the model.

\section{Modeling Difficulties}

No difficulties were experienced with the use of the Test Specification or the values specified therein. The major modeling difficulty arose out of the nature of the test problems themselves. Following the construction of the early DMs (GC30a and GC40a), a first principles method (Crowley and Hashmi 2000) was used to establish the pre-conditioning period for the system. This is identical to (i) the longest thermal time constant for the system and (ii) the time necessary to reach a quasi-steady state. It was needed to determine the required interval of integration. It was estimated by calculating the time taken for the slowest transient solution of the nodal equation set to decay to $0.1 \%$ of its initial value. The period found was 28.25 years - an exceptionally long one in the context of building energy simulation.

Reduced runs were next carried out to estimate the real time required for a 30-40 year interval of integration and it was found to be 1-2 months on the available PC described in Section 1. Because of the number of test runs and confirming runs required, this would have taken the work well beyond the time scale for the project. Initially it was decided to increase the grid spacings in the DMs by a factor of five so that 40 years of simulated time could be processed overnight. However, this led to a $2 \%$ discrepancy between the averaged output of GC40a and the result for GC30a, its steady-state counterpart. This was greater than the difference for TRNSYS and FLUENT ( $<0.6 \%$ variation) so, instead, four more PCs of similar specification were equipped to work on the project and a 10-year integration interval was investigated (using the original high mesh density). It was found that the results for 10-year runs were well within the principal error tolerance specified, that is, that there be at most $0.1 \%$ variation in floor heat loss between the last hour of each of the final two simulated years. This finding does not appear probable in the light of the very long preconditioning period but the apparent contradiction can be understood as follows: (i) performance is judged on floor heat flow rate which involves just a small fraction of the total number of nodal temperatures solved for in each simulation run and (ii) the initial conditions used here for each dynamic test run were just the solution temperatures for the corresponding steady state run. Since the average of the harmonically varying ambient temperature used in the DMs is the same as the outdoor temperature used in the SSMs, this meant that the nodes furthest from the surface (and therefore slowest to respond) were already close to their quasisteady temperatures.

\section{Demonstration of Appropriate Level of Modeling Detail}

The Test Specification calls for supplementary test runs to confirm that the principal result for each of the cases is close to optimal. This is demonstrated by varying problem parameters and confirming minimal sensitivity of results to these changes. The prescribed changes are as follows: 
(i) Reduce the integration interval by one year (does not apply to SSMs).

(ii) Reduce the volume of soil modeled (applies to case GC10a only).

(iii) Reduce the mesh density (i.e. reduce the number of nodes used).

(iv) Increase the error tolerance or convergence tolerance used in the solver (does not apply to LAE solver used in SSMs here).

The specified maximum allowable variation in floor slab heat loss is $0.1 \%$ for any of these changes. A 5\% change in the above parameters was, where possible, used in the confirmatory runs here, i.e. 50 times the permitted change in floor heat loss. For (ii) and (iii) the number of nodes was reduced by $5 \%-$ by reducing E and F simultaneously in the case of (ii). For (iv) the tolerance variables RelTol and AbsTol were each increased by $5 \%$. Because the dynamic runs took so long, sensitivity tests (iii) and (iv) were usually carried out together. For the same reason, not all of the cases were tested in this way; the chosen cases are representative problem types.

The test results are presented in Table $2 \mathrm{C}-1$. The optimal runs are identified and the parameters varied in each of the confirmatory runs are highlighted. In every case, the change in floor slab heat loss was much less than the permitted $0.1 \%$.

Table 2C-1. Optimal and Confirmatory Runs for Selected Cases

\begin{tabular}{|c|c|c|c|c|c|c|c|c|c|c|}
\hline Case & $\begin{array}{c}F \\
(m)\end{array}$ & $\begin{array}{c}E \\
(m)\end{array}$ & $\begin{array}{l}\mathrm{dx0} \\
(\mathrm{m})\end{array}$ & $\begin{array}{l}\mathrm{dz0} \\
(\mathrm{m})\end{array}$ & fxLO & fxFo & $\mathrm{fzO}$ & $\begin{array}{l}\text { Number } \\
\text { of nodes }\end{array}$ & $\begin{array}{l}\text { Floor slab } \\
\text { heat loss }\end{array}$ & Comments \\
\hline GC10a* & 150 & 300 & 0.020 & 0.012 & 1.150 & 1.495 & 1.150 & 892,552 & $2431.82 \mathrm{~W}$ & Optimal run. \\
\hline GC10a & 120 & 240 & 0.020 & 0.012 & 1.150 & 1.495 & 1.150 & 849,120 & $2431.60 \mathrm{~W}$ & $0.009 \%$ change. \\
\hline GC10a & 150 & 300 & 0.020 & 0.012 & 1.155 & 1.5015 & 1.155 & 849,120 & $2431.54 \mathrm{~W}$ & $0.012 \%$ change. \\
\hline GC30a & 20 & 30 & 0.015 & 0.0090 & 1.135 & 1.4755 & 1.135 & 840,840 & $2694.99 \mathrm{~W}$ & Optimal run. \\
\hline GC30a & 20 & 30 & 0.016 & 0.0096 & 1.135 & 1.4755 & 1.135 & 798,720 & $2694.87 \mathrm{~W}$ & $0.004 \%$ change. \\
\hline GC40a & 20 & 30 & 0.015 & 0.0090 & 1.135 & 1.4755 & 1.135 & 840,840 & $23,608.9 \mathrm{kWh} / \mathrm{y}$ & $\begin{array}{l}\text { Optimal run, } \\
\text { (10 year run). }\end{array}$ \\
\hline GC40a & 20 & 30 & 0.015 & 0.0090 & 1.135 & 1.4755 & 1.135 & 840,840 & $23,609.1 \mathrm{kWh} / \mathrm{y}$ & $\begin{array}{l}0.001 \% \text { change, } \\
\text { ( } 9 \text { year run). }\end{array}$ \\
\hline GC40a\# & 20 & 30 & 0.016 & 0.0096 & 1.135 & 1.4755 & 1.135 & 798,720 & $23,607.8 \mathrm{kWh} / \mathrm{y}$ & $\begin{array}{l}0.005 \% \text { change, } \\
\text { (10 year run). }\end{array}$ \\
\hline GC45b & 15 & 15 & 0.020 & 0.012 & 1.135 & 1.4755 & 1.135 & 410,000 & $33,483.5 \mathrm{kWh} / \mathrm{y}$ & $\begin{array}{l}\text { Optimal run, } \\
\text { (10 year run). }\end{array}$ \\
\hline GC45b & 15 & 15 & 0.020 & 0.012 & 1.135 & 1.4755 & 1.135 & 410,000 & $33,483.5 \mathrm{kWh} / \mathrm{y}$ & $\begin{array}{l}0.000 \% \text { change, } \\
\text { ( } 9 \text { year run). }\end{array}$ \\
\hline GC45b\# & 15 & 15 & 0.020 & 0.012 & 1.138 & 1.4794 & 1.138 & 384,160 & $33,479.2 \mathrm{kWh} / \mathrm{y}$ & $\begin{array}{l}0.013 \% \text { change, } \\
\text { (10 year run). }\end{array}$ \\
\hline GC65b & 15 & 15 & 0.015 & 0.0090 & 1.135 & 1.4755 & 1.135 & 715,520 & $2003.66 \mathrm{~W}$ & Optimal run. \\
\hline GC65b & 15 & 15 & 0.015 & 0.0090 & 1.140 & 1.4820 & 1.140 & 677,376 & $2003.50 \mathrm{~W}$ & $0.008 \%$ change. \\
\hline GC80b & 15 & 15 & 0.015 & 0.0090 & 1.135 & 1.4755 & 1.135 & 715,520 & $6151.43 \mathrm{kWh} / \mathrm{y}$ & $\begin{array}{l}\text { Optimal run, } \\
\text { (10 year run). }\end{array}$ \\
\hline GC80b & 15 & 15 & 0.015 & 0.0090 & 1.135 & 1.4755 & 1.135 & 715,520 & $6151.53 \mathrm{kWh} / \mathrm{y}$ & $\begin{array}{l}0.002 \% \text { change, } \\
\text { ( } 9 \text { year run). }\end{array}$ \\
\hline GC80b" & 15 & 15 & 0.015 & 0.0090 & 1.140 & 1.4820 & 1.140 & 677,376 & $6150.86 \mathrm{kWh} / \mathrm{y}$ & $\begin{array}{l}0.009 \% \text { change, } \\
\text { (10 year run). }\end{array}$ \\
\hline
\end{tabular}

${ }^{*}$ Analytical solution is $2432.60 \mathrm{~W}$. " Error tolerance for ODE solver was increased by $5 \%$. 


\section{Software Errors Discovered, and/or Comparison between Different Versions of the Same Software, and/or Lessons Learned regarding Use of Detailed Models}

Two programming errors were discovered in the course of this work, both by comparing the output with the results of others. A 3-D interpolation function was initially used to produce, for each steady-state case, two lines of sub-surface temperatures emanating from the origin (Test Specification, Fig. 1-4). The results were very different to the output produced by others (Fig. 2C-2). When a 1-D interpolation function was used (the required interpolation points being collinear with the sub-surface nodes) the results were very much in agreement with the other participants (Fig. 2C-3). The nature of the problem was not established with certainty. MATLAB's 3-D function interpolates using 64 neighboring points. It may be utilizing unrepresentative nodal temperatures considering the small scale of the perimeter boundary and the large temperature gradients in its vicinity.

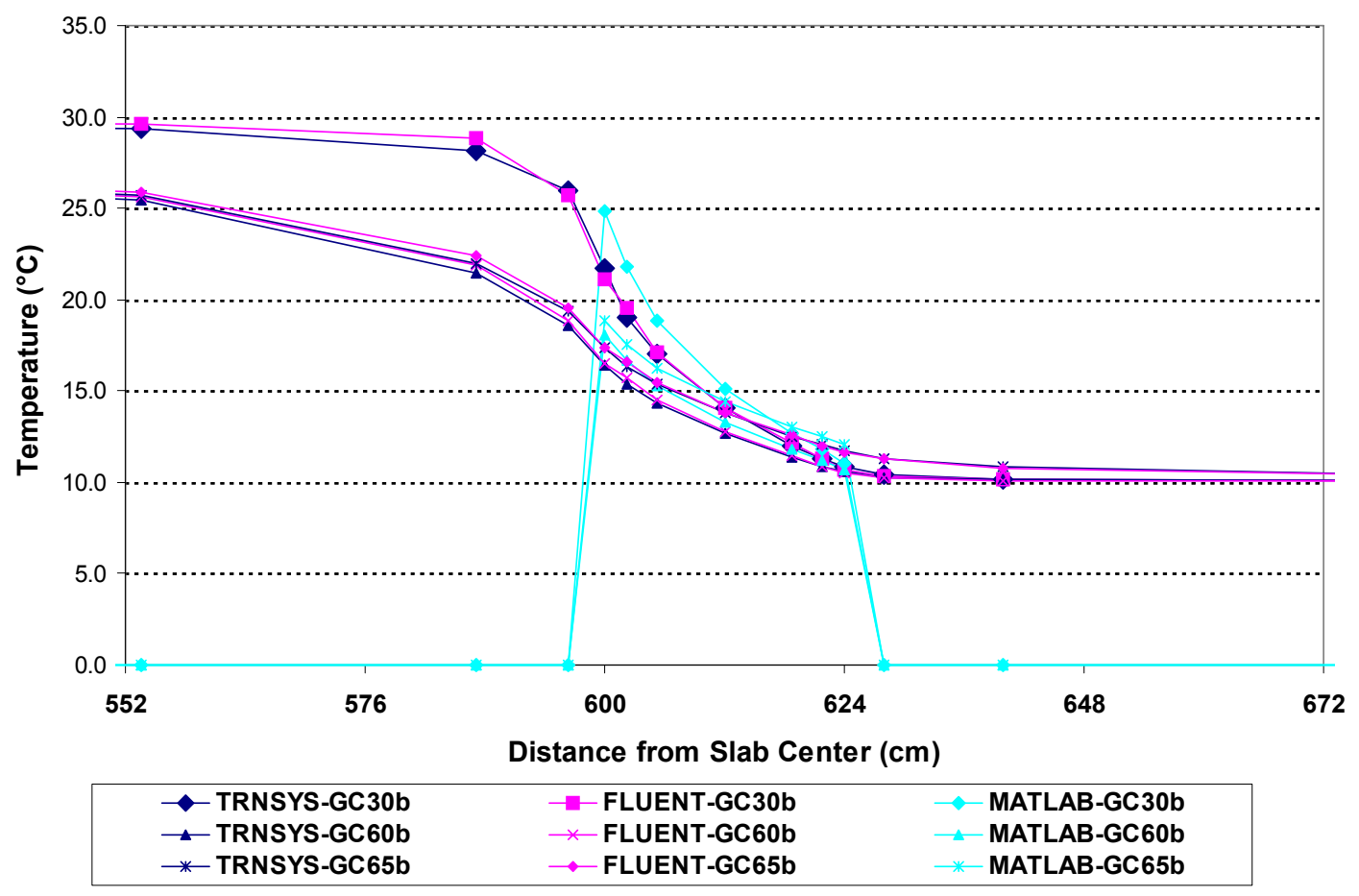

Figure 2C-2 Interpolated subsurface temperatures through corner (3-D interpolation) 


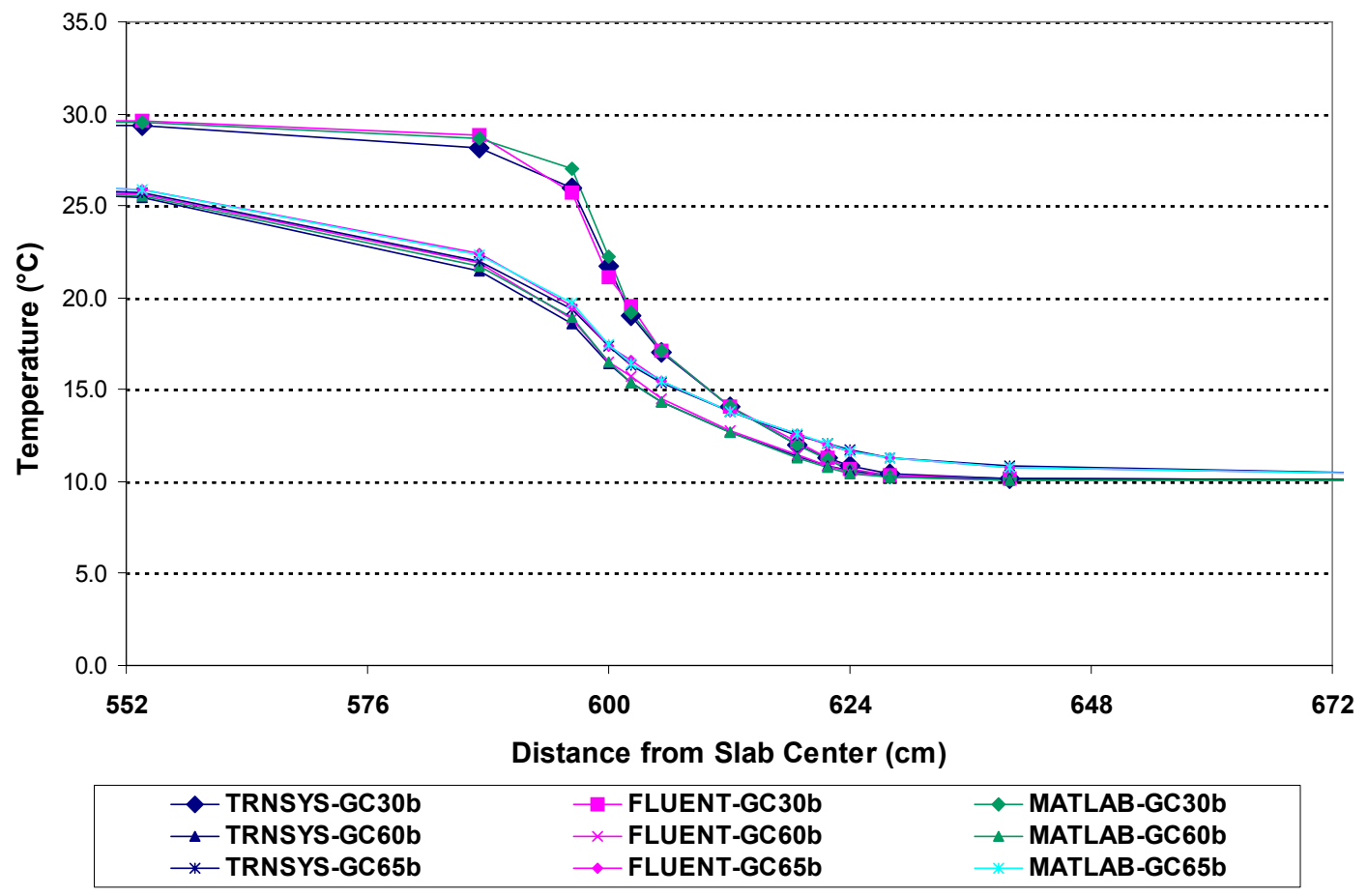

Figure 2C-3 Interpolated subsurface temperatures through corner (1-D interpolation)

Another programming error became apparent when convective boundary conditions were first introduced. MATLAB's floor heat loss predictions for cases GC30b, GC30c, GC60b, and GC65b were initially 3\%-5\% higher than those of TRNSYS and FLUENT. An error in the modeling of convection within the edge loss routine was quickly located and corrected (Table 2C-2). The edge loss subprogram models floor heat loss just inside the perimeter boundary.

Finally, a minor improvement (in interpolation again) was included in the edge loss routine before the lengthy dynamic runs were undertaken. This resulted in a $0.3 \%$ change in the result for GC30a but a $0.002 \%$ deterioration in that of GC10a (Table 2C-3).

Table 2C-2. Effects of Error Related to Convection Modeling within Edge Loss Routine

\begin{tabular}{|c|c|c|c|c|c|c|c|c|c|c|}
\hline Case & $\begin{array}{c}F \\
(m)\end{array}$ & $\begin{array}{c}E \\
(m)\end{array}$ & $\begin{array}{l}\mathrm{dx0} \\
(\mathrm{m})\end{array}$ & $\begin{array}{l}d z 0 \\
(m)\end{array}$ & fxLO & fxFo & fzO & $\begin{array}{l}\text { Number } \\
\text { of nodes }\end{array}$ & $\begin{array}{c}\text { Floor slab } \\
\text { heat loss }\end{array}$ & Comments \\
\hline GC30b & 15 & 15 & 0.015 & 0.009 & 1.135 & 1.4755 & 1.135 & 715,520 & $2591.92 \mathrm{~W}$ & Before correction \\
\hline GC30b & 15 & 15 & 0.015 & 0.009 & 1.135 & 1.4755 & 1.135 & 715,520 & $2569.97 \mathrm{~W}$ & After correction \\
\hline GC30c & 8 & 15 & 0.015 & 0.009 & 1.135 & 1.4755 & 1.135 & 693,504 & $2240.66 \mathrm{~W}$ & Before correction \\
\hline GC30c & 8 & 15 & 0.015 & 0.009 & 1.135 & 1.4755 & 1.135 & 693,504 & $2154.48 \mathrm{~W}$ & After correction \\
\hline GC60b & 15 & 15 & 0.015 & 0.009 & 1.135 & 1.4755 & 1.135 & 715,520 & $2212.15 \mathrm{~W}$ & Before correction \\
\hline GC60b & 15 & 15 & 0.015 & 0.009 & 1.135 & 1.4755 & 1.135 & 715,520 & $2128.28 \mathrm{~W}$ & After correction \\
\hline GC65b & 15 & 15 & 0.015 & 0.009 & 1.135 & 1.4755 & 1.135 & 715,520 & $2079.09 \mathrm{~W}$ & Before correction \\
\hline GC65b & 15 & 15 & 0.015 & 0.009 & 1.135 & 1.4755 & 1.135 & 715,520 & $2003.66 \mathrm{~W}$ & After correction \\
\hline
\end{tabular}


Table 2C-3. Effects of Interpolation Improvement in Edge Loss Routine

\begin{tabular}{lcccccccccc}
\hline Case & $\begin{array}{c}\mathbf{F} \\
(\mathbf{m})\end{array}$ & $\begin{array}{c}\mathbf{E} \\
\mathbf{( m )}\end{array}$ & $\begin{array}{c}\mathbf{d x 0} \\
\mathbf{( m )}\end{array}$ & $\begin{array}{c}\mathbf{d z 0} \\
\mathbf{( m )}\end{array}$ & $\mathbf{f x L 0}$ & $\mathbf{f x F 0}$ & $\mathbf{f z 0}$ & $\begin{array}{c}\text { Number } \\
\text { of nodes }\end{array}$ & $\begin{array}{c}\text { Floor slab } \\
\text { heat loss }\end{array}$ & Comments \\
\hline GC10a $^{*}$ & 150 & 300 & 0.020 & 0.012 & 1.150 & 1.495 & 1.150 & 892,552 & $2431.87 \mathrm{~W}$ & Before improvement \\
GC10a $^{*}$ & 150 & 300 & 0.020 & 0.012 & 1.150 & 1.495 & 1.150 & 892,552 & $2431.82 \mathrm{~W}$ & After improvement \\
GC30a $^{20}$ & 30 & 0.015 & 0.009 & 1.135 & 1.4755 & 1.135 & 840,840 & $2686.33 \mathrm{~W}$ & Before improvement \\
GC30a & 20 & 30 & 0.015 & 0.009 & 1.135 & 1.4755 & 1.135 & 840,840 & $2694.99 \mathrm{~W}$ & After improvement \\
\hline
\end{tabular}

${ }^{*}$ Analytical solution is $2432.60 \mathrm{~W}$.

\section{Results}

The results produced by MATLAB are in good agreement with those of TRNSYS and FLUENT. All three programs are within $0.3 \%$ of the known exact solution for case GC10a. Each of them underpredicts the floor heat loss, with MATLAB producing the highest heat flow of the three. For most other cases MATLAB predicts slightly higher heat flow rates also - typically about $2 \%$ higher. This may be attributable to the denser mesh used in MATLAB, but this has not been confirmed.

\section{Conclusions and Recommendations}

All of the test cases included here are concerned with steady- or quasi-steady state solutions - even for the dynamic problems. Dynamic performance is not severely tested, for example, by step changes in the load. To do this one needs analytical solutions for dynamic cases but these are generally not available. Almost as useful are what can be termed converged solutions (Crowley 2006). These can be generated to arbitrary accuracy for dynamic problems of realistic scale and complexity.

The very lengthy thermal time constants (discussed in Section 5) for ground coupled heat transfer problems such as slab in/on grade (also basements, labyrinth cooling systems etc) have serious consequences for the HVAC design and simulation communities when this heat transfer mode is a significant fraction of the total thermal load. Normally one discards the initial output of a simulation run, that is, the output calculated during the pre-conditioning period - which is defined to be the simulation time required to allow the temperatures of all nodes to converge to values which are no longer affected by their arbitrarily chosen initial values. If the pre-conditioning period is decades in duration, then load predictions are inaccurate for a significant fraction of the building life unless initial conditions are directly measured - using bore-holes for example. Typical subsurface temperature profiles are of little use on most sites which will have been disturbed by site excavation during the construction phase and probably by road works, pipe laying and construction of adjacent buildings prior to that.

\section{References}

Bogacki, P. and Shampine, L.F., 1989. A 3(2) pair of Runge-Kutta formulas. Appl. Math. Lett., 2 (4), 321325.

Crowley, M.E., 2006. Validation of solution methods for building energy simulation. Proceedings of $e$ Sim 2006: $4^{\text {th }}$ Biennial Building Performance Simulation Conference, University of Toronto, Canada, 173-180.

Crowley, M.E., Hashmi, M.S.J., 2000. Improved direct solver for building energy simulation. Proc. CIBSE A: Building Serv. Eng. Res. Technol., 21 (3), 167-173. 
Davis, T. A., 2004. Algorithm 832: UMFPACK V4.3---an unsymmetric-pattern multifrontal method. $\underline{A C M}$ Trans. Math. Software, 30 (2), 196-199.

Delsante, A.E., Stokes, A.N., and Walsh, P.J., 1983. Application of Fourier transforms to periodic heat flow into the ground under a building. Int. J. Heat Mass Transfer, 26 (1) 121-132.

Fletcher, C.A.J., 1991. Computational techniques for fluid dynamics, Vol. 1. (2 $2^{\text {nd }}$ ed.) Berlin: SpringerVerlag.

Heath, M.T., 2002. Scientific computing; An introductory survey. ( $2^{\text {nd }}$ ed.) Boston: McGraw-Hill.

The MathWorks, Inc., 2007. Getting started with MATLAB. Massachusetts: The MathWorks, Inc.

Modeler Report Appendix A

Model Geometry and Thermal Property Allowed Inputs (pro forma)

Figures 2CA-1 and 2CA-2 define components and dimensions used in Table 2CA-1.

\section{$\underline{\text { Uninsulated Slab }}$ \\ Detail (no scale)}

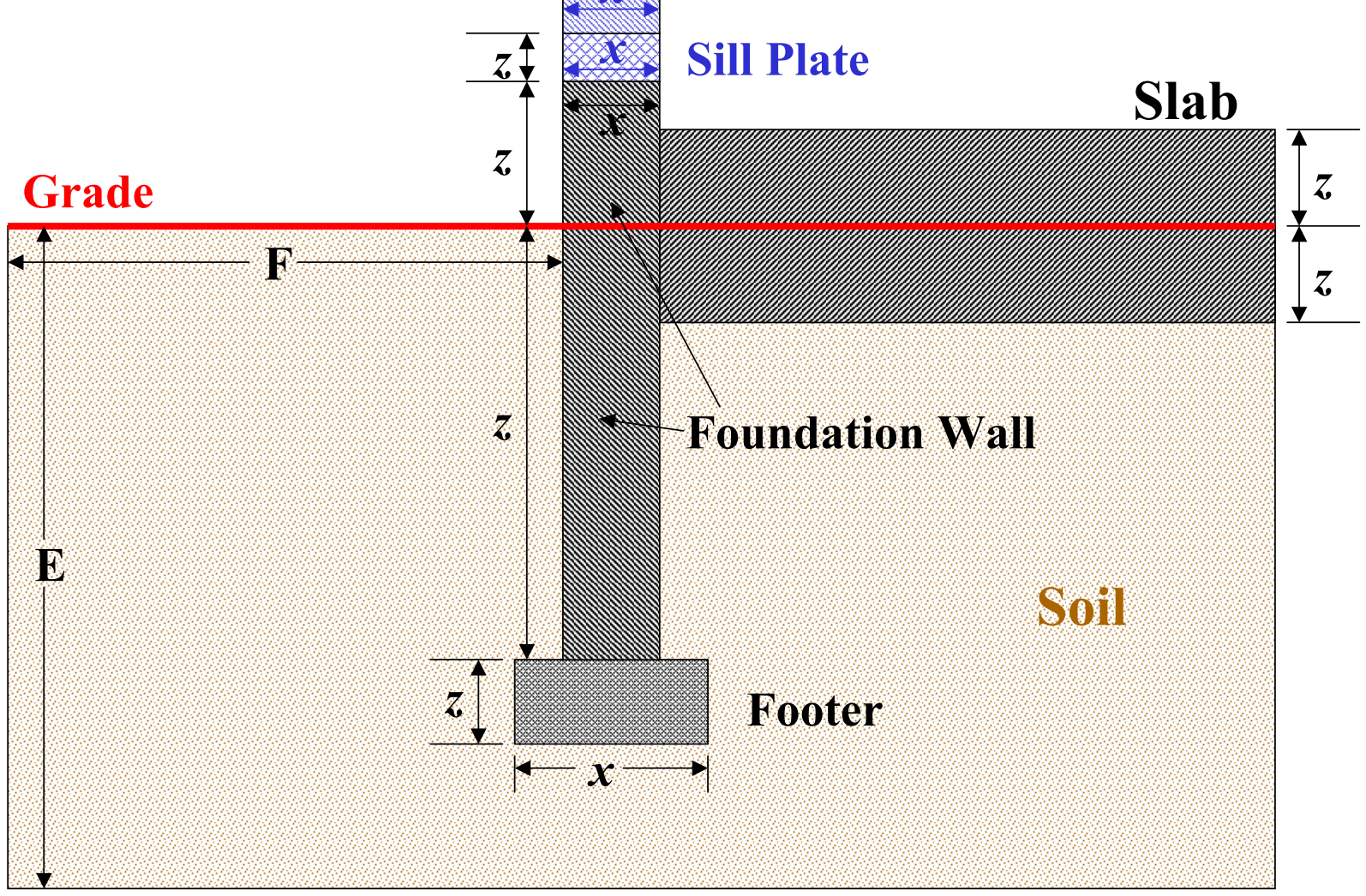

Figure 2CA-1. Uninsulated slab detail 


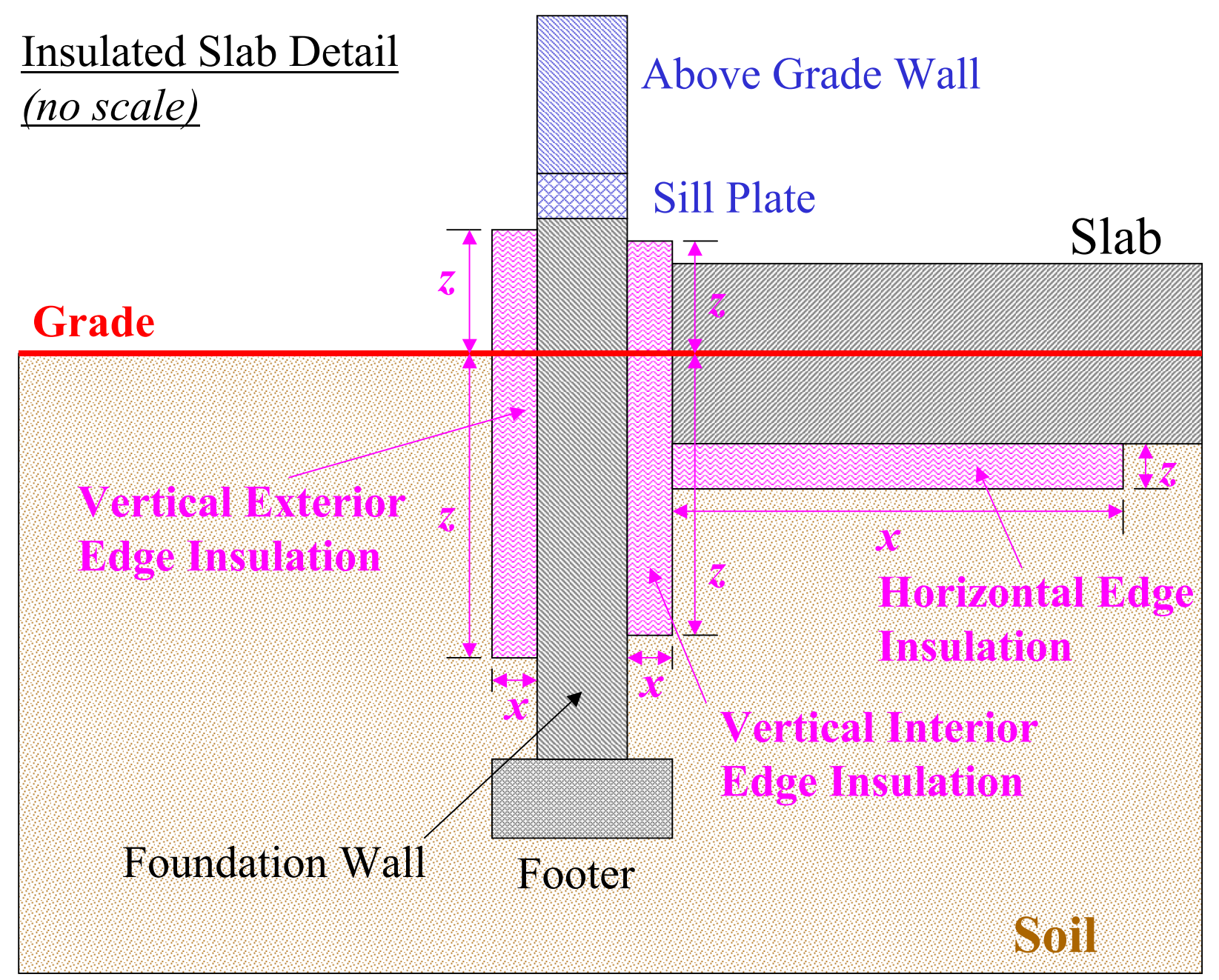

Figure 2CA-2. Insulated slab detail 
Table 2CA-1. Model Geometry and Thermal Property Allowed Inputs (pro forma)

\begin{tabular}{|c|c|c|c|c|c|c|c|c|c|}
\hline \multirow{2}{*}{\multicolumn{7}{|c|}{ Model and Version MATLAB 7.0.4.365 (R14) Service Pack 2}} & \multirow{2}{*}{\multicolumn{3}{|c|}{ Insulation }} \\
\hline & & & & & & & & & \\
\hline & Slab & \begin{tabular}{|c|} 
Foundation \\
Wall
\end{tabular} & Footer & Soil & Sill Plate & \begin{tabular}{|c|} 
Above Grade \\
Wall
\end{tabular} & $\begin{array}{l}\text { Horizontal } \\
\text { Edge }\end{array}$ & \begin{tabular}{c|} 
Vertical \\
Interior Edge
\end{tabular} & $\begin{array}{c}\text { Vertical } \\
\text { Exterior Edge }\end{array}$ \\
\hline \multicolumn{10}{|c|}{\begin{tabular}{l|l|l} 
GEOMETRY* & & \\
\end{tabular}} \\
\hline Floor Slab In (below) Grade ("yes" or "no") & yes & $\mathrm{n} / \mathrm{a}$ & $\mathrm{n} / \mathrm{a}$ & $\mathrm{n} / \mathrm{a}$ & $\mathrm{n} / \mathrm{a}$ & $\mathrm{n} / \mathrm{a}$ & $\mathrm{n} / \mathrm{a}$ & $\mathrm{n} / \mathrm{a}$ & $\mathrm{n} / \mathrm{a}$ \\
\hline Floor Slab On (above) Grade ("yes" or "no") & no & $\mathrm{n} / \mathrm{a}$ & $\mathrm{n} / \mathrm{a}$ & $\mathrm{n} / \mathrm{a}$ & $\mathrm{n} / \mathrm{a}$ & $\mathrm{n} / \mathrm{a}$ & $\mathrm{n} / \mathrm{a}$ & $\mathrm{n} / \mathrm{a}$ & $\mathrm{n} / \mathrm{a}$ \\
\hline Floor Slab Minimum Thickness $(\mathrm{cm})$ & 0 & $\mathrm{n} / \mathrm{a}$ & $\mathrm{n} / \mathrm{a}$ & $\mathrm{n} / \mathrm{a}$ & $\mathrm{n} / \mathrm{a}$ & $\mathrm{n} / \mathrm{a}$ & $\mathrm{n} / \mathrm{a}$ & $\mathrm{n} / \mathrm{a}$ & $\mathrm{n} / \mathrm{a}$ \\
\hline Floor Slab Maximum Thickness $(\mathrm{cm})$ & 0 & $\mathrm{n} / \mathrm{a}$ & $\mathrm{n} / \mathrm{a}$ & $\mathrm{n} / \mathrm{a}$ & $\mathrm{n} / \mathrm{a}$ & $\mathrm{n} / \mathrm{a}$ & $\mathrm{n} / \mathrm{a}$ & $\mathrm{n} / \mathrm{a}$ & $\mathrm{n} / \mathrm{a}$ \\
\hline Minimum $x$-Thickness or Width $(\mathrm{cm})$ & $\mathrm{n} / \mathrm{a}$ & 24 & 0 & $\mathrm{n} / \mathrm{a}$ & 24 & 24 & 0 & 0 & 0 \\
\hline Maximum $x$-Thickness or Width $(\mathrm{cm})$ & $\mathrm{n} / \mathrm{a}$ & 24 & 0 & $\mathrm{n} / \mathrm{a}$ & 24 & 24 & 0 & 0 & 0 \\
\hline Minimum z-Thickness (cm) & $\mathrm{n} / \mathrm{a}$ & $\mathrm{n} / \mathrm{a}$ & 0 & $\mathrm{n} / \mathrm{a}$ & 0 & $\mathrm{n} / \mathrm{a}$ & 0 & $\mathrm{n} / \mathrm{a}$ & $\mathrm{n} / \mathrm{a}$ \\
\hline Maximum z-Thickness $(\mathrm{cm})$ & $\mathrm{n} / \mathrm{a}$ & $\mathrm{n} / \mathrm{a}$ & 0 & $\mathrm{n} / \mathrm{a}$ & 0 & $\mathrm{n} / \mathrm{a}$ & 0 & $\mathrm{n} / \mathrm{a}$ & $\mathrm{n} / \mathrm{a}$ \\
\hline Minimum Bottom-Edge Depth Below Grade $(z, \mathrm{~cm})$ & 0 & 0 & 0 & $\mathrm{n} / \mathrm{a}$ & $\mathrm{n} / \mathrm{a}$ & $\mathrm{n} / \mathrm{a}$ & $\mathrm{n} / \mathrm{a}$ & 0 & 0 \\
\hline Maximum Bottom-Edge Depth Below Grade $(z, \mathrm{~cm})$ & 0 & 0 & 0 & $\mathrm{n} / \mathrm{a}$ & $\mathrm{n} / \mathrm{a}$ & $\mathrm{n} / \mathrm{a}$ & $\mathrm{n} / \mathrm{a}$ & 0 & 0 \\
\hline Minimum Top-Edge Height Above Grade $(z, \mathrm{~cm})$ & 0 & 0 & $\mathrm{n} / \mathrm{a}$ & $\mathrm{n} / \mathrm{a}$ & $\mathrm{n} / \mathrm{a}$ & $\mathrm{n} / \mathrm{a}$ & $\mathrm{n} / \mathrm{a}$ & 0 & 0 \\
\hline Maximum Top-Edge Height Above Grade $(z, \mathrm{~cm})$ & 0 & 0 & $\mathrm{n} / \mathrm{a}$ & $\mathrm{n} / \mathrm{a}$ & $\mathrm{n} / \mathrm{a}$ & $\mathrm{n} / \mathrm{a}$ & $\mathrm{n} / \mathrm{a}$ & 0 & 0 \\
\hline Minimum Soil Depth $(E, m)$ & $\mathrm{n} / \mathrm{a}$ & $\mathrm{n} / \mathrm{a}$ & $\mathrm{n} / \mathrm{a}$ & 2 & $\mathrm{n} / \mathrm{a}$ & $\mathrm{n} / \mathrm{a}$ & $\mathrm{n} / \mathrm{a}$ & $\mathrm{n} / \mathrm{a}$ & $\mathrm{n} / \mathrm{a}$ \\
\hline Maximum Soil Depth $(E, m)$ & n/a & $\mathrm{n} / \mathrm{a}$ & $\mathrm{n} / \mathrm{a}$ & 300 & $\mathrm{n} / \mathrm{a}$ & $\mathrm{n} / \mathrm{a}$ & $\mathrm{n} / \mathrm{a}$ & $\mathrm{n} / \mathrm{a}$ & $\mathrm{n} / \mathrm{a}$ \\
\hline Minimum Soil Far-Field Distance $(F, m)$ & $\mathrm{n} / \mathrm{a}$ & $\mathrm{n} / \mathrm{a}$ & $\mathrm{n} / \mathrm{a}$ & 8 & $\mathrm{n} / \mathrm{a}$ & $\mathrm{n} / \mathrm{a}$ & $\mathrm{n} / \mathrm{a}$ & $\mathrm{n} / \mathrm{a}$ & $\mathrm{n} / \mathrm{a}$ \\
\hline Maximum Soil Far-Field Distance $(F, m)$ & $\mathrm{n} / \mathrm{a}$ & $\mathrm{n} / \mathrm{a}$ & $\mathrm{n} / \mathrm{a}$ & 150 & $\mathrm{n} / \mathrm{a}$ & $\mathrm{n} / \mathrm{a}$ & $\mathrm{n} / \mathrm{a}$ & $\mathrm{n} / \mathrm{a}$ & $\mathrm{n} / \mathrm{a}$ \\
\hline \multicolumn{10}{|c|}{ THERMAL PROPERTIES* } \\
\hline Minimum Conductivity $(\mathrm{W} /(\mathrm{mK}))$ & 0.5 & 0 & 0 & 0.5 & 0 & 0 & 0 & 0 & 0 \\
\hline Maximum Conductivity $(\mathrm{W} /(\mathrm{mK}))$ & 1.9 & 0 & 0 & 1.9 & 0 & 0 & 0 & 0 & 0 \\
\hline Minimum R-Value $\left.\left(\mathrm{m}^{2} \mathrm{~K} / \mathrm{W}\right)\right)$ & $0^{* *}$ & $0^{* *}$ & $0^{* *}$ & $0^{* \star}$ & 0 & 0 & 0 & 0 & 0 \\
\hline Maximum R-Value $\left.\left(\mathrm{m}^{2} \mathrm{~K} / \mathrm{W}\right)\right)$ & $0^{* *}$ & $0^{* *}$ & $0^{* *}$ & $0^{* *}$ & 0 & 0 & 0 & 0 & 0 \\
\hline Minimum Density $\left(\mathrm{kg} / \mathrm{m}^{3}\right)$ & 1490 & 0 & 0 & 1490 & 0 & 0 & 0 & 0 & 0 \\
\hline Maximum Density $\left(\mathrm{kg} / \mathrm{m}^{3}\right)$ & 1490 & 0 & 0 & 1490 & 0 & 0 & 0 & 0 & 0 \\
\hline Minimum Specific Heat $(\mathrm{kJ} /(\mathrm{kgK}))$ & 1800 & 0 & 0 & 1800 & 0 & 0 & 0 & 0 & 0 \\
\hline Maximum Specific Heat $(\mathrm{kJ} /(\mathrm{kgK}))$ & 1800 & 0 & 0 & 1800 & 0 & 0 & 0 & 0 & 0 \\
\hline
\end{tabular}




\begin{tabular}{rl|l|} 
Uninsulated detail (Figure [2C]A-1) ok? ("yes" or no \\
"no") & \\
Insulated detail (Figure [2C]A-2) ok? ("yes" or "no") & no \\
\hline
\end{tabular}

If no, include additional assumptions of My models were much simpler than shown. They included a slab in grade and soil - no walls, your model not covered herefoundation or insulation. Since the slab and soil were both considered to have the same conductivity, density and specific heat, slab thickness was irrelevant. Boundary conditions for the interior, the exterior and the perimeter boundary surface were input directly into the model as specified. The use of large convection coefficients (to simulate isothermal boundary conditions) was therefore not necessary. For the same reason a building zone was not necessary and was not included in the model.

\section{NOTES}

"n/a": not applicable

* If a listed input does not apply to your model, enter " 0 " in the relevant cells

** For below grade high-mass components, only list $R$-value input limits if there is some difference versus what would be calculated based on listed conductivity and thickness limits 
Appendix II-D

\title{
Modeler Report for BESTEST Cases GC10a-GC80c EnergyPlus Version 2.0.0.025
}

\author{
by \\ Robert Henninger and Michael Witte \\ GARD Analytics, Inc. \\ United States
}

September 2007

\section{Introduction}

\section{Software: \\ Authoring Organization:}

Authoring Country:
EnergyPlus Version 2.0.0.025

Lawrence Berkeley National Laboratory, U.S. Department of Energy; University of Illinois

USA

This report describes the modeling methodology and results for the testing done for the Proposed IEA BESTEST In-Depth Diagnostic Cases for Ground-Coupled Heat Transfer Related to Slab-on-Grade Construction, which were simulated using the EnergyPlus software. The specifications for the test suite are described in Proposed IEA BESTEST In-Depth Diagnostic Cases for Ground-Coupled Heat Transfer Related to Slab-on-Grade Conduction, IEA SHC Task 34/Annex 43, March 2006 (referred to as the BESTEST Indepth G-C specification in this report).

\section{Modeling Methodology}

The difficulty behind linking ground heat transfer calculations to EnergyPlus is the fact that the conduction calculations in EnergyPlus (and in DOE-2 and BLAST before it) are 1-D and the ground heat transfer calculations are 2-D or 3-D. This causes severe modeling problems irrespective of the methods being used for the ground heat transfer calculation. The basic heat balance based zone model of EnergyPlus has to be considered as the foundation for building energy simulation at the present time and for some time in the future. Thus, it is necessary to be able to relate ground heat transfer calculations to that model.

The heat balance zone model considers a single room or thermal zone in a building and performs a heat balance on it. A fundamental modeling assumption is that the faces of the enclosure are isothermal planes. A ground heat transfer calculation usually considers an entire building and the earth that surrounds it, resulting in non-isothermal face planes where there is ground contact. While it is not impossible to imagine multi-zone, whole-building models that include the surrounding earth and nonisothermal building surfaces, such models will not be practical for some time in the future, and their usefulness even then is not clear. 
The EnergyPlus development team addressed this question and decided that the most reasonable first step would be to partially decouple the ground heat transfer calculation from the thermal zone calculation. The most important parameter for the zone calculation is the outside face temperature of the building surface that is in contact with the ground. Thus, this becomes a reasonable "separation plane" for the two calculations. It was further decided that the current usage of monthly average ground temperature was reasonable for this separation plane temperature as well, since the time scales of the building heat transfer processes are so much shorter than those of the ground heat transfer processes.

Using the separation plane premise, the 3D ground heat transfer programs for slabs developed by Bahnfleth $(1989,1990)$ were modified by Clements $(2002)$ to produce outside face temperatures. The program has been modified to permit separate monthly average inside temperatures as input. The program produces outside face temperature for the core area and the perimeter area of the slab. It also produces the overall weighted average surface temperature based on the perimeter and core areas used in the calculation.

The independent EnergyPlus Slab program requires the use of the EnergyPlus whole-building simulation program in order to determine the space heating or cooling load and resultant space temperature for each time step of the simulation. Only In-Depth Tests GC30b, GC40b, GC45b, GC50b, GC55b, GC60b, GC65b, GC70b, GC80b, GC30c, GC40c, GC45c, GC55c and GC80c were simulated with EnergyPlus. Each of these cases was simulated using the autogrid feature of the EnergyPlus Slab program.

The simulation of ground-coupled heat transfer is a two-step process with EnergyPlus. First, for each of the BESTEST G-C in-depth cases that were modeled, the characteristics and properties of the soil and slab along with boundary conditions, indoor film coefficients, and monthly average indoor temperature setpoint were input to the EnergyPlus Slab program, which is an auxiliary program that is part of the EnergyPlus suite. Using the slab Area-to-Perimeter (A/P) ratio defined by the user, the Slab program generates an equivalent slab with appropriate perimeter and core areas and simulates the slab heat transfer for a period of years until the temperature convergence tolerance is reached. A set of monthly slab perimeter and core temperatures at the ground-slab interface and heat fluxes are output as shown in tables below. The second step then is to create the EnergyPlus whole building model (IDF file), which includes the monthly average ground temperature values from the Slab program analysis. In the EnergyPlus IDF file these monthly temperatures are input as part of the GROUNDTEMPERATURES object. The whole building simulation is then performed using a one zone building where all surfaces except for the floor were adiabatic. This analysis process is then repeated for each case to be analyzed.

The monthly temperatures calculated by the Slab program for various cases are summarized in the tables below. The temperatures listed in the column labeled "Taverage" were used by EnergyPlus to simulate heat transfer between the slab and the zone interior space. It should be noted that the total slab area (perimeter area + core area) presented in the tables below will not necessarily agree with the total slab area specified for each case in the BESTEST Indepth G-C specification. This is particularly noticeable for Cases GC45b and GC45c. The EnergyPlus Slab program requests that the user input the A/P ratio for each case and not the dimensions or area of the slab. The EnergyPlus Slab program then constructs a square slab with an equivalent $\mathrm{A} / \mathrm{P}$ ratio and then performs its analysis to determine the ground/slab interface temperatures. For those cases where the specification calls for a slab with dimensions of $12 \mathrm{~m} \times$ $12 \mathrm{~m}$ (Cases GC30, GC 40, GC55, GC60, GC65, and GC70), the total floor area used by the Slab program happens to be approximately $144 \mathrm{~m}^{2}$. For the other cases however, where the specification calls for a rectangular floor (Case GC45 with a $36 \mathrm{~m} \times 4 \mathrm{~m}$ floor and Case GC 50 with a $80 \mathrm{~m} \times 80 \mathrm{~m}$ floor), the floor area used by EnergyPlus is not that called for in the specification. The resulting ground/slab 
interface temperatures calculated by the Slab program for these last two cases should be reliable since they are based on a floor with the same $\mathrm{A} / \mathrm{P}$ ratio. The resulting monthly ground/slab interface temperatures (identified in the tables below as (TAverage) are then specified in EnergyPlus along with the actual slab dimensions from the specification for each test case. EnergyPlus then performs simulations based on the correct slab area.

\section{Cases GC30b - Steady-State Comparative Test Base Case}

Monthly Slab Outside Face Temperatures, C and Heat Fluxes(loss), W/(m^2) Perimeter Area: 79.00 Core Area: 64

$\begin{array}{rrrr}\text { Month } & \text { TAverage } & \text { TPerimeter } & \text { TCore } \\ 1 & 28.57 & 27.99 & 29.31 \\ 2 & 28.57 & 27.99 & 29.31 \\ 3 & 28.57 & 27.99 & 29.31 \\ 4 & 28.57 & 27.99 & 29.31 \\ 5 & 28.57 & 27.99 & 29.31 \\ 6 & 28.57 & 27.99 & 29.31 \\ 7 & 28.57 & 27.99 & 29.31 \\ 8 & 28.57 & 27.99 & 29.31 \\ 9 & 28.57 & 27.99 & 29.31 \\ 10 & 28.57 & 27.99 & 29.31 \\ 11 & 28.57 & 27.99 & 29.31 \\ 12 & 28.57 & 27.99 & 29.31\end{array}$

TInside
30
30
30
30
30
30
30
30
30
30
30
30

$\begin{array}{rr}\text { AverageFlux } & \text { PerimeterFlux } \\ 18.39 & 25.94 \\ 18.39 & 25.94 \\ 18.39 & 25.94 \\ 18.39 & 25.94 \\ 18.39 & 25.94 \\ 18.39 & 25.94 \\ 18.38 & 25.94 \\ 18.38 & 25.94 \\ 18.38 & 25.94 \\ 18.38 & 25.94 \\ 18.38 & 25.94 \\ 18.38 & 25.93\end{array}$

CoreFlux
8.95
8.95
8.95
8.95
8.95
8.95
8.95
8.95
8.94
8.95
8.94
8.95

Convergence has been gained.

\section{Case GC40b - Harmonic Variation of Ambient Temperature}

\begin{tabular}{|c|c|c|c|c|c|c|c|}
\hline Month & TAverage & TPerimeter & TCore & TInside & AverageFlux & PerimeterFlux & CoreFlux \\
\hline 1 & 28.39 & 27.66 & 29.30 & 30 & 20.73 & 30.11 & 8.00 \\
\hline 2 & 28.38 & 27.65 & 29.29 & 30 & 20.92 & 30.32 & 9.16 \\
\hline 3 & 28.41 & 27.72 & 29.28 & 30 & 20.46 & 29.41 & 9.28 \\
\hline 4 & 28.49 & 27.86 & 29.28 & 30 & 19.46 & 27.57 & 9.31 \\
\hline 5 & 28.59 & 28.04 & 29.28 & 30 & 18.17 & 25.31 & 9.25 \\
\hline 6 & 28.68 & 28.20 & 29.29 & 30 & 16.95 & 23.22 & 9.11 \\
\hline 7 & 28.75 & 28.30 & 29.31 & 30 & 16.12 & 21.87 & 8.92 \\
\hline 8 & 28.77 & 28.32 & 29.32 & 30 & 15.90 & 21.63 & 8.74 \\
\hline 9 & 28.73 & 28.25 & 29.33 & 30 & 16.36 & 22.55 & 8.63 \\
\hline 10 & 28.65 & 28.11 & 29.33 & 30 & 17.38 & 24.40 & 8.59 \\
\hline 11 & 28.55 & 27.93 & 29.33 & 30 & 18.67 & 26.68 & 8.66 \\
\hline 12 & 28.46 & 27.77 & 29.32 & 30 & 19.89 & 28.76 & 8.80 \\
\hline
\end{tabular}

Convergence has been gained. 
Case GC45b - Aspect Ratio

Monthly Slab Outside Face Temperatures, C and Heat Fluxes(loss), W/(m²) Perimeter Area: 41.60 Core Area: 10.24

$\begin{array}{rrrr}\text { Month } & \text { TAverage } & \text { TPerimeter } & \text { TCore } \\ 1 & 27.65 & 27.32 & 28.99 \\ 2 & 27.62 & 27.29 & 28.97 \\ 3 & 27.68 & 27.37 & 28.95 \\ 4 & 27.81 & 27.53 & 28.95 \\ 5 & 27.98 & 27.74 & 28.96 \\ 6 & 28.13 & 27.92 & 28.99 \\ 7 & 28.24 & 28.04 & 29.03 \\ 8 & 28.26 & 28.07 & 29.06 \\ 9 & 28.20 & 27.99 & 29.08 \\ 10 & 28.07 & 27.83 & 29.08 \\ 11 & 27.91 & 27.62 & 29.06 \\ 12 & 27.75 & 27.44 & 29.03\end{array}$

$\begin{array}{rrr}\text { TInside } & \text { AverageFlux } & \text { PerimeterFlux } \\ 30 & 30.30 & 34.58 \\ 30 & 30.59 & 34.85 \\ 30 & 29.83 & 33.84 \\ 30 & 28.16 & 31.75 \\ 30 & 26.04 & 29.17 \\ 30 & 24.04 & 26.76 \\ 30 & 22.69 & 25.19 \\ 30 & 22.36 & 24.88 \\ 30 & 23.14 & 25.91 \\ 30 & 24.83 & 28.01 \\ 30 & 26.96 & 30.61 \\ 30 & 28.96 & 33.01\end{array}$

CoreFlux
12.95
13.32
13.54
13.55
13.34
12.96
12.52
12.12
11.90
11.89
12.11
12.49

Convergence has been gained

\section{Case GC50b - Large Slab}

Monthly Slab Outside Face Temperatures, C and Heat Fluxes(loss), W/(m^2)

Perimeter Area: 624.00 Core Area: 5776.00

$\begin{array}{rrrr}\text { Month } & \text { TAverage } & \text { TPerimeter } & \text { TCore } \\ 1 & 29.52 & 28.03 & 29.69 \\ 2 & 29.52 & 28.02 & 29.68 \\ 3 & 29.53 & 28.08 & 29.68 \\ 4 & 29.54 & 28.21 & 29.68 \\ 5 & 29.55 & 28.36 & 29.68 \\ 6 & 29.57 & 28.50 & 29.68 \\ 7 & 29.58 & 28.59 & 29.69 \\ 8 & 29.58 & 28.60 & 29.69 \\ 9 & 29.58 & 28.54 & 29.69 \\ 10 & 29.56 & 28.41 & 29.69 \\ 11 & 29.55 & 28.26 & 29.69 \\ 12 & 29.53 & 28.12 & 29.69\end{array}$

$\begin{array}{rrr}\text { TInside } & \text { AverageFlux } & \text { PerimeterFlux } \\ 30 & 6.13 & 25.35 \\ 30 & 6.16 & 25.51 \\ 30 & 6.09 & 24.71 \\ 30 & 5.94 & 23.11 \\ 30 & 5.74 & 21.15 \\ 30 & 5.56 & 19.36 \\ 30 & 5.43 & 18.21 \\ 30 & 5.39 & 18.02 \\ 30 & 5.46 & 18.84 \\ 30 & 5.61 & 20.45 \\ 30 & 5.81 & 22.42 \\ 30 & 5.99 & 24.21\end{array}$

CoreFlux 4.05

4.07

4.08

4.09

4.08

4.06

4.04

4.02

4.01

4.01

4.02

4.03

Convergence has been gained.

\section{Case GC55b - Shallow Deep Ground Temperature}

Monthly Slab Outside Face Temperatures, C and Heat Fluxes(loss), W/(m^2)

Perimeter Area: 79.00 Core Area: 64.00

$\begin{array}{rrr}\text { Month } & \text { TAverage } & \text { TPerimeter } \\ 1 & 27.38 & 26.82 \\ 2 & 27.40 & 26.84 \\ 3 & 27.44 & 26.92 \\ 4 & 27.52 & 27.06 \\ 5 & 27.60 & 27.20 \\ 6 & 27.67 & 27.32 \\ 7 & 27.70 & 27.38 \\ 8 & 27.69 & 27.36 \\ 9 & 27.64 & 27.27 \\ 10 & 27.56 & 27.13 \\ 11 & 27.48 & 26.99 \\ 12 & 27.42 & 26.87\end{array}$

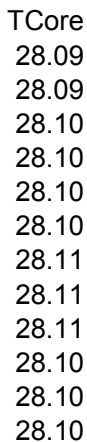

TInside

AverageFlux PerimeterFlux

$33.69 \quad 40.99$

40.74

$\begin{array}{ll}33.54 & 40.74 \\ 32.91 & 39.62\end{array}$

$\begin{array}{ll}31.94 & 37.88 \\ 30.88 & 36.02\end{array}$

$\begin{array}{ll}30.88 & 36.02 \\ 30.04 & 34.53\end{array}$

$\begin{array}{ll}30.04 & 34.53 \\ 29.62 & 33.81\end{array}$

$29.76 \quad 34.05$

$30.40 \quad 35.20$

$31.38 \quad 36.93$

$32.44 \quad 38.80$

33.28

40.29

CoreFlux 24.55

24.55

24.54

24.50

24.46

24.42

24.40

24.39

24.41

24.44

24.48

24.52

Convergence has been gained. 


\section{Case GC60b - Steady State with Typical Interior Surface Convective Coefficient}

Monthly Slab Outside Face Temperatures, C and Heat Fluxes(loss), W/(m^2) Perimeter Area: 79.00 Core Area: 64.00

$\begin{array}{rrrr}\text { Month } & \text { TAverage } & \text { TPerimeter } & \text { TCore } \\ 1 & 27.02 & 25.86 & 28.45 \\ 2 & 27.02 & 25.86 & 28.45 \\ 3 & 27.02 & 25.86 & 28.46 \\ 4 & 27.02 & 25.86 & 28.45 \\ 5 & 27.02 & 25.86 & 28.46 \\ 6 & 27.02 & 25.86 & 28.46 \\ 7 & 27.02 & 25.87 & 28.46 \\ 8 & 27.02 & 25.87 & 28.46 \\ 9 & 27.02 & 25.86 & 28.46 \\ 10 & 27.02 & 25.87 & 28.46 \\ 11 & 27.02 & 25.87 & 28.46 \\ 12 & 27.02 & 25.87 & 28.46\end{array}$

$\begin{array}{rrr}\text { TInside } & \text { AverageFlux } & \text { PerimeterFlux } \\ 30 & 15.43 & 21.38 \\ 30 & 15.43 & 21.38 \\ 30 & 15.43 & 21.38 \\ 30 & 15.43 & 21.38 \\ 30 & 15.43 & 21.38 \\ 30 & 15.43 & 21.38 \\ 30 & 15.43 & 21.38 \\ 30 & 15.43 & 21.38 \\ 30 & 15.42 & 21.38 \\ 30 & 15.43 & 21.38 \\ 30 & 15.42 & 21.38 \\ 30 & 15.43 & 21.38\end{array}$

CoreFlux
7.99
7.99
7.99
7.99
7.99
7.98
7.99
7.99
7.98
7.99
7.98
7.99

Convergence has been gained.

\section{Case GC65b - Steady State with Typical Interior and Exterior Surface Convective Coefficients}

Monthly Slab Outside Face Temperatures, C and Heat Fluxes(loss), W/(m^2) Perimeter Area: 79.00 Core Area: 64.00

$\begin{array}{rrrr}\text { Month } & \text { TAverage } & \text { TPerimeter } & \text { TCore } \\ 1 & 27.83 & 27.14 & 28.68 \\ 2 & 27.83 & 27.14 & 28.68 \\ 3 & 27.83 & 27.14 & 28.68 \\ 4 & 27.83 & 27.14 & 28.68 \\ 5 & 27.83 & 27.14 & 28.68 \\ 6 & 27.83 & 27.14 & 28.68 \\ 7 & 27.83 & 27.14 & 28.68 \\ 8 & 27.83 & 27.14 & 28.68 \\ 9 & 27.83 & 27.14 & 28.68 \\ 10 & 27.83 & 27.14 & 28.68 \\ 11 & 27.83 & 27.14 & 28.68 \\ 12 & 27.83 & 27.14 & 28.68\end{array}$

TInside
30
30
30
30
30
30
30
30
30
30
30
30

AverageFlux PerimeterFlux

$11.24 \quad 14.78$

$11.24 \quad 14.78$

$11.24 \quad 14.77$

$11.24 \quad 14.77$

$11.24 \quad 14.77$

$11.23 \quad 14.77$

$11.23 \quad 14.77$

$11.23 \quad 14.77$

$11.23 \quad 14.77$

$11.23 \quad 14.77$

$11.23 \quad 14.77$

$11.23 \quad 14.77$

CoreFlux
6.82
6.82
6.81
6.81
6.81
6.81
6.81
6.81
6.81
6.81
6.81
6.81

Convergence has been gained.

\section{Case GC70b - Harmonic Variation of Ambient Temperature with Typical Interior and Exterior Surface Convective Coefficients}

\begin{tabular}{|c|c|c|c|c|c|c|c|}
\hline 年 & Core A & & & & & & \\
\hline 1 & 27.46 & 26.56 & 28.60 & 30 & 13.11 & 17.80 & 7.24 \\
\hline 3 & 27.46 & 26.58 & 28.57 & 30 & 13.12 & 17.71 & 7.38 \\
\hline 4 & 27.52 & 26.69 & 28.57 & 30 & 12.80 & 17.12 & 7.40 \\
\hline 5 & 27.61 & 26.83 & 28.57 & 30 & 12.38 & 16.38 & 7.38 \\
\hline 8 & 27.78 & 27.12 & 28.61 & 30 & 11.46 & 14.89 & 7.17 \\
\hline 9 & 27.77 & 27.09 & 28.63 & 30 & 11.50 & 15.02 & 7.11 \\
\hline 10 & 27.72 & 26.99 & 28.63 & 30 & 11.78 & 15.55 & 7.07 \\
\hline 11 & 27.63 & 26.83 & 28.63 & 30 & 12.24 & 16.36 & 7.09 \\
\hline 12 & 27.54 & 26.67 & 28.62 & 30 & 12.73 & 17.19 & 7.15 \\
\hline
\end{tabular}

Convergence has been gained. 


\section{Case GC80b - Reduced Slab and Ground Conductivity}

Monthly Slab Outside Face Temperatures, C and Heat Fluxes(loss), W/(m^2) Perimeter Area: 79.00 Core Area: 64.00

\begin{tabular}{|c|c|c|c|}
\hline Month & TAverage & TPerim eter & TCore \\
\hline 1 & 28.60 & 27.95 & 29.41 \\
\hline 2 & 28.58 & 27.92 & 29.41 \\
\hline 3 & 28.60 & 27.96 & 29.40 \\
\hline 4 & 28.65 & 28.05 & 29.40 \\
\hline 5 & 28.72 & 28.17 & 29.40 \\
\hline 6 & 28.79 & 28.30 & 29.40 \\
\hline 7 & 28.84 & 28.38 & 29.40 \\
\hline 8 & 28.85 & 28.41 & 29.41 \\
\hline 9 & 28.83 & 28.37 & 29.41 \\
\hline 10 & 28.78 & 28.28 & 29.41 \\
\hline 11 & 28.71 & 28.16 & 29.41 \\
\hline 12 & 28.65 & 28.04 & \\
\hline
\end{tabular}

Convergence has been gained.

\section{Cases GC30c - Steady-State Comparative Test Base Case with Baseimp}

Monthly Slab Outside Face Temperatures, C and Heat Fluxes(loss), W/(m^2)

Perimeter Area: 79.00 Core Area: 64

$\begin{array}{rrrr}\text { Month } & \text { TAverage } & \text { TPerimeter } & \text { TCore } \\ 1 & 26.90 & 25.67 & 28.43 \\ 2 & 26.90 & 25.67 & 28.43 \\ 3 & 26.90 & 25.67 & 28.43 \\ 4 & 26.90 & 25.67 & 28.43 \\ 5 & 26.90 & 25.67 & 28.43 \\ 6 & 26.90 & 25.67 & 28.43 \\ 7 & 26.90 & 25.67 & 28.43 \\ 8 & 26.90 & 25.67 & 28.43 \\ 9 & 26.90 & 25.67 & 28.43 \\ 10 & 26.90 & 25.67 & 28.43 \\ 11 & 26.90 & 25.67 & 28.43 \\ 12 & 26.90 & 25.67 & 28.43\end{array}$

TInside
30
30
30
30
30
30
30
30
30
30
30
30

AverageFlux PerimeterFlux

$16.05 \quad 22.41$

$16.05 \quad 22.41$

$16.05 \quad 22.41$

$16.05 \quad 22.40$

$16.05 \quad 22.40$

$16.05 \quad 22.40$

$16.05 \quad 22.40$

$16.05 \quad 22.40$

$16.05 \quad 22.40$

$16.05 \quad 22.40$

$16.05 \quad 22.40$

CoreFlux

2.22

2.24

2.25

2.25

2.25

2.24

2.23

2.21

2.20

2.20

2.20

Convergence has been gained.

\section{Case GC40c - Harmonic Variation of Direct-Input Exterior Surface Temperature with Baseimp Boundary Conditions}

Monthly Slab Outside Face Temperatures, C and Heat Fluxes(loss), W/(m^2) Perimeter Area: 79.00 Core Area: 64

$\begin{array}{rrrr}\text { Month } & \text { TAverage } & \text { TPerimeter } & \text { TCore } \\ 1 & 26.47 & 24.91 & 28.41 \\ 2 & 26.44 & 24.89 & 28.38 \\ 3 & 26.53 & 25.07 & 28.36 \\ 4 & 26.72 & 25.40 & 28.36 \\ 5 & 26.95 & 25.81 & 28.38 \\ 6 & 27.17 & 26.18 & 28.41 \\ 7 & 27.31 & 26.41 & 28.45 \\ 8 & 27.35 & 26.44 & 28.48 \\ 9 & 27.25 & 26.26 & 28.50 \\ 10 & 27.07 & 25.91 & 28.51 \\ 11 & 26.83 & 25.51 & 28.49 \\ 12 & 26.61 & 25.14 & 28.46\end{array}$

$\begin{array}{rrr}\text { TInside } & \text { AverageFlux } & \text { PerimeterFlux } \\ 30 & 18.26 & 26.31 \\ 30 & 18.40 & 26.42 \\ 30 & 17.94 & 25.51 \\ 30 & 16.97 & 23.76 \\ 30 & 15.76 & 21.66 \\ 30 & 14.63 & 19.75 \\ 30 & 13.88 & 18.57 \\ 30 & 13.72 & 18.42 \\ 30 & 14.19 & 19.36 \\ 30 & 15.17 & 21.12 \\ 30 & 16.38 & 23.24 \\ 30 & 17.51 & 25.13\end{array}$

CoreFlux
8.20
8.37
8.48
8.49
8.40
8.23
8.03
7.85
7.73
7.72
7.82
7.99

Convergence has been gained 


\section{Case GC45c - Aspect Ratio with Baseimp Boundary Conditions}

Monthly Slab Outside Face Temperatures, C and Heat Fluxes(loss), W/(m^2) Perimeter Area: 41.60 Core Area: 10.24

\begin{tabular}{|c|c|c|c|c|c|c|c|}
\hline Month & TAverage & TPerimeter & TCore & TInside & AverageFlux & PerimeterFlux & CoreFlux \\
\hline 1 & 24.90 & 24.21 & 27.70 & 30 & 26.35 & 29.91 & 11.90 \\
\hline 2 & 24.86 & 24.18 & 27.63 & 30 & 26.55 & 30.07 & 12.27 \\
\hline 3 & 25.01 & 24.38 & 27.59 & 30 & 25.78 & 29.06 & 12.46 \\
\hline 4 & 25.32 & 24.76 & 27.60 & 30 & 24.19 & 27.09 & 12.42 \\
\hline 5 & 25.70 & 25.22 & 27.65 & 30 & 22.21 & 24.69 & 12.14 \\
\hline 6 & 26.06 & 25.64 & 27.74 & 30 & 20.38 & 22.52 & 11.71 \\
\hline 7 & 26.29 & 25.91 & 27.83 & 30 & 19.19 & 21.15 & 11.24 \\
\hline 8 & 26.33 & 25.95 & 27.90 & 30 & 18.96 & 20.96 & 10.85 \\
\hline 9 & 26.18 & 25.75 & 27.94 & 30 & 19.76 & 21.00 & 10.65 \\
\hline 10 & 25.87 & 25.36 & 27.93 & 30 & 21.36 & 23.99 & 10.71 \\
\hline 11 & 25.48 & 24.90 & 27.88 & 30 & 23.35 & 26.39 & 10.99 \\
\hline 12 & 25.13 & 24.48 & 27.79 & 30 & 25.17 & 28.55 & 11.42 \\
\hline
\end{tabular}

Convergence has been gained.

\section{Case GC55c - Shallow Deep Ground Temperature with Baseimp Boundary Conditions}

Monthly Slab Outside Face Temperatures, C and Heat Fluxes(loss), W/(m^2)

Perimeter Area: 79.00 Core Area: 64.00

$\begin{array}{rrrr}\text { Month } & \text { TAverage } & \text { TPerimeter } & \text { TCore } \\ 1 & 26.09 & 24.58 & 27.98 \\ 2 & 26.07 & 24.56 & 27.94 \\ 3 & 26.16 & 24.75 & 27.93 \\ 4 & 26.36 & 25.10 & 27.93 \\ 5 & 26.61 & 25.52 & 27.96 \\ 6 & 26.83 & 25.90 & 28.00 \\ 7 & 26.98 & 26.13 & 28.05 \\ 8 & 27.01 & 26.15 & 28.08 \\ 9 & 26.91 & 25.96 & 28.10 \\ 10 & 26.71 & 25.61 & 28.09 \\ 11 & 26.47 & 25.19 & 28.07 \\ 12 & 26.24 & 24.81 & 28.02\end{array}$

$\begin{array}{rrr}\text { TInside } & \text { AverageFlux } & \text { PerimeterFlux } \\ 30 & 20.21 & 28.01 \\ 30 & 20.34 & 28.11 \\ 30 & 19.84 & 27.15 \\ 30 & 18.82 & 25.33 \\ 30 & 17.55 & 23.16 \\ 30 & 16.37 & 21.21 \\ 30 & 15.60 & 20.00 \\ 30 & 15.45 & 19.88 \\ 30 & 15.96 & 20.87 \\ 30 & 16.99 & 22.70 \\ 30 & 18.27 & 24.88 \\ 30 & 19.44 & 26.82\end{array}$

CoreFlux 10.45

10.63

10.71

10.68

10.54

10.32

10.09

9.91

9.82

9.86

10.00

10.22

Convergence has been gained.

\section{Case GC80c - Reduced Slab and Ground Conductivity with Baseimp Boundary Conditions}

Monthly Slab Outside Face Temperatures, $\mathrm{C}$ and Heat Fluxes(loss), W/(m^2)

Perimeter Area: 79.00 Core Area: 64.00

\begin{tabular}{|c|c|c|c|c|}
\hline Month & TAverage & TPerim & eter & TCore \\
\hline 1 & 27.52 & 26.35 & & 28.99 \\
\hline 2 & 27.50 & 26.32 & & 28.98 \\
\hline 3 & 27.56 & 26.43 & & 28.97 \\
\hline 4 & 27.67 & 26.64 & & 28.96 \\
\hline 5 & 27.82 & 26.90 & & 28.96 \\
\hline 6 & 27.96 & 27.15 & & 28.97 \\
\hline 7 & 28.05 & 27.31 & & 28.98 \\
\hline 8 & 28.07 & 27.34 & & 28.99 \\
\hline 9 & 28.02 & 27.23 & & 29.00 \\
\hline 10 & 27.90 & 27.02 & & 29.01 \\
\hline 11 & 27.75 & 26.75 & & 29.01 \\
\hline 12 & 27.62 & 26.51 & & 28.00 \\
\hline
\end{tabular}

$\begin{array}{rrr}\text { TInside } & \text { AverageFlux } & \text { PerimeterFlux } \\ 30 & 8.95 & 13.18 \\ 30 & 9.02 & 13.28 \\ 30 & 8.83 & 12.90 \\ 30 & 8.41 & 12.13 \\ 30 & 7.88 & 11.18 \\ 30 & 7.37 & 10.29 \\ 30 & 7.03 & 9.71 \\ 30 & 6.95 & 9.60 \\ 30 & 7.15 & 9.98 \\ 30 & 7.57 & 10.76 \\ 30 & 8.11 & 11.72 \\ 30 & 8.61 & 12.60\end{array}$

CoreFlux
3.66
3.70
3.73
3.75
3.75
3.73
3.69
3.65
3.61
3.59
3.59
3.61

Convergence has been gained. 


\section{Modeling Difficulties}

The boundary condition of zero-vertical heat flux implied for the soil surface just beneath the adiabatic exterior walls of the conditioned zone, as specified in the BESTEST Indepth G-C specification, was not modeled by the EnergyPlus Slab program. The slab program does not have the capability to model this effect. The slab configuration used in the slab program is a slab-in-grade model. That is, the slab top surface is assumed to be level with the outside earth surface. The modeling capabilities of the EnergyPlus Slab program are shown in Figure 2D-1. The insulation layers are optional and were not required for any of the G-C test cases. With the EnergyPlus Slab program the entire slab top surface is exposed to the interior zone condition.

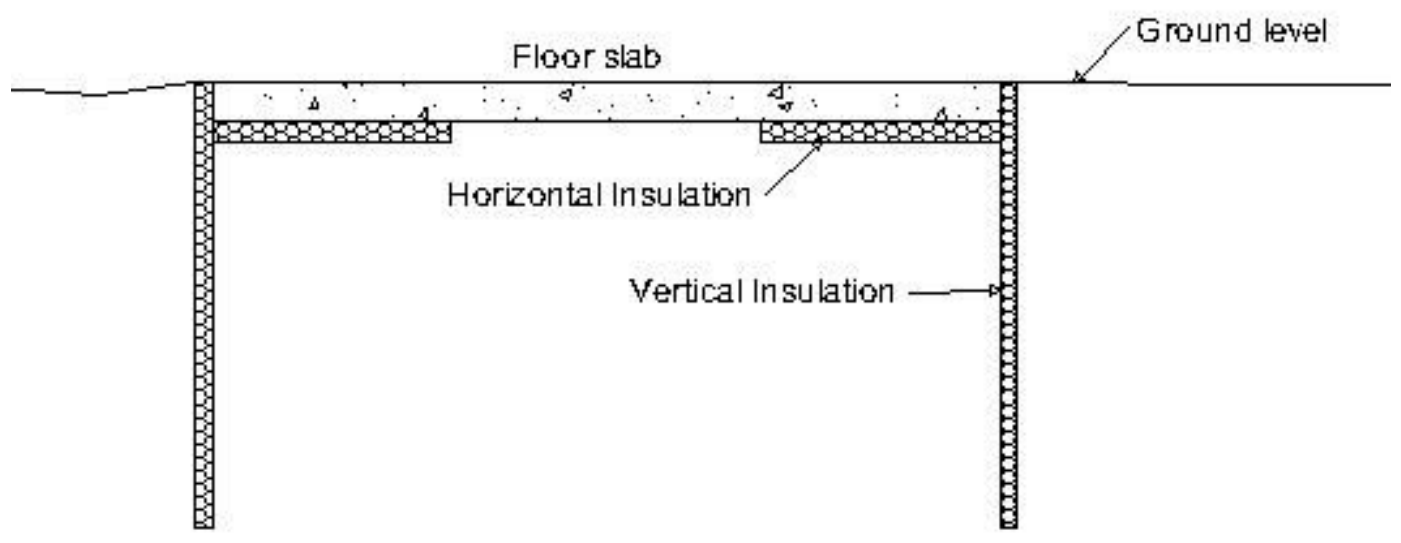

Figure 2D-1 Slab-in-grade illustration

\section{Modeling Assumptions}

Over the duration of this ground-coupling test suite development in which EnergyPlus first participated in December 2004, the EnergyPlus auxiliary Slab program has had two upgrades with changes as summarized below:

- May 2003 Original version used to report results in EnergyPlus Modeler Report dated December 2004

- April 2005 Enhanced to allow optional user inputs for the lower deep boundary temperature and exterior ground heat transfer coefficient and was used to report revised results presented in EnergyPlus Modeler Report dated June 2005. Changes were also made to the gridding scheme to include stability considerations and eliminate "floating overflow" and "array bounds" errors. A scheduling feature was added to the OtherSideCoefficients object in EnergyPlus 1.2.2 to allow the separate simulation of perimeter and core portions of slab floors.

- March 2006 Enhanced to allow user input of the lower deep boundary depth and was used to report revised results presented in EnergyPlus Modeler Report dated March 2006. To make it easier for the user to separately simulate the perimeter and core areas of floor slabs in EnergyPlus, example inputs (IDF) for using the EnergyPlus OtherSideCoefficients object to simulate the perimeter and core of floor slabs were added to the Slab program output. 
Several of the inputs required by the EnergyPlus Slab program to simulate the In-Depth G-C test cases are highlighted below.

1) Ground surface albedo for snow and no snow conditions - both set to 0.0

2) Ground surface emissivity for snow and no snow conditions - both set to 0.000001

3) Ground surface roughness for snow and no snow conditions - both set to 0.000001

4) Slab thickness - The EnergyPlus Slab program requires the user to specify the thickness of the slab. For the results reported in the EnergyPlus Modeler Report dated December 2004, the slab thickness was set to $0.1524 \mathrm{~m}$ (6 inch). In accordance with the G-C In-Depth specification released in June 2005 where it was requested that the thinnest slab allowable be used, all cases were revised to use a slab with thickness of $0.1285 \mathrm{~m}$ ( 5 inch).

5) Surface evapotranspiration - set to FALSE (off)

6) Convergence tolerance - The Slab program iterations continue until the temperature change of all modes are less than this value. For all test cases the convergence tolerance was set to $0.1^{\circ} \mathrm{C}$.

7) For all cases the grid autosizing option was used.

8) For Cases GC30c, GC40c, GC45c and GC80c the exterior ground surface temperature could not be fixed as required by the Indepth G-C specification. To approximate this condition, as suggested in the specification, the exterior ground convective coefficient was set to 100 $\mathrm{W} / \mathrm{m} 2-\mathrm{K}$.

\section{Appropriate Modeling Detail}

The accuracy of results produced by the EnergyPlus Slab program are controlled by the Convergence Tolerance input parameter specified by the user. Annual simulations by the EnergyPlus Slab program continue until the change in temperature for all nodes of the grid are less than this convergence tolerance. For all of the cases simulated as part of this test suite, the convergence tolerance was set to $0.1 \mathrm{C}$. Convergence for the cases that ran successfully occurred within the following time periods:

$\begin{array}{ll}\text { Case GC30b } & 7 \text { years } \\ \text { Case GC40b } & 7 \text { years } \\ \text { Case GC45b } & 7 \text { years } \\ \text { Case GC50b } & 8 \text { years } \\ \text { Case GC55b } & 3 \text { years } \\ \text { Case GC60b } & 7 \text { years } \\ \text { Case GC65b } & 8 \text { years } \\ \text { Case GC70b } & 7 \text { years } \\ \text { Case GC80b } & 16 \text { years } \\ \text { Case GC30c } & 6 \text { years } \\ \text { Case GC40c } & 6 \text { years } \\ \text { Case GC45c } & 6 \text { years } \\ \text { Case GC55c } & 3 \text { years } \\ \text { Case GC80c } & 10 \text { years }\end{array}$




\section{Enhancements to EnergyPlus}

As was discussed in Section 4, a series of enhancements had to be made to the EnergyPlus Slab program in order to accommodate the range of variable testing required by the BESTEST In-Depth G-C

specification. The extreme range of some of these variables would never be seen in real buildings but are convenient for controlled comparative testing. A summary of these enhancements and their impact on results is presented below.

- User definition of a specific lower deep boundary temperature. This capability was required to ensure that all programs participating in the BESTEST In-Depth G-C comparative testing exercise were using the same deep boundary temperature. Previous to this enhancement, this temperature was calculated for the user by the EnergyPlus Slab program and set to the annual mean outdoor dry-bulb temperature as determined from data on the weather file. Since the lower deep boundary temperature required by the specification was $10^{\circ} \mathrm{C}$ for all test cases and each of the weather files used as part of the test suite already had annual mean ambient dry-bulb air temperatures of $10^{\circ} \mathrm{C}$, use of this new capability did not change any of the test results.

- User definition of ground surface heat transfer coefficient. This capability was required to ensure that all programs participating in the BESTEST In-Depth G-C comparative testing exercise were using the same the same ground heat transfer coefficient. Most test cases the In-Depth G-C specification required that this parameter be set to $100 \mathrm{~W} /\left(\mathrm{m}^{2} \mathrm{~K}\right)$, a value far higher than typically seen in real situations. Cases GC65b and GC70b, however, required that this parameter be set at $11.95 \mathrm{~W} /\left(\mathrm{m}^{2} \mathrm{~K}\right)$. In the original version of the EnergyPlus Slab program the user did not have the option of defining this parameter but rather it was calculated internally by the program as a function of the ambient temperature and wind speed from the weather file. Subsequent to this enhancement the ground heat transfer coefficient for each test case was set by input to that required by the specification.

- User definition of the lower deep boundary depth, including allowing the automated gridding option for various depths. This capability was required because the In-Depth G-C specification requested the simulation of shallow as well as deep boundary depths ranging from $2 \mathrm{~m}$ to $30 \mathrm{~m}$. Previous to this enhancement, when the $\mathrm{A} / \mathrm{P}$ ratio was 4.25 or less the deep boundary depth was automatically set to $15 \mathrm{~m}$ and if greater than 4.25 it was set to $20 \mathrm{~m}$. In reality, once you reach $20 \mathrm{~m}$ there would be no change in results beyond that distance. For all test cases except GC55b and GC55c, the deep boundary depth specified is $15 \mathrm{~m}$, and since for all cases except GC50b the $\mathrm{A} / \mathrm{P}$ ratio is less than 4.25 , this new capability affected only 3 of the 14 of the test cases modeled by EnergyPlus.

- With earlier versions of the Slab program documentation there was some confusion about the input parameter "Distance from edge of slab to domain edge." It was unclear if this was the horizontal far field distance or the deep boundary depth. Later documentation changes cleared this up. 


\section{7. $\quad$ Results}

Results for this round of testing with EnergyPlus 2.0.0.025 for the cases modeled are shown below. Some of the requested output results were not available from the EnergyPlus Slab program.

\begin{tabular}{|c|c|c|c|c|c|c|c|}
\hline Software: & EnergyPlus & & & Versior & 2.0 .0 .025 & & Date: $C$ \\
\hline Steady St & te Cases & & & & & GC10 On & \\
\hline & $\begin{array}{l}\mathrm{q}_{\text {floor }} \\
\text { (W) }\end{array}$ & $\begin{array}{l}\mathrm{q}_{\text {zone }} \\
\text { (W) }\end{array}$ & $\begin{array}{l}\mathrm{T}_{\text {zone }} \\
\left({ }^{\circ} \mathrm{C}\right)\end{array}$ & $\begin{array}{c}\mathrm{t}_{\text {sim }} \\
\text { (hours) }\end{array}$ & $\begin{array}{c}Q_{\text {cumulative }} \\
\text { (kWh) }\end{array}$ & $\begin{array}{c}E \\
(\mathrm{~m})\end{array}$ & $\begin{array}{c}\mathrm{F} \\
(\mathrm{m})\end{array}$ \\
\hline $\begin{array}{l}\text { GC10a } \\
\text { GC30a }\end{array}$ & & $\mathrm{n} / \mathrm{a}$ & $\mathrm{n} / \mathrm{a}$ & & $\mathrm{n} / \mathrm{a}$ & & \\
\hline GC30b & 2652 & 2652 & 30 & 61320 & 69706 & & \\
\hline GC30c & 2308 & 2308 & 30 & 52560 & 60652 & & \\
\hline GC60b & 2219 & 2219 & 30 & 61320 & 58304 & & \\
\hline GC65b & 1616 & 1616 & 30 & 70080 & 42457 & & \\
\hline
\end{tabular}

\begin{tabular}{|c|c|c|c|c|c|c|c|c|c|c|c|c|c|c|}
\hline \multicolumn{15}{|c|}{ Harmonic Cases } \\
\hline & \multicolumn{4}{|c|}{ Annual Sums and Means } & \multicolumn{10}{|c|}{ Annual Hourly Integrated Maxima and Minima } \\
\hline & $\mathrm{Q}_{\text {floor }}$ & $Q_{\text {zone }}$ & $T_{\text {zone,mean }}$ & $t_{\text {sim }}$ & $q_{\text {floor, } \max }$ & & & $q_{\text {zone,max }}$ & & & $T_{O D B, \min }$ & (first occu & nce) & Number of hours \\
\hline & $(\mathrm{kWh} / \mathrm{y})$ & $(\mathrm{kWh} / \mathrm{y})$ & $\left({ }^{\circ} \mathrm{C}\right)$ & (hours) & (W) & Date & Hour & (W) & Date & Hour & $\left({ }^{\circ} \mathrm{C}\right)$ & Date & Hour & at $T_{O D B, \min }$ \\
\hline \multicolumn{15}{|l|}{ GC40a } \\
\hline GC40b & 23204 & 23204 & 30 & 61320 & 3005 & $02 / 02$ & 03:00 & 3005 & $02 / 02$ & 03:00 & 2.0375 & $01 / 08$ & 04:00 & 15 \\
\hline GC45b & 33415 & 33415 & 30 & 61320 & 4415 & $02 / 02$ & 04:00 & 4415 & $02 / 02$ & 04:00 & 2.0375 & $01 / 08$ & 04:00 & 15 \\
\hline GC50b & 324257 & 324257 & 30 & 70080 & 39570 & $01 / 01$ & 01:00 & 39570 & $01 / 01$ & 01:00 & 2.0375 & $01 / 08$ & 04:00 & 15 \\
\hline GC55b & 39932 & 39932 & 30 & 26280 & 4860 & $01 / 01$ & 01:00 & 4860 & $01 / 01$ & 01:00 & 2.0375 & $01 / 08$ & 04:00 & 15 \\
\hline GC70b & 15553 & 15553 & 30 & 61320 & 1906 & $02 / 03$ & 08:00 & 1906 & $02 / 03$ & 08:00 & 2.0375 & $01 / 08$ & 04:00 & 15 \\
\hline GC80b & 6059 & 6059 & 30 & 140160 & 766 & $02 / 04$ & 02:00 & 766 & $02 / 04$ & 02:00 & 2.0375 & $01 / 08$ & 04:00 & 15 \\
\hline GC40c & 20255 & 20255 & 30 & 52560 & 2650 & $02 / 03$ & 11:00 & 2650 & $02 / 03$ & 11:00 & 2.0375 & $01 / 08$ & 04:00 & 15 \\
\hline GC45c & 28707 & 28707 & 30 & 52560 & 3827 & $02 / 03$ & 07:00 & 3827 & $02 / 03$ & $07: 00$ & 2.0375 & $01 / 08$ & 04:00 & 15 \\
\hline GC55c & 22570 & 22570 & 30 & 26280 & 2926 & $02 / 03$ & 11:00 & 2926 & $02 / 03$ & $11: 00$ & 2.0375 & $01 / 08$ & 04:00 & 15 \\
\hline GC80c & 10073 & 10073 & 30 & 87600 & 1300 & $02 / 05$ & 05:00 & 1300 & $02 / 05$ & $05: 00$ & 2.0375 & $01 / 08$ & 04:00 & 15 \\
\hline
\end{tabular}

\section{Other}

One issue that came up in the early stages of the work was a disagreement for the results of GC40-GC30, see Figures 2D-2 and 2D-3 below. This disagreement was traced to an input error where the monthly slab perimeter temperatures output by the slab model were input to EnergyPlus, rather than the monthly average (of perimeter and core) slab temperatures. Figure 2D-4 indicates corrected results, which show a roughly $45 \%$ decrease in floor conduction versus Figure 2D-3. A simultaneous secondary effect on these results is the difference between the specified ideal (infinite) surface coefficients of Case GC40 and surface coefficients of $100 \mathrm{~W} / \mathrm{m}^{2} \mathrm{~K}$ for Case GC40b. This secondary effect can account for at most a $4 \%-$ $5 \%$ variation based on FLUENT, SUNREL-GC and TRNSYS results for cases GC40a and GC40b, and is probably less because for Case GC40 EnergyPlus did not run for interior surface coefficient $>180$ $\mathrm{W} / \mathrm{m}^{2} \mathrm{~K}$. Another secondary effect is variation of soil conductivity from $2.0 \mathrm{~W} / \mathrm{mK}$ for Case GC40 to 1.9 $\mathrm{W} / \mathrm{mK}$ for Case GC40b, which should have about a 5\% effect on all model results. Therefore, the effect of correcting the input error is estimated at about a $35-40 \%$ decrease for floor conduction (i.e., $45 \%-$ ( $5 \%$ for reduced conductivity) - (a few $\%$ for reduced surface coefficient). 


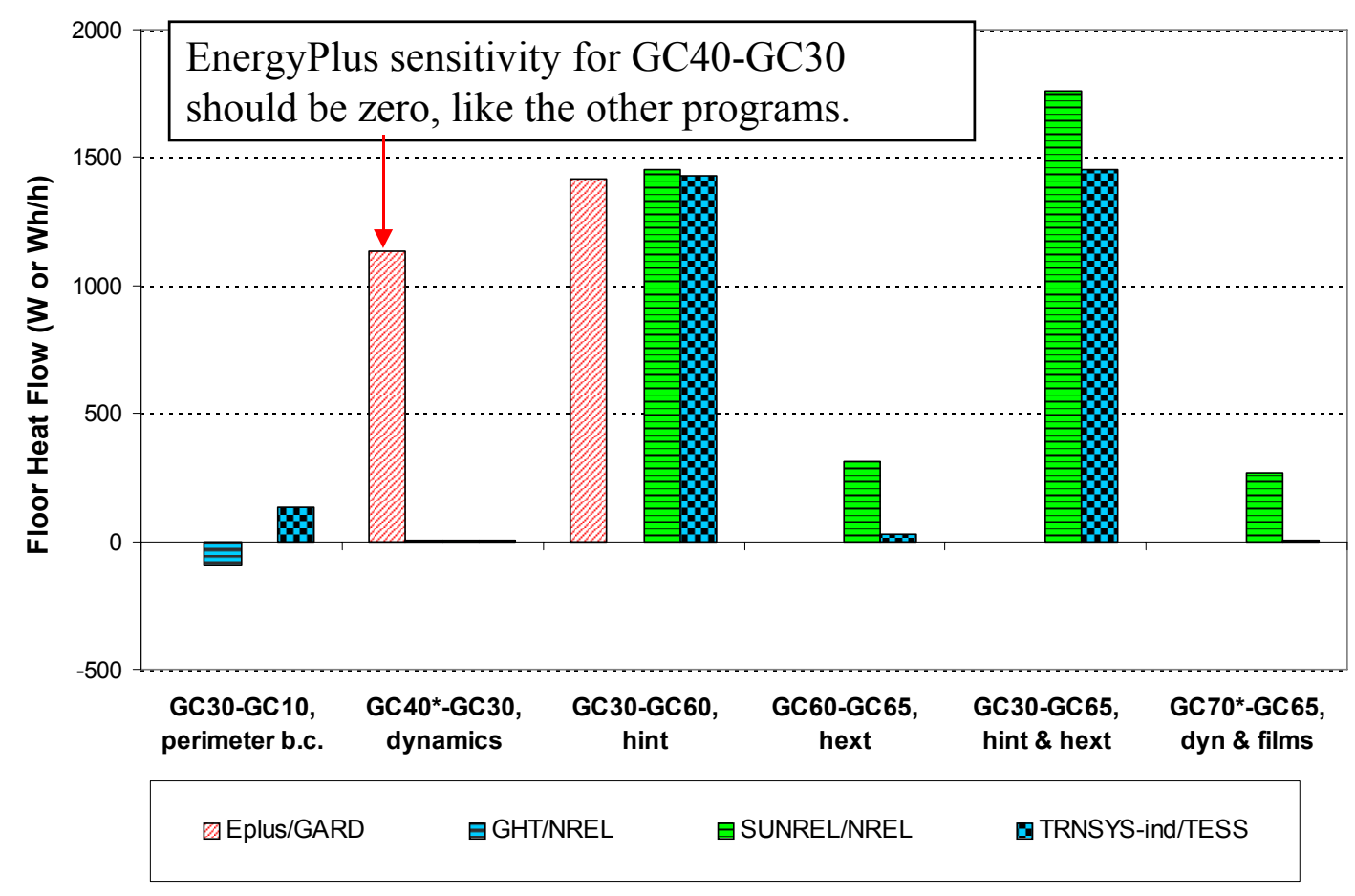

Figure 2D-2. EnergyPlus GC40-GC30 disagreement, February 2005

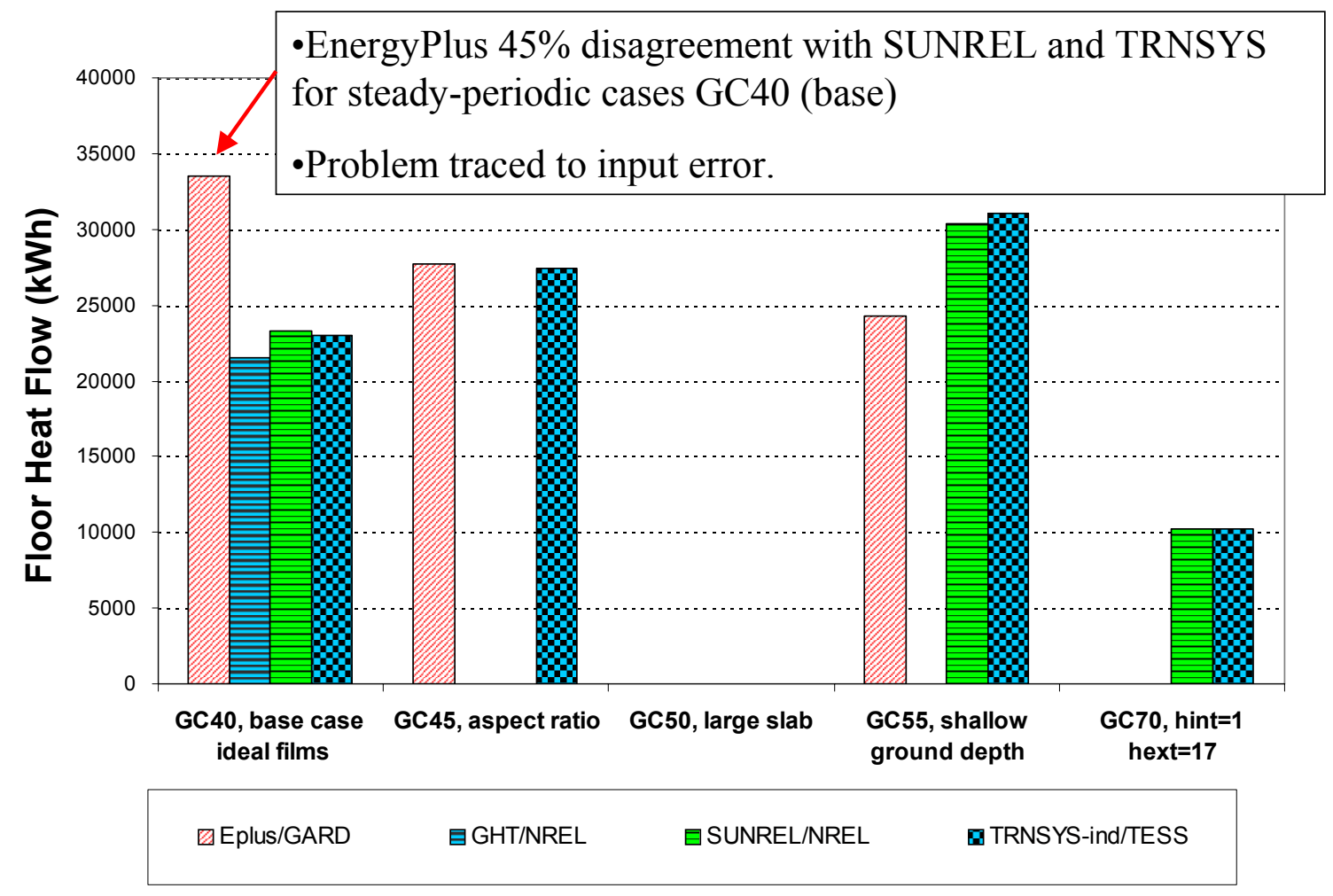

Figure 2D-3. EnergyPlus GC40 disagreement, February 2005 


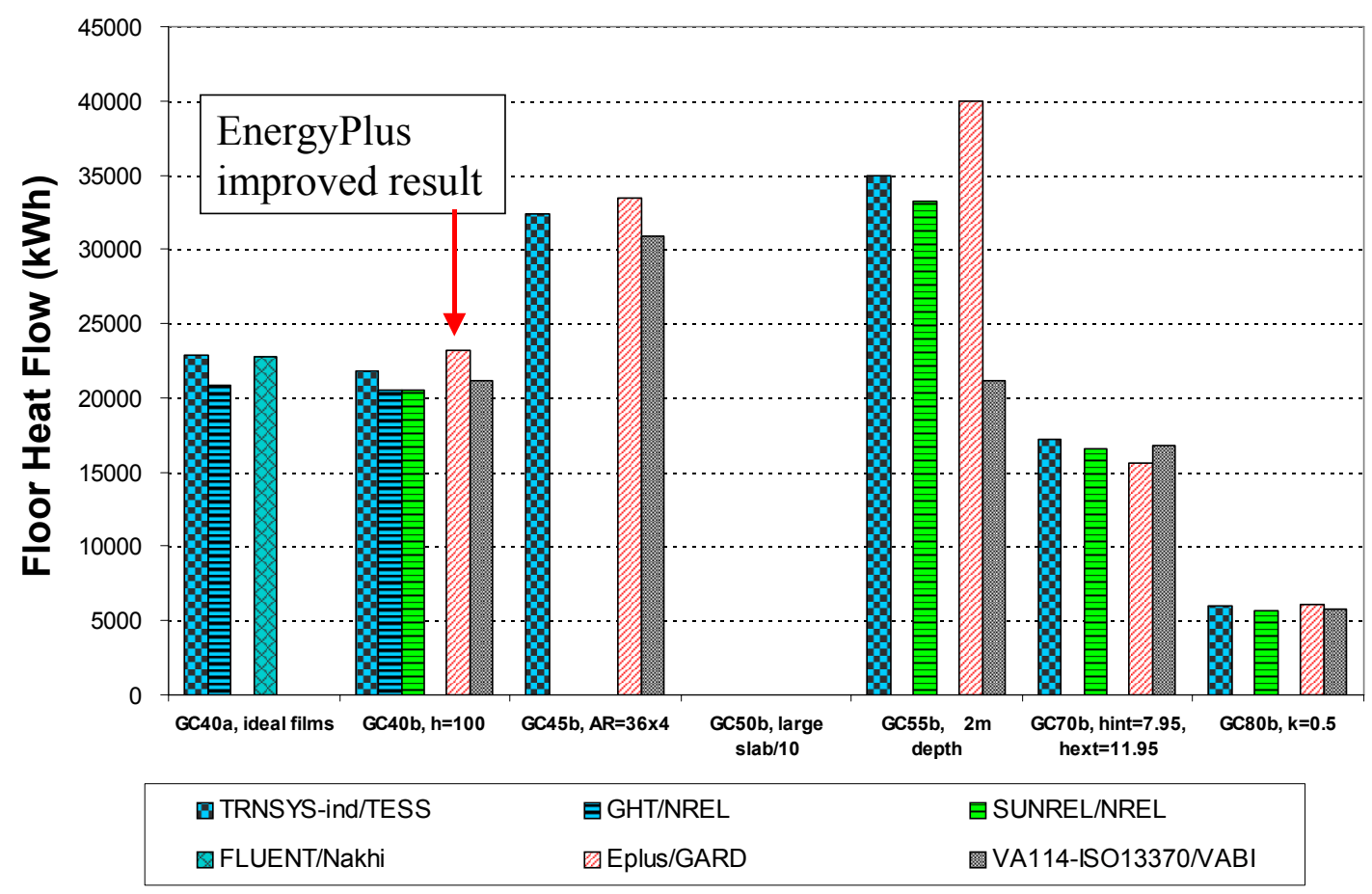

Figure 2D-4. EnergyPlus input error correction, shown with April 2006 results

\section{Conclusions}

The results and comparisons for several ground-coupling programs that participated in the IEA BESTEST Ground-Coupling exercise were presented by Joel Neymark at a meeting in Quebec City, Canada on June 26, 2006 (Neymark 2006b). From those results it appeared that the EnergyPlus results compared to other programs were overly sensitive to exterior ground heat transfer coefficient and ground deep boundary depth. As is suggested by Neymark, much of this increased sensitivity with the EnergyPlus groundcoupling model is probably due to the EnergyPlus Slab program's shorter heat flow path around the exterior wall which would overestimate the slab perimeter heat flow. These EnergyPlus Slab program sensitivities will be further examined by the EnergyPlus development team. 


\section{References}

Bahnfleth, W.P. 1989. Three Dimensional Modeling of Heat Transfer from Slab Floors. Ph.D. diss., also published as USACERL TM E-89/11, University of Illinois.

Bahnfleth, W.P. and C.O. Pedersen. 1990. A Three Dimensional Numerical Study of Slab-onGrade Heat Transfer. ASHRAE Transactions Pt. 2, 96:61-72.

Clements, Edward, 2004, Three Dimensional Foundation Heat Transfer Modules for WholeBuilding Energy Analysis, MS Thesis, Pennsylvania State University.

EnergyPlus 2006. U.S. Department of Energy, Energy Efficiency and Renewable Energy, Office of Building Technologies. www.energyplus.gov

Ground Heat Transfer in EnergyPlus, Auxiliary EnergyPlus Programs, pgs 65-81, September 20, 2006.

Neymark, J., and R. Judkoff. 2006a. Proposed IEA BESTEST In-Depth Diagnostic Cases for Ground Coupled Heat Transfer Related to Slab-on-Grade Construction, IEA SHC Task 34/ Annex 43, National Renewable Energy Laboratory, Golden, Colorado, March 2006.

Neymark, J. 2006b. PowerPoint Presentation titled IEA BESTEST Ground Coupling Review, June 26, 2006 
Model Geometry and Thermal Property Allowed Inputs (pro forma)

\begin{tabular}{|c|c|c|c|c|c|c|c|c|c|}
\hline \multicolumn{7}{|c|}{ Model and Version:|EnergyPlus Auxiliary Slab Program } & \multicolumn{3}{|c|}{ Insulation Components } \\
\hline & \multicolumn{4}{|c|}{ Below-Grade High-Mass Components } & \multicolumn{2}{|c|}{ Low-Mass Components } & \multirow{2}{*}{\begin{tabular}{|c|} 
Horizontal \\
Edge
\end{tabular}} & \multirow{2}{*}{\begin{tabular}{|c|} 
Vertical \\
Interior Edge
\end{tabular}} & \multirow{2}{*}{\begin{tabular}{|c|} 
Vertical \\
Exterior Edge
\end{tabular}} \\
\hline & & Foundation & & & & Above Grade & & & \\
\hline & Slab & Wall & Footer & Soil & Sill Plate & Wall & Insulation & Insulation & Insulation \\
\hline \multicolumn{10}{|l|}{ GEOMETRY* } \\
\hline Floor Slab In (below) Grade ("yes" or "no") & yes & $\mathrm{n} / \mathrm{a}$ & $\mathrm{n} / \mathrm{a}$ & $\mathrm{n} / \mathrm{a}$ & $\mathrm{n} / \mathrm{a}$ & $\mathrm{n} / \mathrm{a}$ & $\mathrm{n} / \mathrm{a}$ & $\mathrm{n} / \mathrm{a}$ & $\mathrm{n} / \mathrm{a}$ \\
\hline Floor Slab On (above) Grade ("yes" or "no") & no & $\mathrm{n} / \mathrm{a}$ & $\mathrm{n} / \mathrm{a}$ & $\mathrm{n} / \mathrm{a}$ & $\mathrm{n} / \mathrm{a}$ & $\mathrm{n} / \mathrm{a}$ & $\mathrm{n} / \mathrm{a}$ & $\mathrm{n} / \mathrm{a}$ & $\mathrm{n} / \mathrm{a}$ \\
\hline Floor Slab Minimum Thickness $(\mathrm{cm})$ & set by sta & $\mathrm{n} / \mathrm{a}$ & $\mathrm{n} / \mathrm{a}$ & $\mathrm{n} / \mathrm{a}$ & $\mathrm{n} / \mathrm{a}$ & $\mathrm{n} / \mathrm{a}$ & $\mathrm{n} / \mathrm{a}$ & $\mathrm{n} / \mathrm{a}$ & $\mathrm{n} / \mathrm{a}$ \\
\hline Floor Slab Maximum Thickness $(\mathrm{cm})$ & $15 \mathrm{~m}$ & $\mathrm{n} / \mathrm{a}$ & $\mathrm{n} / \mathrm{a}$ & $\mathrm{n} / \mathrm{a}$ & $\mathrm{n} / \mathrm{a}$ & $\mathrm{n} / \mathrm{a}$ & $\mathrm{n} / \mathrm{a}$ & $\mathrm{n} / \mathrm{a}$ & $\mathrm{n} / \mathrm{a}$ \\
\hline Minimum $x$-Thickness or Width $(\mathrm{cm})$ & $\mathrm{n} / \mathrm{a}$ & 0 & 0 & $\mathrm{n} / \mathrm{a}$ & 0 & 0 & 0 & 0 & 0 \\
\hline Maximum $x$-Thickness or Width $(\mathrm{cm})$ & $\mathrm{n} / \mathrm{a}$ & 0 & 0 & $\mathrm{n} / \mathrm{a}$ & 0 & 0 & 200 & 0 & 0 \\
\hline Minimum $z$-Thickness $(\mathrm{cm})$ & $\mathrm{n} / \mathrm{a}$ & $\mathrm{n} / \mathrm{a}$ & 0 & $\mathrm{n} / \mathrm{a}$ & 0 & $\mathrm{n} / \mathrm{a}$ & 0 & $\mathrm{n} / \mathrm{a}$ & $\mathrm{n} / \mathrm{a}$ \\
\hline Maximum $z$-Thickness $(\mathrm{cm})$ & $\mathrm{n} / \mathrm{a}$ & $\mathrm{n} / \mathrm{a}$ & 0 & $\mathrm{n} / \mathrm{a}$ & 0 & $\mathrm{n} / \mathrm{a}$ & 0 & $\mathrm{n} / \mathrm{a}$ & $\mathrm{n} / \mathrm{a}$ \\
\hline Minimum Bottom-Edge Depth Below Grade $(z, \mathrm{~cm})$ & set by sta & 0 & 0 & $\mathrm{n} / \mathrm{a}$ & $\mathrm{n} / \mathrm{a}$ & $\mathrm{n} / \mathrm{a}$ & $\mathrm{n} / \mathrm{a}$ & 20 & 0 \\
\hline Maximum Bottom-Edge Depth Below Grade $(z, \mathrm{~cm})$ & 1500 & 0 & 0 & $\mathrm{n} / \mathrm{a}$ & $\mathrm{n} / \mathrm{a}$ & $\mathrm{n} / \mathrm{a}$ & $\mathrm{n} / \mathrm{a}$ & 300 & 0 \\
\hline Minimum Top-Edge Height Above Grade $(z, \mathrm{~cm})$ & 0 & 0 & $\mathrm{n} / \mathrm{a}$ & $\mathrm{n} / \mathrm{a}$ & $\mathrm{n} / \mathrm{a}$ & $\mathrm{n} / \mathrm{a}$ & $\mathrm{n} / \mathrm{a}$ & 0 & 0 \\
\hline Maximum Top-Edge Height Above Grade $(z, \mathrm{~cm})$ & 0 & 0 & $\mathrm{n} / \mathrm{a}$ & $\mathrm{n} / \mathrm{a}$ & $\mathrm{n} / \mathrm{a}$ & $\mathrm{n} / \mathrm{a}$ & $\mathrm{n} / \mathrm{a}$ & 0 & 0 \\
\hline Minimum Soil Depth $(E, m)$ & $\mathrm{n} / \mathrm{a}$ & $\mathrm{n} / \mathrm{a}$ & $\mathrm{n} / \mathrm{a}$ & 0 & $\mathrm{n} / \mathrm{a}$ & $\mathrm{n} / \mathrm{a}$ & $\mathrm{n} / \mathrm{a}$ & $\mathrm{n} / \mathrm{a}$ & $\mathrm{n} / \mathrm{a}$ \\
\hline Maximum Soil Depth $(E, m)$ & $\mathrm{n} / \mathrm{a}$ & $\mathrm{n} / \mathrm{a}$ & $\mathrm{n} / \mathrm{a}$ & 15 & $\mathrm{n} / \mathrm{a}$ & $\mathrm{n} / \mathrm{a}$ & $\mathrm{n} / \mathrm{a}$ & $\mathrm{n} / \mathrm{a}$ & $\mathrm{n} / \mathrm{a}$ \\
\hline Minimum Soil Far-Field Distance $(F, m)$ & $\mathrm{n} / \mathrm{a}$ & $\mathrm{n} / \mathrm{a}$ & $\mathrm{n} / \mathrm{a}$ & 0 & $\mathrm{n} / \mathrm{a}$ & $\mathrm{n} / \mathrm{a}$ & $\mathrm{n} / \mathrm{a}$ & $\mathrm{n} / \mathrm{a}$ & $\mathrm{n} / \mathrm{a}$ \\
\hline Maximum Soil Far-Field Distance $(F, m)$ & $\mathrm{n} / \mathrm{a}$ & $\mathrm{n} / \mathrm{a}$ & $\mathrm{n} / \mathrm{a}$ & 15 & $\mathrm{n} / \mathrm{a}$ & $\mathrm{n} / \mathrm{a}$ & $\mathrm{n} / \mathrm{a}$ & $\mathrm{n} / \mathrm{a}$ & $\mathrm{n} / \mathrm{a}$ \\
\hline \multicolumn{10}{|l|}{ THERMAL PROPERTIES* } \\
\hline Minimum Conductivity $(\mathrm{W} /(\mathrm{mK}))$ & 0 & 0 & 0 & 0 & 0 & 0 & 0 & 0 & 0 \\
\hline Maximum Conductivity $(\mathrm{W} /(\mathrm{mK}))$ & 0 & 0 & 0 & 0 & 0 & 0 & 0 & 0 & 0 \\
\hline Minimum R-Value $\left.\left(\mathrm{m}^{2} \mathrm{~K} / \mathrm{W}\right)\right)$ & 0 & 0 & 0 & 0 & 0 & 0 & 0 & 0 & 0 \\
\hline Maximum R-Value $\left.\left(\mathrm{m}^{2} \mathrm{~K} / \mathrm{W}\right)\right)$ & 0 & 0 & 0 & 0 & 0 & 0 & 0 & 0 & 0 \\
\hline Minimum Density $\left(\mathrm{kg} / \mathrm{m}^{3}\right)$ & 0 & 0 & 0 & 0 & 0 & 0 & 0 & 0 & 0 \\
\hline Maximum Density $\left(\mathrm{kg} / \mathrm{m}^{3}\right)$ & 0 & 0 & 0 & 0 & 0 & 0 & 0 & 0 & 0 \\
\hline Minimum Specific Heat $(\mathrm{kJ} /(\mathrm{kgK}))$ & 0 & 0 & 0 & 0 & 0 & 0 & 0 & 0 & 0 \\
\hline Maximum Specific Heat $(\mathrm{kJ} /(\mathrm{kgK}))$ & 0 & 0 & 0 & 0 & 0 & 0 & 0 & 0 & 0 \\
\hline \multicolumn{10}{|l|}{ COMMENTS } \\
\hline Uninsulated detail (Figure A-1) ok? ("yes" or "no") & yes & & & & & & & & \\
\hline Insulated detail (Figure A-2) ok? ("yes" or "no") & yes & & & & & & & & \\
\hline \multicolumn{10}{|l|}{ If no, include additional assumptions of your model } \\
\hline \multicolumn{10}{|l|}{ not covered here (add rows as needed) } \\
\hline Include other clarfications and/or comments here & \multirow{2}{*}{\multicolumn{9}{|c|}{ Many of the limits are set by stability considerations and can not be specified in isolation. }} \\
\hline (add rows as needed) & & & & & & & & & \\
\hline \multicolumn{10}{|l|}{ NOTES } \\
\hline \multicolumn{10}{|l|}{ "n/a": not applicable } \\
\hline \multicolumn{10}{|c|}{ * If a listed input does not apply to your model, enter "0" in the relevant cells. } \\
\hline \multicolumn{10}{|c|}{${ }^{* *}$ For below grade high-mass components, only list R-value input limits if there is some difference versus what would be calculated based on listed } \\
\hline conductivity and thickness limits & & & & & & & & & \\
\hline
\end{tabular}


Appendix II-E

\title{
Modeler Report for BESTEST Cases GC10a-GC80c BASECALC Version 1.0e and BASESIMP/ESP-r
}

\author{
by \\ Hajo Ribberink, Patrice Pinel ${ }^{1}$ and lan Beausoleil-Morrison ${ }^{2}$ \\ CANMET Energy Technology Centre, Natural Resources Canada \\ Canada
}

January 2007

\section{BASECALC V1.0e}

Results file: GC-InDepth-Out-0606a_Basecalc.xls

\subsection{Introduction}

BASECALC is an independent basement heat losses evaluation software developed by NRCan.

The genesis of the BASECALC technique was the National Research Council of Canada's Mitalas method. Mitalas utilized mainframe computers to perform finite-element analyses of a large number of basements and analyzed the results to produce a series of basement heat-loss factors. BASECALC incorporates the finiteelement approach used by Mitalas to generate his basement heat-loss factors but allows modeling of exact insulation configurations, basement geometries, and site conditions, thus improving accuracy.

The solution is obtained by performing three 2-D finite element simulations and using corner correction factors to obtain quasi-3D solutions. First, a finite element run calculates the above-grade heat losses $\left(\mathrm{Q}_{\mathrm{ag}}\right)$. A steady state run is then performed to obtain the below grade average heat losses $\left(\mathrm{Q}_{\mathrm{bg}, \text { avg }}\right)$. Finally, a transient 3-year run is used to evaluate the below-grade variable heat losses $\left(\mathrm{Q}_{\mathrm{bg}, \text { variable }}\right)$.

The finite element solutions have the form $S_{2 d F E-A G}, S_{2 d F E-B G, a v g}, S_{2 d F E-B G, v a r}$ where:

- $S_{2 d F E-A G}=$ calculated above grade heat loss factor $\left(\mathrm{W} / \mathrm{m}^{\circ} \mathrm{C}\right)$

- $S_{2 d F E-B G, a v g}=$ calculated below grade average heat loss factor $\left(\mathrm{W} / \mathrm{m}^{\circ} \mathrm{C}\right)$

- $S_{2 d F E-B G, v a r}=$ calculated below grade variable heat loss factor $\left(\mathrm{W} / \mathrm{m}^{\circ} \mathrm{C}\right)$

These solutions are then converted into three dimensional parametric heat loss factors using the corner correction method:

- $\mathrm{S}_{\mathrm{agr}}=\mathrm{S}_{2 \mathrm{dFE}, \mathrm{ag}} *[2(\mathrm{~L}+\mathrm{W})]$

- $\mathrm{S}_{\mathrm{bg}, \mathrm{avg}}=\mathrm{S}_{2 \mathrm{dFE}, \mathrm{avg}} *\left[2(\mathrm{~L}-\mathrm{W})+4 \mathrm{~W} * \mathrm{~F}_{\mathrm{c}, \mathrm{avg}}\right]$

- $\mathrm{S}_{\mathrm{bg}, \mathrm{var}}=\mathrm{S}_{2 \mathrm{dFE}, \mathrm{var}} *\left[2(\mathrm{~L}-\mathrm{W})+4 \mathrm{~W}^{*} \mathrm{~F}_{\mathrm{c}, \mathrm{var}}\right]$

\footnotetext{
${ }^{1} \mathrm{Mr}$. Pinel is no longer with Natural Resources Canada.

${ }^{2}$ Mr. Beausoleil-Morrison has recently moved to Carleton University, Canada.
} 
Where:

- $\mathrm{L} \quad=$ length of the basement (m)

- $\mathrm{W} \quad=$ width of the basement $(\mathrm{m})$

- $\mathrm{F}_{\mathrm{c}}=$ corner correction factor evaluated from the correlations of the corner correction method

- $\mathrm{S}_{\mathrm{ag}} \quad=$ calculated above grade heat loss factor $\left(\mathrm{W} /{ }^{\circ} \mathrm{C}\right)$

- $\mathrm{S}_{\mathrm{bg}, a v g}=$ calculated below grade average heat loss factor $\left(\mathrm{W} /{ }^{\circ} \mathrm{C}\right)$

- $\mathrm{S}_{\mathrm{bg}, \mathrm{var}}=$ calculated below grade variable heat loss factor $\left(\mathrm{W} /{ }^{\circ} \mathrm{C}\right)$

These factors are then converted into fluxes for any weather conditions by using:

$Q_{a g, i}=S_{a g}\left(T_{\text {basement }}-T_{a, i}\right)$

$Q_{b g, a v g}=S_{b g, a v g}\left(T_{b a s e m e n t}-T_{g, a v g}\right)$

$Q_{b g, v a r, I}=S_{b g, v a r} T_{g, a m p} \cos \left(2 \pi / 365\right.$ middleday $i+$ phase $\left.-P_{s}\right)$

Where:

- $\mathrm{Q}_{\mathrm{ag}, \mathrm{i}} \quad=$ above grade heat losses for month I (W)

- $\mathrm{Q}_{\text {bg,avg }}=$ average below grade heat losses (W)

- $\mathrm{Q}_{\mathrm{bg}, \mathrm{var}, \mathrm{i}}=$ variable below grade heat losses for month $\mathrm{i}(\mathrm{W})$

- $\mathrm{T}_{\mathrm{a}, \mathrm{i}}=$ the ambient outdoor temperature for month $\mathrm{i}\left({ }^{\circ} \mathrm{C}\right)$

- $\mathrm{T}_{\mathrm{g}, \mathrm{avg}}=$ annually averaged ground surface temperature $\left({ }^{\circ} \mathrm{C}\right)$

- $\mathrm{T}_{\mathrm{g}, \mathrm{amp}}=$ amplitude of the annual variation of the ground surface temperature $\left({ }^{\circ} \mathrm{C}\right)$

- $\mathrm{T}_{\text {basement }}=$ basement temperature $\left({ }^{\circ} \mathrm{C}\right)$

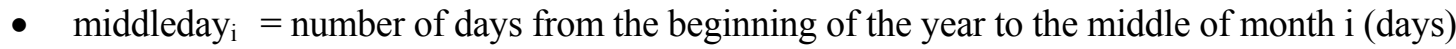

- phase $\quad=$ phase lag, $(\pi-$ phase $)$ is the lag between the coldest ground surface temperature and the largest heat losses (radians)

- $\mathrm{P}_{\mathrm{s}} \quad=$ phase lag of ground surface temperature cosine (radians)

Finally, the total heat losses from the basement for month i is calculated using:

$Q_{b a s e m e n t, i}=Q_{a g, i}+Q_{b g, a v g}+Q_{b g, v a r, i}$

The BASECALC software returns monthly values of above and below grade heat losses but the parametric heat loss factors can be adapted to approximate heat losses using a smaller time scale.

\subsection{Modeling Assumptions}

The modeling assumptions and boundary conditions BASECALC uses for calculating heat losses to the ground are illustrated in Figures 2E-1 and 2E-2. 


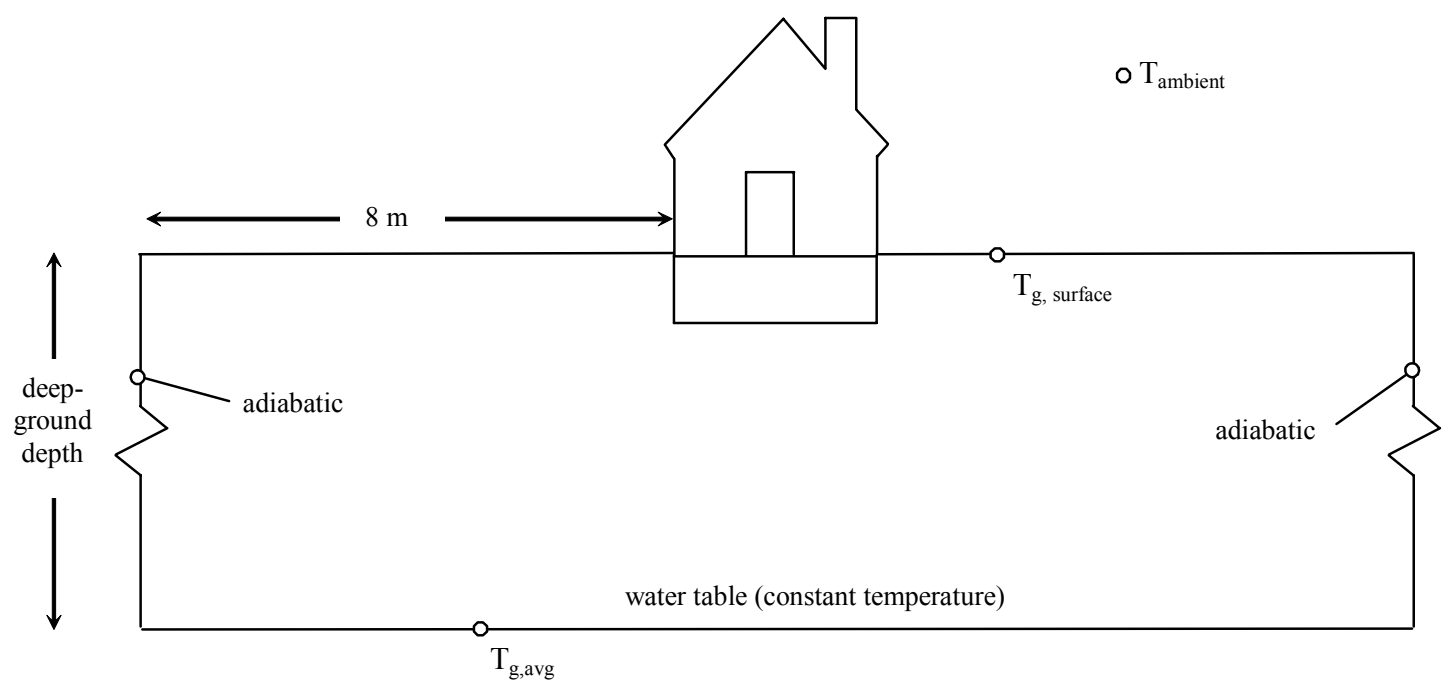

Figure 2E-1 BASECALC heat loss model boundary conditions

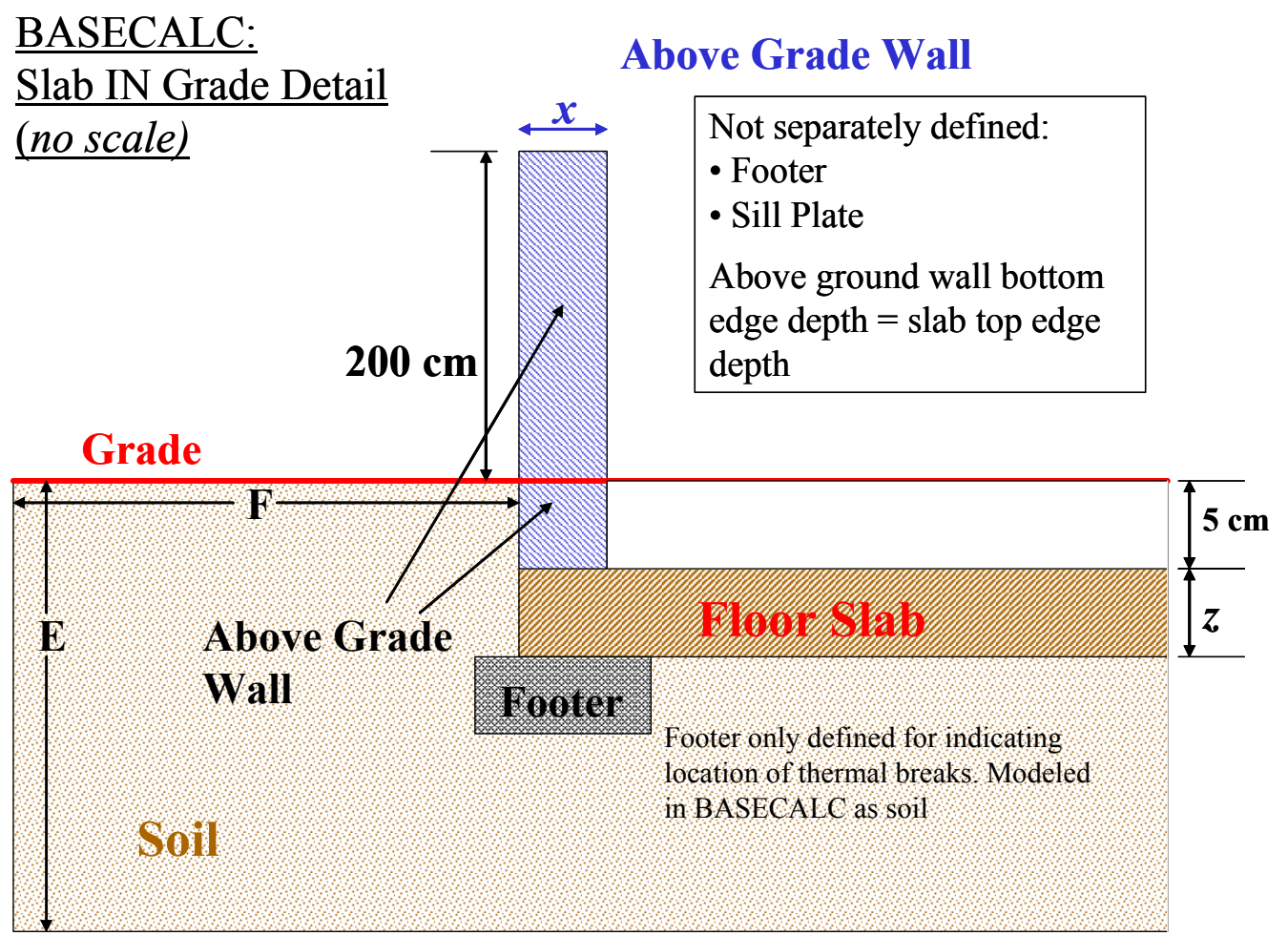

Figure 2E-2 BASECALC slab in grade details (uninsulated) 
For heat losses to the deeper underground, BASECALC assumes a constant temperature (Tg,avg) at a water table depth (E) of $5 \mathrm{~m}-20 \mathrm{~m}$ (user input). An adiabatic boundary condition is used at a far field distance (F) of $8 \mathrm{~m}$.

BASECALC assumes a uniform air temperature inside the basement. From there, a $7.95 \mathrm{~W} / \mathrm{m}^{2 \circ} \mathrm{C}$ coefficient is used to evaluate convection and radiation at the inside face of the floor and walls and a $14.196 \mathrm{~W} / \mathrm{m}^{2 \circ} \mathrm{C}$ convection/radiation coefficient is used at the outside face of the walls. No heat transfer is calculated at the basement ceiling.

BASECALC requires a minimum slab thickness $(\mathrm{z})$ of $5 \mathrm{~cm}$. This value is used in all calculations. The slab must have at least $5 \mathrm{~cm}$ ground above in the interior slab surface level in order for the finite elements calculation method to converge on a solution. This should not result in a large difference in the solution compared to a real slab on grade.

BASECALC requires entering a $2 \mathrm{~m}$ above grade wall height for slabs. So, a wall with a $0.01 \mathrm{~W} / \mathrm{m}^{\circ} \mathrm{C}$ thermal conductivity, the minimum allowable value, is used. Including the inside and outside convective/radiative (7.95 in, 14.196 out) coefficients previously discussed, this wall has a very low equivalent $\mathrm{U}$ value of $0.04 \mathrm{~W} / \mathrm{m}^{2}{ }^{\circ} \mathrm{C}$.

BASECALC requires entering the outside dimensions of the basement. So, for a $12 \mathrm{~m} \times 12 \mathrm{~m}$ slab with a $0.24 \mathrm{~m}$ thick wall, dimensions of $12.48 \mathrm{~m} \times 12.48 \mathrm{~m}(12+2 * 0.24)$ are used.

BASECALC also requires the construction type of the first storey. For the purpose of this work, the "Non brick veneer or thermally broken brick" option is selected. Furthermore, the software offers the possibility to describe thermal breaks around the edge of the slab and between the slab and footing. No thermal breaks are used in this work.

Table 2E-1 presents the allowed inputs related to model geometry and thermal properties.

Details for insulated slab on grade cases are presented in Figure 2E-3. In principle the horizontal insulation is taken to extend from the inner wall inwards. Vertical insulations is taken from the bottom of the slab downwards (skirt). A thermal break can be added around the edge of the wall (1), between the floor slab and the footer (2), or as part of the first storey construction (3). 
BASECALC:

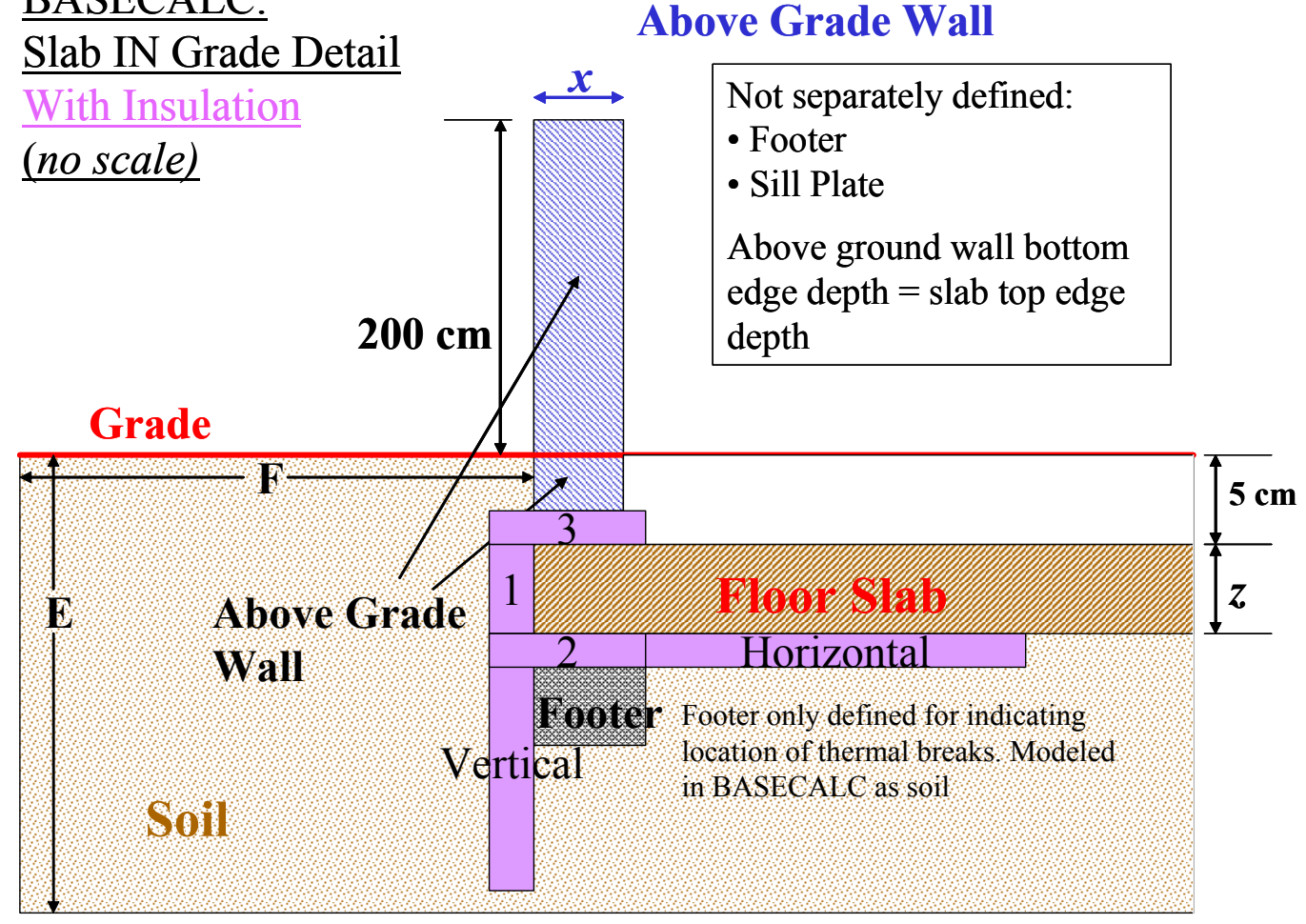

Figure 2E-3 BASECALC slab in grade details (insulated) 
Table 2E-1. BASECALC Slab-on-Grade Model Geometry and Thermal Property Allowed Inputs

\begin{tabular}{|c|c|c|c|c|c|c|c|c|c|}
\hline \multicolumn{7}{|c|}{ Model and Version: BASECALC version 1.0e } & \multicolumn{3}{|c|}{ Insulation Components } \\
\hline & \multicolumn{4}{|c|}{ Below-Grade High-Mass Components } & \multicolumn{2}{|c|}{ Low-Mass Components } & \multirow{2}{*}{\begin{tabular}{|c|} 
Horizontal \\
Edge \\
Insulation
\end{tabular}} & \multirow{2}{*}{$\begin{array}{c}\text { Vertical } \\
\text { Interior Edge } \\
\text { Insulation }\end{array}$} & \multirow{2}{*}{\begin{tabular}{|c|} 
Vertical \\
$\begin{array}{c}\text { Exterior Edge } \\
\text { Insulation }\end{array}$ \\
\end{tabular}} \\
\hline & Slab & \begin{tabular}{|c|} 
Foundation \\
Wall
\end{tabular} & Footer & Soil & Sill Plate & $\begin{array}{c}\text { Above Grade } \\
\text { Wall }\end{array}$ & & & \\
\hline \multicolumn{10}{|l|}{ GEOMETRY* } \\
\hline $\begin{array}{r}\text { Floor Slab In (below) Grade ("yes" or "no") } \\
\text { Floor Slab On (above) Grade ("yes" or "no") } \\
\text { Floor Slab Minimum Thickness (cm) } \\
\text { Floor Slab Maximum Thickness (cm) }\end{array}$ & $\begin{array}{c}\text { yes } \\
\text { no } \\
5 \\
50\end{array}$ & $\begin{array}{l}\mathrm{n} / \mathrm{a} \\
\mathrm{n} / \mathrm{a} \\
\mathrm{n} / \mathrm{a} \\
\mathrm{n} / \mathrm{a}\end{array}$ & $\begin{array}{l}\mathrm{n} / \mathrm{a} \\
\mathrm{n} / \mathrm{a} \\
\mathrm{n} / \mathrm{a} \\
\mathrm{n} / \mathrm{a}\end{array}$ & $\begin{array}{l}\mathrm{n} / \mathrm{a} \\
\mathrm{n} / \mathrm{a} \\
\mathrm{n} / \mathrm{a} \\
\mathrm{n} / \mathrm{a}\end{array}$ & $\begin{array}{l}\mathrm{n} / \mathrm{a} \\
\mathrm{n} / \mathrm{a} \\
\mathrm{n} / \mathrm{a} \\
\mathrm{n} / \mathrm{a}\end{array}$ & $\begin{array}{l}\mathrm{n} / \mathrm{a} \\
\mathrm{n} / \mathrm{a} \\
\mathrm{n} / \mathrm{a} \\
\mathrm{n} / \mathrm{a}\end{array}$ & $\begin{array}{l}\mathrm{n} / \mathrm{a} \\
\mathrm{n} / \mathrm{a} \\
\mathrm{n} / \mathrm{a} \\
\mathrm{n} / \mathrm{a}\end{array}$ & $\begin{array}{l}\mathrm{n} / \mathrm{a} \\
\mathrm{n} / \mathrm{a} \\
\mathrm{n} / \mathrm{a} \\
\mathrm{n} / \mathrm{a}\end{array}$ & $\begin{array}{l}\mathrm{n} / \mathrm{a} \\
\mathrm{n} / \mathrm{a} \\
\mathrm{n} / \mathrm{a} \\
\mathrm{n} / \mathrm{a}\end{array}$ \\
\hline $\begin{array}{r}\text { Minimum } x \text {-Thickness or Width }(\mathrm{cm}) \\
\text { Maximum } x \text {-Thickness or Width }(\mathrm{cm})\end{array}$ & $\begin{array}{l}\mathrm{n} / \mathrm{a} \\
\mathrm{n} / \mathrm{a}\end{array}$ & $\begin{array}{l}0 \\
0\end{array}$ & 0 & $\begin{array}{l}\mathrm{n} / \mathrm{a} \\
\mathrm{n} / \mathrm{a}\end{array}$ & $\begin{array}{l}0 \\
0\end{array}$ & $\begin{array}{c}5 \\
50\end{array}$ & $\begin{array}{c}0 \\
\text { full width }\end{array}$ & 0 & $\begin{array}{l}0 \\
0\end{array}$ \\
\hline $\begin{array}{r}\text { Minimum } z \text {-Thickness }(\mathrm{cm}) \\
\text { Maximum } z \text {-Thickness }(\mathrm{cm})\end{array}$ & $\begin{array}{l}\mathrm{n} / \mathrm{a} \\
\mathrm{n} / \mathrm{a}\end{array}$ & $\begin{array}{l}\mathrm{n} / \mathrm{a} \\
\mathrm{n} / \mathrm{a}\end{array}$ & $\begin{array}{l}0 \\
0 \\
\end{array}$ & $\begin{array}{l}\mathrm{n} / \mathrm{a} \\
\mathrm{n} / \mathrm{a}\end{array}$ & $\begin{array}{l}0 \\
0\end{array}$ & $\begin{array}{l}\mathrm{n} / \mathrm{a} \\
\mathrm{n} / \mathrm{a}\end{array}$ & $\begin{array}{c}0 \\
p(7.6) \text { or } u\end{array}$ & $\begin{array}{l}\mathrm{n} / \mathrm{a} \\
\mathrm{n} / \mathrm{a}\end{array}$ & $\begin{array}{l}\mathrm{n} / \mathrm{a} \\
\mathrm{n} / \mathrm{a}\end{array}$ \\
\hline $\begin{array}{l}\text { Minimum Bottom-Edge Depth Below Grade }(z, c m) \\
\text { Maximum Bottom-Edge Depth Below Grade }(z, c m)\end{array}$ & $\begin{array}{l}10 \\
55\end{array}$ & $\begin{array}{l}0 \\
0\end{array}$ & $\begin{array}{l}0 \\
0\end{array}$ & $\begin{array}{l}\mathrm{n} / \mathrm{a} \\
\mathrm{n} / \mathrm{a}\end{array}$ & $\begin{array}{l}\mathrm{n} / \mathrm{a} \\
\mathrm{n} / \mathrm{a}\end{array}$ & $\begin{array}{l}10 \\
55\end{array}$ & \begin{tabular}{l|l}
$\mathrm{n} / \mathrm{a}$ \\
$\mathrm{n} / \mathrm{a}$
\end{tabular} & $\begin{array}{l}0 \\
0\end{array}$ & $\begin{array}{l}0 \\
0\end{array}$ \\
\hline $\begin{array}{r}\text { Minimum Top-Edge Height Above Grade }(z, c m) \\
\text { Maximum Top-Edge Height Above Grade }(z, c m)\end{array}$ & $\begin{array}{l}0 \\
0\end{array}$ & $\begin{array}{l}0 \\
0\end{array}$ & $\begin{array}{l}\mathrm{n} / \mathrm{a} \\
\mathrm{n} / \mathrm{a}\end{array}$ & $\begin{array}{l}\mathrm{n} / \mathrm{a} \\
\mathrm{n} / \mathrm{a}\end{array}$ & $\begin{array}{l}\mathrm{n} / \mathrm{a} \\
\mathrm{n} / \mathrm{a}\end{array}$ & $\begin{array}{l}200 \\
200\end{array}$ & $\begin{array}{l}\mathrm{n} / \mathrm{a} \\
\mathrm{n} / \mathrm{a}\end{array}$ & $\begin{array}{l}0 \\
0\end{array}$ & $\begin{array}{l}0 \\
0\end{array}$ \\
\hline $\begin{array}{l}\text { Minimum Water Table (slab + soil) Depth (E, m) } \\
\text { Maximum Water Table (slab + soil) Depth }(E, m)\end{array}$ & $\begin{array}{l}\mathrm{n} / \mathrm{a} \\
\mathrm{n} / \mathrm{a}\end{array}$ & $\begin{array}{l}\mathrm{n} / \mathrm{a} \\
\mathrm{n} / \mathrm{a}\end{array}$ & $\begin{array}{l}\mathrm{n} / \mathrm{a} \\
\mathrm{n} / \mathrm{a}\end{array}$ & $\begin{array}{c}5 \\
20 \\
\end{array}$ & $\begin{array}{l}\mathrm{n} / \mathrm{a} \\
\mathrm{n} / \mathrm{a}\end{array}$ & $\begin{array}{l}\mathrm{n} / \mathrm{a} \\
\mathrm{n} / \mathrm{a}\end{array}$ & $\begin{array}{l}\mathrm{n} / \mathrm{a} \\
\mathrm{n} / \mathrm{a}\end{array}$ & $\begin{array}{l}\mathrm{n} / \mathrm{a} \\
\mathrm{n} / \mathrm{a}\end{array}$ & $\begin{array}{l}\mathrm{n} / \mathrm{a} \\
\mathrm{n} / \mathrm{a}\end{array}$ \\
\hline $\begin{array}{r}\text { Minimum Soil Far-Field Distance }(F, m) \\
\text { Maximum Soil Far-Field Distance }(F, m)\end{array}$ & $\begin{array}{l}\mathrm{n} / \mathrm{a} \\
\mathrm{n} / \mathrm{a}\end{array}$ & $\begin{array}{l}\mathrm{n} / \mathrm{a} \\
\mathrm{n} / \mathrm{a}\end{array}$ & $\begin{array}{l}\mathrm{n} / \mathrm{a} \\
\mathrm{n} / \mathrm{a}\end{array}$ & $\begin{array}{l}8 \\
8\end{array}$ & $\begin{array}{l}\mathrm{n} / \mathrm{a} \\
\mathrm{n} / \mathrm{a}\end{array}$ & $\begin{array}{l}\mathrm{n} / \mathrm{a} \\
\mathrm{n} / \mathrm{a}\end{array}$ & $\begin{array}{l}\mathrm{n} / \mathrm{a} \\
\mathrm{n} / \mathrm{a}\end{array}$ & $\begin{array}{l}\mathrm{n} / \mathrm{a} \\
\mathrm{n} / \mathrm{a}\end{array}$ & $\begin{array}{l}\mathrm{n} / \mathrm{a} \\
\mathrm{n} / \mathrm{a}\end{array}$ \\
\hline \multicolumn{10}{|l|}{$\begin{array}{r}\text { THERMAL PROPERTIES* } \\
\end{array}$} \\
\hline $\begin{array}{l}\text { Minimum Conductivity }(\mathrm{W} /(\mathrm{mK})) \\
\text { Maximum Conductivity }(\mathrm{W} /(\mathrm{mK}))\end{array}$ & $\begin{array}{c}0.1 \\
2\end{array}$ & $\begin{array}{l}0 \\
0\end{array}$ & $\begin{array}{l}0 \\
0\end{array}$ & $\begin{array}{c}0.25 \\
10\end{array}$ & $\begin{array}{l}0 \\
0\end{array}$ & $\begin{array}{c}0.1 \\
2\end{array}$ & $\begin{array}{l}0 \\
0\end{array}$ & $\begin{array}{l}0 \\
0\end{array}$ & $\begin{array}{l}0 \\
0\end{array}$ \\
\hline $\begin{array}{r}\left.\text { Minimum R-Value }\left(\mathrm{m}^{2} \mathrm{~K} / \mathrm{W}\right)\right) \\
\left.\text { Maximum R-Value }\left(\mathrm{m}^{2} \mathrm{~K} / \mathrm{W}\right)\right)\end{array}$ & ** & ** & ** & ** & $\begin{array}{l}0 \\
0\end{array}$ & ** & $\begin{array}{c}0 \\
20(u)\end{array}$ & $\begin{array}{l}0 \\
0 \\
\end{array}$ & $\begin{array}{l}0 \\
0 \\
\end{array}$ \\
\hline $\begin{array}{l}\text { Minimum Density }\left(\mathrm{kg} / \mathrm{m}^{3}\right) \\
\text { Maximum Density }\left(\mathrm{kg} / \mathrm{m}^{3}\right)\end{array}$ & $\begin{array}{l}p \\
p\end{array}$ & $\begin{array}{l}p \\
p\end{array}$ & $\begin{array}{l}0 \\
0 \\
\end{array}$ & $\begin{array}{l}p \\
p\end{array}$ & $\begin{array}{l}0 \\
0 \\
\end{array}$ & $\begin{array}{l}p \\
p\end{array}$ & $\begin{array}{l}\mathrm{p} \\
\mathrm{p}\end{array}$ & $\begin{array}{l}0 \\
0\end{array}$ & $\begin{array}{l}0 \\
0 \\
\end{array}$ \\
\hline $\begin{array}{c}\text { Minimum Specific Heat }(\mathrm{kJ} /(\mathrm{kgK})) \\
\text { Maximum Specific Heat }(\mathrm{kJ} /(\mathrm{kgK}))\end{array}$ & $\begin{array}{l}p \\
p\end{array}$ & $\begin{array}{l}p \\
p\end{array}$ & $\begin{array}{l}0 \\
0\end{array}$ & $p$ & $\begin{array}{l}0 \\
0\end{array}$ & $\begin{array}{l}\mathrm{p} \\
\mathrm{p}\end{array}$ & $\begin{array}{l}p \\
p\end{array}$ & $\begin{array}{l}0 \\
0\end{array}$ & $\begin{array}{l}0 \\
0\end{array}$ \\
\hline \multicolumn{10}{|l|}{ COMMENTS } \\
\hline $\begin{array}{l}\text { Uninsulated detail (Figure A-1) ok? ("yes" or "no") } \\
\text { Insulated detail (Figure A-2) ok? ("yes" or "no") }\end{array}$ & no & & & & & & & & \\
\hline \multirow[t]{4}{*}{$\begin{array}{l}\text { If no, include additional assumptions of your model } \\
\text { not covered here (add rows as needed) }\end{array}$} & \multicolumn{9}{|c|}{$\begin{array}{l}\text { In BASECALC a slab-on-grade is defined as a slab of } 5-50 \mathrm{~cm} \text { thickness with top of slab at } 5 \mathrm{~cm} \text { below } \\
\text { grade (fixed value). The-wall height is fixed with the top at } 200 \mathrm{~cm} \text { above grade. }\end{array}$} \\
\hline & \multicolumn{9}{|c|}{$\begin{array}{l}\text { Slab-on-grade can have insulation skirts: } \\
\text { - horizontal }(0-5 \mathrm{~m}) \text { from wall, at } 20 \mathrm{~cm} \text { depth } \\
\text { - vertical }(0-2.5 \mathrm{~m} \text { from bottom of slab) } \\
\text { - insulation skirts are characterizes by R-value }\end{array}$} \\
\hline & \multicolumn{9}{|c|}{$\begin{array}{l}\text { Slab-on-grade can also have thermal breaks: } \\
\text { - around corner } \\
\text { - between wall and footer } \\
\text { - thermal breaks are charachterizes by R-value only ( } 0 \text { - } 20 \mathrm{~m} 2 \mathrm{~K} / \mathrm{W})\end{array}$} \\
\hline & \multicolumn{9}{|c|}{ The 'Water Table Depth' is defined as the depth at which the soil temperature is constant through the year. } \\
\hline $\begin{array}{r}\text { Include other clarfications and/or comments here } \\
\text { (add rows as needed) }\end{array}$ & \multicolumn{9}{|c|}{$\begin{array}{l}p=\text { predefined structure components to choose from } \\
u=\text { user defined by using } \mathrm{R}(\mathrm{SI}) \text { values instead of dimensions }\end{array}$} \\
\hline
\end{tabular}




\subsection{Modeling Adjustments}

\subsubsection{Corrections for length in test GC45C}

BASECALC inputs are limited to $20 \mathrm{~m} \times 20 \mathrm{~m}$ basements. But, since only the width is accounted for in the finite element runs, while the length is taken into account by the corner correction method, it is possible to correct results for lengths that exceed those limits. So, for case GC45 $(36 \mathrm{~m} \times 4 \mathrm{~m})$, the corner correction technique is used to correct for the influence of the length as described in the following example.

A BASECALC simulation using a $20 \mathrm{~m} \times 4.48 \mathrm{~m}$ slab results in:

- $\mathrm{S}_{\mathrm{ag}}=1.145 \mathrm{~W} /{ }^{\circ} \mathrm{C}$

- $\mathrm{S}_{\text {bg,avg }}=77.574 \mathrm{~W} /{ }^{\circ} \mathrm{C}$

- $\mathrm{S}_{\mathrm{bg}, \mathrm{var}}=44.910 \mathrm{~W} /{ }^{\circ} \mathrm{C}$

- Phase $=2.880$ radians

The corner correction method is applied as shown in Equations 1 to 3:

$S=S_{2 d F E} *\left[2(L-W)+4 W^{*} F_{c}\right]$

Evaluation of the corner correction correlations for this configuration yields:

- $\mathrm{F}_{\mathrm{c}, \mathrm{avg}}=0.705$, the average (steady state) corner correction factor

- $\mathrm{F}_{\mathrm{c}, \mathrm{var}}=0.740$, the variable corner correction factor

Reversing equation 8 and using this reversed equation on the results for $\mathrm{L}=20$ and $\mathrm{W}=4.48$, we get:

- $\mathrm{S}_{2 \mathrm{dFE}, \mathrm{ag}}=\mathrm{S}_{\mathrm{ag}} /[2(\mathrm{~L}+\mathrm{W})]=0.0234 \mathrm{~W} / \mathrm{m}^{\circ} \mathrm{C}$

- $\mathrm{S}_{2 \mathrm{dFE}, \text { bg,avg }}=\mathrm{S}_{\mathrm{bg}, \text { avg }} /\left[2(\mathrm{~L}-\mathrm{W})+4 \mathrm{~W}^{*} \mathrm{~F}_{\mathrm{c}, \text { avg }}\right]=1.7764 \mathrm{~W} / \mathrm{m}^{\circ} \mathrm{C}$

- $\mathrm{S}_{2 \mathrm{dFE}, \mathrm{bg}, \mathrm{var}}=\mathrm{S}_{\mathrm{bg}, \mathrm{var}} /\left[2(\mathrm{~L}-\mathrm{W})+4 \mathrm{~W}^{*} \mathrm{~F}_{\mathrm{c}, \mathrm{var}}\right]=1.0136 \mathrm{~W} / \mathrm{m}^{\circ} \mathrm{C}$

Reusing equations 1-3 directly with $\mathrm{L}=36.48$ and $\mathrm{W}=4.48$ and these values of $\mathrm{S}_{2 \mathrm{dFE}}$, we get the heat loss factors adjusted for length:
- $\mathrm{S}_{\mathrm{ag}, \mathrm{cor}}$
$=\mathrm{S}_{2 \mathrm{dFE}, \mathrm{ag}} *[2(\mathrm{~L}+\mathrm{W})]=1.915 \mathrm{~W} /{ }^{\circ} \mathrm{C}$
- $\mathrm{S}_{\mathrm{bg}, \mathrm{avg}, \mathrm{cor}}$
- $\mathrm{S}_{\mathrm{bg}, \text { var,cor }}$
$=\mathrm{S}_{2 \mathrm{dFE}, \text { avg }} *\left[2(\mathrm{~L}-\mathrm{W})+4 \mathrm{~W} * \mathrm{~F}_{\mathrm{c}, \text { avg }}\right]=136.125 \mathrm{~W} /{ }^{\circ} \mathrm{C}$
$=\mathrm{S}_{2 \mathrm{dFE}, \text { var }} *\left[2(\mathrm{~L}-\mathrm{W})+4 \mathrm{~W}^{*} \mathrm{~F}_{\mathrm{c}, \text { var }}\right]=78.317 \mathrm{~W} /{ }^{\circ} \mathrm{C}$

\subsection{Modeling Difficulties}

No difficulties were encountered when modeling these tests.

\subsection{Demonstration of Appropriate Level of Modeling Detail}

Since BASECALC offers no control over the level of modeling details, there are no direct ways to perform these demonstrations. 


\section{BASESIMP/ESP-r}

Results file: GC-InDepth-Out-0107_Basesimp-ESP-r.xls

\subsection{Introduction}

BASESIMP is a regression based algorithm developed by NRCAN from over 100,000 BASECALC runs. The correlations evaluate basement heat losses for different basements and slabs with various insulation configurations, 140 basements and slabs systems are available.

The method has been implanted in different software like ESP-r and HOT2000. The present section evaluates results using NRCan's implementation of the method in ESP-r.

The BASESIMP correlations approximate the results of the 2-D finite element runs from BASECALC. The corner correction method described in Section 1.1 and used in Section 1.3.1 of this report is applied to calculate the heat loss factors described in Equations 1, 2 and 3.

The correlations are described in Reference 2. Reproducing them and the related coefficients here would not serve any use but would make the text considerably heavier.

\subsection{Modeling Assumptions}

BASESIMP is based upon results from BASECALC. The principal model configuration and slab details for BASESIMP are therefore identical to those for BASECALC (see Figure 2E-1, 2E-2, 2E-3). However, as the BASESIMP correlations only cover part of the total envelope of parameter variation of BASECALC, some inputs may differ (see Table 2E-2). An overview of BASESIMP slab on grade configurations is presented in Table 2E-3.

Like BASECALC, BASESIMP requires the construction type of the first storey. For the purpose of this work, the "Non brick veneer or thermally broken brick" with uninsulated walls option (case SCN_1 in BASESIMP terminology), is selected.

The method also offers the possibility to describe thermal breaks around the edge of the slab. No thermal breaks are used in this work.

ESP-r requires the definition of at least one zone. For this purpose, the $2.7 \mathrm{~m}$ high zone described in the specifications for tests GC30C ... GC80C was used for all cases. Since ESP-r does not allow definition of zero coefficients, the walls and ceiling of that zone are described as having:

- thermal conductivity: $0.001 \mathrm{~W} / \mathrm{m}^{\circ} \mathrm{C}$

- $\quad$ solar absorbtivity: 0.01

- solar emissivity: 0.01 .

All four walls and the ceiling of that zone are defined as having adiabatic boundary conditions. So, there are no heat losses from them in steady state.

Finally, ESP-r runs demand the definition of a start up period. Since ESP-r uses a lumped method to evolve zone temperatures to the controller set points in the beginning of the simulation, use of a startup period is recommended for result precision. Tests demonstrated that it takes about 3 days for the zone temperature to 
reach its set point of $30^{\circ} \mathrm{C}$ for the studied cases. A 365 day period was used for all cases.

Table 2E-2 presents the allowed inputs related to the BASESIMP model geometry and thermal properties.

Table 2E-2. BASESIMP Slab-on-Grade Model Geometry and Thermal Property Allowed Inputs

\begin{tabular}{|c|c|c|c|c|c|c|c|c|c|}
\hline \multicolumn{7}{|c|}{ Model and Version: ESP-r BASESIMP } & \multicolumn{3}{|c|}{ Insulation Components } \\
\hline & \multicolumn{4}{|c|}{ Below-Grade High-Mass Components } & \multicolumn{2}{|c|}{ Low-Mass Components } & \multirow{2}{*}{$\begin{array}{l}\text { Horizontal } \\
\text { Edge } \\
\text { Insulation }\end{array}$} & \multirow{2}{*}{$\begin{array}{c}\text { Vertical } \\
\text { Interior Edge } \\
\text { Insulation }\end{array}$} & \multirow{2}{*}{$\begin{array}{c}\text { Vertical } \\
\text { Exterior Edge } \\
\text { Insulation }\end{array}$} \\
\hline & Slab & \begin{tabular}{|c|}
$\begin{array}{c}\text { Foundation } \\
\text { Wall }\end{array}$ \\
\end{tabular} & Footer & Soil & Sill Plate & $\begin{array}{c}\text { Above Grade } \\
\text { Wall }\end{array}$ & & & \\
\hline \multicolumn{10}{|c|}{ 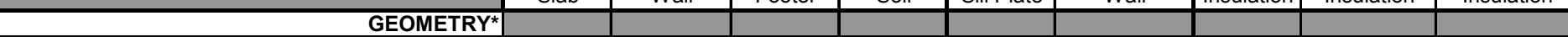 } \\
\hline $\begin{array}{r}\text { Floor Slab In (below) Grade ("yes" or "no") } \\
\text { Floor Slab On (above) Grade ("yes" or "no") } \\
\text { Floor Slab Minimum Thickness (cm) } \\
\text { Floor Slab Maximum Thickness }(\mathrm{cm})\end{array}$ & $\begin{array}{c}\text { yes } \\
\text { no } \\
5 \\
50\end{array}$ & $\begin{array}{l}\mathrm{n} / \mathrm{a} \\
\mathrm{n} / \mathrm{a} \\
\mathrm{n} / \mathrm{a} \\
\mathrm{n} / \mathrm{a}\end{array}$ & $\begin{array}{l}\mathrm{n} / \mathrm{a} \\
\mathrm{n} / \mathrm{a} \\
\mathrm{n} / \mathrm{a} \\
\mathrm{n} / \mathrm{a}\end{array}$ & $\begin{array}{l}\mathrm{n} / \mathrm{a} \\
\mathrm{n} / \mathrm{a} \\
\mathrm{n} / \mathrm{a} \\
\mathrm{n} / \mathrm{a}\end{array}$ & $\begin{array}{l}\mathrm{n} / \mathrm{a} \\
\mathrm{n} / \mathrm{a} \\
\mathrm{n} / \mathrm{a} \\
\mathrm{n} / \mathrm{a}\end{array}$ & $\begin{array}{l}\mathrm{n} / \mathrm{a} \\
\mathrm{n} / \mathrm{a} \\
\mathrm{n} / \mathrm{a} \\
\mathrm{n} / \mathrm{a}\end{array}$ & $\begin{array}{l}\mathrm{n} / \mathrm{a} \\
\mathrm{n} / \mathrm{a} \\
\mathrm{n} / \mathrm{a} \\
\mathrm{n} / \mathrm{a}\end{array}$ & $\begin{array}{l}\mathrm{n} / \mathrm{a} \\
\mathrm{n} / \mathrm{a} \\
\mathrm{n} / \mathrm{a} \\
\mathrm{n} / \mathrm{a}\end{array}$ & $\begin{array}{l}\mathrm{n} / \mathrm{a} \\
\mathrm{n} / \mathrm{a} \\
\mathrm{n} / \mathrm{a} \\
\mathrm{n} / \mathrm{a}\end{array}$ \\
\hline $\begin{array}{l}\text { Minimum } x \text {-Thickness or Width }(\mathrm{cm}) \\
\text { Maximum } x \text {-Thickness or Width }(\mathrm{cm})\end{array}$ & $\begin{array}{l}\mathrm{n} / \mathrm{a} \\
\mathrm{n} / \mathrm{a}\end{array}$ & $\begin{array}{l}0 \\
0\end{array}$ & $\begin{array}{l}0 \\
0\end{array}$ & $\begin{array}{l}\mathrm{n} / \mathrm{a} \\
\mathrm{n} / \mathrm{a}\end{array}$ & $\begin{array}{l}0 \\
0\end{array}$ & $\begin{array}{c}5 \\
50\end{array}$ & $\begin{array}{c}0 \\
\text { full width }\end{array}$ & $\begin{array}{l}0 \\
0\end{array}$ & $\begin{array}{l}0 \\
0\end{array}$ \\
\hline $\begin{array}{r}\text { Minimum } z \text {-Thickness }(\mathrm{cm}) \\
\text { Maximum } z \text {-Thickness }(\mathrm{cm})\end{array}$ & $\begin{array}{l}\mathrm{n} / \mathrm{a} \\
\mathrm{n} / \mathrm{a}\end{array}$ & $\begin{array}{l}\mathrm{n} / \mathrm{a} \\
\mathrm{n} / \mathrm{a}\end{array}$ & $\begin{array}{l}0 \\
0\end{array}$ & $\begin{array}{l}\mathrm{n} / \mathrm{a} \\
\mathrm{n} / \mathrm{a}\end{array}$ & $\begin{array}{l}0 \\
0\end{array}$ & $\begin{array}{l}\mathrm{n} / \mathrm{a} \\
\mathrm{n} / \mathrm{a}\end{array}$ & $\begin{array}{c}0 \\
p(7.6) \text { or } u\end{array}$ & $\begin{array}{l}\mathrm{n} / \mathrm{a} \\
\mathrm{n} / \mathrm{a}\end{array}$ & $\begin{array}{l}\mathrm{n} / \mathrm{a} \\
\mathrm{n} / \mathrm{a}\end{array}$ \\
\hline Minimum Bottom-Edge Depth Below Grade $(z, \mathrm{~cm})$ & 10 & 0 & 0 & $\mathrm{n} / \mathrm{a}$ & $\mathrm{n} / \mathrm{a}$ & 10 & $\mathrm{n} / \mathrm{a}$ & 0 & 0 \\
\hline Maximum Bottom-Edge Depth Below Grade $(z, c m)$ & 55 & 0 & 0 & $\mathrm{n} / \mathrm{a}$ & $\mathrm{n} / \mathrm{a}$ & 55 & $\mathrm{n} / \mathrm{a}$ & 0 & 0 \\
\hline Minimum Top-Edge Height Above Grade $(z, c m)$ & 0 & 0 & $\mathrm{n} / \mathrm{a}$ & $\mathrm{n} / \mathrm{a}$ & $\mathrm{n} / \mathrm{a}$ & 95 & $\mathrm{n} / \mathrm{a}$ & 0 & 0 \\
\hline Maximum Top-Edge Height Above Grade $(z, \mathrm{~cm})$ & 0 & 0 & $\mathrm{n} / \mathrm{a}$ & $\mathrm{n} / \mathrm{a}$ & $\mathrm{n} / \mathrm{a}$ & 245 & $\mathrm{n} / \mathrm{a}$ & 0 & 0 \\
\hline $\begin{array}{l}\text { Minimum Water Table (slab + soil) Depth }(E, m) \\
\text { Maximum Water Table (slab + soil) Depth }(E, m)\end{array}$ & $\begin{array}{l}\mathrm{n} / \mathrm{a} \\
\mathrm{n} / \mathrm{a}\end{array}$ & $\begin{array}{l}\mathrm{n} / \mathrm{a} \\
\mathrm{n} / \mathrm{a}\end{array}$ & $\begin{array}{l}\mathrm{n} / \mathrm{a} \\
\mathrm{n} / \mathrm{a}\end{array}$ & $\begin{array}{c}5 \\
15 \\
\end{array}$ & $\begin{array}{l}\mathrm{n} / \mathrm{a} \\
\mathrm{n} / \mathrm{a}\end{array}$ & $\begin{array}{l}\mathrm{n} / \mathrm{a} \\
\mathrm{n} / \mathrm{a}\end{array}$ & $\begin{array}{l}\mathrm{n} / \mathrm{a} \\
\mathrm{n} / \mathrm{a}\end{array}$ & $\begin{array}{l}\mathrm{n} / \mathrm{a} \\
\mathrm{n} / \mathrm{a}\end{array}$ & $\begin{array}{l}\mathrm{n} / \mathrm{a} \\
\mathrm{n} / \mathrm{a}\end{array}$ \\
\hline $\begin{array}{r}\text { Minimum Soil Far-Field Distance }(F, m) \\
\text { Maximum Soil Far-Field Distance }(F, m)\end{array}$ & $\begin{array}{l}\mathrm{n} / \mathrm{a} \\
\mathrm{n} / \mathrm{a}\end{array}$ & $\begin{array}{l}\mathrm{n} / \mathrm{a} \\
\mathrm{n} / \mathrm{a}\end{array}$ & $\begin{array}{l}\mathrm{n} / \mathrm{a} \\
\mathrm{n} / \mathrm{a}\end{array}$ & $\begin{array}{l}8 \\
8\end{array}$ & $\begin{array}{l}\mathrm{n} / \mathrm{a} \\
\mathrm{n} / \mathrm{a}\end{array}$ & $\begin{array}{l}\mathrm{n} / \mathrm{a} \\
\mathrm{n} / \mathrm{a}\end{array}$ & $\begin{array}{l}\mathrm{n} / \mathrm{a} \\
\mathrm{n} / \mathrm{a}\end{array}$ & $\begin{array}{l}\mathrm{n} / \mathrm{a} \\
\mathrm{n} / \mathrm{a}\end{array}$ & $\begin{array}{l}\mathrm{n} / \mathrm{a} \\
\mathrm{n} / \mathrm{a}\end{array}$ \\
\hline \multicolumn{10}{|l|}{$\begin{array}{l}\text { THERMAL PROPERTIES* } \\
\end{array}$} \\
\hline $\begin{array}{l}\text { Minimum Conductivity }(\mathrm{W} /(\mathrm{mK})) \\
\text { Maximum Conductivity }(\mathrm{W} /(\mathrm{mK}))\end{array}$ & $\begin{array}{c}0.1 \\
2\end{array}$ & $\begin{array}{l}0 \\
0\end{array}$ & $\begin{array}{l}0 \\
0\end{array}$ & $\begin{array}{c}0.85 \\
1.9\end{array}$ & $\begin{array}{l}0 \\
0\end{array}$ & $\begin{array}{c}0.1 \\
2\end{array}$ & $\begin{array}{l}0 \\
0\end{array}$ & $\begin{array}{l}0 \\
0\end{array}$ & $\begin{array}{l}0 \\
0\end{array}$ \\
\hline $\begin{array}{l}\left.\text { Minimum R-Value }\left(\mathrm{m}^{2} \mathrm{~K} / \mathrm{W}\right)\right) \\
\left.\text { Maximum R-Value }\left(\mathrm{m}^{2} \mathrm{~K} / \mathrm{W}\right)\right)\end{array}$ & ** & ** & ** & ** & $\begin{array}{l}0 \\
0\end{array}$ & ** & $\begin{array}{l}0 \\
9 \\
\end{array}$ & $\begin{array}{l}0 \\
0\end{array}$ & $\begin{array}{l}0 \\
0 \\
\end{array}$ \\
\hline $\begin{array}{r}\text { Minimum Density }\left(\mathrm{kg} / \mathrm{m}^{3}\right) \\
\text { Maximum Density }\left(\mathrm{kg} / \mathrm{m}^{3}\right)\end{array}$ & $\begin{array}{l}\mathrm{p} \\
\mathrm{p}\end{array}$ & $\begin{array}{l}\mathrm{p} \\
\mathrm{p}\end{array}$ & $\begin{array}{l}0 \\
0\end{array}$ & $\begin{array}{l}p \\
p\end{array}$ & $\begin{array}{l}0 \\
0\end{array}$ & $\begin{array}{l}\mathrm{p} \\
\mathrm{p}\end{array}$ & $\begin{array}{l}p \\
p\end{array}$ & $\begin{array}{l}0 \\
0\end{array}$ & $\begin{array}{l}0 \\
0\end{array}$ \\
\hline $\begin{array}{l}\text { Minimum Specific Heat }(\mathrm{kJ} /(\mathrm{kgK})) \\
\text { Maximum Specific Heat }(\mathrm{kJ} /(\mathrm{kgK}))\end{array}$ & $\begin{array}{l}p \\
p\end{array}$ & $\begin{array}{l}\mathrm{p} \\
\mathrm{p}\end{array}$ & $\begin{array}{l}0 \\
0 \\
\end{array}$ & $\begin{array}{l}\mathrm{p} \\
\mathrm{p}\end{array}$ & $\begin{array}{l}0 \\
0\end{array}$ & $p$ & $\begin{array}{l}p \\
p\end{array}$ & $\begin{array}{l}0 \\
0\end{array}$ & $\begin{array}{l}0 \\
0\end{array}$ \\
\hline \multicolumn{10}{|l|}{ COMMENTS } \\
\hline \multirow{5}{*}{$\begin{array}{l}\text { Uninsulated detail (Figure A-1) ok? ("yes" or "no") } \\
\text { Insulated detail (Figure A-2) ok? ("yes" or "no") } \\
\text { If no, include additional assumptions of your model } \\
\text { not covered here (add rows as needed) }\end{array}$} & \begin{tabular}{|l|} 
no \\
no \\
\end{tabular} & & & & & & & & \\
\hline & \multicolumn{9}{|c|}{$\begin{array}{l}\text { In BASESIMP a slab-on-grade is defined as a slab of } 5-50 \mathrm{~cm} \text { thickness with top of slab at } 5 \mathrm{~cm} \text { below } \\
\text { grade (fixed value). }\end{array}$} \\
\hline & \multicolumn{9}{|c|}{$\begin{array}{l}\text { Slab-on-grade can have insulation skirts: } \\
\text { - horizontal }(0-5 \mathrm{~m}) \text { from wall, at } 20 \mathrm{~cm} \text { depth } \\
\text { - vertical }(0-2.5 \mathrm{~m} \text { from bottom of slab) } \\
\text { - insulation skirts are characterizes by R-value }\end{array}$} \\
\hline & \multicolumn{9}{|c|}{$\begin{array}{l}\text { Slab-on-grade can also have thermal breaks: } \\
\text { - around corner } \\
\text { - between wall and footer } \\
\text { - thermal breaks are charachterizes by R-valu }\end{array}$} \\
\hline & \multicolumn{9}{|c|}{ The 'Water Table Depth' is defined as the depth at which the soil temperature is constant through the year. } \\
\hline $\begin{array}{r}\text { Include other clarfications and/or comments here } \\
\text { (add rows as needed) }\end{array}$ & \multicolumn{9}{|c|}{$\begin{array}{l}p=\text { predefined structure components to choose from } \\
\mathrm{u}=\text { user defined by using } \mathrm{R}(\mathrm{SI}) \text { values instead of dimensions }\end{array}$} \\
\hline
\end{tabular}


Table 2E-3. Overview of Slab-on-Grade Cases, BASESIMP

\begin{tabular}{|c|c|c|c|c|c|c|c|c|c|c|c|c|c|c|c|}
\hline 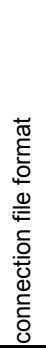 & 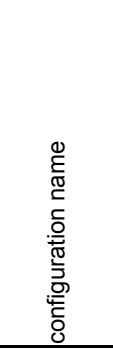 & 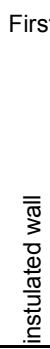 & 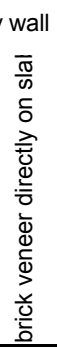 & 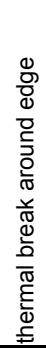 & 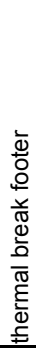 & 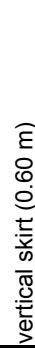 & 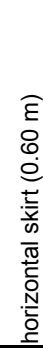 & $\begin{array}{l}E \\
\stackrel{0}{0} \\
0\end{array}$ & $\begin{array}{l}\varepsilon \\
: \\
0\end{array}$ & $\begin{array}{l}E \\
2 \\
\stackrel{2}{0}\end{array}$ & 层 & $\begin{array}{l}\frac{5}{0} \\
3 \\
3 \\
3\end{array}$ & $\begin{array}{l}\varepsilon \\
0 \\
0 \\
0\end{array}$ & $\begin{array}{l}\varepsilon \\
\stackrel{1}{r}\end{array}$ & $\begin{array}{l}\frac{5}{0} \\
\frac{2}{3} \\
\frac{3}{3}\end{array}$ \\
\hline 28 & SCN_1 & $x$ & $y$ & & & & & & & & & & & & \\
\hline $\begin{array}{l}29 \\
30\end{array}$ & $\begin{array}{l}\mathrm{SCN}_{2} \\
\mathrm{SCN} 3\end{array}$ & $x$ & $x$ & $x$ & & & & & & & & & & & \\
\hline 31 & SCN_4 & & $\mathrm{x}$ & $x$ & & & & & & & & & & & \\
\hline 32 & SCN_7 & $x$ & $x$ & $x$ & & $x$ & & & & & & & & & \\
\hline $\begin{array}{l}33 \\
34\end{array}$ & $\begin{array}{l}\text { SCN_8 } \\
\text { SCB }\end{array}$ & $x$ & $x$ & $\mathrm{x}$ & & $x$ & & & $x$ & & & & & & \\
\hline $\begin{array}{l}34 \\
35\end{array}$ & SCB_2 & A & $x$ & & & & & & $\hat{x}$ & & & & & & \\
\hline 36 & SCB_3 & $x$ & & & $x$ & & & & $x$ & & & & & & \\
\hline 37 & SCB_4 & & $x$ & & $x$ & & & & $x$ & & & & & & \\
\hline 38 & SCB_5 & $x$ & & $\mathrm{x}$ & & & & & $x$ & & & & & & \\
\hline 39 & SCB_6 & & $\mathrm{x}$ & $\mathrm{x}$ & & & & & $x$ & & & & & & \\
\hline 40 & SCB_9 & $x$ & & $\mathrm{x}$ & & $\mathrm{x}$ & & & $x$ & & & & & & \\
\hline 41 & SCB_10 & & $x$ & $x$ & & $\mathrm{x}$ & & & $x$ & & & & & & \\
\hline 42 & $\begin{array}{l}\text { SCB_11 } \\
\text { SCB } 12\end{array}$ & $x$ & $x$ & & & & $x$ & & $x$ & & & & & & \\
\hline $\begin{array}{l}43 \\
44\end{array}$ & $\begin{array}{l}\mathrm{SCB}-12 \\
\mathrm{SCB} 13\end{array}$ & $x$ & $x$ & & & & $\mathrm{x}$ & & & & $x$ & & & & \\
\hline 45 & SCB_14 & & $x$ & & & & & & & & $x$ & & & & \\
\hline 46 & SCB_17 & $x$ & & $x$ & & & & & & & $x$ & & & & \\
\hline 47 & SCB_18 & & $x$ & $x$ & & & & & & & $x$ & & & & \\
\hline 48 & SCB_21 & $x$ & & $x$ & & $\mathrm{x}$ & & & & & $x$ & & & & \\
\hline 49 & SCB_22 & & $\mathrm{x}$ & $\mathrm{x}$ & & $\mathrm{x}$ & & & & & $\mathrm{x}$ & & & & \\
\hline 50 & SCB_23 & $x$ & & & & & $x$ & & & & $x$ & & & & \\
\hline 51 & SCB_24 & & $x$ & & & & $x$ & & & & $\mathrm{x}$ & & & & \\
\hline 52 & SCB_25 & $x$ & & & & & & & & & & $x$ & & & \\
\hline 53 & SCB_26 & & $x$ & & & & & & & & & $x$ & & & \\
\hline 54 & SCB_29 & $x$ & & $x$ & & & & & & & & $x$ & & & \\
\hline 55 & SCB_30 & & $x$ & $x$ & & & & & & & & $x$ & & & \\
\hline 56 & SCB_33 & $x$ & & $\mathrm{x}$ & & $\mathrm{x}$ & & & & & & $x$ & & & \\
\hline 57 & SCB_34 & & $\mathrm{x}$ & $\mathrm{x}$ & & $\mathrm{x}$ & & & & & & $x$ & & & \\
\hline 58 & SCB_35 & $x$ & & & & & $x$ & & & & & $x$ & & & \\
\hline 59 & SCB_36 & & $x$ & & & & $x$ & & & & & $x$ & & & \\
\hline 60 & SCA_17 & $x$ & & & & & & & & & & & & & $x$ \\
\hline 61 & SCA_18 & & $x$ & & & & & & & & & & & & $x$ \\
\hline 62 & SCA_19 & $x$ & & $\mathrm{x}$ & & & & & & & & & & & $\mathrm{x}$ \\
\hline 63 & SCA_20 & & $\mathrm{x}$ & $\mathrm{x}$ & & & & & & & & & & & $\mathrm{x}$ \\
\hline 64 & SCA_21 & $x$ & & $x$ & & $\mathrm{x}$ & & & & & & & & & $x$ \\
\hline 65 & SCA_22 & & $\mathrm{x}$ & $\mathrm{x}$ & & $\mathrm{x}$ & & & & & & & & & $x$ \\
\hline 66 & SCA_23 & $x$ & & & & & $x$ & & & & & & & & $x$ \\
\hline 67 & SCA_24 & & $\mathrm{x}$ & & & & $x$ & & & & & & & & $\mathrm{x}$ \\
\hline 81 & SCB 31 & $x$ & & $x$ & $x$ & & & & & & & $\mathrm{x}$ & & & \\
\hline 82 & SCB_32 & & $x$ & $x$ & $x$ & & & & & & & $\mathrm{x}$ & & & \\
\hline 83 & SCB_37 & $x$ & & $\mathrm{x}$ & $x$ & & & $x$ & & & & & & & \\
\hline 84 & SCB_38 & & $\mathrm{x}$ & $\mathrm{x}$ & $x$ & & & $x$ & & & & & & & \\
\hline 85 & SCB_39 & $x$ & & $\mathrm{x}$ & $x$ & & & & & $x$ & & & & & \\
\hline 86 & SCB_40 & & $\mathrm{x}$ & $\mathrm{x}$ & $x$ & & & & & $x$ & & & & & \\
\hline 104 & SCA_1 & $x$ & & & & & & & & & & & $x$ & & \\
\hline 105 & SCA_2 & & $\mathrm{x}$ & & & & & & & & & & $x$ & $x$ & \\
\hline $\begin{array}{l}106 \\
107\end{array}$ & $\begin{array}{l}\text { SCA_- } \\
\text { SCA_ }\end{array}$ & $x$ & $x$ & & & & & & & & & & & $\hat{x}$ & \\
\hline
\end{tabular}




\subsection{Modeling Adjustments}

\subsubsection{Corrections for dimensions}

BASESIMP requires entering the outside dimensions of the basement. So, for a $12 \mathrm{~m} \times 12 \mathrm{~m}$ slab with a $0.24 \mathrm{~m}$ thick wall, dimensions of $12.48 \mathrm{~m} \times 12.48 \mathrm{~m}(12+2 * 0.24)$ should be used.

The BASESIMP correlations were developed for basements with maximum dimensions of $100 \mathrm{~m} \times 12 \mathrm{~m}$. Therefore, using a $12.48 \mathrm{~m}$ width would mean working outside of the correlation ranges. To compensate, a $12.98 \mathrm{~m} \times 12 \mathrm{~m}$ slab is used instead in order to obtain the same area $\left(155.75 \mathrm{~m}^{2}\right)$. Reproducing test GC30C using BASECALC yields Qbg $=1971 \mathrm{~W}$ and $\mathrm{Qag}=32 \mathrm{~W}$ for these dimensions. Since these are very close to the results obtained using a $12.48 \mathrm{~m} \times 12.48 \mathrm{~m}$ slab $(1973 \mathrm{~W}$ and $30 \mathrm{~W})$, it can be assumed that using these dimensions provides the same results as using the required dimensions.

Also, BASESIMP requires all dimensions to be above $5 \mathrm{~m}$. Therefore, modeling test GC45C using all required dimensions is not possible. The $4.48 \mathrm{~m} \times 36.48 \mathrm{~m}\left(163.43 \mathrm{~m}^{2}\right)$ slab was replaced by a $5 \mathrm{~m} \times 32.69$ $\mathrm{m}$ slab, which should give similar results. An additional BASECALC run was made for exact the same dimensions $(5 \mathrm{~m} \times 32.69 \mathrm{~m})$ to check whether this assumption is valid; results are shown in Section 2.7.1.

\subsubsection{Basic configuration for correlations}

The BASESIMP correlations for slab heat losses are based upon BASECALC runs for a realistic configuration. For a concrete slab on grade this configuration is characterized by:

\begin{tabular}{|l|c|c|c|}
\hline & & $\begin{array}{c}\text { BASECALC } \\
\text { GC30C/40C/45C/55C }- \\
\text { GC80C }\end{array}$ & $\begin{array}{c}\text { BASESIMP } \\
\text { GC30C/40C/45C/55C }- \\
\text { GC80C }\end{array}$ \\
\hline Wall thickness & $\mathrm{m}$ & 0.24 & 0.20 \\
\hline Wall conductivity & $\mathrm{W} / \mathrm{mK}$ & 0.01 & 1.73 \\
\hline Slab thickness & $\mathrm{m}$ & 0.05 & 0.10 \\
\hline Slab conductivity & $\mathrm{W} / \mathrm{mK}$ & $1.9-0.85$ & 1.73 \\
\hline Soil conductivity above slab & $\mathrm{W} / \mathrm{mK}$ & $1.9-0.85$ & $1.8-0.8$ \\
\hline Soil conductivity below slab & $\mathrm{W} / \mathrm{mK}$ & $1.9-0.85$ & $2.0-0.9$ \\
\hline
\end{tabular}

These BASESIMP parameter values are fixed in all simulations and result in a slab-on-grade configuration that is slightly different than the one prescribed for the c-series of GC-cases and implemented in BASECALC. BASESIMP results could therefore differ from BASECALC results.

\subsection{Modeling Difficulties}

No modeling difficulties were encountered when performing the "c"-series test cases, see Part I.

\subsection{Demonstration of Appropriate Level of Modeling Detail}

Since BASESIMP offers no control over the level of modeling details, there are no direct ways to perform these demonstrations. 


\subsection{Improvements to Tested Programs}

The current "c"-series of configurations are much better fitted to the specific limitations of BASECALC and BASESIMP (see Table 2E-6 in Section 3 of this modeler report). However, correctional calculations are still needed for both BASECALC and BASESIMP to meet the dimensions of GC45C. Besides, the BASESIMP results for GC80C differ significantly from the BASECALC results due to the limitations of the chosen standard configuration (see $\S 2.3 .2$ ) for developing the BASESIMP correlations. It should be noted here, however, that the BASESIMP case represents a much more realistic configuration than the more theoretical configuration prescribed for GC80C. The GC $80 \mathrm{c}$ configuration is a consequence of using realistic low-range conductivity value for soil, and then applying that same relatively low value to the slab and foundation wall. The differences between the BASESIMP floor conduction results for case GC80C and those produced by BASECALC have been analyzed. Below an overview is given of the differences in modeling assumptions of BASESIMP [on left] and BASECALC [(in parenthesis)] and the contribution these differences in assumptions have in the total difference in floor conduction for the GC $80 \mathrm{C}$ configuration [\% on the right]:

$\begin{array}{llrl}\text { Slab cond. [W/mK] } & 1.73 & (0.85) & 34 \% \\ \text { Soil cond. [W/mK] } & 0.8 / 0.9 & (0.85) & 28 \% \\ \text { Wall cond. [W/mK] } & 1.73 & (0.01) & 19 \% \\ \text { Slab thickness [m] } & 0.10 & (0.05) & 16 \% \\ \text { Wall thickness [m] } & 0.20 & (0.24) & 3 \%\end{array}$

For realistic buildings, the BASESIMP results will therefore be much closer to the BASECALC results as shown in Table 2E-4 below.

The standard BASESIMP correlations cover only part of the operating envelope of BASECALC. In order to allow the user to use BASESIMP within the same limits as BASECALC, a new standard configuration type (type 999) has been developed for BASESIMP that allows the user to input the specific heat loss coefficients calculated by BASECALC for configurations that would normally fall outside of the envelope of parameter variations covered by the current heat loss correlations. The BASESIMP heat loss results for type 999 configurations identical to those of the BASECALC runs were used to supply the heat loss coefficients, as is shown in $\S 2.7 .2$.

\subsection{Results}

\subsubsection{Results using standard BASESIMP correlations}

Comparisons of BASESIMP results (using standard BASESIMP correlations) with BASECALC results are shown in Table 2E-4.

At first glance, the BASESIMP and BASECALC results for cases GC30C, GC40C, and GC55C look to be in good agreement, whereas the cases GC45C and especially GC80C display substantial differences. Further analysis of the results revealed that for all cases the BASESIMP results differ in two ways from the BASECALC results:

- The differences in configuration described in $\$ 2.3 .2$ result generally in a $2 \%-5 \%$ higher heat loss for BASESIMP compared to the BASECALC result for the c-series cases. For case GC80c this difference is even $15 \%$, because in the BASESIMP calculations the slab conductivity has a constant value $(1.73$ $\mathrm{W} / \mathrm{mK})$ that is much higher than the value used by BASECALC $(0.85 \mathrm{~W} / \mathrm{mK})$ for this specific case. 
- The heat loss correlations used by BASESIMP are not a perfect fit to the original BASECALC data, but show a reasonable and expected spread of approximately $5 \%$ around the BASECALC results.

Sometimes the BASESIMP value is lower than the BASECALC result, sometimes higher.

Table 2E-4. Comparison of BASECALC and BASESIMP/ESP-r results for series $c$ tests

\begin{tabular}{|c|c|c|}
\hline \multirow[t]{2}{*}{ Test } & \multicolumn{2}{|c|}{ Below Grade Heat Losses $(\mathrm{kWh} / \mathrm{y})$} \\
\hline & BASECALC & BASESIMP/ESP-r \\
\hline GC30C & 17285 & 17094 \\
\hline $\mathrm{GC} 40 \mathrm{C}$ & 17285 & 17094 \\
\hline $\mathrm{GC} 45 \mathrm{C}$ & $\begin{array}{lr}23849 & (4.48 \mathrm{~m} \times 36.48 \mathrm{~m}) \\
22610 & (5.00 \mathrm{~m} \times 32.69 \mathrm{~m}) \\
\end{array}$ & $24584(5.00 \mathrm{~m} \times 32.69 \mathrm{~m})$ \\
\hline GC55C & 20850 & 19941 \\
\hline $\mathrm{GC} 80 \mathrm{C}$ & 8635 & 10427 \\
\hline
\end{tabular}

For cases GC30C, GC40C, and GC55C the heat losses calculated using the BASESIMP fit are roughly 5\% lower than when the original BASECALC results would be used, overcompensating the higher heat losses due to the configuration difference, and resulting in fairly similar numbers for both programs. The BASESIMP correlations used for cases GC45C and GC80C have a 5\% higher value than the BASECALC values, amplifying the differences already caused by the differences in configuration, and resulting in a total $9 \%$ higher heat loss for case GC45C (5.00 m × $32.69 \mathrm{~m}$ slab) and a 21\% higher heat loss for case GC80C.

The results for the two different BASECALC simulations for GC45C, using a $4.48 \mathrm{~m} \times 36.48 \mathrm{~m}$ slab and a $5.00 \mathrm{~m} \times 32.69 \mathrm{~m}$ slab, differ by $5 \%$.

\subsubsection{Results using BASESIMP type 999}

Comparisons of BASESIMP results (using type 999) with BASECALC results are shown in Table 2E-5.

Table 2E-5. Comparison of BASECALC and BASESIMP/ESP-r Results for Series c Tests using BASESIMP type 999 (Calculations are not based on correlations but on heat loss factors calculated by BASECALC)

\begin{tabular}{|l|c|c|}
\hline \multirow{2}{*}{ Test } & \multicolumn{2}{|c|}{ Below Grade Heat Losses (kWh/y) } \\
\cline { 2 - 3 } & BASECALC & BASESIMP/ESP-r \\
\hline GC30C & 17285 & 17285 \\
\hline GC40C & 17285 & 17285 \\
\hline GC45C & $23849(4.48 \times 36.48 \mathrm{~m})$ & $23849(4.48 \times 36.48 \mathrm{~m})$ \\
\hline GC55C & 20850 & 20850 \\
\hline GC80C & 8635 & 8635 \\
\hline
\end{tabular}

The annually totaled results for the cases GC30C to GC80C using BASESIMP with input of heat loss factors calculated by BASECALC exactly equaled the BASECALC results. This should not be a surprise, because the calculation of heat losses using the heat loss coefficients is identical in both programs. Only small differences in the maximum heat losses for floor and zone were detected (see detailed results in accompanying excel file), due to the difference in time basis for both programs (BASECALC uses monthly averages, while BASESIMP performs hourly simulations). 


\section{Conclusions and Recommendations}

The current $\mathrm{c}$ series of configurations are much better fitted to the specific limitations of BASECALC and BASESIMP (see Table 2E-6). However, correctional calculations are still needed for both BASECALC and BASESIMP to meet the dimensions of GC45C. Besides, the BASESIMP results (using correlations for heat loss coefficients) for GC80C differ significantly from the BASECALC results due to the limitations of the chosen standard configuration (see § 2.3.2) for developing the BASESIMP correlations. It should be noted here, however, that the BASESIMP case represents a much more realistic configuration than the more theoretical configuration prescribed for GC80C. For realistic buildings, the BASESIMP results will therefore be much closer to the BASECALC results.

A new standard configuration type (999) has successfully been implemented in BASESIMP. This type allows the user to input the specific heat loss coefficients calculated by BASECALC for configurations that would normally fall outside of the envelope of parameter variations covered by the current heat loss correlations. The BASESIMP type 999 results show perfect agreement to the BASECALC results for annual total heat losses. Peak heat losses differ slightly due to a difference in time basis between the two programs.

After updating the BASESIMP program, both BASECALC and BASESIMP are able to model the c series test cases sufficiently close to the specs. No further revision of the specs for the $\mathrm{c}$ series test cases is necessary.

Table 2E-6 Limitations of BASECALC and BASESIMP

\begin{tabular}{|l|l|}
\hline Method & Comments \\
\hline BASECALC & $\mathrm{h}_{\mathrm{i}, \text { BASECALC }}=7.95$ (required correction, see section 1.3.1) \\
& $\mathrm{h}_{\text {out,BASECALC }}$ infinite for all cases (not correctable) \\
& Water table depth $5-20 \mathrm{~m}$ \\
& Far field distance $=8 \mathrm{~m}$ \\
& $20 \mathrm{~m} \times 20 \mathrm{~m}$ maximum floor dimensions \\
& Temperatures as a function of position not available \\
& First 3 years of simulation not available \\
\hline BASESIMP & $\mathrm{h}_{\mathrm{i}, \text { BASESIMP }}=7.95$ (required correction, see section 2.3.1) \\
(Correlations) & $\mathrm{h}_{\text {out,BASESIMP }}=$ infinite for all cases (not correctable) \\
& $\mathrm{k}_{\text {soil }} \leq 1.9 \mathrm{~W} / \mathrm{m}^{\circ} \mathrm{C}$ BASESIMP limit \\
& Water table depth 5-15 m \\
& Far field distance $=8 \mathrm{~m}$ \\
& $100 \mathrm{~m} \times 12 \mathrm{~m}$ maximum floor dimensions \\
& Temperatures as a function of position not available \\
& First 3 years of simulation not available \\
\hline BASESIMP & Same limitations as BASECALC \\
(Type 999) & \\
\hline
\end{tabular}




\section{References}

1- Beausoleil-Morrison I., BASESIMP ESP-r implantation (Fortran code)

2- Beausoleil-Morrison I. and Mitalas G. (1997), 'BASESIMP: A Residential-Foundation Heat-Loss Algorithm for Incorporating into Whole-Building Energy-Analysis Programs', Proc. Building Simulation '97, (2) 1-8, Int Building Performance Simulation Association, Prague Czech Republic.

3- Beausoleil-Morrison, I. and Krarti, M. 1997. "Predicting Foundation Heat Losses: Neural Networks Versus the BASESIMP Correlations." Proc. Building Simulation '97, (1) 251-258, Int Building Performance Simulation Association, Prague Czech Republic.

4- NRCAN (1993), BASECALC Help.

5- Beausoleil-Morrison, I., Mitalas, G., and Chin, H. 1995b. "Estimating Three-Dimensional Below-Grade Heat Losses from Houses Using Two-Dimensional Calculations." Thermal Performance of the Exterior Envelopes of Buildings VI. Clearwater Beach FL. pp.95-99.

6- Beausoleil-Morrison, I. 1996. "BASECALC : A Software Tool for Modelling Residential- TM Foundation Heat Losses." Third Canadian Conference on Computing in Civil and Building Engineering. Montreal. pp.117-126. 


\title{
Appendix II-F
}

\section{Modeler Report for BESTEST Cases GC10a-GC80c VA114 Version 2.20 using ISO-13370 ground heat transfer calculation method}

\author{
by \\ Aad Wijsman \\ VABI Software BV \\ The Netherlands \\ September 2007
}

\begin{abstract}
September 9, 2002 (first draft)
November 7, 2002 (second draft)

July 18, 2005 (third draft)

September 9, 2005 (fourth draft)

December 23, 2005 (fifth draft)

May 9, 2006 (sixth draft)

February 5, 2007 (draft 7)

Remark:

This report is draft 7. With respect to draft 6 some more clarification was added based on comments of subtask leader Joel Neymark.

A description of the model and its assumptions are given. The simulation program passed the BESTEST [1],[2],[3]. In the summer of 2005 the simulation program was subjected to the IEA-34/43 Ground Coupling tests (Slab cases only) [4]. In December 2005 the other defined tests and b-series of the In-Depth Diagnostic Cases for Slab-On-Grade [9] were done. Now the In-Depth Diagnostic Cases for Slab-On-Grade[11] were completed (some of the b-series cases were re-done; the c-series are done).
\end{abstract}




\section{Introduction}

The Building simulation program VA114 is developed and distributed by VABI Software bv. The current version is 2.20 .

The program calculates the Demand, the Supply, the Distribution and the Generation of heat and cold for a building with its energy supply system. Moreover the internal comfort temperature and overheating are calculated.

VA114 is a multi-zone program (up to 30 zones). The time step applied in VA114 is 1 hour.

The boundary conditions, that are possible in VA114 are:

- $\quad$ bounded to ambient

- $\quad$ bounded to a neighbour zone

- $\quad$ bounded to a mirror zone

- $\quad$ bounded to the underground.

The current program VA114 models:

- $\quad$ heat exchange within a zone

- $\quad$ heat exchange between zones by conduction

- $\quad$ heat exchange between zones by airflow (ventilation)

- $\quad$ solar gain and solar exchange between zones

- $\quad$ solar shading

- $\quad$ and other processes.

The simulation program VA114 passed the BESTEST [1],[2],[3]. Moreover in 2002 the simulation program was subjected to the IEA SHC Task 22 ground-coupling tests [4]: GC100, GC120, GC125, GC160, GC180, GC190, GC125FF were carried out. Ground heat transfer was modelled with VA114 by describing the underground by one or more 'zones'. Results are given in [5]. Comparison with the results of the other programs showed that this approach with VA114 gave low heat losses to the underground.

In 2002 it was proposed to follow the approach of ISO 13370 [6]. The ground heat flow rate according to ISO 13370 (see Annex E) is treated as consisting of two components:

- a fixed component representing the average heat flow rate through the ground

- a varying component representing the variations in the ground heat flow rate about the average value

The fixed component is obtained using the methods in standard ISO 13370. The varying component is a dynamic term obtained by solution of the heat diffusion equation.

Because of manpower, budget, and priority, the implementation of the approach was delayed.

In July 2005 a start was made with the implementation. In the third draft of this report [7] the new approach was described and results of first calculations were given for Task-22 tests GC100, GC120, GC125 and GC125FF. Based on these results it was decided to continue with the implementation of ISO 13370 in VA114.

In September 2005, the work was continued:

- $\quad$ a spreadsheet was developed that calculates the fixed heat loss component based on ISO 13370 for the given configuration (for the slab-on-grade cases) 
- $\quad$ this fixed component was put into the source of VA114

- the Task-22 Ground Coupling tests (Slab-on-grade cases GC100, GC120, GC125, GC125FF, GC160 and GC180) were carried out

Draft 4 of the report [8] describes the new model and gives the results. Very encouraging.

In December 2005, the following work was done:

- $\quad$ The IEA Task-22 Ground Coupling tests for Slab-on-Grade were redone.

- $\quad$ The IEA 34/43 In-Depth Diagnostic Cases for the slab-on-grade (b-series) were done.

- Spreadsheets were developed for the other configurations: suspended floor, heated basement and unheated basement.

Remark about suspended floor and basements: Output of ISO 13370 is an overall heat loss value in W per $\mathrm{m}^{2}$ of floor area; implementation of suspended floor and basement in VA114 requires a separation of this heat loss in two parts: heat loss through ground coupled floor and heat loss through ground coupled sidewalls. Both this separation in the spread sheet program and the implementation in VA114 are not yet done.

Draft 5 of the report [10] gives the results.

In ISO 13370 the Deep Ground Boundary Depth (E) is assumed to be infinite. In the In-Depth Diagnostic Cases this is not always the case. Now it was studied to take the Deep Ground Boundary Depth (E) into account by ground water table depth and by an infinite ground water flow.

The In-Depth Diagnostic Cases were carried out: some of the b-series were redone, the c-series are done. The results are very promising.

In this report (draft 6 and 7) the results of this work are given.

\section{Model description}

The previous version of VA114 modeled ground heat transfer in a very simple way:

- $\quad$ One-dimensional heat transfer through a 'construction' with at maximum 10 layers.

- $\quad$ At the top this 'construction' is bounded to the building zone, at the bottom it is bounded to a constant temperature.

- $\quad$ At the top of this 'construction' heat transfer takes place by convection, radiation, absorption of solar radiation; at the bottom of this construction heat transfer is modeled by a user given heat transfer coefficient to a constant, user given, temperature.

Because of the IEA-Task-22 tests the ground heat transfer was modeled in more detail with VA114 by describing the underground by one or more 'zones'. By this way in 2002 the Ground Coupling test cases were carried out.

The results showed, that the VA114 approach gave low heat losses to the underground.

In 2002 it was proposed to follow the approach of ISO 13370. The ground heat flow rate according to ISO 13370 is treated as consisting of two components (see Annex E):

- A fixed component representing the average heat flow rate through the ground

- A varying component representing the variations in the ground heat flow rate about the average value. 
The fixed component is obtained using the methods in standard ISO 13370. This component is calculated including any insulation of the floor in the determination of the heat transfer coefficients. Calculated is the total heat flow over the whole floor area. The heat flux density varies over the area of the floor, but an average value is used in the equations written.

The varying component is obtained using the following assumptions and boundary conditions:

- The dynamic heat flow in the ground is assumed to be 1-D.

- The floor construction together with the ground is modelled as a single component consisting of each layer in the floor construction plus $\left.0,50^{*}\right) \mathrm{m}$ depth of ground.

- An adiabatic boundary is taken in the ground at a depth of $0,50^{*} \mathrm{~m}$.

${ }^{*}$ ISO 13370 prescribes $1 \mathrm{~m}$, but in later discussions $0,50 \mathrm{~m}$ was proposed.

The varying component is modelled in VA114 in the same way as other constructions (wall, roof, ...) are modelled, so no specific treatment.

In CEN/TC 89 WG6 a modification on this approach was proposed and is under development now. When crystallized out this modification can be taken over.

Before starting the development of a module to calculated the fixed component according to ISO 13370 an exploratory study was done with VA114:

- $\quad$ The fixed component was user given.

- $\quad$ The varying component was modelled as mentioned above.

Results of this exploratory study were presented in third draft of this report - paragraph 7 [7]. Based on this results it was decided to continue with the implementation of ISO 13370 in VA114.

In September 2005 the work was continued:

$\rightarrow$ A spreadsheet was developed that calculates the fixed heat loss component based on ISO 13370 for the given configuration (for slab-on-grade). The fixed heat loss is expressed in three terms:

$\mathrm{Q}$ "(M) $=\mathrm{Q}$ "Average $-\mathrm{Q}$ " ${ }_{\mathrm{Ti}}{ }^{*} \operatorname{Cos}\left(\arg _{\mathrm{Ti}}(\right.$ time of the year $\left.)\right)+\mathrm{Q}{ }_{\mathrm{Te}}{ }^{*} \operatorname{Cos}\left(\arg _{\mathrm{Te}}(\right.$ time of the year $\left.)\right)$

- Q" $(\mathrm{M})$ is the average rate of heat flow in month $\mathrm{M}$

- The first term contains the annual average indoor (internal) temperature and the annual average ambient (external) temperature.

- The second term takes into account the amplitude of the variation of the internal temperature (the monthly average) about the average value

- $\quad$ The third term does the same for the external temperature

- $\quad \operatorname{Arg}_{\mathrm{Ti}}$ and $\mathrm{Arg}_{\mathrm{Te}}$ contain the month number M and a delay in time (Tau-Alfa) and (Tau+Beta).

$\operatorname{Arg}_{\mathrm{Ti}}($ time of the year $)=2 * \pi^{*}(\mathrm{M}-\mathrm{Tau}+\mathrm{Alfa}) / 12$

$\operatorname{Arg}_{\text {Te }}$ (time of the year $)=2 * \pi *(\mathrm{M}-$ Tau-Beta $) / 12$

$\mathrm{M}=$ number of month of the year $(\mathrm{M}=1=$ January $)$

So the Q"(M) changes per month, so every change of month a step change in this fixed component occurs. 
VABI replaced in above equation the Month number of the year (M) by the Day number of the year (Iday) to get a smooth transition between this ISO-method (spreadsheet with monthly results) and the dynamic simulation program VA114.

$$
\begin{aligned}
& \operatorname{Arg}_{\text {Ti }}(\text { time of the year })=2 * \pi^{*}\left(\mathrm{I}_{\text {day }}-\mathrm{N}_{\text {daygci }}\right) / 365 \\
& \operatorname{Arg}_{\text {Te }}(\text { time of the year })=2 * \pi^{*}\left(\mathrm{I}_{\text {day }}-\mathrm{N}_{\text {daygce }}\right) / 365 \\
& \text { Iday }=\text { number of day of the year }(\text { Iday }=1=\text { January } 1)
\end{aligned}
$$

Ndaygci and Ndaygce contain information about the delay in time.

The spread sheet program has the constants Q" ${ }_{\text {Average }}, \mathrm{Q}$ "Ti, $\mathrm{Q}$ "Te, $\mathrm{N}_{\text {daygci }}$ and $\mathrm{N}_{\text {daygce }}$ as output

$\rightarrow$ the above shown formula (with given constants) was put into the source of VA114; the constants Q" Average , Q" Ti,$Q "$ Te, $\mathrm{N}_{\text {daygci }}$ and $\mathrm{N}_{\text {daygce }}$ are input parameters for VA114 (later on a separate module, as part of VA114, will be developed that deliver these constants)

$\rightarrow$ the IEATask-22 Ground Coupling tests for Slab-on-Grade (GC100, GC120, GC125, GC125FF, GC160 and GC180) were carried out. Each test has its specific constants.

For the September 2005 results see draft 4 of this report [8]

In December 2005, the following work was done:

- $\quad$ The IEA Task-22 Ground Coupling tests for Slab-on-Grade were redone (because of an error in the spreadsheet for slab-on-grade).

- $\quad$ The IEA-34/43 In-Depth Diagnostic Cases for the slab-on-grade (b-series) were done.

- Spreadsheets were developed for the other configurations: suspended floor, heated basement and unheated basement. ISO-13370 heat loss is per $\mathrm{m}^{2}$ of floor area; implementation in VA114 requires a separation between heat loss through ground coupled floor and heat loss through ground coupled side-walls. This separation in the spread sheet and the implementation in VA114 is not yet done.

The belonging results are given in draft 5 of this report [10].

In ISO 13370 the Deep Ground Boundary Depth (E) is assumed to be infinite. In the In-Depth Diagnostic Cases this is not always the case. Now it was studied to take the Deep Ground Boundary Depth (E) into account by ground water table depth and by an infinite ground water flow.

In appendix H of ISO 13370 it is noticed, the effect of flowing ground water can be assessed by multiplying the steady-state heat flow rate by a factor $\mathrm{Gw}$. This factor $\mathrm{Gw}$ is depending on 3 dimensionless ratios:
- $\quad \mathrm{Z}_{\mathrm{w}} / \mathrm{B}^{\prime}$
- $\quad \mathrm{L} / \mathrm{B}^{\prime}$
- $\mathrm{D}_{\mathrm{t}} / \mathrm{B}^{\prime}$ 
With

- $\quad \mathrm{B}^{\prime}=$ characteristic dimension of the floor

- $\quad Z_{\mathrm{w}}=$ the depth of the water table

- $\quad \mathrm{L}=$ proportional to $1 /$ ground water velocity

- $\quad D_{t}=$ total equivalent thickness of the floor

Appendix H of ISO 13370 gives values for the factor $\mathrm{Gw}$ as function of these 3 dimensionless ratios. However, the tables are far from user friendly. By interpolation and extrapolation of the values in these tables VABI made new, more user friendly tables. In Figure 2F-1 these tables are given. Yellow (shaded) cells contain the values from the ISO 13370, the other values were obtained by interpolation and extrapolation.

The IEA-34/43 In-Depth Diagnostic Cases were carried out: some of the b-series were re-done (GC50b and GC55b), the c-series are done. The results are very promising.

The belonging test results are given in Section 7 of this report

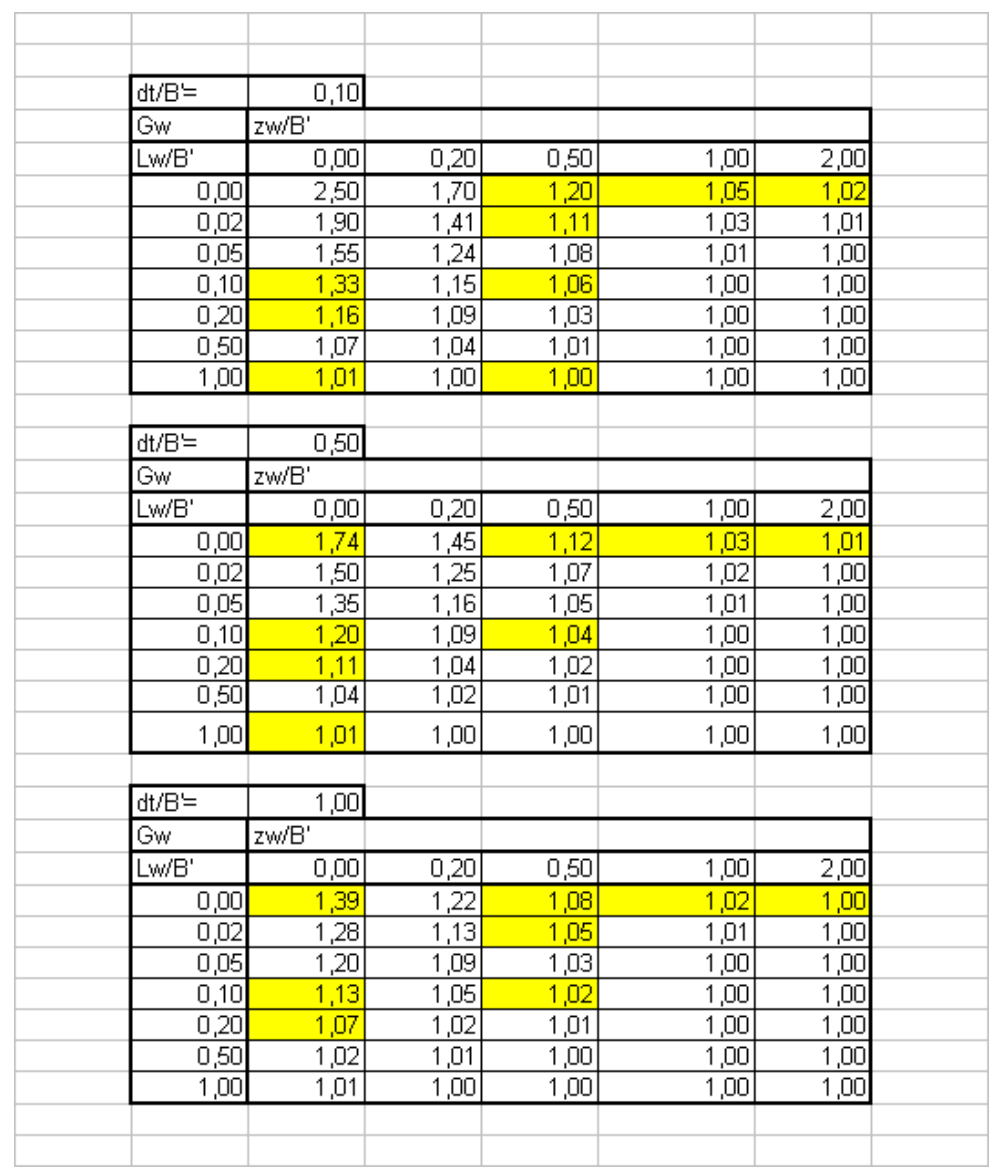

Figure 2F-1: Factor Gw for ground water flow 


\section{Modeling Assumptions}

The IEA BESTEST Ground-Coupled Cases [4] and the IEA BESTEST In-Depth Diagnostic Cases for Ground-Coupled Heat Transfer related to Slab-on-Grade Construction [9,11] were both implemented. In this chapter information about the modeling assumptions are given.

\subsection{Weather}

The TMY2-weather files were made ready. No problems occurred.

\subsection{Soil}

Input as described.

\subsection{Boundary Conditions}

The floor construction together with the ground is modelled as a single component consisting of each layer in the floor construction plus $0,50 \mathrm{~m}$ depth of ground; an adiabatic boundary is taken in the ground at a depth of $0,50 \mathrm{~m}$.

The fixed component Q" describing the average heat loss to the underground was put at the bottom of the above described construction (as a kind of heat sink).

Remark: putting this fixed component at the top of the construction doesn't have a big influence

Zone

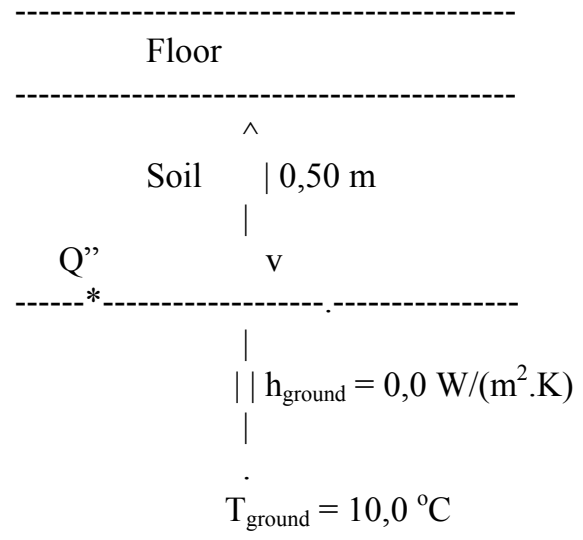

Figure 2F-2: Boundary condition to the ground

The varying component is modelled in VA114 as a construction: bounded at the top to the zone (with all its processes) and at the bottom to $\mathrm{T}_{\text {ground }}$ (in this specific case $\mathrm{h}_{\text {ground }}=0,0 \mathrm{~W} /\left(\mathrm{m}^{2} . \mathrm{K}\right)$ ).

For the IEA-test cases the floor has the same properties as the soil. Floor thickness is assumed to be very small $(0,001 \mathrm{~m})$, so negligible with respect to the $0,50 \mathrm{~m}$ of soil.

\subsection{Initial conditions}

Initialization period is standard 42 days. The calculation need no longer initialization period than this 42 days because only the capacity of the $0,5 \mathrm{~m}$ soil below the floor is taken into account. 


\subsection{Windows}

Input as described (Task 22 cases only).

\subsection{Solar Absorptivity}

Input as described.

Remark: In case the prescribed internal solar absorptivity $=0,0$, a minimum value of 0,01 was taken. For external solar absorptivity $=0,0$ is no problem.

\subsection{Infrared Emissivity}

Input as described.

Remark: In case the prescribed internal infrared emissivity $=0,0$, a minimum value of 0,01 was taken. $(0,06$ $\mathrm{W} / \mathrm{m}^{2} \mathrm{~K}$ ). For external infrared emissivity 0,0 is no problem.

\subsection{Exterior Radiative and Convective Surface Coefficients}

Separate coefficients are used. The radiative surface coefficient is calculated, the convective surface coefficient is constant. See Table 2F-1.

\subsection{Interior Radiative and Convective Surface Coefficients}

Separate coefficients are used. The radiative surface coefficient is calculated, the convective surface coefficient is constant. See Table 2F-1. For horizontal surfaces the convective surface coefficient is the same as for vertical surfaces.

Table 2F-1: Surface Coefficients

\begin{tabular}{|l|l|c|c|c|}
\hline IEA-Bestest Cases & & $\mathrm{IR}$ & Convective & Total \\
\hline & & $\mathrm{W} / \mathrm{m}^{2} \mathrm{~K}$ & $\mathrm{~W} / \mathrm{m}^{2} \mathrm{~K}$ & $\mathrm{~W} / \mathrm{m}^{2} \mathrm{~K}$ \\
\hline IEA-22 GC-Cases & Exterior for wall & 5,00 & 24,3 & 29,3 \\
\hline & Exterior for window & 5,00 & 16,0 & 21,0 \\
\hline & Interior for wall and window & 5,00 & 3,16 & 8,16 \\
\hline IEA-34/43 “b”-series cases & Exterior for soil surface & 0,00 & 100,0 & 100,0 \\
\hline & & 0,00 & 11,95 & 11,95 \\
\hline & Interior for slab surface & 0,06 & 99,94 & 100,0 \\
\hline & & 0,06 & 7,89 & 7,95 \\
\hline IEA-34/43 “c"-series cases & Exterior for soil surface & 0,00 & 5000,0 & 5000,0 \\
\hline & Interior for slab surface & 0,06 & 7,89 & 7,95 \\
\hline
\end{tabular}

\subsection{Interior Solar Distribution (Task-22 cases only)}

The interior solar distribution is calculated. Short wave absorptivity is as prescribed. Separate treatment for direct solar radiation and for diffuse/reflected solar radiation.

\subsection{Mechanical System}

The mechanical supply of fresh air is $0,0 \mathrm{~m}^{3} / \mathrm{h}$. The heating and cooling to the zone is provided by local devices. These local devices have a capacity of $100 \mathrm{~kW}$. For the IEA-22 cases, the set points are $23^{\circ} \mathrm{C}$ for heating and $25^{\circ} \mathrm{C}$ for cooling; for the IEA-34/43 cases, the heating set point is $30^{\circ} \mathrm{C}$ and there is no cooling. 


\subsection{Infiltration}

The infiltration is 0,0 .

\subsection{Internal Loads}

The internal loads is $0,0 \mathrm{~W}$.

\subsection{Above Grade Construction}

Input as described.

\subsection{Slab-on-Grade Cases}

The ISO 13370 approach was followed.

Remark: the Deep Ground Boundary Depth (E) was simulated by ground water table depth and by an infinite ground water flow rate.

\subsection{Basement Cases (IEA-22 cases only)}

ISO 13370 approach was followed.

Remark: Output of ISO 13370 is heat loss per $\mathrm{m}^{2}$ of floor area. A distinction should be made between heat loss through ground coupled floor and heat loss through ground coupled side-walls. This separation is not yet made in the spread sheet program and is not yet implemented in VA114.

\subsection{Walkout Basement Case (IEA-22 cases only)}

ISO 13370 approach was followed. See remark under Basement Cases

\section{Modeling Options}

For this IEA-34/43 work there is the option to have the fixed component attack in two places at the varying component ( $=$ floor construction together with $0,5 \mathrm{~m}$ of ground):

- at the top of that construction

- $\quad$ at the bottom of that construction

It was decided to have it attack at the bottom. The influence is very small (see draft 3 of this report - 7).

At the moment only Slab-on-Grade cases are possible; in future cases with suspended floor and cases with basement will be possible. The ISO 13370 spread sheet for these cases are available, but for simulation by VA114 it is necessary to make a separation between the floor to ground part and the sidewalls to ground part. Both parts are modeled as separate constructions in VA114. The output of the spreadsheet will concern the relevant constants both for the floor to ground part and the sidewalls to ground part. This double number of constants have to be put as input to VA114.

\section{Modeling Difficulties}

See the remark about suspended floor and basements under section 1 .

\section{Software Errors Discovered and/or Comparison between Different Versions of the Same Software}

In preliminary work during IEA SHC Task 22 [4], results for the Task 22 cases using VA114's 1-D conduction model indicated low heating loads compared with other programs; see Figure 2F-3a. Based on these results, VABI decided to explore implementing the ISO-13370 ground heat transfer model into VA114. Figure 2F-3b shows VA114 annual heating load results versus results of other models before and 
after initial implementation of ISO 13370 [13,14], which indicates improved agreement (see results labeled "VA114-ISO13370 (2005)" versus results labeled "VA114/VABI (2002)").

\section{IEA BESTEST Ground Coupling \\ Heating Loads}
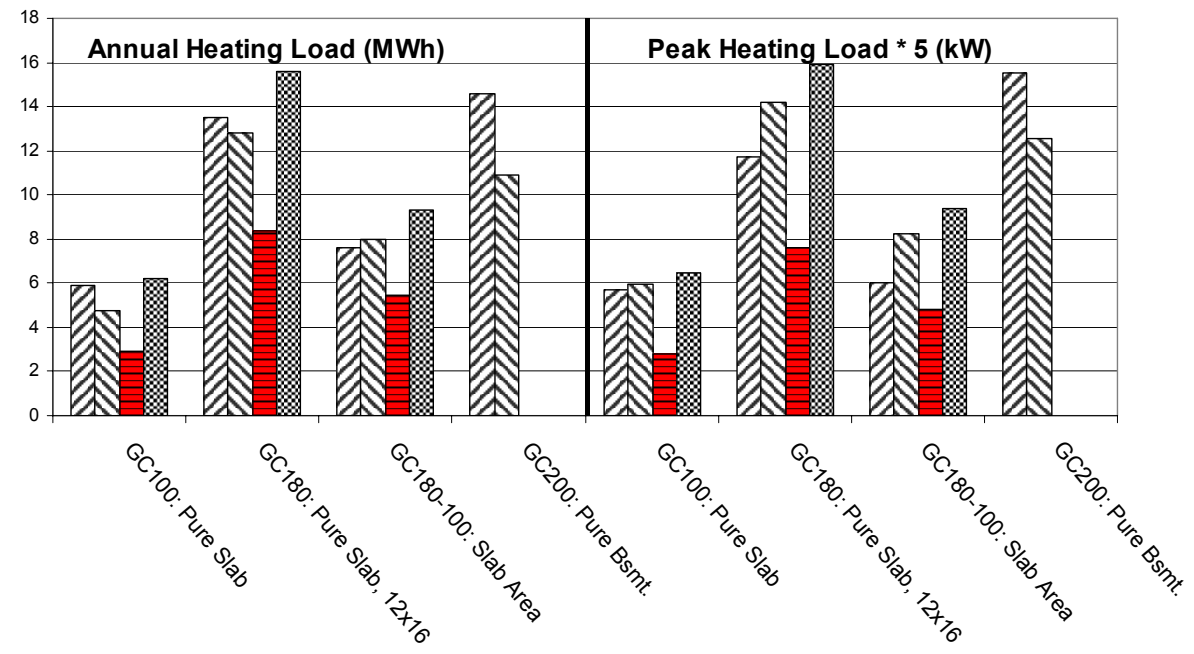

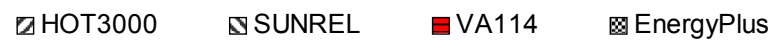

Figure 2F-3a. Task 22 heating loads, from September 2003 IEA-34/43 Zurich meeting presentation

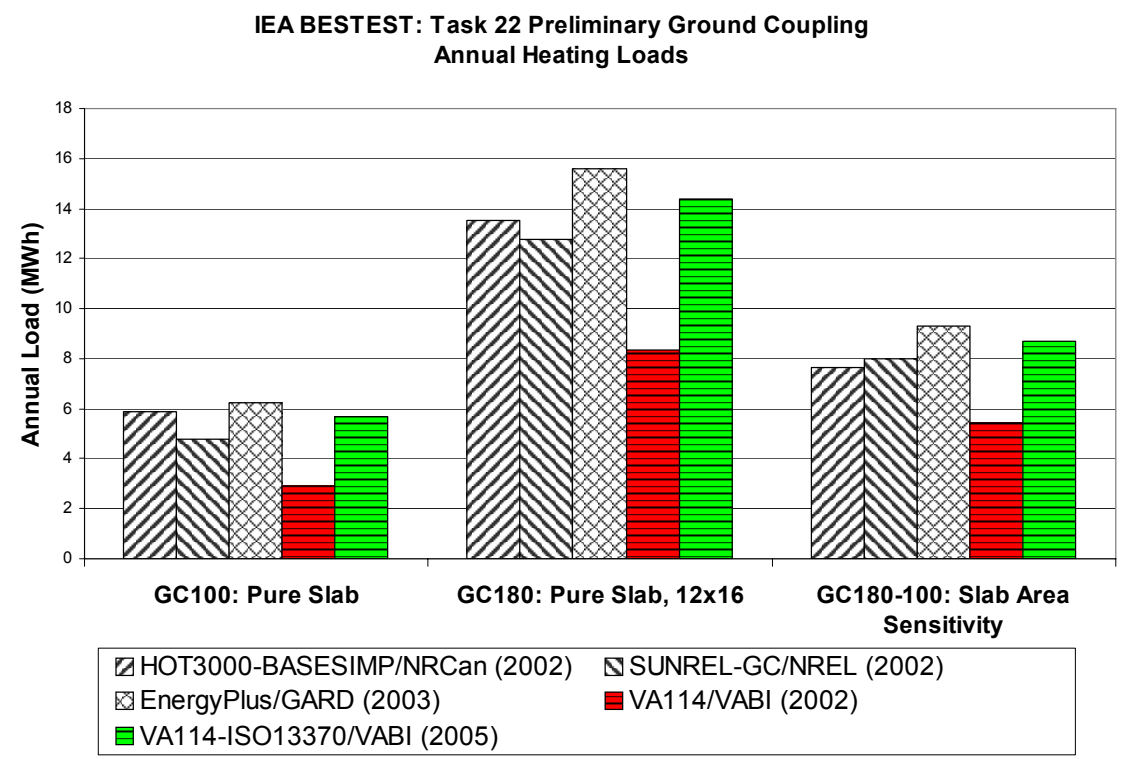

Figure 2F-3b. IEA SHC Task-22 test results for VA114 versus other models, before ("VA114/VABI

(2002)") and after (“VA114-ISO13370/VABI (2005)") preliminary adaptation of the ISO-13370 European standard ground heat transfer calculation method with VA114. 
The initial implementation of ISO-13370 with VA114 was also tested using the IEA-34/43 test cases (see Figure 2F-4). Except for cases GC50b and GC55b, good agreement is indicated for VA114/ISO 13370 versus the TRNSYS and SUNREL-GC detailed 3-D numerical-methods models. The largest disagreement is for Case GC55b, which has shallow water table depth; Case GC50b is for large slab with no change in modeled soil depth versus GC40b, so in GC50b water-table depth also becomes somewhat shallow relative to the slab surface area. The initial implementation of ISO 13370 in VA114 did not include ISO 13370's model for water table depth sensitivity. Based on these results, the ISO-13370 shallow water table depth model was implemented; improved agreement resulting from this implementation is shown in Figure 2F-5.

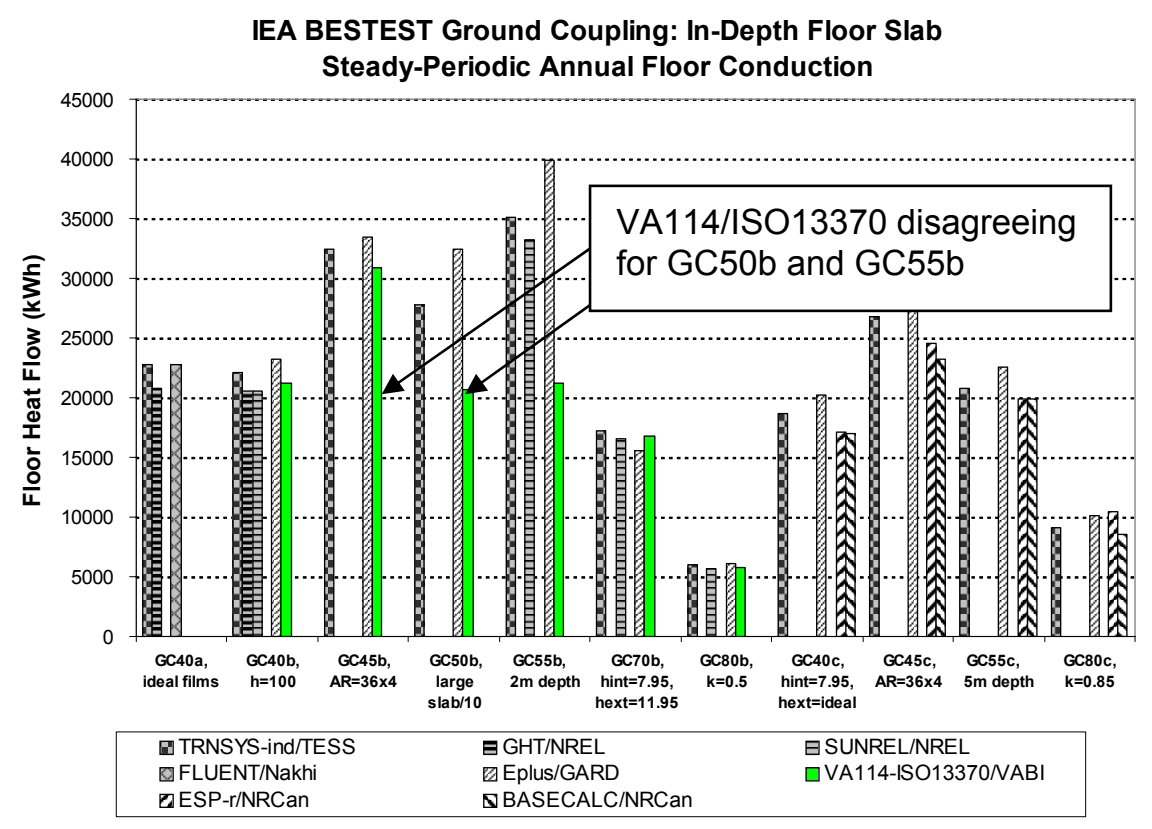

Figure 2F-4. Steady-Periodic Annual Floor Conduction, from April 2006 lowa Meeting Presentation 


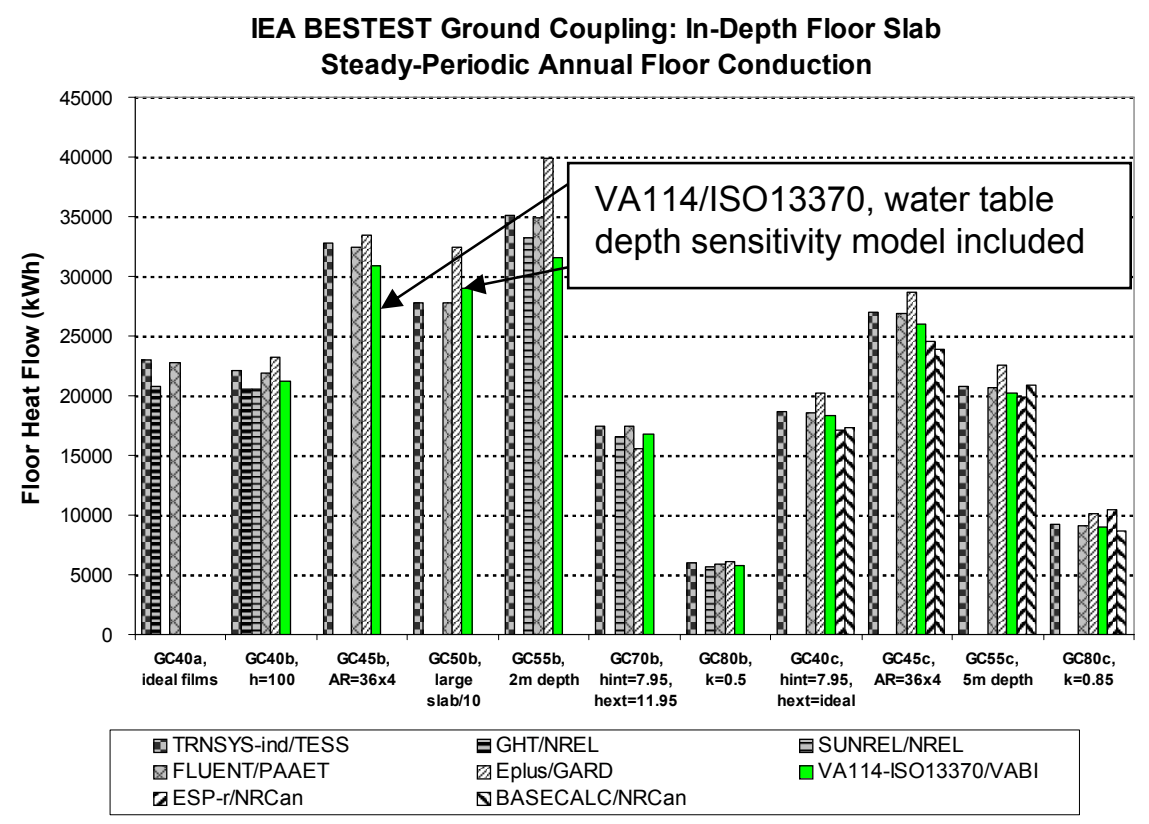

Figure 2F-5. Steady-Periodic Annual Floor Conduction, from October 24, 2006

\section{Results}

Results of earlier steps can be found in draft 3 [7] and draft 4 [8] of this report. Now results of the December 2005 and May 2006 work are presented.

For each configuration (slab on grade, suspended floor, heated basement and unheated basement) a separate spreadsheet was developed that calculates the fixed heat loss component based on ISO 13370.

The heat loss is expressed in 3 terms (see section 2):

$$
\mathrm{Q} \text { " = Q" }{ }_{\text {Average }}-\mathrm{Q}{ }_{\mathrm{Ti}}{ }^{*} \mathrm{Cos}\left(\arg _{\mathrm{Ti}}(\text { time of the year })\right)+\mathrm{Q}{ }_{\mathrm{Te}}{ }^{*} \operatorname{Cos}\left(\arg _{\mathrm{Te}}(\text { time of the year })\right)
$$

With

$$
\begin{aligned}
& \operatorname{Arg}_{\mathrm{Ti}} \text { (time of the year) }=2 * \pi^{*}\left(\mathrm{I}_{\text {day }}-\mathrm{N}_{\text {daygci }}\right) / 365 \\
& \operatorname{Arg}_{\mathrm{Te}}(\text { time of the year })=2 * \pi *\left(\mathrm{I}_{\text {day }}-\mathrm{N}_{\text {daygce }}\right) / 365 \\
& \text { Iday = number of day of the year (Iday }=1=\text { January } 1)
\end{aligned}
$$

Each spreadsheet program has the constants Q" ${ }_{\text {Average }}, \mathrm{Q}$ "Ti, $\mathrm{Q}$ "Te, $\mathrm{N}_{\text {daygci }}$, and $\mathrm{N}_{\text {daygce }}$ as output

The above shown formula (with given constants) is present in the source of VA114; the constants are input values for VA114. 


\section{A. IEA BESTEST GC Cases (test GC100-GC235)}

\begin{tabular}{|l|l|l|l|l|l|l|}
\hline \multicolumn{2}{|l|}{} & & & \\
\hline Summary of ground-coupled cases & & & \\
\hline
\end{tabular}

Table 2F-2 gives the constants for the several test cases

Table 2F-2: Constants for the IEA BESTEST GC Cases

\begin{tabular}{|c|c|c|c|c|c|}
\hline Test case & Q" Average & Q" & Q" & $\mathrm{N}_{\mathrm{day}, \mathrm{gci}}$ & $\mathrm{N}_{\text {day,gce }}$ \\
\hline GC100 & 11,16 & 0,0 & 7,61 & -20 & 54 \\
\hline GC120 & 11,16 & 0,0 & 7,61 & -20 & 54 \\
\hline GC125-1 & 12,01 & 0,71 & 7,61 & -20 & 54 \\
\hline GC125-2 & 12,01 & 0,0 & 7,61 & -20 & 54 \\
\hline GC125FF-1 & 12,01 & 0,71 & 7,61 & -20 & 54 \\
\hline GC125FF-2 & 12,01 & $6,0^{*}$ & 7,61 & -20 & 54 \\
\hline GC160 & 7,98 & 0,71 & 5,21 & -20 & 54 \\
\hline GC180 & 7,12 & 0,0 & 3,81 & -20 & 54 \\
\hline GC190 & 7,12 & 0,0 & 3,81 & -20 & 54 \\
\hline GC200 & 29,46 & 0,0 & 11,46 & -18 & 55 \\
\hline GC260 & 17,17 & 0,0 & 6,04 & 0 & 68 \\
\hline
\end{tabular}

Remarks:

- $\quad \mathrm{GC100,GC120}$ and GC180 have only a heating demand, so internal temperature is always the heating set point $\left(=23^{\circ} \mathrm{C}\right)$. So term Q" ${ }_{\mathrm{Ti}}=0,0$; term Q" ${ }_{\text {Average }}$ is based on average internal temperature of $23^{\circ} \mathrm{C}$

- $\quad \mathrm{GC} 125$ and GC160 have both a heating demand and a cooling demand, so internal temperature swings between both set points $\left(23^{\circ} \mathrm{C}\right.$ in winter and $25^{\circ} \mathrm{C}$ in summer); term Q" ${ }_{\mathrm{Ti}}$ is based on an amplitude of $1 \mathrm{~K}$; term Q" ${ }_{\mathrm{A}}$ is based on average internal temperature of $24^{\circ} \mathrm{C}$. GC125-1 has in winter time $23^{\circ} \mathrm{C}$ and in summer time $25^{\circ} \mathrm{C}$; GC125-2 has both in winter and summer time temperatures between $23^{\circ} \mathrm{C}$ and $25^{\circ} \mathrm{C}$

- $\quad$ GC125FF has an unknown internal temperature. First calculations with the above constants (GC125FF-1) gave the order in which the internal temperature (monthly average) swings: the annual average was in the same order as the other cases $\left(24^{\circ} \mathrm{C}\right)$, the annual swing in monthly averages was much larger than $1 \mathrm{~K}$ (order $6-10 \mathrm{~K} \rightarrow \mathrm{Q}$ " ${ }_{\mathrm{Ti}}=6,0$ is a better number GC125FF-2), the minimum temperature was not in month 1 (January) but in month 4 (April).

- GC200 and GC260 (Basement Cases) are in W/m² of floor area; a separation should be made between heat loss through floor and heat loss through sidewalls. Implementation in VA114 was not yet done. So no annual results for these cases.

The results are given in GCResults-IEA22-20051223.XLS (see appendix B1 of this modeler report). Imported in spreadsheet GCResults-IEA22-0403plotted20051223.XLS it can be seen the results of VA114 are much more close to the other programs. In appendix B1 some figures are given too.

Remark:

The results for GC125FF are for the constants given in Table $2 \mathrm{~F}-2$ (first estimate $\mathrm{Q}_{\mathrm{Ti}}=0,71$ ): actual internal temperature is $6^{\circ}-55$ ${ }^{\circ} \mathrm{C}$. With a better estimate based on the first run results of the internal temperature the temperature range becomes $3^{\circ}-53^{\circ} \mathrm{C}$. So there is a strong interaction between internal temperature and ground heat loss; an iterative calculation procedure seems to be necessary. 


\section{B. IEA BESTEST GC Diagnostic Cases for slab-on-grade (B-series)}

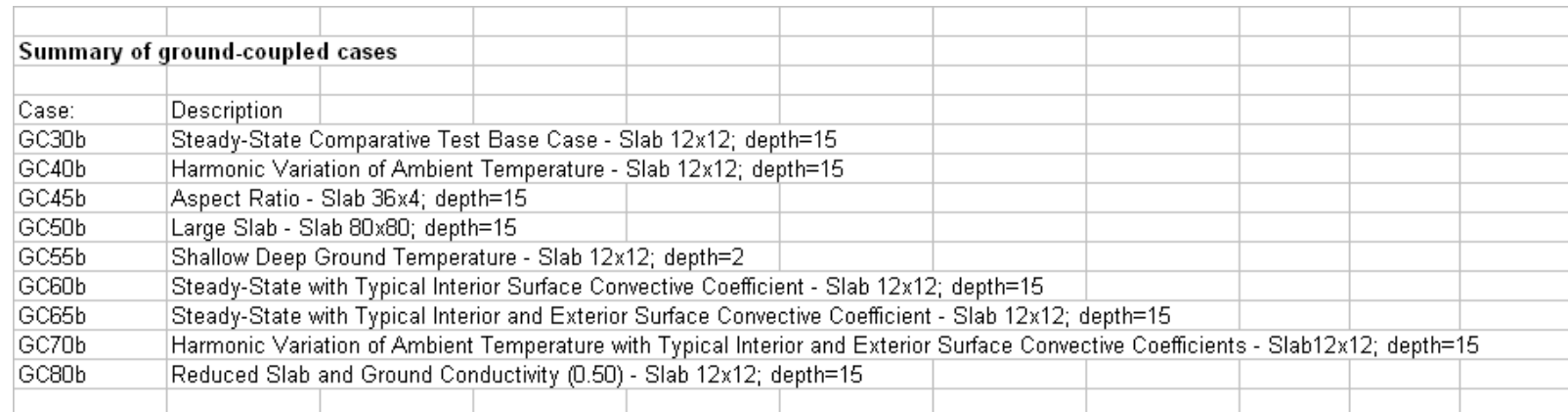

Table 2F-3 gives the constants for the several test cases:

Table 2F-3: Constants for the IEA BESTEST GC Diagnostic Cases for Slab On Grade

\begin{tabular}{|l|c|c|c|l|l|}
\hline Test case & Q" ${ }_{\text {Average }}$ & Q" & Q" & $\mathrm{N}_{\text {Tey }}$ gci & $\mathrm{N}_{\text {day,gce }}$ \\
\hline GC30b & 16,81 & 0,00 & 0,00 & -25 & 51 \\
\hline GC40b & 16,81 & 0,00 & 3,32 & -25 & 51 \\
\hline GC45b & 24,46 & 0,00 & 5,53 & -25 & 51 \\
\hline GC50b & 5,17 & 0,00 & 0,50 & -25 & 51 \\
\hline GC55b & 25,05 & 0,00 & 3,32 & -25 & 51 \\
\hline GC60b & 14,37 & 0,00 & 0,00 & -22 & 53 \\
\hline GC65b & 13,33 & 0,00 & 0,00 & -20 & 54 \\
\hline GC70b & 13,33 & 0,00 & 2,31 & -20 & 54 \\
\hline GC80b & 4,54 & 0,00 & 0,69 & -22 & 59 \\
\hline
\end{tabular}

Remarks:

- $\quad$ The ISO 13370 works with infinite "Deep Ground Boundary Depth (E)" and infinite "Far Field Boundary Distance (F)"; a "Deep Ground Temperature (TDG)" is not required. So different from the required input.

- $\quad$ The Deep Ground Boundary Depth (E) was simulated by ground water table depth and an infinite ground water flow rate. For most cases the influence of that boundary was very small (factor $\mathrm{Gw}<1,01)$ and neglected $(\mathrm{Gw}=1,00)$; only for $\mathrm{GC} 50 \mathrm{~b}(\mathrm{Gw}=1,40)$ and GC55b $(\mathrm{Gw}=1,49)$ the influence of that boundary is present and rather big $(40 \%-49 \%$ extra losses).

The results are given in GC-InDepth-Out-0505-20060509.XLS (see appendix B2 of this modeler report).

\section{IEA BESTEST GC Diagnostic Cases for slab on grade (C-series)}

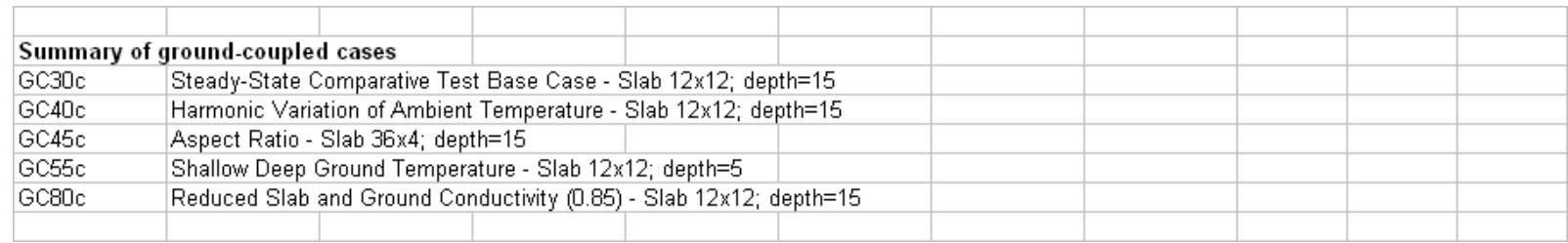


Table 2F-4 gives the constants for the several test cases:

Table 2F-4: Constants for the IEA BESTEST GC Diagnostic Cases for Slab On Grade

\begin{tabular}{|l|c|c|c|c|c|}
\hline Test case & Q" ${ }_{\text {Average }}$ & Q" & Q" & $\mathrm{N}_{\text {day,gci }}$ & $\mathrm{N}_{\text {day,gce }}$ \\
\hline GC30c & 14,53 & 0,00 & 0,00 & -22 & 53 \\
\hline GC40c & 14,53 & 0,00 & 2,64 & -22 & 53 \\
\hline GC45c & 20,64 & 0,00 & 4,41 & -22 & 53 \\
\hline GC55c & 15,99 & 0,00 & 2,64 & -22 & 53 \\
\hline GC80c & 7,11 & 0,00 & 1,14 & -21 & 57 \\
\hline
\end{tabular}

Remarks:

- $\quad$ The ISO 13370 works with infinite "Deep Ground Boundary Depth (E)" and infinite "Far Field Boundary Distance (F)"; a "Deep Ground Temperature (TDG)" is not required. So different from the required input.

- $\quad$ The Deep Ground Boundary Depth (E) was simulated by ground water table depth and an infinite ground water flow rate. For most cases the influence of that boundary was a very small (factor $\mathrm{Gw}<1,01$ ) and neglected $(\mathrm{Gw}=1,00)$; only for GC55c $(\mathrm{Gw}=1,10)$. The influence of that boundary is present and gives about $10 \%$ extra losses .

The results are given in GC-InDepth-Out-0505-20060509.XLS (see appendix B2 of this modeler report).

\section{Other (optional)}

[Editor's note: no comments were provided here by VABI.]

\section{Conclusions and Recommendations}

VA114 uses ISO 13370 to describe the heat losses to the ground. At the moment the calculation is still decoupled:

- Spreadsheet programs calculate the characteristic heat losses for a specific GC-configuration

- These characteristic heat losses are fed to VA114 as input.

In this way reasonable agreement is obtained with the results of other programs.

Spreadsheets are available for slab, suspended floor, heated and unheated basement. The above mentioned decoupled procedure works for slab. For suspended floor and basements a split have to be made between heat loss through ground coupled floor and heat loss through ground coupled side walls. This step is not made yet both in the ISO 13370 spread sheet program; also the implementation in VA114 is not yet done.

The final step will be the development of a module, that can be coupled to VA114. In that way the calculation can be done fully integrated.

\section{References}

[1] Judkoff, R and Neymark, J

"International Energy Agency Building Energy Simulation Test (BESTEST) and Diagnostic Method”, IEA: SHC Task 12/ECBCS Annex 21, February 1995.

[2] Soethout, L. L.

"BESTEST Kwalificatietesten uitgevoerd aan het gebouwsimulatieprogramma VA114, versienummer 1.35”. TNO-rapport 98-BBI-R0830, mei 1998. 
[3] Wijsman, A.J.Th.M.; Plokker, W.

"Eerste thermische gebouwsimulatieprogramma's ondergingen de keurmerktest".

TVVL Magazine, augustus 1999.

[4] Deru, M., Judkoff, R. and Neymark, J.

"Proposed IEA BESTEST Ground-Coupled Cases", IEA: SHC Task 22, July 22, 2002.

[5] Wijsman, A. and Maassen, W.

“Ground Coupling Modeler Report - TNO - Draft 2”, IEA: SHC Task 22, November 2002.

[6] ISO 13370:1998(E)

"Thermal performance of buildings - Heat transfer via the ground - Calculation methods"

[7] Wijsman, A.

“Ground Coupling Modeler Report -VABI - Draft 3", IEA: SHC Task 34/ECBCS Annex 43, July 182005.

[8] Wijsman, A.

“Ground Coupling Modeler Report -VABI - Draft 4", IEA: SHC Task 34/ECBCS Annex 43, September 9, 2005.

[9] Neymark, J. and Judkoff, R.

"Proposed IEA BESTEST In-Depth Diagnostic Cases for Ground-Coupled Heat Transfer Related to Slab-on-Grade Construction”, IEA: SHC Task 34/ECBCS Annex 43, June 2005.

[10] Wijsman, A.

"Ground Coupling Modeler Report -VABI - Draft 5", IEA: SHC Task 34/ECBCS Annex 43, December 23, 2005.

[11] Neymark, J. and Judkoff, R.

"Proposed IEA BESTEST In-Depth Diagnostic Cases for Ground-Coupled Heat Transfer Related to Slab-on-Grade Construction", IEA: SHC Task 34/ECBCS Annex 43, March 2006.

[12] Wijsman, A.

“Ground Coupling Modeler Report -VABI - Draft 6", IEA: SHC Task 34/ECBCS Annex 43, May 9, 2006.

[13] Neymark, J.

"IEA BESTEST Ground Coupling Project Plan Review". Presented at IEA SHC Task 34

Meeting, Duebendorf, Switzerland, September 29, 2003. See "GC-Task22-Results091903revVABI090607.XLS”.

[14] Wijsman, A.

"VA114 Ground Coupling". Presented at IEA Meeting of IEA SHC Task 34/ECBCS Annex 43, Aalborg, Denmark, October 2005. See "Aalborg-Ground Coupling October 2005.ppt". 
Appendix A: Model Geometry and Thermal Property Allowed Inputs - VA114

\begin{tabular}{|c|c|c|c|c|c|c|c|c|c|}
\hline \multirow{2}{*}{\multicolumn{10}{|c|}{1 december 2005}} \\
\hline & & & & & & & & & \\
\hline \multicolumn{10}{|l|}{ A. Wijsman - Vabi Software bv. } \\
\hline & & & & & & & & & \\
\hline \multicolumn{10}{|c|}{ Model Geometry and Thermal Property Allowed Inputs (pro forma) } \\
\hline & & & & & & & & & \\
\hline \multicolumn{7}{|c|}{ Model and Version: VA114 - Excel sheet ISO 13370 - method } & \multicolumn{3}{|c|}{ Insulation Components } \\
\hline & \multicolumn{4}{|c|}{ Below-Grade High-Mass Components } & \multicolumn{2}{|c|}{ Low-Mass Components } & Horizontal & Vertical & Vertical \\
\hline & & Foundation & & & & Above Grade & Edge & Interior Edge & Exterior Edge \\
\hline & Slab & Wall & Footer & Soil & Sill Plate & Wall & Insulation & Insulation & Insulation \\
\hline \multicolumn{10}{|l|}{ GEOMETRY* } \\
\hline Floor Slab In (below) Grade ("yes" or "no") & yes? & $\mathrm{n} / \mathrm{a}$ & $\mathrm{n} / \mathrm{a}$ & $\mathrm{n} / \mathrm{a}$ & $\mathrm{n} / \mathrm{a}$ & $\mathrm{n} / \mathrm{a}$ & $\mathrm{n} / \mathrm{a}$ & $\mathrm{n} / \mathrm{a}$ & $\mathrm{n} / \mathrm{a}$ \\
\hline Floor Slab On (above) Grade ("yes" or "no") & yes & $\mathrm{n} / \mathrm{a}$ & $n / a$ & $\mathrm{n} / \mathrm{a}$ & $\mathrm{n} / \mathrm{a}$ & $\mathrm{n} / \mathrm{a}$ & $\mathrm{n} / \mathrm{a}$ & $\mathrm{n} / \mathrm{a}$ & $n / a$ \\
\hline Floor Slab Minimum Thickness (cm) & 0,0 & $\mathrm{n} / \mathrm{a}$ & $\mathrm{n} / \mathrm{a}$ & $\mathrm{n} / \mathrm{a}$ & $\mathrm{n} / \mathrm{a}$ & $n / a$ & $\mathrm{n} / \mathrm{a}$ & $\mathrm{n} / \mathrm{a}$ & $\mathrm{n} / \mathrm{a}$ \\
\hline Floor Slab Maximum Thickness (cm) & $\mathrm{z}<<\mathrm{B}^{\prime}$ & $\mathrm{n} / \mathrm{a}$ & $\mathrm{n} / \mathrm{a}$ & $n / a$ & $\mathrm{n} / \mathrm{a}$ & $\mathrm{n} / \mathrm{a}$ & $\mathrm{n} / \mathrm{a}$ & $\mathrm{n} / \mathrm{a}$ & $\mathrm{n} / \mathrm{a}$ \\
\hline Minimum $x$-Thickness or Width $(\mathrm{cm})$ & $n / a$ & 0,0 & 0 & $\mathrm{n} / \mathrm{a}$ & 0 & 0,0 & 0,0 & 0,0 & same int \\
\hline Maximum $x$-Thickness or Width $(\mathrm{cm})$ & $n / a$ & $x<<B^{\prime}$ & 0 & $n / a$ & 0 & $x<<B^{\prime}$ & $x<<\mathrm{B}^{\prime}$ & $x<z$ & same int \\
\hline Minimum $z$-Thickness $(\mathrm{cm})$ & $\mathrm{n} / \mathrm{a}$ & $\mathrm{n} / \mathrm{a}$ & 0 & $\mathrm{n} / \mathrm{a}$ & 0 & $n / a$ & 0,0 & $\mathrm{n} / \mathrm{a}$ & $\mathrm{n} / \mathrm{a}$ \\
\hline Maximum $z$-Thickness $(\mathrm{cm})$ & $n / a$ & $n / a$ & 0 & $\mathrm{n} / \mathrm{a}$ & 0 & $n / a$ & $z<<x$ & $\mathrm{n} / \mathrm{a}$ & $\mathrm{n} / \mathrm{a}$ \\
\hline Minimum Bottom-Edge Depth Below Grade $(z, \mathrm{~cm})$ & $?$ & $?$ & 0 & $\mathrm{n} / \mathrm{a}$ & $\mathrm{n} / \mathrm{a}$ & $\mathrm{n} / \mathrm{a}$ & $\mathrm{n} / \mathrm{a}$ & 0,0 & same int \\
\hline Maximum Bottom-Edge Depth Below Grade $(z, \mathrm{~cm})$ & infinitif & infinitif & 0 & $\mathrm{n} / \mathrm{a}$ & $\mathrm{n} / \mathrm{a}$ & $\mathrm{n} / \mathrm{a}$ & $\mathrm{n} / \mathrm{a}$ & infinitif & same int \\
\hline Minimum Top-Edge Height Above Grade $(z, c m)$ & 0,0 & 0,0 & $\mathrm{n} / \mathrm{a}$ & $\mathrm{n} / \mathrm{a}$ & $\mathrm{n} / \mathrm{a}$ & $\mathrm{n} / \mathrm{a}$ & $\mathrm{n} / \mathrm{a}$ & 0,0 & same int \\
\hline Maximum Top-Edge Height Above Grade $(z, c m)$ & $?$ & $?$ & $\mathrm{n} / \mathrm{a}$ & $\mathrm{n} / \mathrm{a}$ & $n / a$ & $n / a$ & $\mathrm{n} / \mathrm{a}$ & $?$ & same int \\
\hline Minimum Soil Depth $(E, m)$ & $\mathrm{n} / \mathrm{a}$ & $\mathrm{n} / \mathrm{a}$ & $n / a$ & $?$ & $\mathrm{n} / \mathrm{a}$ & $\mathrm{n} / \mathrm{a}$ & $n / a$ & $\mathrm{n} / \mathrm{a}$ & $n / a$ \\
\hline Maximum Soil Depth $(E, m)$ & $\mathrm{n} / \mathrm{a}$ & $n / a$ & $\mathrm{n} / \mathrm{a}$ & infinitif & $n / a$ & $n / a$ & $\mathrm{n} / \mathrm{a}$ & $\mathrm{n} / \mathrm{a}$ & $\mathrm{n} / \mathrm{a}$ \\
\hline Minimum Soil Far-Field Distance ( $F, m)$ & $\mathrm{n} / \mathrm{a}$ & $n / a$ & $\mathrm{n} / \mathrm{a}$ & infinitif & $n / a$ & $n / a$ & $\mathrm{n} / \mathrm{a}$ & $\mathrm{n} / \mathrm{a}$ & $\mathrm{n} / \mathrm{a}$ \\
\hline Maximum Soil Far-Field Distance $(F, m)$ & $\mathrm{n} / \mathrm{a}$ & $\mathrm{n} / \mathrm{a}$ & $\mathrm{n} / \mathrm{a}$ & infinitif & $\mathrm{n} / \mathrm{a}$ & $\mathrm{n} / \mathrm{a}$ & $\mathrm{n} / \mathrm{a}$ & $\mathrm{n} / \mathrm{a}$ & $\mathrm{n} / \mathrm{a}$ \\
\hline \multicolumn{10}{|l|}{ THERMAL PROPERTIES ${ }^{\star}$} \\
\hline Minimum Conductivity $(\mathrm{W} /(\mathrm{mK}))$ & No $\min$ & No min & 0 & No $\min$ & 0 & see VA114 & No $\min$ & No $\min$ & same int \\
\hline Maximum Conductivity $(\mathrm{W} /(\mathrm{mK}))$ & No max & No max & 0 & No max & 0 & see VA114 & No max & No max & same int \\
\hline Minimum R-Value $\left(\mathrm{m}^{2} \mathrm{KM}\right)$ & $\#$ & $\#$ & $\#$ & 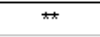 & 0 & see VA114 & $\# ?$ & $* ?$ & same int \\
\hline Maximum R-Value $\left(\mathrm{m}^{2} \mathrm{KM}\right)$ & $\#$ & $\#$ & $\#$ & $\#$ & 0 & see VA.114 & $* ?$ & $\# ?$ & same int \\
\hline Minimum Density $\left(\mathrm{kg} / \mathrm{m}^{3}\right)$ & No $\min$ & No $\min$ & 0 & No $\min$ & 0 & see VA114 & 0 & 0 & same int \\
\hline Maximum Density $\left(\mathrm{kg} / \mathrm{m}^{3}\right)$ & No $\max$ & No max & 0 & No max & 0 & see VA114 & 0 & 0 & same int \\
\hline Minimum Specific Heat $(\mathrm{kJ} /(\mathrm{kgK}))$ & No min & No $\min$ & 0 & No min & 0 & see VA114 & 0 & 0 & same int \\
\hline Maximum Specific Heat $(\mathrm{kJ} /(\mathrm{kgK}))$ & No max & No max & 0 & No max & 0 & see VA.114 & 0 & 0 & same int \\
\hline \multicolumn{10}{|c|}{ COMMENTS } \\
\hline Uninsulated detail (Figure A-1) ok? ("yes" or "no") & yes & & & & & & & & \\
\hline Insulated detail (Figure A-2) ok? ("yes" or "no") & yes & & & & & & & & \\
\hline \multicolumn{10}{|l|}{ If no, include additional assumptions of your model } \\
\hline not covered here (add rows as needed) & & & & & & & & & \\
\hline Include other clarfications and/or comments here & $B^{\prime}$ & \multicolumn{8}{|c|}{ Characteristic dimension of floor $=2^{\star} A$ rea of floor / Exposed Perimeter of floor } \\
\hline & & \multicolumn{8}{|c|}{ I.e. width of floor for an infinitely long floor; half the length of one side for a square floor } \\
\hline & yes? & \multicolumn{8}{|c|}{ ISO 13370 says "a slab in contact with the ground ... situated at or near the level of the } \\
\hline & & external gro & und surfa & ce." & & & & & \\
\hline & & The belong & ing figure & shows the & floor slab & on top of the & grade (so a & above groun & d level). \\
\hline & & I have no ex & tra inform & ation so f & or slab IN $g$ & grade I think 'y & yes'but l at & $m$ not sure "? & \\
\hline & No $\min$ & No minimu & $m$ restricti & & & & & & \\
\hline & No max & No maximu & $m$ restrict & & & & & & \\
\hline & $?$ & Not known, & ISO 1337 & is silent & about this & but I can imag & gine there & will be a valt & \\
\hline & see VA114 & ISO $13370 \mathrm{i}$ & silent $a b$ & out this & & & & & \\
\hline & *x? & I don't knov & $v ;$ think $s$ & & & & & & \\
\hline & 0,0 & Value $=0,0$ & & & & & & & \\
\hline & same int & same limits & as for ver & ical interi & or edge ins: & sulation & & & \\
\hline NOTES & & & & & & & & & \\
\hline "n/a": not applicable & & & & & & & & & \\
\hline${ }^{*}$ If a listed input does not apply to your model, e & nter "0" in & the relevant & cells. & & & & & & \\
\hline${ }^{*}$ For below grade high-mass components, only & list $R$-value & input limits & if there & me dif & erence vers & sus what $w$ & Id be calcu & ulated bas & $n$ listed \\
\hline conductivity and thickness limits & & & & & & & & & \\
\hline & & & & & & & & & \\
\hline
\end{tabular}


See output spreadsheet for Ground Coupling cases: GCResults-IEA22-20051223.XLS.

Remark:

Imported in spreadsheet GCResults-IEA22-0403plotted20051223.XLS a comparison with results of other programs can be made; an example plot is included below.

\section{IEA BESTEST Ground Coupling Heating Loads}

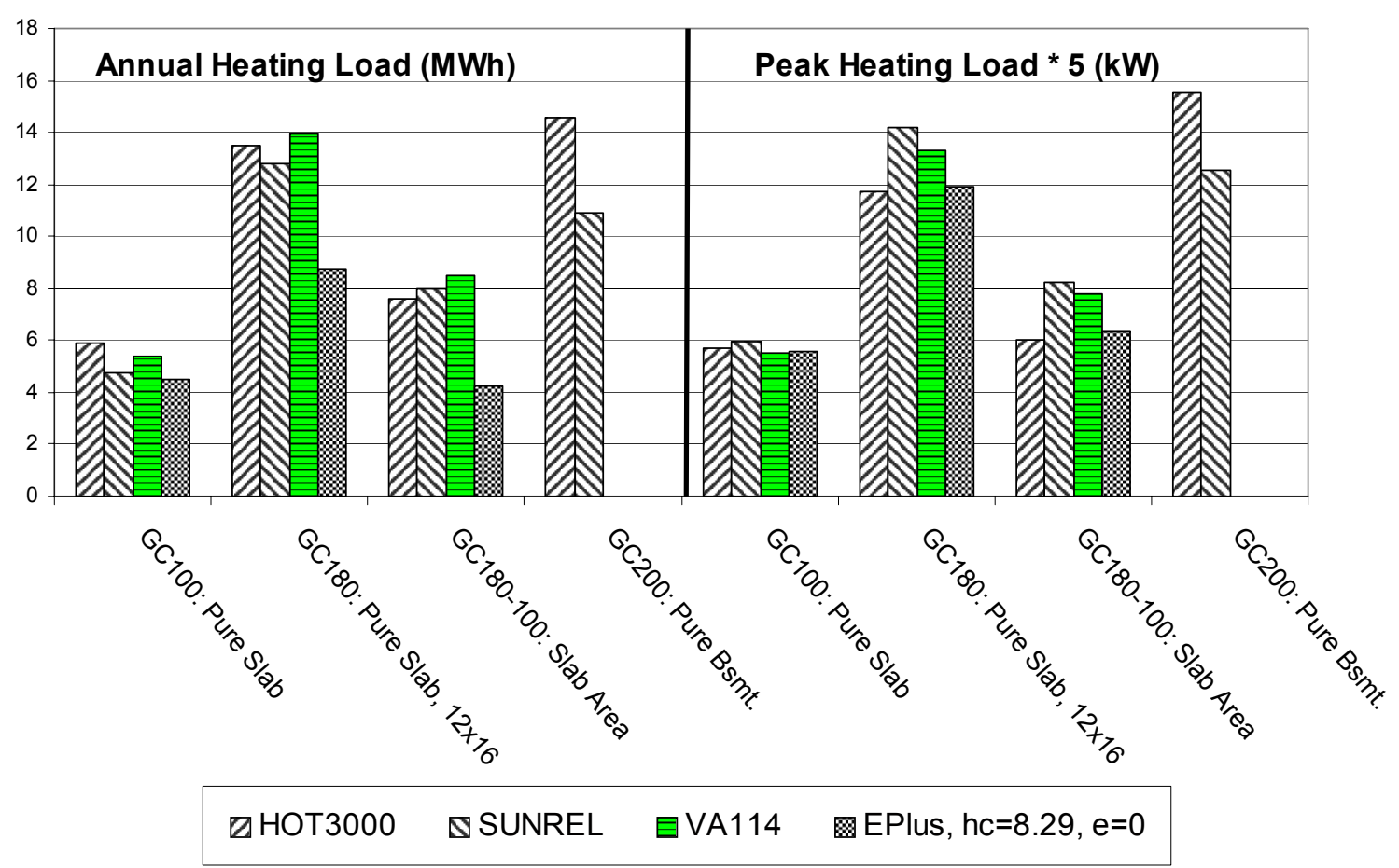


Appendix B2: Results of VA114 for IEA BESTEST In-Depth Diagnostic Cases

- 09 May 2006

Output spreadsheet for Ground Coupling InDepth Diagnostic cases: GC-InDepth-Out-0505-20060509.XLS.

Remark:

Imported in spreadsheet GC-Results040806+PeerRev-20060509.XLS a comparison with results of other programs can be made; an example plot is included below.

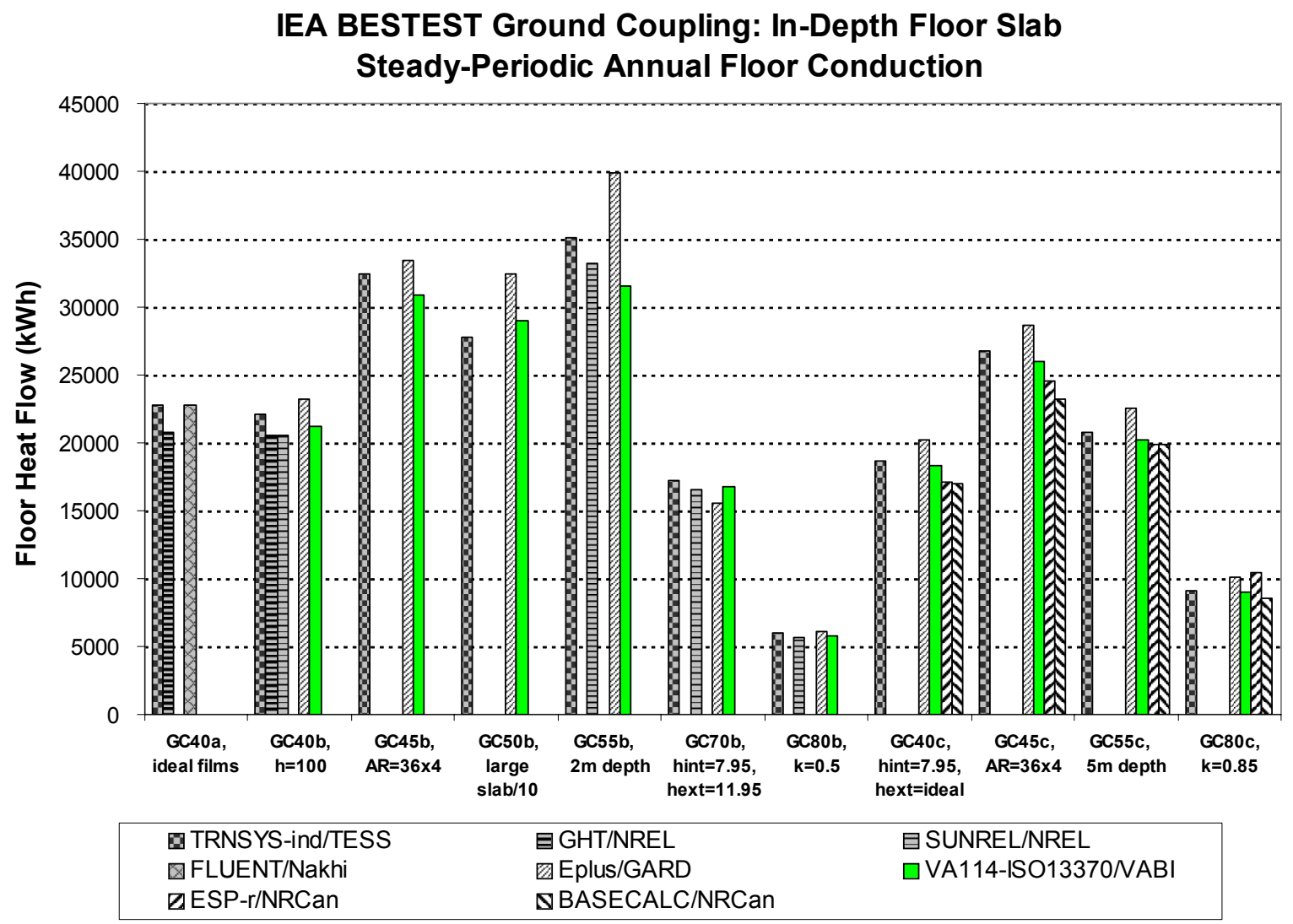

[Editors note: updated final results comparisons are included in Part III of this report.] 


\title{
Appendix II-G
}

\section{Modeler Report for BESTEST Cases GC10a-GC80c SUNREL-GC Version 1.14.01}

\author{
by \\ Michael Deru \\ National Renewable Energy Laboratory \\ United States
}

January 2006

\section{Introduction}

This report documents the use of the SUNREL-GC version 1.14.01 building energy simulation program to perform detailed modeling of the new ground-coupling cases for IEA BESTEST. This is a special version of SUNREL coupled with a ground-coupled heat transfer program called GHT. GHT can be run independently or integrated with SUNREL. The work was completed at NREL, Golden, Colorado, US.

GHT was created specifically for ground heat transfer and uses finite element analysis to model 2-D or 3D heat-conduction problems (Deru 2003). All analyses completed for this report used 3-D linear hexahedron elements. GHT uses an explicit solution method for the 3-D calculations, which reduces the storage requirements and avoids matrix inversions required for an implicit solution. The time step used in the explicit solution can be fixed at a even divisions or fixed at a set of variable divisions. For example, when the program is run with hourly data, the hour can be divided into even divisions of [editor's note: remainder of sentence missing].

GHT allows many options for boundary conditions, including detailed atmospheric boundary conditions with convection, evapotranspiration, short-wave radiation, and long-wave radiation exchange with the environment; simple atmospheric boundary conditions with convection and short-wave radiation; mixed convection and heat flux, or defined temperature. A special boundary condition for GC10 was created to simulate the linear temperature variation across the wall. The convection and evapotranspiration models include the effects of the surface cover. The rate of evapotranspiration is taken as a user defined fraction of the potential value since the moisture at the ground surface is not known. The long-wave radiation model accounts for cloud cover as read from the weather file. The model does not account for shading or snow cover.

In SUNREL-GC, GHT models the 3-D heat transfer in the ground and in the concrete floors in contact with the ground. Each hour SUNREL calls GHT with the new weather parameters, interior solar gains, and zone air temperature inputs. GHT uses this information to calculate the new surface temperatures for the hour, which are passed back to SUNREL. SUNREL then performs the energy balance on the zone air node on sub hourly time steps.

\section{Modeling Assumptions}

In GC10, GHT cannot model a semi-infinite solid. A lower boundary must be chosen and a boundary condition applied to it. The temperature of the lower boundary was maintained at $10^{\circ} \mathrm{C}$ to match the 
surface temperature, and the depth of the lower boundary was varied from $10 \mathrm{~m}$ to $25 \mathrm{~m}$. The results of the varying the depth are presented in Section 5. Other modeling assumptions that differ from the case specifications are noted in the Sections 3 and 4.

\section{Modeling Options}

All cases were modeled to the specifications execpt the walls and as noted in Section 4. The walls were modeled as massless with a thermal reistence of $10,000 \mathrm{~m}^{2} \cdot \mathrm{K} / \mathrm{W}$. This provides effectively adiabatic walls and roof. This was verified in the SUNREL output by zero heat flows through the walls.

\section{Modeling Difficulties}

The most notable difficulty in modeling the cases was the inability to use extremely high convection heat transfer coefficients. High convection coefficients made the solution unstable and resulted in incorrect answers. The convection coefficients were limited to less than $120 \mathrm{~W} / \mathrm{m}^{2} \cdot \mathrm{K}$. The reason for this is unclear and requires further investigation. The interior convection heat transfer coefficient was set to 100 $\mathrm{W} / \mathrm{m}^{2} \cdot \mathrm{K}$ for cases GC $30-\mathrm{GC} 55$. The exterior convection heat transfer coefficient was calculated from the wind speed, ground roughness, and terrain. The ground roughness was adjusted to get a value of 117 $\mathrm{W} / \mathrm{m}^{2} \cdot \mathrm{K}$ for cases GC30-GC60. Previous experience with a 2-D finite element code suggests that using $\mathrm{h}$ $=100 \mathrm{~W} / \mathrm{m}^{2} \cdot \mathrm{K}$ instead of $\mathrm{h}=5000 \mathrm{~W} / \mathrm{m}^{2} \cdot \mathrm{K}$ can introduce an error of up to $3 \%$. The interior coefficient was set to $1 \mathrm{~W} / \mathrm{m}^{2} \cdot \mathrm{K}$ for GC60-GC70 and the outside coefficient was set to 17 for GC65-GC70.

Cases GC45 and GC50 were not modeled due to insufficient time to generate the mesh and run the cases. GC50 will require a very large mesh and long simulation times.

GHT does not allow for the calculation of temperatures that are not at nodal points; therefore, the surface temperature output requirements. Modifications to the program to calculate these temperatures were initiated but there was not enough time to complete the modifications. The work should be completed for any future rounds of simulations.

\section{Demonstration of Appropriate Level of Modeling Detail}

Four meshes were created to explore the effects of the deep ground and the far-field boundaries. The meshes were labeled A-D. All the meshes only modeled one-fourth of the slab and soil. The meshes are summarized in Table 2G-1. The element sizes varied throughout the mesh with small elements at the surface and near the exterior walls. The size of the elements was based on previous experience. The depth of the first element at the surface was $3.5 \mathrm{~cm}$ and then expanded with depth. The dimensions of the elements in the $\mathrm{X}$ and $\mathrm{Y}$ directions varied similarly near the exterior walls.

Table 2G-1 Mesh Dimensions used for GC10

\begin{tabular}{|l|c|c|c|c|}
\hline Mesh & $\begin{array}{c}\text { Deep Ground } \\
(\mathbf{m})\end{array}$ & $\begin{array}{c}\text { Far-field } \\
(\mathbf{m})\end{array}$ & Nodes & Elements \\
\hline \hline A & 10 & 10 & 19,456 & 17,298 \\
\hline B & 15 & 15 & 26,950 & 24,276 \\
\hline C & 20 & 15 & 30,625 & 27,744 \\
\hline D & 25 & 20 & 40,432 & 36,963 \\
\hline
\end{tabular}


The total floor heat loss for each of the meshes is shown in Figure 2G-1 for case GC10. The figure also shows the difference in the annual heat loss compared to mesh $\mathrm{D}$. The difference between meshes $\mathrm{C}$ and $\mathrm{D}$ is less than $0.1 \%$ through year 6 , but it continues to rise slowly and would exceed $0.1 \%$ in year 7 . The other comparison to make is from year to year with the same mesh. Looking at the heat transfer for the last hour of one year to the last hour of the previous year, both meshes $\mathrm{C}$ and $\mathrm{D}$ are less than $0.1 \%$ in year 5. From these results mesh $\mathrm{C}$ was selected to use with the remaining runs. The simulations times for all the runs was approximately one hour per year of simulation on a $3 \mathrm{GHz}$ personal computer.

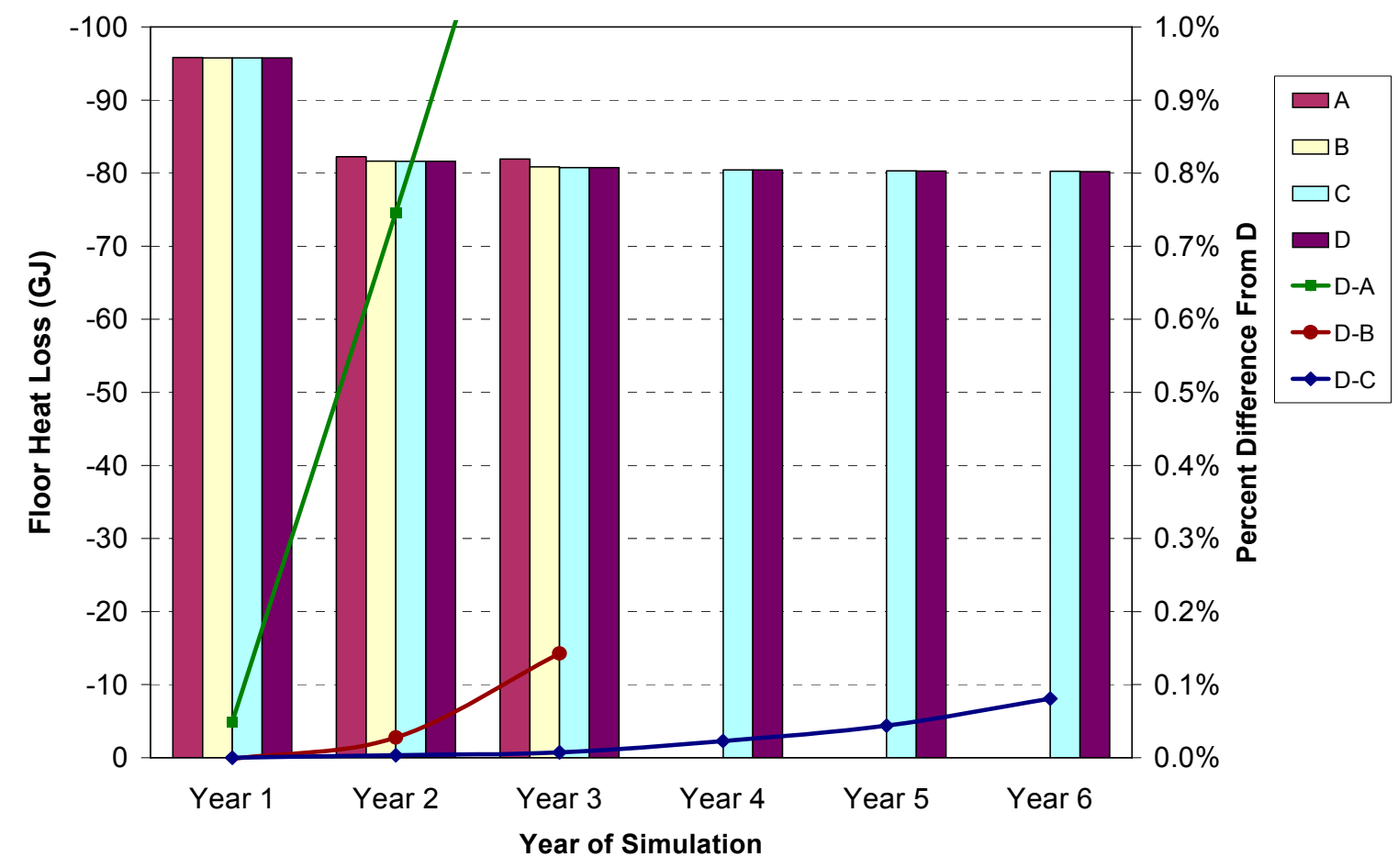

Figure 2G-1 Total floor heat loss for GC10 and comparison with mesh D

6. Software Errors Discovered, and/or Comparison Between Different Versions of the Same Software, and/or Lessons Learned Regarding Use of Detailed Models

\section{Results}

8. Other (optional)

\section{Conclusions and Recommendations}

\section{References}

Deru, M. (2003). A Model for Ground-Coupled Heat and Moisture Transfer From Buildings. NREL/TP550-33954. Golden, CO: National Renewable Energy Laboratory.

Deru, M., R. Judkoff, and J. Neymark. (2003). "Whole-Building Energy Simulation with a ThreeDimensional Ground-Coupled Heat Transfer Model," NREL/CP-550-32690. presented at the ASHRAE Winter Meeting January 25-29, 2003. 


\section{Appendix A: Model Geometry and Thermal Property Allowed Inputs}

Model Geometry and Thermal Property Allowed Inputs (pro forma)

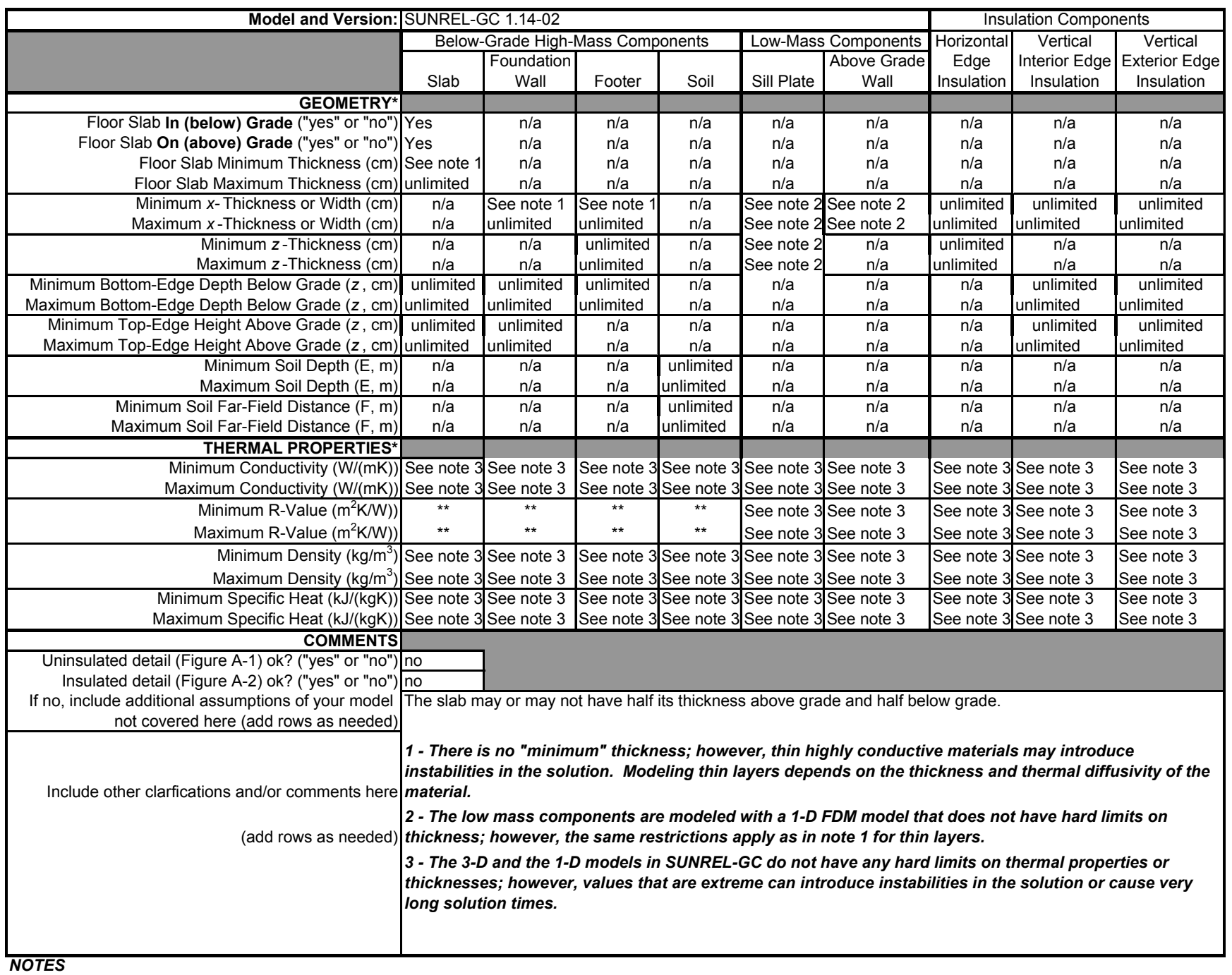

"n/a": not applicable

* If a listed input does not apply to your model, enter " 0 " in the relevant cells.

${ }^{* *}$ For below grade high-mass components, only list $R$-value input limits if there is some difference versus what would be calculated based on listed conductivity and thickness limits 


\subsection{Part III: Simulation Field Trial Results}

\subsection{Introduction}

Here we present the simulation results for the field trials of cases GC10a-GC80c; see Section 3.4 for graphs and tables. These are results after numerous iterations to incorporate clarifications to the test specification, simulation input deck corrections, and simulation software improvements. Where improvements to simulation programs or simulation inputs were made as a result of running the tests, such improvements must have mathematical and physical bases and must be applied consistently across tests. Also, all improvements were required to be documented in modeler reports. Arbitrary modification of a simulation program's input or internal code just for the purpose of more closely matching a given set of results is not allowed. The diagnostic process of trapping bugs discussed in Section 2.4 of Part II also isolated input errors that were corrected, as noted there and in the modeler reports (Part II, Section 2.9).

Table 3-1 summarizes the following information for the nine models and the Case GC10a analytical solution that were implemented by the nine organizations that participated in this project: model-authoring organization, model testing organization ("Implemented by"), and abbreviation labels used in the results graphs and tables.

\subsection{Zone Heating Load versus Floor Conduction Results}

Heat conducted through the floor slab should be equal to the zone-heating load because the test cases specify adiabatic above-grade walls and ceiling such that heating zone air to maintain the thermostat set point drives all heat losses through the floor. The verified numerical models (quasianalytical solutions) were run independently of whole-building energy simulation models, where for the "b"-series and "c"-series cases the zone air temperature is input to those models as an inside boundary condition for an interior convective surface coefficient (thermal resistance between the zone air and floor slab surface). Therefore, verified numerical-model results are included with the floor conduction results only. However, for whole-building simulation programs that do not disaggregate floor conduction in their output, the zone heating load results are directly comparable to the floor conduction results. Minor differences in zone heating load versus floor conduction may occur if a simulation program cannot model strictly adiabatic abovegrade walls and ceilings, but rather is applying the lowest thermal conductance the simulation allows.

\subsection{Multi-Year Versus Single-Year Simulation Runs}

Because of the large thermal mass of the ground adjacent to the floor slab, ground-coupled heat transfer calculations have a large time constant. The modeler reports for the detailed numerical models used as a secondary mathematical truth standard (see Part II, Section 2.9, Appendices IIA, II-B, and II-C) indicate $2 \%-17 \%$ reduction of heat transfer for the second versus first year of simulation, $0.7 \%-1.1 \%$ reduction for the third versus second year, $0.4 \%$ reduction for the fourth versus third year, and so forth. Differences in definition of initial conditions within the ground by the modelers may be the primary cause of variation in the first years of simulation. A groundcoupled heat transfer modeling method that applies a single-year simulation run is likely to produce results more quickly (with less computer processing time), and may be more easily adaptable to a whole-building energy simulation program. However, such a model may be less accurate than a multi-year simulation if multi-year thermal capacitance effects or appropriate initial conditions within the ground are not considered. As required by the test specification, 
results are given only for the final year simulated by a given model. Number of years simulated by the software tools for each test case is included within the following data tables.

Table 3-1. Participating Organizations and Models

\begin{tabular}{|c|c|c|c|}
\hline $\begin{array}{l}\text { Analytical Solution, } \\
\text { Case GC10a }\end{array}$ & Authoring Organization & Implemented by & Abbreviation \\
\hline $\begin{array}{l}\text { Delsante, Stokes, and } \\
\text { Walsh (1983) }\end{array}$ & CSIRO, ${ }^{a}$ Australia & $\begin{array}{l}\text { NREL/JNA, }{ }^{\mathrm{b}, \mathrm{c}} \text { United } \\
\text { States }\end{array}$ & $\begin{array}{l}\text { Analytical } \\
\text { Solution/CSIRO }\end{array}$ \\
\hline $\begin{array}{l}\text { Verified Numerical } \\
\text { Model }\end{array}$ & Authoring Organization & Implemented by & Abbreviation \\
\hline FLUENT 6.0.20 & $\begin{array}{l}\text { Fluent, Incorporated, United } \\
\text { States }\end{array}$ & PAAET, ${ }^{d}$ Kuwait & FLUENT/PAAET \\
\hline $\begin{array}{l}\text { MATLAB 7.0.4.365 } \\
(\mathrm{R} 14)\end{array}$ & $\begin{array}{l}\text { The Math Works, Inc., United } \\
\text { States }\end{array}$ & $\begin{array}{l}\text { Dublin Institute of } \\
\text { Technology, Ireland }\end{array}$ & MATLAB/DIT \\
\hline TRNSYS 16.1 & $\begin{array}{l}\text { University of Wisconsin/TESS, } \\
\text { United States }\end{array}$ & TESS, ${ }^{\mathrm{e}}$ United States & TRNSYS/TESS \\
\hline Simulation Program & Authoring Organization & Implemented by & Abbreviation \\
\hline BASECALC V1.0e & CETC, ${ }^{f}$ Canada & CETC, ${ }^{f}$ Canada & BASECALC/NRCan \\
\hline EnergyPlus 2.0.0.025 & $\begin{array}{l}\text { LBNL/UIUC/DOE-BT, }{ }^{\text {g,h,i }} \text { United } \\
\text { States }\end{array}$ & $\begin{array}{l}\text { GARD Analytics, Inc., } \\
\text { United States }\end{array}$ & EnergyPlus/GARD \\
\hline ESP-r/BASESIMP & $\begin{array}{l}\text { CETC/ESRU, }{ }^{\mathrm{fj} j} \text { Canada/United } \\
\text { Kingdom }\end{array}$ & CETC, ${ }^{f}$ Canada & $\begin{array}{l}\text { ESP-r- } \\
\text { BASESIMP/NRCan }\end{array}$ \\
\hline GHT & NREL, ${ }^{\mathrm{b}}$ United States & NREL, ${ }^{\mathrm{b}}$ United States & GHT/NREL \\
\hline SUNREL-GC 1.14.01 & NREL, ${ }^{\mathrm{b}}$ United States & NREL, ${ }^{\mathrm{b}}$ United States & SUNREL-GC/NREL \\
\hline VA114 2.20/ISO-13370 & $\begin{array}{l}\text { VABI Software BV, The } \\
\text { Netherlands; CEN/ISO }\end{array}$ & $\begin{array}{l}\text { VABI Software BV, } \\
\text { The Netherlands }\end{array}$ & $\begin{array}{l}\text { VA114/ISO- } \\
\text { 13370/VABI }\end{array}$ \\
\hline
\end{tabular}

${ }^{\mathrm{a}}$ CSIRO: Commonwealth Scientific and Industrial Research Organisation, Australia

${ }^{b}$ NREL: National Renewable Energy Laboratory, United States

'JNA: J. Neymark \& Associates, United States

'PAAET: Public Authority for Applied Education and Training, Kuwait

${ }^{\mathrm{e} T E S S:}$ Thermal Energy Systems Specialists, United States

fCETC: CANMET Energy Technology Centre, Natural Resources Canada, Canada

gLBNL: Lawrence Berkeley National Laboratory, United States

hUIUC: University of Illinois Urbana/Champaign, United States

'DOE-BT: U.S. Department of Energy, Office of Building Technologies, Energy Efficiency and Renewable Energy, United States

'ESRU: Energy Systems Research Unit, University of Strathclyde, United Kingdom

${ }^{k}$ CEN: European Committee for Standardization, Belgium

ISO: International Organization for Standardization, Switzerland 


\subsection{Results Graphs and Tables}

This section presents graphs of the results first, followed by tables of the results. Verified numerical-model results are shown in the bar charts with blue shaded background bars, and the analytical solution result (Case GC10a) is shown with a magenta background bar. The X-axis labels of the accompanying graphs include abbreviated descriptions of the test cases. See Section 2.7 of Part II for definitions of the abbreviations and acronyms. Case descriptions are summarized in Tables 1-1 and 1-2 in Part I. The results tables include dates and hours of occurrences for hourly maxima and minima; times of occurrence are not indicated in the graphs depicting hourly maxima and minima.

An electronic version of these results is included with the accompanying files in the file GCInDepth-Results.xls, with its navigation instructions included in GC-InDepth-Results.doc. 
IEA BESTEST Ground Coupling: In-Depth Floor Slab Steady-State Floor Conduction

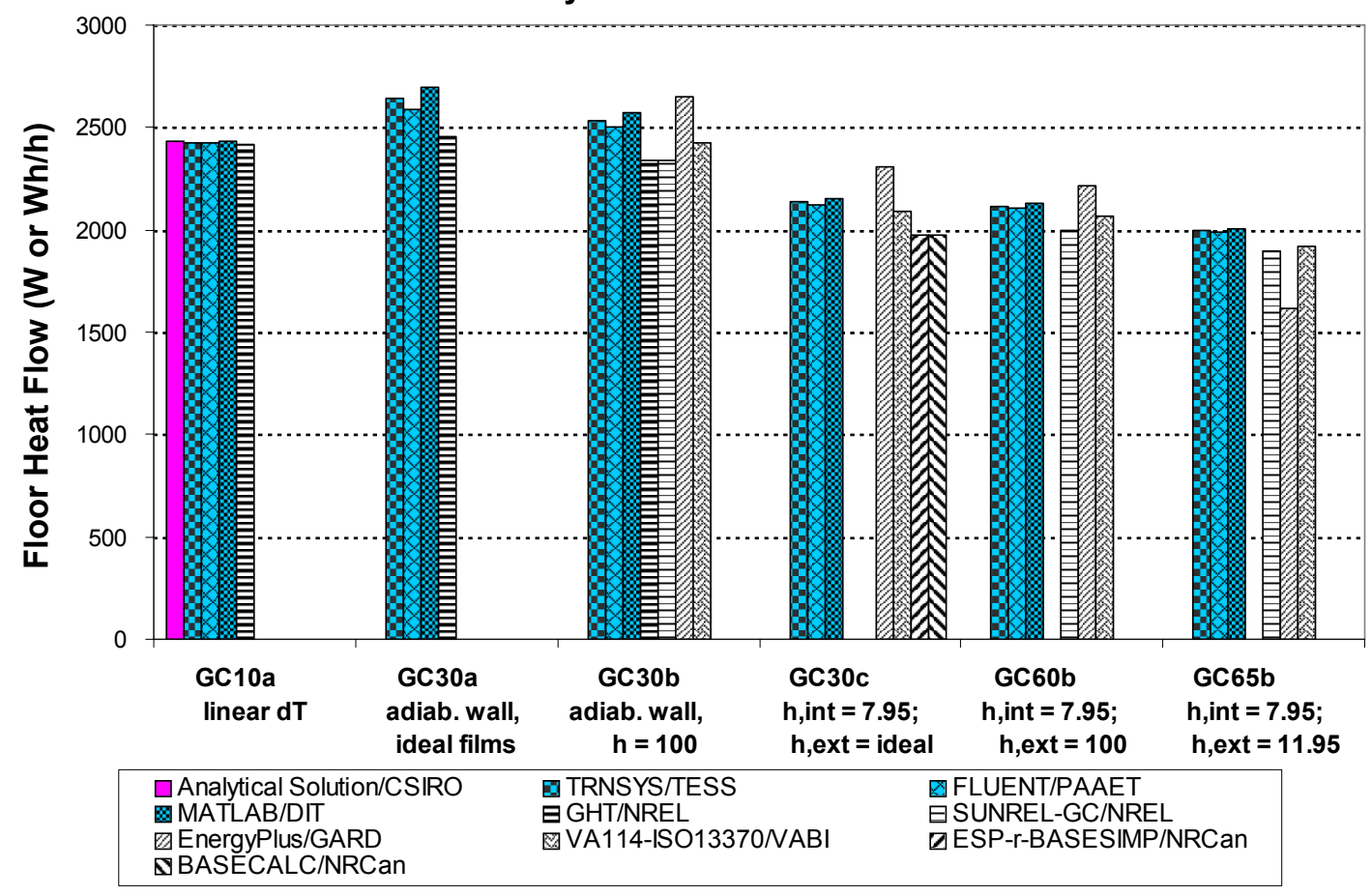

IEA BESTEST Ground Coupling: In-Depth Floor Slab Steady-State Floor Conduction Sensitivity

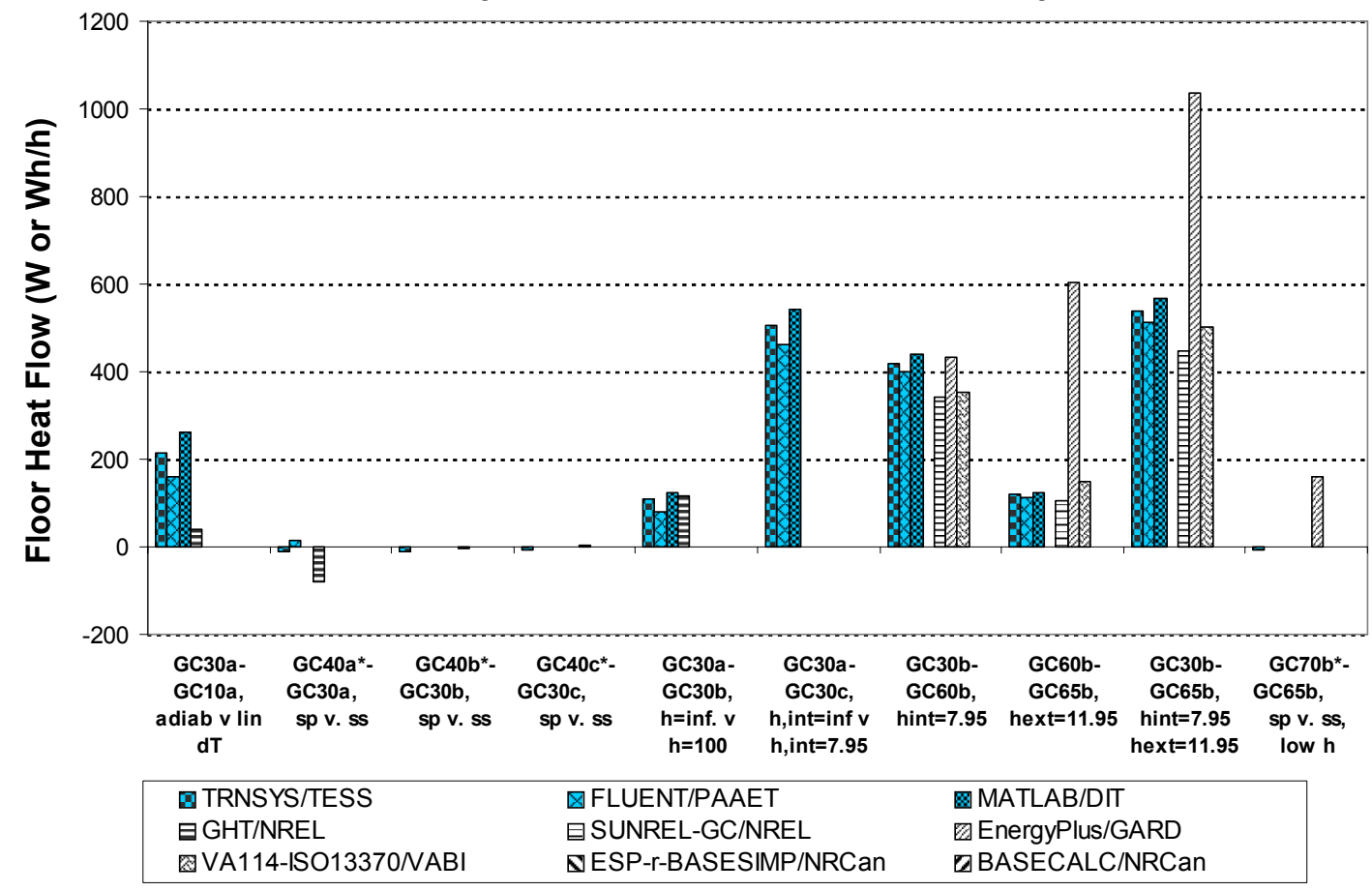

* Values for GC40a, GC40b, GC40c and GC70b are: annual total × $1000(\mathrm{~W} / \mathrm{kW}) / 8760(\mathrm{~h} / \mathrm{y})$ 

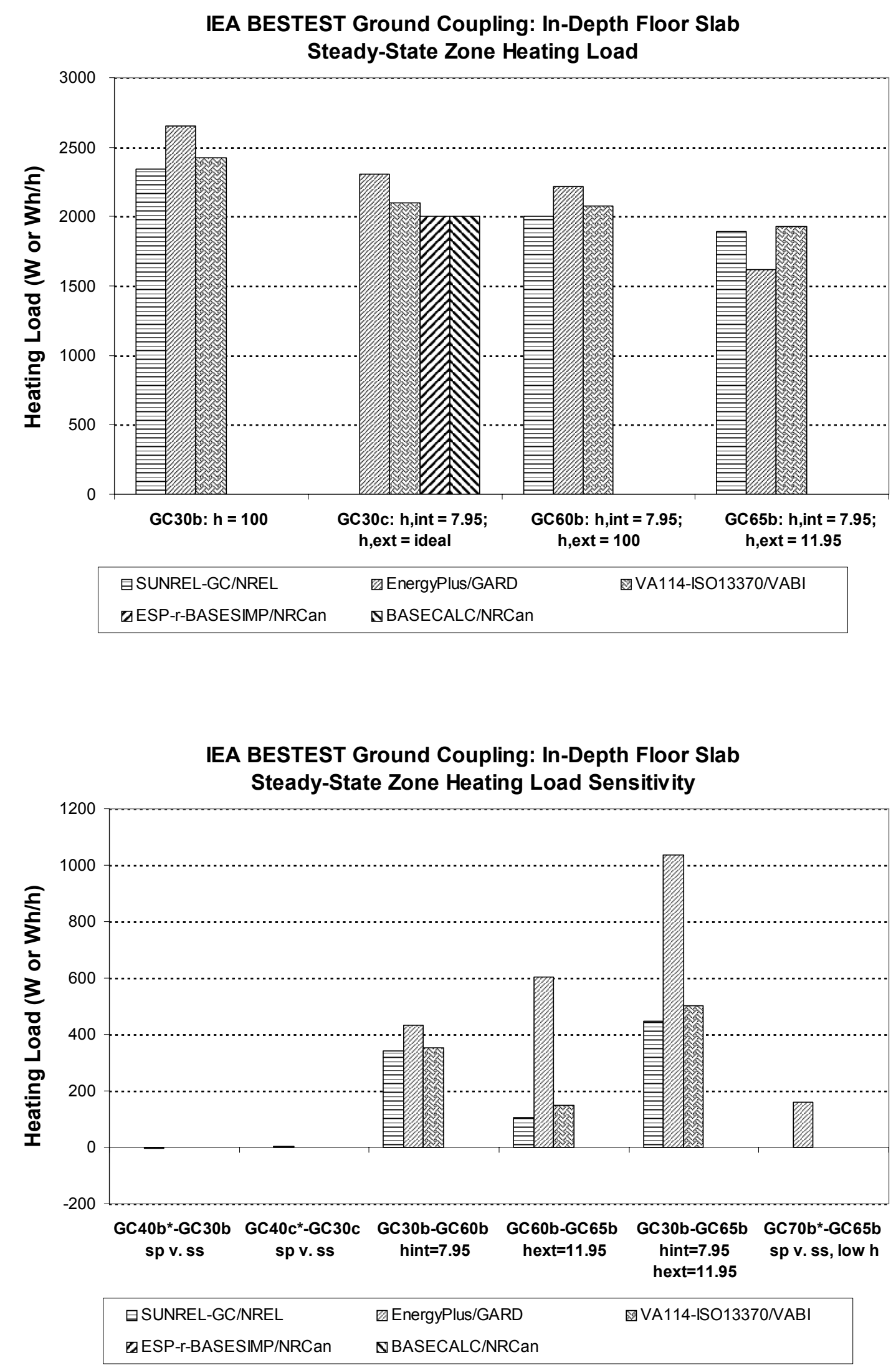

* Values for GC40b, GC40c and GC70b are: annual total × $1000(\mathrm{~W} / \mathrm{kW}) / 8760(\mathrm{~h} / \mathrm{y})$ 

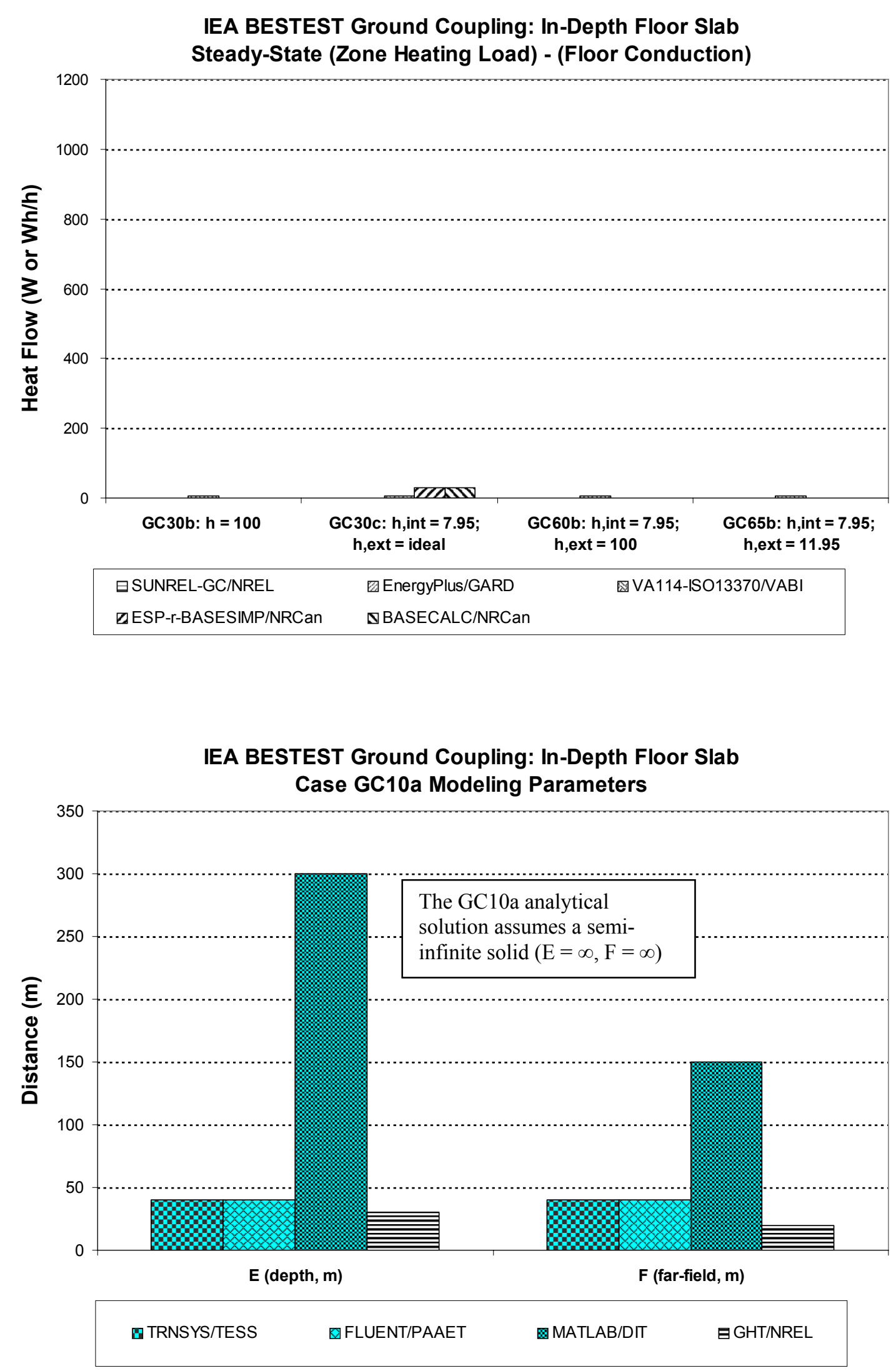
IEA BESTEST Ground Coupling: In-Depth Floor Slab

Steady-State Zone Temperature

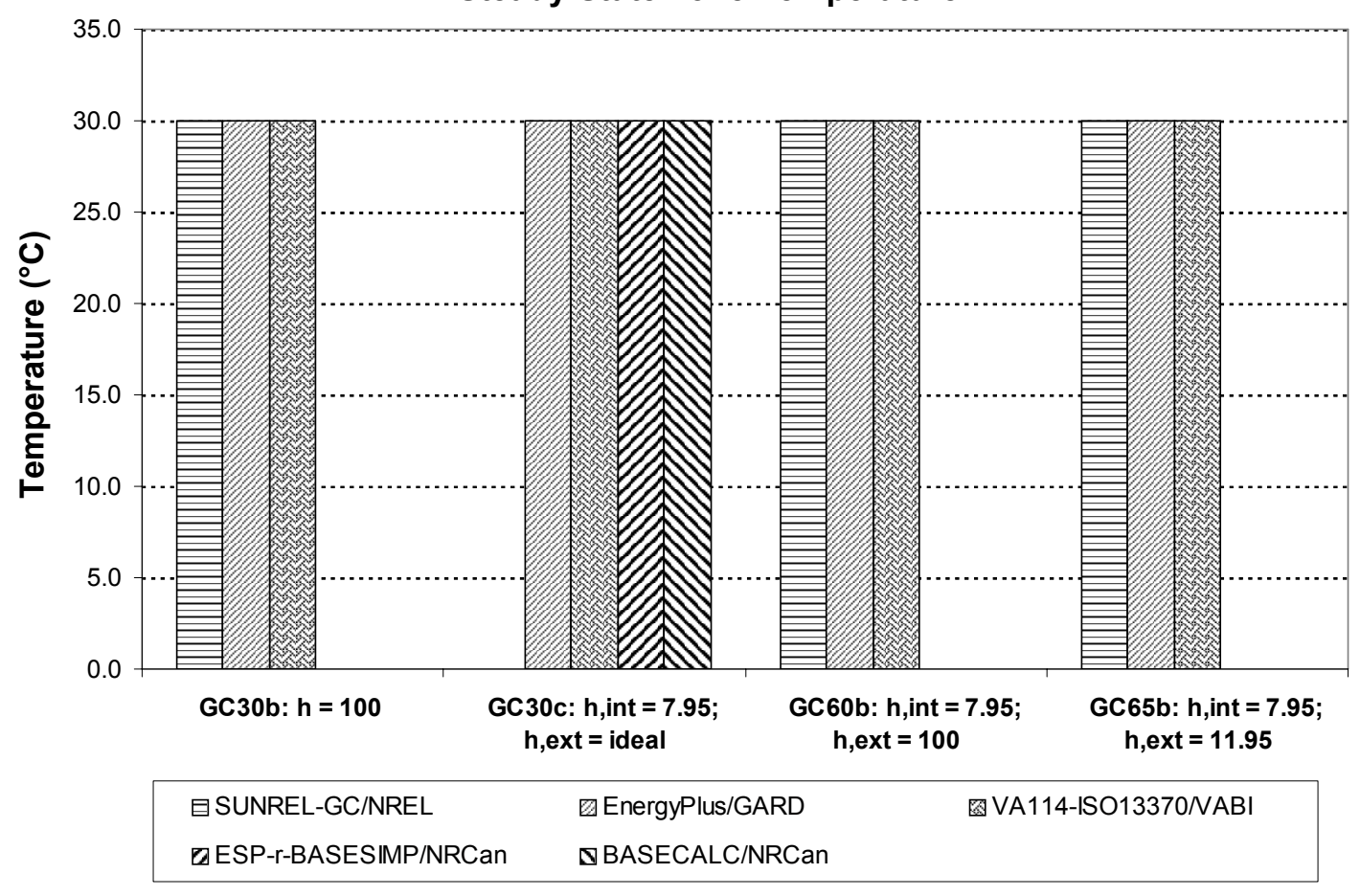


IEA BESTEST Ground Coupling: In-Depth Floor Slab, GC10a

Steady-State Surface Temperatures ( $Y=0$, thru edge center)

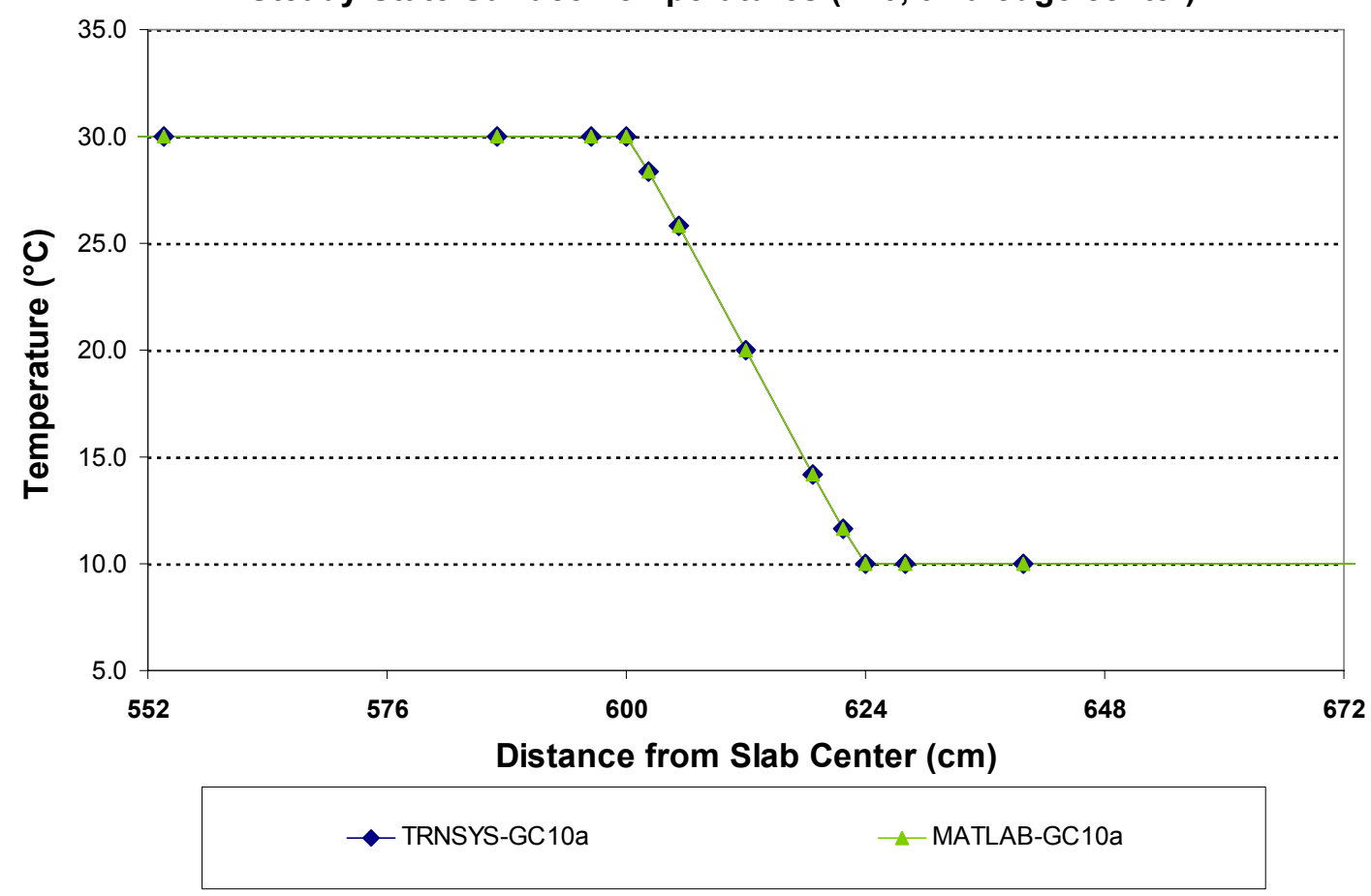

IEA BESTEST Ground Coupling: In-Depth Floor Slab, GC10a Steady-State Surface Temperatures ( $Y=X$, thru corner)

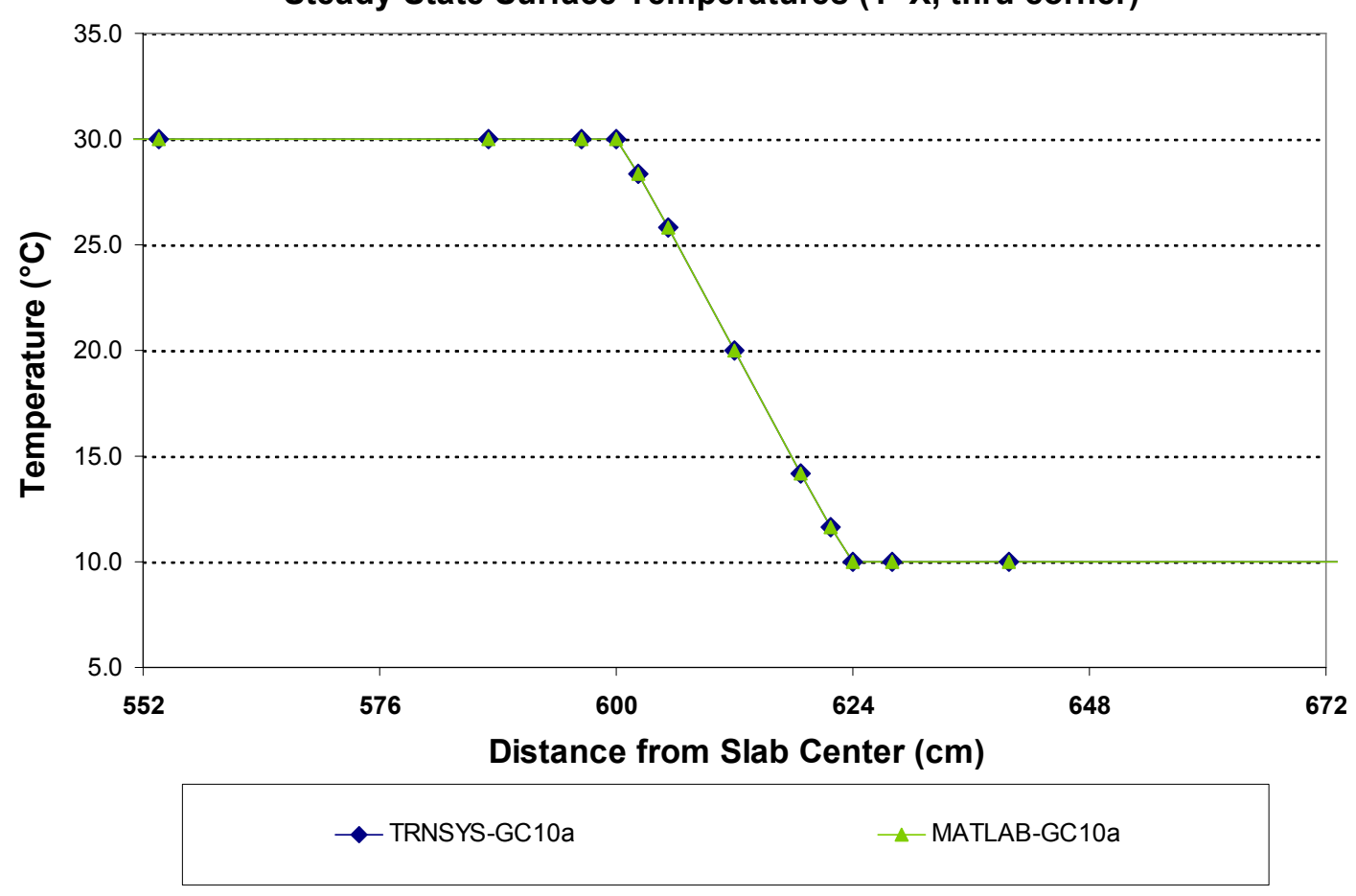


IEA BESTEST Ground Coupling: In-Depth Floor Slab, GC10a, GC30a

Steady-State Near-Surface Temperatures $(Y=0$, thru center of edge)

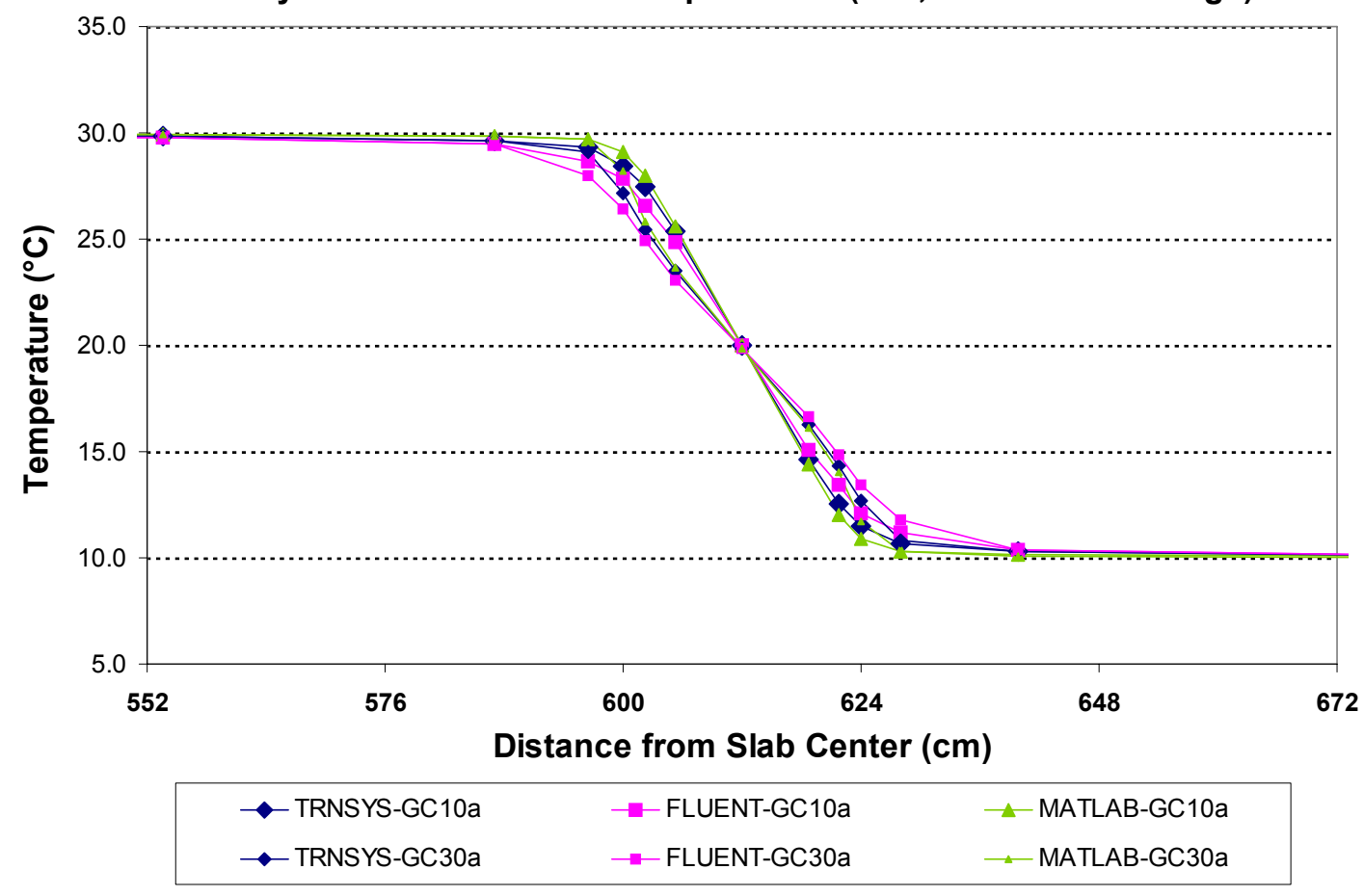

IEA BESTEST Ground Coupling: In-Depth Floor Slab, GC10a, GC30a Steady-State Near-Surface Temperatures ( $Y=X$, thru corner)

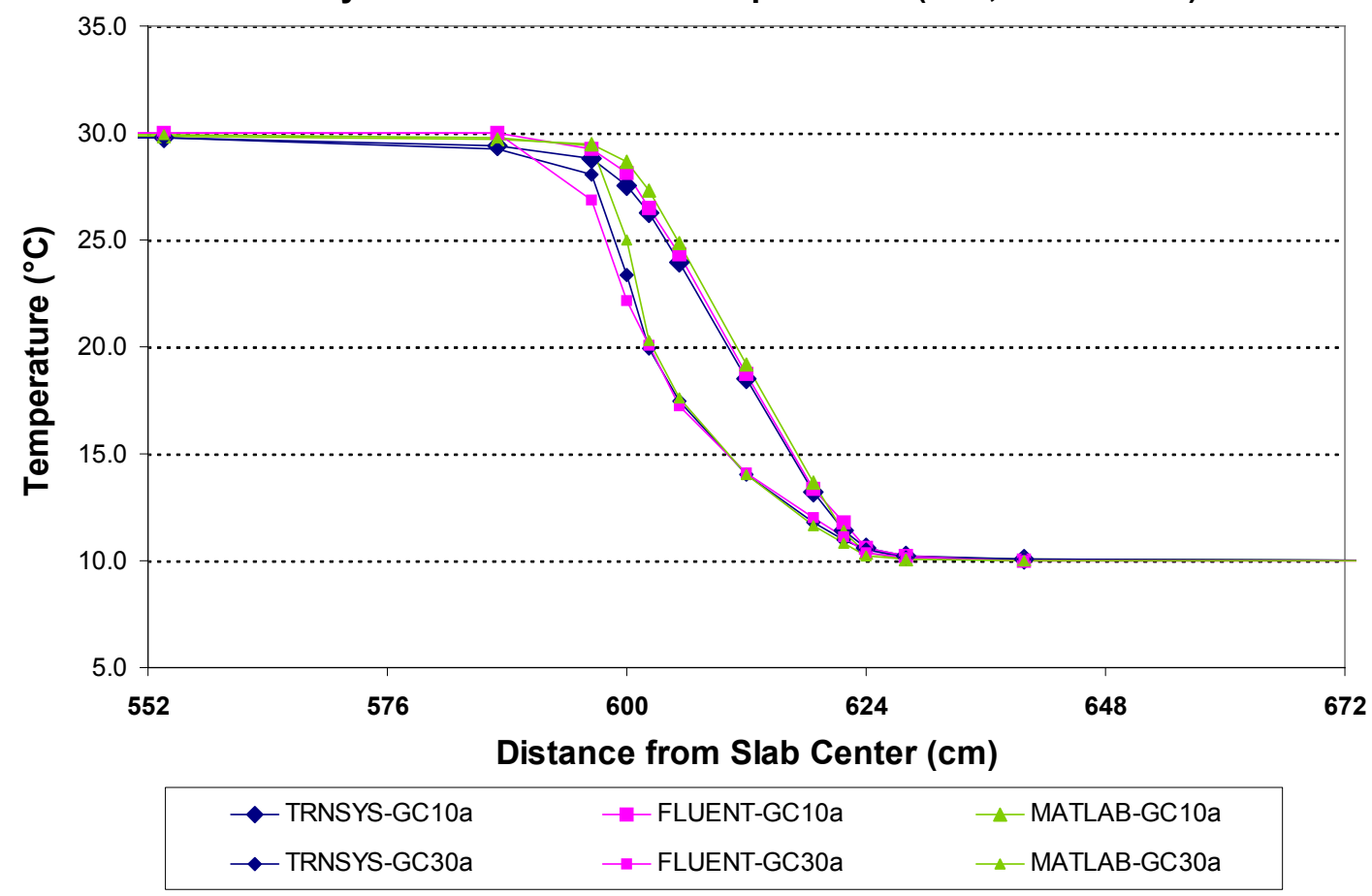


IEA BESTEST: In-Depth Floor Slab, GC30b, GC60b, GC65b Steady-State Near-Surface Temperatures ( $Y=0$, thru center of edge)

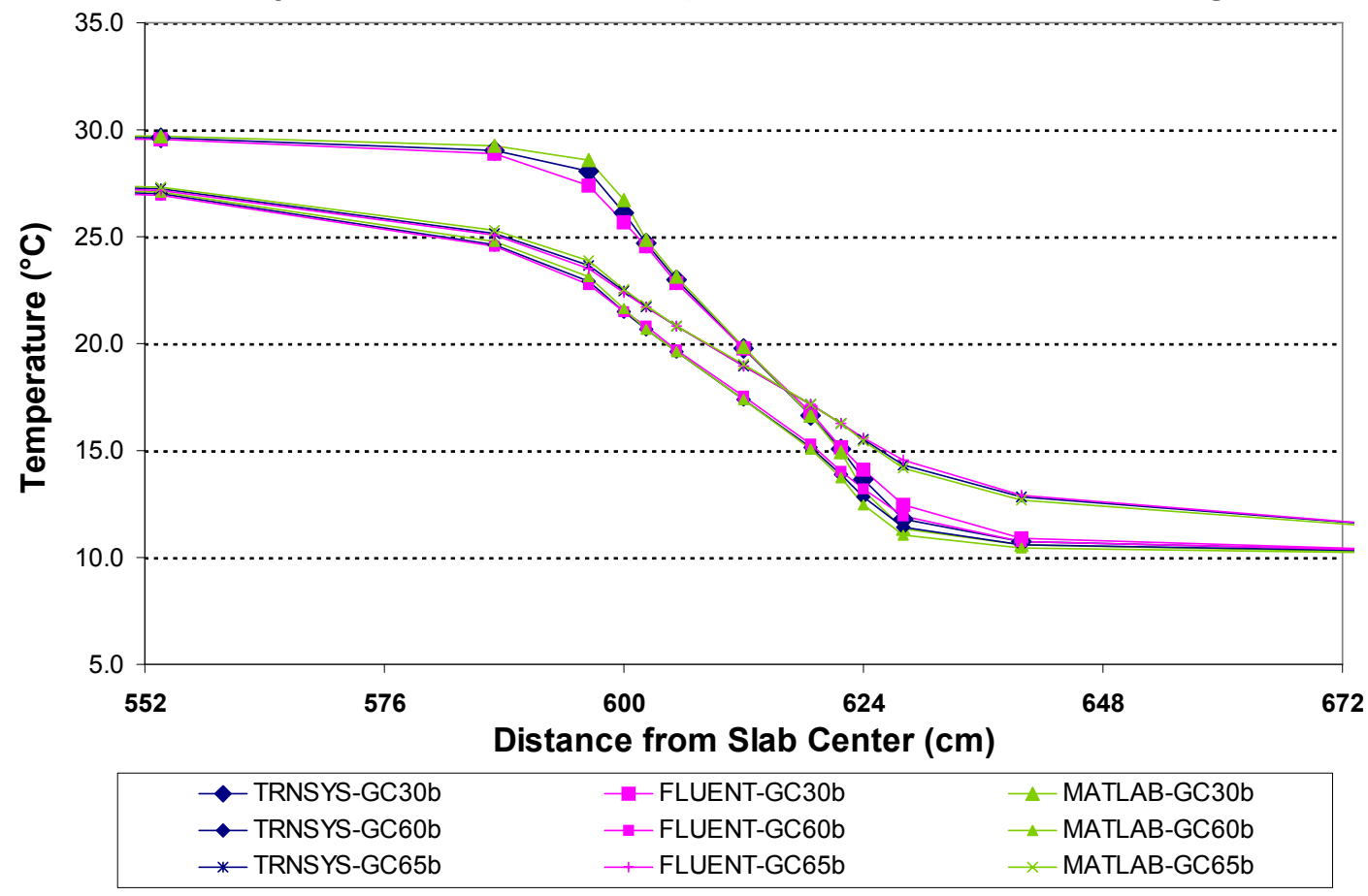

IEA BESTEST: In-Depth Floor Slab, GC30b, GC60b, GC65b Steady-State Near-Surface Temperatures ( $Y=X$, thru corner)

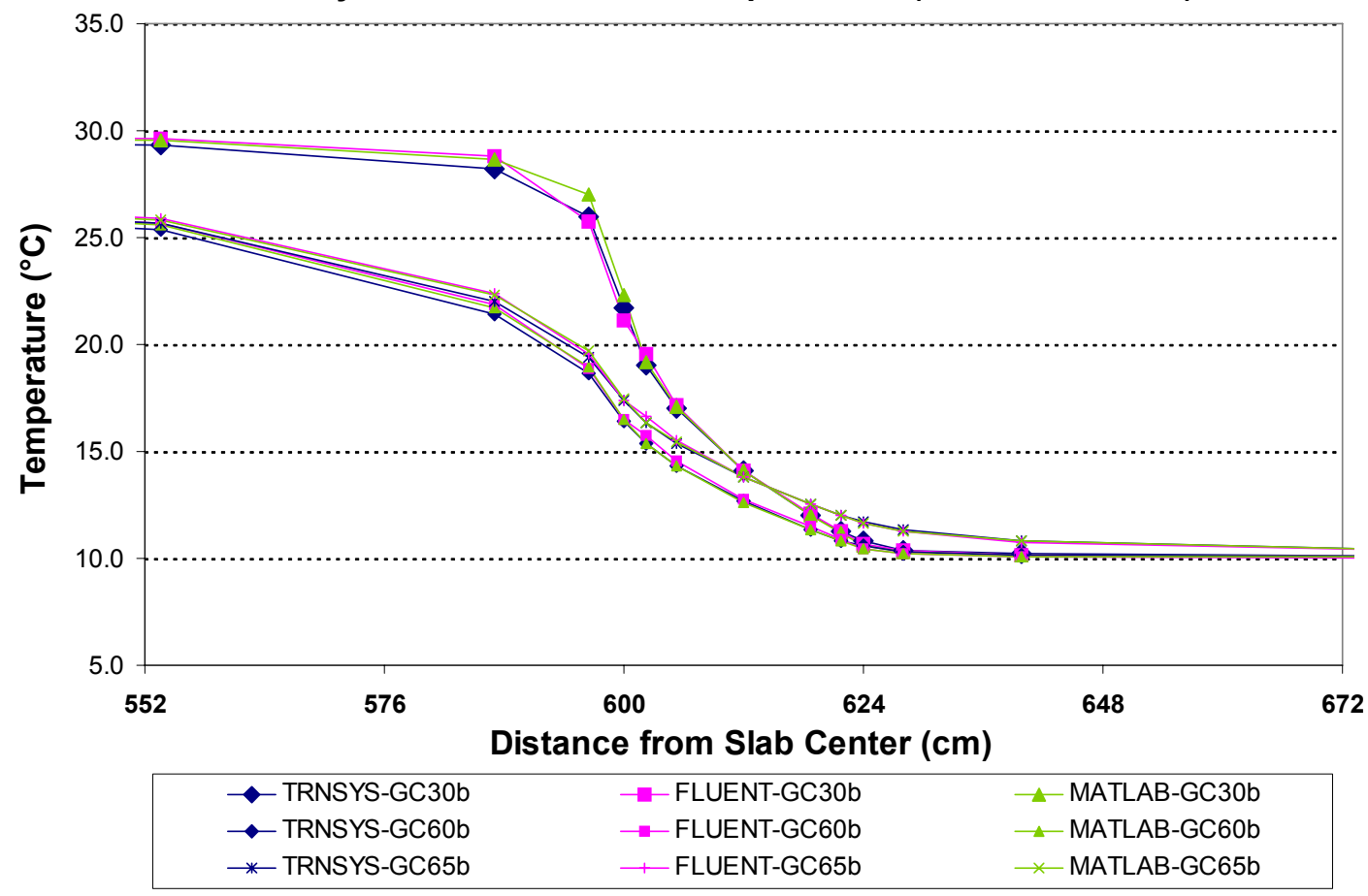




\section{IEA BESTEST Ground Coupling: In-Depth Floor Slab}

Steady-Periodic Annual Floor Conduction
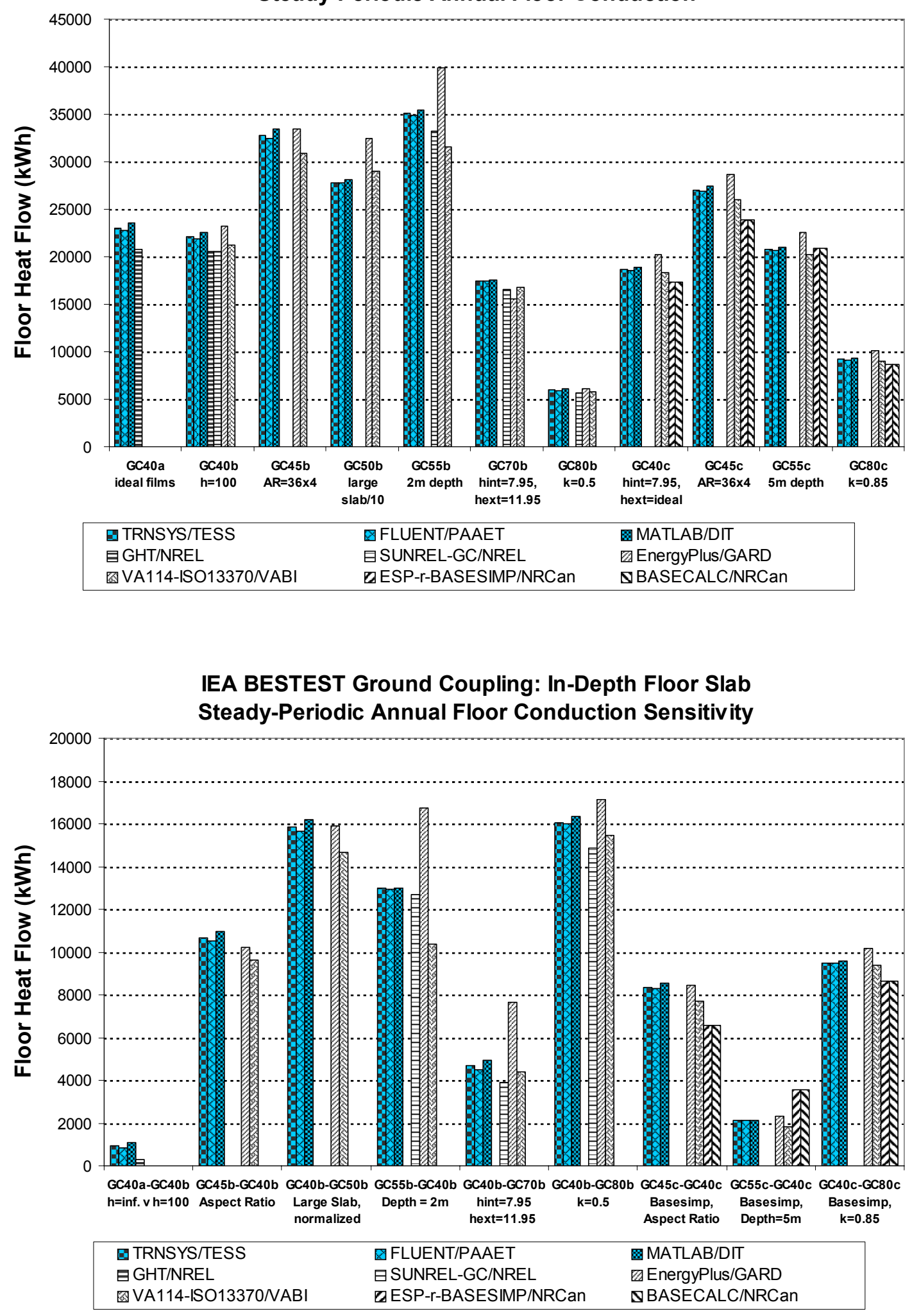

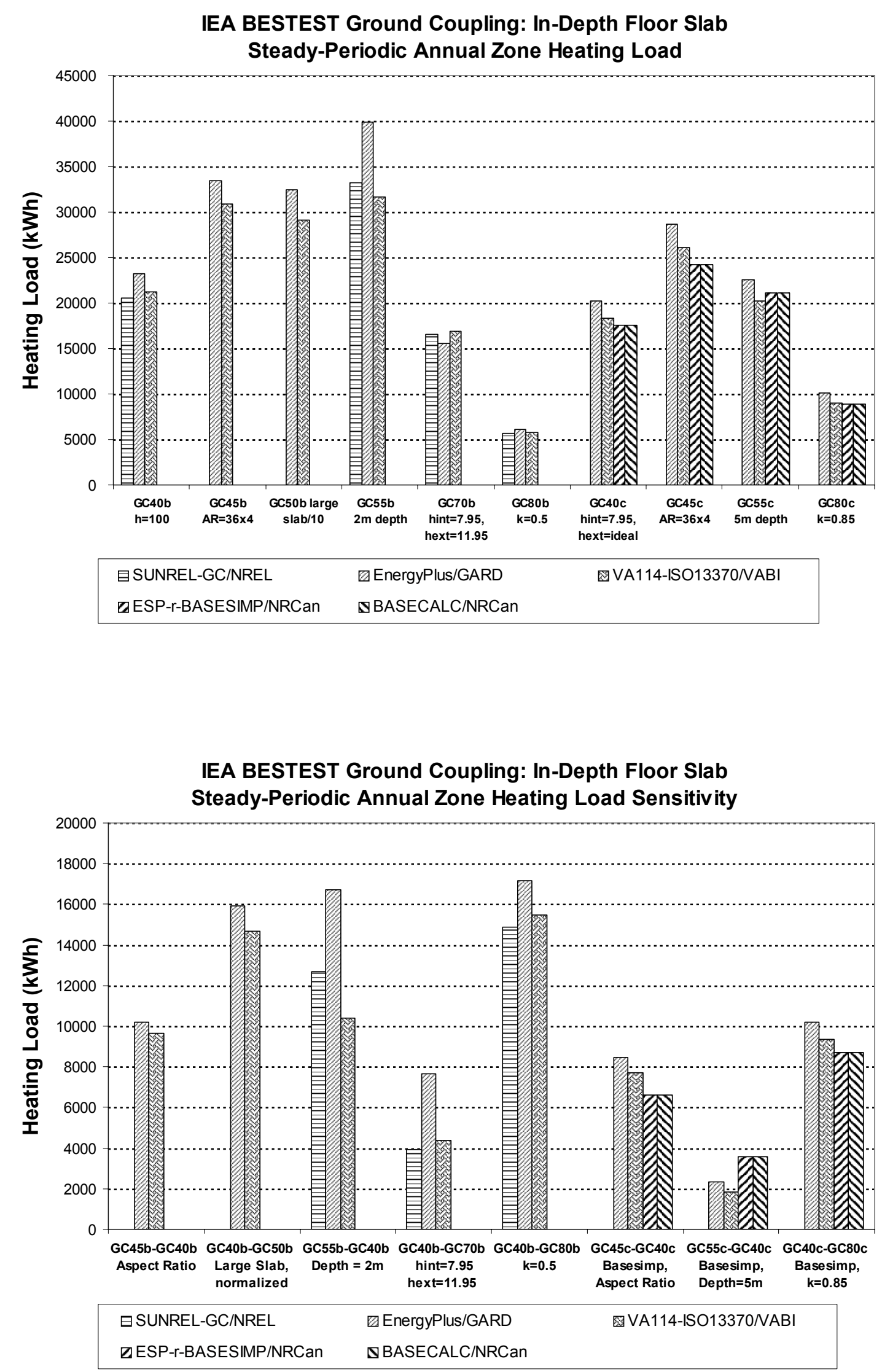
IEA BESTEST Ground Coupling: In-Depth Floor Slab

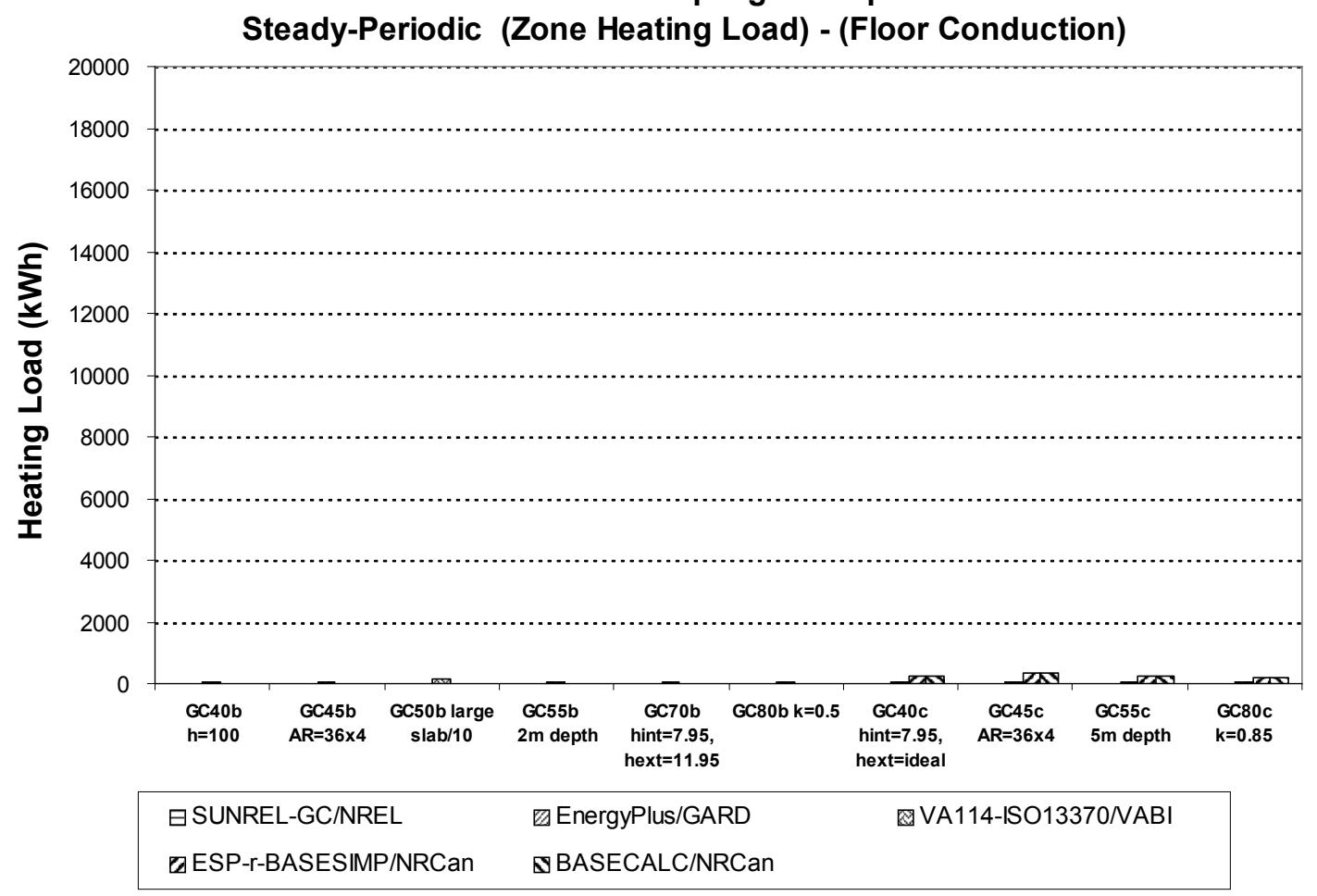

IEA BESTEST Ground Coupling: In-Depth Floor Slab Hourly Floor Conduction, GC40a

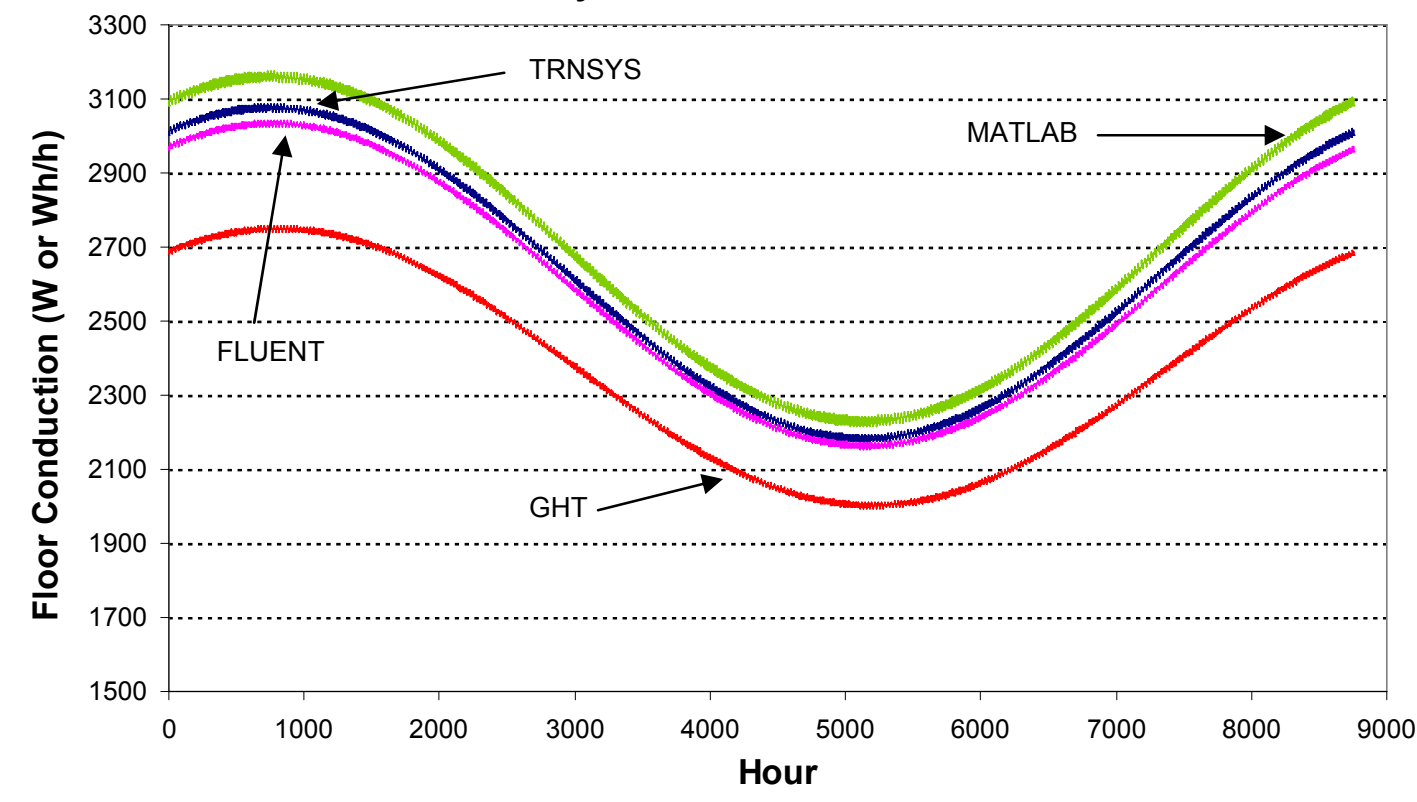

$\begin{array}{llll}\text {-TRNSYS } & \text { - FLUENT } & \text { MATLAB } & \text { - GHT }\end{array}$ 
IEA BESTEST Ground Coupling: In-Depth Floor Slab Hourly Floor Conduction, GC40b

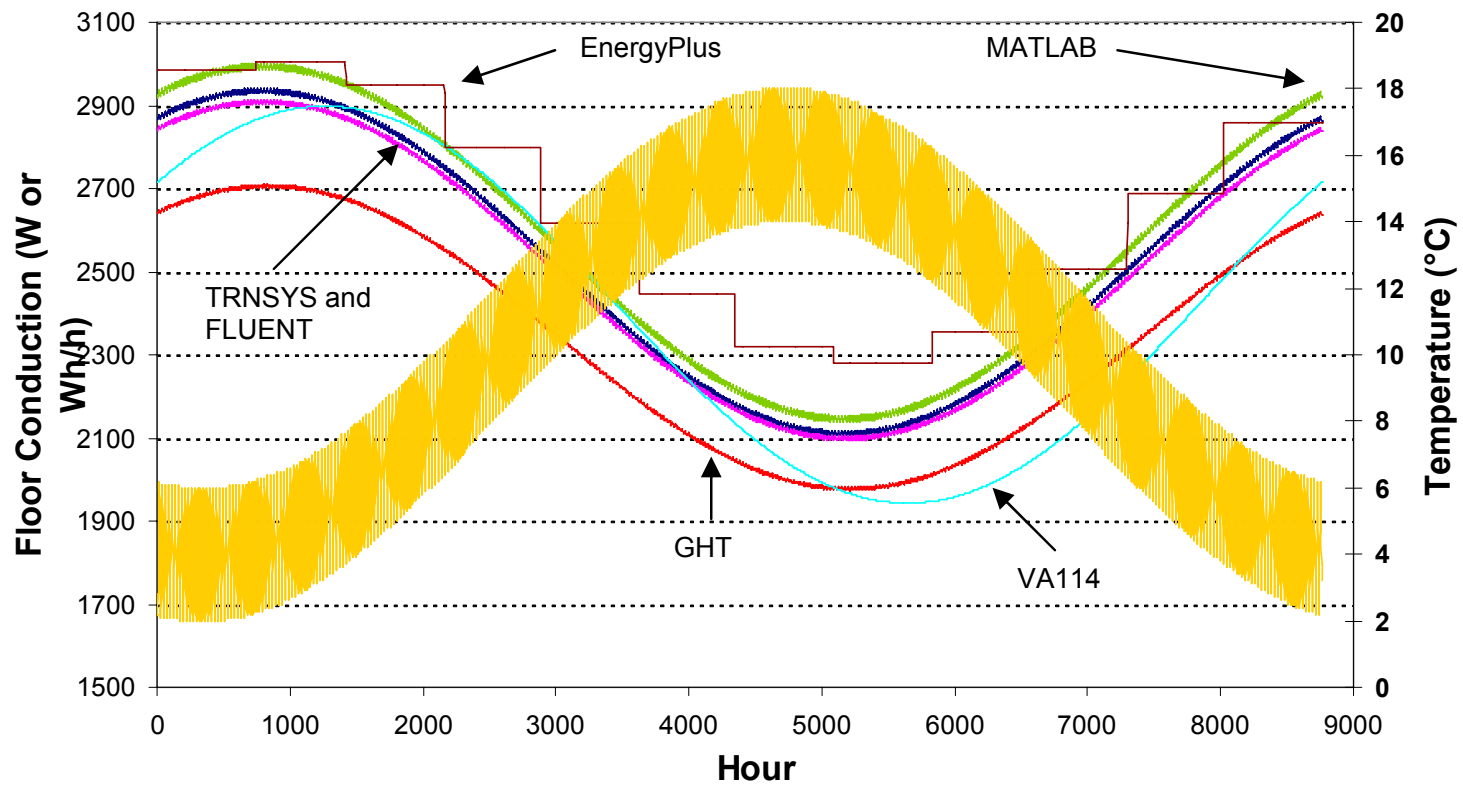

- TRNSYS - FLUENT - MATLAB — GHT —VA114 - EnergyPlus — ODB Temperature

IEA BESTEST Ground Coupling: In-Depth Floor Slab

Hourly Floor Conduction, GC40c

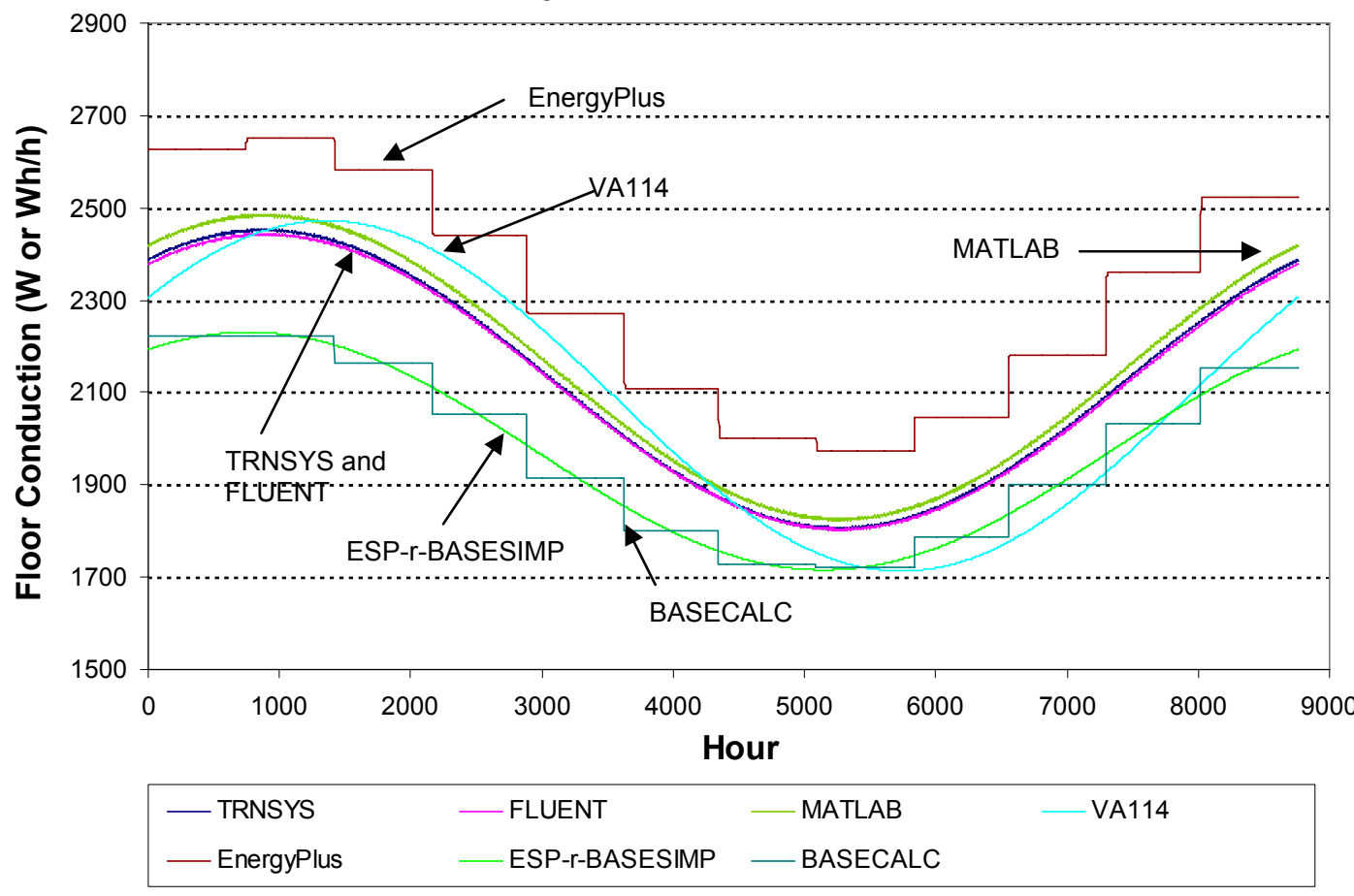


IEA BESTEST Ground Coupling: In-Depth Floor Slab Steady-Periodic Phase Shift, Coldest ODB to Peak Floor Conduction

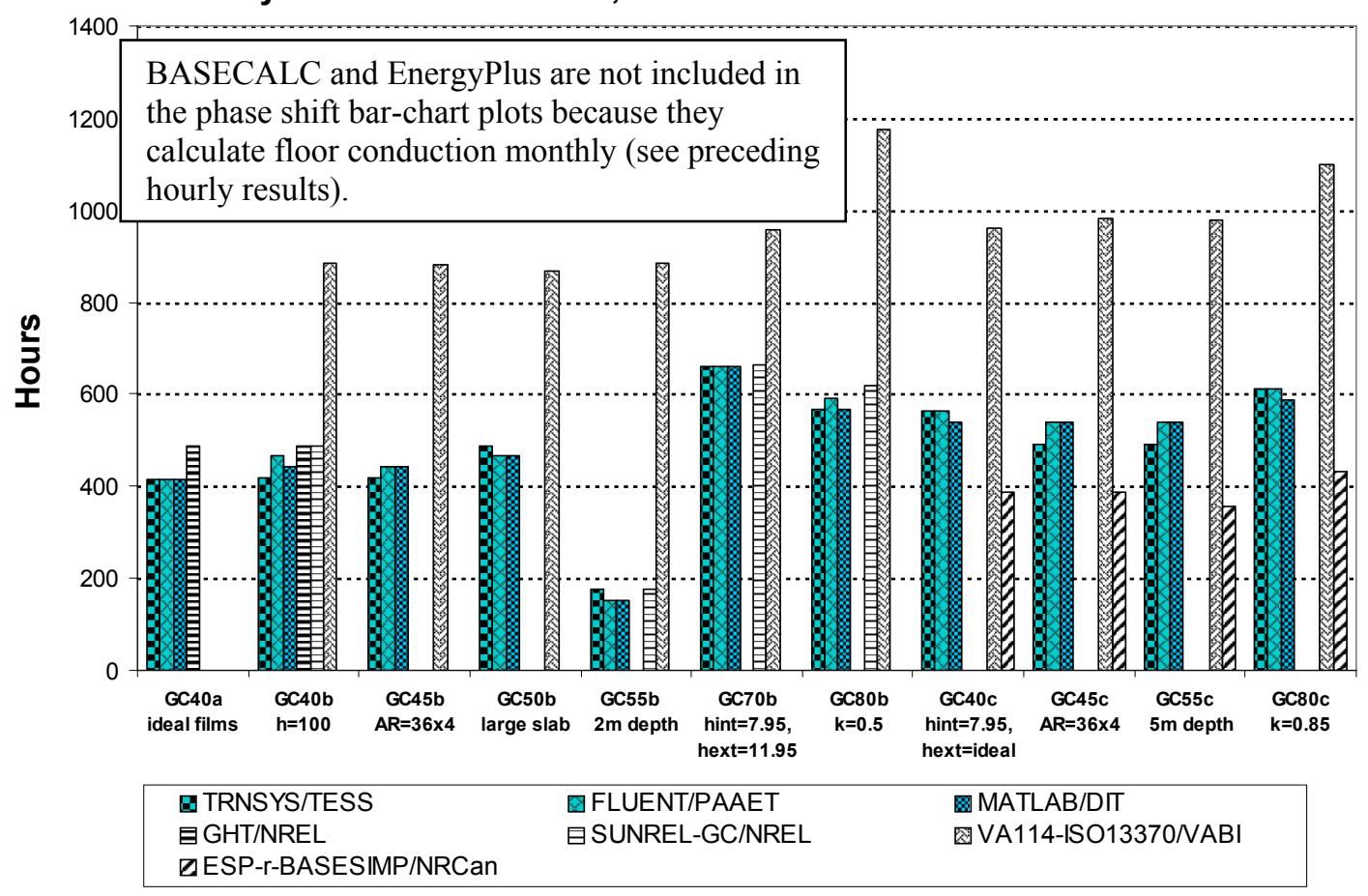

IEA BESTEST Ground Coupling: In-Depth Floor Slab Steady-Periodic Phase Shift Sensitivity, Floor Conduction v. ODB

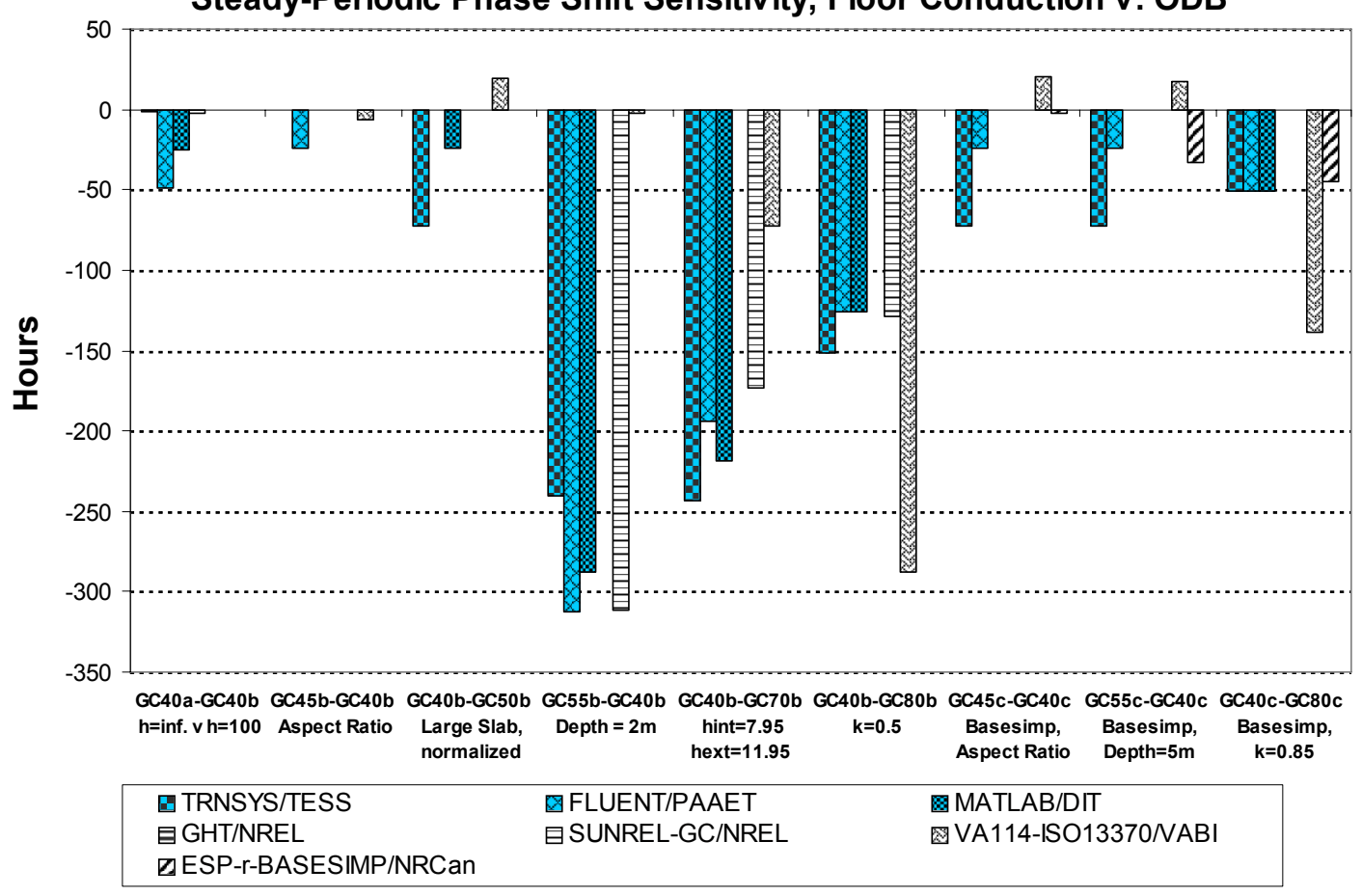



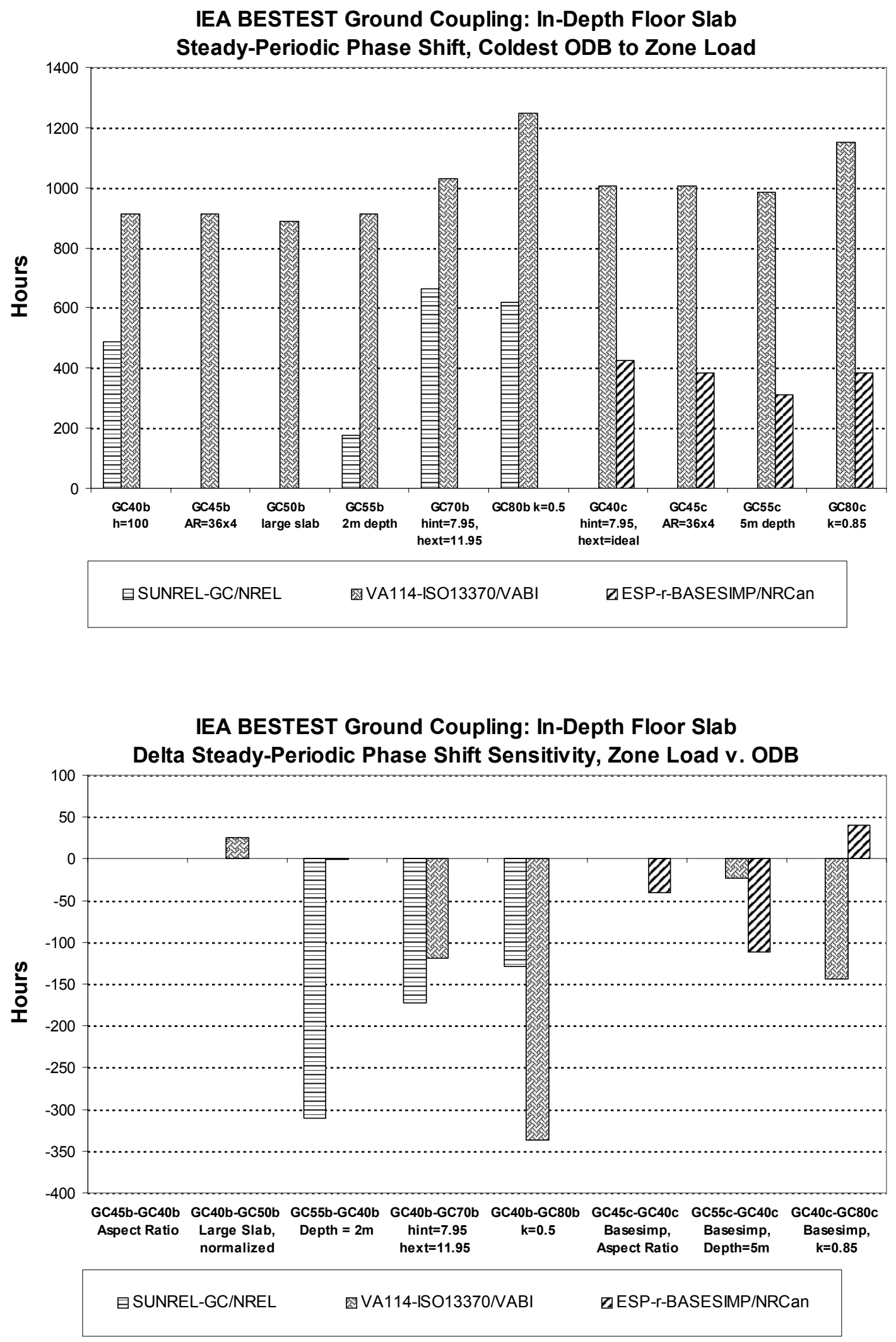
IEA BESTEST Ground Coupling: In-Depth Floor Slab Steady-Periodic Annual Peak-Hour Floor Conduction

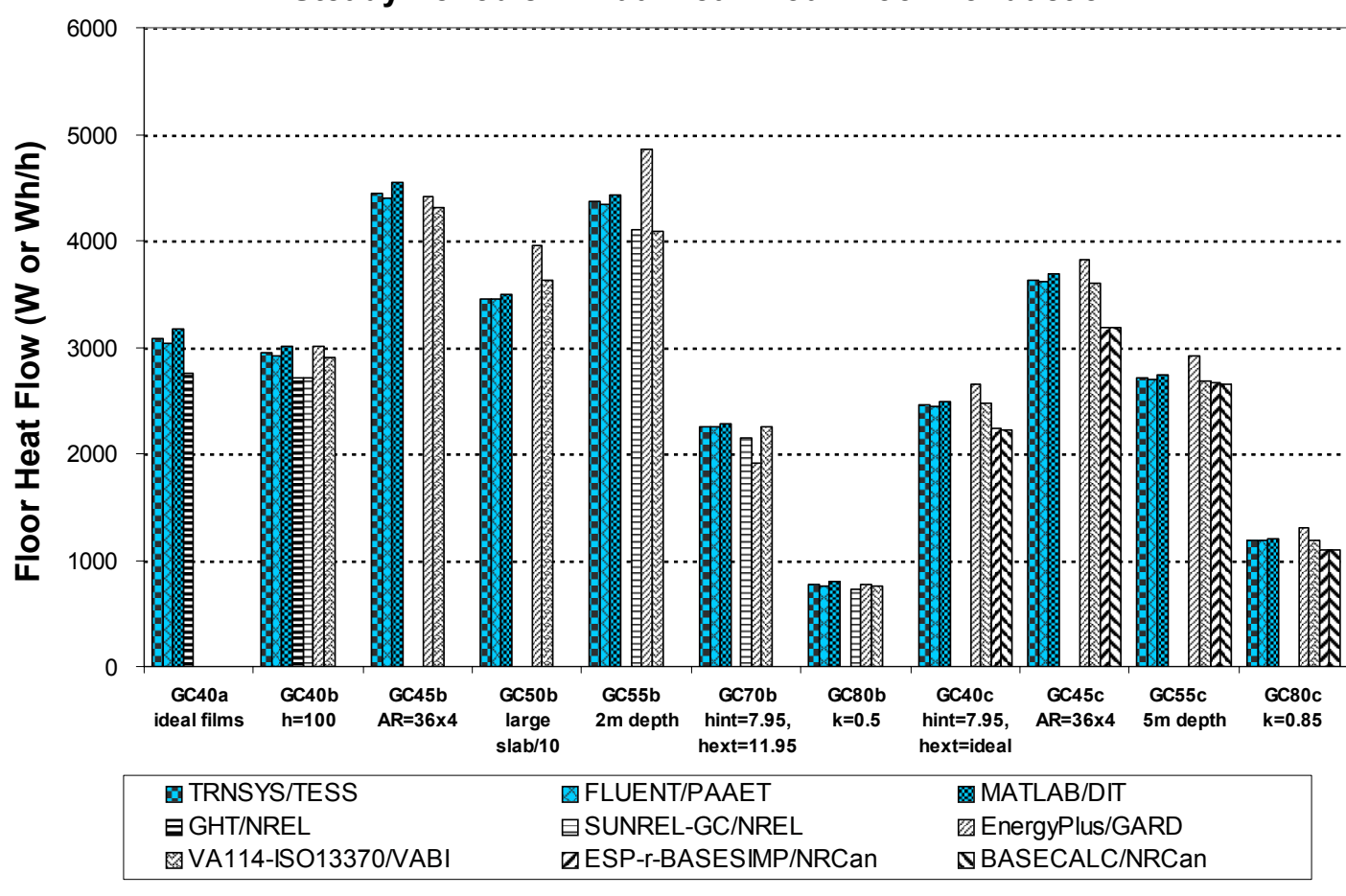

IEA BESTEST Ground Coupling: In-Depth Floor Slab Steady-Periodic Annual Peak-Hour Floor Conduction Sensitivity

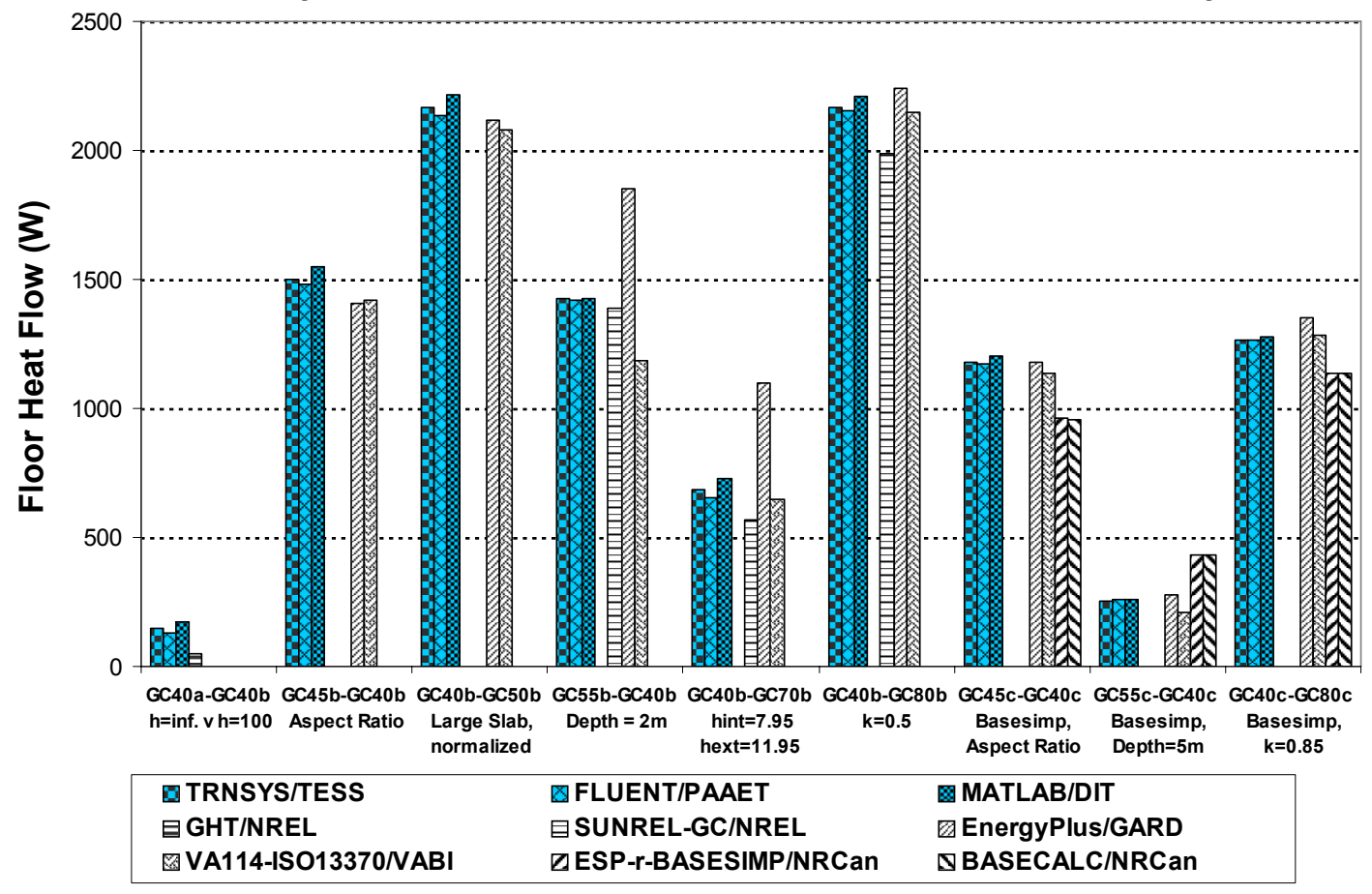


IEA BESTEST Ground Coupling: In-Depth Floor Slab

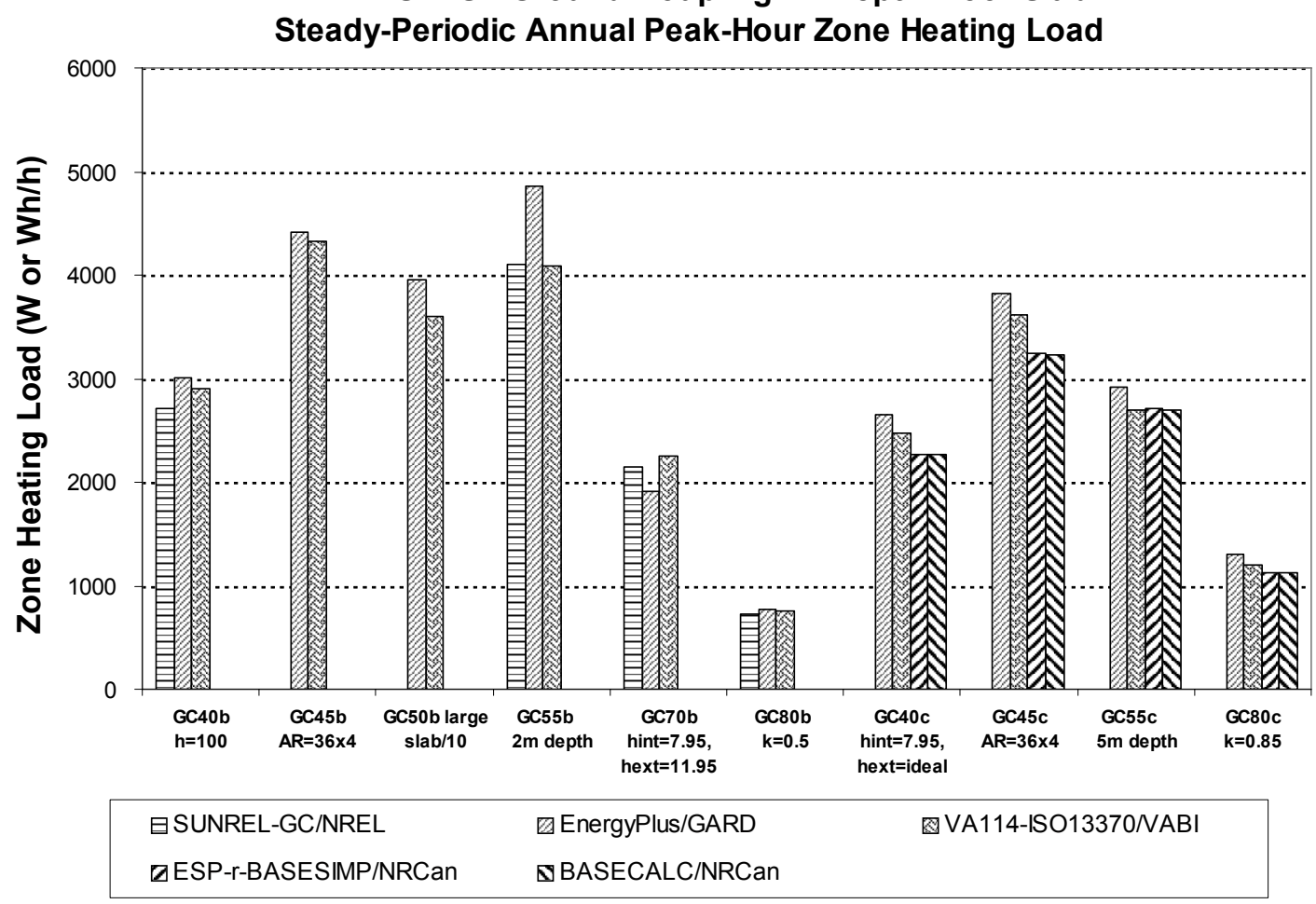

IEA BESTEST Ground Coupling: In-Depth Floor Slab Steady-Periodic Annual Peak-Hour Zone Heating Load Sensitivity

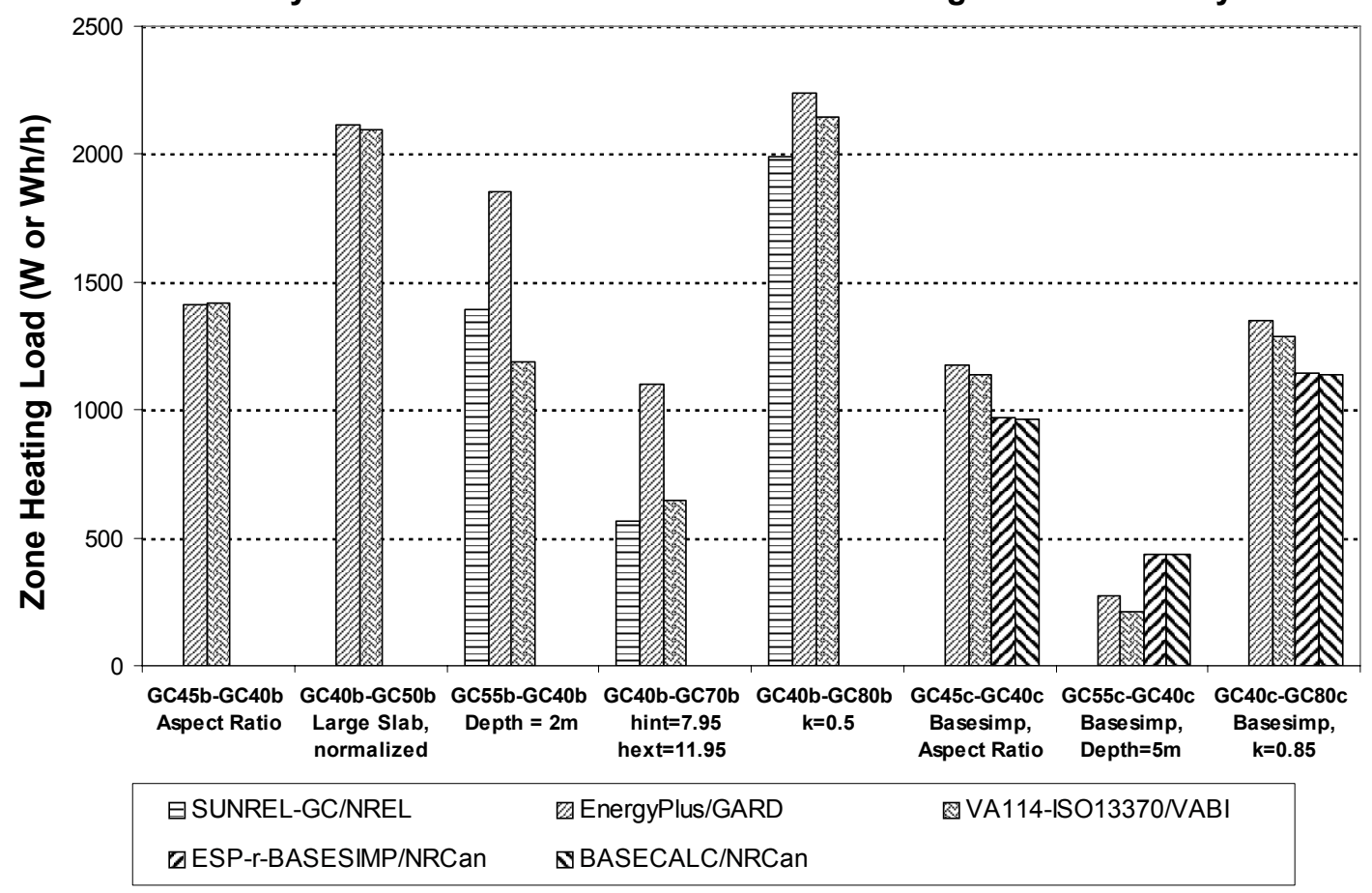


IEA BESTEST Ground Coupling: In-Depth Floor Slab Steady-Periodic (Peak Zone Heating Load) - (Peak Floor Conduction)

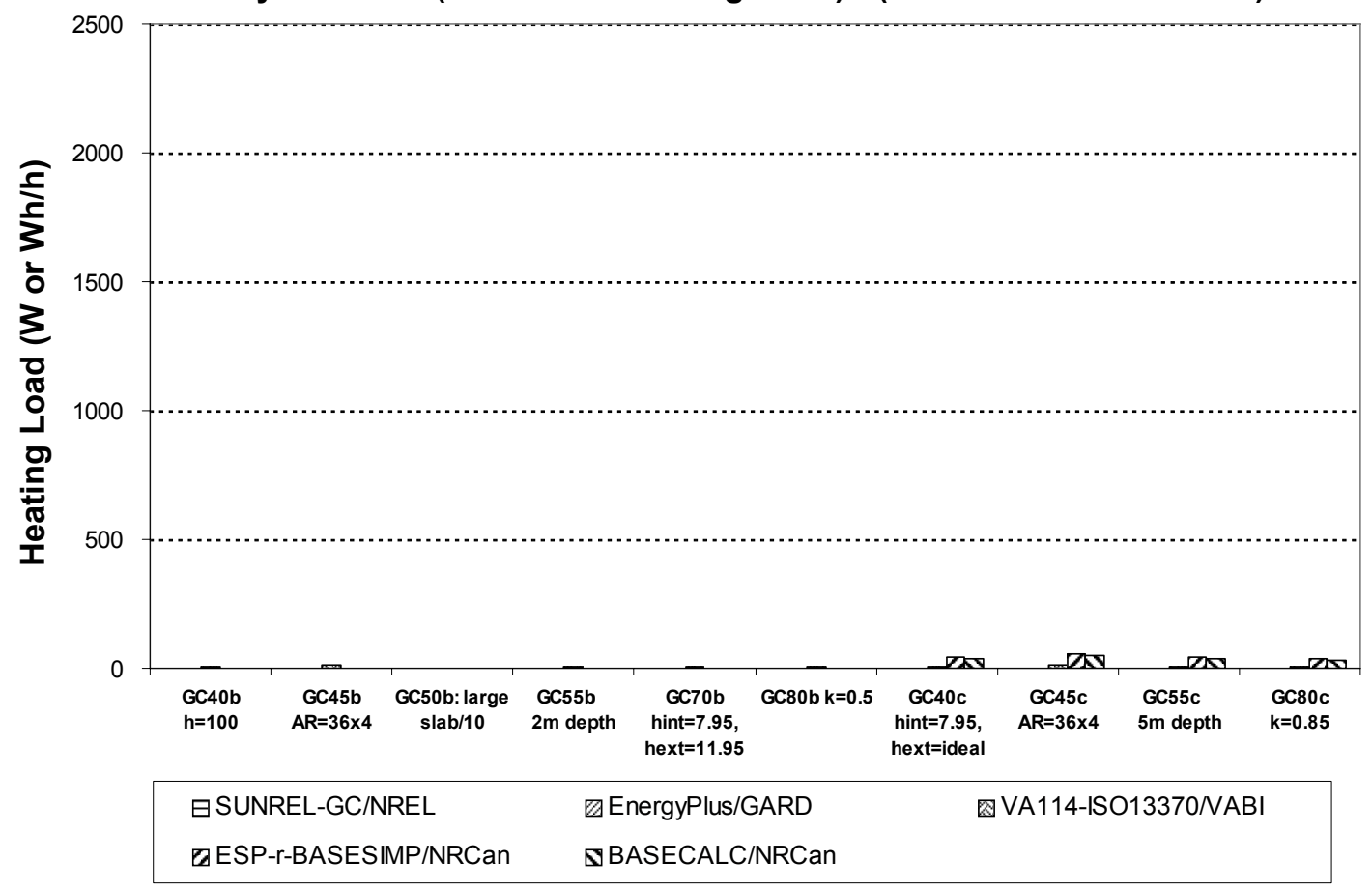


IEA BESTEST Ground Coupling: In-Depth Floor Slab Steady-Periodic Zone Temperature

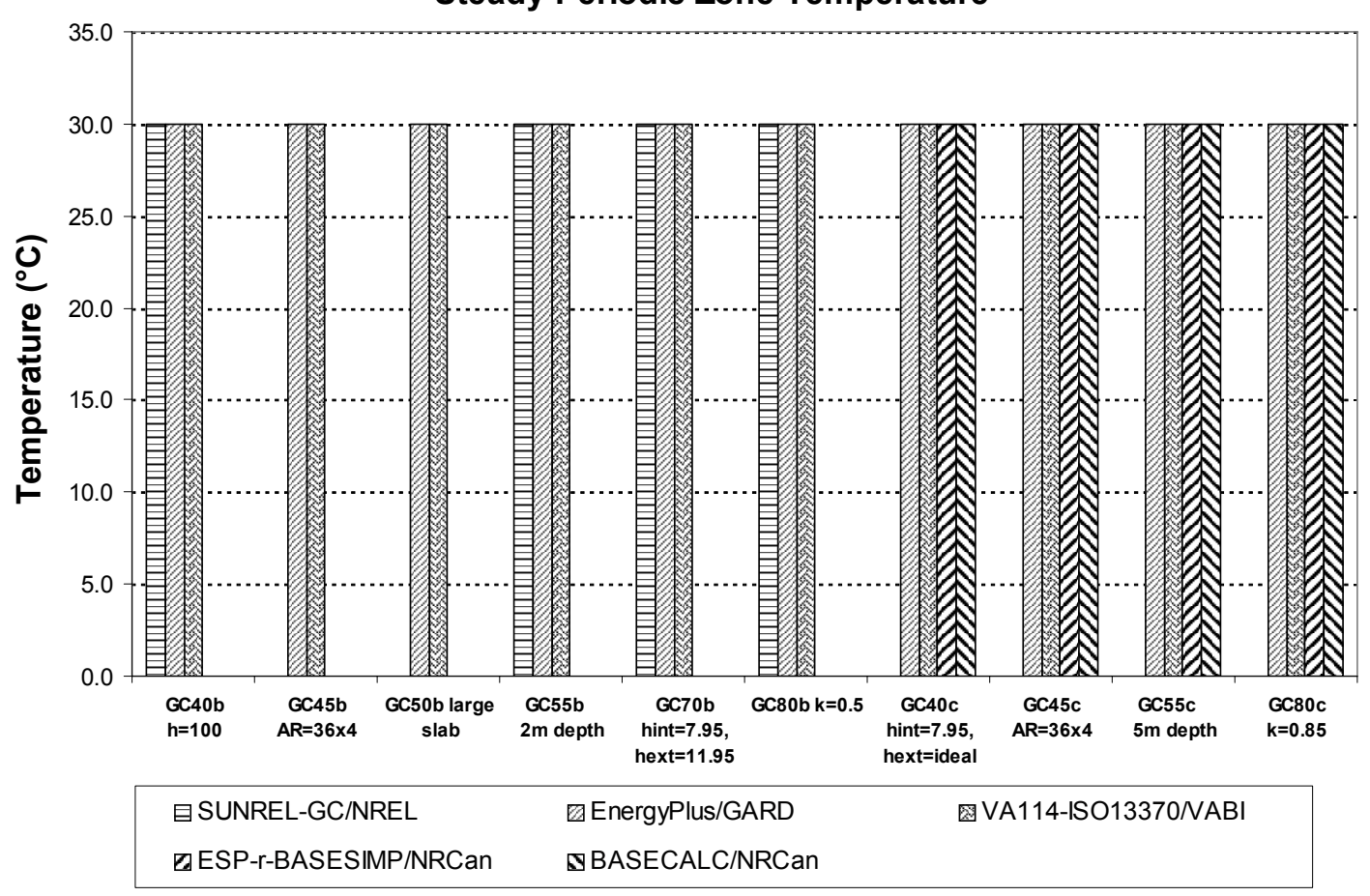

IEA BESTEST Ground Coupling: In-Depth Floor Slab Steady-Periodic Minimum ODB

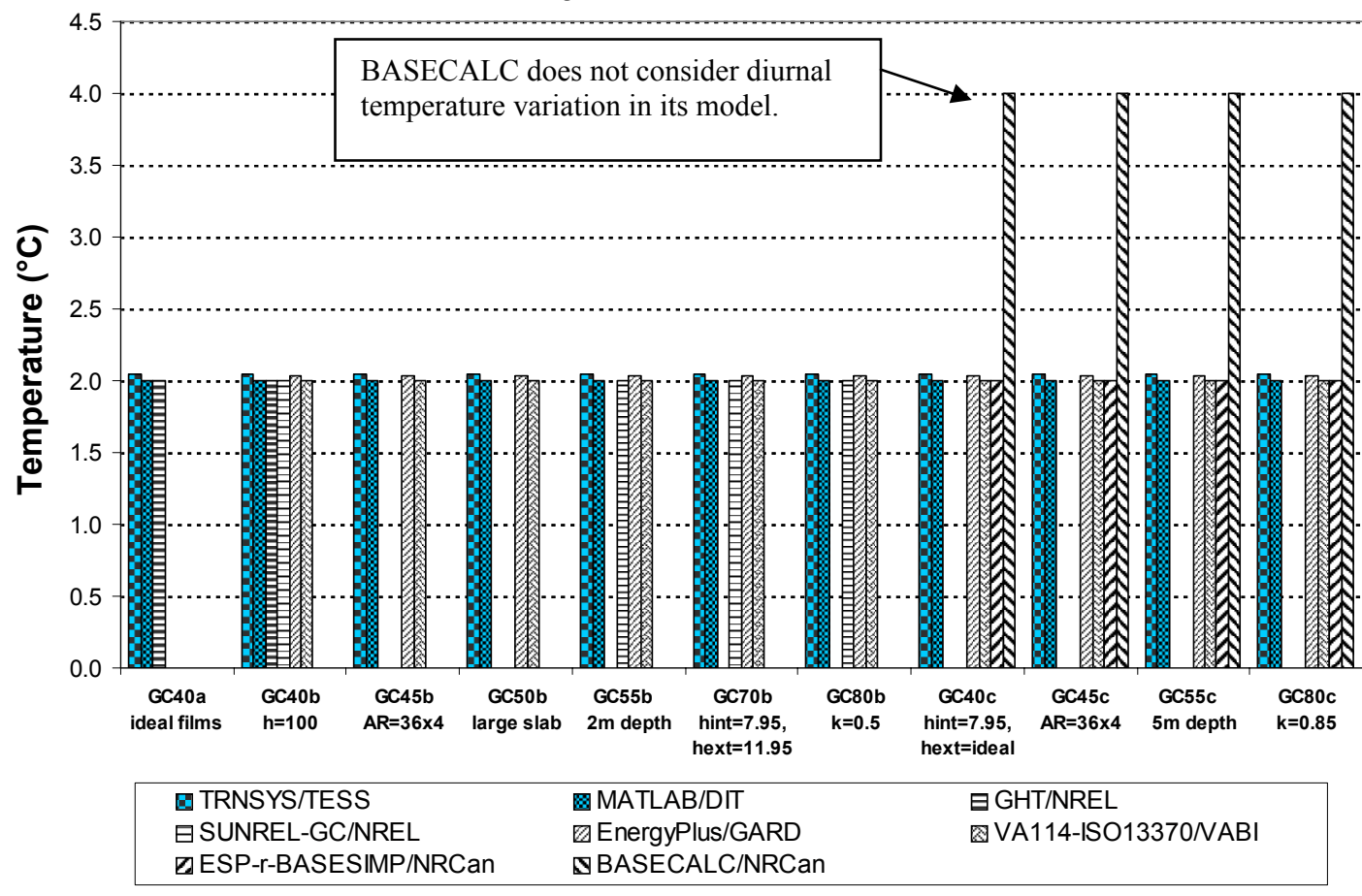




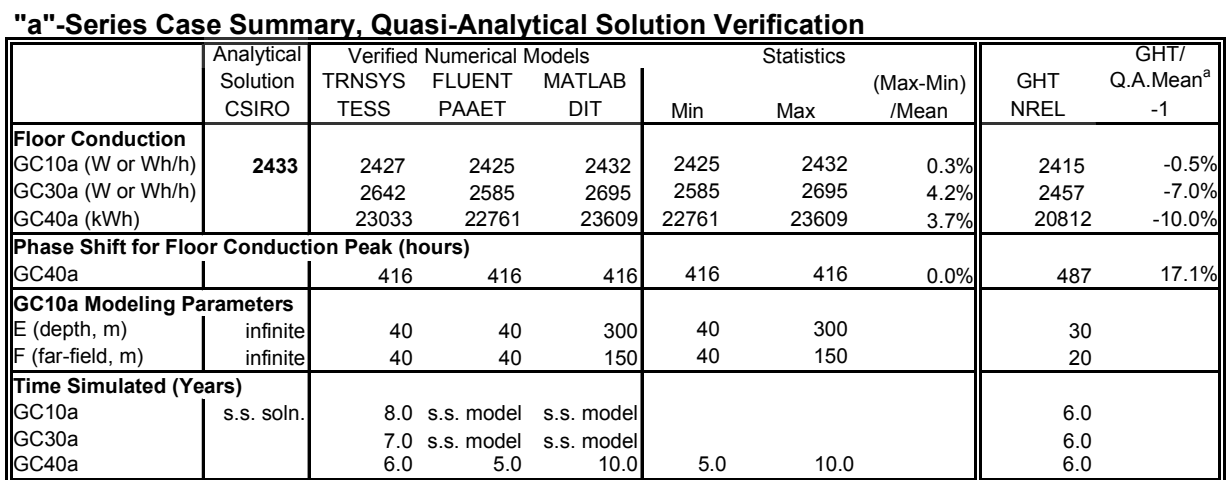

a "Q.A.Mean" is average of verified numerical-model results; for zone results the average of the floor results is used.

\begin{tabular}{|c|c|c|c|c|c|c|c|c|c|c|c|c|c|}
\hline & $\overline{\mathrm{V} V}$ & rified Num & $\overline{\text { ical Model }}$ & & & & & $\overline{~ V A 114 !}$ & ESP-r/ & & $\overline{\text { Statistics, } \mathrm{O}}$ & er Simu & ation Models \\
\hline & TRNSYS & $\begin{array}{l}\text { FLUENT } \\
\text { PL }\end{array}$ & MATLAB & (Max-Min) & & SUNREL-GC & EnergyPlus & ISO-13370 & BASESIMP & BASECALC & & & (Max-Min)/ \\
\hline & TESS & PAAET & DIT & /Mean & NREL & NREL & GARD & VABI & NRCan & NRCan & Min & $\operatorname{Max}$ & (Q.A.Mean) \\
\hline Floor Cor & Nor Wh/h & & & & & & & & & & & & \\
\hline GC30b & 2533 & 2504 & 2570 & $2.6 \%$ & 2341 & 2341 & 2652 & 2421 & & & 2341 & 2652 & $12.3 \%$ \\
\hline GC30c & 2137 & 2123 & 2154 & $1.5 \%$ & & & 2308 & 2092 & 1973 & 1973 & 1973 & 2308 & $15.7 \%$ \\
\hline GC60b & 2113 & 2104 & 2128 & $1.1 \%$ & & 1999 & 2219 & 2069 & & & 1999 & 2219 & $10.4 \%$ \\
\hline GC65b & 1994 & 1991 & 2004 & $0.7 \%$ & & 1895 & 1616 & 1920 & & & 1616 & 1920 & $15.3 \%$ \\
\hline Zone Hea & (W or Wh/ & & & & & & & & & & & & \\
\hline GC30b & & & & & & 2341 & 2652 & 2427 & & & 2341 & 2652 & $12.3 \%$ \\
\hline GC30c & & & & & & & 2308 & 2098 & 2003 & 2003 & 2003 & 2308 & $14.3 \%$ \\
\hline GC60b & & & & & & 1999 & 2219 & 2075 & & & 1999 & 2219 & $10.4 \%$ \\
\hline GC65b & & & & & & 1895 & 1616 & 1925 & & & 1616 & 1925 & $15.5 \%$ \\
\hline (Zone $\mathrm{He}$ & )- (Floor C & onduction & [W or Wh & & & & & & & & & & \\
\hline GC30b & & & & & & 0 & 0 & 6 & & & 0 & 6 & \\
\hline GC30c & & & & & & & 0 & 6 & 30 & 30 & 0 & 30 & \\
\hline GC60b & & & & & & 0 & 0 & 6 & & & 0 & 6 & \\
\hline GC65b & & & & & & 0 & 0 & 5 & & & 0 & 5 & \\
\hline
\end{tabular}

a "Q.A.Mean" is average of verified numerical-model results; for zone results the average of the floor results is used

\section{Steady-State Supporting Information}

\begin{tabular}{|c|c|c|c|c|c|c|c|c|c|c|c|c|}
\hline & \begin{tabular}{|c}
$\mathrm{Ve}$ \\
TRNSYS \\
TESS \\
\end{tabular} & $\begin{array}{c}\text { /erified Nume } \\
\text { FLUENT } \\
\text { PAAET }\end{array}$ & $\begin{array}{c}\text { rical Models } \\
\text { MATLAB } \\
\text { DIT } \\
\end{array}$ & $\begin{array}{c}\text { GHT } \\
\text { NREL }\end{array}$ & $\begin{array}{c}\text { SUNREL-GC } \\
\text { NREL }\end{array}$ & $\begin{array}{c}\text { EnergyPlus } \\
\text { GARD }\end{array}$ & $\begin{array}{c}\text { VA114/ } \\
\text { ISO-13370 } \\
\text { VABI }\end{array}$ & $\begin{array}{c}\text { ESP-r/ } \\
\text { BASESIMP } \\
\text { NRCan } \\
\end{array}$ & $\begin{array}{c}\text { BASECALC } \\
\text { NRCan } \\
\end{array}$ & $\begin{array}{l}\text { Statistics } \\
\end{array}$ & Result & $\begin{array}{r}\text { (Max-Min) } \\
/ \text { Mean } \\
\end{array}$ \\
\hline \multicolumn{4}{|c|}{ Zone Air Temperature $\left({ }^{\circ} \mathrm{C}\right)$} & & & & & \multirow{5}{*}{30.0} & \multirow{5}{*}{30.0} & & & \\
\hline GC30b & & & & & 30.0 & 30.0 & 30.0 & & & 30.0 & 30.0 & $0.0 \%$ \\
\hline GC30c & & & & & & 30.0 & 30.0 & & & 30.0 & 30.0 & $0.0 \%$ \\
\hline GC60b & & & & & 30.0 & 30.0 & 30.0 & & & 30.0 & 30.0 & $0.0 \%$ \\
\hline GC65b & & & & & 30.0 & 30.0 & 30.0 & & & 30.0 & 30.0 & $0.0 \%$ \\
\hline \multicolumn{4}{|c|}{ Simulation Duration (Years) } & \multirow{5}{*}{5.0} & & & & \multirow{5}{*}{2.0} & \multirow{5}{*}{ 3.0 } & & & \\
\hline GC30b & 6.0 & 0 s.s. model & s.s. model & & \multirow{4}{*}{$\begin{array}{l}5.0 \\
5.0\end{array}$} & 7.0 & 1.0 & & & 0.0 & 7.0 & \\
\hline GC30c & 6.0 & 0 s.s. model & s.s. model & & & 6.0 & 1.0 & & & 0.0 & 6.0 & \\
\hline GC60b & 6.0 & 0 s.s. model & s.s. model & & & 7.0 & 1.0 & & & 0.0 & 7.0 & \\
\hline GC65b & 6.0 & 0 s.s. model & s.s. model| & & & 8.0 & 1.0 & & & 0.0 & 8.0 & \\
\hline
\end{tabular}


Steady-Periodic Last-Simulation-Year Conduction

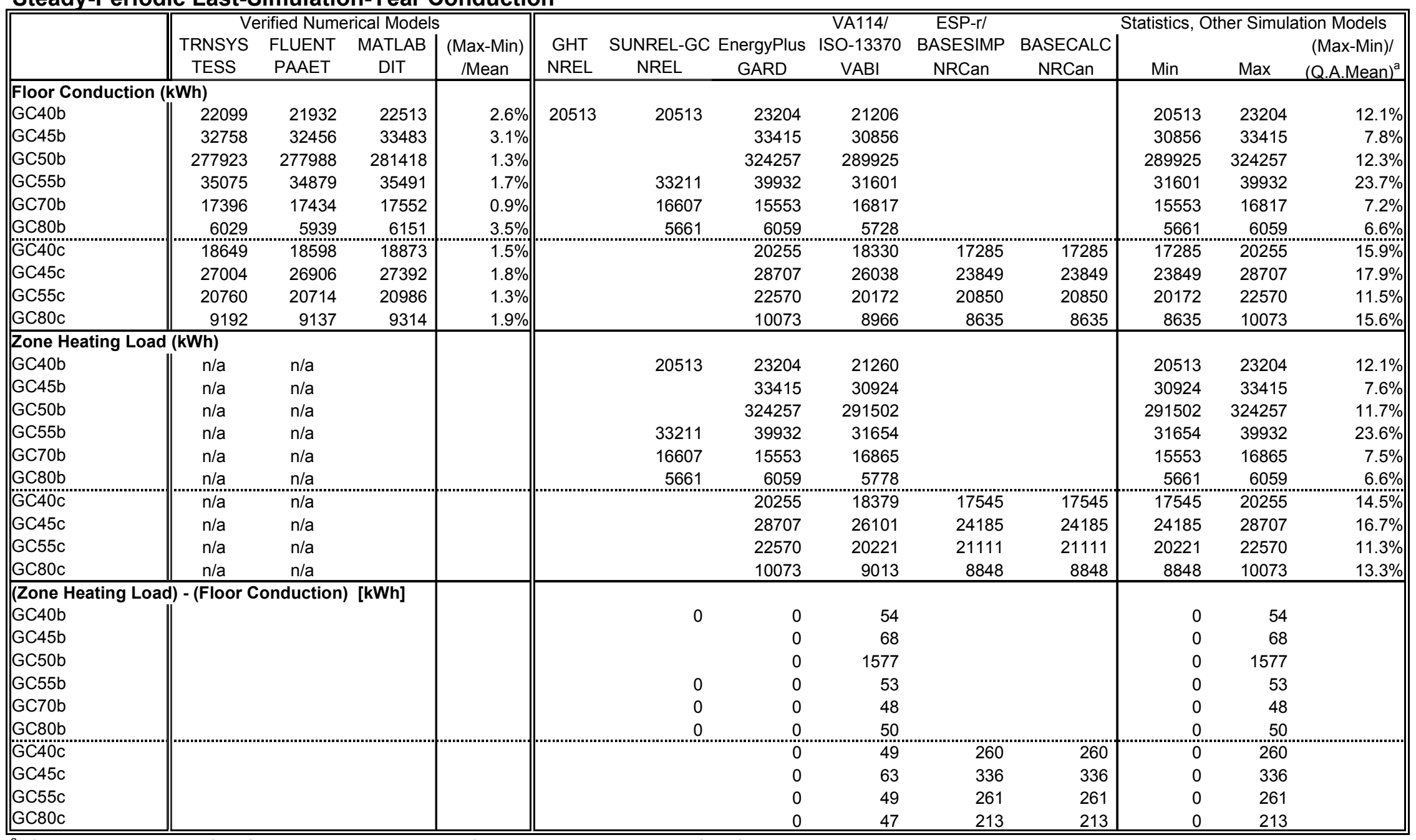

a "Q.A.Mean" is average of verified numerical-model results; for zone results the average of the floor results is used. 


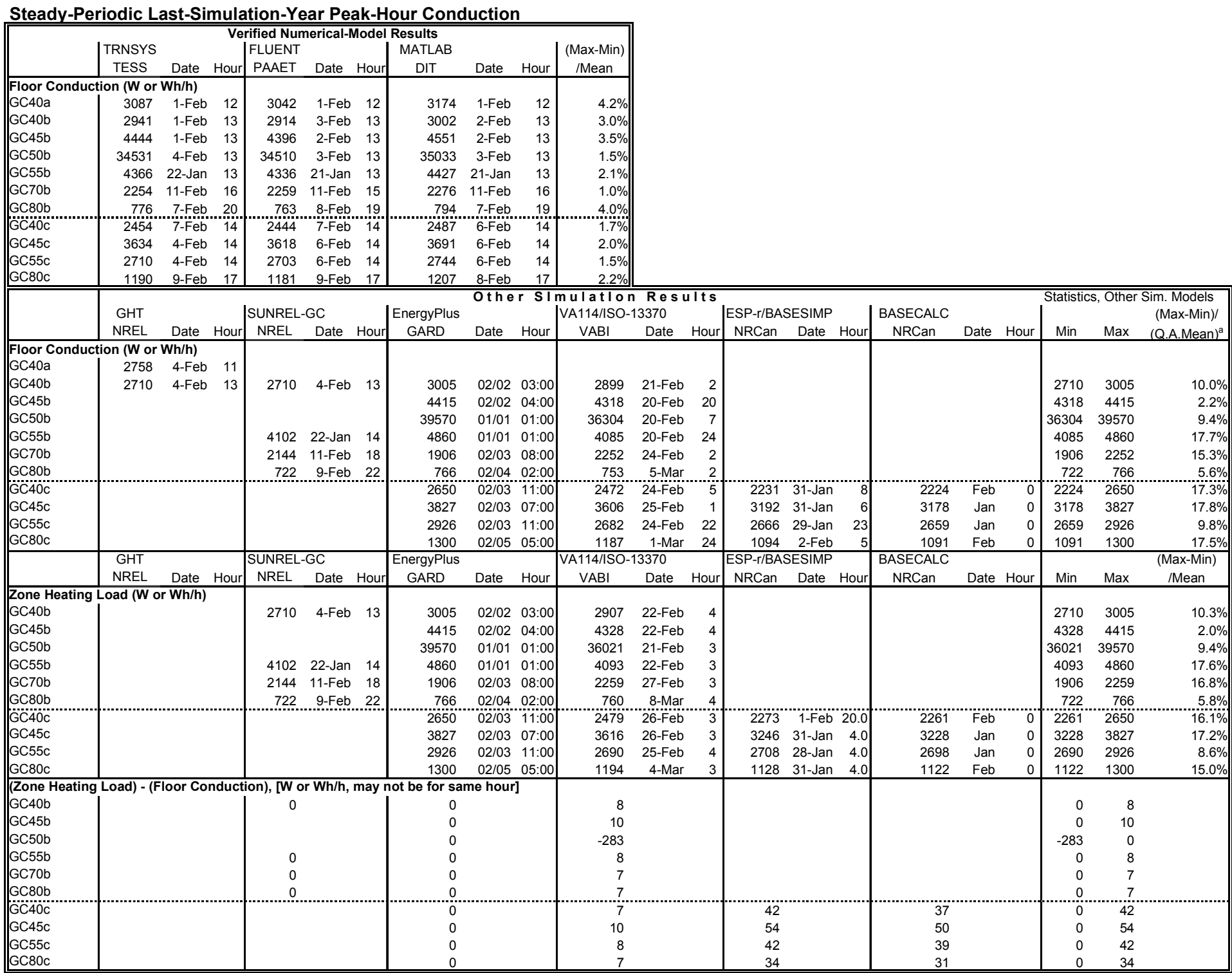

"Q.A.Mean" is average of verified numerical-model results; for zone results the average of the floor results is used. 
Time from Coldest Hour (Jan 15, Hour 4) to Peak Conduction Occurrence

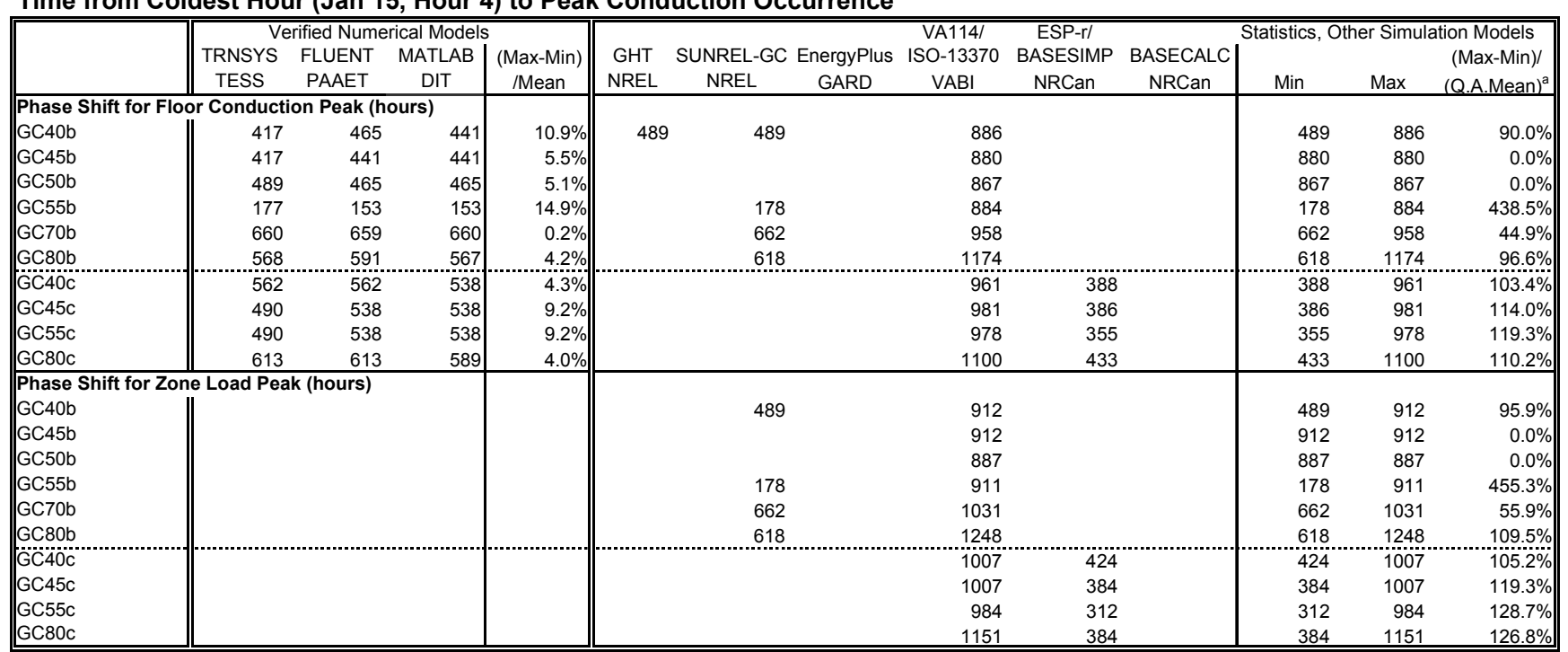

"Q.A.Mean" is average of verified numerical-model results; for zone results the average of the floor results is used.

Steady-Periodic Supporting Information

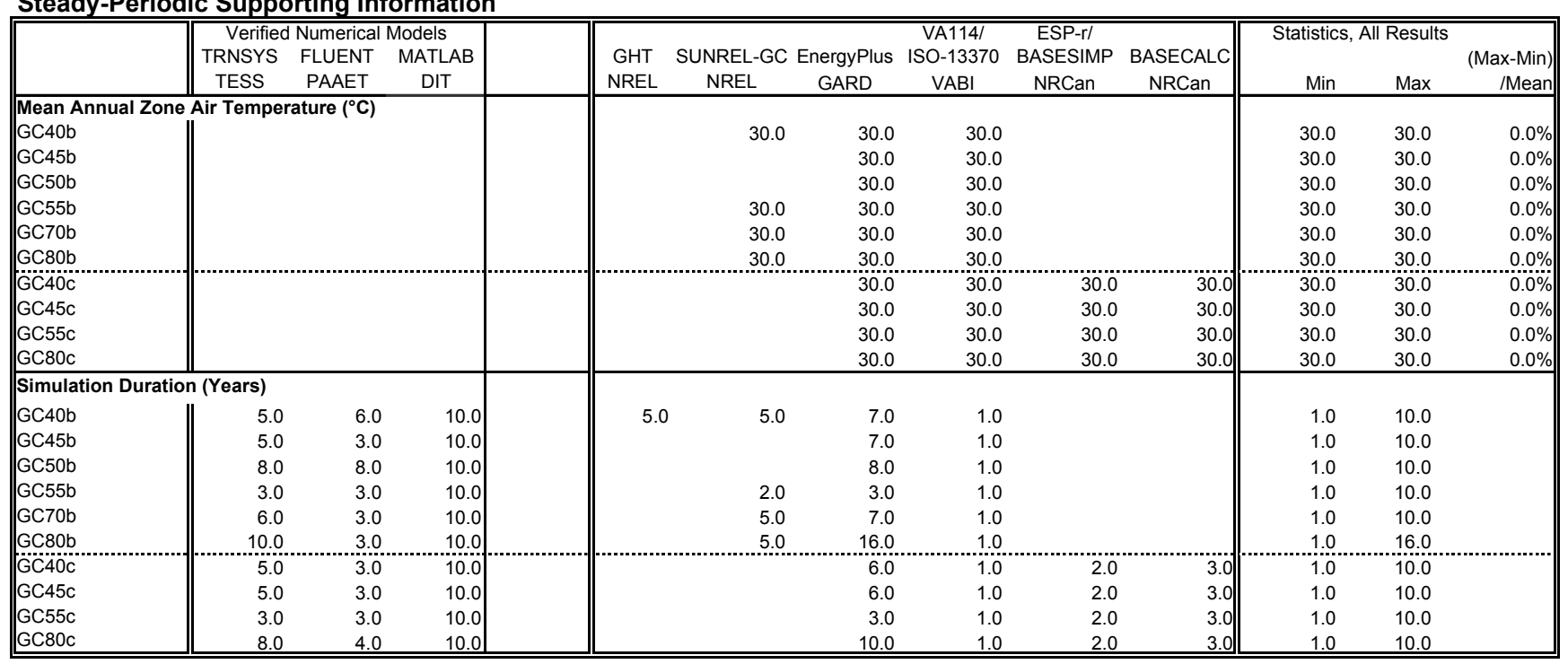


Steady-Periodic Minimum ODB and Time of Occurrence

\begin{tabular}{|c|c|c|c|c|c|c|c|c|c|c|c|c|c|c|c|c|c|c|c|c|c|c|c|c|}
\hline & & & & Veri & fied Num & erical-M & $\overline{\text { Model }}$ & Results & & & & & & & & & & & & & & & & \\
\hline & TRNSY & & & \# hours at & FLUENT & & & \# hours at & MATLAE & & & \# hours at & & & & & & & & & & & & \\
\hline & TESS & Date & Hour & ODBmin & PAAET & Date & Hour & ODBmin & DIT & Date & Hour & ODBmin & & & & & & & & & & & & \\
\hline Outdoo & Dry-Bulb & Temper & rature & $\left({ }^{\circ} \mathrm{C}\right)$ & & & & & & & & & & & & & & & & & & & & \\
\hline GC40a & 2.1 & 8-Jan & 4.0 & 30.0 & & & & & 2.0 & 8-Jan & 4.0 & 15.0 & & & & & & & & & & & & \\
\hline GC40b & 2.1 & 8-Jan & 4.0 & 30.0 & & & & & 2.0 & 8-Jan & 4.0 & 15.0 & & & & & & & & & & & & \\
\hline |GC45b & 2.1 & 8-Jan & 4.0 & 30.0 & & & & & 2.0 & 8-Jan & 4.0 & 15.0 & & & & & & & & & & & & \\
\hline GC50b & 2.1 & 8-Jan & 4.0 & 30.0 & & & & & 2.0 & 8-Jan & 4.0 & 15.0 & & & & & & & & & & & & \\
\hline GC55b & 2.1 & 8-Jan & 4.0 & 30.0 & & & & & 2.0 & 8-Jan & 4.0 & 15.0 & & & & & & & & & & & & \\
\hline GC70b & 2.1 & 8-Jan & 4.0 & 30.0 & & & & & 2.0 & 8-Jan & 4.0 & 15.0 & & & & & & & & & & & & \\
\hline GC80b & 2.1 & 8-Jan & 4.0 & 30.0 & & & & & 2.0 & 8-Jan & 4.0 & 15.0 & & & & & & & & & & & & \\
\hline |G̈C̈40 & 2.1 & 8-Jan & 4.0 & 30.0 & & & & & 2.0 & 8-Jan & 4.0 & 15.0 & & & & & & & & & & & & \\
\hline |GC45c & 2.1 & 8-Jan & 4.0 & 30.0 & & & & & 2.0 & 8-Jan & 4.0 & 15.0 & & & & & & & & & & & & \\
\hline GC55c & 2.1 & 8-Jan & 4.0 & 30.0 & & & & & 2.0 & 8-Jan & 4.0 & 15.0 & & & & & & & & & & & & \\
\hline GC80c & 2.1 & 8-Jan & 4.0 & 30.0 & & & & & 2.0 & 8-Jan & 4.0 & 15.0] & & & & & & & & & & & & \\
\hline & & & & & & & & & EnergyP & $\begin{array}{l}\text { Dther } \\
\text { lus }\end{array}$ & $r \sin$ & 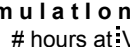 & $\begin{array}{r}\text { Res } \\
\text { VA114/ }\end{array}$ & $\begin{array}{l}\text { iult s } \\
\text { so-133 }\end{array}$ & & & & & & & & & & \\
\hline & GHT & & & \# hours at & SUNREL & $-G C$ & & \# hours at & EnergyP & & & & VA114/ & SO-133 & & A nours at: & $=\mathrm{NRC} / \mathrm{BA}$ & SESIMP & & \# hours at: & BASECAL & LC & & $\begin{array}{c}\text { \# hours at } \\
\text { ODBmin }\end{array}$ \\
\hline Outdoo & $\frac{\mid \text { NREL }}{\text { Dry-Bulb }}$ & $\frac{\text { Date }}{\text { Temper }}$ & $\frac{\text { Hour }}{\text { rature }}$ & ODBmin & NREL & Date & Hour & ODBmin & GARD & Date & Hour & ODBmin & VABI & Date & Hour & 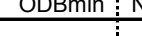 & NRCan & Date & Hour & & NRCan & Date & Hour & \\
\hline GC40a & Dry-Bulb & Temper & rature & $\left({ }^{\circ} \mathrm{C}\right)$ & & & & & & & & & & & & & & & & & & & & \\
\hline & 2.0 & 8-Jan & 4.0 & 15.0 & & & & & & & & & & & & & & & & & & & & \\
\hline GC40b & 2.0 & 8-Jan & 4.0 & 15.0 & 2.0 & 8-Jan & 4.0 & 15.0 & 2.0 & $01 / 08$ & $04: 00$ & 15.0 & 2.0 & 8-Jan & 4.0 & 16.0 & & & & & & & & \\
\hline GC45b & & & & & & & & & 2.0 & $01 / 08$ & $04: 00$ & 15.0 & 2.0 & 8-Jan & 4.0 & 16.0 & & & & & & & & \\
\hline GC50b & & & & & & & & & 2.0 & $01 / 08$ & $04: 00$ & 15.0 & 2.0 & 8-Jan & 4.0 & 16.0 & & & & & & & & \\
\hline GC55b & & & & & 2.0 & 8-Jan & 4.0 & 15.0 & 2.0 & $01 / 08$ & $04: 00$ & 15.0 & 2.0 & 8-Jan & 4.0 & 16.0 & & & & & & & & \\
\hline GC70b & & & & & 2.0 & 8-Jan & 4.0 & 15.0 & 2.0 & $01 / 08$ & $04: 00$ & 15.0 & 2.0 & 8-Jan & 4.0 & 16.0 & & & & & & & & \\
\hline GC80b & & & & & 2.0 & 8-Jan & 4.0 & 15.0 & 2.0 & $01 / 08$ & $04: 00$ & 15.0 & 2.0 & 8-Jan & 4.0 & 16.0 & & & & & & & & \\
\hline GC40 & & & & & & & & & 2.0 & $01 / 08$ & $04: 00$ & 15.0 & 2.0 & 8-Jan & 4.0 & 16.0 & 2.0 & 8-Jan & 4.0 & 15.0 & 4.0 & Jan & 0.0 & 744.0 \\
\hline GC45c & & & & & & & & & 2.0 & $01 / 08$ & $04: 00$ & 15.0 & 2.0 & 8-Jan & 4.0 & 16.0 & 2.0 & 8-Jan & 4.0 & 15.0 & 4.0 & Jan & 0.0 & 744.0 \\
\hline GC55c & & & & & & & & & 2.0 & $01 / 08$ & $04: 00$ & 15.0 & 2.0 & 8-Jan & 4.0 & 16.0 & 2.0 & 8-Jan & 4.0 & 15.0 & 4.0 & Jan & 0.0 & 744.0 \\
\hline GC80c & & & & & & & & & 2.0 & $01 / 08$ & $04: 00$ & 15.0 & 2.0 & 8-Jan & 4.0 & 16.0 & 2.0 & 8-Jan & 4.0 & 15.0 & 4.0 & Jan & 0.0 & 744.0 \\
\hline
\end{tabular}


Delta Steady-State Conduction

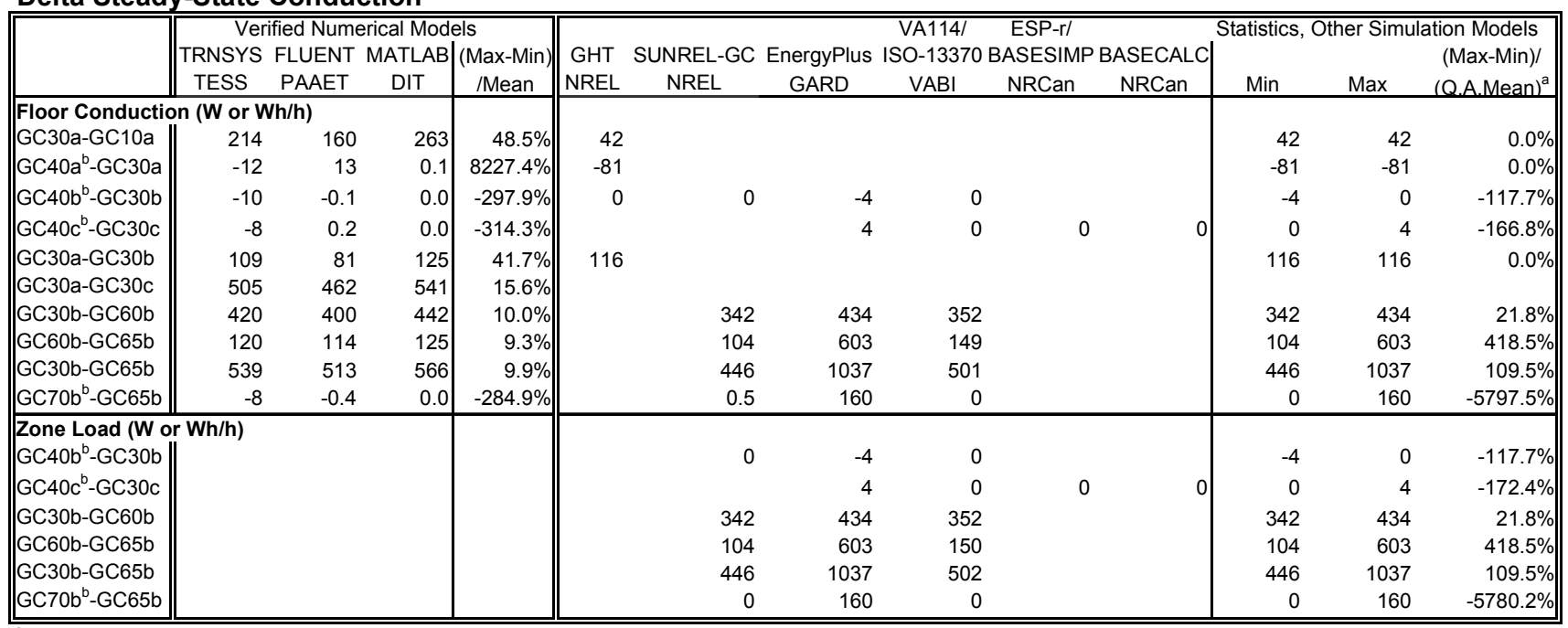

a.A.Mean" is average of verified numerical-model results; for zone results the average of the floor results is used.

${ }^{b}$ Values for GC40a, GC40b, GC40c and GC70 are: annual total $\times 1000(\mathrm{~W} / \mathrm{kW}) / 8760(\mathrm{~h} / \mathrm{y})$

\section{Delta Steady-Periodic Annual Total Conduction}

\begin{tabular}{|c|c|c|c|c|c|c|c|c|c|c|c|c|c|}
\hline & $\begin{array}{r}\begin{array}{r}\text { Ver } \\
\text { TRNSYS }\end{array} \\
\text { TRS }\end{array}$ & $\begin{array}{l}\text { ified Nume } \\
\text { FLUENT }\end{array}$ & $\begin{array}{l}\text { ical Mode } \\
\text { MATLAB }\end{array}$ & (Max-Min) & GHT & SUNREL-GC & EnergyPlus & $\begin{array}{c}\text { VA114/ } \\
\text { ISO-13370 }\end{array}$ & $\begin{array}{l}\text { ESP-r/l } \\
\text { BASESIMP }\end{array}$ & BASECALC & Statistics, & רer Simul & $\begin{array}{l}\text { ation Models } \\
\text { (Max-Min)/ }\end{array}$ \\
\hline & TESS & PAAET & DIT & /Mean & NREL & NREL & GARD & VABI & NRCan & NRCan & Min & $\operatorname{Max}$ & (Q.A.Mean) ${ }^{a}$ \\
\hline Floor Conducti & on (kWh) & & & & & & & & & & & & \\
\hline GC40a-GC40b & 933 & 829 & 1096 & $28.1 \%$ & 299 & & & & & & 299 & 299 & $0.0 \%$ \\
\hline GC45b-GC40b & 10659 & 10524 & 10971 & $4.2 \%$ & & & 10211 & 9650 & & & 9650 & 10211 & $5.2 \%$ \\
\hline$G C 40 b-G C 50 b^{c}$ & 15846 & 15677 & 16181 & $3.2 \%$ & & & 15908 & 14683 & & & 14683 & 15908 & $7.7 \%$ \\
\hline GC55b-GC40b & 12976 & 12947 & 12978 & $0.2 \%$ & & 12698 & 16728 & 10395 & & & 10395 & 16728 & $48.8 \%$ \\
\hline GC40b-GC70b & 4704 & 4498 & 4961 & $9.8 \%$ & & 3906 & 7650 & 4389 & & & 3906 & 7650 & $79.3 \%$ \\
\hline$G C 40 b-G C 80 b$ & 16071 & 15993 & 16362 & $2.3 \%$ & & 14852 & 17145 & 15478 & & & 14852 & 17145 & $14.2 \%$ \\
\hline GCA $45 \mathrm{c}-\mathrm{GC} 40 \mathrm{c}$ & 8355 & 8309 & 8519 & $2.5 \%$ & & & 8452 & 7708 & 6564 & 6564 & 6564 & 8452 & $22.5 \%$ \\
\hline GC55c-GC40c & 2111 & 2117 & 2113 & $0.3 \%$ & & & 2315 & 1842 & 3565 & 3565 & 1842 & 3565 & $81.5 \%$ \\
\hline GC40c-GC80c & 9457 & 9461 & 9559 & $1.1 \%$ & & & 10182 & 9364 & 8650 & 8650 & 8650 & 10182 & $16.1 \%$ \\
\hline Zone Conductic & n (kWh) & & & & & & & & & & & & \\
\hline GC45b-GC40b & & & & & & & 10211 & 9664 & & & 9664 & 10211 & $5.1 \%$ \\
\hline$G C 40 b-G C 50 b^{c}$ & & & & & & & 15908 & 14701 & & & 14701 & 15908 & $7.6 \%$ \\
\hline GC55b-GC40b & & & & & & 12698 & 16728 & 10394 & & & 10394 & 16728 & $48.8 \%$ \\
\hline GC40b-GC70b & & & & & & 3906 & 7650 & 4395 & & & 3906 & 7650 & $79.3 \%$ \\
\hline GC40b-GC80b & & & & & & 14852 & 17145 & 15482 & & & 14852 & 17145 & $14.2 \%$ \\
\hline GCC45c-GC4OC & & & & & & & 8452 & 7722 & 6640 & 6640 & 6640 & 8452 & $21.6 \%$ \\
\hline GC55 & & & & & & & 2315 & 1842 & 3566 & 3566 & 1842 & 3566 & $81.6 \%$ \\
\hline GC40c-GC80c & & & & & & & 10182 & 9366 & 8697 & 8697 & 8697 & 10182 & $15.6 \%$ \\
\hline
\end{tabular}

"Q.A.Mean" is average of verified numerical-model results; for zone results the average of the floor results is used.

GC50b with normalized floor area: GC50b / $(80 \times 80) \times(12 \times 12)$ 
Delta Steady-Periodic Last-Year Peak Hour Floor Conduction

\begin{tabular}{|c|c|c|c|c|c|c|c|c|c|c|c|c|c|}
\hline & \multicolumn{4}{|c|}{\begin{tabular}{|c|} 
Verified Numerical Models \\
TRNSYS FLUENT MATLAB|(Max-Min)
\end{tabular}} & \multirow{2}{*}{$\begin{array}{l}\text { GHT } \\
\text { NREL } \\
\end{array}$} & \multirow{2}{*}{$\begin{array}{l}\text { SUNREL-GC } \\
\text { NREL }\end{array}$} & \multirow{2}{*}{$\begin{array}{l}\text { EnergyPlus } \\
\text { GARD }\end{array}$} & \multicolumn{3}{|c|}{$\begin{array}{l}\text { VA114/ } \text { ESP-r/ } \\
\text { ISO-13370 BASESIMP BASECALC }\end{array}$} & \multicolumn{3}{|c|}{$\begin{array}{r}\text { Statistics, Other Simulation Models } \\
(\text { Max-Min)/ }\end{array}$} \\
\hline & | TESS & PAAET & DIT & /Mean & & & & VABI & NRCan & NRCan & Min & $\operatorname{Max}$ & \\
\hline \multicolumn{14}{|c|}{ Floor Conduction (W or Wh/h) } \\
\hline GC40a-GC40b & 145 & 128 & 171 & $29.1 \%$ & 48 & & & & & & 48 & 48 & $0.0 \%$ \\
\hline GC45b-GC40b & 1503 & 1482 & 1549 & $4.4 \%$ & & & 1410 & 1419 & & & 1410 & 1419 & $0.6 \%$ \\
\hline GC40b-GC50b ${ }^{\mathrm{C}}$ & 2164 & 2138 & 2214 & $3.5 \%$ & & & 2115 & 2082 & & & 2082 & 2115 & $1.5 \%$ \\
\hline GC55b-GC40b & 1425 & 1422 & 1425 & $0.2 \%$ & & 1391 & 1855 & 1186 & & & 1186 & 1855 & $47.0 \%$ \\
\hline GC40b-GC70b & 687 & 655 & 726 & $10.2 \%$ & & 566 & 1099 & 647 & & & 566 & 1099 & $77.3 \%$ \\
\hline GC40b-GC80b & 2166 & 2151 & 2208 & $2.6 \%$ & & 1988 & 2239 & 2146 & & & 1988 & 2239 & $11.5 \%$ \\
\hline GัČ̈ & 1180 & 1173 & 1205 & $2.7 \%$ & & & 1176 & 1134 & 961 & 954 & 954 & 1176 & $18.7 \%$ \\
\hline GC55c-GC40c & 256 & 258 & 258 & $0.9 \%$ & & & 275 & 210 & 435 & 435 & 210 & 435 & $87.4 \%$ \\
\hline GC40c-GC80c & 1265 & 1264 & 1279 & $1.2 \%$ & & & 1351 & 1285 & 1137 & 1133 & 1133 & 1351 & $17.1 \%$ \\
\hline \multicolumn{14}{|c|}{ Zone Conduction (W or Wh/h) } \\
\hline GC45b-GC40b & & & & & & & 1410 & 1421 & & & 1410 & 1421 & 0.7 \\
\hline GC40b-GC50b ${ }^{\mathrm{C}}$ & & & & & & & 2115 & 2097 & & & 2097 & 2115 & 0.8 \\
\hline GC55b-GC40b & & & & & & 1391 & 1855 & 1186 & & & 1186 & 1855 & $47.0 \%$ \\
\hline GC40b-GC70b & & & & & & 566 & 1099 & 648 & & & 566 & 1099 & 77.3 \\
\hline GC40b-GC80b & & & & & & 1988 & 2239 & 2147 & & & 1988 & 2239 & $11.5 \%$ \\
\hline 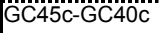 & & & & & & & 1176 & 1137 & 973 & 967 & 967 & 1176 & $17.6 \%$ \\
\hline GC55c-GC40c & & & & & & & 275 & 211 & 435 & 437| & 211 & 437 & $87.8 \%$ \\
\hline GC40c-GC80c & & & & & & & 1351 & 1285 & 1145 & 1139 & 1139 & 1351 & $16.7 \%$ \\
\hline
\end{tabular}

"Q.A.Mean" is average of verified numerical-model results; for zone results the average of the floor results is used.

${ }^{\circ}$ GC50b with normalized floor area: GC50b / $(80 \times 80) \times(12 \times 12)$

\section{Delta Steady-Periodic Conduction v Coldest Hour Phase Shift}

\begin{tabular}{|c|c|c|c|c|c|c|c|c|c|c|c|c|c|}
\hline & \multicolumn{4}{|c|}{\begin{tabular}{|c|} 
Verified Numerical Models \\
TRNSYS FLUENT MATLAB|(Max-Min)
\end{tabular}} & \multirow{2}{*}{\begin{tabular}{|c} 
GHT \\
NREL
\end{tabular}} & SUNREL-GC & \multicolumn{4}{|c|}{$\begin{array}{c}\text { VA114/ } \\
\text { ESP-r/ } \\
\text { EnergyPlus ISO-13370 BASESIMP }\end{array}$} & \multicolumn{3}{|c|}{$\begin{array}{r}\text { Statistics, Other Simulation Models } \\
\text { (Max-Min)/ }\end{array}$} \\
\hline & TESS & PAAET & DIT & /Mean & & NREL & GARD & VABI & NRCan & NRCan & Min & $\operatorname{Max}$ & (Q.A.Mean) ${ }^{\mathrm{a}}$ \\
\hline Floor (Hours) & & & & & & & & & & & & & \\
\hline GC40a-GC40b & -1 & -49 & -25 & $-192.0 \%$ & -2 & & & & & & -2 & -2 & $0.0 \%$ \\
\hline GC45b-GC40b & 0 & -24 & 0 & $-300.0 \%$ & & & & -6 & & & -6 & -6 & $0.0 \%$ \\
\hline$G C 40 b-G C 50 b^{c}$ & -72 & 0 & -24 & $-225.0 \%$ & & & & 19 & & & 19 & 19 & $0.0 \%$ \\
\hline GC55b-GC40b & -240 & -312 & -288 & $-25.7 \%$ & & -311 & & -2 & & & -311 & -2 & $-110.4 \%$ \\
\hline GC40b-GC70b & -243 & -194 & -219 & $-22.4 \%$ & & -173 & & -72 & & & -173 & -72 & $-46.2 \%$ \\
\hline GC40b-GC80b & -151 & -126 & -126 & $-18.6 \%$ & & .129 & & -288 & & & -288 & -129 & $-118.4 \%$ \\
\hline G̈C45c-GC40c & -72 & -24 & $\ddot{0}$ & $-225.0 \%$ & & & & 20 & -2 & & -2 & 20 & $-68.8 \%$ \\
\hline GC55c-GC40c & -72 & -24 & 0 & $-225.0 \%$ & & & & 17 & -33 & & -33 & 17 & $-156.3 \%$ \\
\hline GC40c-GC80c & -51 & -51 & -51 & $0.0 \%$ & & & & -139 & -45 & & -139 & -45 & $-184.3 \%$ \\
\hline Zone (Hours) & & & & & & & & & & & & & \\
\hline GC45b-GC40b & & & & & & & & 0 & & & 0 & 0 & $0.0 \%$ \\
\hline GC40b-GC50b & & & & & & & & 25 & & & 25 & 25 & $0.0 \%$ \\
\hline GC55b-GC40b & & & & & & -311 & & -1 & & & -311 & -1 & $-110.7 \%$ \\
\hline GC40b-GC70b & & & & & & -173 & & -119 & & & -173 & -119 & $-24.7 \%$ \\
\hline$G C 40 b-G C 80 b$ & & & & & & -129 & & -336 & & & -336 & -129 & $-154.1 \%$ \\
\hline GCA45c-GC4OC & & & & & & & & 0 & -40 & & -40 & 0 & $-125.0 \%$ \\
\hline GC55c-GC40c & & & & & & & & -23 & -112 & & -112 & -23 & $-278.1 \%$ \\
\hline GC40c-GC80c & & & & & & & & -144 & 40 & & -144 & 40 & $-360.8 \%$ \\
\hline
\end{tabular}

a "Q.A.Mean" is average of verified numerical-model results; for zone results the average of the floor results is used.

${ }^{\circ}$ GC50b with normalized floor area: GC50b / $(80 \times 80) \times(12 \times 12)$ 


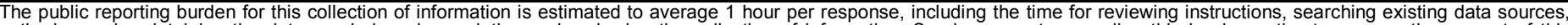

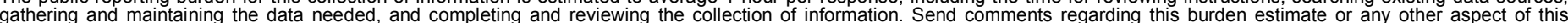

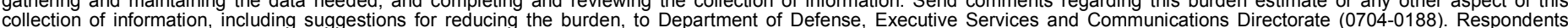

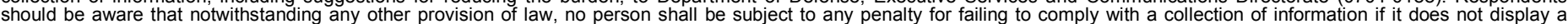

should be aware that notwithstanding

PLEASE DO NOT RETURN YOUR FORM TO THE ABOVE ORGANIZATION.

\begin{tabular}{l|l|l|l} 
1. REPORT DATE $(D D-M M-Y Y Y Y)$ & 2. & REPORT TYPE & 3. DATES COVERED (FrOm - TO)
\end{tabular}

September 2008

4. TITLE AND SUBTITLE

International Energy Agency Building Energy Simulation Test and

Diagnostic Method (IEA BESTEST): In-Depth Diagnostic Cases for

Ground Coupled Heat Transfer Related to Slab-on-Grade

Construction 5a. CONTRACT NUMBER

DE-AC36-99-GO10337

5b. GRANT NUMBER

5c. PROGRAM ELEMENT NUMBER

5d. PROJECT NUMBER

NREL/TP-550-43388

5e. TASK NUMBER

BEC7.6051

5f. WORK UNIT NUMBER

I. Beausoleil-Morrison, A. Ben-Nakhi, M. Crowley, M. Deru,

R. Henninger, H. Ribberink, J. Thornton, A. Wijsman, and

M. Witte

7. PERFORMING ORGANIZATION NAME(S) AND ADDRESS(ES)

National Renewable Energy Laboratory

1617 Cole Blvd.

8. PERFORMING ORGANIZATION REPORT NUMBER

Golden, CO 80401-3393

NREL/TP-550-43388

9. SPONSORING/MONITORING AGENCY NAME(S) AND ADDRESS(ES)

10. SPONSOR/MONITOR'S ACRONYM(S)

NREL

11. SPONSORING/MONITORING AGENCY REPORT NUMBER

12. DISTRIBUTION AVAILABILITY STATEMENT

National Technical Information Service

U.S. Department of Commerce

5285 Port Royal Road

Springfield, VA 22161

13. SUPPLEMENTARY NOTES

14. ABSTRACT (Maximum 200 Words)

This report documents a set of idealized in-depth diagnostic test cases for use in validating ground-coupled floor slab heat transfer models. These test cases represent an extension to IEA BESTEST, which originally focused on testing and validation of building thermal fabric models, but addressed only cursorily the modeling of heat transfer between the building and the ground.

15. SUBJECT TERMS

iea; international energy agency; bestest; building energy simulation test

\begin{tabular}{|c|c|c|}
\hline $\begin{array}{l}\text { a. REPORT } \\
\text { Unclassified }\end{array}$ & $\begin{array}{l}\text { b. ABSTRACT } \\
\text { Unclassified }\end{array}$ & $\begin{array}{l}\text { c. THIS PAGE } \\
\text { Unclassified }\end{array}$ \\
\hline
\end{tabular}

\begin{tabular}{|c|c|}
\hline $\begin{array}{l}\text { 17. LIMITATION } \\
\text { OF ABSTRACT }\end{array}$ & $\begin{array}{l}\text { 18. NUMBER } \\
\text { OF PAGES }\end{array}$ \\
\hline UL & \\
\hline
\end{tabular}

19a. NAME OF RESPONSIBLE PERSON

19b. TELEPHONE NUMBER (Include area code) 